\title{
La toma de decisiones en investigación educativa con SPSS
}

Alfredo Leonardo Hurtado Melgoza

Cynthia Lizette Hurtado Espinosa 



\section{La toma de decisiones en investigación educativa con SPSS}


Esta obra está editada bajo una licencia Creative Commons

Reconocimiento-NoComercial-SinObraDerivada 4.0 Internacional

(CC BY-NC-ND 4.0)

\section{(c) $96 \ominus$ \\ BY NC ND}

Publicación dictaminada por:

Miriam Yerith Jiménez

Karla Fabiola Acuña Meléndrez 


\section{La toma de decisiones en investigación educativa con SPSS}

Alfredo Leonardo Hurtado Melgoza

Cynthia Lizette Hurtado Espinosa 
SPSS $^{\circledR}$ es una marca registrada propiedad de International Business Machines Corp.

La toma de decisiones en investigación educativa con SPSS

Primera edición, Diciembre 2015.

ISBN: 978-607-96359-4-7

D.R. ( 2015. Alfredo Leonardo Hurtado Melgoza y Cynthia Lizette Hurtado Espinosa D.R. (c) 2015. Qartuppi, S. de R.L. de C.V.

Diseño Editorial: Arym H. Shepperd y León Felipe Irigoyen

Corrección de Estilo: Aline Espíndola Hernández

Ilustración de Portada: Melman/Shutterstock.com 


\section{Contenido abreviado}

PARTE UnO

¿Qué investigar en educación?

PARTE dos

¿Cómo recolectar los datos en la investigación educativa?

PARTE TRES

¿Qué se requiere saber sobre la estadística?

PARTE CuATRO

¿Qué tipo de estadístico utilizar?

PARTE CINCO

¿Cuándo utilizar las pruebas no paramétricas?

PARTe SeIS

¿Cuándo utilizar las pruebas paramétricas?

PARTE SIETE

¿Cómo relacionar las variables?

APÉNDICES

REFERENCIAS BIBLIOGRÁFICAS

ÍNDICE DE GRÁFICAS

ÍNDICE DE FIGURAS

ÍNDICE DE CUADROS 


\section{Contenido}

PARTE I

¿Qué investigar en educación?

\section{Capítulo 1. Investigación en educación}

$\begin{array}{ll}1.1 \text { ¿Cómo sería un mundo sin educación? } & 17\end{array}$

$\begin{array}{ll}1.2 \text { El Maestro } & 18\end{array}$

1.2.1 Sugerencias de investigación sobre el maestro 19

$\begin{array}{ll}1.3 \text { El Alumno } & 20\end{array}$

1.3.1 Sugerencias de investigación sobre el alumno 20

$\begin{array}{ll}1.4 \text { Las estrategias didácticas } & 21\end{array}$

1.4.1 ¿Qué son las estrategias de enseñanza? 22

1.4.2 ¿Qué son las estrategias de aprendizaje? 22

1.4.3 Las técnicas como estrategias didácticas, ¿Qué actividades 22 de enseñanza-aprendizaje se pueden utilizar?

1.4.4 Sugerencias de investigación sobre técnicas 22

$\begin{array}{ll}1.5 \text { Recursos audiovisuales } & 24\end{array}$

1.5.1 La tecnología educativa $\quad 24$

1.5.2 Medios visuales fijos $\quad 26$

1.5.3 Medios audiovisuales $\quad 26$

$\begin{array}{ll}\text { 1.5.4 Medios multimedia } & 27\end{array}$

$\begin{array}{ll}\text { 1.5.5 Medios en la red } & 28\end{array}$

1.5.6 Sugerencias de investigación sobre los medios 28

$\begin{array}{ll}1.6 \text { La evaluación } & 29\end{array}$

1.6.1 Técnicas, procedimientos e instrumentos de evaluación $\quad 30$

$\begin{array}{ll}\text { 1.6.2 Funciones de la evaluación } & 32\end{array}$

1.6.3 Sugerencias de investigación sobre la práctica de evaluación $\quad 33$

$\begin{array}{ll}1.7 \text { El contexto } & 34\end{array}$

1.7.1 El contexto dentro del salón de clase o aula 34

$\begin{array}{ll}\text { 1.7.1.1 El espacio } & 34\end{array}$

$\begin{array}{ll}\text { 1.7.1.2 El tiempo } & 34\end{array}$

$\begin{array}{ll}\text { 1.7.1.3 Modelos organizativos } & 35\end{array}$

$\begin{array}{ll}\text { 1.7.2 El contexto familiar } & 35\end{array}$

1.7.2.1 La función educadora de los padres $\quad 36$

$\begin{array}{ll}\text { 1.7.2.2 Participación de padres en la escuela } & 37\end{array}$

$\begin{array}{ll}1.7 .3 \text { El Contexto Social } & 37\end{array}$

1.7.4 Sugerencias de investigación sobre el contexto 38 


\section{PARTE II}

¿Cómo recolectar los datos en la investigación educativa?

\section{Capítulo 2. Técnicas e instrumentos para la recolección de datos} en investigación educativa

2.1 La observación

2.1.1 Observación sistematizada

2.1.2 Observación no sistematizada (ocasional o no controlada) 50

2.1.3 Tipos de registros observacionales 51

2.1.4 Fiabilidad y validez de los registros observacionales 53

2.2 La encuesta 53

2.2.1 La entrevista $\quad 54$

2.2.2 Entrevistas estructuradas $\quad 54$

2.2.3 El cuestionario $\quad 55$

2.2.3.1 La elaboración de cuestionarios $\quad 56$

2.2.3.2 Formulación y selección de preguntas para la elaboración $\quad 59$ de cuestionarios y entrevistas estructuradas

$\begin{array}{ll}2.3 \text { El test y la prueba } & 61\end{array}$

2.3.1 Test estandarizado $\quad 62$

2.3.1.1 Los resultados y su aplicación 63

2.3.1.2 Test psicométrico 63

2.3.1.3 Test de inteligencia $\quad 64$

$\begin{array}{ll}\text { 2.3.1.4 Test de aptitudes } & 65\end{array}$

$\begin{array}{ll}\text { 2.3.1.5 Test de personalidad } & 68\end{array}$

$\begin{array}{ll}\text { 2.3.1.6 Test de conocimientos } & 74\end{array}$

2.3.2 Las pruebas Objetivas $\quad 75$

$\begin{array}{ll}\text { 2.3.3 Los tipos de ítems } & 78\end{array}$

$\begin{array}{ll}\text { 2.3.3.1 Ítems de falso o verdadero } & 78\end{array}$

2.3.3.2 Ítems de opción múltiple $\quad 79$

2.3.3.3 Ítems de complementación (llenar espacio) 80

2.3.3.4 Ítems de correlación (emparejamiento) 80

$\begin{array}{ll}\text { 2.3.4 El número de ítems } & 81\end{array}$

2.3.5 El nivel de dificultad de los ítems $\quad 81$

2.3.6 Los objetivos de aprendizaje $\quad 82$

2.3.7 Otras técnicas e instrumentos para la recolección de datos 83 en investigación educativa 
PARTE III

¿Qué se requiere saber sobre la estadística?

$\begin{array}{ll}\text { Capítulo 3. Conceptos de estadística } & \mathbf{8 7}\end{array}$

3.1 Concepto de Hipótesis 88

3.1.1 La hipótesis y el método experimental 88

3.1.2 Características de una hipótesis en educación 90

3.1.3 Tipos de hipótesis 90

3.1.3.1 Hipótesis de investigación 90

$\begin{array}{ll}\text { 3.1.3.2 Hipótesis nula } & 91\end{array}$

$\begin{array}{ll}\text { 3.1.3.3 Hipótesis alternativa } & 91\end{array}$

$\begin{array}{ll}\text { 3.1.3.4 Hipótesis estadísticas } & 91\end{array}$

3.2 El nivel de medición $\quad 92$

3.3 Análisis estadístico de los datos $\quad 97$

$\begin{array}{ll}\text { 3.3.1 Medidas descriptivas } & 97\end{array}$

3.3.1.1 Medidas de tendencia central $\quad 97$

$\begin{array}{lr}\text { 3.3.1.2 Medidas de dispersión } & 102\end{array}$

3.4 La curva normal $\quad 111$

$\begin{array}{ll}\text { 3.4.1 Curvas normales y la realidad } & 112\end{array}$

3.4.2 El área bajo la curva normal 113

3.4.3 Aplicación práctica de la curva normal $\quad 114$

3.5 La puntuación Zo estándar $\quad 115$

3.6 Toma de decisiones $\quad 118$

$\begin{array}{ll}\text { 3.6.1 Contrastación de hipótesis } & 119\end{array}$

3.6.2 El nivel de significación (o confianza) $\quad 124$

$\begin{array}{ll}\text { 3.6.2.1 Para muestras pequeñas } & 126\end{array}$

3.6.2.2 Para muestras de distinto tamaño 129

$\begin{array}{ll}\text { 3.6.2.3 Para la misma muestra medida dos veces } & 131\end{array}$

PARTE IV 135

¿Qué tipo de estadístico utilizar?

$\begin{array}{ll}\text { Capítulo 4.Pruebas estadísticas } & 137\end{array}$

4.1 ¿Qué prueba estadística utilizar? $\quad 138$

4.1.1 Pruebas no paramétricas 139

$\begin{array}{ll}\text { 4.1.1.1 Asignación de categorías relacionadas } & 139\end{array}$

4.1.2 Pruebas Paramétricas 140

$\begin{array}{ll}\text { 4.1.3 Relaciones entre variables } & 141\end{array}$

4.2 Muestras relacionadas $\quad 142$

4.3 Muestras no relacionadas 143

4.4 Introducción al programa SPSS 
PARTE V

¿Cuándo utilizar las pruebas no paramétricas?

Capítulo 5. Prueba Wilcoxon (muestras relacionadas) 153

5.1 Estado situacional 153

5.2 Explicación 153

5.3 Procedimiento para determinar el valor de $W \quad 154$

5.4 Prueba Wilcoxon utilizando el programa SPSS 155

Capítulo 6. Prueba Mann-Whitney (para muestras independientes) 161

$\begin{array}{ll}6.1 \text { Estado situacional } & 161\end{array}$

6.2 Explicación $\quad 162$

6.3 Procedimiento para determinar el valor de $U \quad 162$

6.4 Prueba Mann-Whitney utilizando el programa SPSS 164

Capítulo 7. Prueba Friedman (muestras relacionadas) 171

$\begin{array}{ll}7.1 \text { Estado situacional } & 171\end{array}$

7.2 Explicación 172

7.3 Procedimiento para determinar el valor de $X^{2}{ }_{r} \quad 172$

7.4 Prueba Friedman utilizando el programa SPSS 173

Capítulo 8. Prueba Kruskal-Wallis (muestras independientes) $\quad 181$

$\begin{array}{ll}\text { 8.1 Estado situacional } & 181\end{array}$

$\begin{array}{ll}8.2 \text { Explicación } & 181\end{array}$

8.3 Procedimiento para determinar el valor de $H \quad 182$

8.4 Prueba Kruskal-Wallis utilizando el programa SPSS 184

PARTE VI 193

¿Cuándo utilizar las pruebas paramétricas?

Capítulo 9. Prueba $t$ (muestras relacionadas) 195

$\begin{array}{ll}\text { 9.1 Estado situacional } & 195\end{array}$

9.2 Explicación 195

9.3 Procedimiento para determinar el valor de $t$ (relacionada) $\quad 197$

9.4 Prueba $t$ (relacionada) utilizando el programa SPSS 198

Capítulo 10. Prueba t (para muestras independientes) 203

10.1 Estado situacional 203

10.2 Explicación 203

10.3 Procedimiento para determinar el valor de $t$ (independiente) 205

10.4 Prueba $t$ (independiente) utilizando el programa SPSS 207 
Capítulo 11. Prueba ANOVA Unifactorial (muestras relacionadas) 213

$\begin{array}{ll}11.1 \text { Estado situacional } & 213\end{array}$

$\begin{array}{ll}11.2 \text { Explicación } & 214\end{array}$

11.3 Procedimiento para determinar el valor de ANOVA Unifactorial 215

(relacionada)

11.4 Prueba ANOVA Unifactorial (relacionada) utilizando el programa SPSS $\quad 217$

Capítulo 12. Prueba ANOVA Unifactorial (muestras independientes) 225

$\begin{array}{ll}12.1 \text { Estado situacional } & 225\end{array}$

12.2 Explicación $\quad 225$

$\begin{array}{ll}\text { 12.3 Procedimiento para determinar el valor de ANOVA Unifactorial } & 227\end{array}$ (independiente)

12.4 Prueba ANOVA Unifactorial (independiente) utilizando el programa SPSS 229

Capítulo 13. Prueba ANOVA Bifactorial (muestras relacionadas) 235

$\begin{array}{ll}\text { 13.1 Estado situacional } & 235\end{array}$

13.2 Explicación $\quad 236$

13.3 Procedimiento para determinar el valor de ANOVA Bifactorial 237

(relacionada)

13.4 Prueba ANOVA Bifactorial (relacionada) utilizando el programa SPSS $\quad 244$

13.5 Comprobación de interacciones por medio de gráficas 249

13.6 Elaboración de las gráficas por medio del programa SPSS $\quad 249$

Capítulo 14. Prueba ANOVA Bifactorial (muestras independientes) 255

14.1 Estado situacional 255

14.2 Explicación $\quad 256$

14.3 Procedimiento para determinar el valor de ANOVA Bifactorial $\quad 256$ (independiente)

14.4 Prueba ANOVA Bifactorial (independiente) utilizando el programa SPSS $\quad 261$

14.5 Comprobación de interacciones por medio de gráficas 266

14.6 Elaboración de las gráficas por medio del programa SPSS 266

PARTE VII $\quad 271$

¿Cómo relacionar las variables?

Capítulo 15. Prueba de Chi-Cuadrado 273

$\begin{array}{ll}15.1 \text { Estado situacional } & 273\end{array}$

$\begin{array}{ll}15.2 \text { Explicación } & 274\end{array}$

15.3 Procedimiento para determinar el valor Chi-Cuadrado $\quad 276$

15.4 Prueba de Chi-cuadrado con el programa SPSS 279

Capítulo 16. Coeficiente de correlación para datos de intervalo 289

momento-producto de Pearson
16.1 Estado situacional

$\begin{array}{ll}16.2 \text { Explicación } & 290\end{array}$

16.3 Procedimiento para determinar el valor del ratio $r \quad 290$ 
Capítulo 17. Coeficiente de correlación para datos ordinales de Spearman $\left(r_{s}\right)$

17.1 Estado situacional

17.2 Explicación

299

17.3 Procedimiento para determinar el valor de $r_{s}$ 301

17.4 Prueba del Coeficiente de correlación para datos ordinales

$\begin{array}{ll}18.1 \text { Estado situacional } & 309\end{array}$

18.2 Explicación 310

18.3 Construcción de la recta de regresión por mínimos cuadrados 310

18.3.1 Procedimiento para determinar el valor del pronóstico $Y^{\prime}$ para 312

la construcción de la recta de regresión por mínimos cuadrados

18.4 Construcción de la recta de regresión utilizando el coeficiente 314 de correlación

18.4.1 Procedimiento para determinar el valor del pronóstico $Y^{\prime}$ para

314

la construcción de la recta de regresión utilizando el coeficiente de correlación

18.5 Elaboración del gráfico utilizando el programa SPSS 317

18.6 El error estándar de la estimación 322

18.6.1 Procedimiento para determinar el valor del error estándar 323 de la estimación

18.6.1.1 La suma de los cuadrados de las desviaciones 323 (errores de predicción)

18.6.1.2 El Proceso matemático 323

18.7 Prueba de Regresión Lineal utilizando el programa SPSS 325

Capítulo 19. Análisis de regresión lineal Múltiple 333

$\begin{array}{ll}19.1 \text { Estado situacional } & 333\end{array}$

19.2 Explicación 334

19.3 Procedimiento para determinar la ecuación de regresión múltiple 335

19.4 Análisis de regresión lineal múltiple con el programa SPSS 335

APÉndices

Apéndice A. Respuestas a los ejemplos del Capítulo 1

Apéndice B. Prueba objetiva acorde a las unidades 1 y 2 del Capítulo $2 \quad 345$

Apéndice C. Solución al Ejercicio 1 del Capítulo $3 \quad 347$

$\begin{array}{ll}\text { Apéndice D. Tablas Estadísticas } & \mathbf{3 4 8}\end{array}$

REFERENCIAS BIBLIOGRÁFICAS $\quad 362$

ÍNDICE DE GRÁFICAS $\quad 364$

ÍNDICE DE FIGURAS $\quad 366$

ÍNDICE DE CUADROS $\quad 373$

$\begin{array}{ll}\text { ÍNDICE DE TABLAS } & 376\end{array}$ 



\section{PARTE I \\ ¿Qué investigar en educación?}





\section{Capítulo 1}

\section{La investigación en educación}

La investigación en educación pretende determinar cómo la eficiencia de la enseñanza del docente, el uso adecuado de los recursos o medios audiovisuales, el alumno, la familia, el entorno que rodea al proceso educativo, entre otros factores, producen como consecuencia el aprendizaje en el alumno, teniendo como objetivo mejorar alguno de estos factores del proceso educativo para lograr un aprendizaje significativo.

\section{1. ¿Cómo sería un mundo sin educación?}

Sin educación el ser humano como individuo, familia o integrante de un grupo social se vería en la necesidad de reconstruir el patrimonio de la humanidad en una aventura que le exigiría un esfuerzo tal, que sería imposible de lograr durante toda la trayectoria de su vida, de ahí la importancia de recibir una educación que reduzca este esfuerzo durante el proceso de aprendizaje del individuo.

Se requiere de un proceso que vincule y cree conciencia cultural, moral y conductual, esto es, mediante la educación es posible que se aprendan por las nuevas generaciones los saberes que el hombre ha desarrollado a través de la historia y que además de aprender las normas de conducta, modos de ser y formas de ver el mundo establecidos por estos saberes, se produzcan otros nuevos.

La palabra educación etimológicamente hablando proviene del latín y se divide en educare (formar, instruir, crear, nutrir) y educere (sacar, llevar, extraer). A su vez, Prellezco (2010) la define como:

- Todos aquellos procesos que son multidireccionales mediante los cuales se pueden transmitir conocimientos, costumbres, valores y formas de actuar y no sólo se produce a través de la palabra, pues está presente en todas nuestras acciones, sentimientos y actitudes.

- El fin del proceso de socialización en los individuos, en donde se pueden apreciar una serie de habilidades, actitudes, conocimientos y valores adquiridos, que producen en estos cambios de orden intelectual, social, emocional, etc.

- El proceso mediante el cual una sociedad particular reproduce su cultura, a través de distintas instituciones ya sea de manera formal o informal.

La educación se puede clasificar según Coombs (1971) en: formal, no formal e informal.

- La educación formal. Se refiere particularmente a los ámbitos de las escuelas, institutos, universidades y módulos.

- La no formal. Se refiere a los cursos, academias e instituciones, que no se rigen por un particular currículo de estudios.

- La educación informal. Se refiere a aquella que se recibe en los ámbitos sociales, que se adquiere a lo largo de toda la vida. 
Este libro pretende servir de guía a los profesores que busquen realizar investigaciones dentro de su ámbito de trabajo en el proceso educativo. Es por esto que el tipo de educación que se propone trabajar es la formal, lo que no significa que las estrategias y técnicas utilizadas en este libro no son necesariamente aplicables en escenarios de educación no formal o informal.

La educación formal también recibe el nombre de educación escolar, ésta requiere de una presentación sistemática de ideas, hechos y técnicas a los estudiantes. Esto es, el maestro ejerce una influencia ordenada y voluntaria sobre el alumno, con la intención de formarle. De esta manera es como el sistema escolar adquiere el compromiso social de transmitir y conservar los saberes que permitan la existencia colectiva entre las nuevas generaciones.

A fin de cuentas lo que se pretende es que se logre como producto final una educación de calidad, cuya meta es lograr una educación que se sustente como un proceso que permita la construcción y distribución de los saberes socialmente válidos, que promuevan que el alumno:

- Contribuya a la construcción de un modelo social democrático por medio de la apropiación de instrumentos para participar en la vida económica, política y social.

- Se le permita "aprender a aprender" mediante el desarrollo de procesos de pensamiento y estrategias cognitivas.

- Desarrolle las habilidades básicas que le posibiliten la inserción en condiciones adecuadas en el nivel siguiente del sistema educativo o la incorporación a la vida activa.

- Transfiera los saberes para operar sobre la realidad en la que se encuentra inmerso.

- Desarrolle la posibilidad de la duda y la discusión mientras se consideran las características propias del sujeto de aprendizaje, en sus aspectos cognitivos, socio-afectivos y psicomotrices, para culminar con el crecimiento profesional del docente.

La investigación educativa busca la eficacia del proceso enseñanza-aprendizaje para lograr que el alumno se relacione de modo significativo con los saberes, mediante la intervención de las siguientes variables: maestro, alumno, estrategias didácticas, recursos audiovisuales, contexto y evaluación.

\subsection{El Maestro}

Cada maestro tiene características particulares que le permiten lograr que los alumnos aprendan los saberes. Según Gutiérrez (2006), los maestros se pueden clasificar de acuerdo a su preparación de la siguiente forma:

El Instructor. Es el maestro que tiene amplio conocimiento en su especialidad como profesionista, pero ignora cómo mediarlo a sus alumnos para lograr que éstos lo aprendan y lo puedan aplicar de una manera práctica en su vida cotidiana como futuros profesionistas.

No siente la necesidad de capacitarse en pedagogía, no elabora un plan de clase, solo va siguiendo la información apegado al texto que utiliza, impartiendo la clase como considera que debe hacerse.

El docente. Es el profesionista que es contratado para impartir cátedra en su especialidad y que a diferencia del instructor, ha recibido de alguna manera capacitación en el área técnico-didáctica. Como profesional experto de su área es a quien con frecuencia se le encomienda la realización y elaboración de la planeación y actualización curricular, para mantener vigentes los conocimientos que se median.

Establece las interrelaciones curriculares con la finalidad de que coincidan los contenidos en tiempo de materias de apoyo, por ejemplo, las matemáticas requeridas para desarrollar un contenido de electrónica en un nivel superior o en caso de la primaria el uso de programas de cómputo relacionados con las materias de español, matemáticas, etc. 
Busca estrategias de aprendizaje didácticas, metodológicas e innovadoras, para lograr los aprendizajes significativos en sus alumnos y no sólo por repetición. Reconoce sus limitaciones técnico-didácticas por lo que constantemente busca su capacitación en esta área para ser un buen docente por convicción.

El Profesor. Es el profesionista de la educación por lo que debe ser capaz de implementar la planeación de cursos, desarrollar estrategias didácticas y metodológicas para lograr un aprendizaje significativo, detectar problemas de aprendizaje, implementar sistemas de evaluación que realmente midan lo aprendido, lograr trabajo interactivo involucrando maestros y alumnos, establecer interrelaciones curriculares, dominar los saberes que imparte a los educandos.

En conclusión, si se pretende que el maestro logre que el aprendizaje en sus alumnos sea significativo entonces su función debe ser la de un facilitador del encuentro de los alumnos con los saberes, siendo además un mediador y organizador que debe colaborar para establecer las relaciones entre los conocimientos previos del alumno y los nuevos por aprender. Debe promover y desarrollar las estrategias cognitivas por medio de las experiencias interpersonales.

\subsubsection{Sugerencias de investigación sobre el maestro}

A continuación se describen algunas características que pueden ser motivo de investigación de la actividad del maestro.

- El perfil del maestro como expositor comprende dos grandes rasgos:

a. Comunicación verbal, que comprende algunos aspectos como: vocabulario, pronunciación, modulación, timbre, intensidad, pausas, dicción, etc.

b. Comunicación no verbal, que comprende algunos aspectos tales como: la postura, ademanes, expresión facial, vista, memoria, actitud positiva, de manera más profunda: sensibilidad, responsabilidad, creatividad, compromiso, laxitud, empatía, autocontrol emocional, etc.

- Conocimiento de la disciplina: el saber, el contenido de la materia a enseñar, dominio del tema, actualización de conocimientos del contenido programático.

- Conocimiento didáctico: el saber hacer, los procesos de enseñanza-aprendizaje, vocación docente, actualización didáctica.

- Habilidades durante el proceso enseñanza-aprendizaje para: fomentar las buenas relaciones humanas; lograr que los alumnos signifiquen los saberes; mejorar su práctica docente permanente; selección y preparación de medios audiovisuales; seleccionar y preparar estrategias de enseñanza-aprendizaje; planificar, evaluar, motivar, enseñar, innovar, crear un clima favorable, etc.

- La actitud del maestro: puede analizarse desde diferentes puntos de vista ansiedad, inquietud y angustia o estabilidad y satisfacción. El estudio de estas actitudes puede dirigirse hacia los alumnos, la escuela, otros maestros, o hacia sí mismo.

- La relación del maestro frente al grupo ya que resulta interesante determinar cuál sería la relación ideal entre el maestro y el alumno como: de acercamiento, barrera, cordialidad, tensión, imposición, amistad, etc. 
Ejemplo 1. El maestro inicia la clase explicando lo que son las palancas de primer orden y pone algunos ejemplos. Para los alumnos, es un tema nuevo y no lo comprenden, por lo que solicitan al maestro volver a explicar porque no entendieron; el maestro siguiendo el mismo procedimiento que utilizó, procede a repetir la explicación, pero los alumnos siguen sin entender.

¿Qué está pasando?, ¿Cuál es el problema?

¿Cuál es la posible solución? NOTA: Ver posible respuesta en Apéndice A.

\subsection{El Alumno}

La finalidad del alumno es aprender, y lo aprendido es un acto individual. La apropiación de los saberes implica un cambio tanto grupal como individual que conlleva transformar las ideas o creencias que se tienen como verdades, por los nuevos saberes, éstos adquiridos como consecuencia de una interacción con los otros: compañeros, maestros, padres de familia, amigos, etc. (Gutiérrez, 2006).

Para que el alumno logre un verdadero aprendizaje debe trabajar activamente por sí mismo ante los temas que son motivo de enseñanza, debe vivir el aprendizaje.

Es interesante aprender a partir de las experiencias de los alumnos en un intercambio constante apoyado por actividades didácticas. Se sabe que el alumno es poseedor de experiencias adquiridas por acciones a lo largo de su vida lo que permite lograr el aprendizaje mediante esas experiencias; asumiendo así sus responsabilidades mediante una acción reflexiva y crítica.

Como grupo debe ser fuente para generar experiencias de aprendizaje en una transformación constante entre sus miembros, en forma individual el alumno cambia por la influencia del grupo, a su vez éste es modificado por la acción de los participantes. También los fracasos de los alumnos los conducen a adquirir un nuevo aprendizaje.

El alumno ha vivido por mucho tiempo el rol donde el maestro lo "educa" mediante la mediación de los saberes, donde éste pasivamente repite y escucha para que aprenda. $\mathrm{El}$ alumno debe informarse, consultar, criticar, organizar, sistematizar, planificar, autoevaluar, tomando una postura ante los nuevos saberes.

Este proceso lo conduce al estudio autodidacta en donde debe tomar la iniciativa para realizar un diagnóstico de sus necesidades de aprendizaje, debe establecer metas, identificar los recursos materiales y humanos, plantearse e implementar estrategias de estudio solo y en grupo apoyado por maestros, tutores y compañeros.

\subsubsection{Sugerencias de investigación sobre el alumno}

Al igual que en el caso anterior a continuación se describen algunas características que pueden ser motivo de investigación de la actividad del alumno.

- Desarrollo social:

a. En la escuela: Grupos de iguales, relación con sus compañeros, desarrollo como grupo, integración del grupo, aprendizaje, cooperación, interacción del alumno, etc.

b. En los medios de comunicación: formación de valores, socialización, forma de vestir, lenguaje, música, etc.

- Desarrollo de identidad: logro, exclusión, difusión, moratoria psicosocial, autoestima, autoconcepto, autoevaluación, etc. 
Ejemplo 2. En una clase de matemáticas cuando el maestro termina de explicar lo que había anotado en el pintarrón, el alumno Miguel levanta la mano y solicita al maestro que explique de nuevo el tema; el maestro se molesta de momento pues Miguel de manera constante repite este hecho. El maestro pregunta al grupo si entendieron y todos contestan que sí excepto Miguel.

El maestro sabe que Miguel es un buen estudiante, por lo que vuelve a explicar, pero decide observarlo para descubrir qué sucede. Al hacerlo se da cuenta que mientras efectúa nuevamente la explicación Miguel está copiando lo que está anotado en el pintarrón, en lugar de estar atento a lo que está explicando.

\section{¿Qué está pasando?, ¿Cuál es el problema?}

$$
\text { ¿Cuál es la posible solución? NOTA: Ver posible respuesta en Apéndice A. }
$$

- Desarrollo humano: cognición, destrezas físicas, etc.

- Hábitos, actitudes, valores, respeto, adquirir destrezas intelectuales y académicas, trato a semejantes, rol sexual, autonomía, independencia, normas orales, conciencia, ansiedad, conflicto, su papel dentro del grupo, acoplamiento de conducta, estilo interactivo, etc.

- Desarrollo de habilidades: lingüísticas, lógico-matemáticas, éticas, musicales, espaciales, habilidades del pensamiento, cinestésico-corporales, interpersonales, etc.

- Desarrollo individual, estilo cognoscitivos: adecuación de la información (conocerla, comprenderla y manejarla), saber estudiar, independencia de campo, nivel conceptual, dominio de conocimientos, motivación de aprendizaje, autoestima, autoeficacia, autoevaluación, etc.

- Desarrollo de competencias lingüísticas: escuchar, preguntar, leer, hablar, escribir, etc.

\subsection{Las estrategias didácticas}

Es necesario que el alumno para ser autodidacta y que pueda construir, descubrir y organizar los saberes, que tanto él como el maestro estén involucrados en lograr los aprendizajes que se proponen como meta, pero cuando el alumno no está acostumbrado a esta forma de trabajo es el maestro quien debe conducirlo para que participe mediante acciones que requieran que el alumno tenga que tomar sus propias decisiones al respecto (Gutiérrez, 2006).

La estrategia didáctica involucra una doble acción: por una parte, la participación del maestro en el proceso de enseñanza, el cual debe ser una guía para que el alumno logre cumplir con su participación como la segunda acción que se refiere al aprendizaje. El maestro debe facilitar que el alumno se apropie de los saberes ya sea que los construya, descubra o utilice alguna otra actividad que le permita alcanzar los objetivos planteados relacionados con su aprendizaje y que éste sea significativo.

Por otra parte, el aprendizaje del alumno debe ser el producto de sus propias experiencias y su participación activa en el proceso de enseñanza, de esta manera el alumno desarrolla sus propias estrategias logrando un mayor aprovechamiento en sus esfuerzos para apropiarse de la información que el maestro media. Se puede decir, que el maestro no sólo media el contenido de la información que pretende que el alumno aprenda, sino que también le proporciona las estrategias para que lo logre significar y no quede como un simple recuerdo o lo olvide, esto es, aprender a aprender. 


\subsection{1 ¿Qué son las estrategias de enseñanza?}

Son los procedimientos propuestos por el maestro para facilitar y promover en los alumnos el aprendizaje significativo, de manera reflexiva y adaptada a las características y circunstancias propias del grupo. El maestro debe considerar al grupo al momento de elaborar sus estrategias tomando en cuenta factores como: edad, materia, saberes, intereses, etc. (Gutiérrez, 2006).

\subsection{2 ¿Qué son las estrategias de aprendizaje?}

Son los procedimientos que el alumno utiliza para integrar, organizar y elaborar la información para la adquisición de nuevos saberes de manera que le sean significativos. Estos procedimientos consisten en una serie de técnicas, pasos, habilidades, cuyo objetivo es facilitar que el alumno adquiera los saberes y lo conduzca a ser un autodidacta (Castañeda, 2004).

Se ha comprobado que al utilizar las estrategias de aprendizaje, promovidas por la nueva psicopedagogía, los estudiantes con éxito mejoran a los estudiantes con menos éxito debido a que, utilizaron estrategias de aprendizaje más elaboradas que la simple repetición mecánica.

El maestro es el responsable de enseñarle al alumno estas estrategias para que el alumno las conozca y pueda implementarlas para lograr un aprendizaje significativo logrando el éxito, favoreciendo de esta forma su rendimiento académico ampliando sus posibilidades de trabajo y estudio. El maestro por consecuencia debe estar formado para enseñar dichas estrategias, conocer su propio aprendizaje, las estrategias que posee y cómo las utiliza en la cotidianidad.

\subsubsection{Las técnicas como estrategias didácticas,} ¿Qué actividades de enseñanza-aprendizaje se pueden utilizar?

Es necesario desarrollar diferentes actividades de manera coherente para la mediación de saberes, algunas comunes con toda la clase y otras diferenciadas por equipo o por alumno.

En la actualidad existen textos que presentan diferentes técnicas para lograr con eficacia los objetivos planteados para el aprendizaje de la información propuesta. Técnica, en este libro, se define como el conjunto de procedimientos utilizados para que un grupo funcione, produzca y logre con eficiencia las metas propuestas.

La técnica está constituida por diferentes pasos concretos conocidos como tácticas que siguen una estructura lógica para darle sentido, la técnica es la estructura, sin embargo la táctica puede variar de acuerdo a las reacciones de los participantes, pueden ser pasivos o agresivos o simplemente no participar lo que da origen a que el conductor pueda manejar la táctica más adecuada (González, Monroy y Kupferman, 1999).

La teoría de la técnica trata los aspectos estratégicos de una escuela o corriente que estudia los grupos. Esta estrategia se constituye por una serie de técnicas y a su vez la técnica engloba varias tácticas. Por ejemplo, la técnica de mesa redonda se constituye por tácticas como elegir un grupo de expertos, nombrar un moderador, seleccionar el tema a tratar y la manera de exponerlo, la participación del auditorio y la realización de conclusiones.

\subsubsection{Sugerencias de investigación sobre técnicas}

A continuación se describen algunas técnicas que pueden ser motivo de investigación de la actividad del maestro-alumno mediante: 
a. La clasificación de las técnicas de acuerdo a los participantes en el proceso educativo:

- Centradas en el trabajo del maestro: exposición, demostración para trabajos prácticos, resolución de problemas en el pintarrón.

- Centradas en expertos: conferencia, debate, panel, simposio, mesa redonda, entrevista.

- Centradas en el trabajo del alumno: resolución de problemas, lectura de material específico, realización de experimentos y prácticas, redacción de ensayos breves, resolución de casos, desarrollo de investigaciones a largo plazo, lectura de material específico, etc.

- Centradas en la participación activa de todos los participantes en el grupo: seminario, Phillips 66, corrillos o grupo de discusión, cuchicheo, representantes, espíritu de colaboración, toma de decisiones, etc.

- Centradas en la participación total del grupo: foro, plenaria, discusión dirigida, integración afectiva, manejo de conflictos, etc.

- Centradas en la toma de decisiones grupal: grupo de verbalización, grupo de observación, estudio de casos, estado mayor, concordar y discordar, proceso de incidentes, construcción de esquemas conceptuales, liderazgos grupales, etc.

- Centradas en la creatividad del grupo: escenificación, lluvia de ideas, valores e ideología, desempeño de papeles, dramatización, sociodrama o psicodrama, etc.

b. La clasificación de las técnicas de acuerdo a los objetivos perseguidos en forma grupal:

- Motivación: Brillante pero apático; cáscara de cebolla; por qué merece la pena esforzarse; inventario de esperanza; incremento de la motivación; juego de roles; mini lab; conductas ante la frustración.

- Programación: caso isla; programación de una actividad; planificación de la carrera; estudio de un caso, una unidad verdaderamente suya; regreso al hogar.

- Dirección: capacidad y actitudes; identificación de la propia actividad como maestro; estilos de dirección; estilos de maestros.

- Comunicación: diálogo controlado; clínica del rumor; otro día; la imagen de mi yo; el mensaje de mi rostro; juego experimental: círculo, cadena, estrella, horquilla.

- Aprendizaje: gabinete de asesoramiento; buscar ayuda, prestar ayuda; aceptación rechazo; solución de problemas; inventario de estilos de aprendizaje; el sistema de numeración Worabura; el sistema de numeración Odoboko; estudio de un caso.

- Actitudes: juego del "es necesario" y "se debe"; el aborto; el experimento de Asch; la infanticida; guía para tratar a cada participante según su personalidad; caso Elle; tipografía de alumnos; mecanismos de defensa.

- Retroalimentación: grupo en imagen; la leyenda hindú; entrevista por parejas; intercambio de siluetas; alter ego; GT observa a GT; elección de profesión; la ventana de Johari; intercambio de roles; los rectángulos de Leavitt.

- Percepción: observación de roles; ejercicio del cuadrado; firma de cosmética; las figuras; mujer anciana mujer joven; el problema de los nueve puntos; las ilusiones ópticas; niños negros; percepción interpersonal; muchacha de Cognac.

- Cooperación, competición: el dilema del prisionero; juego espacial de la NASA; sociedad carbonífera; el árbol genealógico; las prioridades; construcción de una torre; casa, árbol, perro; juego de rojos y negros; el misterio del secuestro; juego de planificación.

- Toma de decisiones y solución de problemas: seminario de cooperación; operación suburbio; coche de servicio; la herencia; ejercicio del cuadrado; grupo de la ONU; me das la regla y yo te la doy; en el planeta Atlantis. 
Por supuesto que éstas son sólo algunas técnicas que se pueden utilizar, en las librerías existen una gran cantidad de títulos que presentan éstas y otras técnicas bajo el concepto de dinámicas de grupo o grupales, pero el límite para crear estrategias específicas para el nivel escolar y un tema determinado es la imaginación de cada maestro que es quien cuenta con la experiencia frente al grupo.

Las estrategias por sí solas no construyen los saberes, es necesario darle el valor agregado. Por ejemplo, si se utiliza un video, es necesario que al alumno se le cuestione sobre lo que sabe del tema que se va a tratar en el video, se le presenta la información y se le vuelve a cuestionar sobre el tema presentado para que con sus saberes previos, más la nueva información, construya su conocimiento por medio de la asimilación, acomodación y apropiación de la nueva información.

Ejemplo 3. En la clase de Geografía, el maestro diseña como estrategia que los alumnos jueguen a la lotería geográfica para tratar el tema de los diferentes tipos de mapas; por lo que elaboró las cartas con los mapas y las tablas para que los alumnos vayan jugando. El maestro empieza a gritar las cartas iniciando así, el mapa turístico, a lo que los alumnos que tienen este tipo de mapa en sus tablas colocan un papelito, de esta manera continúa el juego hasta que uno de los alumnos grita lotería, el maestro verifica que es verdad y continúa cantando las cartas hasta que se agoten las cartas con los mapas.

Al finalizar, el maestro aplica un examen para verificar el grado de retención del conocimiento, mostrando mucho entusiasmo pues parte del razonamiento de que el juego es algo que les gusta a los niños ( $5^{\circ}$ de primaria), pero los resultados del examen no son tan altos como él esperaba, incluso hay un alto porcentaje de reprobados.

¿Qué está pasando?, ¿Cuál es el problema? ¿Cuál es la posible solución?

NOTA: Ver posible respuesta en Apéndice A.

\subsection{Recursos audiovisuales}

Resulta interesante conocer cómo fueron evolucionando los medios audiovisuales para clarificar algunos conceptos que pueden causar confusión debido a sus diferentes designaciones. En un inicio surge el concepto de medios audiovisuales como recursos de apoyo para la enseñanza con fines formativos, surgen en seguida los medios de comunicación masiva como influencia social, lo que ocasionó una revisión de los modelos de comunicación con aplicación en la educación.

Con el desarrollo de la informática se integran las computadoras con fines educativos, tal es el caso de la enseñanza asistida por computadora (EAC), con las computadoras personales se concibe la enseñanza individualizada. Estos fueron los antecedentes que dieron origen a las Tecnologías de la Información y de la Comunicación (TIC), desarrollo tecnológico de gran impacto por medio del uso de dispositivos capaces de procesar, almacenar y transmitir grandes cantidades de información.

Esta innovación constante de la tecnología trae como consecuencia la creación de nuevos materiales audiovisuales y su consecuente necesidad de diseñar aplicaciones dentro del proceso de enseñanza-aprendizaje.

\subsubsection{La tecnología educativa}

La tecnología educativa requiere de un medio para transportar el mensaje, pero este mensaje requiere de un proceso o estrategia didáctica para lograr que los alumnos alcancen los objetivos de aprendizaje que propone el mensaje. 
Los medios de comunicación de la información sólo permiten de alguna manera poner la información a la disposición del alumno, mientras que las estrategias didácticas representan el valor agregado de la tecnología educativa pues facilita al alumno el camino para que se apropie de la información y la logre significar.

Un ejemplo puede ser leer un libro (el medio), el cual contiene la información, pero existen técnicas de lectura (la estrategia) que le permiten al alumno identificar las partes del libro así como determinar cuál es la información de mayor relevancia relativa al tema que esté investigando, obteniendo más beneficios de aprendizaje que el simple hecho de leer.

De acuerdo a lo anterior, se podría definir a la tecnología educativa como los medios de comunicación de la información complementados con las estrategias didácticas, integrando de esta manera el transporte del mensaje y el procedimiento que facilite el aprendizaje.

Los medios de comunicación se constituyen desde el más simple (la transmisión oral -solo la voz-) hasta la utilización de instrumentos como apoyo al proceso de enseñanzaaprendizaje, como son los libros, el proyector de imágenes, la computadora, el pizarrón, etc.; todos ellos requieren de una estrategia para su uso. De acuerdo a lo anterior, se pueden clasificar en:

a. Naturales: La vista, la voz, el oído, el tacto, etc.

b. Artificiales: El pizarrón, las diapositivas, el video, la computadora, el proyector, etc.

Un ejemplo lo representa el más antiguo de los medios, como es la utilización del gis y el pizarrón, que requiere de una técnica para su uso correcto, es decir, utilizar un tamaño y tipo de escritura visible y legible para los alumnos desde cualquier punto del salón de clase, escribir siguiendo un orden y estructura, y por qué no, utilizando alguna estrategia didáctica. También resulta importante aclarar algunos conceptos utilizados, tales como:

Medio. Se relaciona por lo general con los procesos comunicativos que exige una información que se transmite y un entorno físico que la transporte (mensaje y canal). En el caso de la educación deben perseguirse fines didácticos (Villaseñor, 1998).

Recursos. Son los medios o conjunto de instrumentos (materiales, procedimientos, personal, etc.) que se utilizan en apoyo al proceso de enseñanza-aprendizaje, como mediador entre la realidad y los saberes disciplinares. Se pueden clasificar en:

a. Materiales de soporte: papel, lápiz, cuaderno, pupitre, colores, juego de geometría, etc.

b. Materiales instructivos: libros de texto, revistas, grabaciones de audio o video, programas para computadora, etc.

Materiales didácticos. Son instrumentos, herramientas o dispositivos que permiten comunicar contenidos para su aprendizaje y facilitan el proceso de enseñanza-aprendizaje. Se pueden clasificar en:

a. Globalizadores: libros, material curricular, notas, revistas, cuadernos de trabajo, etc.

b. Auxiliares: proyector, computadora, radio, televisión, reproductor de audio y video, etc.

Nuevas tecnologías. Con los constantes avances tecnológicos muchos de los medios "antiguos" se actualizan y mejoran obteniéndose como consecuencia la nueva tecnología, como es el caso de los reproductores de cinta (antigua), que fueron reemplazados por los reproductores de DVD (medio) y éstos a su vez son reemplazados por las computadoras (nueva).

Las estrategias didácticas, que le dan el valor agregado a los medios de comunicación de la información, dependen en todo caso del ingenio y preparación del maestro o de algunas técnicas que se expusieron en el tema anterior, por lo que en este caso solo se expondrán algunos de los medios utilizados en la tecnología educativa. 
Medios impresos. Su característica consiste en la facilidad de lecturay transporte, ofreciendo grandes cantidades de información textual, gráfica y fotográfica en poco espacio; dentro de estos medios se encuentran: los libros, revistas, reportes científicos, periódicos, tesis, etc.

\subsubsection{Medios visuales fijos}

Visuales fijos. En este caso se cuenta con diferentes tipos de medios que presentan características propias para su uso, y que permiten facilitar el proceso de enseñanza aprendizaje y ahorrar tiempo al ser elaboradas previamente $o$ adquiridas con anterioridad en las tiendas especializadas en educación (Escamilla, 2002).

- El gis y pizarrón o el marcador y pintarrón. Actualmente se emplean para resolver imprevistos o preguntas de temas que no se incluyen en algún otro medio. También son útiles para la exposición de trabajos de alumnos tales como solución de problemas, ejercicios, presentación de conclusiones, elaboración de tablas, lluvia de ideas, etc.

- Las Cartulinas y rotafolios. Su tamaño generalmente es más reducido que el pizarrón, por lo que se utiliza como complemento de éste, permite presentar información que se requiere de manera permanente, como fórmulas o ecuaciones, pasos o reglas sencillas de seguir, diagramas, mapas, croquis, etc.

- Diapositivas. Se presentan materiales gráficos, tales como imágenes de diagramas, esquemas, obras de arte como pinturas y/o esculturas, así como la imaginación lo permita, pues casi todo se puede fotografiar; por ejemplo, si se presenta en la clase de Física palancas de primer orden, para ejemplificar se puede fotografiar a un hombre con una carretilla o niños en un sube y baja para mostrar lo que es el fulcro.

- Filminas. Representa una secuencia de diapositivas que están contenidas en un rollo fotográfico continuo, el proyector difiere en cuanto a la colocación del rollo y su desplazamiento, mientras que las diapositivas pueden ser presentadas en forma individual o se montan en un carrusel; en ambos casos se requiere de obscurecer la sala de proyección.

- Proyector de Acetatos. No requiere oscurecer la sala por completo y se utiliza al frente del salón, se puede utilizar como sustituto del pizarrón pues se puede escribir sobre los acetatos con marcadores, estos acetatos también se pueden realizar por medio de fotocopiado de diagramas o escribir textos previamente, ahorrando tiempo.

\subsubsection{Medios audiovisuales}

Audiovisuales. En este caso el concepto de audio visual implica utilizar medios que presenten la información en audio, video o la combinación de ambos (Escamilla, 2002).

- Radio y televisión. Se caracterizan por ser medios masivos de comunicación en un solo sentido, existen muchos programas que poseen características de instrucción única.

- Teleconferencias. Su característica es que mantiene una conversación a distancia, pueden ser sincrónicas cuando se utilizan medios analógicos (líneas telefónicas) o asincrónicas cuando los medios utilizados son digitales (en ocasiones en Internet).

- Audioconferencia. Discusión en donde se utilizan amplificadores de audio con bocinas y micrófonos especiales que mediante un enlace telefónico permite a los conferencistas con el auditorio a gran distancia, de uno o varios a muchos.

- Videoconferencia. Por medio de cámaras y monitores de televisión se efectúa una comunicación auditiva y visual con movimiento entre el conferencista y su auditorio, generalmente es un enlace de uno a muchos, por medio de líneas telefónicas, redes de microondas, satelitales o digitales. 
Los medios grabados. Su principal característica consiste en que son asincrónicos, proporcionan mayor control por el alumno, se pueden regresar y repetir la información para una mayor comprensión, a diferencia de las teleconferencias la comunicación sólo se realiza en un solo sentido y pueden ser utilizados dentro del aula, evitando una ruptura entre el medio y el trabajo posterior.

- Reproductores de CD. Permiten un mayor control, por medio de un mensaje auditivo se propicia que se repitan palabras o frases completas para mejorar su pronunciación al aprender idiomas; ideales para el alumno auditivo, para la comunicación de la información mediante grabaciones como son: el audio-libro, conferencias, entrevistas, etc.

- Reproductores de DVD. Requiere de un monitor de televisión como complemento; como medio didáctico, el audio y el video son integrados con un planteamiento, ritmo y cadencia que dosifica la información según se requiere. Estos medios permiten el análisis de documentales, conferencias, programas educativos, fenómenos sociales, cursos educativos globales o personalizados, etc.

\subsubsection{Medios multimedia}

La computadora. El concepto de multimedia se refiere a la combinación de varios medios de comunicación de la información; en el caso de la computadora se refiere al uso de proyectores o monitores de gran tamaño que permitan que los alumnos visualicen la información adecuadamente dentro del salón de clase, un auditorio o sala de proyección (Escamilla, 2002).

- Programa multimedia. Cualquier software que permite la reproducción de contenidos e información de texto, gráficos en movimiento, etc. para los canales visual y auditivo.

- Documento hipermedia. Consiste en una aplicación multimedia que permite realizar hiperligas de texto o gráficos con otros documentos hipermedia. Son de acceso fácil, permiten un mayor control por los alumnos, es una tecnología permanente, en un solo sentido y estructura grandes cantidades de información.

- Enciclopedias o bases de datos. En la actualidad es muy común poder adquirir enciclopedias o bases de datos en formatos físicos como son el Disco Compacto, DVD y memorias portátiles, de bajo costo, fácil transporte y que permiten almacenar grandes cantidades de información, pudiendo estructurar grandes cuerpos de información sobre un tema específico en un formato de fácil acceso.

- Simuladores. Son programas que contienen modelos referentes a algún tema que se desea estudiar, el alumno puede cambiar algunos parámetros o variables de entrada, y al ejecutar el programa se presentan en pantalla los resultados. Un ejemplo puede ser predecir el comportamiento de consumo de energía si se cambian variables dentro de la ecuación matemática que define el concepto de energía; también se puede aplicar a fenómenos sociales para simular tendencias, alterar procesos o procedimientos de laboratorio, etc.

- Tutoriales. Su objetivo es proporcionar la información a cada uno de los alumnos en un área específica del conocimiento, se basan en su mayoría en modelos de diálogo cerrado presentando la información y por medio de preguntas presenta diferentes opciones de acuerdo a los intereses del alumno, presentándole más información, repitiendo el proceso con nuevas preguntas. Suelen ser diseñados con antelación, pero es posible que el maestro genere material propio utilizando lenguajes de autor.

- Programas de demostración. Son programas auxiliares para el maestro en la instrucción de los alumnos con el objetivo de ejemplificar sus explicaciones o como material de revisión para los alumnos, permitiendo el uso de gráficos, colores y sonidos. 
- Programas de práctica y ejercitación. Estos programas proporcionan al alumno ejercicios para que logre dominar determinadas destrezas, generando tantos ejercicios como el alumno requiera. Estos programas son convenientes en aprendizajes en donde se precisa realizar prácticas en forma sistemática y continua.

\subsubsection{Medios en la red}

La computadora, tableta o celular en la red. El internet consiste en realizar la comunicación de la información por medio de un conjunto de computadoras unidas entre sí utilizando como medio de enlace líneas telefónicas, cable coaxial, fibra óptica, microondas, satélites, etc. que intercambian información destinada a los canales sensoriales auditivo, visual fijo, visual con movimiento, auditivo visual y textual (Escamilla, 2002).

- Tecnología sincrónica textual. Permiten transmitir información textual, en tiempo real de uno a uno, de uno a muchos, o de muchos a muchos, en ambos sentidos. Facilita la interacción grupal entre los participantes en cursos a distancia, en interacciones maestro-alumno y alumno-alumno.

- Tecnología sincrónica audiovisual. Es posible integrar a la comunicación: audio, gráficos y video en tiempo real, utilizando aplicaciones como Skype o Google Hangouts.

- Tecnología textual asincrónica. Tiene la característica de que no se debe participar dentro de un horario estipulado, simplemente se deja el mensaje, tarea, comentario, pregunta, etc. y se espera una respuesta de acuerdo al tiempo de que dispongan los demás participantes, solo pueden transmitir información textual, en ambos sentidos, de muchos a muchos y de manera permanente. Su modalidad más popular es el correo electrónico y los grupos de discusión.

- Correo electrónico. Consiste en la transmisión de información textual con la facilidad de anexar archivos electrónicos. Sus principales aplicaciones con fines didácticos son: mensajería asincrónica, envío y recepción de tareas, interacción a distancia profesoralumno e interacción a distancia alumno-alumno.

- Grupos de discusión. Consiste en la transmisión de información textual, solo que en este caso si un mensaje es enviado a un grupo de discusión puede ser leído por todos los participantes, estos mensajes se acumulan permitiendo a los participantes tener una visión global de la información, algunas de sus ventajas son que: se adapta a los estudiantes de bajo rendimiento, permite mayor tiempo de reflexión, incita mejorar la calidad de las contribuciones, propicia mayor retención de los conocimientos, desarrolla las habilidades de escritura y síntesis.

\subsubsection{Sugerencias de investigación sobre los medios}

A continuación se describen algunos aspectos que pueden ser motivo de investigación de la actividad del maestro-medio-alumno:

- Utilizar los medios de comunicación de la información para crear nuevas experiencias de aprendizaje.

- Utilizar estos medios para ayudar a los alumnos a aprender a aprender.

- Seleccionar o utilizar los medios de comunicación de la información no sólo para transmitir información, también para estimular en el estudiante el pensamiento crítico, creativo y metacognitivo. 
- Propiciar el descubrimiento y la construcción personal de los saberes en el alumno mediante la utilización de los medios de comunicación de la información.

- Propiciar en los alumnos la motivación y el interés para que aprendan nuevos saberes mediante la utilización de los medios de comunicación de la información.

- Utilizar los medios de comunicación de la información para que los alumnos se acerquen al conocimiento, probando, explorando e innovando a su propio ritmo, tomando en cuenta sus estilos de aprendizaje.

- Propiciar que los maestros se familiaricen con la tecnología educativa en los aspectos referentes a los medios y a las estrategias didácticas.

- Integrar los medios de información como un elemento más en el diseño curricular.

- Utilizar estrategias didácticas con los medios de comunicación disponibles.

- Propiciar una relación comunicativa dentro del aula con los alumnos mediante la comunicación de la información utilizando diversos medios.

- Propiciar que el alumno y el maestro, se familiaricen con los lenguajes utilizados en las imágenes como en la comunicación informática (tecnicismos, visuales, cromáticos, etc.).

- Determinar la relación de los medios de comunicación de la información y las materias que se imparten tomando conciencia de su papel socializador.

- Determinar el uso didáctico de los medios de comunicación de la información para seleccionar los más adecuados acorde al tipo de aprendizaje que se pretende alcanzar.

- Adquirir las destrezas técnicas necesarias para la utilización de los medios de comunicación de la información.

- Diseñar y producir medios de comunicación de la información que respondan a las necesidades educativas propias de la materia que se imparte y no ser sólo un usuario más de los medios existentes.

- Seleccionar los medios de comunicación de la información tomando en cuenta al grupo, al maestro, los objetivos a alcanzar, los contenidos del aprendizaje y el contexto.

- Realizar investigaciones con los medios y sobre los medios para obtener una participación consciente del maestro en el proceso didáctico, yendo más allá de ser un mero ejecutor y usuario de los medios, logrando una mayor comprensión sobre cómo funcionan los medios en un determinado contexto educativo.

\subsection{La evaluación}

Dentro del campo de la educación, otro aspecto clave es la evaluación, la cual presenta los resultados del proceso de enseñanza y aprendizaje. La evaluación contribuye a mejorar la educación y, en cierta forma, nunca se termina, ya que cada actividad que realiza un individuo es sometida a análisis para determinar si consiguió lo estipulado. La evaluación tiene el carácter de ser multifuncional, dependiendo del objetivo que se desea evaluar, ya sea al alumno, maestro, proceso educativo, institución escolar, familia, sociedad, etc. El proceso de evaluar no surge precisamente en el sector educativo como una necesidad de conocer al alumno o los procesos utilizados para educarlo, se evalúa por una función social que se relaciona con la evolución de las funciones que persigue la institución educativa como exigencia de una sociedad en constante cambio y del proceso de la necesidad de continuar preparándose para finalmente ser aceptado en un mercado de trabajo.

El significado de la evaluación depende de lo que se pretende evaluar, en el caso de la educación, el interés se centra en las funciones pedagógicas a saber: comprensión, regulación y mejora del proceso de enseñanza-aprendizaje, pero estas funciones generan consecuencias 
en otro tipo de funciones como son las sociales, psicológicas, de investigación, organización escolar, poder de control, construyendo categorías como: rendimiento educativo, calidad de la enseñanza, fracaso o éxito escolar, maestro eficiente o deficiente, alumnos buenos o malos, centro escolar eficiente o deficiente, etc.

Ejemplo 4. El maestro de Historia decide no dar clase ya que proyectará una película sobre la Guerra Cristera, que dura aproximadamente lo mismo que la clase, por lo que cita a los alumnos en la sala audiovisual y sin más preámbulo, el maestro dice: "Vamos a ver un pedazo de la Historia". Al estar pasando los créditos finales, el maestro interrumpe la proyección y les indica a los alumnos que se terminó el tiempo de la clase.

En la siguiente clase, el maestro quiere reafirmar los conocimientos de los alumnos sobre el tema entregándoles un cuestionario sobre los datos más relevantes de la película para que los respondan y comenten por equipo; pero cuál es su sorpresa, que la mayoría de los equipos sólo contestaron una pregunta de manera correcta y sólo un equipo respondió dos preguntas correctamente.

El maestro no entiende el porqué de esos resultados, pues considera que las películas siempre son atractivas y motivantes.

¿Qué está pasando?,¿Cuál es el problema? ¿Cuál es la posible solución?

NOTA: Ver posible respuesta en Apéndice A.

Se puede afirmar que la función didáctica de la evaluación es su integración como un elemento continuo del proceso de enseñanza-aprendizaje. No se puede concebir el proceso educativo sin la evaluación.

La evaluación es una actividad necesaria al proceso de enseñanza-aprendizaje que permite al maestro dar cuenta de los logros del aprendizaje en el alumno, determina la eficiencia y resultado de la labor del maestro y de los procedimientos o estrategias de enseñanza utilizados permitiendo realizar los ajustes, mejoras o correcciones requeridas. Algunos aspectos que se pueden evaluar dentro del proceso educativo involucran la enseñanza, la acción docente, procesos estratégicos, el aprendizaje, programas, currículo, aspectos institucionales, contexto educativo y físico.

La evaluación es un proceso que permite emitir un juicio de valor sobre los efectos de un programa y verificar si se cumplen las metas que se proponen alcanzar para de esta manera llevar a cabo correcciones y mejoras al proceso de enseñanza-aprendizaje dentro del aula.

\subsubsection{Técnicas, procedimientos e instrumentos de evaluación}

Los problemas de la evaluación no se solucionan con el simple hecho de que los maestros conozcan las técnicas, procedimientos e instrumentos para evaluar y que sepan aplicarlos, es necesario enfrentarlos con instrumentos técnicos, conceptos robustos que permitan realizar un análisis con mayor claridad del significado y sentido de la educación dentro del salón de clases (Díaz-Barriga y Hernández, 2002).

Técnicas de evaluación informal. Se utilizan en procesos de enseñanza breves, pueden ser utilizados para evaluar tanto la enseñanza como el aprendizaje, no suelen ser presentados a los alumnos, por lo que se utilizan para evaluar los desempeños tanto de los maestros como de los alumnos, se utilizan como técnicas para obtener los datos por medio de registros anecdóticos, listas de control, diarios de clase, guías de observación, etc. Se pueden clasificar en:

a. Observación de actividades de los maestros. Su principal función es conocer las estrategias didácticas, de programación y plan de clase, momentos de la clase, características del 
maestro, interacción con los alumnos, etc. Pueden ser sistemáticas o asistemáticas, generalmente son del tipo no participante, pero en algunos casos se convierte en participante cuando a algún alumno se le encomienda o él esté investigando al realizar la observación.

b. Observación de actividades de los Alumnos. La utiliza el maestro en forma incidental o intencional durante el proceso de enseñanza-aprendizaje, puede ser sistemática o asistemática, abierta o focalizada, en forma natural o artificial (dinámica de grupos), participante o no participante, permite realizar una evaluación formativa y procesal.

c. Exploración con preguntas. El maestro formula una serie de preguntas, cuya finalidad es estimar el nivel de comprensión de los alumnos, sobre el tema que se está abordando y poder determinar si es necesario aclarar, reformar, repetir o profundizar sobre algún concepto. También permite evaluar los saberes previos de los alumnos para utilizarlos como referencia para ir construyendo conocimientos nuevos.

Técnicas semiformales. Se caracterizan por demandar más tiempo para valorarlas, mayor tiempo de preparación y exigencia en las respuestas; a diferencia de las informales, se puede considerar como una actividad de evaluación que sí representa un valor para los alumnos. Se pueden clasificar en:

a. Trabajos y ejercicios dentro de la clase. Consisten en una serie de actividades para evaluar la comprensión o ejecución de lo que son capaces de hacer y decir los alumnos en un momento determinado. Se deben planear de tal manera que haga al alumno practicar reflexivamente, revisar y aprender.

b. Trabajos y ejercicios fuera de la clase. Consisten en tareas y trabajos que los maestros encomiendan a los alumnos como actividad de investigación o ejercitación de lo aprendido en clase. Como ejemplo, se puede mencionar la investigación en la biblioteca o en internet, visitas a lugares relacionados con los temas específicos (museos, empresas, etc.), solución de problemas, realización de prácticas, entrevistas. Estas actividades pueden ser individuales o por equipo.

c. Evaluación de carpetas. Consiste en elaborar un álbum donde se coleccionan los trabajos realizados por los alumnos, éstos pueden ser: resúmenes, dibujos, ensayos, composiciones, reflexiones, solución de problemas, etc.; la finalidad es disponer de evidencia física de los aprendizajes y progresos de los alumnos, permitiendo evaluar habilidades, destrezas, actitudes, valores, uso y aplicación de conceptos, etc.

Técnicas formales. Requieren de un proceso más sofisticado en su planeación y elaboración, con un mayor grado de control. Se aplican periódicamente, después de cada tema o al final de cada ciclo.

- Pruebas o exámenes. Pretenden evaluar el grado de rendimiento o aprendizaje alcanzado por los alumnos en situaciones controladas; se pueden clasificar en estandarizadas y formuladas por los maestros de acuerdo al proceso didáctico. Se prefieren elaborar como pruebas objetivas, con respuestas cerradas para evitar la subjetividad al interpretar las respuestas.

- Mapas conceptuales. Consisten en recursos gráficos que presentan jerárquicamente conceptos y proposiciones sobre un tema específico, permiten evaluar contenidos declarativos (reconocer, relacionar, evocar, etc.).

- Pruebas de desempeño o ejecución. Consisten en diseños de situaciones para que el alumno demuestre sus habilidades aprendidas; como ejemplo, se puede mencionar: reparar equipos, realizar experimentos, solucionar problemas, escribir reportes o composiciones, etc. Se pretende evaluar el uso funcional de lo aprendido, poniendo en práctica el grado de comprensión y significatividad de lo aprendido. 
Las pruebas o exámenes son los instrumentos de mayor uso por los maestros por lo que se analizarán algunas técnicas en cuanto a su aplicación.

Prueba oral. Consiste en preguntas que el alumno responde de forma verbal con respuestas orientadoras (responde a un cuestionario) libres (el alumno desarrolla un tema específico designado).

Prueba escrita. Consiste en preguntas que el alumno responde en forma escrita, pueden ser de diferentes tipos:

a. Prueba objetiva. Pueden ser estructuradas o semiestructuradas, cuyas respuestas son concretas y certeras, se seleccionan de un conjunto de opciones, evitando el juicio subjetivo del maestro al calificar. Permiten evaluar aprendizajes de comprensión, valores, actitudes, habilidades. Éstas pueden ser:

- Opción múltiple. Requiere que el alumno seleccione sólo una respuesta entre varias opciónes.

- Ordenamiento. Requiere que el alumno ordene fenómenos, hechos o componentes de un todo que se le muestran en forma desordenada.

- Relación. Requiere que el alumno relacione dos columnas cuyos contenidos estén relacionados; un ejemplo puede ser una columna con conceptos u objetos y otra con definiciones o características.

- Complemento. Requiere al alumno que complete la información de un enunciado con una palabra, número o signo.

b. Pruebas subjetivas. No son las más recomendadas, debido a la interpretación que debe hacer el maestro de las respuestas de los alumnos, permiten evaluar opiniones de los alumnos, tendencias, situaciones, solución de problemas, creatividad, valores, etc. No son muy confiables para evaluar aprendizajes de comprensión. Éstas pueden ser:

- Respuesta abierta. Requiere que el alumno conteste preguntas en forma escrita sin tener opción de respuesta, sino que es libre de contestar lo que "sabe". Las respuestas pueden ser restringidas (consiste en una explicación breve) y extensa (consiste en dar amplia libertad al alumno para dar su respuesta).

Ejemplo 5. El maestro de Ciencias Sociales elaboró un examen de preguntas abiertas, de 20 preguntas de respuesta corta; decide aplicarlo como cierre de la clase aprovechando la última media hora. El maestro procura que las preguntas estén correctamente estructuradas para disminuir la apreciación subjetiva y para emitir un juicio de valor más justo.

Una vez aplicado el examen, el maestro se dispone a evaluarlo y cuál es su sorpresa cuando encuentra que la totalidad de los alumnos no aprobaron el examen.

¿Qué está pasando?,¿Cuál es el problema? ¿Cuál es la posible solución?

NOTA: Ver posible respuesta en Apéndice A.

- Ensayo. Requiere que el alumno dé una respuesta original ante un conjunto de preguntas y/o indicaciones, se puede realizar en el salón de clase, laboratorio, taller o extracurricular y al igual que en la respuesta abierta puede ser restringida o extensa.

\subsubsection{Funciones de la evaluación}

Según Díaz-Barriga y Hernández (2002), las funciones que cubre la evaluación son:

Diagnóstica. Es aquella que se realiza para determinar el estado del alumno de manera previa al desarrollo del proceso educativo, ésta puede ser: 
a. Puntual. Se realiza en distintos momentos al inicio de cada tema de enseñanza correspondiente a un curso específico, su función evaluativa tiene como finalidad identificar y utilizar de manera continua los saberes previos de los alumnos.

b. Inicial. Se realiza en un solo momento y exclusivamente para determinar el estado inicial del alumno de manera previa al inicio de un ciclo o proceso educativo amplio.

Formativa. Permite durante el proceso de enseñanza-aprendizaje, conocer los aprendizajes alcanzados y sus posibles causas que los afectan para retroalimentar al grupo y realizar las adecuaciones que se requieran.

Sumativa. Permite verificar elaprendizaje alcanzado en una unidad o curso permitiendo certificar el aprendizaje de los alumnos.

\subsubsection{Sugerencias de investigación sobre la práctica de evaluación}

A continuación se describen algunas características que pueden ser motivo de investigación sobre la práctica de evaluación.

- Analizar el diseño y verificación de la validez (que evalúen aquello para lo que fueron elaboradas) y la confiabilidad (en condiciones similares los resultados son similares) de los instrumentos, para evaluar:

- Saberes: utilizando pruebas o exámenes, presentaciones frente al grupo por los alumnos, ensayos, exposiciones, etc.

- Compresión: utilizando demostraciones, proyectos de investigación, estudio de casos, resolución de problemas, simulaciones, etc.

- Habilidades: utilizando la lectura oral, experimentación, dibujo, ejecución de instrumentos musicales, el baile, etc.

- Habilidades de trabajo: utilizando equipos de medición, herramienta, protección, etc.; recursos de capacidad creadora, la planeación, liderazgo, etc.

- Actitudes sociales: utilizando instrumentos para evaluar el respeto, la colaboración, sensibilidad, participación grupal, preocupación por el bienestar de los otros, etc.

- Actitudes científicas: utilizar instrumentos para evaluar percepción y comprensión de los fenómenos (causa y efecto), capacidades para la investigación, indagación y comprobación.

- Valores: utilizando instrumentos para evaluar los diferentes valores de vida, morales, éticos y sociales dependiendo de las necesidades de la investigación como pueden ser el respeto, la tolerancia, el desempeño, los sentimientos, etc.

- Analizar la naturaleza y uso de los procedimientos de evaluación utilizada por el maestro, valorando los procesos, no sólo el producto.

- Analizar la contextualización de la evaluación buscando la relación entre el contexto y los saberes para formular una teoría.

- Analizar la coherencia que debe existir entre la actividad evaluativa y el proceso de enseñanza-aprendizaje (tal es el caso de los exámenes estandarizados, elaborados por especialistas de la educación).

- Analizar el desarrollo de la capacidad de autoevaluación en los alumnos para proponer situaciones y espacios en donde aprendan a evaluar los procesos y resultados de sus propios aprendizajes. 


\subsection{El contexto}

La escuela representa una situación social que va más allá de sus fronteras, por lo que su contexto se debe tratar desde un enfoque globalizador en donde intervienen todos los sectores involucrados, tomando en cuenta el contexto político, económico, cultural, familiar, el sistema educativo, los medios de comunicación, etc. buscando ayudar a mejorar la situación de los alumnos, profesores y familias.

Los alumnos desarrollan su vida en este contexto, de aquí la importancia de que relacionen los saberes que adquieren con la vida real y cotidiana que ocurre en éste. Es por esto que se requiere trabajar con tareas auténticas que le signifiquen dentro de su ámbito cultural, ante la necesidad de aprender a resolver problemas que se le presentan dentro de su realidad, requiriendo como consecuencia de un aprendizaje contextualizado que le dé un significado real a los saberes aprendidos.

\subsubsection{El contexto dentro del salón de clase o aula}

El salón de clase es un espacio social dinámico donde se desarrollan actividades complejas que se correlacionan entre sí mediante la participación y el diálogo que propician actitudes, valores, roles, conflictos, como producto del proceso de enseñanza-aprendizaje. El salón de clase cobra importancia en su organización para sacarle el mayor provecho, creando un clima adecuado de trabajo y así mejorar el proceso de enseñanza-aprendizaje.

Existen dos componentes que intervienen en la organización del salón de clase: el espacio y el tiempo, que se orientan hacia los alumnos y el maestro, pero se estructuran en función de las necesidades del currículo y los objetivos instruccionales (Vázquez, 2004).

\subsubsection{El espacio}

La disposición del espacio y la ubicación del mobiliario, promueven los procesos de aprendizaje en el salón de clase y el trabajo de los alumnos dependiendo del estilo del maestro. Es común utilizar dos modelos de organización:

a. La organización tradicional. Donde el principal protagonista es el maestro, que presenta un ángulo de influencia fuerte para los pupitres del frente que disminuye conforme se alarga la distancia hacia los pupitres de atrás en las últimas filas. Predomina la comunicación de transmisión de contenidos, la recepción y el trabajo individual de los alumnos.

b. La organización activa. Se considera el salón de clase como un espacio de servicio de aprendizaje donde se alterna el trabajo individual con el grupal, el espacio se organiza en función del tipo de aprendizaje y la interacción que se pretende lograr. Se basa en agrupamientos flexibles que propician la convivencia y la comunicación facilitando el trabajo entre compañeros.

\subsubsection{El tiempo}

El tiempo debe organizarse como un componente del salón de clase para satisfacer las necesidades sociales del contexto y la sociedad plural que la integra, de aquí la importancia de seleccionar los momentos más adecuados para los distintos tipos de aprendizaje, así como los apoyos que se requieran dentro y fuera del salón de clase.

Es el maestro quien debe seleccionar qué tipo de organización del salón de clase requiere y la disposición del tiempo, a lo largo del proceso educativo según se requiera configurar el proceso de enseñanza-aprendizaje. Utilizando algunas opciones de estrategias de acuerdo al tipo de organización que esté aplicando y de los objetivos que persigue. 


\subsubsection{Modelos organizativos}

Dependiendo de los objetivos que se persiguen y de las estrategias que se pretende emplear, el salón de clase puede ser utilizado siguiendo algunos modelos preconcebidos de acuerdo a las características y edades de los alumnos. A continuación se presentan algunos ejemplos.

- Rincones. Son espacios del salón de clase creados para fomentar la participación de los alumnos, por medio de la realización de diferentes actividades actitudinales o intelectuales. Son utilizados para trabajar con grupos pequeños a partir del segundo ciclo en preescolar (3 a 6 años), en donde no todos los alumnos realizan la misma actividad.

- Talleres. Su referente se encuentra en el desarrollo de contenidos, principalmente procedimentales y actitudinales, donde el alumno participa activamente en torno a una temática, en pequeños grupos, por parejas o en forma individual. Algunos ejemplos que se pueden mencionar, consisten en la elaboración de textos, construcciones matemáticas, el reciclaje, etc. Se consolida a partir de la primaria.

- Agrupamientos flexibles. Se reagrupa a los alumnos cambiando de equipo cada que se requiera de acuerdo a sus diferencias individuales como pueden ser intereses, ritmo de aprendizaje, necesidades, etc.

- Modelos cooperativos. Se basa en el aprendizaje a través de grupos pequeños heterogéneos (4 05 alumnos). Implica para los alumnos compartir los saberes adquiridos, la información, para construir el conocimiento con las aportaciones de todo el equipo.

- Plan de trabajo individualizado. El alumno trabaja en forma autónoma, organizando el contenido que va a trabajar y su tiempo, finalizando con una autoevaluación. Su destinatario es por lo general el alumno de primaria y secundaria.

\subsubsection{El contexto familiar}

Se considera a la familia como la célula de la sociedad, siendo ésta una organización social primaria, que se constituye como un microsistema de la organización social, cuya característica primordial son los vínculos y relaciones afectivas que se desarrollan en su interior en donde los integrantes de la familia desempeñan roles y funciones como parte esencial de ésta; estos roles y funciones propician la relación con los sistemas externos como son la escuela, el barrio, el trabajo, etc. Es la familia en donde se aprenden los valores y se transmite la cultura, siendo un factor determinante la ubicación geográfica en donde está inmersa la familia, lo que determina en muchas ocasiones algunas características de su organización y los roles que se dan en su interior. Es una función social básica de la familia, la educación de los hijos, que se debe cumplir según los tiempos y sociedades, adecuándose a los contenidos y formas, el tiempo y el lugar. Es usual que muchas familias deleguen una sustantiva parte de esa educación a la escuela.

Los contextos familiar y educativo constituyen los principales entornos del desarrollo del alumno (infantil y adolescente), de aquí la importancia de las relaciones que deben existir entre los dos contextos.

En la idea tradicional de familia, una de las funciones de la figura paterna es la de "proveedor", imponiendo de esta manera su autoridad y fuerza, recayendo casi toda la responsabilidad de la formación sobre la figura materna. Dicha idea ha sufrido importantes cambios en las últimas décadas, resultado de los nuevos roles sociales y de trabajo de los padres, así como por el contexto de cambio social y nuevos estilos de vida, generando los nuevos modelos de relaciones dentro de la familia.

Se ve facilitada la convivencia entre padres e hijos, en donde los padres actuales evitan las situaciones de enfrentamiento que vivieron como adolescentes con sus padres, 
sustituyendo la norma del "respeto", que imponía la obediencia y el temor a la reacción de los padres, por buscar tener una buena comunicación, fomentar las potencialidades y capacidades de sus hijos y comprender sus necesidades y sus puntos de vista.

Sin embargo, estas décadas también trajeron cambios en los modelos tradicionales de la familia que se constituyen de la siguiente manera (Quintero, 2007):

- Las familias nucleares son aquellas conformadas por los dos padres e hijos.

- Las familias extensas donde conviven los dos padres o uno de los dos, los hijos, además de miembros de familia, tales como tíos, abuelos y primos, etc.

- Las familias sobre-compuestas donde conviven padre y madre, más los hijos que se hayan tenido en otras relaciones anteriores.

- Las familias monoparentales, las que solo poseen uno de los dos padres y ejecuta el rol de los dos a la vez.

El aumento de las familias monoparentales causadas por viudez, adopción, madre soltera, separaciones, divorcios, hospitalización, etc., y la incorporación de las madres al mercado laboral, considerando que hasta hace poco era la madre la que atendía, la que se quedaba en casa y por tanto, realizaba la función educadora de sus hijos, representan aspectos que dificultan la conciliación de la vida familiar y laboral, afectando el tiempo dedicado a los hijos, siendo cada vez más frecuente, que cuando sale el niño de la escuela no encuentre a sus padres al volver a casa para que se hagan cargo de su cuidado y atención, exponiéndolo a los peligros de los medios de comunicación y el contexto social que rodea al hogar.

\subsubsection{La función educadora de los padres}

La relación de los esposos se convierte en fraternal con la llegada del primer hijo, lo que requiere como actividad principal de la pareja el cuidado del bebé, desde ese momento inicia el proceso educativo de los padres. Con la etapa escolar los padres establecen las reglas, normas y límites en la educación del niño. Los padres de manera intuitiva van cubriendo el proceso de educar a sus hijos en los siguientes términos:

- Transmisión de valores. Los padres pretenden fomentar la responsabilidad en sus hijos mediante la obligación que les imponen de realizar algunas tareas dentro del hogar, por ejemplo: tender su cama, recoger su habitación, recoger la ropa, guardar los libros, etc. Los padres transmiten los valores con el ejemplo de sus comportamientos, actitudes, gestos, etc. que son observados, imitados, interpretados de manera inconsciente por sus hijos (Ramírez, Ávila, Barrios y Vázquez, 2012).

También utilizan incentivos o premios para promover los comportamientos en los hijos que los conduzcan a la adquisición de valores, así como de las visiones que les presentan para que obtengan el éxito dentro de la sociedad por medio del esfuerzo individual y el trabajo mediante una convivencia en paz (tolerancia y responsabilidad).

Los padres pretenden fomentar en sus hijos valores como honradez, responsabilidad, tolerancia, solidaridad, etc. tomando en cuenta los intereses de sus hijos referentes a la familia, la amistad, las relaciones personales, el amor, los estudios o el trabajo.

- Incentivos para que estudien. Es necesario que los padres se preocupen por fomentar el estudio y la adquisición de conocimientos en sus hijos y que vigilen si estudian lo necesario brindándoles además su ayuda. Los resultados educativos de los hijos dependen de la supervisión de los padres y de la valoración que hacen de su rendimiento educativo. Esta supervisión e incentivación al estudio debe ser continua y no esporádica como sucede en la realidad en la mayoría de los casos. 
- Apoyos para el rendimiento escolar. Los padres generalmente ayudan a los hijos con sus deberes adquiridos dentro de la educación formal, estos deberes son tareas que deben realizar los hijos solos sin ayuda, como complemento y confirmación de lo que se explicó en clase, pero en la realidad es que surgen dudas y requieren de ayuda normalmente en el entorno familiar, pero no todos los padres pueden proporcionarla, ya sea por su nivel educativo o porque ambos padres trabajan. Sin embargo, muchos padres que están en este último caso, sí supervisan estrechamente el estudio de sus hijos, pues su mayor capital cultural se traduce en una mayor posibilidad de prestar apoyo a sus hijos en sus deberes.

- Apoyo con recursos educativos. A pesar de que los padres delegan a la escuela la educación formal de sus hijos, apoyan a ésta por otros medios como son: las actividades extraescolares (completando la formación con actividades como los idiomas, música, deportes, etc.), recursos educativos y culturales en el hogar como son libros, enciclopedias, colecciones, revistas, computadoras, internet, programas didácticos para computadora, televisión, DVD didácticos o enciclopédicos, etc.

\subsubsection{Participación de padres en la escuela}

Los padres para determinar las condiciones en que se encuentra la educación de su hijo utilizan diversos caminos: 1) por medio de las calificaciones de sus asignaturas, que le permiten observar los progresos de los niños; 2) trato personal o telefónico con tutores, profesores o la dirección de la escuela que proporcionan información acerca del rendimiento y la conducta de su hijo y de sus compañeros y algunos otros aspectos; 3) por las diferentes informaciones que se dan a conocer por escrito (citatorios, eventos, calificaciones, etc.); y 4) por las reuniones de padres de familia a lo largo del curso con el tutor o profesor en donde se tratan las calificaciones, el rendimiento y comportamiento.

Se pueden observar los comportamientos y las actitudes de los padres a través de su participación en la vida de la comunidad escolar por medio de dos instancias: la participación en el gobierno de las escuelas y la participación en la organización o realización de actividades colectivas.

- Participación en el gobierno de la escuela. El medio utilizado para participar es el consejo escolar, que está representado por maestros, padres, alumnos y personal administrativo y cumple funciones tan relevantes como el nombramiento del equipo directivo en los centros públicos.

- Participación en asociaciones de padres de alumnos y otras actividades. Tienen una doble vertiente. Por una parte, son una institución por la que, indirectamente, los padres participan en el gobierno de los centros y por otra, actúan como cualquier asociación voluntaria que presta servicios a sus miembros, en este caso, a los hijos de sus miembros (con o sin el sostén financiero del centro escolar).

\subsubsection{El Contexto Social}

La escuela debe educar para la ciudadanía y los derechos humanos cuyos contenidos se organizan en tres temas desde una perspectiva integradora:

- La vida individual y sus relaciones interpersonales y sociales. Partiendo de situaciones cotidianas se analiza la igualdad de hombres, mujeres en la familia, la sociedad y el trabajo.

- La vida en comunidad. Analiza la convivencia en las relaciones con el entorno, cómo abordarla y analiza los conflictos que pueden presentarse en grupos (familia, escuela, localidad, amigos), así como de los derechos y deberes individuales dentro de los grupos. 
- La vida en sociedad. El análisis social es más amplio, involucra el conocimiento y necesidad de las normas y principios de convivencia que establece la Constitución de los derechos y deberes de las administraciones públicas y de los ciudadanos en su mantenimiento.

La comunidad que rodea a la escuela es siempre una unidad compleja e interrelacionada con una variedad de organizaciones y grupos sociales, como consecuencia cada comunidad tiene características que le dan cierta identidad, a manera de una personalidad social.

Cada comunidad es única por lo que los procedimientos que se empleen para su estudio no deben ser rígidos, varían dependiendo del espacio, tipo de comunidad donde está enclavada la escuela, y el tiempo histórico de ésta, su pasado, la realidad presente y las expectativas futuras de sus habitantes.

En las condiciones actuales, la sociedad exige a la escuela instruir y educar en valores, desarrollar la independencia cognoscitiva de los alumnos, potenciar la creatividad, así como la capacidad de observar. Para ello se hace evidente el vínculo con el entorno que rodea al escolar, donde vive y se desarrolla: la comunidad.

En la actualidad el contexto cultural, es el encuentro de diversas culturas. Esas diferencias se manifiestan en cualquier atributo de la sociedad humana: lenguaje, creencias religiosas, el arte, la música, la estructura social. Es por esto que se requiere adaptar el proceso educativo a las necesidades y características sociales, afectivas y cognitivas de esta diversidad cultural que existe en los distintos alumnos.

La diversidad personal y cultural es una característica propia del ser humano que contribuye a que éste se enriquezca mediante las diferencias de sentir, vivir, pensar y convivir. Las escuelas deben diseñar, seleccionar y poner en práctica un plan de atención a la diversidad que consiste en un conjunto de actuaciones, adaptaciones al currículo, medidas organizativas, apoyos y refuerzos para proporcionar a los alumnos una respuesta que se ajuste a sus necesidades educativas.

\subsubsection{Sugerencias de investigación sobre el contexto}

Algunas características motivo de investigación sobre el contexto pueden ser:

- La ubicación de los elementos espaciales y su adecuada planificación de acuerdo a los objetivos propuestos.

- Determinantes de tipo ambiental y su normativa (por ejemplo, si la escuela está ubicada en una zona sin ruido excesivo).

- La disposición de espacio para realizar distintas actividades en el aula.

- Posibilitar espacios para distintos tipos de agrupamientos con apoyo fuera del aula.

- El fenómeno del bullying dentro y fuera de la escuela.

- Contar con espacios concretos, requeridos por los objetivos programados.

- El aprovechamiento de los espacios disponibles en la escuela.

- Conflictos en el aula y su mediación, tales como confrontación de creencias, valores, ideas, estilos de vida, opiniones, comportamientos, etc.

- Determinar el rendimiento escolar dentro de un sistema familiar violento.

- Métodos y estrategias para enseñar a solucionar problemas en el entorno escolar.

- La influencia de los medios de comunicación en los valores o falta de ellos en los alumnos.

- La influencia del contexto social en los valores y la violencia en los alumnos.

- Determinar el rendimiento escolar de los alumnos que pertenecen a un sistema monoparental. 
- Determinar el rendimiento escolar de los alumnos que pertenecen a un sistema familiar donde los dos padres trabajan.

Ejemplo 6. Juanito era uno de los niños con mayor aprovechamiento de la clase, pero últimamente sus calificaciones han disminuido considerablemente, se ha vuelto poco sociable, al grado que ya no quiere salir del salón de clase a jugar en los recreos. El maestro preocupado mandó llamar a sus padres, para investigar si tiene algún problema familiar; al acudir éstos, la mamá explicó al maestro que en casa todo era cordial, ya que decidieron que ella no trabajaría para que pudiera atender a sus hijos, y su papá convivía con ellos después del trabajo.

El maestro habló entonces con Juanito para preguntarle si tenía algún problema en su casa, el barrio o la escuela, que no le permitiera estudiar; Juanito contestó que no, que ya no le gustaba estudiar ni quería ir a la escuela.

¿Qué está pasando?, ¿Cuál es el problema?

¿Cuál es la posible solución?

NOTA: Ver posible respuesta en Apéndice A. 



\section{PARTE II \\ ¿Cómo recolectar datos en la investigación educativa?}





\section{Capítulo 2}

\section{Técnicas e instrumentos para la recolección de datos}

El objetivo de la recolección de datos en la investigación educativa tiene como función principal la evaluación de factores que intervienen en la formación de los alumnos dentro del proceso educativo. No basta con señalar las técnicas o instrumentos que evalúen las actividades de los alumnos, también se deben considerar los factores que las afectan de manera significativa como el maestro, las estrategias didácticas, los programas, las reformas educativas, el contexto, las instituciones, entre otras.

Para emitir un juicio sobre el estado en que se encuentran los alumnos dentro del proceso educativo es común realizar dos tipos de recolección de información de acuerdo a los parámetros que se deseen medir, ya sea para realizar un diagnóstico o una evaluación.

El diagnóstico tiene un carácter descriptivo, se aplica a sujetos y en el campo escolar se encuentra vinculado a la valoración de aspectos como las aptitudes, los intereses, la personalidad, entre otros. Cada alumno como individuo es especial, por lo que la enseñanza debe adecuarse al estudiante como parte de un grupo, tomando en cuenta estas individualidades (educación individualizada), por lo que el diagnóstico adquiere un carácter preventivo y de desarrollo de las potencialidades que van más allá de la función terapéutica y correctiva.

El diagnóstico dirige su atención hacia el sujeto y su entorno, refiriéndose entonces a situaciones que expliquen y pronostiquen las exigencias sociales y escolares, siendo necesaria la participación de los agentes educativos que intervienen (pedagogos, orientadores, padres de familia, maestros, alumnos).

En el caso de la evaluación, se lleva a cabo en relación al currículo, los programas, las estrategias didácticas, profesores y alumnos. La evaluación es un proceso que conlleva a la toma de decisiones y a la formulación de juicios de valor. La evaluación está vinculada con los aprendizajes incidiendo en ámbitos académicos del dominio cognoscitivo (Padilla, 2002).

El proceso de evaluación implica entonces realizar un análisis de los exámenes, registro de notas, test, diarios de campo y guías de observación. Se puede decir que la evaluación es consustancial a la actividad cotidiana del investigador en educación.

La evaluación requiere especificar de manera clara y sistemática los pasos que deben seguirse durante su proceso para poder ser implementada en cualquier tipo de problema que se presente y sea fácil de usar y entender.

En el contexto de lo anterior, se parte de la siguiente definición de evaluación:

Proceso de obtener información para formular juicios que permitan la toma de decisiones.

La evaluación es cada vez menos acreditadora y sancionadora para convertirse en formativa y continua, con un interés no sólo en los resultados, sino también en los procesos que 
se requieren para mejorarlos; evaluando además del alumno a los programas, maestros, metodologías, contextos e instituciones.

Ante esta situación, tanto el diagnóstico como la evaluación cobran sentido dentro de la intervención educativa enfocándose a la intervención y mejora de la situación. Requieren de las mismas técnicas o procedimientos de recogida de información, deben seguir un proceso sistemático que garantice los resultados que se requieren en un trabajo científico, permitiendo validar el análisis e interpretación de la información recogida.

Para elaborar un instrumento para la recolección de información (datos), se debe determinar el tipo de información que se requiere para formular adecuadamente los juicios o la toma de decisiones; y una vez definido el siguiente paso es la preparación para obtener dicha información mediante las siguientes estrategias:

1. Localizar la información que se encuentra disponible (expedientes, archivos, notas personales, entre otros documentos).

2. Determinar cómo, dónde y cuándo obtener la información que se requiere y que no esté disponible (constatando su validez y confiabilidad).

3. Elaborar o seleccionar los instrumentos de recogida de la información que cumplan con la validez y confiabilidad requeridas.

En forma general se pueden tomar en cuenta cuatro técnicas o métodos para la recogida de información, éstas son: la observación, la interrogación, el análisis y los test.

La observación. La información se puede obtener con el hecho de observar, determinando cuáles son los elementos importantes que dan origen a un fenómeno, suceso o la ocurrencia de un evento o producto. El objetivo es proporcionar información sobre algún hecho o fenómeno, que permita identificarlo y diferenciarlo de otros, conocer sus características y las variables asociadas a él; es decir, cuándo, cómo y en qué circunstancias ocurre.

La interrogación. Una de las formas más simples de obtener información es preguntando, permite obtener información sobre opiniones, intereses, actitudes o relaciones interpersonales. Los instrumentos más comunes para la obtención de información son los cuestionarios, las entrevistas y las técnicas sociométricas.

El análisis. Esta estrategia parte del principio de dividir un todo en sus partes. Tal es el caso del contenido de una clase presentada por el docente, un programa o los trabajos de los alumnos (tareas, proyectos, etc.) los cuales pueden ser analizados en una gran diversidad de elementos o factores.

Los test. Son instrumentos más exactos y eficientes para la recolección de información; debe cumplir con las siguientes características: los sujetos responden a una situación común; los reactivos se ajustan a un conjunto de instrucciones comunes; la puntuación de las respuestas debe corresponder a un conjunto de reglas comunes; $y$ las respuestas de cada sujeto deben corresponder a una descripción numérica. Para asegurar que los procedimientos sean estandarizados y exista objetividad en la puntuación se debe cumplir con las tres primeras características, mientras que la cuarta da precisión a los resultados permitiendo realizar cálculos matemáticos con éstos.

\subsection{La observación}

Para que la observación sea considerada como una técnica científica requiere reunir una serie de características: ser planificada sistemáticamente, controlada (objetiva, comprobable), estructurada (vinculada a teorías e hipótesis), intencionada (quién, qué y cómo se observará) y con proposiciones generales; servir a objetivos planteados; y estar sujeta a comprobaciones de validez y fiabilidad que presuponen que sea susceptible de ser cuantificada (Padilla, 2002). 
Asimismo, la observación requiere de un sistema de registro que permita dejar constancia de lo que se ha percibido, permitiendo codificar la información para ser interpretada de acuerdo a un marco explicativo o teórico relacionado con el objeto de observación. La percepción e interpretación de la realidad no debe ser subjetiva, sino que debe ser apoyada por un registro riguroso y organizado que dé constancia fiel de lo observado. Las modalidades de la observación más comunes son:

a. Observación participante. El investigador participa en la vida diaria del grupo objeto de estudio, interactúa como uno más de sus integrantes con el objeto de obtener información, registrarla e interpretar datos. Le permite captar la perspectiva interna de los hechos y registrarlos tal como los percibe. Sin embargo, se puede presentar una desventaja si el investigador es absorbido por el grupo y pierde objetividad (Albert, 2007).

b. Observación no participante. El investigador no pertenece al grupo objeto de estudio, es un elemento externo al mismo. Este tipo de observación puede ser: directa, hecha sobre el terreno en contacto con la realidad; o indirecta, la que utiliza datos y fuentes documentales en donde el investigador ejerce control sobre la forma de obtención y elaboración de los documentos, se limita a seleccionar, observar e interpretar dichos documentos (Padilla, 2002).

c. Observación sistematizada o controlada. El investigador debe preparar con antelación y detalle el plan específico que llevará a cabo en el momento de la observación. Se puede construir sobre una teoría específica que permita definir las variables de comportamiento del fenómeno estudiado. El proceso de la observación se estructura en categorías bien definidas (Goode y Hatt, 2004).

d. Observación no sistematizada, ocasional o no controlada. No responde a alguna regla explícita. Su finalidad es conocer con más profundidad el objeto a investigar cuando se sabe relativamente poco de su entorno; pretende que el conocimiento que el investigador tiene de la situación o conducta aumente y como consecuencia estreche el campo de la observación (Padilla, 2002).

\subsubsection{Observación sistematizada}

Con la finalidad de evitar errores o imprecisiones en la observación es conveniente establecer un proceso que la sistematice para que el investigador determine previamente la categoría a observar, fije los datos que se deben recoger y si es posible cuantificarlos (Padilla, 2002).

Las variables se deben operacionalizar por medio de operadores accesibles a la observación directa, en donde las condiciones situacionales de partida deben ser sometidas a controles con la finalidad de posibilitar observaciones comparables. La observación consiste en prestar atención a la ocurrencia de las conductas previamente definidas para registrar la frecuencia, duración y magnitud. El hecho de definir con antelación el plan específico para proceder a la observación permite que diferentes investigadores registren siempre las mismas conductas, permitiendo así la comparación y cuantificación de la observación.

Rodríguez, Gil y García (1999) proponen una secuencia que sirve como guía para la planeación y sistematización de la práctica de observación, la cual consiste en:

1. Determinar la finalidad de la observación. Definir cuál es el objetivo, las preguntas o problema a resolver (por ejemplo, determinar si todos los alumnos participan en equipo en la realización de una práctica de laboratorio).

2. Elaborar un marco teórico, conceptual o de referencia. Especificar la teoría, los supuestos y las condiciones de las cuales se parte (por ejemplo, definir en qué consiste el trabajo en equipo, qué factores afectan el buen funcionamiento, entre otros). 
3. Definir el objeto de observación. Determinar con precisión y sin ambigüedades qué es lo que se quiere observar (por ejemplo, definir las conductas observables que indiquen la participación de los alumnos durante la realización de la práctica —-manipulan el equipo, registran datos, realizan cálculos-).

4. Definir qué categorías se deben incluir en el sistema y definir su significado y campo de acción. Éstas deben ser:

- Claras: de fácil comprensión y memorización, sin ambigüedades.

- Completas: definir el límite de cada conducta que permita discriminarlas entre si.

- Mutuamente excluyente: sólo se debe asignar un caso a cada categoría sin que se confunda con otras categorías.

- Exhaustivas: deben agotar todas las posibilidades del fenómeno.

- Homogéneas: la variable debe guardar una relación lógica con las demás.

5. Seleccionar el número de categorías que compondrán el sistema. El número de categorías dependerá de la complejidad del fenómeno a observar y la situación en que se observa. A más categorías mayor dificultad para diferenciar los matices entre ellas (por ejemplo, el número de categorías seleccionado son cuatro: manipular el equipo, registrar datos, realizar cálculos e interpretar datos).

6. Preparación de la hoja de registro. Se trata de elaborar un formato que facilite su aplicación en situaciones reales, por lo general consiste en la elaboración de una tabla de doble entrada para registrar la ocurrencia de las categorías, su secuencia, frecuencia, duración, entre otras dimensiones de ocurrencia.

En la guía anterior se propone el uso de sistemas categoriales, los cuales son sistemas cerrados en los que la observación se realiza siempre desde categorías prefijadas por el observador (Rodríguez et al., 1999). Los instrumentos más comunes para el registro de las observaciones son:

a. Sistemas de categorías. Modelos que concretan la explicación de fenómenos o constructos que pretenden garantizar la fiabilidad y validez del sistema diseñado, estableciendo intervalos de tiempo para obtener muestras representativas de la conducta o fenómeno estudiado en términos de su frecuencia y duración.

Ejemplo 7. Sistemas de categorías. En la secundaria mixta de la zona 1 de Guadalajara, un grupo de 12 alumnos se reúnen para intercalar ideas sobre el bullying utilizando una dinámica de grupo conocida como "pequeños grupos de discusión".

En este ejemplo se pretende observar el sistema que se utiliza en la dinámica grupal. Para tal efecto se elabora una guía de observación, en la cual se reúnen las categorías del sistema y se consigna el número de ellas que representan las conductas observadas durante los intervalos de observación.

b. Listas de control. Consisten en un conjunto de conductas (a priori) registrando su presencia o ausencia durante el periodo de observación (Best, 1981). Este registro debe tener una fundamentación conceptual que dé sentido a las categorías, no requiere establecer intervalos de tiempo. Es útil cuando se quiere observar conductas poco frecuentes o muy diversificadas, sólo se indica la presencia o ausencia de la conducta en el sujeto o grupo de sujetos que se observe.

c. Escalas de estimación. Consisten en una serie de características o comportamientos para ser observados y valorados de acuerdo a una relación jerarquica que representa diferentes 
grados de atributos. Estas escalas son adecuadas para conductas con alta frecuencia de aparición o poca diversificación en sus manifestaciones, permiten cuantificar las impresiones obtenidas a partir de las observaciones exigiendo juicios cuantitativos sobre el grado o magnitud de la conducta.

\section{Cuadro 1. Sistema de categorías.}

PROFESOR: Roberto. FECHA: 27/05/2013.

\section{GRUPO: A.}

\section{INTERVALO DE DURACIÓN: 5 segundos de observación.}

1. Formular el tema: informa con precisión el tema o problema a debatir a los participantes con anticipación para que se preparen, informen y fundamenten la discusión.

2. Solicitar intervención: solicita que sea breve para recapitular. Destaca los objetivos logrados.

3. Propiciar la exposición: solicita que sea libre para que expresen sus ideas y puntos de vista.

Participación del Director.

Participación de los miembros del equipo.

4. Otorgar la palabra: regula el tiempo, limita a los acaparadores y alienta a los que no participan para que lo hagan.

5. Estimular la participación: solicita que todos participen dentro del grupo de discusión aportando ideas, argumentos y puntos de vista.

6. Redirigir las dudas al grupo: devuelve al grupo las preguntas que se le hacen de manera directa, por ejemplo, ¿qué harían en ese caso?

7. Mantener un ambiente sano: propicia en todo momento un ambiente informal, cordial y participativo.

8. Propiciar la expresión de ideas: en el transcurso de la discusión logra que los integrantes del equipo expresen sus ideas, evita expresar sus ideas personales en el momento de formular el resumen.

9. Designar al director: el equipo selecciona a Miguel para que conduzca la discusión del grupo ese día.

10. Designar un secretario: el equipo selecciona a Martha para que realice la función como secretaria y registre la información resultante de la discusión.

11. Escuchar a los demás: lo hacen con sentido comprensivo, centrándose en las ideas y no en las personas.

12. Reconocer errores: admiten sus equivocaciónes y los rectifican cuando se requiere.

13. Ser solidarios con las conclusiones: participan en la elaboración de las conclusiones de manera participativa y democrática.

14. Establecer normas: proponen las normas, tiempo de duración de la discusión así como el tiempo de cada intervención de los participantes.

15. Elaborar un resumen: con el acuerdo del grupo formula las conclusiones.

Participación del secretario.

16. Registrar las conclusiones: toma nota de las ideas que se expresan durante la discusión.

17. Propiciar las conclusiones: interviene para llegar a las conclusiones por acuerdo o consenso, cuando se requiere, registra por votación. 
Ejemplo 8. Listas de control. Los alumnos de la Normal Superior deben exponer una clase que presente el encuadre de la materia de su especialidad. Para constatar la presencia de los elementos mínimos necesarios para la realización del encuadre se preparó una lista de control (Cuadro 2).

\section{Cuadro 2. Lista de control.}

\section{CENTRO: Normal Superior. OBSERVADOR: Roberto.}

\section{FECHA: 27/05/2013.}

Actividad observada.

Sí No

\section{+ Presentación del curso.}

- Menciona la importancia de la materia.

- Menciona cuál es su contenido.

- Menciona su ubicación en el plan de estudios.

- Menciona la relación con otras asignaturas.

\section{+ Objetivos de aprendizaje.}

- Incluye Objetivos informativos.

- Incluye Objetivos formativos.

\section{+ Contenidos temáticos.}

- Indica cómo se trabajará durante la clase.

- Indica cómo se trabajará con las tareas.

- Indica cómo se trabajará con las tareas o productos fuera de clase.

- Indica cómo se trabajará individualmente.

- Indica cómo se trabajará en equipo.

\section{+ Evaluación.}

- Explicita los criterios y mecanismos para la acreditación, calificación y evaluación.

- Explicita los juicios de calidad para otorgar calificaciones.

\section{+ Bibliografía.}

- Incluye bibliografía básica u obligatoria.

- Incluye bibliografía complementaria o de apoyo. 
Ejemplo 9. Escalas de estimación. Los alumnos de bachillerato de la carrera de Técnico en Electrónica, requieren realizar una práctica que consiste en tomar lecturas de corriente y voltaje utilizando como medidor un multímetro digital, así como identificar los puntos de medición de circuitos serie y paralelo realizando las conexiones correspondientes.

La escala de estimación seleccionada (Cuadro 3) permite observar el comportamiento de los alumnos durante el desarrollo de una práctica de electrónica, la cual requiere colaboración en equipo para resolver de modo efectivo los requerimientos.

Cuadro 3. Escala de estimación.

\section{SUJETO: A1. OBSERVADOR: Roberto.}

FECHA: 27/05/2013.

\begin{tabular}{|c|c|c|c|c|c|}
\hline Actividad observada & Nunca & $\begin{array}{l}\text { Pocas } \\
\text { veces }\end{array}$ & $\begin{array}{l}\text { Algunas } \\
\text { veces }\end{array}$ & $\begin{array}{c}\text { Muchas } \\
\text { veces }\end{array}$ & Siempre \\
\hline \multicolumn{6}{|l|}{ Toma lectura de las mediciones. } \\
\hline \multicolumn{6}{|l|}{ Manipula el equipo de medición. } \\
\hline \multicolumn{6}{|l|}{$\begin{array}{l}\text { Registra los datos obtenidos } \\
\text { durante las mediciones. }\end{array}$} \\
\hline \multicolumn{6}{|l|}{$\begin{array}{l}\text { Realiza las conexiones requeridas } \\
\text { en los circuitos. }\end{array}$} \\
\hline \multicolumn{6}{|l|}{ Comenta los resultados obtenidos. } \\
\hline \multicolumn{6}{|l|}{$\begin{array}{l}\text { Hace comentarios que ayuden } \\
\text { a organizar el equipo. }\end{array}$} \\
\hline \multicolumn{6}{|l|}{$\begin{array}{l}\text { Permanece en el equipo durante } \\
\text { la práctica. }\end{array}$} \\
\hline \multicolumn{6}{|l|}{$\begin{array}{l}\text { Respeta las opiniones } \\
\text { de sus compañeros de equipo. }\end{array}$} \\
\hline \multicolumn{6}{|l|}{$\begin{array}{l}\text { Ubica los puntos de medición } \\
\text { en los circuitos. }\end{array}$} \\
\hline \multicolumn{6}{|l|}{$\begin{array}{l}\text { Aporta opiniones para la } \\
\text { elaboración de las conclusiones. }\end{array}$} \\
\hline $\begin{array}{l}\text { Hace intervenciones que faciliten } \\
\text { la realización de la práctica. }\end{array}$ & & & & & \\
\hline
\end{tabular}

Las escalas de estimación más comunes, según Rodríguez et al. (1999) son:

- Escalas descriptivas o verbales. Los rangos o escalas se manifiestan por medio de expresiones verbales más o menos descriptivas. 
Ejemplo 10. Escala de estimación descriptiva o verbal.

Categoría: Utiliza el equipo de medición correctamente:

Rangos:（）Nunca ( ) Pocas veces ( )A veces ( ) Casi siempre ( ) Siempre

- Escalas descriptivas con información adicional. Los rasgos o escalas se manifiestan por medio de expresiones verbales con una descripción más amplia, relacionado con el rasgo y la actividad efectuada.

Ejemplo 11. Escala de estimación descriptiva con información adicional.

Categoría: Utiliza el equipo de medición correctamente:

Rangos:

( ) Nunca, sólo sus compañeros realizan las mediciones.

( ) Pocas veces solicita a sus compañeros realizar las mediciones.

( ) A veces solicita a sus compañeros realizar las mediciones.

( ) Casi siempre realiza las mediciones.

( ) Siempre es el primero en realizar las mediciones.

- Escalas numéricas. Los rangos o escalas se manifiestan por medio de números asignados al grado de magnitud (fuerza) de la conducta. Pueden ser crecientes (mínimo a máximo) o decreciente (máximo a mínimo).

Ejemplo 12. Escala de estimación numérica.

Categoría: Utiliza el equipo de medición correctamente:

Rangos: ( $1 \begin{array}{llllll}1 & ()_{2} & ()_{3} & \text { ( ) } 4 & \text { ( ) } 5\end{array}$

- Escalas gráficas. Los rangos se manifiestan por medio de líneas o barras que sitúan las frases descriptivas o valores numéricos otorgando una mayor precisión en la selección del rango.

Ejemplo 13. Escala de estimación gráfica.

Categoría: Utiliza el equipo de medición correctamente:

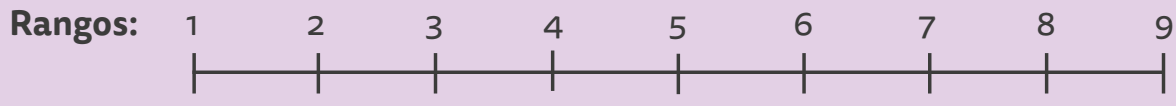

\subsubsection{Observación no sistematizada (ocasional o no controlada)}

Este tipo de observación no se define por las conductas o categorías en que se centra la observación sistematizada, sólo parte de ideas muy generalizadas, su importancia radica en proporcionar una descripción de la conducta o categoría y su contexto, proporcionando información valiosa y abundante sobre las conductas críticas y sus circunstancias (Padilla, 2002).

La observación no sistematizada usualmente inicia su proceso con una observación muy general, donde no está definido lo que se quiere observar y las unidades de observación son muy amplias (observación descriptiva). Después de esa primera fase, comienzan a hacerse presentes unidades de observación de mayor frecuencia y relevancia relacionadas con el problema que dio origen a la investigación, reduciéndose esas unidades (observación focalizada). 
Por último, se seleccionan sólo aquellos sucesos que permitan al investigador comprobar la hipótesis planteada (observación selectiva).

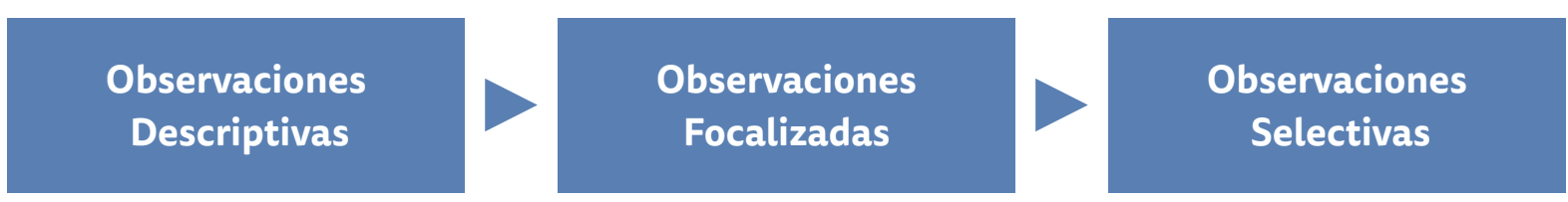

Figura 1. Proceso que sigue usualmente la observación no sistematizada.

\subsubsection{Tipos de registros observacionales}

El registro de la información depende del sistema perceptivo del investigador y su habilidad para describir en lenguaje ordinario lo que observó. Existen diferentes tipos de registros mediante los cuales se pueden realizar las observaciones sistematizadas y no sistematizadas (Padilla, 2002).

a. Registros de acuerdo al grado de sistematización.

- Registros no sistematizados. Son aquellos registros narrativos como los diarios, registros anecdóticos, continuos o de muestras.

- Registros sistematizados parcialmente. Son aquellos que se preparan a detalle, restringiendo la libertad de observación de ciertos fenómenos. En esta categoría se pueden enunciar las listas de control (sistemas de signos y lista de rasgos) y escalas de estimación.

- Registros sistematizados. Se construyen sobre la base de una teoría explícita que permiten estructurar categorías definidas con precisión y sometidas a un control con la modalidad de datos categoriales.

b. Registros abiertos o cerrados.

- Registros categoriales. Se construyen para ser usados en una gran variedad de situaciones y no en casos individuales; se pretende identificar leyes generales de comportamiento.

- Registros descriptivos. Se construyen para obtener una descripción detallada de los fenómenos observados; se pretende explicar procesos en desarrollo para su comprensión. Los datos se registran dentro de los límites naturales de los acontecimientos y el contexto dentro de un periodo de observación que puede variar en longitud. Es muy usual combinarlos con los registros tecnológicos.

- Registros narrativos. Al igual que en los registros descriptivos, se pretende explicar procesos en desarrollo pero no se limita sólo a la comprensión del fenómeno sino también a identificar los factores que inciden en la aparición de las conductas estudiadas desde una perspectiva cronológica. Los datos pueden realizarse en el sitio o en vivo (registros de incidentes críticos, de muestras y notas de campo). Es muy usual combinarlos con los registros tecnológicos.

- Registros tecnológicos. Consisten en grabaciones en vivo (video o audio) de acontecimientos y datos; registros permanentes que permiten estudiar con mayor profundidad los acontecimientos en momentos posteriores a la obtención de la información.

c. Registros en el sitio o en vivo.

- Notas de campo. Son registros en lenguaje cotidiano sobre lo que se observa (apuntes o notas breves). En estas notas se registra cualquier información que el investigador considere de utilidad para sus propósitos de investigación, como pueden ser las expresiones, hechos, fuentes de información y diagramas. 
- Registros anecdóticos (registros de incidentes o críticos). Como su nombre lo indica, registran anécdotas o breves descripciones de conductas o eventos, suelen hacer referencia a comportamientos poco usuales y que son significativos con relación al fenómeno objeto de estudio o problema que dio origen a la investigación. Son descripciones escritas de las observaciones realizadas por el investigador, deben ser notas factuales no interpretativas de los hechos en un clima natural.

- Registros de lista de control. Permiten investigar comportamientos específicos para determinar si lo que se investiga está presente; se elabora una lista de lo que se busca y se marca cada uno de los aspectos encontrados, determinando de esta forma qué conductas o características enlistadas están presentes o no. Representa una técnica fácil y objetiva obteniendo mayor fiabilidad comparado con el registro anecdótico.

- Registros de muestras. Describen acontecimientos que se sitúan en forma sistemática e intensiva durante la observación, registran lo que hace o dice un sujeto o grupo de sujetos y la información relativa al contexto, procurando que el registro sea cronológico durante un periodo de tiempo preestablecido y lo más detallado posible.

Ejemplo 14. Registro Anecdótico.

FECHA: 27/05/2013 HORA: 14:00 hrs.

PARTICIPANTES DEL INCIDENTE: Academia de Español.

OBSERVADOR: Roberto.

CONTEXTO: Reunión mensual de la Academia de Español.

DESCRIPCIÓN DEL INCIDENTE: Se discute que cinco alumnos crean problemas dentro del grupo $5^{\circ} \mathrm{B}$. Una de las maestras propone suspenderlos durante una semana, pero otro maestro se opone de manera tajante argumentado que se debe dejar a los alumnos que se expresen libremente. La maestra responde que una cosa es la libertad y otra el libertinaje, lo que propicia una discusión entre los maestros. Finalmente, la propuesta se acepta por medio de una votación.

VALORACIÓN: Existe una gran influencia de las nuevas corrientes que proponen que el alumno sea auténtico y propicie su autoformación preparándose para la vida. Sin embargo, el maestro tiene una gran responsabilidad en la formación del alumno, no solo en la transmisión de estrategias para que el alumno se apropie del conocimiento, sino también en aspectos de disciplina que las apoyen. Es importante que los maestros se sensibilicen en una educación integral.

- Registros de escalas de evaluación. Consiste en un conjunto de conductas o características que se gradúan para ser juzgadas, estipulando por adelantado las características a juzgar y las formulaciones descriptivas que se utilizarán para realizar el juicio, logrando que las observaciones sean más objetivas y precisas.

d. Registros posteriores.

- El diario. Se elabora apoyado en las notas de campo, se anota lo que el investigador recuerda, las reflexiones o impresiones provocadas por lo que observó. Permiten captar el carácter longitudinal, cronológico y procesual de los eventos observados. Los patrones de conducta se extraen del texto creando unidades inferidas para identificarlos y describirlos de acuerdo a lo que se está investigando.

- Ordenación. Consiste en ordenar personas u objetos de acuerdo al grado en que poseen la característica que se mide. Se utiliza sólo cuando se requiere de un cálculo grosso modo en grupos relativamente pequeños de individuos u objetos. Los procesos más comunes son cuando se dividen temas u objetos en la media, arriba y por debajo de ésta, 
o por emparejamiento en el que cada alumno se compara con los otros designándole una posición, lo cual representa una desventaja al ser subjetivo.

\subsubsection{Fiabilidad y validez de los registros observacionales}

Es necesario determinar los criterios y garantías de fiabilidad y validez que deben satisfacer la observación. Por esta razón, se plantean algunas sugerencias que pueden ser utilizadas como argumento para satisfacer a los científicos con respecto a estos conceptos.

Fiabilidad. Algunos de los procedimientos para determinar la fiabilidad interjueces son el cálculo del porcentaje de acuerdos y el índice Kappa para sistemas de registros de intervalos, o la correlación de Pearson y el análisis de varianza para casos como las escalas de estimación (Padilla, 2002).

Se sugieren como registros fiables las siguientes situaciones:

- Cuando el mismo observador repita la misma observación en distintos momentos y obtenga siempre los mismos datos.

- Cuando diferentes observadores repitan la misma observación en distintos momentos y obtengan siempre los mismos datos.

- Cuando diferentes observadores que perciben simultáneamente una realidad y obtengan siempre los mismos datos.

- Cuando el mismo observador en dos momentos diferentes de una sesión gracias a la grabación en video obtiene los mismos datos en los dos registros.

Validez. En los sistemas categoriales (sistemas de categorías, listas de control y escala de estimación) se puede determinar la validez de contenido de los instrumentos diseñados mediante la opinión de un grupo de expertos (en la materia o tema a observar). Los coeficientes de correlación ofrecen índices empíricos de concordancia. En el caso de la validez de constructo se requiere la aplicación del instrumento a sujetos distintos en muchas ocasiones, utilizando técnicas estadísticas (intercorrelaciones y análisis factorial) para determinar si el comportamiento de los registros concuerda con la estructura teórica desde la cual está diseñado el instrumento.

Se sugieren los siguientes criterios de validez aplicables a los registros observacionales:

- Los datos deben obtenerse de tal manera que se puedan realizar inferencias legítimas desde el nivel manifiesto al latente.

- La relación que existe entre lo que se evalúa y lo que se desea evaluar (validez de constructo).

- Relevancia y significatividad de las conductas observadas (validez de contenido).

- Coherencia y concordancia de los datos obtenidos a través de los instrumentos observacionales (validez de criterio).

\subsection{La encuesta}

Este método consiste en solicitar información desde el punto de vista de otras personas a través de la formulación de preguntas, es decir, preguntar a quien tiene la información que se busca, sobre qué sabe, cree, espera, siente o quiere, intenta hacer o ha hecho y acerca de sus explicaciones o razones. La formulación de estas preguntas tiene dos modalidades: La entrevista y el cuestionario-encuesta (Rojas, 2007).

La encuesta como técnica involucra dos formas de interacción entre el encuestador y el encuestado. La primera consiste en la interacción personal, en la cual el investigador y el entrevistado se encuentran cara a cara y mediante la entrevista el primero formula las preguntas a este último; la segunda consiste en la interacción impersonal, en la cual el investigador por medio de un cuestionario-encuesta formula las preguntas que hace llegar 
al entrevistado, pero no lo hace cara a cara. En algunas ocasiones se pueden mezclar estas dos formas de encuesta con el objeto de indicar de manera oral el procedimiento de llenar el cuestionario-encuesta y aclarar las dudas que puedan surgir.

\subsubsection{La entrevista}

Consiste en una conversación en la cual dos o más personas interactúan de forma verbal y no verbal, y en la que uno de los participantes ejerce el control con el propósito de cumplir un objetivo predeterminado.

La entrevista es una estrategia que puede usarse como medio para recabar información de grandes poblaciones con el fin de probar hipótesis científicas, como medio para conocer opiniones de los estudiantes, maestros y padres de familia, relacionados con aspectos educativos, cambios de conducta, diagnósticos y de orientación.

Además de recoger información sobre alguna situación o problema, permite ser utilizada como una estrategia de intervención, cumpliendo con las funciones diagnóstica, motivadora, terapéutica y la recogida amplia de información sobre el entrevistado, siendo su característica más significativa la interacción personal (Albert, 2007).

De acuerdo a Santiago y Lukas (2014) las entrevistas se pueden clasificar atendiendo a diferentes criterios:

1. Según los objetivos, las que persiguen la recogida de información y las que persiguen la intervención.

2. Según el marco teórico del entrevistador, se distinguen entre entrevistas fenomenológicas, psicodinámicas y conductuales.

3. Según el grado de estructuración, se clasifican en:

a. Entrevistas estructuradas. En este caso se prefijan el texto y la secuencia de las preguntas y en algunos casos también la situación de la entrevista y las respuestas que debe dar el entrevistado.

b. Entrevistas semiestructuradas. Constan de preguntas abiertas y una secuencia que puede ser prefijada o no, esto es, se cuenta con las preguntas prefijadas y poseen una pauta o esquema de entrevista.

c. Entrevistas no estructuradas. En este caso no existen esquemas o indicaciones que marquen el rumbo de la entrevista, ni las preguntas están prefijadas, aunque puede estar guiada por esquemas implícitos.

\subsubsection{Entrevistas estructuradas}

En este tipo de entrevistas el protocolo del que dispone el entrevistador recoge todas las preguntas realizadas, en algunas ocasiones, también dispone de las posibles respuestas entre las que debe elegir el entrevistado. Es común definir esta entrevista como la aplicación oral del cuestionario al entrevistado por parte del entrevistador (Rojas, 2007).

Como técnica estructurada se debe delimitar previamente el marco conceptual desde el cual se realiza la entrevista, éste da sentido a las preguntas y alternativas de respuesta, permitiendo reforzar o desestimar los supuestos previos de los que parte el entrevistador.

La entrevista estructurada se realiza con un cuestionario y con una cédula que se debe utilizar a medida que se desarrolla. La cédula debe ser llenada por el entrevistador y no por el entrevistado, en ésta aparecen todas las instrucciones, preguntas y opciones de respuesta, así como espacios o casillas vacías para anotar las respuestas del entrevistado. Según Padilla (2002) algunas de las funciones que debe cubrir esta cédula son: 
- Constituir una guía para el entrevistador indicándole las preguntas a realizar y el orden que deben seguir.

- Garantizar que a todos los entrevistados se les pregunta lo mismo y de la misma forma.

- Funcionar como formularios para el entrevistador en los que se podrán anotar y recoger las respuestas.

El contenido de la cédula debe incluir:

- Una breve introducción, con la referencia de los fines que se persiguen y el proceso que se busca desarrollar.

- Instrucciones de cómo se debe responder de acuerdo al tipo de pregunta, confidencialidad, entre otros.

- Preguntas a formular y las alternativas de respuesta con sus espacios y casillas en blanco para registrar las respuestas.

- Agradecimientos, al finalizar la entrevista se debe consignar la fórmula de agradecimientos.

La utilidad de este tipo de entrevista consiste en analizar situaciones desde una óptica exploratoria y sondear las opiniones de un colectivo ante las mismas; al estar presente el entrevistador cuando se formulan las instrucciones y preguntas existe flexibilidad en conseguir la información por parte del entrevistado, pero esto requiere de un interrogatorio individual y por separado, lo cual representa una desventaja al elevar el costo de la investigación. Por otra parte, el entrevistado tiene que verbalizar sus respuestas frente al entrevistador, existiendo la posibilidad de que este último conozca su nombre y dirección, lo que provoca dudas con respecto a la confidencialidad del encuestado.

\subsubsection{El cuestionario}

Es un instrumento de investigación que consiste en una serie de preguntas escritas que se pueden responder sistemáticamente, se utilizan generalmente para obtener opiniones y conocer actitudes.

El cuestionario auto-administrado soluciona el problema que representa la entrevista estructurada cuando el número de encuestados que pueden proporcionar información es numeroso, resultando una estrategia más económica.

Debido a que son muchas las semejanzas entre el cuestionario y la entrevista estructurada se requiere resaltar las ventajas que presenta el cuestionario con relación a la entrevista:

- La información se obtiene sin que medie la relación personal entre encuestado y encuestador.

- Es menos costoso, debido a que se puede aplicar a gran número de encuestados simultáneamente.

- Puede enviarse por correo.

- Existe mayor sensación de anonimato y por consecuencia, mayor libertad de expresarse.

- El encuestado dispone de más tiempo para dar la respuesta.

Entre las desventajas se encuentran las siguientes:

- No se puede aplicar a encuestados que no saben leer ni escribir o les es difícil expresarse por escrito.

- Si se envía por correo, no todos lo regresan. 
Según Padilla (2002), los cuestionarios pueden clasificarse de acuerdo con:

- El tipo de ítems que lo conforma, pueden ser cuestionarios abiertos, cerrados, elección múltiple o escalas de estimación.

- La escala de respuesta, pueden ser cuestionarios que buscan juicios categóricos o los que buscan juicios continuos.

- El método de administración (correo, teléfono, internet, personal).

- El tipo de información, pueden ser cuestionarios de información general o cuestionarios específicos.

\subsubsection{La elaboración de cuestionarios}

Como ya se ha mencionado, los cuestionarios consisten en un listado de preguntas que se presentan por escrito a responder de manera sistemática, en el cual no hay respuestas correctas; la finalidad del instrumento es obtener opiniones y conocer actitudes en lugar de medidas de rendimiento como sucede con un test. A decir de Albert (2007), la elaboración de un cuestionario está sujeto a las siguientes fases:

1. Describir la información que se requiere.

2. Elaborar las preguntas necesarias para obtener la información requerida.

3. Organizar las preguntas en el orden más adecuado.

4. Elaborar un instrumento para recolectar las respuestas.

5. Redactar las instrucciones para facilitar las respuestas.

6. Reproducir el cuestionario de acuerdo al número de participantes.

Fase 1. Describir la información que se requiere. Se debe tener claro el objeto de la opinión que se desea recabar, determinar sobre qué o quién se requiere y el tipo de información por obtener.

Ejemplo 15. El maestro desea saber la opinión de sus alumnos en lo referente a la presentación del video utilizado para analizar el tema sobre cuerpos en caída libre. Desea saber si el contenido del video se presentó en forma clara, si siguió un orden adecuado y si facilitó la comprensión.

- Sobre qué: presentación del video.

- Tipo de información: características del contenido del video.

- La opinión de quién: los alumnos.

La información que se obtenga diferirá de acuerdo al tipo de pregunta que se realice. En el ejemplo podría referirse a la secuencia que utilizó el maestro al presentar el video: ¿se realizó una presentación previa del contenido?, ¿hubo una motivación para ver el video?, ¿durante la presentación se aclararon dudas?, refiriéndose al tipo de información relativa al uso del video.

Las preguntas del cuestionario deben ser redactadas de acuerdo al nivel de lectura de quienes lo deben contestar (vocabulario y estructura de las oraciones), no es lo mismo que respondan alumnos, maestros o expertos; también es indispensable que quienes respondan sepan algo y tengan una opinión sobre lo que se pregunta.

Fase 2. Elaborar las preguntas necesarias para obtener la información requerida. Las preguntas deben ser claras y concisas, ser adecuadas a quienes las van a contestar y ser redactadas de tal manera que sus respuestas proporcionen el tipo de información requerida. 
Fase 3. Organizar las preguntas en el orden más adecuado. Esta fase se relaciona directamente con la razón de la evaluación, para tal efecto las cuatro maneras más utilizadas para ordenar las preguntas son:

- De lo general a lo específico. Se debe de ordenar las preguntas iniciando con las de naturaleza general, para finalizar con las más específicas. La utilidad de ordenarlas consiste en obtener opiniones en diversos niveles de generalidad o comparar opiniones generales con opiniones de ejemplos específicos.

- De no comprometido a sensible. Con el objetivo de darle confianza al que debe responder se debe iniciar con preguntas que no exigen un compromiso, para continuar con el planteamiento de preguntas sobre temas que involucran un mayor grado de sensibilidad para el que responde.

\section{Cuadro 4. Tipos de preguntas que se pueden elaborar.}

\begin{tabular}{|c|c|c|}
\hline Tipo de pregunta & Descripción & Ejemplo \\
\hline Directas & Se puede usar para abrir un tema. & $\begin{array}{l}\text { ¿Qué piensas sobre } \\
\text { el contenido del video? }\end{array}$ \\
\hline Comparativas & $\begin{array}{l}\text { Permite hacer juicios generalmente } \\
\text { entre elementos de contenido. }\end{array}$ & $\begin{array}{l}\text { ¿Harías la tarea o estudiarías } \\
\text { para el examen? }\end{array}$ \\
\hline Causa-efecto & $\begin{array}{l}\text { Permite averiguar razones ante } \\
\text { acontecimientos o situaciones } \\
\text { concretas. }\end{array}$ & $\begin{array}{l}\text { ¿Por qué dejó el maestro } \\
\text { el doble de tarea? }\end{array}$ \\
\hline Debería & $\begin{array}{l}\text { Permite averiguar las opiniones sobre } \\
\text { acciones y situaciones preferidas e } \\
\text { ideales. }\end{array}$ & $\begin{array}{l}\text { ¿Cómo consideras que se debería } \\
\text { de evaluar en educación física? }\end{array}$ \\
\hline Qué harías & $\begin{array}{l}\text { Permite averiguar sobre las creencias y } \\
\text { modelos. }\end{array}$ & $\begin{array}{l}\text { Si fueras el director y presencias } \\
\text { alguna forma de bullying, } \\
\text { ¿qué harías? }\end{array}$ \\
\hline Para recordar & $\begin{array}{l}\text { Permite averiguar lo que se recuerda } \\
\text { de un acontecimiento que pasó. }\end{array}$ & $\begin{array}{l}\text { ¿Qué recuerdas sobre el video } \\
\text { que se proyectó el viernes? }\end{array}$ \\
\hline Comportamientos & $\begin{array}{l}\text { Permite establecer hechos de cómo } \\
\text { se conducen; si el comportamiento es } \\
\text { típico se puede acompañar con otras } \\
\text { preguntas. }\end{array}$ & $\begin{array}{l}\text { ¿Puedes recordar por qué le } \\
\text { gritaste a tu compañera?, ¿estás } \\
\text { acostumbrado a gritarle } \\
\text { a los demás? }\end{array}$ \\
\hline De sentimientos & $\begin{array}{l}\text { Permite obtener reacciones subjetivas } \\
\text { y afectivas sobre algún hecho. }\end{array}$ & $\begin{array}{l}\text { ¿Cómo te sentiste cuando } \\
\text { el maestro te dio tu calificación? }\end{array}$ \\
\hline De reacciones & $\begin{array}{l}\text { Permite obtener detalles } \\
\text { sobre reacciones, opiniones o } \\
\text { acontecimientos. }\end{array}$ & $\begin{array}{l}\text { ¿Qué te molestó sobre la evaluación } \\
\text { de las tareas? }\end{array}$ \\
\hline Por qué & $\begin{array}{l}\text { Permite buscar razones para algunas } \\
\text { opiniones. }\end{array}$ & $\begin{array}{l}\text { ¿Por qué cada sexenio se presenta } \\
\text { una nueva reforma educativa? }\end{array}$ \\
\hline
\end{tabular}

- Orden temático. Consiste en agrupar las preguntas en temas y subtemas, permitiendo al que debe responder considerar todas las preguntas relacionadas con éstos, ayudándole a ser más consistente, expresando todas sus opiniones sobre un tema específico en un plazo corto. 
- Orden mezclado. Si la razón de la evaluación es averiguar si el que debe responder es consistente en sus actitudes hacia ciertas personas, lugares o cosas, entonces se mezclan las preguntas, reduciendo la posibilidad de que se dé cuenta de cualquier inconsistencia en sus respuestas y refleje sus verdaderas opiniones.

Fase 4. Elaborar un instrumento para recolectar las respuestas. Una vez especificadas las preguntas y su orden, se determina como consecuencia el tipo de respuesta que se debe obtener, por lo que es necesario especificar de qué manera el que debe responder registrará sus respuestas. Éstas pueden anotarse en el mismo cuestionario o en hojas por separado. Hacerlo en hojas por separado es un poco más difícil pero presenta la ventaja de que los cuestionarios se pueden utilizar varias veces y resulta más fácil puntualizar en las hojas separadas. Por otra parte si las respuestas son abiertas, se recomienda dejar espacio suficiente porque la respuesta puede ser larga; en el caso de utilizar respuestas de escalas no se deben amontonar, lo que causaría dificultad para marcarlas; y por último si las respuestas son de inventario conviene tener cada alternativa por separado.

Fase 5. Redactar las instrucciones para facilitar las respuestas. Las instrucciones deben ser claras y estar bien redactadas, ya que un buen diseño del cuestionario puede fracasar con un mal diseño de instrucciones. Las instrucciones que acompañan a un cuestionario deben contener los siguientes elementos:

- Razones para el cuestionario. Consiste en una introducción que debe darle legitimidad al cuestionario; quien lo responde debe saber para qué y por qué debe contestarlo. Esta parte de las instrucciones puede ser breve pero creíble.

Ejemplo 16. El cuestionario está diseñado para conocer tu opinión acerca del servicio de la biblioteca. Se desea conocer cómo mejorarlos. Tus respuestas permitirán determinar los cambios que se requieren para lograrlo.

- Procedimientos para utilizarlo. Consiste en una serie de instrucciones para describir los procedimientos para responder un cuestionario, indicando cómo responderlo e informando cualquier límite que se quiera imponer a las respuestas; ayuda sobre todo en casos donde el que debe de responder no está familiarizado con el tipo de respuesta que el investigador desea que dé.

Ejemplo 17. Para cada pregunta subraya el número entre el 1 al 5 que se aproxima más a tu percepción sobre los servicios de la biblioteca.

Te cuesta trabajo localizar los libros en la estantería:

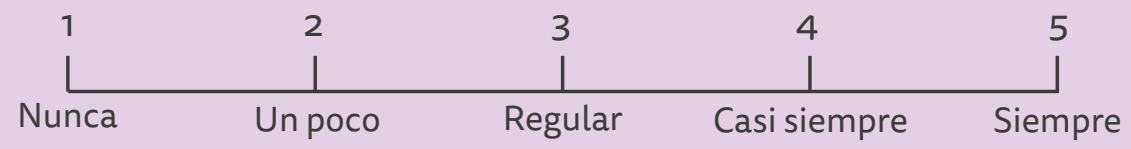

- Confidencialidad. Las instrucciones deben indicar si los resultados serán confidenciales o no.

Ejemplo 18. Confidencialidad. Estas respuestas son confidenciales, por favor no incluya sus datos personales. 
Fase 6. Reproducir el cuestionario de acuerdo al número de participantes. El uso de las computadoras permite elaborar los instrumentos de una manera fácil y agradable a la vista, basta con imprimir un tanto y el resto se obtiene en una fotocopiadora hasta completar el número de cuestionarios requeridos. Hay que asegurarse que se emplea un formato fácil de leer, cuidando no amontonar las preguntas para ahorrarse papel y dejando suficiente espacio entre ellas para que se registren correctamente las respuestas.

\subsubsection{Formulación y selección de preguntas para la elaboración de cuestionarios y entrevistas estructuradas}

Partiendo del método de la encuesta, basado en preguntas, se puede afirmar que el arte de preguntar consiste en elaborar y aplicar procedimientos de entrevistas y cuestionarios. La formulación y selección de preguntas representa una tarea de suma importancia en la elaboración de estos instrumentos; son tantos los tipos de preguntas, los criterios a considerar para su formulación y las fuentes de sesgos, que es necesario ser muy cuidadosos para recabar la información que corresponda a las necesidades de la investigación. Ante esta situación, Padilla (2002) sugiere las siguientes consideraciones para el proceso de la elaboración de cuestionarios y encuestas estructuradas:

1. Contextualizar el uso de la técnica en el proceso, es decir, construir los instrumentos partiendo de la formulación del problema o los objetivos que se proponen para la investigación.

2. Plantear y explicitar el marco teórico conceptual; éste es el cimiento necesario para construir un buen instrumento. Lo que implica definir constructos o características de lo que se está investigando, esta tarea se puede sintetizar en:

- Definir el constructo, característica o tema a investigar, teniendo como referencia a la población objeto de la investigación. Determinar de qué conceptos se parte, cómo se entiende esa característica, qué elementos esenciales la componen, entre otros aspectos.

- Explicar y definir las dimensiones que componen el tema objeto de investigación. El constructo puede ser uni o multifuncional dependiendo del fenómeno que se investiga y de la perspectiva del investigador. Dentro del cuestionario o la entrevista estructurada se pueden abordar temas que engloban a su vez, subtemas relacionados entre sí y con el constructo general (multifuncional); también se puede partir de características unidimensionales, que no se pueden dividir en distintas partes diferenciadas porque todas tratan de lo mismo.

- Enumerary definir los indicadores observables que operativizan el significado de las dimensiones establecidas. Dentro de lo posible, los indicadores se deben referir a hechos, conductas y acciones concretas, sin ambigüedades y que se entiendan de la manera más objetiva posible.

3. Elaborar un banco amplio de posibles preguntas a realizar. De acuerdo a los indicadores del paso anterior recogiendo el contenido de cada uno de ellos.

4. Seleccionar las mejores preguntas y reformularlas de acuerdo a los criterios de uso. Elegir las que reúnen mejor los requisitos preestablecidos.

5. Confeccionar el primer borrador del cuestionario o de la cédula de la entrevista. Debe estudiarse el orden de las preguntas y la presentación del instrumento, indicando las finalidades de la investigación y las instrucciones.

6. Realizar estudios piloto de la versión inicial. Se trata de poner diferentes filtros que vayan contribuyendo a la mejora continua del cuestionario o entrevista dependiendo del alcance del proyecto y de las condiciones de partida. Algunos de estos filtros pueden ser: 
- Revisión por parte de especialistas. Tanto en la construcción del instrumento como en la temática abordada en éste.

- Revisión por parte de sujetos. Utilizando sujetos con características similares a los que compondrán la muestra del estudio, opinando sobre las dificultades que encontraron para interpretar y comprender las preguntas.

- Prueba piloto. Utilizando sujetos con características similares a los que compondrán la muestra del estudio, los cuales son sometidos al instrumento y sus respuestas son procesadas por análisis estadísticos que permitan detectar los defectos en su construcción.

Dentro del proceso anterior, es importante considerar el tipo de preguntas que serán utilizadas. De acuerdo al tipo de respuesta se puede realizar una clasificación:

a. Pregunta de respuesta libre o abierta, en la cual el que debe responder tiene la libertad para elaborar su respuesta.

Ejemplo 19. Un investigador desea saber si se utiliza el video correctamente como estrategia educativa, por lo que entrevistó a 20 maestros que utilizan con frecuencia la sala audiovisual para proyectar videos.

¿Por qué utiliza el video como apoyo didáctico?

¿Qué temas son los que se transmiten mediante el uso del video?

¿Cómo utilizaría el video para reforzar lo tratado en el salón de clase?

¿Cómo utilizaría el video para tratar temas nuevos?

¿Cómo utilizaría el video para motivar a los alumnos?

¿Qué pasos realiza al utilizar el video?

b. Pregunta de respuesta estructurada o cerrada, en las que se sugieren algunas o todas las respuestas potenciales para que el participante elija una o varias de ellas. No elabora su respuesta sino que elige entre las que se le ofrecen.

- Pregunta cerrada dicotómica. Sólo se plantean dos opciones de respuesta, generalmente una afirmativa y la otra negativa o desestimativa.

Ejemplo 20. Para determinar el fenómeno del bullying un investigador en educación planteó las siguientes preguntas:

¿Has visto cuando algún alumno molesta a alguno de tus compañeros?

¿Ayudas a tu compañero que molestan?

SI NO

¿Le avisas a tu maestro (a) o algún adulto?

SI NO

¿Tienes miedo cuando esto sucede?

SI NO

¿Te han molestado a ti?

SI NO

SI NO

- Pregunta de elección múltiple en abanico o inventarios. Se plantean como opciones una lista de comportamientos, opiniones, intereses y percepciones, se le pide al participante que señale aquellos aspectos que le son representativos de sus propias percepciones o sentimientos. 
Ejemplo 21. Se desea saber ¿Cuál es el sentido que más utilizan los alumnos para aprender? Consideras que aprendes mucho:
( ) Leyendo un libro.
( ) Escuchando una lectura en voz alta.
( ) Viendo videos educativos.
() Realizando prácticas.
() Buscando información en internet. ( ) Jugando maratón.
( ) Escuchando audio-libros.

c. Pregunta de elección múltiple de estimación o escala de actitud. Se plantean diversas frases al participante y como respuesta debe indicar en una escala de 5 puntos si está de acuerdo o no con cada afirmación, la más fácil de realizar es la escala de Likert.

Ejemplo 22. Un investigador desea saber si los alumnos que ingresan a secundaria tienen conocimientos básicos de computación.

¿Qué tan bien sabes operar una computadora?

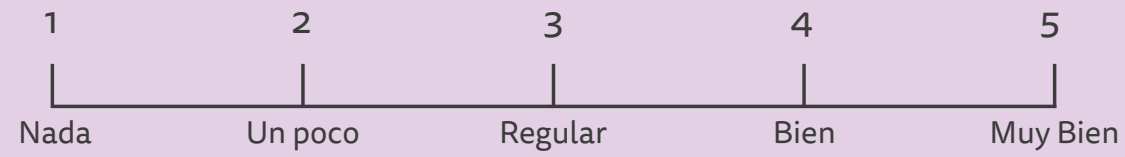

¿Qué tan bien manejas el programa Excel?

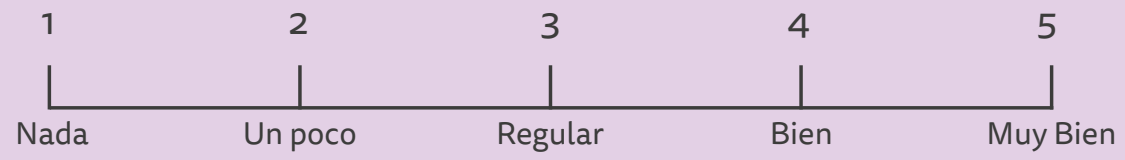

¿Qué tan bien manejas el programa Word?

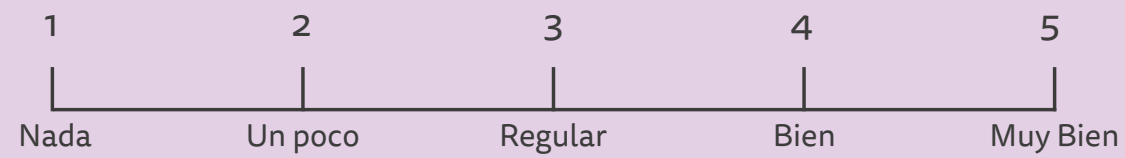

¿Qué tan bien manejas el programa Power Point?

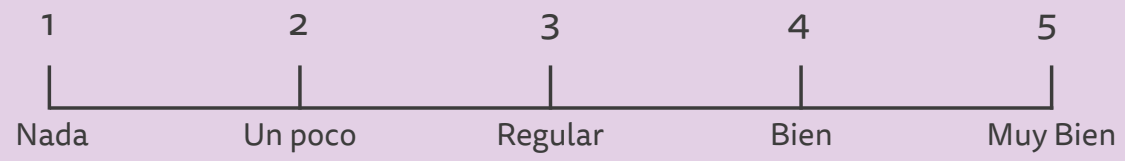

O también:

Ejemplo 23. Un investigador desea saber si los alumnos que ingresan a secundaria tienen conocimientos básicos de computación.

¿Qué tan bien sabes operar una computadora?:
( ) Nada
( ) Un poco
( ) Regular
( ) Bien
( ) Muy bien

\subsection{El test y la prueba}

El test es un instrumento que intenta medir el comportamiento humano; está constituido por estímulos o reactivos ante los cuales se pone a prueba al sujeto para que manifieste o ponga en evidencia algunas de sus conductas o características como: habilidades (razonamiento, memoria), aptitudes (numéricas, administrativas, verbales) o dominio de conocimientos (español, física, informática); bajo este concepto los test son en esencia una prueba. 
Una de sus características clave es que deben ser tipificados de tal manera que su uniformidad de procedimiento en la aplicación y puntuación garantice que las condiciones de su aplicación son las mismas para todos los que deben responderlos, permitiendo comparar las puntuaciones obtenidas.

Otra, es la objetividad en su medición, es decir, la forma en que se aplican, se puntúan e interpretan y son independientes del juicio subjetivo del examinador, lo que significa que una persona debe obtener la misma puntuación de manera independiente de quién sea su examinador en un test.

Dos aspectos que contribuyen a la objetividad de los test son su fiabilidad y validez, que se pueden determinar utilizando procedimientos empíricos y objetivos. De acuerdo a Padilla (2002) es conveniente precisar algunas de las características propias de un test:

- Elaboracióny construcción. Construir un test implica un conocimiento profundo de las diferentes teorías en torno al rasgo a medir.

- Aplicación. Asegurar la igualdad de condiciones de los distintos participantes al aplicar el test (como medida tipificada del comportamiento humano).

- Valoración. Ofrecer instrucciones precisas a los examinadores y valerse de respuestas concretas para evitar discrepancias.

- Características técnicas. Respaldar la calidad de la medida ofrecida por el instrumento siendo preciso y válido, y describiendo con claridad los procedimientos aplicados para su estimación.

- Interpretación de sus puntuaciones. Valorar la comparación que se establece entre la ejecución del sujeto y la de otros sujetos de características similares que se consideran representativos de la población.

Dentro de los instrumentos elaborados para evaluar el rendimiento escolar o profesional, es necesario diferenciar entre test y prueba objetiva. El test se refiere a una prueba que está estandarizada y tipificada y se destina para ser utilizado en una gran variedad de situaciones, por ejemplo, en todas las escuelas del país (para medir rendimiento escolar) o puestos de trabajo administrativo (para medir rendimiento del personal administrativo).

La prueba objetiva como tal, participa de las características apuntadas para el test estandarizado, pero se construye con un planteamiento menos ambicioso, sus reactivos tratan de determinar el dominio por parte del sujeto de determinados objetivos educativos (evaluar el aprendizaje), su universo es mucho más pequeño, se limita al salón de clase o a los grupos pertenecientes a una misma academia. Los elementos que marcan las diferencias entre el test estandarizado y la prueba objetiva son los siguientes:

- El contenido del test suele ser más amplio, pero no implica un mayor número de reactivos.

- Ambos requieren de un proceso de elaboración cuidadoso, pero en el test el detenimiento y costo son mayores.

- En las pruebas objetivas por lo general no existen reglas tan rigurosas y específicas de aplicación estándar.

- Las pruebas objetivas no suelen acompañarse de normas de interpretación de los resultados.

\subsubsection{Test estandarizado}

Para utilizar este tipo de test se requiere seleccionar un instrumento estándar concreto entre una gran cantidad de instrumentos disponibles. En este apartado se pondrán como ejemplo unos cuantos que están relacionados con el proceso educativo, ya que resulta poco práctico 
tratar cada uno de los cientos de test que se publican. Estos ejemplos se relacionan con las conductas o características para obtener evidencias de habilidades (razonamiento, memoria), aptitudes (numéricas, administrativas, verbales) y dominio de conocimientos o rendimiento (español, física, informática).

El test estandarizado es un instrumento que se diseña para obtener muchos tipos de información en condiciones estándar, usualmente se acompañan con un manual y unos baremos. La información que proporciona tiene las siguientes características:

a. Está claramente definida. Los test estandarizados se diseñan con claridad para medir un objetivo o conjunto de objetivos especificados. Los expertos que los diseñan tienen mucho interés en que se sepa específicamente qué tipo de información se obtiene al utilizar estos instrumentos.

b. Tiene parámetros conocidos. Los expertos, dentro del proceso de estandarización de este tipo de test, aplican éstos a grandes muestras de individuos, distintos en status socioeconómico, edad y lugar geográfico. Los resultados obtenidos son sometidos a un análisis cuidadoso y se determinan una gran cantidad de parámetros, por ejemplo: rendimiento medio de grupos por edad, status o lugar geográfico. Este análisis permite establecer de manera aproximada los resultados que se esperan obtener si se aplicará a un grupo semejante de personas que se encuentren dentro del parámetro establecido (en condiciones similares).

c. Se obtiene en condiciones ideales. Los expertos diseñan el instrumento de tal forma que asegure que las condiciones de su aplicación sean las ideales cada vez que se utilice. Por ejemplo, preparación previa (ubicación y materiales), horario (sesiones consecutivas en la mañana o tarde), distribución y recogida, cronometraje (anotar la hora de entrega y recogida), preparación de los participantes (informarles por qué y para qué).

\subsubsection{Los resultados y su aplicación}

Dentro del contexto educativo uno de los objetivos de la aplicación de los test estandarizados es la toma de decisiones de acuerdo a los resultados obtenidos, principalmente en el ámbito directivo, de orientación y de enseñanza.

- Decisiones administrativas (aptitudes y rendimiento). Se relacionan con situaciones como: agrupar a los alumnos, selección de admisión, promociones y premios, cambio de currículum, selección de libro de texto, distribución del tiempo, espacio y dinero. Sobre los profesores: asignarles algunos tipos de tareas de enseñanza.

- Decisiones de orientación (aptitudes, rendimiento, intereses y actitudes). Se relacionan con problemas educacionales y vocacionales como: la elección de universidad o carrera, si requiere de ayuda especial, clínica o educacional, o el grado de éxito que logrará en la escuela.

- Decisiones de enseñanza (rendimiento). Se relacionan con problemas educacionales como: asignar textos complementarios, velocidad de cada materia, seleccionar coordinadores de investigación, cantidad de repasos por materia. Es poco usual que los maestros utilicen test estandarizados para ayudarse a tomar decisiones de enseñanza, más bien utilizan las pruebas objetivas.

\subsubsection{Test psicométrico}

En el caso de la investigación educativa, el test psicométrico está determinado por el tipo de institución educativa (escolarizada, semiescolarizada, técnica); el nivel (básico, medio, superior) y funciones que deberá enfrentar el egresado (ingresar al siguiente nivel educativo). 
En general este tipo de test se diseña para analizar aptitudes específicas, capacidades para el aprendizaje, rasgos de personalidad, nivel de inteligencia, intereses y valores personales que la institución educativa propone para sus egresados.

Los test psicométricos son herramientas que permiten recolectar información de una manera concreta y funcional, en la mayoría de los casos, pretenden evaluar tres rasgos concretos:

- Inteligencia y aptitudes. Busca su relación con la capacidad de aprendizaje y análisis que desarrolla un alumno ante diferentes situaciones. Permite medir habilidades para resolver problemas, organizar la información, visualizar resultados, la comprensión verbal, el razonamiento abstracto, entre otras.

- Personalidad. Evalúa la tendencia de los involucrados (maestros, alumnos, padres de familia, directivos) a poseer o no determinadas características de comportamiento, valorando las áreas emocional, social y normas de valores.

- Conocimientos. Evalúa la capacidad para aprender determinadas materias y permiten predecir el desempeño del sujeto (maestro, alumno), determinando factores como: atención, percepción, habilidades, capacidad mecánica, retención.

\subsubsection{Test de inteligencia}

Las capacidades intelectuales se pueden expresar desde un factor general, es decir, la inteligencia común a todas las aptitudes y un punto específico propio de una aptitud en particular a considerar. Algunos autores distinguen tres tipos de inteligencia: la abstracta o conceptual, la práctica y la social (Mateos, 2005).

Ejemplo 24. Test de inteligencia.

\section{Cuestionario recomendado}

Serie de números: La tarea consiste en encontrar que número continuaría la serie. Todas las preguntas son series de números.

Serie de letras: La tarea consiste en encontrar que letra continuaría la serie. Todas las preguntas son series de letras.

Series de números y letras: La tarea consiste en encontrar qué número y letra continuaría la serie.

Dominó: La tarea consiste en averiguar cuál es la ficha que continúa la serie, tomando en cuenta que las fichas están colocadas siguiendo un orden.

Diagramas: La tarea consiste en seleccionar de las figuras de abajo la que corresponda a cómo quedaría la figura de arriba de acuerdo a las instrucciones que plantea el problema.

\section{Ejemplo}

Hay que encontrar el número que completaría la siguiente serie:

1. $3,5,6,10,9,15$,
a) 18
b) 50
C) 12
$\begin{array}{lll}\text { d) } 30 & \text { c) } 27\end{array}$

Hay que encontrar la letra que completaría la siguiente serie:

1. $A, C, A, F, H, F, K, M, K, O, Q, O$, :
a) $R \quad$ b) $S$
c) $T$
$\begin{array}{lll}\text { d) } U & \text { c) } V\end{array}$

Hay que encontrar la letra y el número que completaría la siguiente serie:

1. $1, M, 5, P, \longrightarrow, 13, W$ :
a) $7, R$
b) $9, S$
c) $12, T$
d) $9, U$ c) $15, \mathrm{~V}$

Hay que encontrar la ficha que completaría la siguiente serie:

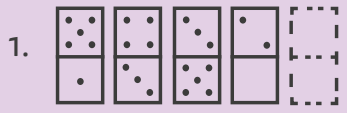
a) $6 / 0$
b) $1 / 2$
c) $0 / 6$
$\begin{array}{lll}\text { d) } 1 / 4 & \text { c) } 4 / 0\end{array}$

Hay que rotar las figuras en la dirección derecha - izquierda y seleccionar de las figuras la que sería igual:

1.

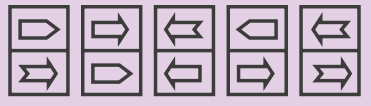
a) b)
c)
d)
e) 
Los test de inteligencia permiten determinar la capacidad intelectual general de las personas para adaptarse con eficiencia a nuevos problemas y aprender a resolverlos con rapidez y precisión ya que existe una estrecha relación con el éxito en el estudio, además del interés y los hábitos de trabajo (Ver Ejemplo 24).

La rapidez mental es una de las características que influye para que el individuo logre el éxito o fracaso, afectando tanto a problemas sencillos como complejos, por esta razón es importante la limitación del tiempo para resolver este tipo de test, de lo contrario, casi todos serían capaces de obtener la máxima puntuación. En el Ejemplo 24, solo se presentan algunos ejemplos de este tipo de test; sin embargo, existen muchos y es posible encontrarlos con relativa facilidad, inclusive en internet.

\subsubsection{Test de aptitudes}

Este tipo de test permite determinar la aptitud de una persona ante una tarea prediciendo su actuación en ella, formulando juicios predictivos, por lo cual es importante en la mayoría de la toma de decisiones educativas. Las estimaciones de aptitud son de mucha ayuda en la enseñanza para evaluar con exactitud a los individuos, los programas educativos, así como sus procesos (Ponce, García, Gil, Martín y Rodríguez, 2008).

Si se requiere seleccionar a un grupo de alumnos para una tarea concreta es necesario conocer cuál es la aptitud de cada uno para realizarla, o si se pretende designar a un alumno a un programa de educación es necesario conocer para qué aspectos de éste tiene más aptitudes, lo cual es importante considerar en el momento de designarle alguna tarea al alumno.

En algunas situaciones se requiere conocer la actitud del individuo, por ejemplo: cuando el maestro se pregunta si un determinado examen es demasiado fácil o difícil para los alumnos de un determinado curso; el orientador debe decidir quién debe estudiar cierta carrera técnica o especialidad (mecánica, construcción, electricidad) o el director debe decidir a quién promover para ocupar la coordinación de alguna academia.

Este tipo de test es uno de los instrumentos que ofrece a los investigadores herramientas para la obtención de información que le permita dar respuesta a sus preguntas de investigación o confirmar o rechazar las hipótesis planteadas. De acuerdo con su utilidad en esta sección se presentan algunos ejemplos referentes a los test de aptitudes verbales, numéricas, de razonamiento y de memoria.

Las aptitudes verbales se refieren a la capacidad para utilizar y comprender símbolos de este tipo, se trata de medir la aptitud para manejar la información que llega a través del lenguaje oral o escrito.

Las aptitudes numéricas se refieren a la capacidad para comprender y resolver con rapidez y precisión operaciones de tipo aritmético.

El razonamiento consiste en la capacidad para comprender y resolver correctamente problemas lógicos de tipo concreto no expresado con palabras. Se trata de una aptitud que facilita encontrar reglas, principios y leyes que permiten comprender problemas relacionados con tareas de base lógica. 
Ejemplo 25. Test de Aptitudes verbales.

\begin{tabular}{|l|l|}
\hline $\begin{array}{l}\text { Cuestionario recomendado } \\
\text { Lectura de comprensión. La }\end{array}$ & $\begin{array}{l}\text { Lea con atención el texto y elija la opción que } \\
\text { tarea consiste en leer atenta- } \\
\text { mente un texto y elegir la op- } \\
\text { ción que responda a la pregun- }\end{array}$ \\
$\begin{array}{l}\text { En la emblemática plaza del Salvador se encuentra } \\
\text { ta planteada. }\end{array}$ & $\begin{array}{l}\text { situada la Parroquia del mismo nombre, de estilo barroco, } \\
\text { levantada en los siglos XVII y XVIII en un solar ocupado } \\
\text { sucesivamente por un templo romano, una basílica } \\
\text { paleocristiana, visigoda y mozárabe y desde el siglo IX por } \\
\text { la mezquita mayor de Sevilla, de la que se conservan restos } \\
\text { del patioyel arranque de la torre. }\end{array}$ \\
\hline $\begin{array}{l}\text { 1. La Parroquia del Salvador se construyó: } \\
\text { 1) En el siglo IX. }\end{array}$ \\
2) Después de la construcción de la mezquita mayor \\
3) de Sevilla. \\
4) Tras la conquista.
\end{tabular}

Ortografía. La tarea consiste en seleccionar la opción que contenga errores ortográficos, de cuatro frases presentadas.

¿Cuál de las siguientes frases tiene un error ortográfico?

a) No encuentro la formula adecuada.

b) Es imposible acceder a ese puesto.

c) El niño ingirió lejía por equivocación.

d) El rostro del hombre era pálido y enjuto.

Vocabulario. La tarea consiste de un grupo de palabras definir su significado en un tiempo concreto.

Sinónimos, antónimos y palabras polisémicas. La tarea consiste en buscar sinónimos, antónimos o palabras polisémicas (semejanza de forma o etimológica).

Series de números, letras y símbolos. La tarea consiste en averiguar la opción correcta que completa la serie. Razonamiento lógico e inteligencia.

Indique que significa cada una de las palabras que se le presentan a continuación:

Pizarra

Mendigo Arrasar

Ápice Hambre

¿Cuál de las siguientes palabras expresan un significado más parecido a la que se indica?

1. Observancia
a) Cumplimiento
b) Advertencia
c) Vigilancia
d) Seguimiento

¿Cuáles de las siguientes series de palabras no siguen un orden alfabético?

a) Iceberg, iguana, isótopo, ítem.

b) Dinosaurio, dominó, dulce, duna.

c) Salsa, sedar, sembrar, sémola.

d) Salchicha, soplo, serpiente, suavizante. 
Ejemplo 26. Test de aptitudes numéricas.

\section{Cuestionario recomendado}

Operaciones de cálculo. La tarea consiste en encontrar la opción correcta.

Problemas simples. La tarea consiste en encontrar la opción correcta como solución de problemas simples planteados.

Problemas complejos. La tarea consiste en encontrar la opción correcta como solución de problemas complejos planteados.

Matrices numéricas. La tarea consiste en detectar si existe o no error alguno en los cálculos, considerado B (bien) si todas las sumas son correctas y M (mal) si existe un error.

\section{Ejemplo}

Resuelva las siguientes operaciones y seleccione la opción correcta (no usar calculadora):
1. $38+6(3-7)=$ a) 49
b) 14
c) 62
d) 12

Resuelva el siguiente problema y seleccione la opción correcta:

1. Si recorremos en coche 250 kilómetros en 3 horas y mantenemos esa velocidad, ¿cuántos kilómetros recorreremos en $\mathbf{5}$ horas y media?
a) $458.33 \mathrm{~km}$
b) $375 \mathrm{~km}$
c) $416.66 \mathrm{~km}$
d) $470 \mathrm{~km}$

Resuelva el siguiente problema y seleccione la opción correcta:

1. El precio de un par de zapatos que costaban $\$ 800.00$ pesos subió un $10 \%$ y un mes después bajó un $5 \%$ sobre ese precio. ¿Cuánto costaban al final?
a) $\$ 880$
b) $\$ 840$
c) $\$ 836$
d) $\$ 756$

Determine si existe o no algún error en los cálculos (suma de columnas y filas) de la siguiente matriz, marque la B (bien) si todas las sumas son correctas o M (mal) si al menos una no lo es:

\begin{tabular}{cccc|c}
85 & 22 & 75 & 182 & \\
28 & 37 & 40 & 105 & $\mathrm{~B}$ \\
57 & 61 & 24 & 142 & $\mathrm{M}$ \\
\cline { 1 - 3 } 170 & 120 & 138 & 429 &
\end{tabular}

Agilidad mental numérica. La tarea consiste en resolver problemas con rapidez de reacción al operar con elementos numéricos.
Resuelva el siguiente problema y seleccione la opción correcta:

1. ¿Cuál es el doble de la raíz cuadrada de 144 ?
a) 22
b) 24
c) 28
d) 36 
Ejemplo 27. Test de razonamiento.

Cuestionario recomendado

Analogías simples. La tarea requerida consiste en identificar entre cuatro opciones distintas cuál de ellas completa la analogía sugerida correctamente.

Palabras no relacionadas. La tarea requerida consiste en indicar de tres elementos, los dos elementos que están relacionados.

Análogas complejas. La tarea consiste en identificar entre cuatro parejas de palabras distintas, cuáles deben sustituirse por $A$ y $C$ en algunos casos o por $B$ y $D$ en otros, para completar la analogía propuesta de forma correcta.

Cálculo abstracto. La tarea consiste en hallar de una cadena que combina números y símbolos, los valores numéricos de esos símbolos.

\section{Ejemplo}

Intente completar la siguiente analogía verbal simple:

1. 20 es a 4 como 32 es a:
a) 9
b) 6
c) 7
d) 8

Lea con atención la siguiente serie de palabras: a) Pierna b) Cama c) Brazo ¿Cuáles diría que están relacionadas?

Intente completar la siguiente analogía verbal compleja:

1. Uñas es a _ como cabello es a _.

a) pierna-cabeza b) pie-mano

c) cabeza - pie

d) mano - cabeza

Calcule el valor de cada una de estas letras basándose en las siguientes operaciones:

$\mathbf{F}=\mathbf{J}=\mathbf{D}=$

a) $5+D=5$

b) $\mathrm{F}-\mathrm{D}=1$

c) $3 \mathrm{~J}+2 \mathrm{~F}=8$

Intente completar la siguiente serie:

1. 6373 - 93103113123133

$\begin{array}{llll}\text { a) } 61 & \text { b) } 72 & \text { c) } 83 & \text { d) } 94\end{array}$

Series de números. La tarea consiste en hallar de una serie de números que siguen un orden lógico, la opción correcta que completa la serie.

La aptitud de la memoria consiste en evocar contenidos mentales que estuvieron presentes en la realidad exterior y ya no están, así como soluciones y decisiones que se realizaron en el pasado y se hacen presentes de nuevo. Esta aptitud implica la memoria de corto plazo que consiste en la actividad de la retención de los elementos y la memoria a largo plazo que es la actividad de transformación de estos elementos o su almacenamiento.

Dentro de este campo se encuentran también las aptitudes para recordar imágenes o evocar figuras, formas y relaciones espaciales (memoria visual) y la aptitud para recordar información que llega de forma escrita u oral (memoria verbal). Otras formas de memoria son la llamadas sensoriales (visual, auditiva, táctil).

\subsubsection{Test de personalidad}

Este tipo de test permite medir los principales rasgos del carácter de un individuo como pueden ser: iniciativa, persuasión, empatía, madurez, responsabilidad, motivación, la adaptación social a las normas o cambios y la estabilidad emocional (Schultz y Schultz, 2002).

En los test de personalidad no existen respuestas malas o buenas, sólo reflejan el carácter del sujeto o su forma de pensar entre ciertas situaciones. Lo que se busca es determinar el perfil adecuado del examinado a las actividades propuestas por la institución 
Ejemplo 28. Test de memoria.

\section{Cuestionario recomendado}

Retención visual simbólica contextualizada. La tarea consiste en observar una imagen durante un tiempo límite de exposición, para en seguida responder a una serie de cuestiones que se plantean sobre ciertos aspectos y detalles de su contenido.

Emparejamientos: La tarea consiste en observar una serie de pares de palabras durante un tiempo límite de exposición, para en seguida completar las palabras que conforman los pares.

Textos incompletos. La tarea consiste en recordar palabras dentro de un contexto (memoria semántica).

\section{Ejemplo}

Observe con atención la siguiente imagen, dispone para ello de 4 minutos. Transcurrido ese tiempo debe responder a las preguntas que se plantean sin volver a visualizarla.

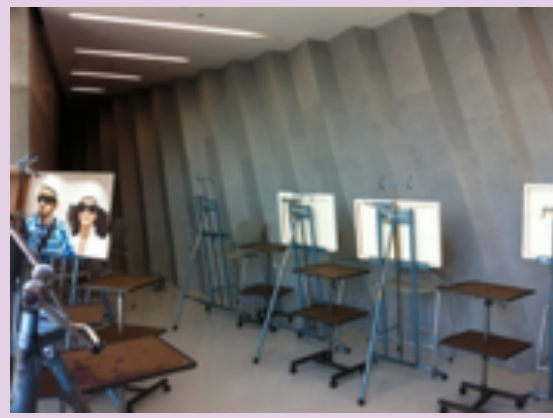

\section{Preguntas:}

1) ¿Cuántos caballetes se mostraron en la imagen?

2) ¿De qué color es la blusa de la mujer de la pintura?

3) ¿Cuántos caballetes se muestran completos?

4) ¿Cuántas mesas se muestran completas?

5) ¿Cuántas rueditas de las mesas se pueden observar?

6) ¿Cuántos relieves se observan en la pared?

Observe el siguiente listado durante 4 minutos, tápelo y complete el listado.

$$
\begin{gathered}
\text { Casa-familia } \\
\text { Parque - juegos } \\
\text { Estrellas - noche } \\
\text { Cochera - automóvil } \\
\downarrow \\
\text { Mecánico-taller }
\end{gathered}
$$

\section{Complete la siguiente lista con las palabras que} faltan:

1. Parque-__ - familia
3._- noche
20. Mecánico-

Lea con atención el texto, tápelo o de vuelta a la hoja.

Original: En la emblemática plaza del Salvador se encuentra situada la Parroquia del mismo nombre, de estilo barroco, levantada en los siglos XVII y XVIII en un solar ocupado sucesivamente por un templo romano, una basílica paleocristiana, visigoda y mozárabey desde el siglo IX por la mezquita mayor de Sevilla, de la que se conservan restos del patio y el arranque de la torre. 
Retención visual simbólica. La tarea consiste en la reproducción de figuras presentadas en un plano, ésta puede ser reproducida:

- Tal y como se presenta.

- Reducida de tamaño.

- Como reflejo de espejo.

- Encuadrantes.

Retención visual simbólica con tareas distractoras. La tarea consiste en la reproducción de figuras presentadas en un plano, pero se incluyen después de la observación de la figura tareas distractoras de la huella amnésica, ésta puede ser reproducida:

- En símbolos encuadrados en una matriz.

- Figura en cuadrantes.
1. Coloque en los huecos las palabras que faltan:

Copia: En la emblemática plaza del se encuentra situada la Parroquia del mismo nombre, de estilo levantada en los siglos XVII y XVIII en un solar ocupado sucesivamente por un templo romano, una paleocristiana, visigoda y mozárabe y desde el siglo IX por la mezquita mayor de yel arranque de la torre. de la que se conservan restos del patio

Fíjese bien en los detalles de la siguiente figura durante dos minutos, tape el dibujo y reproduzca la figura.
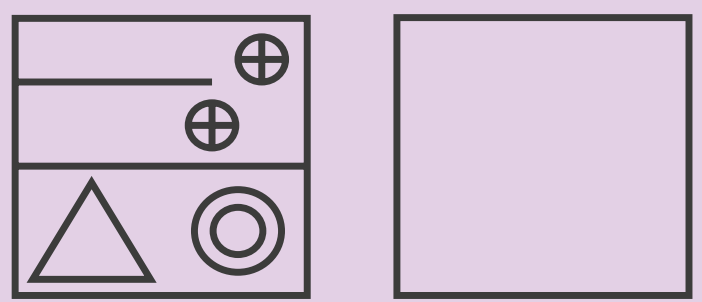

Fíjese bien en los detalles de la siguiente tabla durante dos minutos, tape el dibujo y resuelva el siguiente ejercicio: enumere cinco nombres de pila de sus familiares más cercanos.

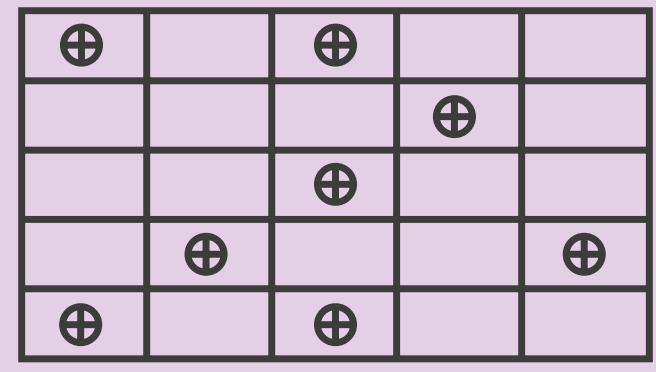

1. Una vez realizado el ejercicio proceda a reproducir el dibujo presentado anteriormente.

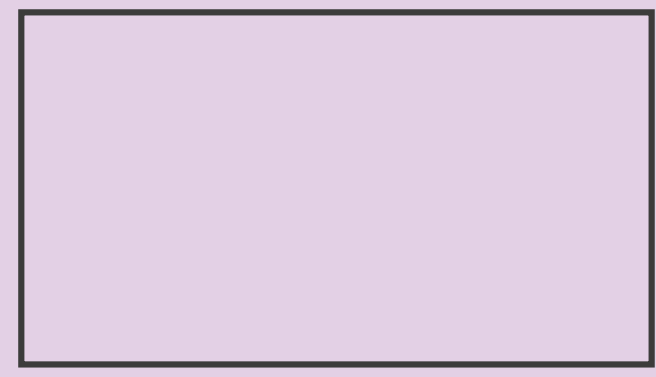

educativa (normalista, técnico, abogado o simplemente cambiar de grado escolar), para ello en algunos test las preguntas se repiten, con la finalidad de medir un rasgo de la personalidad, se utilizan distintos ítems que sumados dan como resultado ese rasgo que se busca. Estos test se pueden clasificar en: 
1. Proyectivos. Se plantean diferentes situaciones creíbles ante las que se deben proponer soluciones o respuestas abiertas, que implica una identificación propia con la pregunta o problema, proyectando en la respuesta su personalidad. A continuación se muestran los más usuales (Aguirre, 1989):

- Test de Rorschach. Consiste en una serie de 10 láminas que presentan manchas de tinta que se caracterizan por su ambigüedad y falta de estructuración, estas imágenes tienen una simetría bilateral. Se pide al sujeto que diga qué podrían ser las imágenes que ve en las manchas, de la misma forma que uno identifica cosas en las nubes o en las brasas.

Las respuestas se registran tal cual las emite el participante por el especialista que dirige el test. Se anotan también comentarios sobre el tono de voz, y las reacciones observadas en la persona. A partir de sus respuestas, el especialista puede establecer o contrastar hipótesis acerca del funcionamiento psíquico de la persona examinada.

Ejemplo 29. Test de Rorschach.

Es de aplicación individual, aporta información sobre la forma de operar mentalmente del sujeto, habilidad emocional, distorsión en la percepción de la realidad, uso de la inteligencia o emoción en la solución de problemas.

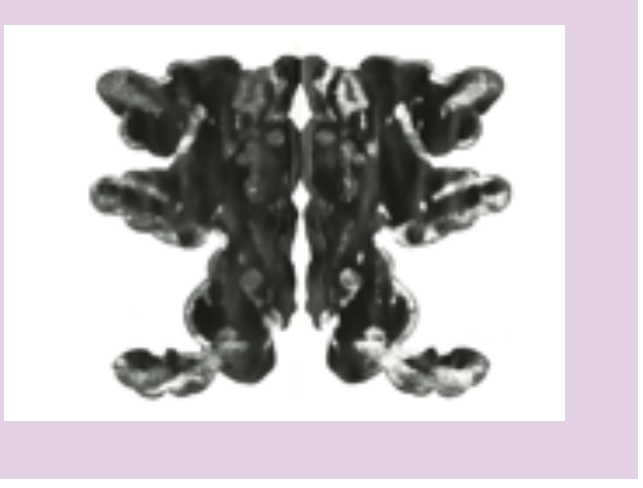

- Test del árbol. Es un test proyectivo de la personalidad profunda. A través de sus distintos contenidos se exploran las áreas de la personalidad. Estos contenidos son:

- El tronco: Da cuenta de los aspectos más conscientes del psiquismo, permite evaluar: estabilidad emocional, como se siente actualmente la persona, la fortaleza de su Yo, el aquí y ahora de su personalidad, el tronco es el que sostiene al árbol.

- La copa: representa la vida mental, las fantasías, la riqueza o no de la imaginación, como la persona concibe a la realidad.

- Las ramas: conforman dos cuestiones, la capacidad para establecer vínculos y la modalidad de las relaciones con los otros, pero también la capacidad de la persona para obtener del ambiente aquello que necesita.

- El suelo: representa la realidad, el piso en donde uno se instala.

- Las raíces: Representa una necesidad de arraigo y de mayor estabilidad.

Es positivo que el tronco sea en ambos lados curvos porque eso significa flexibilidad y adaptación al ambiente, cuando aparece un tronco recto significa inflexibilidad mucho autocontrol y rigidez, se suma a este análisis otros factores tales como el tamaño, la ubicación en la hoja, la calidad del trazo. 
Ejemplo 30. Test del árbol.

Evalúa la personalidad profunda. El test consiste en dibujar un árbol. Es una técnica muy utilizada tanto en la práctica clínica como en la práctica laboral.

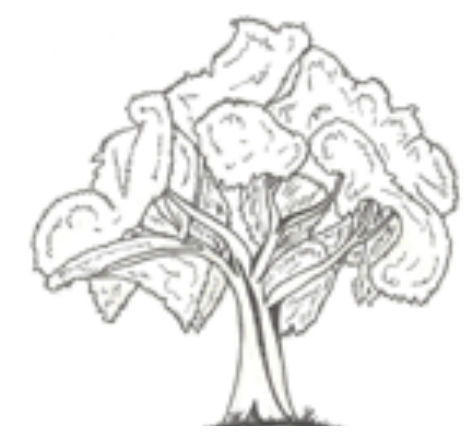

- Test del dibujo de la figura humana. Éste relaciona especialmente aspectos de la personalidad del sujeto de acuerdo a su autoconcepto y a su imagen corporal, cada vez que un sujeto dibuja una persona es la proyección de su propio Yo, en ésta confluyen:

- Experiencias personales y sus representaciones psíquicas.

- Imágenes de estereotipos: sociales y culturales que tienen un mayor o menor peso para el sujeto.

- Aceptación o no de su etapa vital.

- Identificación y asunción del propio sexo.

- El grado de estabilidad y dominio de sí mismo.

La figura dibujada debe asemejarse en sus atributos e imagen al sujeto mismo, es como que ante ella deberíamos poder decir, es igual a él/ella.

Ejemplo 31. Test del dibujo de la figura humana.

Consiste en el dibujo de una figura humana reflejando cómo se ve y qué piensa de sí mismo, qué imagen tiene de sí mismo y de su cuerpo.

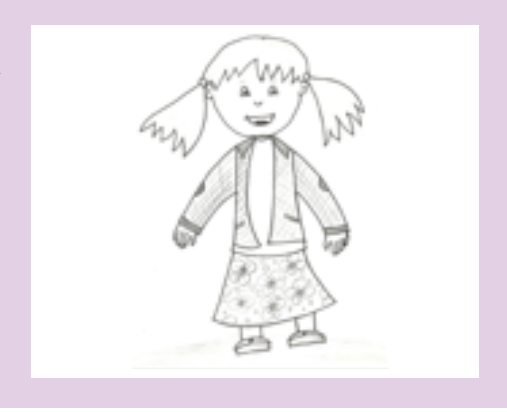

- Test de Grafología. Es un test proyectivo que permite obtener un conocimiento profundo de la personalidad del individuo. Con la Grafología se pueden determinar diversos aspectos de la personalidad, a saber:

- Capacidades intelectuales: como agilidad mental, capacidad de síntesis y análisis, claridad de ideas, intuición, lógica, creatividad.

- Aptitudes para el trabajo y el estudio, tanto en lo relativo a la capacidad como la constancia, la diligencia, la concentración, la memoria, la intensidad laboral; como en la actitud que se adopta hacia él mismo: grado de orden y detallismo, puntualidad, capacidad de organización, dotes de mando, iniciativa, decisión, nivel de aspiraciones.

- Características de personalidad: si la persona es más o menos extrovertida, si se deja llevar más por los sentimientos o bien es más cerebral, como suele ser su estado de ánimo, la energía interna de que dispone, su autoconcepto, si es capaz de 
controlar sus impulsos, si se adapta a los ambientes nuevos, su canalización de la sexualidad, su agresividad.

Ejemplo 32. Test de Grafología.

Su objeto de estudio es la escritura; a través de su análisis y con una metodología propia, permite conocer la personalidad de un individuo de forma integral. En términos generales se analizan ocho aspectos fundamentales de la escritura: orden, tamaño, inclinación, dirección, presión, rapidez, forma y continuidad.

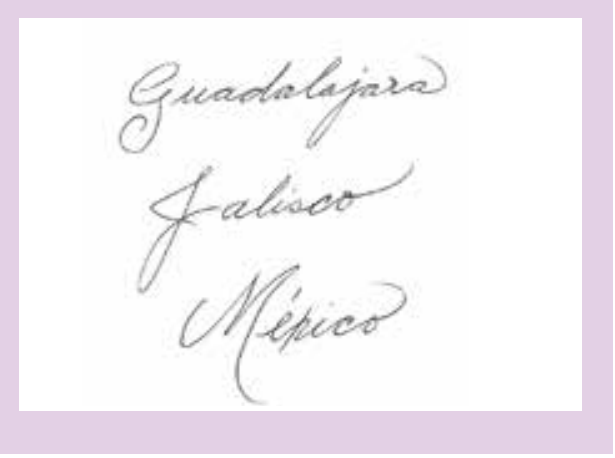

2. Introspectivos. Plantean al candidato la necesidad de definirse ante una serie de afirmaciones, considerándolas correctas o incorrectas, o decantándose en algún sentido.

Ejemplo 33. Test de personalidad afirmativa.

\section{Cuestionario recomendado}

Dos afirmaciones. La tarea consiste en elegir entre dos afirmaciones la que se considere más acorde a la personalidad del sujeto, según la respuesta es el significado, por ejemplo:

En las opciones 1:

* Capacidad para el estudio.

+ Disposición para el estudio.

En las opciones 2:

* Perfeccionista.

+Pesimista.

\section{Ejemplo}

Elegir entre las siguientes afirmaciones la que va más acorde a su personalidad.

1. ( ) Soy buen estudiante. *

( ) Me gusta hacer las tareas. +

2. ( ) Me gusta hacer bien las prácticas de laboratorio. *

( ) Como no estudié, no quiero ir a la escuela. +

En otra variante de los test introspectivos, se plantean en un listado de preguntas cerradas varias opciones de respuesta, en las cuales las opciones de respuesta de los extremos son opuestas, pasando por opciones intermedias en la cual la central se mantiene neutral, logrando de esta forma identificar a los indecisos, esta situación permite estructurar un perfil de rasgos diferenciales de la personalidad midiendo aspectos como el grado de sociabilidad, estabilidad emocional, autonomía, lealtad, agresividad, introversión.

Ejemplo 34. Test de personalidad grado de opción.

\section{Cuestionario recomendado}

Grado de opción: La tarea consiste en elegir entre 5 afirmaciones de acuerdo a la respuesta que requiere cada pregunta, si no se requiere que el perfil de rasgos diferencial se extienda, sólo se pueden utilizar tres opciones dejando los extremos y la central (neutral).

\section{Ejemplo}

Elegir entre las siguientes afirmaciones la que va más acorde a su manera de actuar.

1. Nunca participo en el salón de clase

) Totalmente de acuerdo.

) De acuerdo.

) Término medio.

) En desacuerdo.

) Totalmente en desacuerdo. 
En los test introspectivos se requiere responder con sinceridad, si se pretende manipularlos para mostrar una personalidad diferente a la real, no se puede engañar puesto que son diseñados con sistemas que evalúan la sinceridad en las respuestas. A estos test, también se les conoce como factoriales, ya que facilitan las puntuaciones individuales en diez o más rasgos o factores de personalidad, tales como represión, sociabilidad, estabilidad.

\subsubsection{Test de conocimientos}

Los test de conocimientos o rendimiento permiten medir los conocimientos y el grado de destreza requeridos para llevar a cabo un trabajo concreto, lo que se busca es obtener información sobre la formación, experiencia y conocimientos específicos en el sujeto.

Este tipo de test se construye principalmente para hacer juicios estimativos no predictivos. En el caso de los test de rendimiento diagnóstico éstos permiten emitir juicios sobre los puntos fuertes y débiles de los alumnos individualmente, para que el profesor pueda proveer las experiencias de aprendizaje a cada alumno.

La información obtenida de los test estandarizados se debe completar con las pruebas objetivas elaboradas por el profesor, el análisis de tareas, los trabajos de laboratorio y de talleres, y las observaciones de clase, puesto que, el nivel de aptitud del alumno, el tipo de materia que se enseña y los objetivos del profesor afectan los resultados (Buendía, 1996).

Por otra parte los test de conocimientos deben determinar el grado de destreza el cual involucra una habilidad motriz, siendo la motricidad, la destreza y la habilidad formas de aptitud, factores que no son tan evidentes de medir. Partiendo del concepto de habilidad motora lo que se requiere determinar es la capacidad aprendida para realizar el objetivo de una tarea que hay que ejecutar, es decir, la consecución de un objetivo motor concreto. Esta habilidad aprendida se sustenta en la aptitud motriz del individuo.

Los test estandarizados más conocidos en México son los correspondientes a la prueba PISA (Program for International Student Assessment) y la prueba ENLACE (Evaluación Nacional del Logro Académico de Centros Escolares). En México, la aplicación de PISA está a cargo del INEE (Instituto Nacional para la Evaluación de la Educación) y se hace con una muestra ampliada que permite el análisis por entidad.

Para la OCDE (Organización de Cooperación y Desarrollo Económico), las evaluaciones de PISA no se refieren sólo a las escuelas, sino a toda la sociedad. Si en un país los resultados son insatisfactorios, no se está consiguiendo que los jóvenes desarrollen, en medida suficiente, algunas competencias que hoy se identifican como importantes para la vida en las sociedades contemporáneas.

La prueba PISA está compuesta por diferentes tipos de reactivos que comprende desde los muy conocidos, en los cuales se selecciona una sola opción de respuesta, hasta otros en los cuales las opciones de respuesta se presentan en dos partes; en otro tipo de reactivo se pide como respuesta una frase corta o una cantidad; y los predominantes son aquéllos en los cuales se pide que el estudiante construya la respuesta. En todos los casos, los reactivos no se presentan en aislado, se acompañan de un estímulo introductorio que bien puede ser un texto, una gráfica, un diagrama o un mapa. Para responderlos, el estudiante debe leer y comprender el estímulo introductorio para poder resolver cada tarea solicitada en el reactivo.

Para medir las competencias en Ciencias, Matemáticas y Lectura, la prueba abarca muchos más reactivos. La medición completa incluye, en promedio, ciento ochenta reactivos, esta cantidad varía dependiendo del ciclo. Es claro que un estudiante no puede, además de leer el estímulo introductorio, dar respuesta a todos los reactivos de la prueba en un tiempo 
de dos horas. Por lo tanto, el total de reactivos se organiza en grupos, y éstos se distribuyen en las diferentes versiones de cuadernillos; y cada uno de ellos tiene cuatro grupos distintos de reactivos. Un estudiante responde una versión del cuadernillo que le fue repartido de forma aleatoria y que cuenta con alrededor de sesenta reactivos de las tres áreas.

Por su parte, la prueba ENLACE está a cargo de la DGEP-SEP (Dirección General de Evaluación de Políticas-Secretaría de Educación Pública), su aplicación permite recopilar datos y producir información respecto del logro académico de cada alumno de las escuelas de educación primaria y secundaria del país. Con el procesamiento de los resultados se cuenta con información específica de la población objetivo para: (1) identificar áreas donde hay progreso, (2) reconocer deficiencias y, por tanto, se erigen como áreas de oportunidad para diseñar mediaciones pedagógicas a realizar en clase por los docentes, (3) intercambiar opiniones de las que emanen acciones donde intervengan los padres de familia para incidir en el aprendizaje y el desarrollo de sus hijos, (4) socializar el trabajo de la escuela y (5) fortalecer la idea de comunidad escolar y su participación en los procesos formativos de los estudiantes (SEP-IEIA, 2013).

En Educación Básica, ENLACE evalúa los conocimientos y las habilidades de los estudiantes en las asignaturas de Matemáticas y Español. Además, para lograr una evaluación integral, a partir de 2008 en cada aplicación también se incluye una tercera asignatura que se va rotando cada año, de acuerdo a la siguiente programación: Ciencias (2008 y 2012), Formación Cívica y Ética (2009 y 2013), Historia (2010) y Geografía (2011).

En particular la prueba ENLACE 2012 aplicada en secundaria básica de primer grado estuvo compuesta de 163 preguntas en 8 secciones y distribuidas de la siguiente manera: 50 para Español, 61 para Matemáticas y 43 para Ciencias, siendo anuladas 9 por su alto grado de dificultad o mal redactadas.

Ejemplo 35. Prueba ENLACE.

\section{Cuestionario recomendado}

Opción múltiple. Obtenido del examen de Secundaria Básica de Primer Grado de ENLACE aplicado en 2012.

\section{Ejemplo}

Lea con atención y encuentre la solución a los siguientes problemas:

1. ¿Cuántos metros de alambre se requieren para cercar un campo circular con un diámetro de 16 metros? (considerar $\pi=3.14$ )
a) $25.12 \mathrm{~m}$
c) $50.24 \mathrm{~m}$
b) $259.14 \mathrm{~m}$
d) $200.96 \mathrm{~m}$

\subsubsection{Las pruebas Objetivas}

Como se ha mencionado, los test son instrumentos que requieren de muchas exigencias de acuerdo al tipo de medición que se debe realizar, lo que implica que su proceso de elaboración sea lento, complejo y que se elabore por expertos en pedagogía o psicología.

Sin embargo, en la elaboración que realizan los maestros de las pruebas objetivas de conocimientos se pretende solo examinar un material específico, delimitando cuáles contenidos se quieren incluir en la prueba. Se debe explicitar como se estructuran estos contenidos en unidades y sub-unidades, correspondientes a un programa sobre el que se organiza la enseñanza, permitiendo darle significado a la prueba dentro de este contenido (Morales, 2006).

Para clarificar esta situación se puede partir del supuesto de querer construir una prueba para examinar a los alumnos de tercer grado de una secundaria técnica en la asignatura de 
Radio; es necesario determinar qué conocimientos se desean examinar sobre lo aprendido por los alumnos durante el curso, esto se puede establecer por el contenido de las unidades. En el Ejemplo 36 se muestran los contenidos impartidos durante la enseñanza, los cuales deben incluirse (la prueba objetiva se muestra en el Apéndice B).

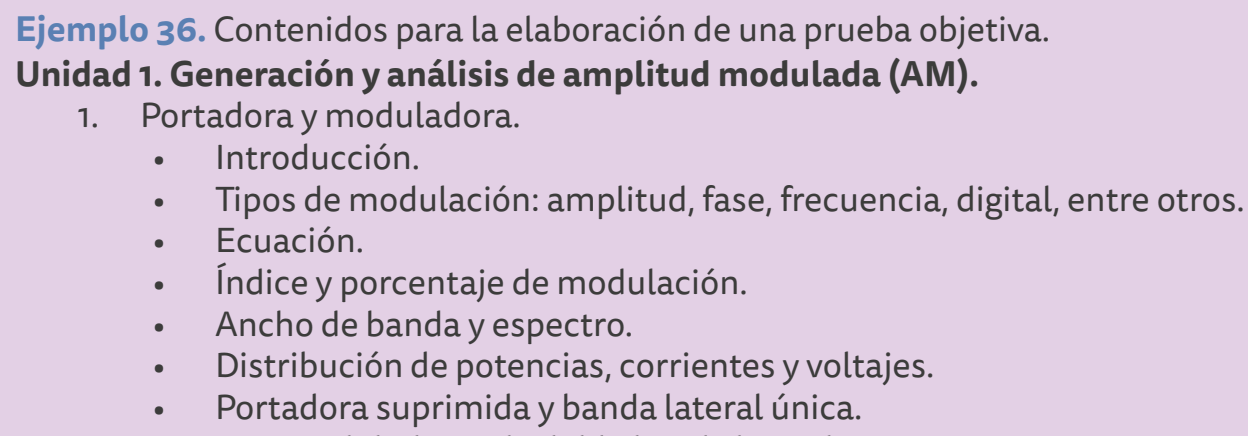

2. Circuitos moduladores de doble banda lateral.

- Moduladores con BJT, FET y Cl.

3. Circuitos moduladores de doble banda lateral con portadora suprimida y banda lateral única.

- Descripción del fundamento.

- Aplicaciones.

Unidad 2. Transmisores de amplitud modulada (AM).

1. Características generales de las etapas constitutivas del transmisor de AM.

- Fuentes de la señal de audio.

- Preamplificador y amplificador de audio.

- Generador de portadora.

- Modulador.

- Amplificador sintonizado y de potencia de radio frecuencia (RF).

- Supresores de banda lateral.

2. Análisis de transmisores.

- Onda larga, media y corta. - Acopladores de antena.

- Banda lateral única y ciudadana. - Ancho de banda.

Conocer estos contenidos permite identificar y visualizar algunos puntos significativos al momento de elaborar la prueba, como:

- Incluir todos los aspectos importantes en el instrumento (examen).

- Incluir más reactivos de las unidades o sub-unidades más amplias.

- Darle peso a cada unidad o sub-unidad en función de su importancia intrínseca y relativa.

- Ponderar y estimar el nivel de los alumnos en distintas pruebas.

En el ejemplo anterior sólo se presentan los contenidos de las unidades a examinar, pero es necesario completar esta información con los objetivos de aprendizaje al momento de elaborar la prueba, ya que, un mismo contenido puede perseguir objetivos de aprendizaje diferentes. Asimismo, para dar validez a la prueba es requisito que los objetivos sean coherentes con la forma de trabajar la asignatura (prácticas en grupo, análisis crítico, entre otros aspectos).

A continuación se presentan algunos de los posibles objetivos de aprendizaje utilizados en las pruebas:

- Conocimiento y comprensión. El alumno pone en práctica actividades cognitivas con los contenidos de la asignatura: Comprender principios teóricos, significados de términos; identificar fases de proyectos, principios, memorizar términos; reconocer conceptos.

- Relación. El alumno establece relaciones entre contenidos de distintos temas con separación temporal y física, no de un mismo tema o unidad. 
- Aplicación. El alumno pone en práctica actividades cognitivas necesarias para aplicar los conceptos y principios incluidos en los contenidos a situaciones o casos concretos.

Una vez que se conocen los contenidos y se identifican los objetivos de aprendizaje se procede a diseñar una tabla de especificaciones. Ésta puede consistir en el listado de temas por cada unidad, como el que se muestra en el Ejemplo 37, indicando cuántos ítems se van a incluir en cada una de éstas (de acuerdo a la relevancia de los temas y subtemas contenidos). Ampliando la tabla se puede elaborar un cuadro de doble entrada en el que se cruzan los contenidos con los objetivos, tomando en cuenta el tipo de aprendizaje relacionado. Otro aspecto importante es determinar el nivel de dificultad de los ítems, es decir si un ítem es contestado correctamente por una gran mayoría de alumnos examinados se puede aseverar que es un ítem fácil. El nivel de dificultad será, como consecuencia, mayor o menor de acuerdo al número de alumnos que lo contesten correctamente.

Cuando el maestro elabora por primera vez un banco de reactivos para ser utilizado en una prueba objetiva, no dispone de la evidencia empírica mencionada en el párrafo anterior, ya que apenas los está creando, entonces es necesario que el maestro determine los niveles de dificultad por medio de una estimación intuitiva. El maestro como protagonista en la impartición de la asignatura, puede intuir cuando un ítem puede presentar un nivel de dificultad bajo, medio o alto, quedando sujeto a la verificación una vez que se aplique el instrumento (o pilotee).

\begin{tabular}{|c|c|c|c|c|}
\hline $\begin{array}{l}\text { Objetivos } \\
\text { Contenidos }\end{array}$ & $\begin{array}{c}\text { Conocimiento } \\
Y \\
\text { Comprensión }\end{array}$ & Relación & Aplicación & $\begin{array}{c}\text { Total } \\
\text { De } \\
\text { Reactivos }\end{array}$ \\
\hline Unidad 1. & $8\left(5_{b}, 1_{m}, 2_{a}\right)$ & $3\left(1_{b}, 1_{m}, 1_{a}\right)$ & $4\left(O_{b^{\prime}} 3_{m^{\prime}} 1_{a}\right)$ & 15 \\
\hline $\begin{array}{l}\text { Portadora y } \\
\text { moduladora. }\end{array}$ & $5 b$ & $1_{b}$ & & 6 \\
\hline $\begin{array}{l}\text { Circuitos } \\
\text { moduladores de doble } \\
\text { banda lateral. }\end{array}$ & $1_{a}$ & $1_{m^{\prime}} 1_{a}$ & $1_{\mathrm{m}}$ & 4 \\
\hline $\begin{array}{l}\text { Circuitos modulado- } \\
\text { res de doble banda } \\
\text { lateral con portadora } \\
\text { suprimida y banda } \\
\text { lateral única. }\end{array}$ & $1_{m^{\prime}} 1_{a}$ & & $2_{m^{\prime}} 1_{a}$ & 5 \\
\hline Unidad 2. & $3\left(O_{b^{\prime}}, 3_{m^{\prime}}, O_{a}\right)$ & $12\left(o_{b^{\prime}} 8_{m^{\prime}} 4_{a}\right)$ & $3\left(1_{b^{\prime}}, 2, o_{a}\right)$ & 18 \\
\hline $\begin{array}{l}\text { Características ge- } \\
\text { nerales de las etapas } \\
\text { constitutivas del } \\
\text { transmisor de AM. }\end{array}$ & & $6_{m^{\prime}} 3_{a}$ & $1_{b}$ & 10 \\
\hline $\begin{array}{l}\text { Análisis de } \\
\text { transmisores. }\end{array}$ & $3_{m}$ & $2_{m^{\prime}}, 1_{a}$ & $2_{m}$ & 8 \\
\hline Totales & 11 & 15 & 7 & 33 \\
\hline
\end{tabular}


En el Ejemplo 37 se muestra la construcción de la tabla de especificaciones tomando en cuenta aquellas planteadas en los párrafos anteriores; para no realizar un análisis demasiado complejo, sólo se presentan los temas contenidos en cada unidad, considerando que los subtemas están incluidos en éstos; sin embargo, en la realidad esta tabla debe contener todos los temas y sub-temas a examinar.

Si se observa el Ejemplo 37, el número de ítems propuesto por el maestro es de 33, dándole mayor peso a la unidad 2 y otorgándole ítems de mayor dificultad posiblemente por lo complejo del contenido al tratar circuitos de aplicación electrónicos y la descripción de su funcionamiento.

Por otra parte, tomó la decisión acerca del número de ítems que se van a utilizar para examinar cada uno de los tres grandes objetivos, predominando en la unidad 1 los objetivos de conocimiento y comprensión, debido a que los temas a tratar son más teóricos, mientras que en la unidad 2 predominan los objetivos de relación y el análisis de circuitos vinculados a elementos electrónicos reales (Ver Apéndice B).

Como consecuencia de la necesidad de elaborar una tabla de especificaciones surgen una serie de cuestionamientos, por ejemplo:

1. ¿Qué tipo de ítem se deben proponer?

2. ¿Cuántos ítems se deben proponer?

3. ¿Qué nivel de dificultad deben ofrecer?

4. ¿Cómo determinar los objetivos de aprendizaje que se persiguen?

\subsubsection{Los tipos de ítems}

Una prueba se construye a partir de un determinado número de ítems, pueden ser todos del mismo tipo o combinarse varios tipos; los ítems se pueden categorizar en dos dimensiones: la primera de acuerdo al método de puntuación y la segunda de acuerdo a la libertad que tiene el alumno de dar sus respuestas (Tenbrink, 2006).

Si las pruebas se puntúan objetivamente se llaman pruebas objetivas, tal es el caso de las pruebas de opción múltiple, las cuales se puntúan a una sola respuesta de entre una serie de cuatro o cinco opciones; si el maestro dice que la respuesta es la opción c) de acuerdo con lo aprendido por el alumno en clase, no hay lugar a la subjetividad, si el alumno contestó la opción c) entonces la respuesta es correcta, pero si contestó cualquier otra opción la respuesta es incorrecta.

Si las pruebas se puntúan subjetivamente se llaman pruebas subjetivas, tal es el caso del ensayo, en el cual el maestro al puntuar debe tomar numerosas decisiones subjetivas sobre cuánto se acerca la respuesta del alumno a la repuesta ideal.

Otro modo de categorizar los ítems de una prueba es de acuerdo con la libertad que se permite al alumno al dar su respuesta. Entre los ítems objetivos se identifican normalmente dos tipos:

- Preguntas de selección. En este caso se permite al alumno seleccionar entre varias alternativas por ejemplo: falso o verdadero, opción múltiple y correlación.

- Preguntas de provisión. En este caso requiere que el alumno llene espacios por ejemplo: complementación y de respuesta corta.

\subsubsection{1 Ítems de falso o verdadero}

En este tipo de ítem se hace un enunciado y el alumno debe determinar si es verdadero o falso, son los más adecuados para recabar información sobre resultados de aprendizaje simple, se 
pueden utilizar para obtener información a nivel de comprensión o aplicación. Si se construyen bien se pueden emplear en alumnos de casi todas las edades, son fáciles de aplicar y puntuar.

Pasos para construir pruebas de falso o verdadero:

1. Dirigir la atención a un ámbito importante del conocimiento. La dimensión de contenido de una tabla de especificaciones es muy útil para dirigirse a un ámbito de conocimiento concreto y así determinar qué información es importante que tenga el alumno.

2. Seleccionar una proposición a examinar que valga la pena. Ésta debe ser: esencial al dominio del ámbito de conocimiento que se examina, defendible como verdadera y una verdad obvia para quienes comprenden el ámbito de conocimiento examinado.

3. Convertir la proposición en un ítem. Éste consiste en elaborar un re-enunciado de la proposición, puede ser una versión verdadera o falsa de la original.

Ejemplo 38. Ítem de falso o verdadero.

I. Coloque en el paréntesis una $\mathrm{V}$ si lo que se afirma es verdadero o una $\mathrm{F}$ si es falso.

1. La señal moduladora debe ser alrededor del $30 \%$ de la potencia del amplificador de $\mathrm{RF}$, si se modula en la salida de éste es con la finalidad de obtener una modulación correcta ( ).

\subsubsection{2 İtems de opción múltiple}

Se estructuran en función de un enunciado, una alternativa correcta y distractores. El enunciado se diseña para presentar una pregunta o problema lo más conciso posible y la respuesta se encuentra entre una serie de cuatro o cinco alternativas en donde sólo una es correcta (alternativa correcta) y las demás opciones son plausibles pero incorrectas (distractores).

Se pueden diseñar y ser aplicados para obtener resultados de aprendizaje a casi cualquier nivel, sin embargo, cuando la memorización es un factor importante no son muy adecuados, lo son para medir los niveles de comprensión, aplicación y análisis. Las preguntas bien redactadas suelen ser muy fiables, de fácil aplicación y de puntuación rápida.

Pasos para construir pruebas de opción múltiple (Tenbrink, 2006):

1. Analizar el resultado del aprendizaje a medir. Se trata de decidir si el resultado del aprendizaje que se está tratando de medir se puede demostrar por medio del proceso de opción múltiple. En el caso de que se requiera de memorización, este proceso no es adecuado. Puede funcionar en casos donde se requiera medir niveles de aprendizaje como conocimiento, comprensión, aplicación, análisis, síntesis y evaluación.

2. Redactar el enunciado y la alternativa correcta. La respuesta debe seguir lógica y gramaticalmente al enunciado, la mejor forma de hacerlo es redactar el enunciado y la alternativa correcta al mismo tiempo.

3. Redactar distractores plausibles. Éstos deben redactarse específicamente para responder o completar el enunciado de tal forma que parezca la alternativa correcta.

4. Ordenar los distractores y las alternativas correctas. Se puede lograr siguiendo un orden lógico (o cronológico) inherente en las alternativas: numérico, cronológico o alfabético.

5. Comprobar la ambigüedad y claves irrelevantes. Verificar que esté libre de imprecisiones y que no existan indicios que revelen la respuesta. 
Ejemplo 39. Ítem de opción múltiple.

II. Coloque en el paréntesis la letra que corresponda a la opción que considere que complete las siguientes oraciones.

1. En una onda electromagnética el parámetro que define el número de ondas que se transmiten por segundo es: ( )
a) La longitud de onda
b) La frecuencia
c) La fase
d) La velocidad

\subsubsection{3 İtems de complementación (llenar espacio)}

Consiste en hacer un enunciado, se deja una palabra o frase fuera, se reemplaza por una línea y se le solicita al alumno que escriba en la línea, la palabra o frase adecuada. Permite medir con precisión el recuerdo de datos específicos en niveles muy bajos de aprendizaje. Este tipo de reactivos presentan dificultad para medir niveles de comprensión, aplicación y análisis, sobre todo en niveles superiores. Son de fácil construcción pero puede ser problemático puntuarlos.

Pasos para construir pruebas de complementación:

1. Dirigir la atención a un ámbito importante de conocimiento. La dimensión de contenido de una tabla de especificaciones es muy útil para dirigirse a un ámbito de conocimiento concreto para determinar qué información es importante que tenga el alumno.

2. Seleccionar una proposición a examinar que valga la pena examinar. Esta proposición debe ser esencial al dominio del ámbito de conocimiento que se examina, defendible como verdadera y una verdad obvia para quienes comprenden el ámbito de conocimiento examinado.

3. Convertir la proposición en un ítem de una prueba. Éste consiste en elaborar un reenunciado de la proposición, debe ser una versión verdadera.

4. Tomar la versión verdadera de una proposición verdadera y reemplazar un término clave por un espacio.

Ejemplo 40. Ítem de complementación.

III. Complete el siguiente enunciado:

1. A la señal de audio que produce los cambios de amplitud en la señal de radio frecuencia se le conoce como

\subsubsection{4 İtems de correlación (emparejamiento)}

Permiten medir la capacidad del alumno de asociar dos fragmentos de información, se puede obtener información sobre el conocimiento de los hechos que tiene. Consiste en presentar dos listas al alumno y solicitarle que empareje cada ítem de una lista con uno de la otra, ya sea trazando líneas o colocando letras o números en los espacios indicados.

Los elementos de la primer columna se llaman premisas y los de la segunda columna se llaman respuestas. Una sola premisa y su respuesta correcta se considera un ítem de la prueba, debe haber varios elementos que sean parecidos en cierto modo para forzar al alumno a discriminar entre las premisas y las respuestas en su intento de formar las parejas correctas. La característica de las parejas consiste en su relación entre un término y sus definiciones.

Se critica a este ítem por que solo se puede utilizar para medir resultados simples de aprendizaje, sin embargo, se puede relacionar con medidas de habilidad, comprensión, todo depende de cómo se estructuren las premisas y sus respuestas. 
Ejemplo 41. Ítem de correlación.

IV. Coloque en el paréntesis el número que corresponda:

1. Eleva el nivel de la señal para ser transmitida por la ( ) Amplificador clase A. antena.

) Amplificador clase B.

2. Permite que la señal de audio pueda hacer variar la amplitud de la portadora.

3. Eleva la señal de la fuente de audio (micrófono, pastilla) para ser aplicada al amplificador de potencia.

4. Convierte las señales eléctricas en ondas electromagnéticas para ser radiadas al espacio.

) Amplificador clase C.

) Amplificador magnético.

) Oscilador de RF.

) Modulador balanceado.

) Acoplador.

( ) Antena.

Pasos para construir pruebas de correlación (Tenbrink, 2006):

1. Decidir qué se va a medir. Es necesario definir los siguientes puntos: a) el contenido de las premisas y respuestas; b) la relación que existe entre ellas; y c) el nivel de aprendizaje requerido para responder. Estos puntos deben estar claros en la tabla de especificaciones.

2. Enumerar las premisas y respuestas a utilizar. Un ejemplo sería enumerar los acontecimientos importantes y sus fechas, o escribir los enunciados declarativos simples que representen ejemplos importantes del tipo de relación que se pretende examinar. Después se dividen estos enunciados en dos partes (sujeto y predicado) constituyendo así las premisas y las respuestas.

3. Añadir premisas o respuestas como distractor. Agregar respuestas que no se emparejan con las premisas, que sean capaces de distraer al alumno que no conoce la materia lo suficiente para que realice un mal emparejamiento.

4. Ordenar las preguntas. Los ítems de respuesta se pueden ordenar de alguna manera, ya sea cronológica, lógica o alfabéticamente. La columna de premisas se ordena al azar.

5. Escribir las instrucciones. Las instrucciones deben indicar claramente el tipo de relación que existe entre las premisas y sus respuestas, evitando la ambigüedad y la confusión.

\subsubsection{El número de ítems}

La cantidad de ítems en la mayoría de los casos depende del tiempo disponible para su aplicación, la duración de respuesta por ítem es difícil de determinar pues depende de la dificultad de la materia y de la velocidad de respuesta de los alumnos (lentos para la lectura, comprensión). Resulta interesante tomar en cuenta que mientras más larga sea la prueba, su fiabilidad sería probablemente mayor. El grado de exactitud tiende a estar vinculado con el de extensión.

\subsubsection{El nivel de dificultad de los ítems}

Para determinar el nivel de dificultad de una prueba se debe tomar en cuenta los tipos de juicios y decisiones que se plantea formular y tomar. Si estas decisiones de selección requieren juicios por referencia a una norma los ítems deberían estar aproximadamente a un nivel del 50\% de dificultad, es decir, que alrededor de un 50\% de los alumnos contestarían correctamente. Resulta obvio pensar que cada ítem no se encuentra exactamente a un nivel de dificultad del $50 \%$, pero la puntuación media de la prueba en general debe estar en torno al 50\%, lo que permite hacer juicios sobre qué alumno trabajó mejor. 
La dificultad de los ítems se determina en parte por el nivel de rendimiento alcanzado por el alumno, por otro lado esta dificultad depende del modo en que se formula el ítem a través de aspectos como el vocabulario, la estructura de la oración y los distractores. Siempre es más conveniente manipular la dificultad basándose en la complejidad de los resultados del aprendizaje y no utilizando un vocabulario difícil o estructuras gramaticales complicadas.

\subsubsection{Los objetivos de aprendizaje}

Las pruebas objetivas no sólo sirven para medir conocimientos memorizados, también permiten evaluar objetivos de aprendizaje como son los de conocimiento y comprensión, relación, aplicación o síntesis. Estos objetivos deben ser coherentes con la manera en que se trabaja la asignatura (realización de prácticas, participación grupal e individual, análisis crítico y autoevaluaciones), lo que favorece la validez y medición exacta de los conocimientos adquiridos por los alumnos durante el proceso de enseñanza-aprendizaje.

Un objetivo educativo es el resultado que se pretende obtener a través del proceso de enseñanza-aprendizaje, se expresa en forma de un enunciado que describe, en términos de cambios en la conducta, lo que se espera del alumno.

Un objetivo consta de cinco elementos de los cuales cuatro son indispensables:

- Quién efectuará la conducta.

- La conducta, es decir, un verbo que debe ser claro, objetivo, sin ambigüedades y conjugado en futuro. Este verbo corresponde a uno de los dominios del aprendizaje.

- El contenido a través del cual se logrará el objetivo.

- Las circunstancias que delimitan la ejecución de la conducta.

- El criterio de ejecución aceptable (este elemento puede omitirse).

Además, es necesario identificar el dominio del aprendizaje al que corresponde el objetivo, que puede ser:

a. Cognoscitivo o cognitivo. Está relacionado con procesos o habilidades de pensamiento.

b. Afectivo. Está relacionado con el desarrollo de sentimientos y actitudes.

c. Psicomotriz. Está relacionado con movimientos que deben ejecutarse de manera automática e integrada con procesos cognitivos.

A continuación se presentan algunos verbos que corresponden al dominio cognoscitivo:

- Conocimiento. Recordar información (apuntar, definir, enlistar, enunciar, marcar, nombrar, recordar, relatar, repetir, subrayar).

- Comprensión. Interpretar información poniéndola en sus propias palabras (describir, explicar, expresar, identificar, localizar, ordenar, predecir, reportar, seleccionar, traducir, ubicar).

- Relación. Usar el conocimiento para establecer relaciones entre distintos contenidos del temario (analizar, calcular, categorizar, comparar, contrastar, criticar, diagramar, diferenciar, discriminar, distinguir, examinar, experimentar, investigar).

- Aplicación. Usar el conocimiento o la generalización en una nueva situación (aplicar, demostrar, dramatizar, emplear, ilustrar, interpretar, operar, practicar, programar, solucionar).

- Síntesis. Juntar o unir, partes o fragmentos de conocimiento para formar un todo y construir relaciones para situaciones nuevas (arreglar, componer, construir, crear, diseñar, ensamblar, formular, organizar, planear, proponer, recopilar, sintetizar).

- Evaluación. Hacer juicios con base en criterios dados (apoyar, argumentar, calificar, defender, elegir, estimar, evaluar, juzgar, otorgar puntajes, predecir, sustentar, valorar). 
2.3.7 Otras técnicas e instrumentos para la recolección de datos en investigación educativa Es importante mencionar que el maestro investigador debe ser innovador al realizar su investigación, no debe limitarse a las técnicas para la recolección de los datos establecidas en este capítulo, por el contrario, debe ser creativo para diseñar e implementar sus propios instrumentos de acuerdo a las necesidades particulares de su objeto de estudio.

Resulta interesante dar cuenta de las constantes propuestas que van surgiendo del producto de los investigadores en educación para diseñar, crear e implementar técnicas o instrumentos para la recolección de datos que se van requiriendo.

A continuación se plantean algunos ejemplos sin ahondar en ellos, sólo se pretende despertar la imaginación del lector con el objetivo de que no limite su visión al producir sus propios instrumentos:

- El portafolio. Es un procedimiento que consiste en la recogida de información de una manera sistemática y organizada de las evidencias de aprendizaje. Permite evaluar las ejecuciones de los alumnos y cómo progresan sus habilidades, actitudes y conocimiento.

- El juego didáctico. Es una técnica que consiste en la elaboración y aplicación de juegos populares para obtener registros de los alumnos de una manera sistemática y organizada que permitan evidenciar habilidades, actitudes y conocimiento.

- La práctica de laboratorio. Es una técnica que permite mediante la auto-elaboración de la misma, aplicar el método científico, permitiendo la recogida sistemática y organizada de información que ponga en evidencia el dominio teórico, práctico e investigativo del alumno.

- La historia de vida. Es un proceso metodológico que requiere de la confección de textos personales cuya tarea central es la de redactar la historia personal de cada participante (alumno) para determinar el dominio en la escritura e informática.

- El grupo de discusión. Es una técnica que más que explicar los hechos, pretende comprender los fenómenos educativos desde la perspectiva del participante (alumno), debe reflejar la experiencia educativa y social que construye, organiza y percibe por lo que se considera de tipo cualitativo fenomenológico.

- La rejilla de constructos personales. Es una técnica que permite que el sujeto genere su propia matriz de información, trabajando desde un marco interpretativo de la realidad, valorando un conjunto de elementos y decidiendo cuáles deben ser valorados, así como los criterios para hacerlo. Parte de las entrevistas, textos y documentos personales de carácter autobiográfico o autodescriptivo. 



\section{PARTE III \\ ¿Qué se requiere saber sobre la estadística?}





\section{Capítulo 3}

\section{Conceptos de estadística}

Los maestros en muchas ocasiones hacen pronósticos relativos a lo que sucederá ante nuevas situaciones o experiencias educativas. Conforme acontecen, se confirman los pronósticos, pero a veces no es así y el resultado son experiencias con consecuencias desagradables.

Se ponen a consideración del lector algunos ejemplos educativos: la implementación de dinámicas grupales de aprendizaje, el uso de recursos didácticos, la planeación meticulosa y bien cuidada de las sesiones de clase, el uso adecuado de las instalaciones dentro del salón de clase para organizar diferentes tipos de estrategias pedagógicas, la participación activa del alumno en forma individual o grupal.

Una predicción razonable es considerar que si se utilizan de manera eficiente estas actividades se pueden esperar buenos resultados en el aprovechamiento del alumno y como consecuencia mayor capacidad de retener los conocimientos. Pero no siempre sucede de esta forma, en ocasiones intervienen factores ajenos al proceso que determinan el éxito o fracaso de los resultados.

El investigador en educación plantea estas predicciones (que se definen como hipótesis), y con frecuencia las comprueba por medio de una investigación sistemática. Se puede plantear como ejemplo la siguiente hipótesis: "El uso de los cuadernos de planeación de clase proporcionados por la SEP para la materia de matemáticas, aumenta el aprovechamiento escolar en los alumnos de segundo grado de secundaria", el investigador podría aplicar un examen de conocimientos diagnóstico para conocer el estado inicial de los alumnos, utilizar los cuadernos de planeación aplicando posteriormente otro examen de conocimientos y mediante una prueba estadística comprobar si existió una diferencia significativa.

El investigador en educación debe comprobar sistemáticamente las hipótesis aunque parezcan lógicas, verdaderas o evidentes, ya que las "pruebas" de sentido común se basan en concepciones parcializadas, a veces reducidas o en la experiencia personal, convirtiéndolas en interpretaciones subjetivas que pueden conducir a aceptar conclusiones sin valor respecto a la naturaleza de los fenómenos educativos.

Regresando a la hipótesis planteada y considerando que los cuadernos de planeación de clase fueron diseñados por pedagogos expertos que conocen las características propias de los estudiantes para quienes fueron hechos, se podría suponer que esta hipótesis tiene suficiente sentido común como para someterla a una prueba sistemática; sin embargo, las evidencias y el resultado del análisis estadístico permitió determinar que no existe mejora alguna en el aprovechamiento de los alumnos e incluso disminuyó.

Por lo general el proceso de las investigaciones cuantitativas en educación se realizan siguiendo una secuencia que inicia con la detección de un problema o necesidad de mejorar la práctica en el proceso de enseñanza-aprendizaje, se delimita y se plantean las preguntas 
de investigación y se establecen los objetivos, se construye un marco teórico que permita formular la hipótesis (no siempre), se selecciona la muestra, se plantean las estrategias o procedimientos para comprobar esta hipótesis, y se diseñan los instrumentos de recolección de información, misma que se estudia; en muchas ocasiones se realiza un análisis estadístico, para finalmente presentar los resultados y conclusiones.

\subsection{Concepto de Hipótesis}

La hipótesis puede ser concebida como una proposición que pone de manifiesto lo que se está buscando o tratando de probar, presentándose como una propuesta que pretende explicar el fenómeno objeto de investigación (explicaciones tentativas) para ser comprobada o rechazada (Méndez, Namihira, Moreno y Sosa, 2001).

Las hipótesis pueden involucrar dos o más variables y en ocasiones son generales o precisas. Una de las características de las variables es que sus propiedades están sujetas a variaciones, las cuales son susceptibles de medirse u observarse.

Dentro de la investigación el valor de las variables adquieren importancia cuando llegan a relacionarse con otras y se constituyen como parte de una hipótesis o teoría, concibiéndose como constructos o construcciones hipotéticas.

\subsubsection{La hipótesis y el método experimental}

Dentro de la investigación experimental, los investigadores de la educación proponen predicciones que conllevan una relación entre dos o más variables prediciendo el comportamiento de los involucrados en el proceso educativo (maestros, alumnos, padres de familia, tutores). El investigador manipula una variable para verificar si ésta produce algún efecto sobre una segunda variable, considerando que la variabilidad propia de los humanos, solo le permite proponer probabilidades de sus predicciones y no afirmaciones sobre las respuestas de los participantes.

Buendía, Colás y Hernández (1988) señalan que el investigador en educación cuando plantea su hipótesis, propone alterar una variable independiente para observar si afecta a otra variable dependiente en los siguientes términos:

a. Variable independiente: se denomina así a aquella que se pretende comprobar. Retomando la hipótesis planteada, el concepto de variable independiente se debe a que el investigador selecciona de manera independiente las condiciones "utilizando los cuadernos de planeación de clase" y "sin utilizarlos" en el proceso del diseño del experimento.

b. Variable dependiente: lo que se desea comprobar es si la variable dependiente, que representa "el aprovechamiento escolar" en los alumnos se vio afectada. Se pretende comprobar la predicción de la hipótesis sobre el efecto de la variable independiente y tratar de eliminar otras variables irrelevantes que puedan afectar el comportamiento de los alumnos.

c. Variables irrelevantes: son aquellas que no están pronosticadas por la hipótesis de la investigación, se pretende evitarlas diseñando un experimento en donde la única diferencia entre las dos condiciones sea causada por la variable independiente.

Es usual que el investigador en educación utilice una condición de control para comparar sus efectos con los de la variable independiente. El hecho de que los alumnos no se vean afectados por la condición experimental, permite comparar las dos condiciones "utilizando los cuadernos de planeación de clase" y "sin utilizarlos".

De acuerdo a la hipótesis se espera que la condición experimental al utilizar los cuadernos de planeación de clase los alumnos lograrán un mayor aprovechamiento que en el caso de la condición de control. 
Ejemplo 42. Diseño experimental para las condiciones control y experimental.

Diseño experimental

Condición experimental

utilizando los cuadernos de planeación de clase

Condición de control

sin utilizar los cuadernos de planeación de clase

Aprovechamiento escolar

Aprovechamiento escolar

En otras ocasiones el investigador en educación, en lugar de utilizar una condición de control, considera comparar dos niveles de una misma variable independiente. Un ejemplo puede ser, verificar si el nivel de apropiación de conocimientos es mayor cuando se utiliza un video interactivo, que cuando se utiliza un video en forma tradicional durante el proceso educativo.

Ejemplo 43. Diseño experimental para dos condiciones experimentales diferentes.

Diseño experimental

Condición experimental A:

utilizando videos interactivos

Nivel de apropiación de conocimientos

Condición Experimental B:

utilizando videos en forma tradicional

Nivel de apropiación de conocimientos

En este ejemplo el diseño experimental compararía el nivel de apropiación de conocimientos en dos circunstancias diferentes de las condiciones experimentales. Puede ocurrir que se compare con más de dos condiciones, en esta circunstancia una tercera condición sería no utilizar el video.

Ejemplo 44. Diseño experimental para tres condiciones experimentales diferentes.

Diseño experimental

Condición experimental A:

utilizando videos interactivos

Nivel de apropiación de conocimientos

Condición Experimental B:

utilizando videos en forma tradicional

Nivel de apropiación de conocimientos

Condición Experimental C:

no utilizar videos, exposición del maestro

Nivel de apropiación de conocimientos

De acuerdo a la hipótesis de investigación se espera que en la condición experimental A, los alumnos obtuvieran un mayor nivel de apropiación de conocimientos al utilizar los videos interactivos.

Diseños relacionados. Estos diseños se utilizan cuando se trabaja con los mismos alumnos participantes, ya que son ellos los que se comparan y los resultados que se obtienen de cada uno se relacionan. Esta situación pretende limitar las diferencias entre los participantes al ser sometidos a todas las condiciones considerando que los datos son homogéneos con todas éstas.

Una desventaja es que los alumnos pueden verse afectados por su experiencia con las condiciones aplicadas con anterioridad, para reducir este problema se puede variar el orden de las condiciones de tal forma que la mitad de los alumnos se sometan a la Condición A y 
luego a la Condición B y la otra mitad invierta el proceso, primero la Condición B y luego la A, tratando de compensar así cualquier efecto irrelevante causado por la experiencia.

Diseños independientes. Estos diseños se utilizan cuando se trabaja con grupos de alumnos participantes diferentes para cada condición experimental, en la cual cada alumno es expuesto a una sola condición, sin verse afectados por los efectos de otra. En este caso la comparación se hace entre alumnos distintos y los resultados de cada uno de ellos no están relacionados, siendo por lo tanto independientes. En este caso un problema consiste en que las condiciones de los grupos a comparar deben ser iguales, por lo que sería necesario que los grupos de alumnos que se formen tengan características similares, por ejemplo, si los alumnos se seleccionan en forma aleatoria entonces los alumnos con edades y capacidades distintas tienen la misma probabilidad de encontrarse en todos los grupos experimentales.

\subsubsection{Características de una hipótesis en educación}

Una hipótesis en educación para poder ser verificada debe reunir los siguientes requisitos:

- La hipótesis debe referirse a una situación educativa real. Dentro de un universo y un contexto educativo bien definido.

- Las variables dentro de una hipótesis deben ser comprensibles, precisas y concretas.

- La relación de las variables dentro de una hipótesis deben ser claras, lógicas y creíbles.

- Los términos y relaciones de la hipótesis deben ser observables y medibles, tener un referente con la realidad.

- La hipótesis debe relacionarse con técnicas disponibles para probarlas.

\subsubsection{Tipos de hipótesis}

Existen diferentes tipos de hipótesis, de acuerdo a Hernández, Fernández y Baptista (2014), pueden ser clasificadas de la siguiente manera:
a. Hipótesis de investigación;
b. Hipótesis nulas;
c. Hipótesis alternativas, e
d. Hipótesis estadísticas.

\subsubsection{Hipótesis de investigación}

Son proposiciones tentativas acerca de las posibles relaciones entre dos o más variables. También se les suele llamar hipótesis de trabajo y se representa por $\mathrm{Hi}$ o si son varias $\mathrm{H}_{1}, \mathrm{H}_{2}, \mathrm{H}_{3}$, se agrupan en:

a. Hipótesis descriptivas. Se utilizan a veces en estudios descriptivos para intentar predecir un dato o valor en una o más variables que se van a medir u observar, aclarando que no en todos los estudios descriptivos se formulan hipótesis o consisten en afirmaciones generales. Un ejemplo sería: "el bajo rendimiento escolar de los niños que proceden de familias desintegradas es elevado", en algunas ocasiones se plantea que es una variable que se manifiesta en una constante. Pero ante la dificultad de la comprensión de este planteamiento, también se habla de hipótesis descriptivas que relacionan dos variables.

b. Hipótesis correlacionales. Establecen la relación entre dos o más variables; corresponden a estudios correlacionales. Un ejemplo sería: "a mayor asistencia al salón de clase, mayor preparación del alumno".

c. Hipótesis de la diferencia entre grupos. Corresponden a estudios cuya finalidad es comparar grupos. Un ejemplo sería: "el aprovechamiento escolar no será igual en los alumnos que 
provienen de una familia desintegrada que en los alumnos que provienen de una familia integrada".

d. Hipótesis de causalidad. Establecen relaciones de causa-efecto. Afirman la o las relaciones entre dos o más variables y la manera en que se manifiestan, proponiendo un sentido de entendimiento de éstas. Un ejemplo sería: "si los alumnos del primer semestre del bachillerato realizan prácticas de laboratorio de Biología siguiendo el proceso del método científico entonces el alumno logrará significar sus conocimientos".

\subsubsection{Hipótesis nula}

Son proposiciones que refutan o niegan lo que afirma la hipótesis de investigación mediante proposiciones de las relaciones entre las variables; se simboliza por $\mathrm{H}_{\mathrm{o}}$. Un ejemplo sería, de acuerdo a la hipótesis de causalidad planteada en el párrafo anterior: "si los alumnos del primer semestre del bachillerato realizan prácticas de laboratorio de Biología siguiendo el proceso del método científico entonces el alumno no logrará significar sus conocimientos". Hay tantas hipótesis nulas como las de investigación.

\subsubsection{Hipótesis alternativa}

Son otras posibilidades diferentes o alternas a las hipótesis de investigación o nula, presentando explicaciones distintas a las expuestas por éstas, se simboliza como $\mathrm{H}_{\mathrm{a}^{\prime}}$ sólo se formulan cuando efectivamente hay otras posibilidades. Un ejemplo sería:

$\mathrm{H}_{\mathrm{i}}$ : Si el tutor aplica la guía de desafíos como estrategia de tutoría, mejorará el rendimiento académico en un $50 \%$ de los alumnos de primer grado de secundaria.

$\mathrm{H}_{\mathrm{o}}$ : Si el tutor aplica la guía de desafíos como estrategia de tutoría, no mejorará el rendimiento académico en un 50\% de los alumnos de primer grado de secundaria.

$\mathrm{H}_{\mathrm{a}}$ : Si el tutor aplica la guía de desafíos como estrategia de tutoría, mejorará el rendimiento académico en un $80 \%$ de los alumnos de primer grado de secundaria.

\subsubsection{Hipótesis estadísticas}

Permiten transformar las hipótesis de investigación, nulas o alternativas en términos estadísticos, sólo se pueden utilizar en enfoques cuantitativos, es decir, cuando los datos recolectados en la investigación se pueden cuantificar ya sea con números, promedios o porcentajes que permitan aprobar o rechazar las hipótesis. Éstas pueden ser:

a. Hipótesis de estimación. Corresponde a las hipótesis descriptivas de una variable observada dentro de un contexto, permite evaluar la suposición respecto al valor de alguna característica en una muestra de alumnos, población escolar u objetos cuyo fundamento se asienta en información previa (Ejemplo 45).

b. Hipótesis estadística de correlación. Corresponde a ésta transformar en términos estadísticos si existe una correlación entre dos o más variables; se simboliza de dos maneras " $r$ " si se trata de una correlación entre dos variables o " $R$ " si son más de dos variables (Ejemplo 46).

c. Hipótesis estadísticas de la diferencia de las medias. Consiste en comparar el valor de las medias (promedios) entre dos o más grupos; sin embargo, también pueden ser utilizadas para comparar entre el mismo grupo los valores de las medias antes y después de una intervención educativa (estrategia, técnica, proceso) (Ejemplo 47). 
Ejemplo 45. "El número de alumnos reprobados en la materia de matemáticas en la escuela Flores Magón, representó un promedio bimestral menor a 60". Para transformarla en hipótesis estadística se requiere identificar cuál es el estadístico que presenta la hipótesis, en este caso se refiere al promedio bimestral de reprobados que en estadística representa el valor de la media y se representa como $\bar{x}$; se traduce como:

$\mathrm{H}_{\mathrm{i}}: \overline{\mathrm{x}}<60$ (Promedio bimestral de alumnos reprobados es menor a 60 ).

La hipótesis estadística nula es:

$\mathrm{H}_{\mathrm{o}}: \overline{\mathrm{x}}>60$ (Promedio bimestral de alumnos reprobados es mayor a 60 ).

La hipótesis estadística alternativa es:

$\mathrm{H}_{\mathrm{a}}: \overline{\mathrm{x}}=60$ (Promedio bimestral de alumnos reprobados es igual a 60 ).

La hipótesis estadística nula también puede incluir la igualdad dependiendo del interés del investigador, si es el caso, entonces $\bar{x} \geq 60$ reuniendo todas las posibilidades de la propuesta y como consecuencia no existiría la hipótesis estadística alternativa. Una vez planteadas las hipótesis estadísticas el investigador debe comparar el promedio estimado con el problema real y actual de la muestra seleccionada.

En este ejemplo se utilizó el promedio para estimar las hipótesis pero también se pueden utilizar otros estadísticos como los porcentajes, la moda y la mediana.

Ejemplo 46. A mayor promedio de las calificaciones de los egresados de primaria mayor será su rendimiento en la secundaria. Donde A es la variable promedio de primaria y B es el rendimiento en secundaria; transformando a hipótesis estadística quedaría así:

$\mathrm{H}_{\mathrm{i}:} r_{\mathrm{AB}} \neq \mathrm{O}$ (no es igual a cero, por lo tanto las dos variables están correlacionadas).

$\mathrm{H}_{\mathrm{O}}: r_{\mathrm{AB}}=\mathrm{O}$ (es igual a cero, por lo tanto las dos variables no están correlacionadas).

En este caso no hay hipótesis alternativa porque las hipótesis estadísticas de investigación y nula cubren todas las posibilidades. El investigador tendrá que utilizar el proceso adecuado para determinar el valor de ry aceptar o rechazar la hipótesis de investigación.

Ejemplo 47. El caso presentado en la hipótesis de investigación con dos grupos, el experimental y el de control: "Si los alumnos del primer semestre del bachillerato realizan prácticas de laboratorio de Biología siguiendo el método científico entonces el alumno logrará significar sus conocimientos".

En este caso el grupo experimental realiza las prácticas siguiendo el método científico, mientras que el grupo de control las realiza en la forma tradicional; se pretende verificar si existe alguna diferencia entre las medias pronosticando que la del grupo experimental sea mayor que la del grupo piloto. De acuerdo a esto, la hipótesis estadística quedaría así:

$\mathrm{H}_{\mathrm{i}}: \overline{\mathrm{x}}_{1} \neq \overline{\mathrm{x}}_{2}$ (existe diferencia entre los valores de las medias de los dos grupos).

$\mathrm{H}_{\mathrm{o}}: \overline{\mathrm{x}}_{1}=\overline{\mathrm{x}}_{2}$ (no existe diferencia entre los valores de las medias de los dos grupos).

En donde:

$\bar{x}_{1}$ corresponde al valor de la media del grupo experimental.

$\overline{\mathrm{x}}_{2}$ al valor de la media del grupo piloto o de control.

\subsection{El nivel de medición}

Dentro del proceso de la recolección de información, en la mayoría de las ocasiones el investigador educativo requiere realizar mediciones o una serie de números para analizar sus datos. Los números tienen mínimo cuatro funciones importantes dentro de la investigación educativa (Ritchey, 2008), de acuerdo al nivel de medida que se utilice éstos son:

El nivel de medición nominal. Es un proceso que denomina o etiqueta, es decir, coloca los casos en categorías y cuenta las frecuencias de ocurrencia. Es necesario resaltar que cada caso debe colocarse en una sola categoría, un ejemplo puede ser el sexo, al cual se le dan dos categorías: femenino o masculino, al clasificar al alumno como masculino no se le puede clasificar también como femenino. 
Cuadro 5. Resumen de la clasificación de las hipótesis en el enfoque cuantitativo.

\section{Clasificación de las hipótesis en el enfoque cuantitativo}

Hipótesis de investigación Son proposiciones acerca de las relaciones entre dos o más variables.

Hipótesis nulas

Son proposiciones que afirman o refutan las hipótesis de investigación.

Hipótesis alternativas

Ofrecen alternativas a las hipótesis de investigación y nula.

Hipótesis estadísticas

Transforman a las hipótesis de investigación, nula y alternativa en símbolos estadísticos.

Las hipótesis de investigación, nulas y alternativas se clasifican como se indica en los siguientes apartados, pero con los elementos que caracterizan a cada una de ellas.

\begin{tabular}{|c|c|c|}
\hline \multirow{2}{*}{ Hipótesis descriptivas } & Establecen relación entre variable y constante. & Monovariadas \\
\hline & Establecen relación entre dos variables. & Bivariadas \\
\hline \multirow{4}{*}{ Hipótesis correlacionales } & \multirow{2}{*}{ Establecen sólo la relación entre las variables. } & Bivariadas \\
\hline & & Multivariadas \\
\hline & \multirow{2}{*}{ Establecen como es la relación entre las variables. } & Bivariadas \\
\hline & & Multivariadas \\
\hline \multirow{4}{*}{$\begin{array}{l}\text { Hipótesis de la diferencia } \\
\text { de medias }\end{array}$} & \multirow{2}{*}{$\begin{array}{l}\text { Establecen sólo la diferencia entre } \\
\text { los valores de las medias. }\end{array}$} & Mismo grupo \\
\hline & & Dos o más grupos \\
\hline & \multirow{2}{*}{$\begin{array}{l}\text { Establecen en favor de qué valor de media es la } \\
\text { diferencia. }\end{array}$} & Mismo grupo \\
\hline & & Dos o más grupos \\
\hline \multirow{6}{*}{ Hipótesis causales } & Una variable independiente y una dependiente & Bivariadas \\
\hline & $\begin{array}{l}\text { Varias variables independientes } \\
\text { y una dependiente. }\end{array}$ & \multirow{5}{*}{ Multivariadas } \\
\hline & Una variable independiente y varias dependientes. & \\
\hline & $\begin{array}{l}\text { Varias variables independientes } \\
\text { y varias dependientes. }\end{array}$ & \\
\hline & Variables intervinientes presentes. & \\
\hline & Hipótesis muy complejas. & \\
\hline
\end{tabular}

Las hipótesis estadísticas se clasifican como se muestra en los siguientes apartados.

Hipótesis descriptivas monovariable en un contexto.

Hipótesis de estimación

Evalúan un supuesto referente al valor de alguna

característica de una muestra de individuos,

población u objetos.

Ejemplo de forma

estadística:

$H_{\mathrm{i}}: \overline{\mathrm{x}}<\mathrm{A}$

$H_{0}: \bar{x}>A$

$\mathrm{H}_{\mathrm{a}}: \overline{\mathrm{x}}=\mathrm{A}$

Ejemplo de forma

Hipótesis de correlación

Traduce en términos estadísticos una correlación entre dos variables. estadística:

$\mathrm{Hi}: r_{A B} \neq 0$

Ho: $r_{A B}=0$

Compara los valores del estadístico de la media,

Hipótesis de diferencia

de medias entre dos o más grupos o en una relación antes y después de un solo grupo.

Ejemplo de forma estadística:

$\mathrm{Hi}: \overline{\mathrm{x}}_{1} \neq \overline{\mathrm{X}}_{2}$

$H_{0}: \bar{x}_{1}=\bar{x}_{2}$ 
Un ejemplo es el siguiente, en el cual se utiliza una medida de nivel nominal para indicar cuántos de los alumnos del Grupo A de segundo grado reprobaron y cuántos no. Como se muestra, el grupo se compone de 30 alumnos determinando que 9 reprobaron y 21 no lo hicieron.

Ejemplo 48. Estado de los alumnos del Grupo A, datos nominales.

\begin{tabular}{|l|c|}
\hline Estado de los alumnos (categorías) & Frecuencia $(\boldsymbol{F})$ \\
\hline $1=$ Reprobados & 9 \\
\hline $2=$ Aprobados & 21 \\
\hline Total & 30 \\
\hline
\end{tabular}

En algunas ocasiones se utiliza el término de datos categóricos para designar a los datos nominales debido a que los datos se miden como el número de participantes en cada categoría.

El nivel de medición ordinal. Se emplea cuando el investigador busca ordenar sus casos en términos del grado que poseen en determinada característica (se pueden ordenar de menor a mayor).

La relación que existe entre las categorías ordinales depende de las características de lo que se pretende medir. Por ejemplo, una de las características puede ser observar quién tiene más habilidades y ordenarlos como se muestra en el siguiente ejemplo donde se designa la clasificación de los estudiantes del Grupo B, para evaluar sus habilidades para realizar prácticas de laboratorio. A este tipo de datos se les conoce como designación de categorías a los resultados.

Ejemplo 49. Habilidades para realizar prácticas de laboratorio de los alumnos de
datos ordinales, con designación de categorías a los resultados.
\begin{tabular}{|l|l|}
\hline Estudiante & Categorías \\
\hline Miguel & 1. Menor habilidad \\
\hline Ángel & 2. Segundo \\
\hline Luz María & 3. Tercero \\
\hline Roberto & 4. Cuarto \\
\hline Luis Alfonso & 5. Quinto \\
\hline Rosaura & 6. Sexto \\
\hline Margarita & 7. Séptimo \\
\hline Raúl & 8. Octavo \\
\hline Martha & 9. Noveno \\
\hline Melesio & 10. Décimo \\
\hline Juan Carlos & 11. Décimo primero \\
\hline José Juan & 12. Mayor habilidad \\
\hline
\end{tabular}

Pero si las características pretenden medir estas habilidades mediante una guía de observación, que involucra un puntaje obtenido de los resultados de la evaluación del reporte de la práctica (máximo 15 puntos), donde estos resultados pueden repetirse, se les conoce como categorías relacionadas. Es decir, algunos de los alumnos podrían tener los mismos resultados. 
En el siguiente ejemplo se muestran los resultados obtenidos por los estudiantes del Grupo B mediante este procedimiento, se ordenaron de menor a mayor designándole la Categoría 1 al resultado menor 1 , pero como hay dos resultados 1 al siguiente se la designa la Categoría 2 y así sucesivamente (ver columna de pre-categorías).

En este ejemplo se puede apreciar que Luz María y Melesio obtuvieron la misma evaluación igual a uno, mientras que Ángel, Raúl y Juan Carlos obtuvieron una evaluación de tres; cabe preguntar si los resultados son iguales, ¿cómo designarles las categorías si tienen el mismo valor?, ¿por qué no ponerle el uno a Melesio en lugar de Luz María? o ¿los dos deberían de tener la Categoría 1?

Ejemplo 50. Habilidades para realizar prácticas de laboratorio de los alumnos del Grupo B,
datos ordinales, con designación de categorías relacionadas.
\begin{tabular}{|l|c|c|c|}
\hline Estudiante & Resultados & Pre-categorías & Categorías \\
\hline Miguel & 7 & 10 & 10 \\
\hline Ángel & 3 & 4 & 5 \\
\hline Luz María & $\mathbf{1}$ & $\mathbf{1}$ & $\mathbf{1 . 5}$ \\
\hline Roberto & 4 & 7 & 7 \\
\hline Luis Alfonso & 5 & 8 & 8 \\
\hline Rosaura & 8 & 11 & 11 \\
\hline Margarita & 2 & 3 & 3 \\
\hline Raúl & 3 & 5 & 5 \\
\hline Martha & 6 & 9 & 9 \\
\hline Melesio & $\mathbf{1}$ & $\mathbf{2}$ & $\mathbf{1 . 5}$ \\
\hline Juan Carlos & $\mathbf{3}$ & $\mathbf{6}$ & $\mathbf{5}$ \\
\hline José Juan & 13 & 12 & 12 \\
\hline
\end{tabular}

El procedimiento en estos casos consiste en asignar a los dos resultados la media de las categorías que le hubieran correspondido. Esto es, a los dos resultados 1 les corresponden las categorías 1 y 2 (pre-categoría) por ser los resultados menores, entonces a estos dos resultados se les asigna la categoría de la media donde $(1+2) / 2=1.5$ como consecuencia a los dos resultados iguales a 1 se les asigna la categoría media 1.5 como se puede observar en el ejemplo anterior.

En este caso ya se usaron las categorías 1 y 2 por lo tanto la siguiente categoría es el 3 que se le asigna a Margarita por obtener el resultado 2, así se continúa designando todas las categorías. En el Ejemplo 50 se representan en la columna de las pre-categorías.

Siguiendo el mismo proceso se determina la categoría para los resultados tres que se repiten tres veces y que les corresponderían las categorías 4, 5 y 6 (pre-categoría), se calcula la media $(4+5+6) / 3=5$ y se les asigna como categoría a los tres resultados, quedando finalmente ordenadas las categorías como se muestra en la columna de categorías del Ejemplo 50.

En caso de grupos más numerosos que pueden presentar categorías relacionadas complicadas es recomendable contar el número total de resultados, en este ejemplo es de 12. Esto se debe realizar para confirmar si la categoría mayor 12 ha sido asignada al resultado mayor 13. También se puede apreciar que los intervalos entre los puntos o rangos de los resultados no son iguales, conocidos o significativos. 
El nivel de medición por intervalos. Indica tanto el orden de las categorías como la distancia exacta entre ellas, empleando unidades constantes de medición, las que proporcionan intervalos iguales entre los puntos de la escala.

Ejemplo 51. Diferencia entre el nivel de medición por intervalo y el de razón con intervalo
constante.
Cero arbitrario
\begin{tabular}{|c|c|c|c|c|c|c|c|c|c|c|c|}
\hline 0 & 1 & 2 & 3 & 4 & 5 & 6 & 7 & 8 & 9 & 10 \\
\hline 0 & 1 & 2 & 3 & 4 & 5 & 6 & 7 & 8 & 9 & 10
\end{tabular}
Cero real

Una de las propiedades es que el cero (o) en la medición es un cero arbitrario, no es real, el ejemplo típico es el de la escala de temperatura, si se menciona "cero grados centígrados", no implica que no exista temperatura. Además, permite utilizar las operaciones aritméticas básicas y algunas estadísticas modernas.

El nivel de medición de razón. Posee todas las características del nivel de intervalos, pero la diferencia la marca que el cero es real y es absoluto (no arbitrario), lo que implica que es posible indicar la completa ausencia de una propiedad, por ejemplo, si se mide la altura en centímetros el cero indica que no existe ésta.

Ejemplo 52. Una medición del aprovechamiento de los alumnos del Grupo A en donde se utilizó una prueba objetiva, con una serie de preguntas sobre la materia de español, calificada en una escala de $\mathrm{O}$ a 100, donde el 100 representa la calificación más alta, arrojó los resultados que se muestran en la Tabla 1.

Se pueden ordenar a los alumnos en términos de su aprovechamiento, indicar las distancias que los separan a unos de otros y además determinar a los que aprobaron y a los reprobados (mínima aprobatoria es 60).

Tabla 1. Puntuación obtenida por los alumnos del Grupo A referente al aprovechamiento.

\begin{tabular}{|c|c|c|c|}
\hline № de alumno & Puntuación & № de alumno & Puntuación \\
\hline 1 & 98 & 16 & 70 \\
\hline 2 & 96 & 17 & 68 \\
\hline 3 & 92 & 18 & 65 \\
\hline 4 & 90 & 19 & 65 \\
\hline 5 & 90 & 20 & 64 \\
\hline 6 & 87 & 21 & 60 \\
\hline 7 & 85 & 22 & 52 \\
\hline 8 & 80 & 23 & 50 \\
\hline 9 & 80 & 24 & 48 \\
\hline 10 & 80 & 25 & 46 \\
\hline 11 & 79 & 26 & 46 \\
\hline 12 & 76 & 27 & 35 \\
\hline 13 & 73 & 28 & 34 \\
\hline 14 & 73 & 29 & 28 \\
\hline 15 & 70 & 30 & 20 \\
\hline
\end{tabular}




\subsection{Análisis estadístico de los datos}

La exposición que en este apartado se presenta sobre estadística pretende solo dar a conocer los términos utilizados en las diferentes pruebas de corte estadístico que se tratarán en los capítulos posteriores, presentando algunos conceptos, buscando que se comprenda el vocabulario básico, los conceptos utilizados, su aplicación y cómo realizar trabajos estadísticos de una manera sencilla.

La investigación educativa generalmente trabaja dos tipos de datos estadísticos (Best, 1981):

- Análisis estadístico descriptivo. La estadística descriptiva proporciona información acerca de la naturaleza de un grupo en particular por medio de una descripción numérica, los datos sólo describen a este grupo.

- Análisis estadístico deductivo. La estadística deductiva se basa sobre un pequeño grupo denominado muestra que se supone representativo de un grupo más numeroso denominado población o universo para un estudio. Para que la muestra sea representativa de su población o universo debe ser sometida a un procedimiento riguroso de muestreo y los hallazgos que se encuentren sólo son aplicables a la población de donde se extrajo.

\subsubsection{Medidas descriptivas}

Para describir los datos obtenidos, procesarlos y analizarlos de manera significativa, es conveniente utilizar varios tipos de medidas estadísticas, las cuales se presentan a continuación.

\subsubsection{Medidas de tendencia central}

Se refieren valores como promedios, puntuaciones o series de características, definiendo a los grupos de datos en términos de alguna medida que se halla próxima al centro de la distribución y que la puede tipificar. Las más utilizadas son:

La media $(\bar{x})$. Corresponde a lo que comúnmente se le denomina el valor promedio o media aritmética. Se calcula sumando todas las puntuaciones y dividiéndolas entre el número de puntuaciones que son. Su ecuación es:

a. Datos en seriación (no agrupados).

$$
\overline{\mathrm{x}}=\frac{\sum \mathrm{x}}{N}
$$

Donde:

$$
\begin{aligned}
& \overline{\mathrm{x}}=\text { la media de las puntuaciones (x barra). } \\
& \Sigma=\text { la suma (sigma). } \\
& \mathrm{x}=\text { la puntuación directa (cruda o no procesada). } \\
& N=\text { el número total de puntuaciones. }
\end{aligned}
$$

Aplicando la fórmula en el siguiente ejemplo, se encuentra que la media es de 56.36 correspondiente a las calificaciones de Geografía de los 11 alumnos examinados. 
Ejemplo 53. Procedimiento para la media de las calificaciones de los alumnos de Geografía.

\begin{tabular}{|l|l|l|}
\hline \multicolumn{1}{|c|}{ Nombre del alumno } & \multicolumn{1}{|c|}{ Calificación $\mathbf{x}$} \\
\hline 1. Axel & 20 & \\
\hline 2. Jessica & 60 & $\overline{\mathrm{x}}=\frac{\sum \mathrm{x}}{N}$ \\
\hline 3. Carlos & 60 & \\
\hline 4. Leonardo & 80 & $\overline{\mathrm{x}}=\frac{620}{11}$ \\
\hline 5. Carolina & 80 & \\
\hline 6. Nayeli & 100 & $\overline{\mathrm{x}}=56.36$ \\
\hline 7. Andrés & 40 & \\
\hline 8. Yesmi & 40 & \\
\hline 9. Brayan & 20 & \\
\hline 10. Ernesto & 40 & \\
\hline 11. Jorge & 80 & \\
\hline$N=11$ & $\sum \mathrm{x}=620$ & \\
\hline
\end{tabular}

b. Datos agrupados.

Si los datos se encuentran agrupados entonces la ecuación es:

$$
\overline{\mathrm{x}}=\frac{\Sigma(f) \mathrm{Xm}}{N}
$$

$\mathrm{Xm}=$ punto medio de cada intervalo.

$f=$ frecuencia (número de puntuaciones en cada

intervalo).

Donde:

La frecuencia de cada intervalo se multiplica con su correspondiente medio de intervalo y la suma de estos productos se divide entre el número de puntuaciones, obteniéndose el valor de la media igual a 55.86, como se muestra en el Ejemplo 54.

Ejemplo 54. Procedimiento para la media con el método de datos agrupados de las calificaciones de los alumnos de Geografía.

\begin{tabular}{|c|c|c|c|c|}
\hline Puntuación & $\boldsymbol{f}$ & $\mathbf{X m}$ & $(\boldsymbol{f}) \mathbf{X m}$ & $\overline{\mathrm{X}}=\frac{\sum(f) \mathbf{X m}}{N}$ \\
\hline $90-109$ & 1 & 99.5 & 99.5 & \\
\hline $70-89$ & 3 & 79.5 & 238.5 & \\
\hline $50-69$ & 2 & 59.5 & 119 & $\overline{\mathrm{X}}=\frac{614.5}{11}$ \\
\hline $30-49$ & 3 & 39.5 & 118.5 & \\
\hline $10-29$ & 2 & 19.5 & 39 & $\overline{\mathrm{X}}=55.86$ \\
\hline$N=11$ & & $\sum(f) \mathrm{Xm}=614.5$ & \\
\hline
\end{tabular}

Se puede apreciar que existe una pequeña diferencia entre las medias calculadas por estos procedimientos. 
La mediana $\left(M_{d n}\right)$. Es el punto que se encuentra situado en el centro de una distribución de valores, es una medida de posición más que de magnitud.

a. Datos en seriación.

Es necesario tomar en cuenta las siguientes recomendaciones:

- Ordenar las puntuaciones de mayor a menor.

- Si el número de puntuaciones es impar, la mediana es la puntuación que se encuentra en el lugar medio de la puntuación.

- Si el número de puntuaciones es par, la mediana es un punto medio entre las dos puntuaciones centrales.

La posición del valor de la mediana puede localizarse por medio de la observación o utilizando la siguiente ecuación:

$$
\mathrm{P}_{\mathrm{OS}}=\frac{N+1}{2}
$$

En el Ejemplo 55 se presenta el proceso de cómo determinar el valor de la mediana. Se observa que éste se encuentra en la posición seis, por encima se encuentran cinco posiciones y por debajo también.

\begin{tabular}{|c|c|c|c|}
\hline Posición & Nombre del alumno & Calificación $x$ & \multirow{4}{*}{$\begin{array}{l}P_{\text {OS }}=\frac{\mathrm{N}+1}{2} \\
P_{\text {OS }}=11+1\end{array}$} \\
\hline 11 & Nayeli & 100 & \\
\hline 10 & Jorge & 80 & \\
\hline 9 & Carolina & 80 & \\
\hline 8 & Leonardo & 80 & \multirow{2}{*}{$P_{\text {os }}=6$} \\
\hline 7 & Carlos & 60 & \\
\hline 6 & Jessica & 60 & \multirow{7}{*}{$\begin{array}{l}\leftarrow \\
\text { Posición } 6 \\
\text { entonces } \\
M_{d n}=60\end{array}$} \\
\hline 5 & Ernesto & 40 & \\
\hline 4 & Yesmi & 40 & \\
\hline 3 & Andrés & 40 & \\
\hline 2 & Brayan & 20 & \\
\hline 1 & Axel & 20 & \\
\hline$N=11$ & & & \\
\hline
\end{tabular}

b. Datos agrupados.

En este caso para determinar la mediana se requiere, además de la columna de frecuencias, una de frecuencias acumuladas en la cual se anotan las puntuaciones sumadas por intervalos, iniciando desde el tope inferior. También se requiere los verdaderos límites del intervalo, en lugar de los establecidos, por ejemplo: los verdaderos límites del intervalo 10 - 29 son 9.5 29.5 (ver Ejemplo 56).

Si se considera que la mediana es el punto en el que caen la mitad de las puntuaciones, se requiere localizar el intervalo $N / 2$ ó o.5N, además las puntuaciones entre los intervalos deben ser iguales en lo que se refiere a los espacios. En el ejemplo, entre 10 y 29 existen 20 números con sus respectivos espacios. 
Una vez identificado el intervalo correspondiente al valor de la media denominado intervalo de la media, se localiza el límite más bajo de este intervalo y se le añade la diferencia entre $0.5 \mathrm{~N}$ y la frecuencia acumulativa de puntuaciones bajo del intervalo de la mediana se multiplica por la amplitud del intervalo (i) y se divide en la frecuencia dentro del intervalo de la media quedando calculado el valor de la mediana. En términos estadísticos la ecuación queda como sigue:

$$
\mathrm{M}_{\mathrm{dn}}=\mathrm{L}+\frac{\mathrm{i}\left(0.5 N-f_{\mathrm{a}}\right)}{f_{\mathrm{d}}}
$$

En donde:

$$
\begin{aligned}
& \mathrm{L}=\text { límite inferior del intervalo de la mediana. } \\
& \mathrm{i}=\text { amplitud del intervalo. } \\
& f_{\mathrm{a}}=\text { frecuencia acumulativa bajo el intervalo de la } \\
& \text { mediana. } \\
& f_{\mathrm{d}}=\text { frecuencia dentro del intervalo de la mediana. }
\end{aligned}
$$

\begin{tabular}{|c|c|c|c|c|c|}
\hline $\begin{array}{l}\text { Límites } \\
\text { establecidos }\end{array}$ & $\begin{array}{l}\text { Límites } \\
\text { verdaderos }\end{array}$ & $f$ & & $\begin{array}{l}\text { Frecuencia } \\
\text { umulada) }\end{array}$ & \\
\hline $90-109$ & $89.5-109.5$ & 1 & & 11 & \\
\hline $70-89$ & $69.5-89.5$ & 3 & & 10 & \\
\hline $50-69$ & $49.5-69.5$ & \multicolumn{2}{|c|}{$2 \longleftarrow f_{\mathrm{d}}$} & 7 & $L=49.5$ \\
\hline $30-49$ & $29.5-49.5$ & 3 & $f_{\mathrm{a}} \longrightarrow$ & 5 & \\
\hline $10-29$ & $9.5-29.5$ & 2 & & 2 & \\
\hline ntervalo i = 20 & & $N=11$ & & & \\
\hline
\end{tabular}

En el Ejemplo 56 se presentan los datos correspondientes a las calificaciones de los niños de Geografía, con la finalidad de ilustrar como se realiza este proceso.

Datos:

$$
\begin{aligned}
& N=11 \\
& \mathrm{i}=20 \\
& \mathrm{~L}=49.5 \\
& f_{\mathrm{a}}=5 \\
& f_{\mathrm{d}}=2
\end{aligned}
$$

Sustituyendo

$$
\mathrm{M}_{\mathrm{dn}}=\mathrm{L}+\frac{\mathrm{i}\left(0.5 N-f_{\mathrm{a}}\right)}{f_{\mathrm{d}}}=49.5+\frac{20(0.5(11)-5)}{2}=54.5
$$


En el Ejemplo 57 se presenta otro caso en donde el número de intervalos es par; se efectúa el cálculo de la mediana para datos agrupados en ocho intervalos de la puntuación obtenida por los alumnos del Grupo A referente al aprovechamiento (ver Ejemplo 52).

\section{Ejemplo 57. Cálculo de la mediana para datos agrupados en ocho intervalos de la puntua-} ción obtenida por los alumnos del Grupo A referente al aprovechamiento.

\begin{tabular}{|c|c|c|c|}
\hline $\begin{array}{c}\text { Límites } \\
\text { establecidos }\end{array}$ & $\begin{array}{l}\text { Límites } \\
\text { verdaderos }\end{array}$ & $f$ & $\begin{array}{c}f_{\mathrm{a}} \text { (Frecuencia } \\
\text { acumulada) }\end{array}$ \\
\hline $90-99$ & $89.5-99.5$ & 5 & 30 \\
\hline $80-89$ & $79.5-89.5$ & 5 & 25 \\
\hline $70-79$ & $69.5-79.5$ & 6 & 20 \\
\hline $60-69$ & $59.5-69.5$ & $5 \longleftarrow f_{\mathrm{d}}$ & 14 \\
\hline
\end{tabular}

\begin{tabular}{|c|c|c|c|c|c|}
\hline $50-59$ & $49.5-59.5$ & 2 & $f_{\mathrm{a}} \rightarrow$ & 9 \\
\hline $40-49$ & $39.5-49.5$ & 3 & & 7 \\
\hline $30-39$ & $29.5-39.5$ & 2 & & 4 \\
\hline $20-29$ & $19.5-29.5$ & 2 & & 2 \\
\hline Intervalo i $=10$ & & $N=30$ & & \\
\hline
\end{tabular}

Datos:

$$
\begin{aligned}
& N=30 \\
& \mathrm{i}=10 \\
& \mathrm{~L}=59.5 \\
& f_{\mathrm{a}}=9 \\
& f_{\mathrm{d}}=5
\end{aligned}
$$

Sustituyendo:

$$
\mathrm{M}_{\mathrm{dn}}=\mathrm{L}+\frac{\mathrm{i}\left(0.5 N-f_{\mathrm{a}}\right)}{f_{\mathrm{d}}}=59.5+\frac{10(0.5(30)-9)}{5}=71.5
$$

La moda. Representa la puntuación que se presenta con mayor frecuencia en una distribución, es una medida de posición que se localiza por medio de la observación de los datos o con el valor que aparece más a menudo en la columna de frecuencias. Puede presentarse en ocasiones que algunas distribuciones de frecuencia contengan dos o más modas, cuando presentan dos modas se conocen como bimodales.

Utilizando los datos del Ejemplo 52, se muestra en el Ejemplo 58, cómo se puede determinar el valor de la moda, tomando en cuenta la calificación (80) que se repite con mayor frecuencia (3).

En los datos agrupados la moda corresponde a la puntuación central del intervalo en el que se presenta la mayor frecuencia. 
Ejemplo 58. Cómo encontrar la moda $\left(M_{0}\right)$ en una distribución simple.

\begin{tabular}{|c|c|c|}
\hline La moda & Puntuación & Frecuencia \\
\hline & 98 & 1 \\
\hline & 96 & 1 \\
\hline & 92 & 1 \\
\hline & 90 & 2 \\
\hline & 87 & 1 \\
\hline & 85 & 1 \\
\hline \multirow[t]{17}{*}{$M_{0}$} & 80 & 3 \\
\hline & 79 & 1 \\
\hline & 76 & 1 \\
\hline & 73 & 2 \\
\hline & 70 & 2 \\
\hline & 68 & 1 \\
\hline & 65 & 2 \\
\hline & 64 & 1 \\
\hline & 60 & 1 \\
\hline & 52 & 1 \\
\hline & 50 & 1 \\
\hline & 48 & 1 \\
\hline & 46 & 2 \\
\hline & 35 & 1 \\
\hline & 34 & 1 \\
\hline & 28 & 1 \\
\hline & 20 & 1 \\
\hline
\end{tabular}

Gráfica 1. Distribuciones unimodales y bimodales.
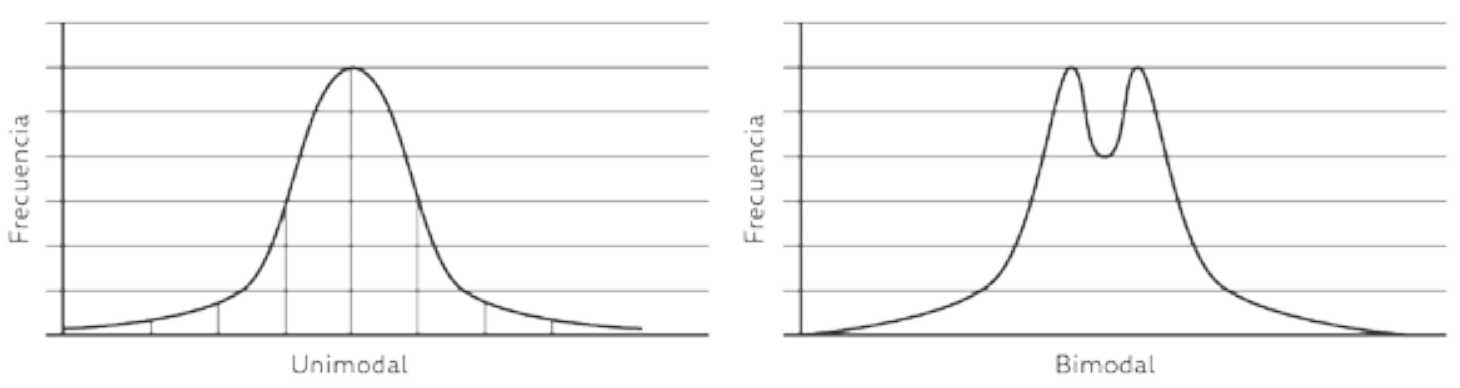

\subsubsection{Medidas de dispersión}

Las medidas de dispersión representan un complemento de las medidas de tendencia central, es por esto que se requiere de un índice que determine cómo están diseminados los puntajes alrededor del centro de la distribución, las medidas de dispersión que se requieren para los análisis estadísticos que se utilizan en los capítulos posteriores son: el rango, la desviación media y la desviación estándar.

Las medidas de tendencia central (media, moda y mediana), representan un solo valor, un promedio de una distribución, por eso cuando se utiliza cualquier medida de tendencia central, sólo se obtiene un cuadro completo de un conjunto de datos, que puede conducir a conclusiones equivocadas. 
Ejemplo 59. Relación de calificaciones obtenidas por los alumnos de los grupos de 4ํㅡ y 4으 B de primaria.

\begin{tabular}{|c|c|c|c|c|c|}
\hline$N=11$ & \multicolumn{2}{|c|}{ Grupo A } & \multicolumn{2}{|c|}{ Grupo B } & \multirow{3}{*}{$\mathrm{P}_{\mathrm{os}}=\frac{N+1}{2}$} \\
\hline Posición & Alumno & Calificación & Alumno & Calificación & \\
\hline 11 & Miguel & 80 & Nayeli & 100 & \\
\hline 10 & Joaquín & 76 & Carolina & 95 & \multirow{2}{*}{$P_{\text {os }}=\frac{11+1}{2}$} \\
\hline 9 & Alma & 74 & Jorge & 80 & \\
\hline 8 & María & 72 & Leonardo & 75 & \multirow{2}{*}{$P_{o s}=6$} \\
\hline 7 & Karla & 71 & Carlos & 72 & \\
\hline 6 & Armando & 70 & Jessica & 70 & Posición 6 \\
\hline 5 & Rosa & 65 & Ernesto & 68 & \multirow{3}{*}{$\begin{array}{l}\text { Entonces } \\
M_{d n}=70 y\end{array}$} \\
\hline 4 & Josefina & 60 & Yesmi & 60 & \\
\hline 3 & Pedro & 52 & Andrés & 40 & \\
\hline 2 & Luis & 50 & Brayan & 35 & \multirow{2}{*}{$\overline{\mathrm{x}}=\frac{\sum \mathrm{x}}{N}$} \\
\hline 1 & Carlos & 45 & Axel & 20 & \\
\hline Sumatoria & $\sum x_{A}$ & $=715$ & $\sum x_{B}$ & $=715$ & \multirow[t]{2}{*}{$\bar{x}=\frac{715}{11}$} \\
\hline Media & $\bar{x}_{A}$ & $=65$ & $\bar{x}_{B}$ & $=65$ & \\
\hline Mediana & $\mathrm{M}_{\mathrm{dn}} \mathrm{A}$ & $=70$ & $M_{d n} B$ & $=70$ & $\bar{x}=65$ \\
\hline
\end{tabular}

Para ilustrar lo anterior veamos los datos que se presentan en el Ejemplo 59, en donde se comparan los resultados obtenidos de una evaluación aplicada a dos grupos de estudiantes de cuarto grado de primaria ( $\mathrm{A}$ y $\mathrm{B}$ ).

Donde:

$$
\begin{aligned}
& \sum \mathrm{x}=\text { suma de las calificaciones. } \\
& N=\text { número de calificaciones. } \\
& \overline{\mathrm{x}}=\text { valor de la media. } \\
& \mathrm{M}_{\mathrm{dn}}=\text { valor de la mediana. }
\end{aligned}
$$

Se observa que el valor de la media en los dos grupos es el mismo (65), también son iguales los valores de la mediana (70); sin embargo, se puede notar que el Grupo A es homogéneo con pocas diferencias entre las puntuaciones contiguas, mientras que el Grupo B es más heterogéneo con grandes variaciones entre sus puntuaciones contiguas y sobre todo en sus puntuaciones más elevadas y más bajas.

Resulta evidente que las medidas de tendencia central no describen en su totalidad el comportamiento del rendimiento de los grupos, por lo que se requiere complementarlas con las medidas de dispersión para comparar los rendimientos de los grupos.

El rango $(R)$. En algunos textos se le designan también los nombres de Amplitud total o gama, consiste en determinar la diferencia entre el puntaje más alto y el más bajo de la distribución. El rango depende de sólo dos valores de puntaje, como consecuencia sólo da un índice no procesado de la dispersión de la distribución.

$$
\text { Rango = Puntuación más alta }- \text { Puntuación más baja }
$$


De acuerdo al Ejemplo 59 los rangos correspondientes a los grupos A y B son:

$$
\begin{aligned}
& R_{\mathrm{A}}=\mathrm{x}_{11 \mathrm{~A}}-\mathrm{x}_{1 \mathrm{~A}}=80-45=35 \\
& R_{\mathrm{B}}=\mathrm{x}_{11 \mathrm{~B}}-\mathrm{x}_{1 \mathrm{~B}}=100-20=80
\end{aligned}
$$

Donde:

$$
\begin{aligned}
& R=\text { rango. } \\
& \mathrm{x}_{11}=\text { puntuación más alta. } \\
& \mathrm{x}_{1}=\text { puntuación más baja. }
\end{aligned}
$$

La desviación media (DM). Es la relación que existe entre la suma de las desviaciones absolutas y el número total de puntajes y se representa por la siguiente ecuación:

Donde:

$$
\begin{gathered}
\mathrm{DM}=\frac{\sum[x]}{N} \text { Para datos en seriación. } \\
\mathrm{DM}=\frac{\sum[f \mathrm{xm}]}{N} \text { Para datos agrupados. }
\end{gathered}
$$

$\mathrm{DM}=$ desviación media.

$\Sigma[x]=$ suma de las desviaciones absolutas (sin considerar los signos $+y-$ ).

$N=$ número total de puntajes.

$\Sigma[f \times m]=$ suma de la diferencia con el punto medio del intervalo.

La desviación ( $x$ minúscula) es la distancia desde la media de la distribución a cualquier puntuación, se representa por la siguiente ecuación:

$$
\begin{aligned}
& x=(\mathrm{x}-\overline{\mathrm{x}}) \text { Para datos en seriación. } \\
& x=(\mathrm{xm}-\overline{\mathrm{x}}) \text { Para datos Agrupados. }
\end{aligned}
$$

Donde:

$$
\begin{aligned}
& x m=\text { valor medio de los datos agrupados. } \\
& \text { Ejemplo: } \\
& \begin{array}{ll}
85-89 & x_{m 1}=87 \\
80-84 & x_{m 2}=82 \\
75-79 & x_{m 3}=77
\end{array}
\end{aligned}
$$

Se ilustra en el Ejemplo 60 cómo determinar el valor de la desviación media correspondiente al grupo 4 A, tomando los datos del Ejemplo 59.

1. En el primer paso es necesario determinar el valor de la media de la distribución:

$$
\overline{\mathrm{X}}=\frac{\sum x}{N}=\frac{715}{11}=65
$$


Ejemplo 60. Cómo encontrar la moda (Mo) en una distribución simple.

\begin{tabular}{|c|c|}
\hline \multicolumn{1}{|c|}{ Grupo A } & $x$ \\
\hline 80 & +15 \\
\hline 76 & +11 \\
\hline 74 & +9 \\
\hline 72 & +7 \\
\hline 71 & +6 \\
\hline 70 & $\mathbf{+ 5}$ \\
\hline 65 & 0 \\
\hline 60 & -5 \\
\hline 52 & -13 \\
\hline 50 & -15 \\
\hline 45 & -20 \\
\hline$\Sigma x_{A}=715$ & $\sum[x]=\mathbf{1 0 6}$ \\
\hline
\end{tabular}

2. Restarle la media a cualquier puntaje no procesado y completar la tabla, por ejemplo:

$$
\begin{gathered}
x_{11}=(\mathrm{x}-\overline{\mathrm{x}})=(80-65)=+15 \\
x_{10}=(\mathrm{x}-\overline{\mathrm{x}})=(76-65)=+11 \\
\ldots \\
x_{1}=(\mathrm{x}-\overline{\mathrm{x}})=(45-65)=-20
\end{gathered}
$$

3. Sumar las desviaciones de los puntajes:

$$
\Sigma[x]=106
$$

4. Determinar el valor de la desviación media:

\begin{tabular}{|c|c|c|c|}
\hline \multicolumn{2}{|c|}{ Grupo A } & \multicolumn{2}{|c|}{ Grupo B } \\
\hline$X$ & $x$ & $x$ & $x$ \\
\hline 80 & +15 & 100 & +35 \\
\hline 76 & +11 & 95 & +30 \\
\hline 74 & +9 & 80 & +15 \\
\hline 72 & +7 & 75 & +10 \\
\hline 71 & +6 & 72 & +7 \\
\hline 70 & +5 & 70 & +5 \\
\hline 65 & 0 & 68 & +3 \\
\hline 60 & -5 & 60 & -5 \\
\hline 52 & -13 & 40 & -25 \\
\hline 50 & -15 & 35 & -30 \\
\hline 45 & -20 & 20 & -45 \\
\hline$\sum x_{A}=715$ & $\sum[x]=106$ & $\sum x_{A}=715$ & $\Sigma[x]=\mathbf{2 1 0}$ \\
\hline \multicolumn{2}{|c|}{$\bar{x}=65$} & \multicolumn{2}{|c|}{$\bar{x}=65$} \\
\hline \multicolumn{2}{|c|}{$R=35$} & \multicolumn{2}{|c|}{$R=80$} \\
\hline \multicolumn{2}{|c|}{$\mathrm{DM}=9.63$} & \multicolumn{2}{|c|}{$\mathrm{DM}=19.09$} \\
\hline \multicolumn{2}{|c|}{ Menor dispersión } & \multicolumn{2}{|c|}{ Mayor dispersión } \\
\hline
\end{tabular}

$$
\mathrm{DM}=\frac{\sum[x]}{N}=\frac{106}{11}=9.63
$$

Ejemplo 61. Dispersión en las distribuciones de las calificaciones de los grupos A y B de 4ํㅡㄴ de primaria. 
Esto indica que en promedio los puntajes de esta distribución se desvían de la media por 9.63 unidades.

En el Ejemplo 61 se realiza el cálculo comparativo entre el Grupo A y B siguiendo el procedimiento hasta ahora descrito. Se observa que en los dos grupos existe mucha dispersión, en mayor proporción en el Grupo B; de esta manera se puede comprobar la necesidad de utilizar además de las medidas de tendencia central las medidas de dispersión.

La desviación típica o estándar $(\sigma)$. Es el resultado que se obtiene de la raíz cuadrada de la suma de las desviaciones de la media de una distribución elevada al cuadrado.

En los análisis estadísticos más avanzados la desviación de la media presenta un problema al utilizar los valores absolutos cancelando así los valores negativos y positivos, mismos que no siempre son útiles debido a que no se pueden manipular algebraicamente con facilidad.

Para evitar esto y tener una medida de dispersión más tratable en los procesos estadísticos más avanzados, se eleva al cuadrado las desviaciones reales de la media y se suman, eliminando así los signos (-).

$$
\frac{\sum x^{2}}{N}
$$

Esto altera las unidades de medición, para recuperarla es necesario sacar la raíz cuadrada de la suma de las desviaciones elevadas al cuadrado, el resultado de estas operaciones es lo que se define como la desviación típica simbolizado por la letra griega sigma ( $\sigma$ ) y se usa como medida de variabilidad o dispersión.

$$
\sigma=2 \sqrt{\frac{\sum x^{2}}{N}}
$$

Donde:

$\sigma=$ desviación estándar o típica.

$\sum x^{2}=$ suma de las desviaciones de la media elevadas al cuadrado.

$N=$ número total de puntajes.

Para ejemplificar el procedimiento de cómo calcular la desviación típica, se retoma el ejemplo del Grupo A de 4ㅇde primaria, siguiendo los mismos pasos en este proceso (ver Tabla 2):

1. Determinar el valor de la media de la distribución:

$$
\overline{\mathrm{x}}=\frac{\sum x}{N}=\frac{715}{11}=65
$$

2. Restarle la media a cualquier puntaje directo y completar la Tabla 2, por ejemplo:

$$
\begin{gathered}
x_{11}=(\mathrm{x}-\overline{\mathrm{x}})=(80-65)=+15 \\
x_{10}=(\mathrm{x}-\overline{\mathrm{x}})=(76-65)=+11 \\
\ldots \\
x_{1}=(\mathrm{x}-\overline{\mathrm{x}})=(45-65)=-20
\end{gathered}
$$


Tabla 2. Puntajes de desviaciones cuadráticas para eliminarlos números negativos.

\begin{tabular}{|c|c|c|}
\hline \multicolumn{3}{|c|}{ Grupo A $(\mathbf{N = 1 1})$} \\
\hline $\mathbf{X}$ & $x$ & $x^{2}$ \\
\hline 80 & +15 & 225 \\
\hline 76 & +11 & 121 \\
\hline 74 & +9 & 81 \\
\hline 72 & +7 & 49 \\
\hline 71 & +6 & 36 \\
\hline 70 & +5 & 25 \\
\hline 65 & 0 & 0 \\
\hline 60 & -5 & 25 \\
\hline 52 & -13 & 169 \\
\hline 50 & -15 & 225 \\
\hline 45 & -20 & 400 \\
\hline$\Sigma X_{A}=715$ & $\sum[x]=106$ & $\sum x^{2}=1356$ \\
\hline
\end{tabular}

3. Elevar cada desviación al cuadrado y completar la Tabla 2:

$$
\begin{gathered}
\left(x_{11}\right)^{2}=(+15)^{2}=225 \\
\left(x_{10}\right)^{2}=(+11)^{2}=121 \\
\cdots \\
\left(x_{1}\right)^{2}=(-20)^{2}=400
\end{gathered}
$$

4. Reemplazar los valores en la ecuación:

$$
\sigma_{\mathrm{A}}=2 \sqrt{\frac{\sum x^{2}}{N}}=2 \sqrt{\frac{\sum 1356}{11}}=11.1
$$

Se concluye que la desviación típica para el Grupo A de 4을 de primaria es de $\sigma_{\mathrm{A}}=11.1$

- Ecuación de puntajes directos (crudos o no procesados). Existe un método que no requiere de buscar las desviaciones, ya que trabaja con los puntajes directos no procesados y por lo tanto es más sencillo. Su ecuación es la siguiente:

$$
\sigma=2 \sqrt{\frac{\sum x^{2}}{N}-\bar{x}^{2}}
$$

Donde:

$$
\begin{aligned}
& \sigma=\text { desviación estándar o típica. } \\
& \sum \mathrm{x}^{2}=\text { suma de las desviaciones de la media elevadas al cuadrado. } \\
& N=\text { número total de puntajes. } \\
& \overline{\mathrm{X}}^{2}=\text { media elevada al cuadrado. }
\end{aligned}
$$

Ejemplo 62. Aplicar los puntajes directos o crudos con los datos del Grupo A de 4은 de primaria y comparar los resultados. 
1. Determinar el valor de la media de la distribución:

$$
\overline{\mathrm{x}}=\frac{\sum \mathrm{x}}{N}=\frac{715}{11}=65
$$

2. Elevar al cuadrado cada puntaje directo, completar la Tabla 3.

3. Sumar el cuadrado del puntaje directo, completar la tabla y reemplazar los datos en la ecuación:

$$
\sigma_{\mathrm{A}}=\sqrt[2]{\frac{\sum \mathrm{x}^{2}}{N}-\overline{\mathrm{X}}^{2}}=\sqrt[2]{\frac{47831}{11}-65^{2}}=11.1
$$

Tabla 3. Puntajes directos cuadráticos para facilitar el cálculo de la desviación típica.

\begin{tabular}{|c|c|}
\hline \multicolumn{2}{|c|}{ Grupo $A(N=11)$} \\
\hline$x$ & $x^{2}$ \\
\hline 80 & 6400 \\
\hline 76 & 5776 \\
\hline 72 & 5476 \\
\hline 71 & 5184 \\
\hline 70 & 5041 \\
\hline 65 & 4900 \\
\hline 60 & 4225 \\
\hline 52 & 3600 \\
\hline 50 & 2704 \\
\hline $5 x=715$ & 2500 \\
\hline
\end{tabular}

Se observa que el resultado obtenido es el mismo que en el ejemplo anterior lo que implica que se puede utilizar cualquiera de las dos fórmulas para calcular el valor de la desviación típica.

Ejercicio 1. Realizar los cálculos correspondientes por el proceso que se elija para determinar la desviación típica con los datos correspondientes al Grupo B del 4ํㅡ̃o de primaria y compárelo con los resultados del Grupo A (Respuesta: $\sigma_{B}=23.56$ ) Ver Apéndice $C$.

Cálculos para una distribución de frecuencia simple. Cuando los datos se ordenan en forma de distribución de frecuencia simple la desviación típica se puede calcular con la siguiente ecuación:

$$
\sigma_{\mathrm{A}}=\sqrt{\frac{\sum f \mathrm{x}^{2}}{N}-\overline{\mathrm{x}}^{2}}
$$

Ejemplo 63. Se utiliza la siguiente distribución, que corresponde a un grupo de secundaria que fue evaluado en la materia de Historia mediante una prueba objetiva de 10 reactivos obteniéndose los resultados que se muestran en la Tabla 4. 
Tabla 4. Calificaciones obtenidas por los alumnos del Grupo C de segundo de secundaria en la materia de Historia.

\begin{tabular}{|c|c|c|c|}
\hline \multicolumn{4}{|c|}{ Grupo $2^{\circ}$ C, Historia } \\
\hline № Alumno & Calificación & No Alumno & Calificación \\
\hline 1 & 7 & 11 & 8 \\
\hline 2 & 8 & 12 & 8 \\
\hline 3 & 7 & 13 & 9 \\
\hline 4 & 6 & 14 & 10 \\
\hline 5 & 7 & 15 & 5 \\
\hline 6 & 9 & 16 & 7 \\
\hline 7 & 6 & 17 & 6 \\
\hline 8 & 5 & 18 & 6 \\
\hline 9 & 6 & 19 & 9 \\
\hline 10 & 7 & 20 & 8 \\
\hline
\end{tabular}

1. Se requiere como primer paso ordenar los valores en orden descendente y asignarles las frecuencias con que se repiten.

Tabla 5. Ordenar los valores descendentes y asignarles frecuencias.

\begin{tabular}{|c|c|c|c|c|}
\hline \multicolumn{5}{|c|}{ Grupo $\mathbf{2}^{\circ} \mathbf{C}$, Historia } \\
\hline $\mathbf{x}$ & $f$ & $f \mathrm{x}$ & $\mathrm{x}^{2}$ & $f \mathrm{x}^{2}$ \\
\hline 10 & 1 & 10 & 100 & 100 \\
\hline 9 & 3 & 27 & 81 & 243 \\
\hline 8 & 4 & 32 & 64 & 256 \\
\hline 7 & 5 & 35 & 49 & 245 \\
\hline 6 & 5 & 30 & 36 & 180 \\
\hline 5 & 2 & 10 & 25 & 50 \\
\hline & $N=20$ & $\sum f x=144$ & & $\sum f x^{2}=1074$ \\
\hline
\end{tabular}

2. Multiplicar la frecuencia por el valor de $x$ y completar la columna $f x$, elevar al cuadrado el producto de $f x$ y completar la columna $(f x)^{2}$ en la Tabla 5.

3. Sumar los valores de $f x^{2} y$ determinar:

$$
\sum f x^{2}=1074
$$

4. Calcular el valor de la media y elevarlo al cuadrado:

$$
\begin{gathered}
\overline{\mathrm{x}}=\frac{\sum f \mathrm{x}}{N}=\frac{144}{20}=7.2 \\
\overline{\mathrm{x}}^{2}=51.84
\end{gathered}
$$

5. Sustituir los valores en la ecuación:

$$
\sigma=\sqrt{\frac{\sum f \mathrm{x}^{2}}{N}-\overline{\mathrm{x}}^{2}}=\sqrt{\frac{1074}{20}-51.84}=1.36
$$


La desviación estándar o típica representa la variabilidad promedio de una distribución, puesto que mide el promedio de las desviaciones de la media, se puede deducir que mientras mayor sea la dispersión alrededor de la media en una distribución, mayor será la distribución estándar, tal es el caso de la desviación estándar de los grupos A y B de 4ํㅡㄹ de primaria donde $\sigma_{A}=11.1$ mientras que $\sigma_{B}=23.56$ indicando que existe una mayor variabilidad en el Grupo $\mathrm{B}$ y como consecuencia una mayor dispersión (ver Ejemplo 61 y Ejercicio 1).

La desviación típica también permite determinar el puntaje directo que está situado exactamente a una desviación estándar de la media.

Ejemplo 64. En el Grupo A de 4ㅇ de primaria se encontró que el valor de la media $\bar{x}=65$ y el de la desviación típica es $\sigma_{\mathrm{A}}=11.1$, entonces se puede elaborar la Gráfica 2.

Gráfica 2. Trazado de la línea base en unidades de desviación típica para $\bar{x}=65$ y $\sigma_{A}=11.1$ del ejemplo del Grupo A de $4^{\circ}$ de primaria.

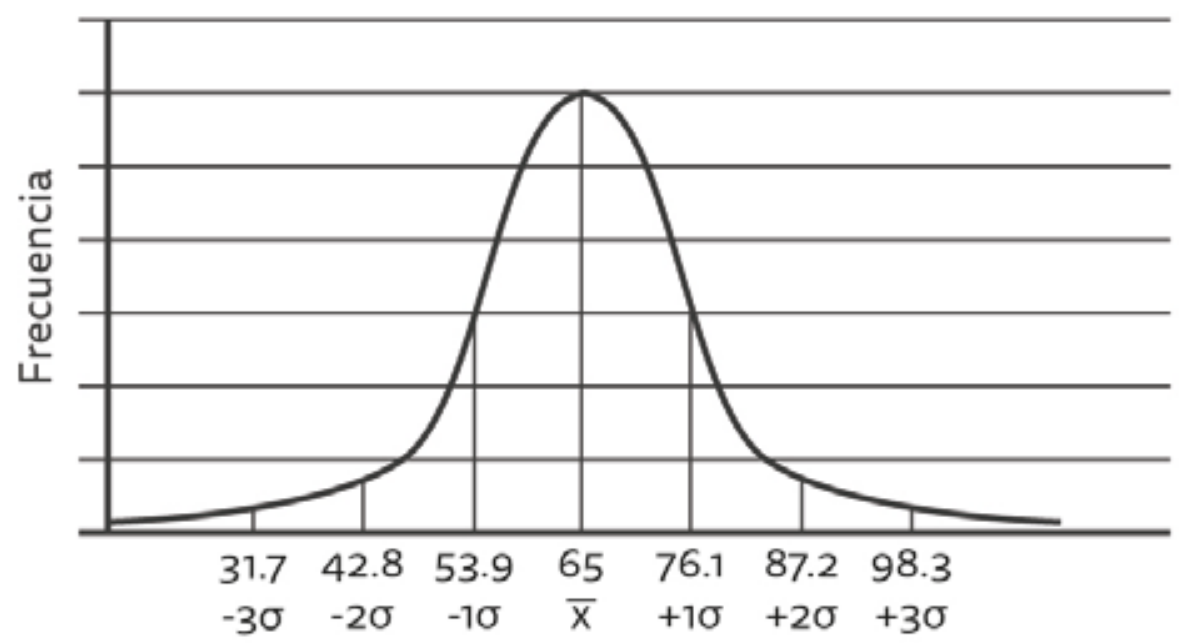

Como se puede observar en la Gráfica 2 el puntaje directo es 76.1, está exactamente a una desviación típica por encima de la media $(65+11.1)$ esto es $+1 \sigma$, siendo ésta positiva porque todas las desviaciones sobre la media son positivas y como consecuencia todas las desviaciones que están por debajo de la media son negativas (-). Siguiendo este procedimiento se obtienen los valores directos 87.2 y 98.3 correspondientes a los valores de $+2 \sigma$ y $+3 \sigma$, de igual manera se obtienen los valores directos $53.9,42.8$ y 37.1 restando a la media $-1 \sigma,-2 \sigma y-3 \sigma$ respectivamente.

Ejemplo 65. En el Grupo B de $4^{\circ}$ de primaria se encontró que el valor de la media $\bar{x}=65$ y el de la desviación típica es $\sigma_{B}=23.56$, entonces se puede elaborar la Gráfica 3.

En la Gráfica 3 se puede observar que el puntaje directo es 88.56 está exactamente a una desviación típica por encima de la media $(65+23.56)$ esto es $+1 \sigma$, recordando que ésta es positiva porque todas las desviaciones sobre la media son positivas y como consecuencia todas las desviaciones que están por debajo de la media son negativas (-).

Siguiendo este procedimiento se obtiene el valor directo 112.12 que corresponde al valor de $+2 \sigma$, mediante la resta la desviación típica al valor de la media se obtienen los valores directos 41.44 y 17.88 que corresponden a $-1 \sigma$ y $-2 \sigma$ respectivamente. 
Gráfica 3. Trazado de la línea base en unidades de desviación típica para $\bar{x}=65$ y $\sigma_{B}=23.56$ del ejemplo del Grupo B de $4^{\circ}$ de primaria.

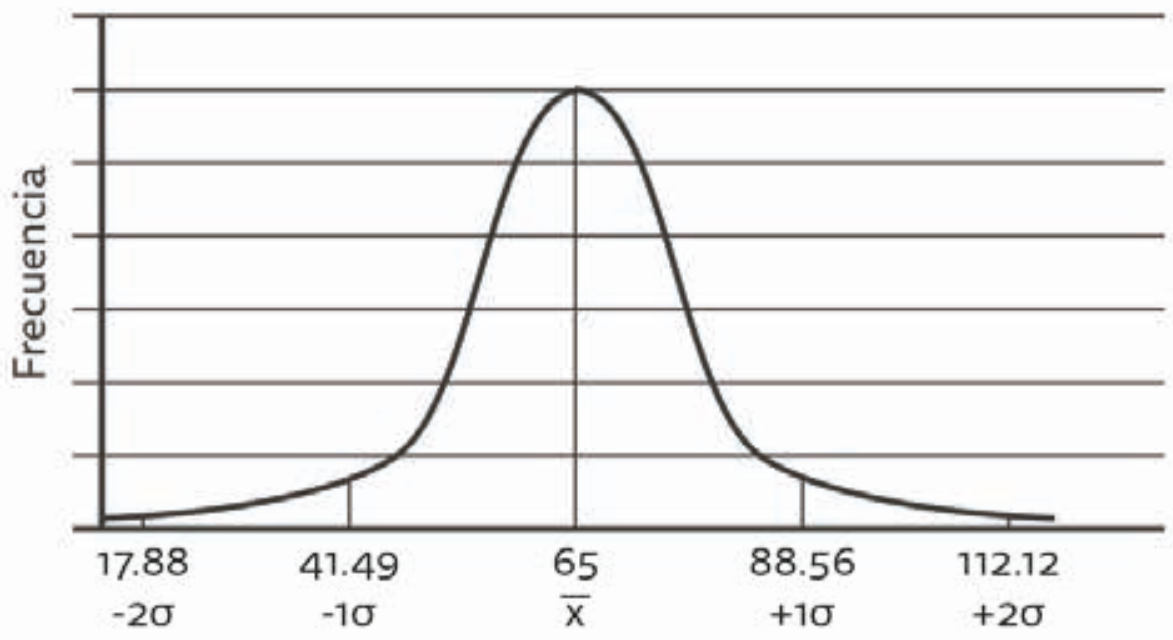

Si se compara la Gráfica 2 con la 3 se puede observar que los datos se encuentran mucho más dispersos en la Gráfica 3, puesto que con solo $2 \sigma$ se está rebasando el límite superior de la curva, mientras que en la Gráfica 2 se obtienen valores de hasta $3 \sigma$.

Esta comparación viene a comprobar la deducción de que mientras mayor sea la dispersión alrededor de la media en una distribución, mayor será la distribución estándar.

\subsection{La curva normal}

Las distribuciones de frecuencias pueden tomar muchas formas: sesgadas ya sea positiva o negativamente, unimodal o multimodal, perfectamente simétricas o libres de sesgo. Pero existe una curva cuya distribución se conoce como "curva normal", que consiste en un modelo teórico o ideal determinado por medio de una ecuación matemática, más que por el resultado de una investigación y de la recolección de datos reales.

$$
\mathrm{Y}=\frac{N}{\sigma \sqrt{2 \pi}} \mathrm{e}^{-(\mathrm{x}-\overline{\mathrm{x}})^{2} / 2 \sigma^{2}}
$$

Donde:

$$
\begin{aligned}
& Y=\text { la ordenada para un valor dado de } x \text { (frecuencia con que ocurre). } \\
& \pi=3.1416 . \\
& e=2,7183 . \\
& \sigma=\text { desviación típica o estándar. } \\
& \bar{X}=\text { valor de la media de la distribución. } \\
& X=\text { puntaje directo (crudo o no procesado). }
\end{aligned}
$$

La curva normal posee las siguientes características: es uniforme y simétrica en forma de campana, su punto más alto se encuentra en el centro donde coinciden la media, la mediana y la moda; es unimodal, es decir, desde un pico central redondeado la curva cae gradualmente en ambas colas, extendiéndose indefinidamente en las dos direcciones y acercándose a la línea base sin alcanzarla realmente. 


\subsubsection{Curvas normales y la realidad}

Las curvas reales que se obtienen de los datos reales recogidos por los investigadores en educación ¿qué tanto se pueden relacionar con las curvas normales? Si se puede suponer que todos los datos relacionados con el proceso educativo están distribuidos normalmente ¿cómo sería este mundo hipotético?

En lo relativo a las evaluaciones requeridas por la Secretaría de Educación, la mínima aprobatoria es de 60 y la máxima 100, la mayoría de los alumnos obtendrían puntuaciones entre 75 y 85 siendo muy pocos los que obtendrían 60 ó 100, se vería una caída gradual de las puntuaciones en una y otra cola con unos pocos "sabios" que marcarían más del 100 (calificación perfecta más puntos extra) y pocos que marcarían menos de 60 reprobando, pues la expectativa del maestro es que no repruebe ninguno, en la Gráfica 4 se ejemplifica esta distribución de manera hipotética o ideal.

Gráfica 4. Distribución hipotética de puntajes de calificaciones esperadas.

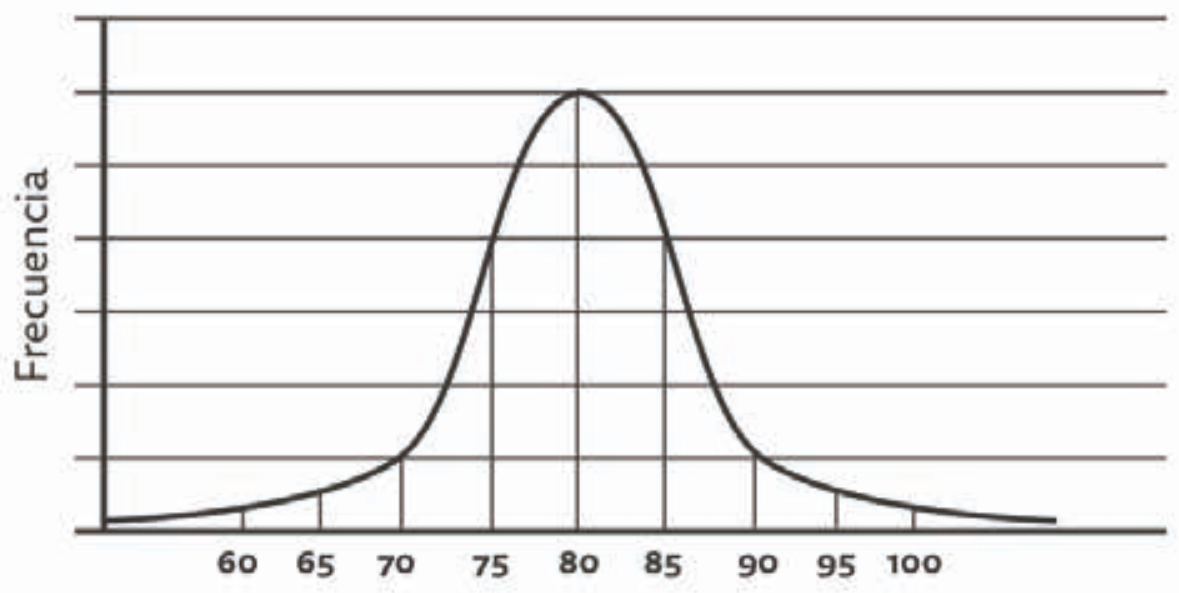

Gráfica 5. La distribución de los puntajes reales obtenidos en lectura por un grupo de $3^{\circ}$ de primaria.

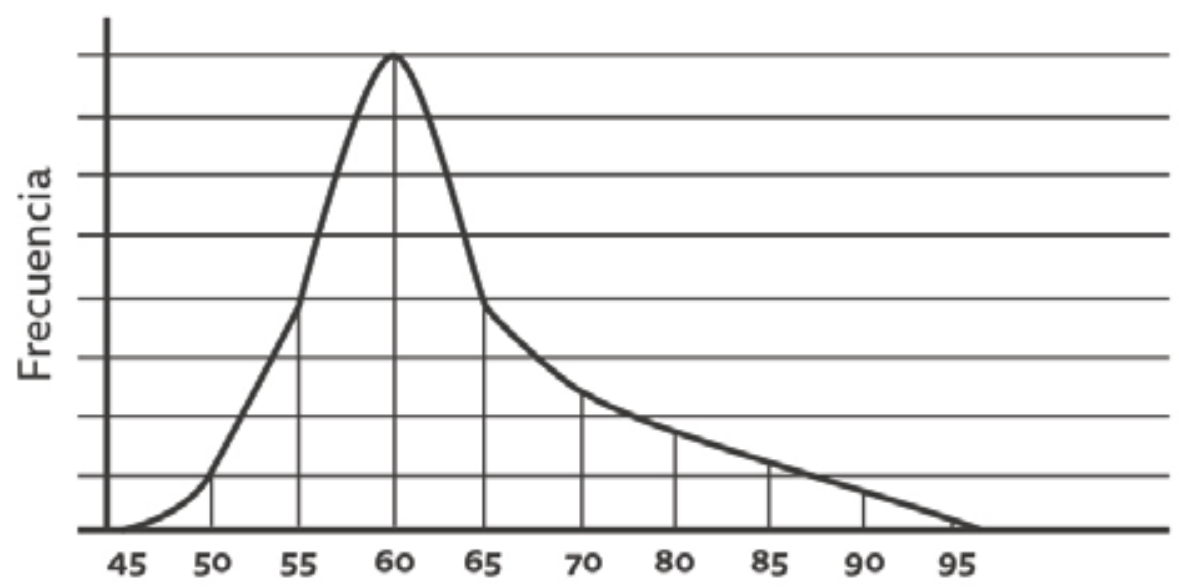


Sin embargo existen casos que no se ajustan al concepto teórico de la distribución normal, existen muchas distribuciones que son sesgadas, o pueden ser bimodales o multimodales (tienen más de un máximo), pueden ser simétricas pero su forma no es de una campana. Como ejemplo se puede observar la Gráfica 5, en la cual se muestra una distribución de las calificaciones de lectura de un grupo de tercero de primaria, esta distribución se encuentra aparentemente muy sesgada de tal manera que en su gran mayoría los alumnos obtuvieron calificaciones que oscilan alrededor del 60, mientras que sólo una pequeña porción recibe una calificación elevada.

Ante esta situación cabe preguntar ¿qué ocasionó el sesgo en esta distribución? La respuesta podría ser: las estrategias utilizadas en el proceso, las carencias de los alumnos, una mala dirección del maestro, el contexto del centro escolar o de los alumnos. Este tipo de situaciones representan un problema que puede ser motivo de investigación, generando objetivos, hipótesis y una metodología que permita determinar las causas que generaron tal sesgo y plantear propuestas de solución.

\subsubsection{El área bajo la curva normal}

El área bajo la curva normal es aquella que está entre la curva y la línea horizontal o base (eje $X)$ y que contiene el 100\% (todos los casos) en una distribución normal dada.

Si sólo se desea obtener una porción de área dentro de la curva normal se trazan dos líneas verticales desde la línea horizontal (eje X) hasta el límite de la curva. Por ejemplo una línea se puede ubicar en donde se encuentra el valor de la media $(\bar{x})$ y la otra línea a una distancia equivalente a una desviación típica $(+1 \sigma)$ sobre el valor de la media. En la Gráfica 6 se puede observar que el área bajo la curva en este caso corresponde al $34.13 \%$ de la frecuencia total (Pagano, 1999).

Gráfica 6. Porcentaje del área comprendida entre la media $(\bar{x})$ y la primera desviación típica $(+1 \sigma)$ sobre el valor de ésta.

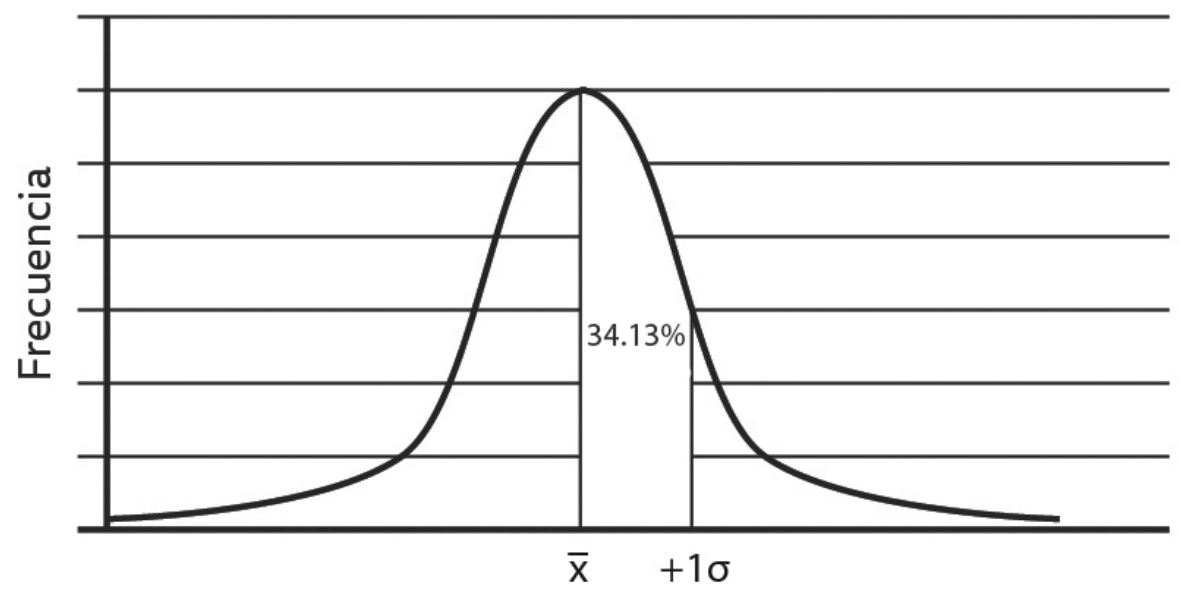

Debido a que la curva normal es simétrica, cualquier distancia sigma dada por encima de la media $(\bar{x})$ contiene una proporción idéntica de casos que la misma distancia sigma $(\sigma)$ por debajo, es decir, si desde la media marcamos la distancia a $+1 \sigma$ por encima, entonces existe una distancia por debajo de la media correspondiente a - $1 \sigma$. En las gráficas 7 y 8 se observa esta situación, incluyendo los porcentajes del área de la distribución correspondientes a diferentes valores de sigma $(\sigma)$. 
Gráfica 7. Porcentaje del área comprendida entre la media $(\bar{x})$ y los puntos 1,2 y 3 de desviación típica $(+1 \sigma,+2 \sigma,+3 \sigma)$ sobre el valor de ésta.

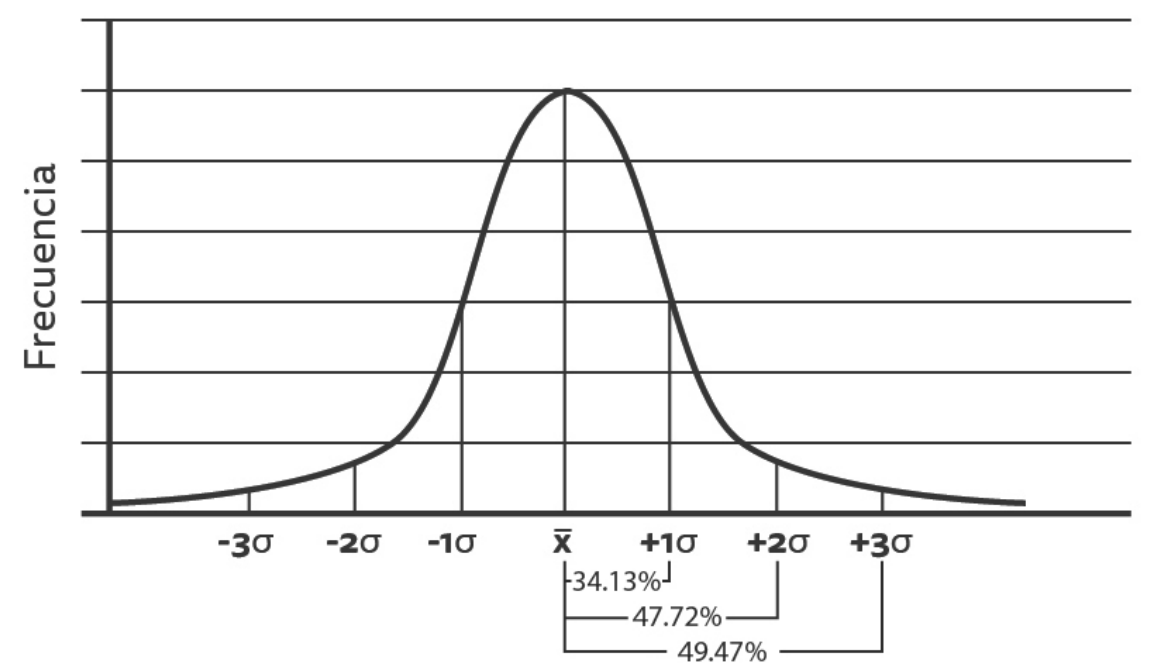

Gráfica 8. Porcentaje del área comprendida entre los puntos de desviación típica sobre el valor de la media y sus valores correspondientes por debajo de ésta $(-1 \sigma,-2 \sigma,-3 \sigma)$.

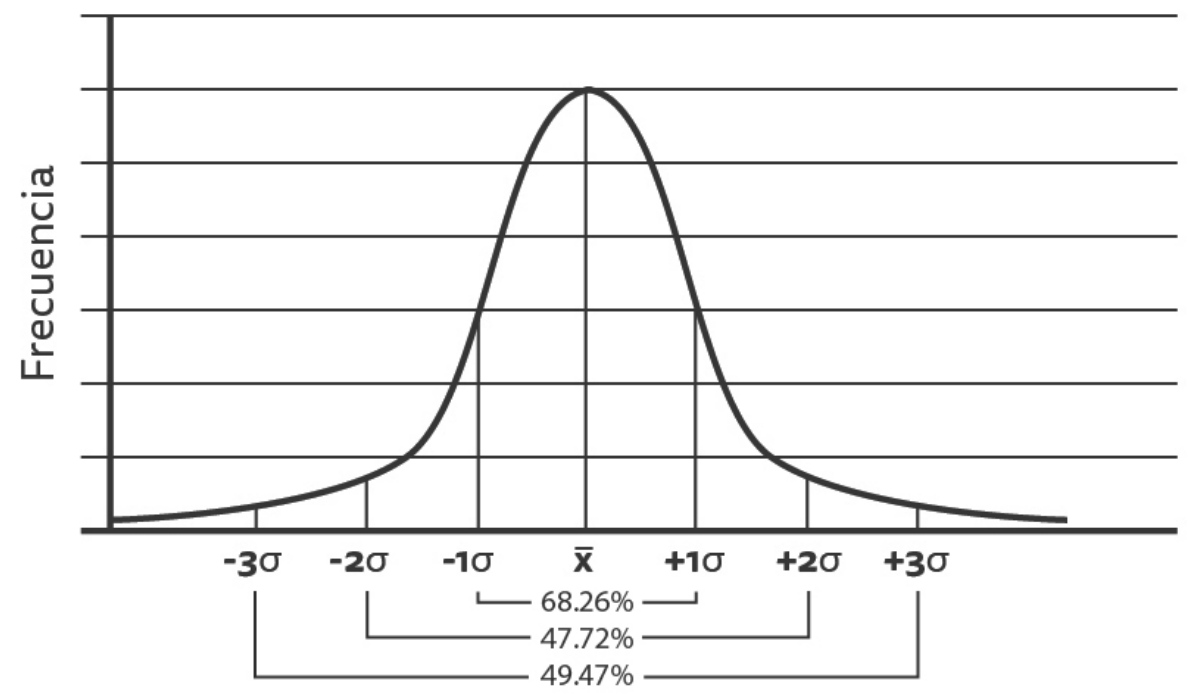

\subsubsection{Aplicación práctica de la curva normal}

Hasta aquí sólo se han analizado las distancias de la media que son múltiplos exactos de la desviación estándar, ya sea por arriba o debajo de la media. Pero ¿qué sucede si se quiere determinar el porcentaje de casos para las distancias entre dos ordenadas cualesquiera? ¿Qué hay que hacer si se quiere determinar el porcentaje de la frecuencia total que cae entre la media y un puntaje directo que se localiza en 1.35 desviaciones estándar $(\sigma)$ por arriba de la media?

En la Gráfica 9 se observa que un puntaje directo a 1.35 desviaciones estándar por encima de la media se encuentra entre $1 \sigma$ y $2 \sigma$ lo que significa que este puntaje directo de $1.35 \sigma$ tendrá un valor de porcentaje superior a 34.13\% pero menor de $47.72 \%$ del área total bajo la curva normal. Para determinar el porcentaje exacto es necesario conocer los siguientes antecedentes.

La investigación pedagógica permite la aplicación práctica en algunos casos de la distribución normal, como un ejemplo se tienen: 
1. Convertir puntuaciones directas en puntuaciones típicas.

2. Ordenar datos cualitativos convirtiéndolos en puntuaciones directas.

3. Normalizar una distribución de frecuencias.

4. Comprobar la significación de los valores obtenidos en experimentos sobre muestras.

Las puntuaciones típicas y sus escalas proporcionan un método que permite expresar cualquier puntuación en términos de su distancia desde la media, en unidades de desviación típica o estándar, sin olvidar el supuesto de una normalidad de la distribución cuando se usan las puntuaciones típicas. En este caso sólo se requiere de la puntuación o escala típica $Z$ (puntuación sigma).

Gráfica 9. Posición de un puntaje directo que está a 1.35 0 por encima de $\bar{x}$.

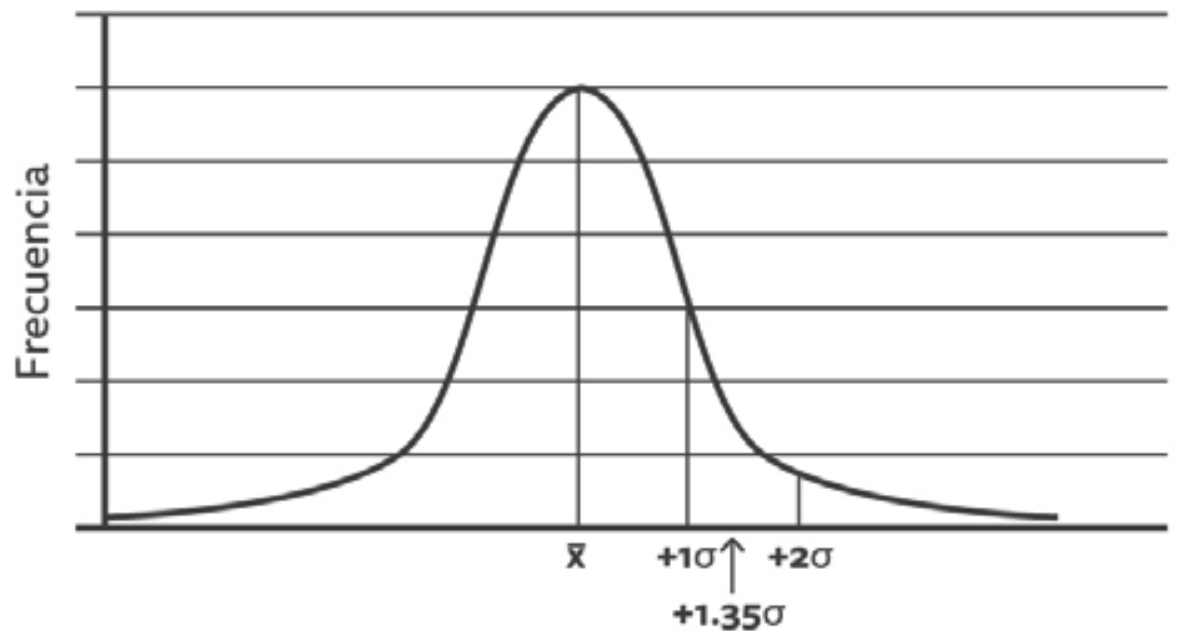

\subsection{La puntuación $Z$ o estándar}

Con frecuencia es más significativo describir una puntuación en una distribución, por medio de su desviación desde la media, expresada en valores numéricos de desviaciones típicas, que la puntuación misma. La puntuación $Z$ reduce las puntuaciones de distribuciones diferentes a una unidad de medida común y comparable.

Para obtener un puntaje $Z$ es necesario encontrar el puntaje de la desviación $(x=\mathrm{x}-\overline{\mathrm{x}})$ siendo éste la distancia entre el puntaje directo y la media, y dividiéndolo entre la desviación estándar de la distribución $(\sigma)$.

Donde:

$$
Z=\frac{\mathrm{x}-\overline{\mathrm{x}}}{\sigma}=\frac{x}{\sigma}
$$

$$
\begin{aligned}
& \mathrm{x}=\text { puntuación directa } \\
& x=\text { desviación }(x-\bar{x}) . \\
& \sigma=\text { desviación típica. }
\end{aligned}
$$

Ejemplo 66. Para comprender lo anterior se toman los datos correspondientes al Grupo A de $4^{\circ}$ grado del Ejemplo 57 en el cual el valor de la media es $\bar{x}=65$, el alumno que obtuvo el máximo puntaje fue de $x=80$ y se calculó un valor de desviación típica $\sigma=11.1$, aplicando la ecuación anterior se determina un valor de desviación:

$$
Z=\frac{x-\bar{x}}{\sigma}=\frac{61-80}{11.1}=1.35 \text { desviaciones estándar }(\sigma)=1.35 \sigma
$$


Para determinar el porcentaje exacto de la frecuencia total dentro de este intervalo, es necesario utilizar la Tabla $A$ que se encuentra en el Apéndice $D$, que presenta el porcentaje bajo la curva normal entre la media y varias distancias $\sigma$ de ella. Estas distancias de $\sigma$ (entre o.0 a 5.0) se encuentran en la primer columna (del lado izquierdo) de la Tabla A y se le ha designado el primer número decimal, el segundo decimal se localiza en la primera hilera de la tabla (superior).

Continuando con el problema ubicamos el valor en 1.350, siguiendo los siguientes pasos: 1. Localizar el entero y el primer decimal (1.3) en la primera columna designada como $Z$.

2. Localizar el número correspondiente al segundo decimal (0.05) en la primer fila (superior).

3. Localizar el valor del porcentaje de la frecuencia total bajo la curva que cae entre el puntaje $x$ y la media $(Z=1.35)$ en la intercepción de los puntos 1 y $2(P=41.15 \%)$.

Entonces se puede decir que el porcentaje del área total bajo la curva normal entre el valor de la media $\bar{x}=65$ y Puntaje $x=80$ que corresponde a un valor de $Z=1.35$ es:

$$
P=41.15 \%
$$

Para una mayor comprensión en la Gráfica 10 se ilustra este resultado.

Ahora bien, si lo que se requiere es saber cuál es la probabilidad de que los alumnos puedan obtener 80 o más de calificación, es necesario determinar el porcentaje que queda fuera del área encontrada, por lo que es necesario restar el porcentaje obtenido en la Tabla $A$ del $50 \%$, tomando en cuenta que el área total bajo la curva es el $100 \%$ y en este caso solo se considera el área de la media hacia arriba que representa el 50\%.

Gráfica 10. Porcentaje del área total bajo la curva normal entre 65 y 80 para $Z=1.35 \sigma$.

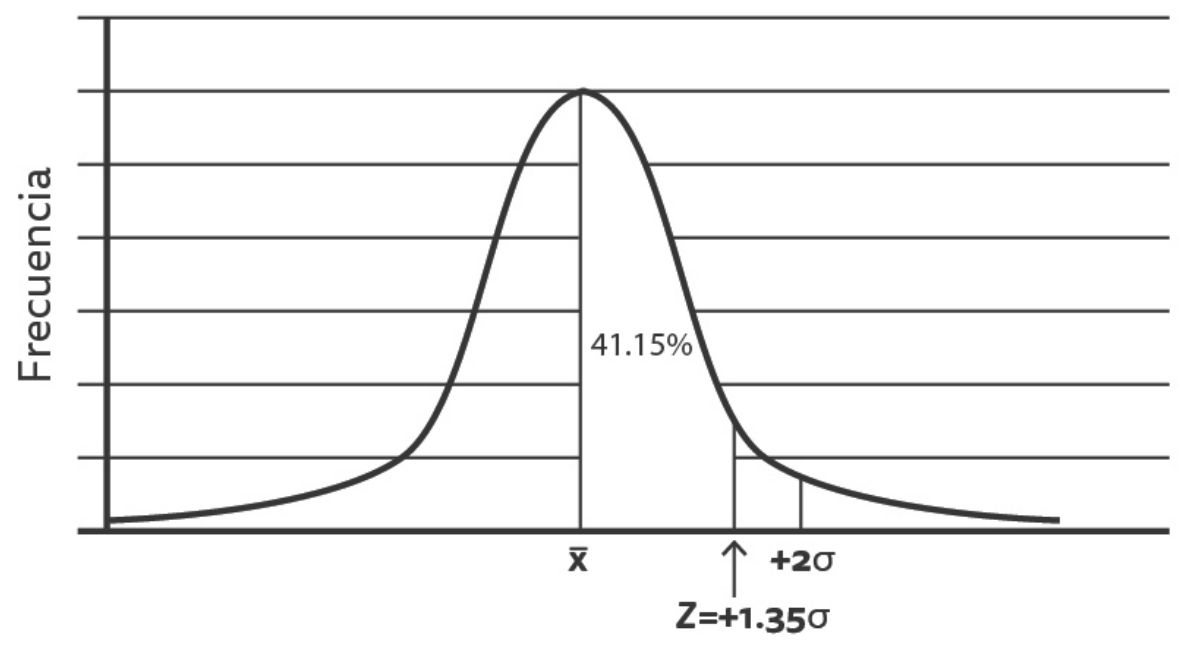

Por lo que restando $41.15 \%$ del $50 \%$ se obtiene el valor de $8.85 \%$ que representa el porcentaje de los que pueden obtener 80 o más. Si lo que se quiere determinar es la probabilidad, es necesario quitar el porcentaje dividiendo este resultado entre 100 ó dicho de otra forma, se puede decir que hay una oportunidad de $8.85 \%$, entre $100(P=0.0885)$, de encontrar un alumno del Grupo A que obtenga una calificación de 80 o más.

Recordando que cualquier distancia $\sigma$ dada por encima de la media contiene una proporción idéntica de casos de la misma distancia $\sigma$ por debajo de la media. Si se requiere encontrar probabilidades asociadas con puntos por debajo de la media, el procedimiento es el mismo que se siguió en el ejemplo anterior. 
Gráfica 11. La porción del área total bajo la curva normal para la cual se busca determinar la probabilidad de que ocurra.

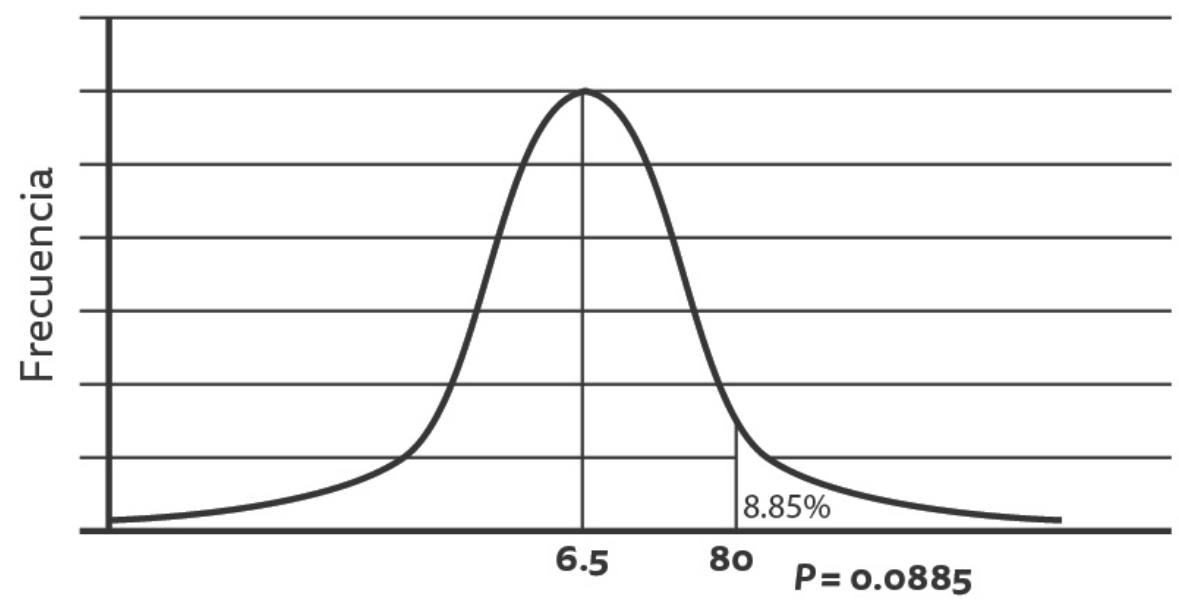

Ejemplo 67. Para este caso la frecuencia total entre el puntaje $Z=-1.35$ (calificación de 50) y la media, es idéntico al porcentaje entre el puntaje $Z=+1.35$ (calificación de 80 ) y la media, como consecuencia el alumno que obtiene una calificación que varíe entre 50 y 65 obtiene una probabilidad de: $P=41.15 \% / 100=0.4115$

Nota: se determina en términos de probabilidad y no de porcentaje de frecuencia total por lo que es necesario dividirlo entre 100.

De la misma forma que en el caso anterior la probabilidad de que algún alumno obtenga 50 de calificación o menos sería de:

$$
\rho=0.5-0.4115=0.0885
$$

Nota: Hay que recordar que la mitad por debajo de la media representa el 50\% del porcentaje de frecuencia total y se ajusta como probabilidad dividiéndolo entre 100 quedando como 0.5 .

Para determinar la probabilidad de que los alumnos obtengan calificaciones entre 50 y 80 basta con sumar las probabilidades asociadas a los puntajes $Z$ correspondientes a 1.35 a cada lado de la media, por lo tanto, la probabilidad dentro será:

$$
\rho_{d}=0.4115+0.4115=0.823
$$

De igual manera para determinar la probabilidad de que queden fuera se suman los valores de la probabilidad correspondiente a los alumnos que obtengan 50 ó menos de calificación y los que obtengan 80 ó más, esto es, la probabilidad fuera será:

$$
\rho_{f}=0.0885+0.0885=0.177
$$

Nota: Se puede observar que si se suman estos resultados $0.823+0.177$ es igual a 1 , significando que todos los posibles eventos están representados bajo la curva normal. 


\subsection{Toma de decisiones}

El enfoque descriptivo y de recolección de datos de la estimación de las medias y proporciones es importante, pero no es propiamente el objetivo de la toma de decisiones o de la actividad de la investigación educativa. La preocupación principal de los investigadores en educación consiste en contrastar las hipótesis que se plantean acerca de la relación entre las variables que las integran y las diferencias entre dos o más muestras.

En este texto se considera como un proceso para la toma de decisiones (Levin, 1999) el análisis estadístico que permite:

1. La comprobación de la hipótesis nula: ninguna diferencia entre las medias.

2. La comprobación de la hipótesis de investigación: alguna diferencia entre las medias.

3. Determinar los niveles de confianza: también conocido como niveles de significancia o significación.

La comprobación de la hipótesis nula. Es usual iniciar el análisis estadístico con la comprobación de la hipótesis nula. Tomando en cuenta que las dos muestras forman parte de la misma población, cualquier diferencia observada entre las muestras se considera como un hecho casual como resultado de un error de muestreo, por lo que se propone que la diferencia que existe entre dos medias extraídas de diferentes muestras, no representa una diferencia real entre sus medias poblacionales.

Como consecuencia la hipótesis nula se puede representar como:

Donde:

$$
\mu_{1}=\mu_{2}
$$

$\mu_{1}=$ la media de la primera población.

$\mu_{2}=$ la media de la segunda población.

Es importante resaltar que la hipótesis nula no niega la posibilidad de obtener diferencias entre las medias de las muestras, lo que pretende es explicar estas diferencias atribuyéndolas a la operación del error de muestreo.

Hipótesis Nula, $H_{0}$ : No existe diferencia entre las calificaciones obtenidas por los alumnos y las alumnas en la escuela "Sol".

Ejemplo 68. De acuerdo a la hipótesis nula, se encontró en una muestra aleatoria de alumnas, que éstas obtienen mejores calificaciones $(\bar{x}=80)$ comparadas con una muestra aleatoria de alumnos $(\bar{x}=75)$. Se puede concluir que la población de alumnos obtienen calificaciones más bajas que las alumnas. En lugar de esto, se determina la diferencia muestral obtenida $(80-75=5)$ como consecuencia del error de muestreo.

La comprobación de la hipótesis de investigación. Si se rechaza la hipótesis nula automáticamente se acepta la hipótesis de investigación, la cual plantea que sí existe una diferencia poblacional. Esta hipótesis establece que las dos muestras que se han tomado de la población tienen medias diferentes y que estas diferencias son demasiado grandes como para ser justificadas por el error de muestreo.

Como consecuencia, la hipótesis de investigación para diferencias entre medias se puede representar como:

$$
\mu_{1} \neq \mu_{2}
$$


Donde:

$\mu_{1}=$ la media de la primera población.

$\mu_{2}=$ la media de la segunda población.

El signo $\neq$ se lee: diferente de o no igual.

Hipótesis de investigación, $H_{i}$ : las alumnas obtienen mejores calificaciones que los alumnos en la escuela "Sol".

\subsubsection{Contrastación de hipótesis}

Lo que se pretende ahora es hacer afirmaciones de probabilidad con respecto a los puntajes de diferencia en una distribución muestral de diferencias entre medias, esta distribución normal toma la forma de la curva normal, por lo que se puede considerar como una distribución de probabilidad. Se puede afirmar que la probabilidad de comprobar la hipótesis nula disminuye a medida que se aleja el valor más de la media de diferencias $\left(\mu_{1}-\mu_{2}=0\right)$.

En la Gráfica 12 se observa cómo sería esta distribución muestral (como modelo teórico o ideal) de diferencias como una distribución de probabilidad. Se observa que el 68.26 \% de la diferencia entre medias caen entre $-1 \sigma$ y $+1 \sigma$ de cero. En términos de probabilidad significa que $P=0.68$ de que cualquier diferencia entre medias muestrales esté contenida dentro de este intervalo. De manera similar se determinan las probabilidades de que estén contenidas cualquier diferencia entre medias muestrales entre los diferentes valores de $\sigma$ positivas 0 negativas, para el porcentaje contenido entre $\pm 2 \sigma$ la probabilidad es $P=0.95$ y para el rango $\pm 3 \sigma$ es de $P=0.99$.

La distribución muestral de diferencias es una fuerte herramienta para comprobar hipótesis acerca de la diferencia de medias entre dos muestras aleatorias. Se puede entonces pensar que si la diferencia entre medias muestrales cae muy cerca de cero implica que la probabilidad de que ocurra es grande, se debe aceptar la hipótesis nula y tratar esta diferencia como resultado del error de muestreo.

Gráfica 12. Distribución muestral de diferencias como una distribución de probabilidad.

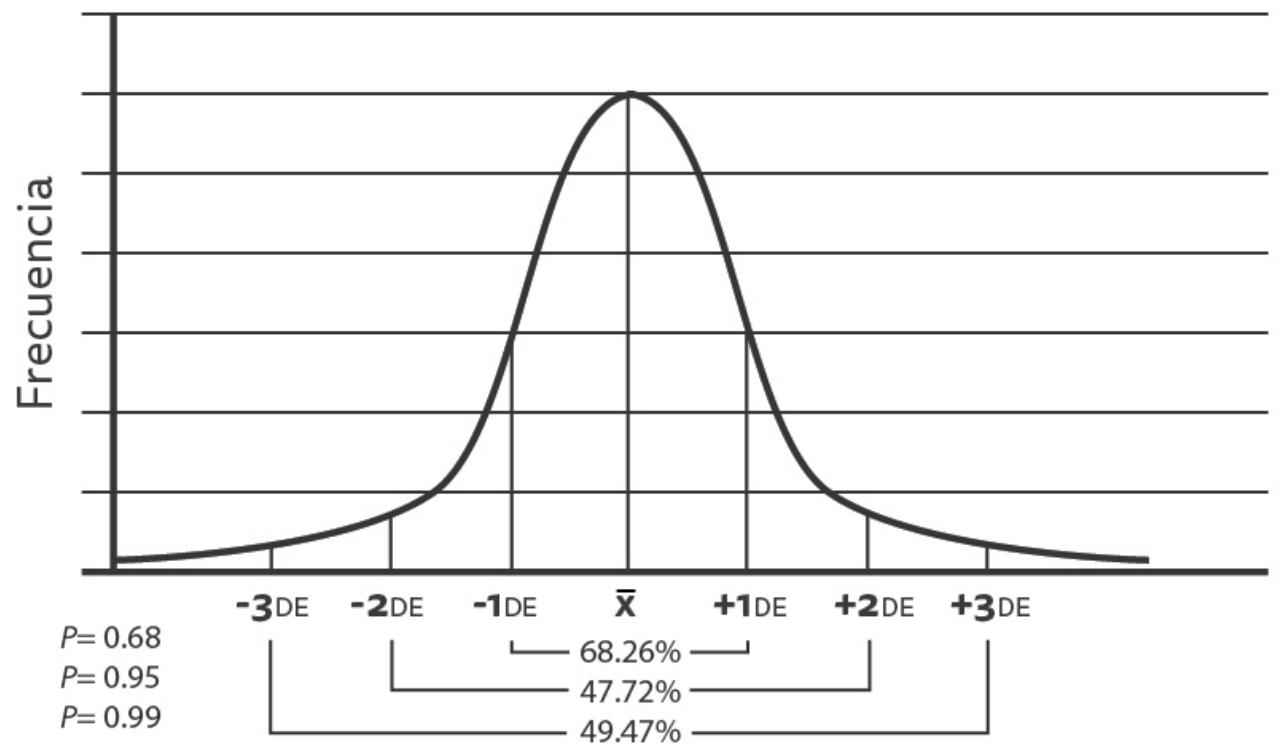


Pero si la diferencia entre medias muestrales cae muy lejos de cero, es que sólo tiene una pequeña probabilidad de que ocurra en la distribución muestral, por lo que se debe rechazar la hipótesis nula y aceptar la hipótesis de investigación que es la que establece que la diferencia obtenida no es resultado del error de muestreo.

En otras palabras, mientras más grande sea el valor de la probabilidad la diferencia será más significativa, por lo tanto no es resultado del error de muestreo y se acepta la hipótesis de investigación, rechazándose la hipótesis nula.

Lo que procede entonces, es determinar que tan significativa puede ser esta diferencia entre las medias del valor de cero. Para poder determinar esto es necesario convertir la diferencia obtenida a unidades de desviación estándar.

Para realizar esta conversión es necesario recordar que para convertir los puntajes directos (o crudos) a unidades de desviación estándar se utiliza la siguiente ecuación:

Donde:

$$
Z=\frac{x-\bar{x}}{\sigma}
$$

$x=$ puntuación directa.

$\bar{x}=$ media de la distribución de puntajes directos.

$\sigma=$ desviación estándar de la distribución de puntajes directos.

Siguiendo la misma relación se convierten los puntajes medios de una distribución de medias muestrales a unidades de desviación estándar mediante la ecuación:

$$
Z=\frac{\bar{x}-\mu}{\sigma_{\bar{x}}}
$$

Donde:

$\overline{\mathrm{x}}=$ media muestral.

$\mu=$ media poblacional (media de medias).

$\sigma_{\bar{x}}=$ error estándar de las medias (estimación de la desviación estándar de la distribución de medias).

De la misma manera se busca traducir la diferencia entre medias a unidades de desviación estándar mediante la siguiente ecuación:

$$
Z=\frac{\left(\bar{x}_{1}-\bar{x}_{2}\right)-0}{\sigma_{\text {dif }}}
$$

Donde:

$\overline{\mathrm{x}}_{1}=$ media de la primera muestra.

$\overline{\mathrm{x}}_{2}=$ media de la segunda muestra.

0 = cero, el valor de la media de la distribución muestral de diferencias (suponemos que $\mu_{1}-\mu_{2}=0$ ).

$\sigma_{\text {dif }}=$ desviación estándar de la distribución muestral de diferencias. 
Como siempre se supone que el valor de la media de la distribución de diferencias es cero, la última ecuación queda:

$$
Z=\frac{\bar{x}_{1}-\bar{x}_{2}}{\sigma_{\text {dif }}}
$$

A esta estimación de la desviación estándar de la distribución de muestras de diferen-

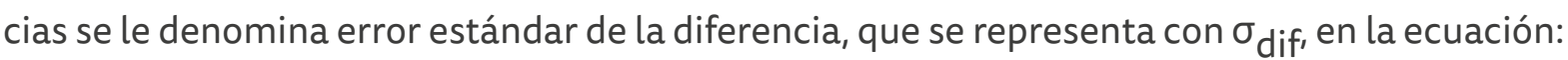

$$
\sigma_{\mathrm{dif}}=\sqrt[2]{\sigma_{\overline{\mathrm{x}} 1}^{2}+\sigma_{\overline{\mathrm{x}} 2}^{2}}
$$

Donde:

$$
\begin{aligned}
& \sigma_{\mathrm{dif}}=\text { error estándar de la diferencia. } \\
& \sigma_{\overline{\mathrm{x}} 1}=\text { error estándar de la primera media muestral. } \\
& \sigma_{\overline{\mathrm{x}} 2}=\text { error estándar de la segunda media muestral. }
\end{aligned}
$$

Pero todavía es necesario conocer el error estándar para cada media muestral, esto se hace a partir de la desviación estándar mediante la siguiente ecuación:

$$
\sigma_{\overline{\mathrm{x}} 1}=\frac{\sigma_{1}}{\sqrt[2]{N-1}} \text { y } \quad \sigma_{\overline{\mathrm{x}} 2}=\frac{\sigma_{2}}{\sqrt[2]{N-1}}
$$

Donde:

$$
\begin{aligned}
& \sigma_{1}=\text { desviación estándar de la muestra } 1 . \\
& \sigma_{2}=\text { desviación estándar de la muestra } 2 . \\
& N=\text { número de participantes en la muestra. }
\end{aligned}
$$

En la escuela "Sol" se aplicó un examen de conocimientos a todos los alumnos de 6 은 grado de primaria, con la finalidad de conocer cuál es la situación cognitiva de los alumnos que están a punto de egresar, la población está constituida por cuatro grupos integrados por 20 alumnos cada uno, conformando una población total de 80 alumnos, los grupos son mixtos.

Ejemplo 69. A las autoridades les interesa saber si existe diferencia entre los puntajes obtenidos por los alumnos y las alumnas, considerando que las alumnas obtuvieron mejor promedio que los alumnos en dos muestras (33 alumnos y 33 alumnas) obteniendo los resultados que se presentan en la Tabla 6.

Las hipótesis que se plantearon fueron las siguientes:

Hipótesis Nula, $\mathrm{H}_{\mathrm{O}}$ : no hay diferencia entre las calificaciones obtenidas por los alumnos y las alumnas en la escuela "Sol" $\left(\mu_{1}=\mu_{2}\right)$.

Hipótesis de investigación, $H_{i}$ : las alumnas obtienen mejores calificaciones que los alumnos en la escuela "Sol" $\left(\mu_{1} \neq \mu_{2}\right)$. 
El procedimiento detallado para comprobar o rechazar la hipótesis nula se describe a continuación:

1. Como primer paso se deben calcular los valores de las medias muestrales.

$$
\overline{\mathrm{x}}_{1}=\frac{\sum \mathrm{x}_{1}}{N}=\frac{2640}{33}=80 \quad \mathrm{y} \quad \overline{\mathrm{x}}_{2}=\frac{\sum \mathrm{x}_{2}}{N}=\frac{2475}{33}=75
$$

Tabla 6. Relación de puntajes obtenidos de dos muestras de los alumnos de 6 grado de la escuela "Sol".

\begin{tabular}{|c|c|c|c|c|}
\hline \multirow{2}{*}{$\begin{array}{c}N=33 \\
\quad №\end{array}$} & \multicolumn{2}{|c|}{ Calificación Alumnas } & \multicolumn{2}{|c|}{ Calificación Alumnos } \\
\hline & $x_{1}$ & $x_{1}^{2}$ & $x_{2}$ & $x_{2}^{2}$ \\
\hline 1 & 100 & 10000 & 95 & 9025 \\
\hline 2 & 95 & 9025 & 90 & 8100 \\
\hline 3 & 100 & 10000 & 80 & 6400 \\
\hline 4 & 65 & 4226 & 80 & 6400 \\
\hline 5 & 90 & 8100 & 100 & 10000 \\
\hline 6 & 65 & 4225 & 60 & 3600 \\
\hline 7 & 85 & 7225 & 75 & 5625 \\
\hline 8 & 85 & 7225 & 80 & 6400 \\
\hline 9 & 80 & 6400 & 60 & 3600 \\
\hline 10 & 80 & 6400 & 70 & 4900 \\
\hline 11 & 75 & 5625 & 70 & 4900 \\
\hline 12 & 70 & 4900 & 80 & 6400 \\
\hline 13 & 70 & 4900 & 60 & 3600 \\
\hline 14 & 100 & 10000 & 90 & 8100 \\
\hline 15 & 95 & 9025 & 60 & 3600 \\
\hline 16 & 100 & 10000 & 70 & 4900 \\
\hline 17 & 80 & 6400 & 60 & 3600 \\
\hline 18 & 90 & 8100 & 80 & 6400 \\
\hline 19 & 90 & 8100 & 90 & 8100 \\
\hline 20 & 70 & 4900 & 60 & 3600 \\
\hline 21 & 70 & 4900 & 70 & 4900 \\
\hline 22 & 90 & 8100 & 100 & 10000 \\
\hline 23 & 75 & 5625 & 65 & 4225 \\
\hline 24 & 70 & 4900 & 60 & 3600 \\
\hline 25 & 65 & 4225 & 60 & 3600 \\
\hline 26 & 80 & 6400 & 90 & 8100 \\
\hline 27 & 80 & 6400 & 70 & 4900 \\
\hline 28 & 70 & 4900 & 80 & 6400 \\
\hline 29 & 60 & 3600 & 75 & 5625 \\
\hline 30 & 80 & 6400 & 90 & 8100 \\
\hline 31 & 55 & 3025 & 55 & 3025 \\
\hline 32 & 70 & 4900 & 70 & 4900 \\
\hline 33 & 90 & 8100 & 80 & 6400 \\
\hline$\Sigma$ & $\sum x_{1}=2640$ & $\sum x_{1}^{2}=216251$ & $\sum x_{2}=2475$ & $\sum x_{2}^{2}=191025$ \\
\hline
\end{tabular}


Se aprecia que sí existe diferencia entre las medias muestrales pero estarán lo suficiente separadas del cero bajo la curva de distribución muestral de diferencias como una distribución de probabilidad.

2. Para comprobar qué tan cerca o alejados están las puntuaciones del cero, el siguiente paso es encontrar la desviación estándar para cada muestra.

$$
\begin{aligned}
& \sigma_{1}=2 \sqrt{\frac{\sum x_{1}^{2}}{N_{1}}-\bar{x}_{1}^{2}}=\sqrt[2]{\frac{216251}{33}-6400}=12.37 \\
& \sigma_{2}=2 \sqrt{\frac{\sum x_{2}^{2}}{N_{2}}-\bar{x}_{2}^{2}}=\sqrt[2]{\frac{191025}{33}-5625}=12.79
\end{aligned}
$$

3. En seguida se procede a determinar el error estándar de cada media.

$$
\begin{gathered}
\sigma_{\overline{\mathrm{x}} 1}=\frac{\sigma_{1}}{\sqrt[2]{N-1}}=\frac{12.37}{\sqrt[2]{33-1}}=\frac{12.37}{5.656}=2.187 \\
\mathrm{y} \\
\sigma_{\overline{\mathrm{x}} 2}=\frac{\sigma_{2}}{\sqrt[2]{N-1}}=\frac{12.79}{\sqrt[2]{33-1}}=\frac{12.79}{5.656}=2.261
\end{gathered}
$$

4. Calcular el error estándar de las diferencias.

$$
\sigma_{\text {dif }}=\sqrt[2]{\sigma_{\bar{x} 1}^{2}+\sigma_{\bar{x} 2}^{2}}=\sqrt{2.187^{2}+2.261^{2}}=3.145
$$

5. Determinar las unidades de error estándar de la diferencia o puntaje $Z$ a partir de la diferencia entre medias muestrales.

$$
Z=\frac{\bar{x}_{1}-\bar{x}_{2}}{\sigma_{\text {dif }}}=\frac{80-75}{3.145}=1.59
$$

6. Localizar en la Tabla A (Apéndice D) el valor de $Z$.

Se localiza en la primer columna el valor de 1.5 y se ubica en la primera fila el valor complementario 0.09, donde se interceptan se localiza el valor del porcentaje del área debajo de la curva normal entre $\bar{x}$ y $Z$.

$$
P=44.41 \%
$$

7. Encontrar el porcentaje del área total bajo la curva normal entre cero y los valores de $\pm Z$.

$44.41 \%$

$\frac{+44.41 \%}{88.82 \%}$

8. Determinar el porcentaje del área total asociado con la diferencia entre medias muestrales obtenidas, restando el porcentaje del área total del $100 \%$.

$100.00 \%$

$+88.82 \%$

$11.18 \%$ 
9. Conclusión: de acuerdo a este resultado se puede decir que la probabilidad encontrada es de 0.1118 lo que significa que la probabilidad de que la diferencia entre medias sea significativa entre alumnos y alumnas es igual a 11 de 100. En otras palabras el nivel de significación o de confianza es de $\rho=0.11$ normalmente se redondea solo a dos decimales.

Para llegar al paso 10 es necesario conocer la siguiente información.

\subsubsection{El nivel de significación (o confianza)}

Esto qué significa, ¿es bueno o malo?, ¿se comprueba la hipótesis nula o se rechaza? La aceptación o rechazo de una hipótesis nula debe tener como criterio algún nivel de significación.

En la investigación social, psicológica y educativa, el nivel de significación del 5\% ( $\rho=$ 0.05) se considera aceptable como típico para el rechazo (Levin, 1999).

Al rechazar la hipótesis nula en un nivel del $5 \%$ significa que una diferencia en las medias muestrales, como puede ser las encontradas en los grupos experimentales y de control, no es resultado del error de la muestra en más de 5 de 100 repeticiones del experimento. Lo anterior sugiere un $95 \%$ de probabilidad de que la diferencia se debe a la variable experimental más que al error de la muestra.

Sin embargo, cuando se requiere una prueba de significado más rigurosa se selecciona un nivel de significación del 1\%, lo que significa que el rendimiento no ha resultado del error de muestra en más de $1 \%$ de los casos.

Cuando las muestras son grandes (más de 30 casos), la razón crítica se expresa como $Z$ o puntuación de probabilidad, si ésta es mayor de 1.96 y menor de 2.58 se puede concluir que las diferencias entre las medias es significativa al $5 \%$ y se acepta la hipótesis de investigación, por otro lado si la razón critica es menor de 1.96, la hipótesis nula puede aceptarse al nivel del 5\%.

El nivel de significación de $\rho=0.05(5 \%)$ se representa en la Gráfica 13; como se observa el nivel de significación de 0.05 se encuentra en las áreas de las "colas" de la distribución de diferencias de medias que representan las áreas bajo la curva equivalentes a una distancia de más o menos 1.96 desviaciones estándar de una diferencia media de cero.

Gráfica 13. Representación gráfica del nivel de confianza de $\rho=0.05(2.5 \%$ en cada extremo).

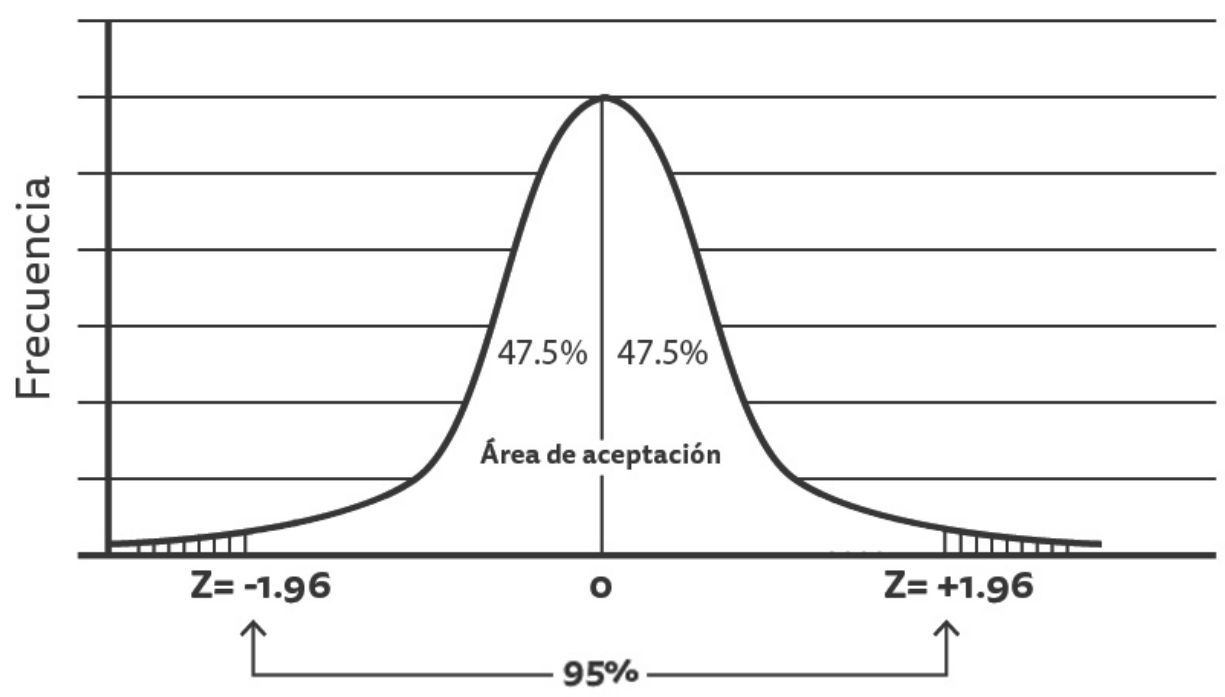


Con la finalidad de una mejor comprensión de por qué en este caso la distribución muestral representa el nivel de confianza del 0.05, se recurre a la Tabla A del Apéndice D, para determinar el porcentaje de frecuencia total asociado con $Z=1.96$ desviaciones estándar de la media y se localiza el valor de $47.5 \%$ que representa el porcentaje total entre el valor de $Z$ y cero, si este valor encontrado se resta al 50\% que representa esta mitad de la curva se puede determinar 1.96 desviaciones estándar en una u otra dirección representan el $2.5 \%$ de las diferencias entre medias muestrales $(50 \%-47.5 \%=2.5 \%)$.

Tomando en cuenta la simetría de la gráfica, se puede decir que el $95 \%$ de las diferencias muestrales se encuentra entre $-1.96 \sigma y+1.96 \sigma$ de una diferencia de media de cero, siendo sólo un $5 \%$ que cae en este punto o más allá de él $(2.5 \%+2.5 \%=5 \%)$.

10. El momento de decidir.

Una vez conociendo el nivel de significación estandarizado por los investigadores en educación que corresponde a 0.05 (5\%) o en un caso de más rigor 0.01 (1\%), siguiendo el mismo proceso para elaborar la gráfica que representa el nivel de confianza de 0.05 , con los datos obtenidos en el ejemplo se procede a elaborar la gráfica correspondiente al problema planteado (Gráfica 14).

Se observa que el área de aceptación es más reducida que en la gráfica representativa con un 0.05 de nivel de confianza. Es importante recordar que mientras más se alejen los valores de $Z$ del punto cero, más lejos se encuentra la aprobación de la hipótesis nula. Asimismo, se observa que el área de rechazo es mayor que en el caso deseado.

Gráfica 14. Representación gráfica del ejemplo con un nivel de confianza de $\rho=0.1118$ (5.59\% en cada extremo).

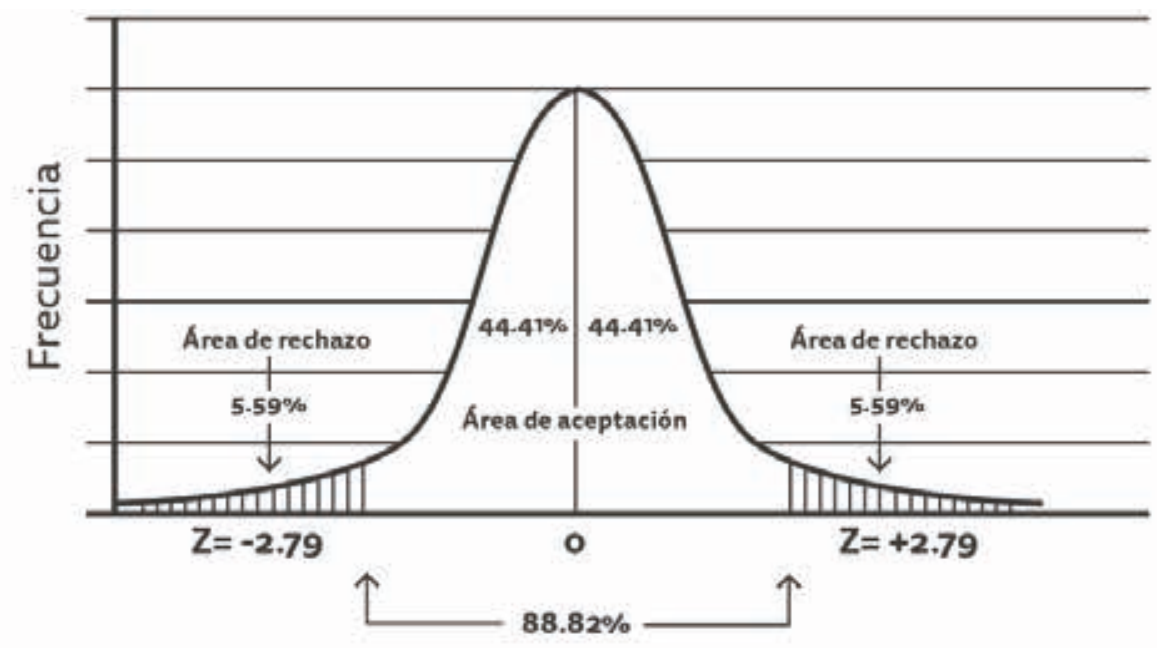

Finalmente, para que se rechace la hipótesis de investigación el valor del nivel de significación o confianza debe de ser menor o igual a 0.05. En este ejemplo este valor corresponde a 0.11 por lo que se puede decir que el valor encontrado es mayor que el deseado:

$$
\rho=0.11>0.05
$$

En el ejemplo se encontró que $\rho=0.11$ de obtener una diferencia de media de 5 (80 - 75) por error de muestreo. Por lo tanto, se debe aceptar la hipótesis nula y rechazar la hipótesis de investigación a un nivel de confianza de 0.05. 
Es decir, la probabilidad de que ocurra la diferencia entre las medias obtenidas entre alumnas y alumnos es mayor a 5 de 100. En este caso es igual a 11 de 100, por lo que se puede afirmar que "no existe diferencia entre las calificaciones obtenidas por los alumnos y las alumnas en la escuela Sol", y que no existe diferencia entre las medias de la población:

$$
\mu_{1}=\mu_{2}
$$

\subsubsection{Para muestras pequeñas}

Es muy frecuente que la investigación se realice dentro del salón de clase con muestras que contienen un pequeño número de participantes (alumnos, maestros, padres de familia) en donde el número no excede de 30. Los resultados obtenidos de muestras pequeñas pueden ser engañosos si se interpretan de acuerdo al área señalada bajo la curva normal en la Tabla $A$ del Apéndice $D$, pues la distribución muestral de diferencias toma la forma de la curva normal sólo si las muestras utilizadas son grandes.

Como consecuencia no se pueden usar puntajes $Z$ basados en una distribución normal. Para compensar este alejamiento de la normalidad, en la distribución de las diferencias se aplica otros puntajes conocidos como la razón $t$, que al igual que el puntaje $Z$, puede usarse para convertir una diferencia entre medias muestrales a unidades de error estándar de las diferencias. La razón $t$ se determina por medio de la diferencia entre las medias muestrales, dividiéndolas entre el error estándar de la diferencia como se muestra en la siguiente ecuación:

$$
t=\frac{\overline{\mathrm{x}}_{1}-\overline{\mathrm{x}}_{2}}{\sigma_{\mathrm{dif}}}
$$

Donde:

$$
\begin{aligned}
& \overline{\mathrm{x}}_{1}=\text { media de la primera muestra. } \\
& \overline{\mathrm{x}}_{2}=\text { media de la segunda muestra. } \\
& \sigma_{\text {dif }}=\text { error estándar de la diferencia. }
\end{aligned}
$$

En la ecuación se observa que la razón $t$ es idéntica a la fórmula para el puntaje $Z$ mostrada anteriormente, la diferencia consiste en que la razón $t$ debe interpretarse en función de los grados de libertad $(g l)$, éstos varían directamente con el tamaño de la muestra y determinan la forma de la distribución muestral de diferencias.

Los grados de libertad se refieren desde el punto de vista técnico a la libertad de variación entre un conjunto de puntaje. Como ejemplo, si se tiene una muestra de 14 puntajes, entonces 13 son libres de variar y sólo uno es de valor fijo, entonces en una muestra de 14 participantes, $g l=N-1=14-1=13$.

Se entiende que a mayor tamaño de la muestra mayor el número de grados de libertad y mientras mayor sea el número de grados de libertad, más se acerca la distribución de diferencias a una aproximación de la curva normal. Con infinitos grados de libertad, la razón $t$ se convierte en puntaje $Z$ y de este modo se puede emplear la Tabla A para interpretar los resultados.

En el caso de una razón $t$ que representa dos medias muestrales, el número de grados de libertad puede encontrarse por medio de la siguiente ecuación:

$$
g l=N_{1}+N_{2}-2
$$


Donde:

$$
\begin{aligned}
& N_{1}=\text { tamaño de la primera muestra. } \\
& N_{2}=\text { tamaño de la segunda muestra. }
\end{aligned}
$$

Se puede interpretar cualquier razón $t$ que se obtenga con la ayuda de la Tabla G Apéndice $D$ y el número de grados de libertad calculado. En la Tabla $G$ se encuentran los valores de $t$ que se requieren para rechazar la hipótesis nula a los niveles de significación o confianza de 0.05 y 0.01 para varios grados de libertad. En la Tabla $G$ se observa que la primer columna (izquierda) corresponde a los grados de libertad $(g l)$ y en las siguientes columnas se localizan listas de valores $t$ para cada uno de éstos. Los valores $t$ pueden usarse para interpretar la razón $t$ obtenida por medio del cálculo.

Ejemplo 70. Un investigador en educación aplicó como estrategia pedagógica el uso de un video educativo interactivo a una muestra de 14 alumnos para tratar el tema de palancas de primer grado y desea saber si los alumnos retuvieron el contenido de manera significativa. Para determinar si existe diferencia se aplicó una prueba objetiva, que también fue aplicada a un grupo de alumnos (control) que recibieron la misma información de manera tradicional (expositiva) cuyo tamaño de la muestra es de 14 participantes. Los puntajes obtenidos se muestran en la Tabla 7.

El investigador plantea las siguientes hipótesis:

$\mathrm{H}_{\mathrm{o}}=\mathrm{Si}$ los alumnos reciben la información por medio de un video interactivo entonces retendrán la misma cantidad de conceptos que los alumnos que recibieron la información en forma tradicional $\left(\mu_{1}=\mu_{2}\right)$.

$\mathrm{H}_{\mathrm{i}}=\mathrm{Si}$ los alumnos reciben la información por medio de un video interactivo entonces retendrán más conceptos que los alumnos que recibieron la información en forma tradicional $\left(\mu_{1} \neq \mu_{2}\right)$.

Tabla 7. Puntajes obtenidos por los alumnos de $3^{\circ}$ de primaria que recibieron la información por medio de un video interactivo (experimental) y en forma tradicional (control).

\begin{tabular}{|c|c|c|c|c|}
\hline \multirow{2}{*}{ No de alumno } & \multicolumn{2}{|c|}{ Video interactivo $(\mathbf{N}=\mathbf{1 4})$} & \multicolumn{2}{|c|}{ Forma tradicional $(\mathbf{N}=\mathbf{1 4})$} \\
\cline { 2 - 5 } & $\mathrm{x}_{1}$ & $\mathrm{x}_{1}^{2}$ & $\mathrm{x}_{2}$ & $\mathrm{x}_{2}{ }^{2}$ \\
\hline 1 & 8 & 64 & 8 & 64 \\
\hline 2 & 9 & 81 & 7 & 49 \\
\hline 3 & 9 & 81 & 7 & 49 \\
\hline 4 & 8 & 64 & 9 & 81 \\
\hline 5 & 7 & 49 & 8 & 64 \\
\hline 6 & 10 & 100 & 7 & 49 \\
\hline 7 & 10 & 100 & 6 & 36 \\
\hline 8 & 9 & 81 & 7 & 49 \\
\hline 9 & 6 & 36 & 5 & 25 \\
\hline 10 & 7 & 49 & 8 & 64 \\
\hline 11 & 7 & 49 & 6 & 36 \\
\hline 13 & 9 & 81 & 10 & 100 \\
\hline 14 & 7 & 49 & 7 & 49 \\
\hline$\Sigma$ & 8 & 64 & 6 & 36 \\
\hline
\end{tabular}


A continuación se describe el procedimiento detallado para comprobar o rechazar la hipótesis:

1. Calcular los valores de las medias muestrales.

$$
\overline{\mathrm{x}}_{1}=\frac{\sum \mathrm{x}_{1}}{N_{1}}=\frac{114}{14}=8.14 \quad \mathrm{y} \quad \overline{\mathrm{x}}_{2}=\frac{\sum \mathrm{x}_{2}}{N_{2}}=\frac{101}{14}=7.21
$$

2. Encontrar la desviación estándar para cada muestra.

$$
\sigma_{1}=\sqrt[2]{\frac{\sum x_{1}^{2}}{N_{1}}-\bar{x}_{1}^{2}}=\sqrt[2]{\frac{948}{14}-8.14^{2}}=1.206 \text { y } \quad \sigma_{2}=\sqrt[2]{\frac{\sum x_{2}^{2}}{N_{2}}-\bar{x}_{2}^{2}}=\sqrt[2]{\frac{751}{14}-7.21^{2}}=1.287
$$

3. Encontrar el error estándar de cada media.

$$
\sigma_{\overline{\mathrm{x}} 1}=\frac{\sigma_{1}}{\sqrt[2]{N_{1}-1}}=\frac{1.206}{\sqrt[2]{14-1}}=\frac{1.206}{3.6}=0.335 \quad y \quad \sigma_{\bar{x} 2}=\frac{\sigma_{2}}{\sqrt[2]{N_{2}-1}}=\frac{1.287}{\sqrt[2]{14-1}}=\frac{1.287}{3.6}=0.357
$$

4. Calcular el valor del error estándar de las diferencias.

$$
\sigma_{\text {dif }}=\sqrt[2]{\sigma_{\overline{\mathrm{x}} 1}^{2}+\sigma_{\overline{\mathrm{x}} 2}{ }^{2}}=\sqrt{0.335^{2}+0.357^{2}=0.489}
$$

5. Determinar las unidades de error estándar de la diferencia o razón de $t$ a partir de la diferencia entre medias muestrales.

$$
t=\frac{\bar{x}_{1}-\bar{x}_{2}}{\sigma_{\text {dif }}}=\frac{8.14-7.21}{0.489}=1.901
$$

6. Calcular los grados de libertad.

$$
g l=N_{1}+N_{2}-2=14+14-2=26
$$

7. Localizar en la Tabla $\mathrm{G}$ del Apéndice $\mathrm{D}$ el valor de la razón $t$; se busca en la primer columna el valor de $g l=26$ y en la columna superior el valor correspondiente a 0.05 como nivel de significación o confianza en donde se interceptan las dos se localiza el valor de $t=2.056$.

8. Decidir la aceptación o rechazo de la hipótesis.

Razón $t$ calculada $=1.901$

Razón $t$ de la tabla $=2.056$

$g l=26$

$\rho=0.05$

De acuerdo a estos datos, para poder rechazar la hipótesis nula al nivel de confianza de 0.05 con 26 grados de libertad la razón $t$ calculada debe ser 2.056 o más. En este ejemplo la razón $t$ calculada fue de 1.901 por lo tanto se acepta la hipótesis nula y se rechaza la hipótesis de investigación. Esto es, "si los alumnos reciben la información por medio de un video interactivo entonces retendrán la misma cantidad de conceptos que los alumnos que recibieron la información en forma tradicional" por lo que no existen diferencias entre las medias de la población:

$$
\mu_{1}=\mu_{2}
$$




\section{6.2.2 Para muestras de distinto tamaño}

Cuando se realiza una investigación es común encontrar con frecuencia que las muestras difieren en tamaño, por ejemplo, si se quiere comparar dos grupos de secundaria en una misma materia, normalmente éstos no están integrados por el mismo número de estudiantes. Así se puede tomar una muestra del Grupo A de 20 estudiantes y del Grupo B de 25 estudiantes, 0 una muestra de 15 alumnas y 23 alumnos.

Al realizar comparaciones entre muestras de distinto tamaño es necesario determinar cómo darle el peso a la influencia relativa de cada muestra, esto sucede de manera natural en el caso de determina el valor de $\bar{x}$ puesto que siempre se divide $\Sigma x$ entre el valor de $N$. En este caso se utiliza una ecuación para el error estándar de la diferencia, en donde la influencia relativa de cada desviación estándar puede ser ponderada en términos del tamaño de la muestra, a continuación se muestra esta ecuación:

$$
\sigma_{\text {dif }}=\sqrt[2]{\left(\frac{N_{1} \sigma_{1}{ }^{2}+N_{2} \sigma_{2}^{2}}{N_{1}+N_{2}-2}\right)\left(\frac{1}{N_{1}}+\frac{1}{N_{2}}\right)}
$$

Donde:

$$
\begin{aligned}
& \sigma_{1}=\text { desviación estándar de la primera muestra. } \\
& \sigma_{2}=\text { desviación estándar de la segunda muestra. } \\
& N_{1}=\text { número total en la primera muestra. } \\
& N_{2}=\text { número total en la segunda muestra. }
\end{aligned}
$$

Ejemplo 71. Un investigador en educación requiere determinar si las prácticas de laboratorio en la materia de química influyen en los alumnos para que éstos se apropien del conocimiento, por lo que seleccionó una muestra de 20 alumnos para que realicen una práctica de laboratorio y una muestra de 25 alumnos como referencia (control) que no realizaron la práctica mencionada.

El investigador planteó las siguientes hipótesis:

$\mathrm{H}_{\mathrm{o}}$ : Si los alumnos realizan una práctica de laboratorio como complemento de la información recibida en el salón de clase retendrán la misma información que los alumnos que no la realizaron $\left(\mu_{1}=\mu_{2}\right)$.

$\mathrm{H}_{\mathrm{i}}$ : Si los alumnos realizan una práctica de laboratorio como complemento de la información recibida en el salón de clase retendrán mayor información que los alumnos que no la realizaron $\left(\mu_{1} \neq \mu_{2}\right)$.

Como instrumento de recolección de información el investigador diseñó y aplicó una prueba objetiva con el contenido de los temas de química tratados en el salón de clase, obteniéndose los resultados que se muestran en la Tabla 8.

El procedimiento detallado para comprobar o rechazar la hipótesis nula se describe a continuación:

1. Calcular los valores de las medias muestrales.

$$
\bar{x}_{1}=\frac{\sum x_{1}}{N_{1}}=\frac{164}{20}=8.2 \quad \text { y } \quad \bar{x}_{2}=\frac{\sum x_{2}}{N_{2}}=\frac{171}{25}=6.84
$$


2. Encontrar la desviación estándar para cada muestra.

$$
\begin{aligned}
& \sigma_{1}=\sqrt[2]{\frac{\sum x_{1}^{2}}{N_{1}}-\bar{x}_{1}^{2}}=\sqrt[2]{\frac{1388}{20}-(8.2)^{2}}=1.469 \\
& \sigma_{2}=\sqrt{\frac{\sum x_{2}^{2}}{N_{2}}-\bar{x}_{2}^{2}}=\sqrt[2]{\frac{1225}{25}-6.84^{2}}=1.488
\end{aligned}
$$

3. Encontrar el error estándar de las diferencias.

$$
\begin{gathered}
\sigma_{\text {dif }}=2 \sqrt{\left(\frac{N_{1} \sigma_{1}{ }^{2}+N_{2} \sigma_{2}^{2}}{N_{1}+N_{2}{ }^{-2}}\right)\left(\frac{1}{N_{1}}+\frac{1}{N_{2}}\right)} \\
\sigma_{\text {dif }}=\sqrt[2]{\left(\frac{20(1.469)^{2}+25(1.448)^{2}}{20+25-2}\right)\left(\frac{1}{20}+\frac{1}{25}\right)} \\
\sigma_{\text {dif }}=0.447
\end{gathered}
$$

4. Determinar las unidades de error estándar de la diferencia o razón de $t$ a partir de la diferencia entre medias muestrales.

$$
t=\frac{\bar{x}_{1}-\bar{x}_{2}}{\sigma_{\text {dif }}}=\frac{8.2-6.84}{0.447}=3.042
$$

5. Calcular los grados de libertad.

$$
g l=N_{1}+N_{2}-2=20+25-2=43
$$

6. Localizar en la Tabla $\mathrm{G}$ del Apéndice $\mathrm{D}$, el valor de la razón $t$ se busca en la primer columna el valor de $g l=43$ y en la columna superior el valor correspondiente a 0.05 como nivel de significación o confianza en donde se interceptan las dos se localiza el valor de $t=2.021$

7. Decidir la aceptación o rechazo de la hipótesis.

Razón $t$ calculada $=3.042$

Razón $t$ de la tabla $=2.021$

$g l=26$

$\rho=0.05$

De acuerdo a estos datos, para poder rechazar la hipótesis nula al nivel de confianza de 0.05 con 26 grados de libertad, la razón $t$ calculada debe ser 2.056 o más. En este ejemplo, la razón t calculada fue de 3.042, por lo tanto, se rechaza la hipótesis nula y se acepta la hipótesis de investigación. Esto es, "si los alumnos realizan una práctica de laboratorio como complemento de la información recibida en el salón de clase, retendrán mayor información que los alumnos que no la realizaron", y que existe diferencia entre las medias de la población: $\mu_{1} \neq \mu_{2}$. 
Tabla 8. Relación de puntajes obtenidos por los alumnos de química de los grupos experimental y de control.

\begin{tabular}{|c|c|c|c|c|}
\hline \multirow{2}{*}{ № de alumno } & \multicolumn{2}{|c|}{$\begin{array}{l}\text { Con práctica de laboratorio } \\
\qquad\left(N_{1}=20\right)\end{array}$} & \multicolumn{2}{|c|}{$\begin{array}{l}\text { Sin práctica de laboratorio } \\
\qquad\left(N_{2}=25\right)\end{array}$} \\
\hline & $x_{1}$ & $x_{1}^{2}$ & $x_{2}$ & $x_{2}^{2}$ \\
\hline 1 & 9 & 81 & 7 & 49 \\
\hline 2 & 8 & 64 & 6 & 36 \\
\hline 3 & 10 & 100 & 9 & 81 \\
\hline 4 & 7 & 49 & 7 & 49 \\
\hline 5 & 10 & 100 & 6 & 36 \\
\hline 6 & 8 & 64 & 5 & 25 \\
\hline 7 & 8 & 64 & 5 & 25 \\
\hline 8 & 8 & 64 & 7 & 49 \\
\hline 9 & 9 & 81 & 10 & 100 \\
\hline 10 & 6 & 36 & 6 & 36 \\
\hline 11 & 7 & 49 & 6 & 36 \\
\hline 12 & 8 & 64 & 8 & 64 \\
\hline 13 & 5 & 25 & 7 & 49 \\
\hline 14 & 10 & 100 & 7 & 49 \\
\hline 15 & 9 & 81 & 9 & 81 \\
\hline 16 & 10 & 100 & 10 & 100 \\
\hline 17 & 10 & 100 & 5 & 25 \\
\hline 18 & 9 & 81 & 7 & 49 \\
\hline 19 & 7 & 49 & 5 & 25 \\
\hline 20 & 6 & 36 & 6 & 36 \\
\hline 21 & & & 8 & 64 \\
\hline 22 & & & 5 & 25 \\
\hline 23 & & & 6 & 36 \\
\hline 24 & & & 6 & 36 \\
\hline 25 & & & 8 & 64 \\
\hline$\Sigma$ & $\sum x_{1}=164$ & $\sum x_{1}^{2}=1388$ & $\sum x_{2}=171$ & $\sum x_{2}^{2}=1225$ \\
\hline
\end{tabular}

\subsubsection{Para la misma muestra medida dos veces}

Es muy común que el investigador en educación requiere de medir las reacciones que experimenta una sola muestra de estudiantes, tanto antes como después de participar en alguna estrategia pedagógica, utilización de algún instrumento o recurso audiovisual. A una sola muestra medida en dos puntos diferentes en el tiempo se le conoce como un diseño antes-después, de panel o relacionado.

Al hecho de trabajar con una comparación antes-después, involucra tomar en cuenta la diferencia que hay entre el Tiempo 1 y el Tiempo 2, esta situación se refleja en la ecuación para la obtención de la desviación estándar para distribución de diferencias antes-después.

$$
\sigma=\sqrt[2]{\frac{\sum D^{2}}{N}-\left(\bar{x}_{1}-\bar{x}_{2}\right)^{2}}
$$


Donde:

$\sigma$ = desviación estándar de la distribución de puntajes de diferencias antes-después.

$\mathrm{D}=$ puntaje directo después, restado del puntaje directo antes.

$N=$ número de casos o participantes en la muestra.

Ejemplo 72. Un investigador en educación desea saber si influye en la retención de conocimientos adquiridos durante su carrera la proyección de la película "Contacto" y el uso de una guía de observación con la que los alumnos rescaten la información más relevante relacionada con su carrera (Electrónica en Comunicaciones).

Tabla 9. Los puntajes obtenidos por los alumnos antes y después de la proyección de la película.

\begin{tabular}{|c|c|c|c|c|}
\hline$N=\mathbf{2 0}$ & Antes & Después & Diferencia & $\begin{array}{l}\text { Diferencia al } \\
\text { cuadrado }\end{array}$ \\
\hline № & $x_{1}$ & $x_{2}$ & $x_{1}-x_{2}=D$ & $D^{2}$ \\
\hline 1 & 75 & 80 & -5 & 25 \\
\hline 2 & 80 & 80 & 0 & 0 \\
\hline 3 & 60 & 65 & -5 & 25 \\
\hline 4 & 70 & 70 & 0 & 0 \\
\hline 5 & 50 & 60 & -10 & 100 \\
\hline 6 & 80 & 75 & +5 & 25 \\
\hline 7 & 60 & 60 & 0 & 0 \\
\hline 8 & 60 & 65 & -5 & 25 \\
\hline 9 & 70 & 65 & -5 & 25 \\
\hline 10 & 75 & 70 & +5 & 25 \\
\hline 11 & 80 & 90 & -10 & 100 \\
\hline 12 & 60 & 65 & -5 & 25 \\
\hline 13 & 70 & 80 & -10 & 100 \\
\hline 14 & 50 & 60 & -10 & 100 \\
\hline 15 & 60 & 65 & -5 & 25 \\
\hline 16 & 70 & 75 & -5 & 25 \\
\hline 17 & 60 & 70 & -10 & 100 \\
\hline 18 & 50 & 60 & -10 & 100 \\
\hline 19 & 80 & 90 & -10 & 100 \\
\hline 20 & 70 & 75 & -5 & 25 \\
\hline$\Sigma$ & $\sum x_{1}=1330$ & $\sum x_{2}=1420$ & & $\Sigma D^{2}=950$ \\
\hline
\end{tabular}

Con el fin de constatar esta situación, elaboró dos pruebas objetivas, la primera la aplicó una semana antes de ver la proyección y la otra una semana después de proyectar la película. Los puntajes obtenidos por los alumnos se muestran en la Tabla 9 y las hipótesis planteadas por el investigador fueron las siguientes:

$\mathrm{H}_{\mathrm{o}}$ : Si los alumnos observan la película "Contacto" y utilizan una guía de observación, no retendrán ni mayor, ni menor cantidad de conocimientos adquiridos durante su carrera $\left(\mu_{1}=\mu_{2}\right)$.

$\mathrm{H}_{\mathrm{i}}$ : Si los alumnos observan la película "Contacto" y utiliza una guía de observación, retendrán mayor cantidad de conocimientos adquiridos durante su carrera $\left(\mu_{1} \neq \mu_{2}\right)$.

El procedimiento detallado para comprobar o rechazar la hipótesis nula se describe a continuación: 
1. Calcular los valores de las medias para cada punto en el tiempo.

$$
\overline{\mathrm{X}}_{1}=\frac{\sum \mathrm{x}_{1}}{N_{1}}=\frac{1330}{20}=66.5 \quad \mathrm{y} \quad \overline{\mathrm{x}}_{2}=\frac{\sum \mathrm{x}_{2}}{N_{2}}=\frac{1420}{20}=71
$$

2. Encontrar la desviación estándar para la diferencia entre el tiempo 1 y el tiempo 2.

$$
\begin{gathered}
\sigma=\sqrt[2]{\frac{\sum D^{2}}{N}-\left(\bar{x}_{1}-\bar{x}_{2}\right)^{2}} \\
\sigma=\sqrt[2]{\frac{950}{20}-(66.5-71)^{2}} \\
\sigma=\sqrt[2]{47.5-20.25}=5.22
\end{gathered}
$$

3. Encontrar el error estándar de las diferencias.

$$
\begin{gathered}
\sigma_{\text {dif }}=\frac{\sigma}{\sqrt[2]{N-1}} \\
\sigma_{\text {dif }}=\frac{5.22}{2 \sqrt{20-1}}=1.197 \\
\sigma_{\text {dif }}=1.197
\end{gathered}
$$

4. Determinar las unidades de error estándar de la diferencia o razón de $t$ a partir de la diferencia entre medias muestrales.

$$
t=\frac{\overline{\mathrm{x}}_{1}-\overline{\mathrm{x}}_{2}}{\sigma_{\mathrm{dif}}}=\frac{66.5-71}{1.197}=3.759
$$

5. Calcular los de grados de libertad.

$$
g l=N-1=20-1=19
$$

6. Localizar en la Tabla G del Apéndice D, el valor de la razón $t$, se busca en la primer columna el valor de $g l=19$ y en la columna superior el valor correspondiente a 0.05 como nivel de significación o confianza. Donde se interceptan las dos se localiza el valor de $t=2.093$.

7. Decidir la aceptación o rechazo de la hipótesis.

Razón $t$ calculada $=3.759$

Razón $t$ de la tabla $=2.093$

$g l=19$

$\rho=0.05$

De acuerdo a estos datos, para poder rechazar la hipótesis nula al nivel de confianza de 0.05 con 19 grados de libertad la razón $t$ calculada debe ser 2.093 o más. En este ejemplo, la razón $t$ calculada fue de 3.759, por lo tanto, se rechaza la hipótesis nula y se acepta la hipótesis de investigación. Esto es, "si los alumnos observan la película "Contacto" y "utiliza una guía de observación, retendrán mayor cantidad de conocimientos adquiridos durante su carrera", y que existe diferencia entre las medias de la población: 


$$
\mu_{1} \neq \mu_{2}
$$

En este apartado se presentaron las herramientas y conocimientos requeridos para una mejor comprensión para la selección y aplicación de las pruebas estadísticas así como la interpretación de los resultados que éstas arrojen. Se inició con los conceptos de lo que es la estadística y como puede ser aprovechada en la investigación educativa. El investigador en educación debe ser capaz de formular sus hipótesis, por lo que se integraron los temas sobre el concepto de Hipótesis, su relación con el método experimental y las características que presenta una hipótesis en educación. Otro aspecto necesario consiste en conocer los niveles de medición para determinar el tipo de prueba estadística que se debe utilizar de acuerdo al tipo de datos que arrojen los instrumentos diseñados por el investigador en educación.

Una vez recolectados los datos, se requiere realizar un análisis estadístico, ya sea por medio de una medición descriptiva, de tendencia central o de dispersión.

Para el análisis y toma de decisiones se proporciona la información necesaria para entender lo que es la curva normal ideal y su relación con la realidad, analizando la aplicación práctica de la curva normal, la puntuación $Z$ o estándar para muestras grandes y la determinación del nivel de significación (o confianza) para comprobar o rechazar las hipótesis planteadas. De igual manera, se trata la razón $t$ como proceso para el análisis de muestras pequeñas, de distinto tamaño y para la misma muestra medida dos veces.

\section{Resumen:}

- Los investigadores en educación hacen predicciones de diferencias en los resultados entre las distintas condiciones.

- Siempre habrá variabilidad aleatoria (error de muestreo, variables irrelevantes) en los resultados que no se deben a las diferencias pronosticadas.

- En las tablas estadísticas se encuentran posibilidades de que los resultados se deban a la variabilidad aleatoria, como lo propone la hipótesis nula.

- Si la variabilidad aleatoria es baja se puede descartar la hipótesis nula.

- Los investigadores en educación aceptan los niveles de significación convencionales, que suelen $\operatorname{ser} \rho<0.05$ ó $\rho<0.01$.

- Si los datos son iguales o por debajo de estos niveles de significación, se rechaza la hipótesis nula y se acepta la hipótesis de investigación. 


\section{PARTE IV \\ ¿Qué tipo de estadístico utilizar?}





\section{Capítulo 4}

\section{Pruebas estadísticas}

Las pruebas estadísticas se fundamentan en la determinación del grado de variabilidad que presentan los datos obtenidos como consecuencia de un experimento (estrategia pedagógica, recurso audiovisual, juegos educativos). Los investigadores en educación utilizan este tipo de pruebas para confirmar si los resultados del experimento apoyan a la hipótesis de investigación o se deben al error de muestra, como lo establece la hipótesis nula.

El investigador en educación que realiza un diseño experimental básico pretende aplicar condiciones experimentales que representan la variable independiente a los participantes, para hacer una comparación entre los resultados obtenidos y alcanzar la variable independiente. En este contexto se requieren las pruebas estadísticas.

Las situaciones que se pueden presentar al investigador en relación a los participantes y que influyen en la selección de la prueba estadística son de dos tipos (Greene y D'oliveira, 2006):

a. Mismos participantes. Si se aplican todas las condiciones a los mismos participantes se limitan las diferencias entre ellos, puesto que, todos los datos sobre éstos serán homogéneos en todas las condiciones.

Debido a que las comparaciones se realizan con los mismos participantes, los resultados de cada uno de ellos estarán relacionados, por lo que se les denominan diseños relacionados.

La desventaja de trabajar con diseños relacionados en todas las condiciones es que todos los participantes trabajan todas las condiciones experimentales, creándose la posibilidad de que los resultados se vean afectados por las experiencias de los participantes con las condiciones aplicadas previamente.

Una posible solución de reducir estos efectos consiste en contrarrestar el orden de las condiciones, variándolas de modo que la mitad de los participantes vean primero un video interactivo y en seguida el tradicional y la otra mitad en el orden opuesto.

b. Participantes distintos. En este caso se usan grupos de participantes diferentes para cada condición experimental. A la inversa del caso anterior, cada participante es expuesto sólo a una condición, lo que implica que una condición no puede verse afectada por los efectos de la otra, lo que representa una ventaja.

Debido a que las comparaciones se realizan con distintos participantes, los resultados de cada participante no se encuentran relacionados, por lo que se les denominan diseños independientes o no relacionados.

El problema en esta situación consiste en determinar grupos homogéneos, siendo una posible solución intentar formar grupos de participantes con características similares mediante un examen diagnóstico para comprobar si entre los grupos existe una diferencia significativa. Otra propuesta es determinar las muestras de los grupos participantes de 
forma aleatoria para ser sometidos a las condiciones experimentales, de manera que los participantes con edades o capacidades distintas tengan la misma posibilidad de encontrarse en todos los grupos experimentales.

\section{1 ¿Qué prueba estadística utilizar?}

Las pruebas estadísticas están directamente relacionadas con el diseño de investigación, éstas deben comparar la hipótesis de investigación con la hipótesis nula, en donde se presenta variabilidad aleatoria en los resultados.

La selección de una prueba estadística adecuada depende del diseño de la investigación para comprobar la hipótesis. Algunos criterios de selección pueden ser:

- Experimentos. Muchas de las pruebas estadísticas son diseñadas para comprobar los resultados de los experimentos, éstos permiten verificar predicciones que el investigador propone para demostrar los efectos en una variable dependiente como consecuencia de la aplicación de una variable independiente.

Ejemplo 73. Un experimento consiste en verificar si los alumnos aprenden más con el empleo de películas o videos educativos, que sin ellos.

- Número de condiciones experimentales. Generalmente las pruebas estadísticas más simples están diseñadas para el análisis de experimentos con dos condiciones, pero en diseños experimentales con más de éstas requieren pruebas estadísticas de mayor complejidad para determinar las relaciones entre las variables.

\section{Ejemplo 74. Se desea verificar si los alumnos retienen mayor información en las siguientes} condiciones:

- Con clases tradicionales.

- Con el uso de videos educativos.

- Con el uso de videos educativos interactivos.

- Diseños relacionados e independientes. Al existir diferentes condiciones ahora se requiere saber si se ha trabajado con los mismos grupos (los mismos alumnos) en todas las condiciones, entonces se tiene un diseño relacionado, pero si se ha trabajado en cada una de las condiciones con grupos diferentes (alumnos diferentes) entonces se trata de un diseño no relacionado o independiente.

- Pruebas no paramétricas o paramétricas. En este caso el tipo de prueba estadística depende de cómo se miden los resultados o datos, las pruebas no paramétricas trabajan con resultados de datos ordinales, que se pueden ordenar de menor a mayor; mientras que las pruebas paramétricas trabajan con resultados o datos de intervalo, que se refiere a datos con intervalos iguales entre ellos, permitiendo realizar cálculos numéricos.

Ejemplo 75.

Prueba no paramétrica: seleccionar el nivel de atención del 1 al 5, en donde 1 representa muy distraído y 5 muy atento.

Prueba paramétrica: las calificaciones obtenidas en una prueba objetiva de conocimientos varían entre 1 a 10 con valores sólo enteros. 
De acuerdo a las características de selección de la prueba estadística que se mencionan en los párrafos anteriores y considerando que esta propuesta es para la realización de experimentos, se propone clasificar a las pruebas estadísticas en tres grupos:

a. Pruebas no paramétricas.

b. Pruebas paramétricas.

c. Pruebas de relación entre variables.

\subsubsection{Pruebas no paramétricas}

Las pruebas no paramétricas se fundamentan en los resultados que pueden clasificarse siguiendo un orden de menor a mayor o viceversa, en distintas condiciones, cuando los participantes son expuestos a condiciones experimentales. Este proceso permite verificar una hipótesis de investigación comparando si existe una diferencia significativa entre las dos condiciones. Lo anterior implica que en este tipo de prueba se utilicen los datos ordinales ya que su principal característica es que se pueden ordenar de menor a mayor.

Asignación de categorías no relacionadas. Cuando los resultados obtenidos no se repiten se considera que se pueden asignar categorías no relacionadas. Para ordenar los resultados se deben clasificar en función de su valor relativo, de menor a mayor, asignándole las categorías de 1, 2, 3, a cada resultado, en función a su magnitud, iniciando por el menor.

El procedimiento más usual es asignar la categoría más baja al resultado menor y la más alta al resultado mayor para visualizarse rápidamente.

En el Ejemplo 76 se observa que son 10 resultados, la categoría más alta es 10 y corresponde al resultado mayor (13). Por otro lado, el resultado menor corresponde al 3 por lo que se le asignó la Categoría 1, siguiendo esta secuencia, al resultado 4 se le asigna el 2 y así se continúa como se muestra en el ejemplo.

Ejemplo 76. Asignación de categorías no relacionadas.

\begin{tabular}{|c|c|}
\hline Resultados & Categorías \\
\hline 8 & 6 \\
\hline 12 & 9 \\
\hline 3 & 1 \\
\hline 9 & 7 \\
\hline 7 & 5 \\
\hline 6 & 4 \\
\hline 10 & 8 \\
\hline 4 & 2 \\
\hline 13 & 10 \\
\hline 5 & 3 \\
\hline
\end{tabular}

\subsubsection{Asignación de categorías relacionadas}

Es muy difícil que en los resultados no se repita algún número y más si es resultado de la aplicación de algún instrumento para recabar información; por ejemplo, si varios participantes obtuvieran un 7 como resultado ¿qué se puede hacer en este caso?

En el ejemplo 77 se muestra lo anterior y se plantea una propuesta de solución a este dilema. Se observa que se repite el número 3 dos veces y el 8 tres veces, se procede a ordenarlos conforme aparecen en la tabla quedando como se muestra en la columna dos (orden inicial).

Para designar la categoría correspondiente al resultado 3 se saca el promedio de sus números asignados en el orden inicial, esto es $(1+2) / 2=1.5$, siguiendo el mismo procedimiento 
para el 8 , entonces $(6+7+8) / 2=7$ resultando entonces las categorías correspondientes al 3 y 8 . De la misma manera que en el caso anterior la categoría más alta corresponde al 13 (10) y la mínima al 3 (1.5).

Ejemplo 77. Asignación de categorías relacionadas.

\begin{tabular}{|c|c|c|}
\hline Resultados & Orden inicial & Categorías \\
\hline 8 & 6 & 7 \\
\hline 12 & 9 & 9 \\
\hline 3 & 1 & 1.5 \\
\hline 8 & 7 & 7 \\
\hline 7 & 5 & 5 \\
\hline 6 & 4 & 4 \\
\hline 3 & 8 & 7 \\
\hline 13 & 2 & 1.5 \\
\hline 5 & 10 & 10 \\
\hline
\end{tabular}

En el Cuadro 6 se muestran los tipos de pruebas estadísticas no paramétricas y sus características, la selección del tipo de prueba depende de las necesidades del tipo de investigación que se realice, que permita dar respuesta a las hipótesis planteadas.

Cuadro 6. Pruebas estadísticas no paramétricas para una sola variable.

\begin{tabular}{|l|l|l|l|}
\hline \multicolumn{1}{|c|}{ Prueba } & \multicolumn{1}{|c|}{ Muestras } & \multicolumn{1}{|c|}{ Datos } & \multicolumn{1}{c|}{ Comentario } \\
\hline Wilcoxon & Relacionadas & Ordinales o nominales & $\begin{array}{l}\text { Se utilizan cuando las dos } \\
\text { condiciones se aplican a los } \\
\text { mismos participantes y los datos } \\
\text { son ordinales o nominales. }\end{array}$ \\
\hline Mann-Whitney & $\begin{array}{l}\text { No relacionadas o } \\
\text { independientes }\end{array}$ & Ordinales o nominales & $\begin{array}{l}\text { Se utilizan cuando las dos } \\
\text { condiciones se aplican a distintos } \\
\text { participantes y los datos son }\end{array}$ \\
\hline Friedman & Relacionadas & Ordinales o nominales o nominales.
\end{tabular}

\subsubsection{Pruebas Paramétricas}

Utilizar los datos de intervalos permite calcular la cantidad exacta de variabilidad entre los resultados obtenidos por los participantes, las diferencias calculadas con los resultados obtenidos de las dos condiciones se comparan con esta cantidad total de la variabilidad en los resultados. En este tipo de pruebas el término convencional para describir la variabilidad es la varianza, en donde ésta representa un cálculo aproximado de la variabilidad en los resultados.

En el Cuadro 7 se muestran los tipos de pruebas estadísticas paramétricas y sus características para decidir cuál seleccionar de acuerdo a las necesidades del tipo de investigación que se realice y que permita dar respuesta a las hipótesis planteadas (Greene y D'oliveira, 2006). 
En las pruebas paramétricas se propone trabajar con dos varianzas:

- La varianza esperada en donde se predice si existen diferencias significativas entre dos condiciones causada por el efecto de la variable independiente propuesta por el investigador.

- La varianza total como consecuencia de todas las variables que intervienen en la actuación de los participantes, es decir, la varianza esperada y la varianza no prevista originada por la diferencia entre los participantes y los efectos de variables irrelevantes.

Se comparan estas dos varianzas por la relación (ratio):

Varianza esperada debida a la variable independiente

Varianza total debida a todas las variables $x$

Las pruebas paramétricas pretenden verificar si la varianza esperada es suficientemente grande como para producir un ratio de varianza elevado y como consecuencia la existencia de una diferencia significativa entre las dos varianzas.

Cuadro 7. Pruebas estadísticas paramétricas.

\begin{tabular}{|c|c|c|c|}
\hline \multicolumn{4}{|c|}{ Pruebas estadísticas paramétricas para una sola variable } \\
\hline Prueba & Muestras & Datos & Comentario \\
\hline$t$ (relacionada) & Relacionadas & Intervalos & $\begin{array}{l}\text { Se utilizan cuando las dos condiciones se } \\
\text { aplican a los mismos participantes y los } \\
\text { datos son de intervalos. }\end{array}$ \\
\hline$t$ (independiente) & $\begin{array}{l}\text { No relacionadas o } \\
\text { independientes }\end{array}$ & Intervalos & $\begin{array}{l}\text { Se utilizan cuando las dos condiciones se } \\
\text { aplican a distintos participantes y los da- } \\
\text { tos son de intervalos. }\end{array}$ \\
\hline $\begin{array}{l}\text { ANOVA } \\
\text { Unifactorial } \\
\text { (relacionada) }\end{array}$ & Relacionadas & Intervalos & $\begin{array}{l}\text { Se utilizan cuando tres o más condiciones } \\
\text { se aplican a los mismos participantes y } \\
\text { los datos son de intervalos. }\end{array}$ \\
\hline $\begin{array}{l}\text { ANOVA } \\
\text { Unifactorial } \\
\text { (independiente) }\end{array}$ & $\begin{array}{l}\text { No relacionadas o } \\
\text { independientes }\end{array}$ & Intervalos & $\begin{array}{l}\text { Se utilizan cuando tres o más condiciones } \\
\text { se aplican a distintos participantes y los } \\
\text { datos son de intervalos. }\end{array}$ \\
\hline \multicolumn{4}{|c|}{ Pruebas estadísticas paramétricas para dos variables } \\
\hline $\begin{array}{l}\text { ANOVA bifactorial } \\
\text { (relacionada) }\end{array}$ & Relacionadas & Intervalos & $\begin{array}{l}\text { Se utilizan cuando dos o más condiciones } \\
\text { se aplican a los mismos participantes y } \\
\text { los datos son de intervalos. }\end{array}$ \\
\hline $\begin{array}{l}\text { ANOVA bifactorial } \\
\text { (independiente) }\end{array}$ & $\begin{array}{l}\text { No relacionadas o } \\
\text { independientes }\end{array}$ & Intervalos & $\begin{array}{l}\text { Se utilizan cuando dos o más condiciones } \\
\text { se aplican a distintos participantes y los } \\
\text { datos son de intervalos. }\end{array}$ \\
\hline
\end{tabular}

\subsubsection{Relaciones entre variables}

El investigador en educación puede comprobar una hipótesis que su pronóstico afirma que existen relaciones entre variables, sin embargo ¿hasta dónde puede el investigador controlar las variables de su experimento? Se pueden agrupar bajo el concepto de la relación entre variables tres tipos de pruebas en donde se buscan estas relaciones con características muy variadas (Ritchey, 2008). 
Medición de categorías. Se utiliza la prueba Chi cuadrado, en este caso, no se analizan los resultados sino que las dos variables se representan como categorías. En esta prueba el número de participantes en cada categoría es la medida que se busca, a esta medida se le denomina como datos nominales, esto es, a este tipo de medición solo se le asigna una etiqueta o nombre a las categorías. Los datos nominales son datos categóricos cuando se miden como el número de participantes en cada categoría.

Medición de variables en correlación. En este caso se utiliza la prueba de correlación de Pearson, en la cual las correlaciones de la hipótesis pronostican que existe una relación recíproca entre dos variables, mismas que se representan como un continuo de resultados. Éstos son generados por las medidas del comportamiento de los participantes con las dos variables. Los datos en este caso son de intervalo ya que se representan las variables por series continuas de resultados.

Regresión Lineal. Al igual que la correlación analiza la relación entre variables, los resultados de los participantes para las dos variables son continuos y son datos de intervalo; la diferencia consiste en el objetivo del investigador, en este caso los resultados de una variable se usan para predecir los resultados de la otra.

Cuadro 8. Pruebas estadísticas de relaciones entre variables.

\begin{tabular}{|l|l|l|l|}
\hline \multicolumn{1}{|c|}{ Prueba } & \multicolumn{1}{|c|}{ Tipo de relación } & \multicolumn{1}{c|}{ Datos } & \multicolumn{1}{c|}{ Comentario } \\
\hline Chi cuadrado & Categorías nominales & $\begin{array}{c}\text { Categóricos o } \\
\text { nominales }\end{array}$ & $\begin{array}{l}\text { Se aplican cuando las dos variables se } \\
\text { representan como categorías, no se } \\
\text { analizan los resultados. }\end{array}$ \\
\hline $\begin{array}{l}\text { Correlación de } \\
\text { Pearson }\end{array}$ & Correlacionar & Intervalos & $\begin{array}{l}\text { Se utilizan cuando la hipótesis de } \\
\text { investigación predice que existe una } \\
\text { relación recíproca entre dos variables. }\end{array}$ \\
\hline $\begin{array}{l}\text { Regresión } \\
\text { lineal (simple o } \\
\text { múltiple) }\end{array}$ & Variables explicativas & Intervalos & $\begin{array}{l}\text { Se aplican para calcular en qué } \\
\text { medida los resultados de la variable } \\
\text { explicativa X se vincula con los }\end{array}$ \\
\hline
\end{tabular}

\subsection{Muestras relacionadas}

En las muestras relacionadas los mismos participantes son sometidos a las dos condiciones, esto es, cada participante genera un par de resultados relacionados, uno por cada condición, lo que permite calcular las diferencias entre estos pares de resultados por participante (Coolican, 2005).

En el Ejemplo 78 se observa que en la columna izquierda se sitúan los participantes, indicando que cada uno de ellos tiene un par de resultados relacionados por cada condición. Para calcular las diferencias basta con restar a la Condición 1 la Condición 2, se puede apreciar que los resultados de estas diferencias presentan signos positivos o negativos como consecuencia de realizar esta operación.

Como se observa, no todas las diferencias tienen signo positivo. Es de esperar que los participantes después de ser sometidos a alguna estrategia pedagógica, obtuvieran mayores resultados en la Condición 2. Se acostumbra en estos casos restar los resultados de la Condición 2 a la Condición 1, por lo que cuando la Condición 1 es menor, los resultados llevan signo negativo. En el ejemplo se puede ver con claridad que los participantes 2,5 y 7 producen resultados positivos y en el resto son negativos. 
Ejemplo 78. Resultados de los mismos participantes en las dos condiciones, sus diferencias y su clasificación.

\begin{tabular}{|c|c|c|c|c|c|}
\hline Participantes & Condición 1 & Condición 2 & Diferencias & Ordenar & $\begin{array}{c}\text { Clasificación } \\
\text { de las } \\
\text { diferencias }\end{array}$ \\
\hline 1 & 7 & 8 & -1 & 1 & 3.5 \\
\hline 2 & 7 & 6 & +2 & 7 & 7.5 \\
\hline 3 & 5 & 8 & -3 & 9 & 9 \\
\hline 4 & 6 & 7 & -1 & 2 & 3.5 \\
\hline 5 & 10 & 8 & +2 & 8 & 7.5 \\
\hline 7 & 8 & 9 & -1 & 3 & 3.5 \\
\hline 8 & 7 & 6 & +1 & 4 & 3.5 \\
\hline 9 & 5 & 9 & -4 & 10 & 10 \\
\hline 10 & 9 & 10 & -1 & 5 & 3.5 \\
\hline Medias & 8 & 9 & -1 & 6 & 3.5 \\
\hline
\end{tabular}

Para poder clasificar las diferencias, se ordenan de menor a mayor sin tomar en cuenta los signos negativo o positivo. En el ejemplo se observa este orden, en donde el alumno 1 su diferencia es -1 y se le asigna el número 1 , el alumno 4 también tiene - 1 entonces se le asigna el orden 2, al alumno 6 el orden 3, al 7 el 4 y así hasta ordenar las diferencias de los participantes.

Una vez ordenadas las diferencias se procede a asignarles las categorías correspondientes, siguiendo los pasos indicados en el apartado titulado Asignación de categorías relacionadas en este mismo capítulo. Se observa en el ejemplo que aparecen 6 , unos con diferentes signos, los cuales se ordenan del 1 al 6 . El valor de su clasificación es la suma de sus números de orden entre el número total, esto es: $(1+2+3+4+5+6) / 6=3.5$, que es el valor con que se clasifican todos los unos, siguiendo el mismo proceso se calcula el valor de clasificación para el dos $(7+8) / 2=7.5$, para el 3 y 4 solo existen uno de cada uno por lo tanto se les coloca el número de orden directo, al 3 le corresponde el $9, y$ al 4 el 10.

\subsection{Muestras no relacionadas}

En las muestras no relacionadas (independientes) cada participante es sometido a una sola condición, por lo que cada una de éstas se aplican a participantes distintos. En este caso no se pueden comparar los resultados de las dos condiciones para cada participante, por lo que es necesario clasificar como un conjunto todos los resultados de las dos condiciones (Coolican, 2005).

\begin{tabular}{|c|c|c|}
\hline Ejemplo 79. Resultados de participantes distintos por condición. \\
$\qquad$\begin{tabular}{c|c} 
Condición 1 \\
Participantes 1
\end{tabular} \\
\hline 10 & Condición 2 \\
\hline 4 & 9 \\
\hline 6 & 8 \\
\hline 6 & 7 \\
\hline 7 & 5 \\
\hline 8 & 7 \\
\hline 5 & 10 \\
\hline Medias & 8 & 8 \\
\hline 7 & 10 \\
\hline
\end{tabular}


Se puede observar en el Ejemplo 79 que no existe la columna de participantes como en el Ejemplo 78, puesto que son diferentes los participantes se presentan los resultados para las dos condiciones especificando los dos grupos en cada condición.

\subsection{Introducción al programa SPSS}

SPSS (Statistical Package for the Social Sciences) ofrece dos diferentes formas de elaborar archivos de datos. La primera es creándolo directamente en el Editor de datos, introduciendo la información (Variables y Casos) dentro de las casillas de la Vista de datos; la segunda es importando la información desde una fuente externa (Programa de computadora), donde la información se encuentra previamente organizada y cuyo formato debe ser compatible con SPSS (Ritchey, 2008).

En el caso del uso del estadístico utilizando el programa SPSS lo más complicado es alimentar la planilla de datos para obtener la respuesta esperada, es por eso que se iniciará explicando cómo anexar los datos al programa (Ver el Ejemplo 80 del Capítulo 5).

Como primer paso se abre el programa SPSS: con el cursor dar clic en el botón de Inicio, desplegar Todos los programas, seleccionar IBM SPSS statistics, dar un clic con el botón izquierdo del ratón seleccionando la última opción IBM SPSS Statistics 20, dar doble clic con el botón izquierdo del ratón y aparece el cuadro de diálogo de la Figura 3.

En este caso se utilizó la versión SPSS 20.0, pero puede utilizarse otra versión. Para crear la base de datos se da un clic en la opción Introducir datos y luego clic en el botón Aceptar.

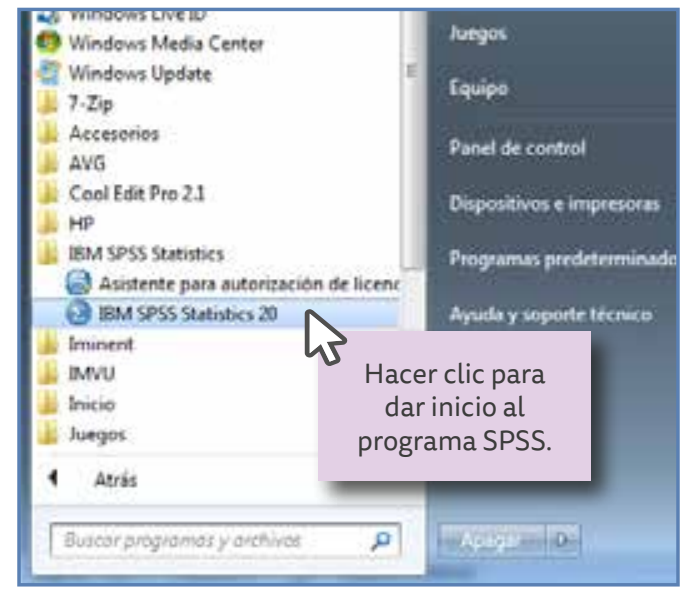

Figura 2. Secuencia para abrir el programa SPSS versión 20.0

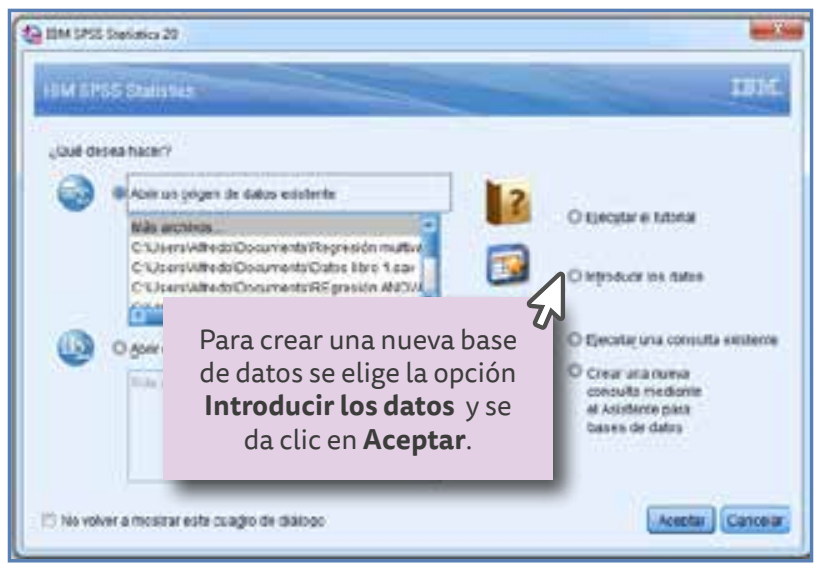

Figura 3. Secuencia para crear la base de datos. 
En seguida aparece la tabla (ver Figura 4) para crear la base de datos en la cual se observa que para ingresar los datos en el SPSS, las filas representan "sujetos o casos", y las columnas constituyen las "características o atributos" de cada sujeto en una determinada variable.

Antes de insertar los datos es necesario designar las variables de la investigación, para lograr esto es necesario hacer un clic con el cursor en la pestaña de Vista de variables que se encuentra en parte inferior de la tabla (ver Figura 4).

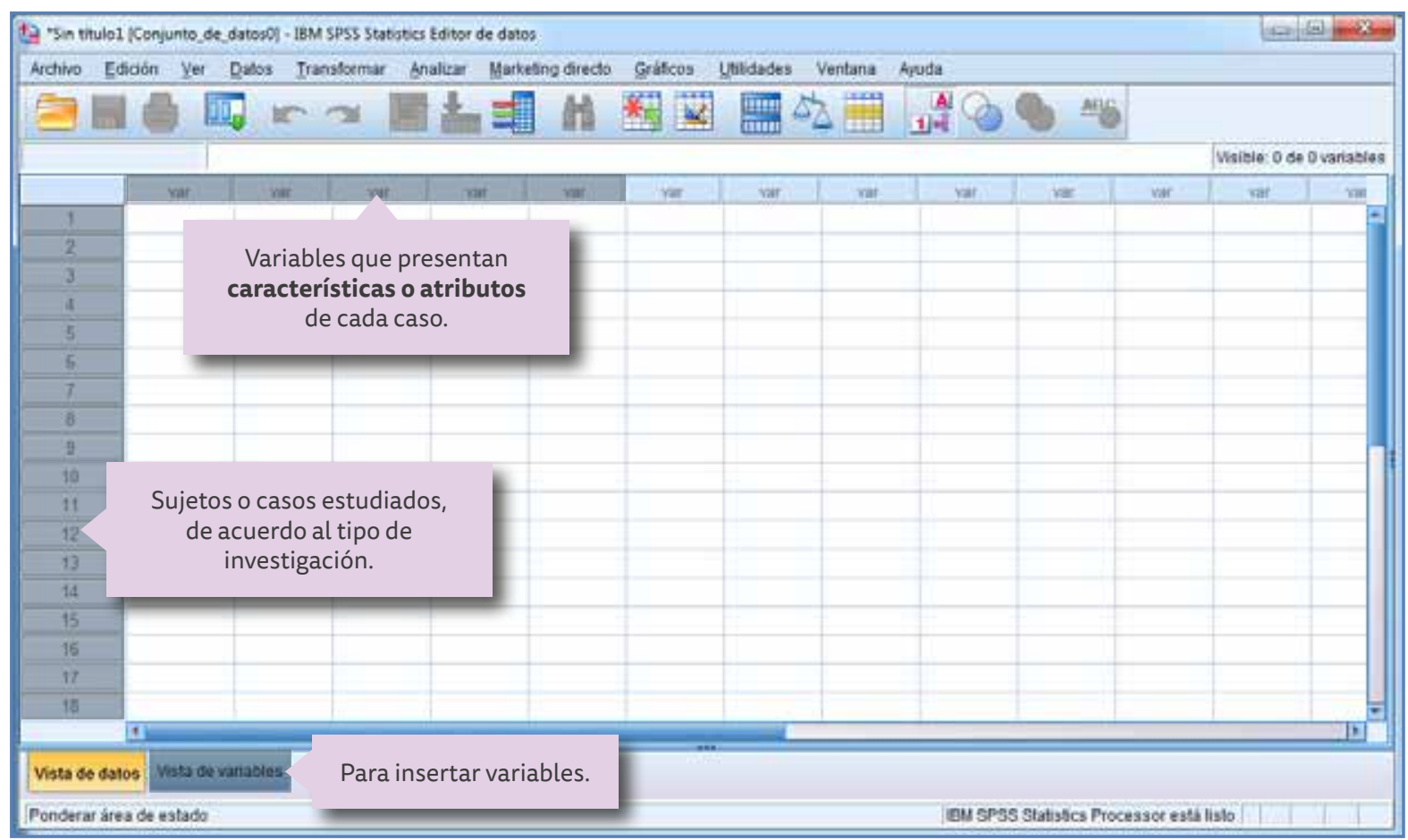

Figura 4. Relación entre líneas (características o atributos) y columnas (sujetos o casos).

En este caso se tienen dos variables, la primera corresponde al nombre de las variables que se agregarán en la tabla, es decir, se anotan los títulos que tendrán las columnas con los datos proporcionados por los participantes. En este ejemplo son dos opciones que se manejan, designadas como Condición 1 (antes de la intervención) y Condición 2 (después de la intervención) como se muestra en la Figura 5. Hacer clic con el ratón en el espacio de la primer casilla de la columna Nombre y teclee la palabra Condición1 y repita el proceso en la segunda casilla para la Condición2.

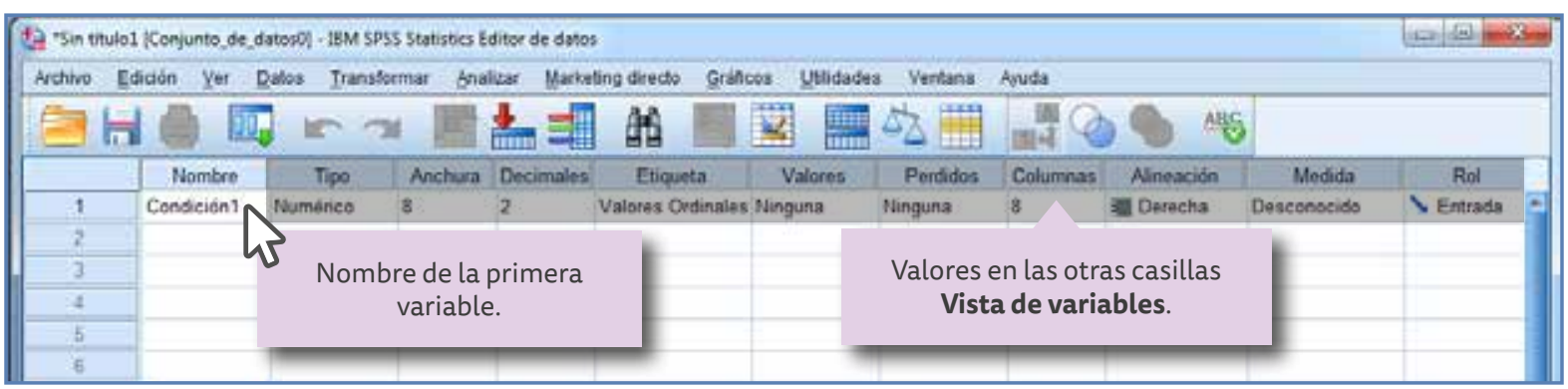

Figura 5. Introducción de la primera variable Nombrey los valores iniciales en las otras casillas.

A continuación es necesario trabajar con los valores en las otras casillas que se designan como Vista de variables de acuerdo a las características de las variables: Condición1 y Condición2 (El programa no acepta espacios en los nombres). 
En primer término aparece el Tipo de variable de que se trata, es necesario especificarlos. El programa SPSS asume que todas las variables son del "tipo numérico". En este ejemplo se asume que los datos se codificaron en números donde cada uno corresponde a un opción de respuesta diferente, se podría considerar que corresponde a una variable numérica que en este caso se designa como de "tipo numérico", al dar un clic con el ratón en el espacio numérico aparece el cuadro de diálogo como se muestra en la Figura 6, con diferentes opciones se selecciona la opción Numérico y en la ventana Anchura se selecciona el valor del número de dígitos (incluyendo el punto) que se requieren para los valores de las dos condiciones; en este ejemplo no se ocupan más de dos, pero antes es necesario seleccionar las cifras decimales, puesto que los dígitos no pueden ser menos que los decimales, para este ejemplo no se ocupan decimales por lo que se pone el valor de cero (o). También se pueden seleccionar estos datos de manera directa en las ventanas que muestra la tabla.

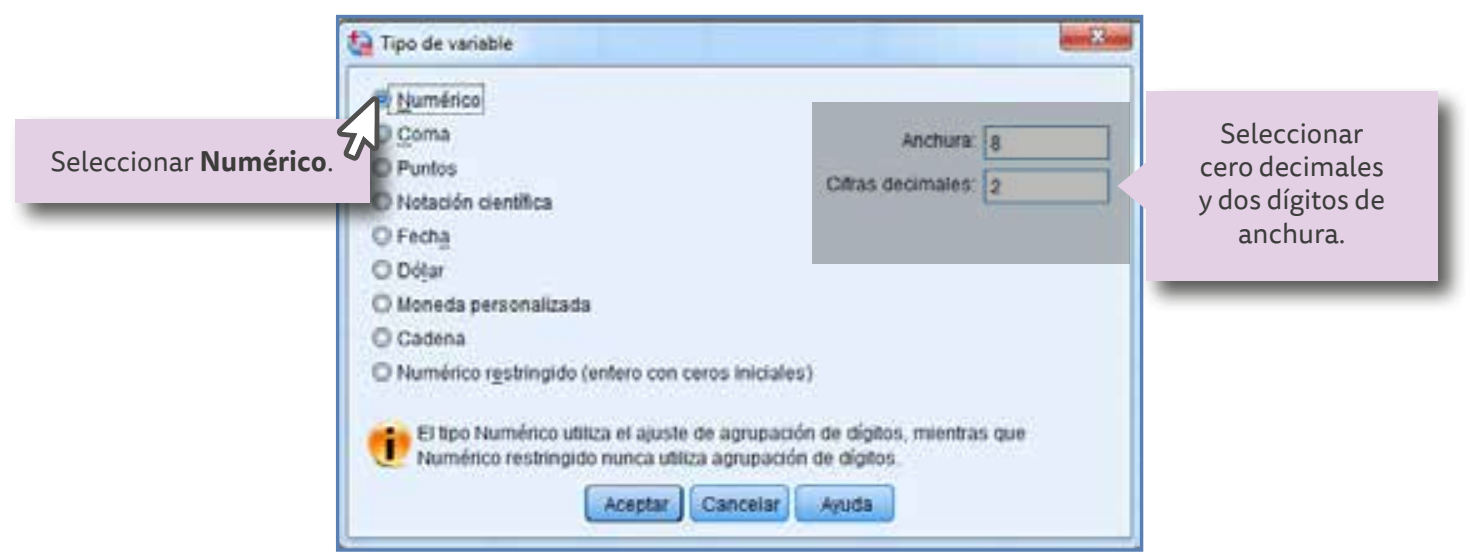

Figura 6. Cuadro de diálogo para seleccionar el tipo de variable, la anchura de los dígitos y los decimales.

La columna Etiqueta permite colocar el nombre como se desea que aparezca en las tablas del análisis, en este caso se le coloca el título como "Valores ordinales" ya que es lo que representa cada número en la tabla de datos. Para realizar esta operación basta con teclear "Valores ordinales" en la casilla correspondiente como se muestra en la Figura 7.

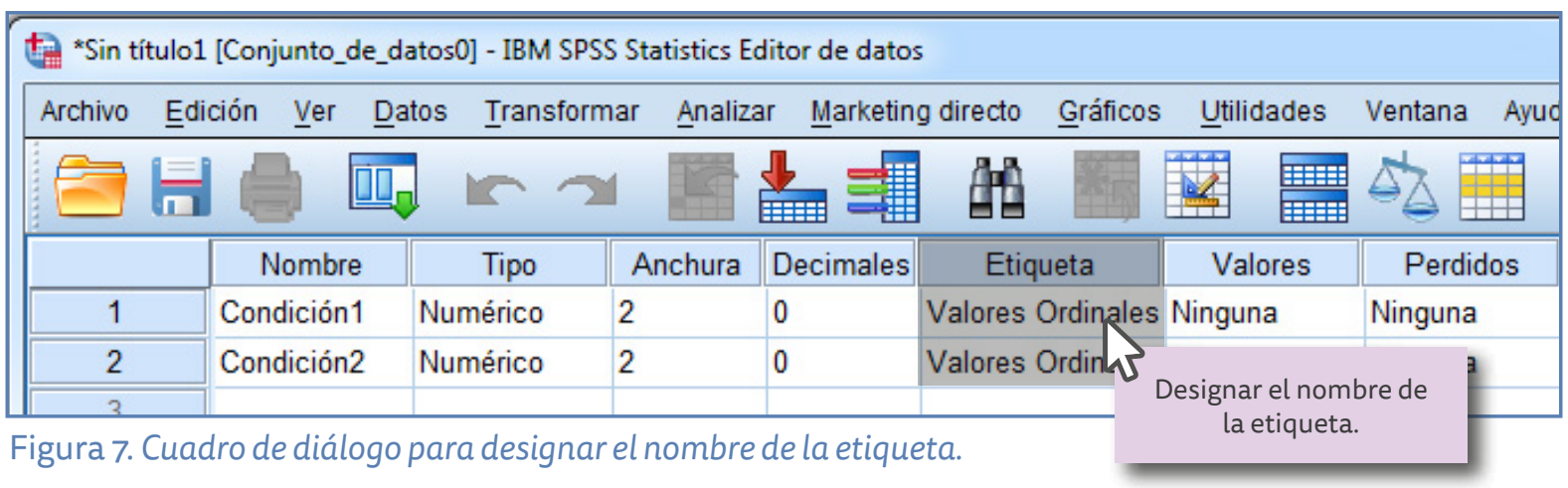

En la columna Valores se combinan números con palabras, los que permitirán identificar los atributos o características de los números asignados a cada condición. Para realizar este proceso se da un clic en la casilla donde aparece la palabra "Ninguna", en la opción Valores como se observa en la Figura 8, apareciendo el cuadro de diálogo designado como Etiquetas de valor. 
En el cuadro de diálogo se deben codificar los números con sus atributos, en este caso para la variable opción se designan de acuerdo a la tabla de datos de la siguiente manera:

$$
\begin{aligned}
& 1=\text { Primero } \\
& 2=\text { Segundo } \\
& 3=\text { Tercero } \\
& 4=\text { Cuarto } \\
& 5=\text { Quinto }
\end{aligned}
$$

Se anota el número en la ventana denominada Valory el atributo en la ventana Etiqueta de valor, para ingresar todos los datos se presiona el botón Añadir, una vez ingresados todos los valores se procede a guardarlos en la columna de valores presionando el botón Aceptar como se muestra en la Figura 8.

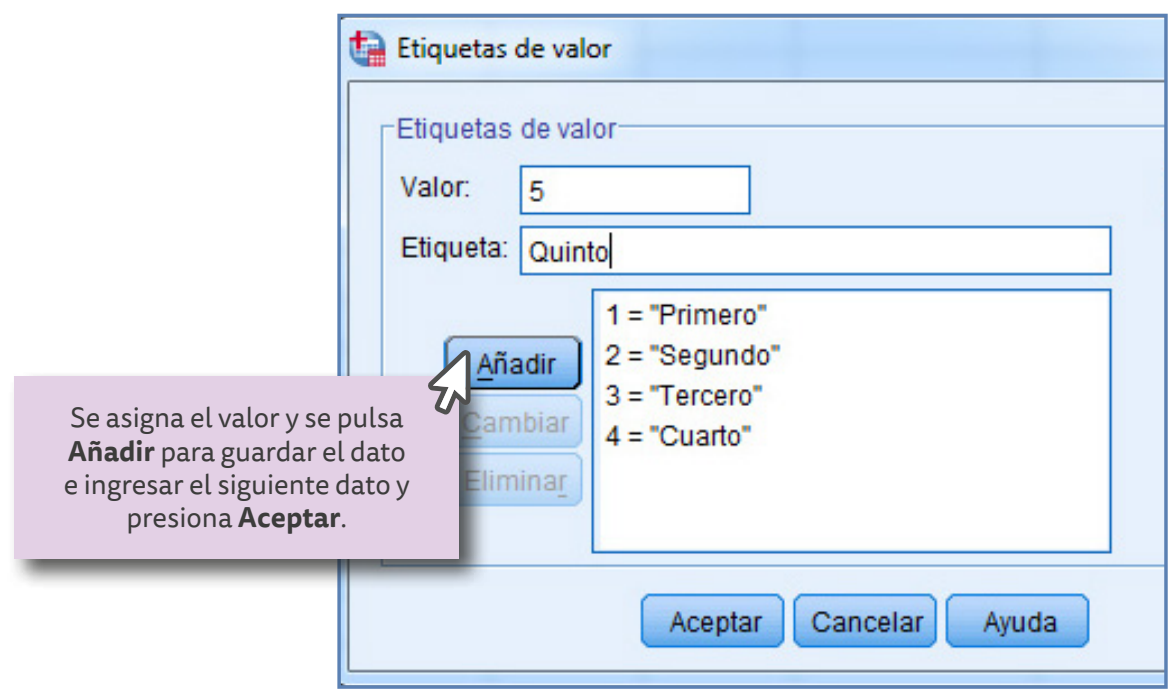

Figura 8. Cuadro de diálogo para designar la correspondencia de los números con sus atributos.

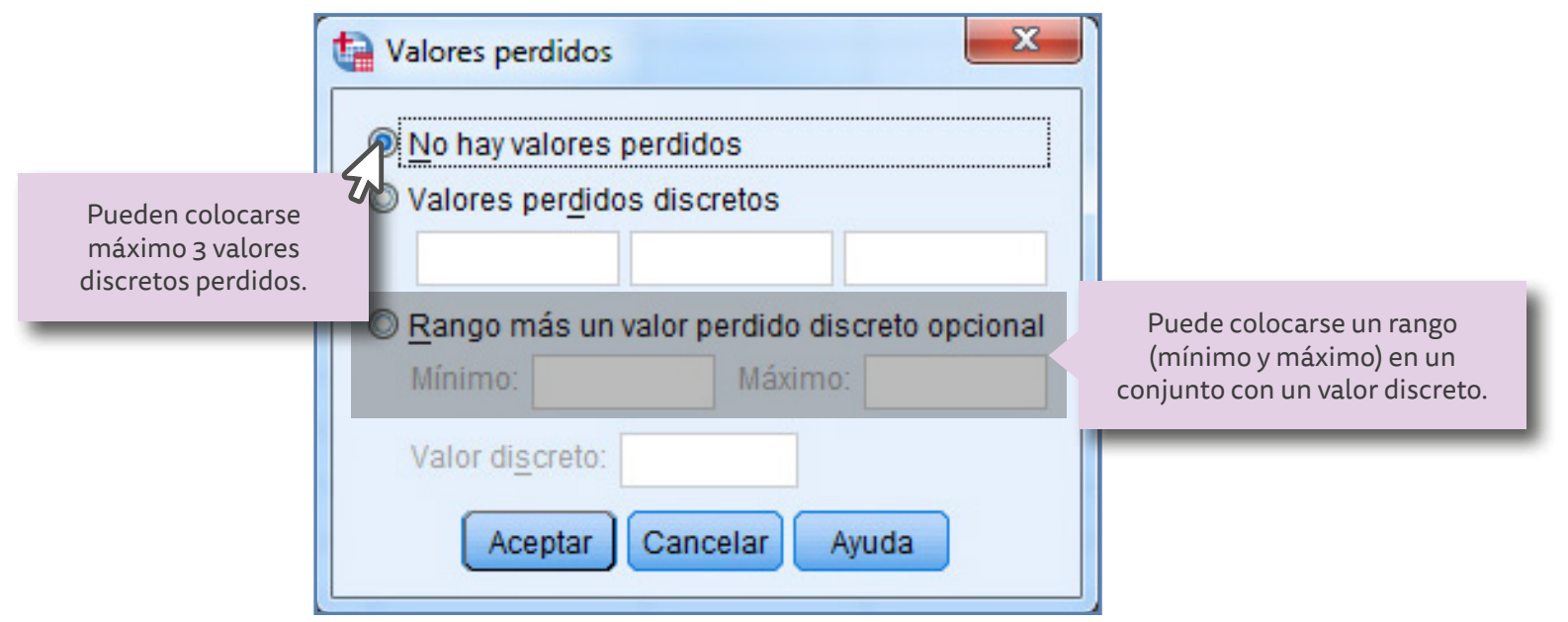

Figura 9. Cuadro de diálogo de Valores perdidos.

En la opción de Valores Perdidos se anotan los datos que no se obtuvieron, por ejemplo, que algún participante omitiera algún dato o no contestara algún reactivo. En este caso se asume que no se tienen valores perdidos. Como indicador de un valor perdido se sugiere utilizar el número 99, esto es, omisión de dato o ausencia de respuesta. 
En la opción Columnas seleccionamos el número de caracteres que se utilizan en cada una.

La opción Alineación permite ordenar los datos o conceptos dentro de las casillas, es decir: a la derecha, izquierda o centrado.

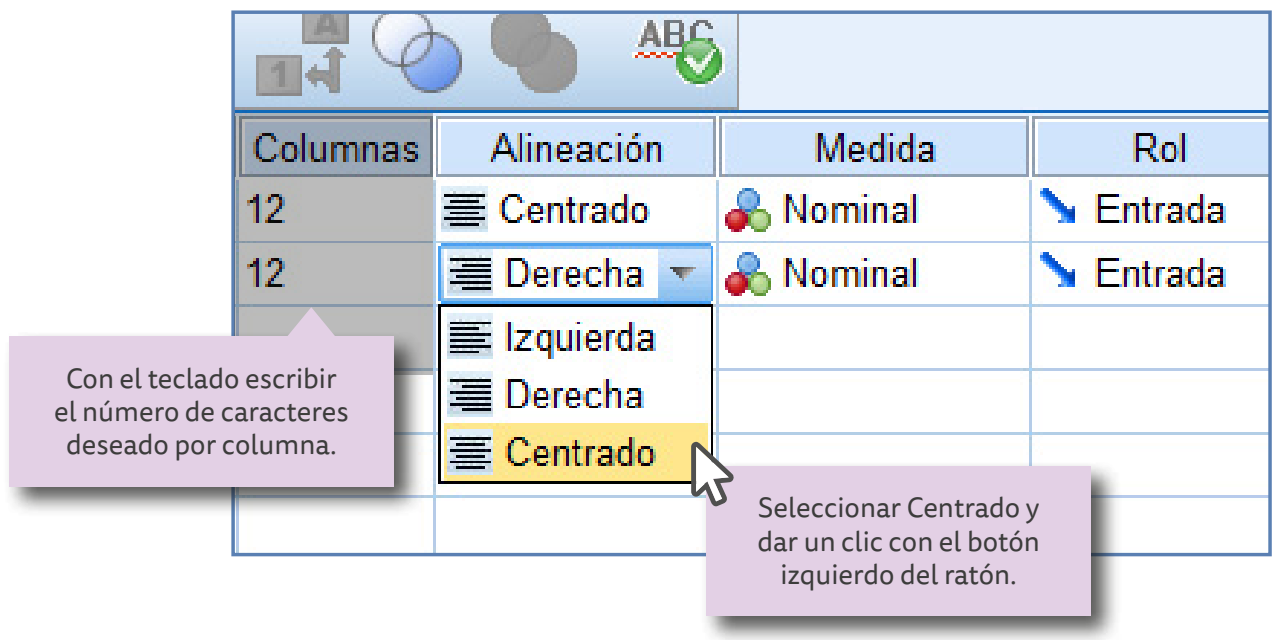

Figura 10. Cuadro de diálogo de columnasy Alineación.

La opción Medida cataloga a las variables de acuerdo a sus características:

- Nominal: cuando el orden no interesa.

- Ordinal: cuando los datos están ordenados de menor a mayor o viceversa.

- Escala: cuando los datos son por intervalo.

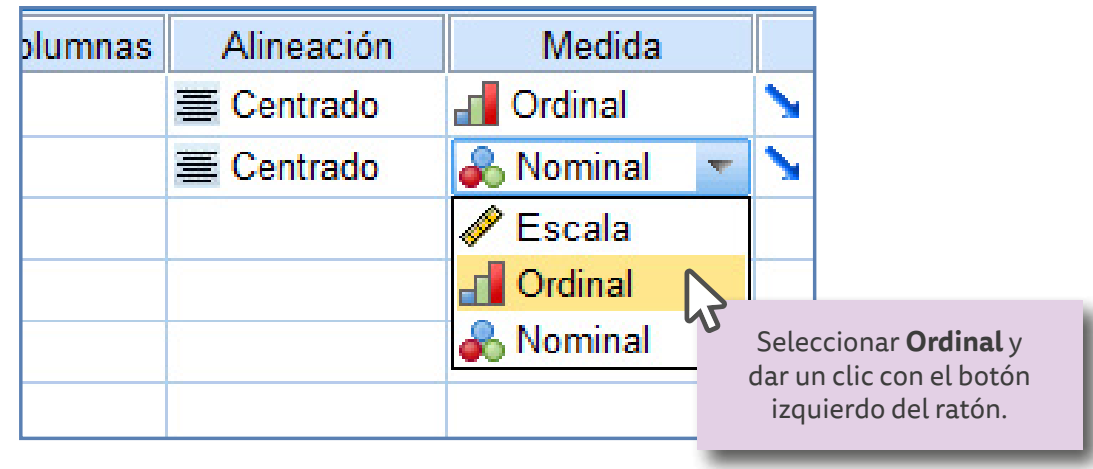

Figura 11. Cuadro de diálogo de Medida.

\begin{tabular}{|c|c|c|}
\hline Alineación & Medida & Rol \\
\hline 豆 Centrado & -1 Ordinal & $\searrow$ Entrada \\
\hline 至 Centrado & -1 Ordinal & $\searrow$ Entr... \\
\hline & \multirow{2}{*}{$\begin{array}{l}\text { Seleccionar Entraday } \\
\text { dar un clic con el botón } \\
\text { izquierdo del ratón. }\end{array}$} & $D$ Entrada \\
\hline & & (5) Objetivo \\
\hline
\end{tabular}

Figura 12. Cuadro de diálogo de Rol. 
En la opción Rol se determina la organización de los datos, si estos se utilizan como datos de entrada, objetivo si se utilizan sectores determinados (partición) o se dividen. Normalmente se utiliza para introducir los datos por lo que se preselecciona la opción Entrada.

El siguiente paso es introducir los datos de la segunda variable que se denominan con el término de Condiciónz, en este caso sólo se utilizan los valores correspondientes a los resultados obtenidos después de haber aplicado la estrategia, con las mismas características utilizadas en la Condición 1:

Nombre: Condición2.

Tipo de variable: numérica.

Anchura: 2.

Decimales: cero.

Etiquetas: valores ordinales.

Valores: 1 = primero, 2 = segundo, 3 = tercero, 4 = cuarto y $5=$ quinto.

Medida: ordinal.

\begin{tabular}{|c|c|c|c|c|c|c|c|c|c|c|c|}
\hline$Q-\sin b$ & Culol iConyarto,de & datos:l]- IBM & PSS Statiatio & dittor de dator & & & & & & & 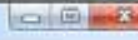 \\
\hline Nectovo & Eaoson vor & onos Irons & ormar Lnale & of Exoseon & ig arecto Grinces & Unargades & Wertana Agv & & & & \\
\hline E & 前量 & 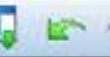 & 푤 & 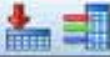 & 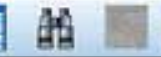 & 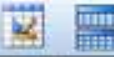 & $\Delta 2$ & ates & ay & & \\
\hline & Nambre & Tipo & Anchura & Decimales & Eliqueta & Valores & Perdidos & Columas & Alineación & Medida & Rol \\
\hline 1 & Condiciónt & Pumérico & 2 & 0 & Valoces ordinales & (1. Primero] & Ninguna & 12 & בencentrado & dOrdinal & $>$ Entrada \\
\hline 2 & Conđición2 & Numeớrico & 2 & 0 & Valores ordinales & (1. Primero) & Ninguna & 12 & E Centrado & All Ordinal & $>$ Entrada \\
\hline 3 & & & & & & & & & & & \\
\hline 4 & & & & & Los datos d & eben dec & bincidir & & & & \\
\hline 5 & & & & & con los mo & strados & tara la & & & & \\
\hline 5 & & & & & variable & Condici & n1. & & & & \\
\hline 7 & & & & & & & & & & & \\
\hline a & & & & & & & & & & & \\
\hline 9 & & & & & & & & & & & \\
\hline
\end{tabular}

Figura 13. Resultados de la segunda variable "Condición 2".

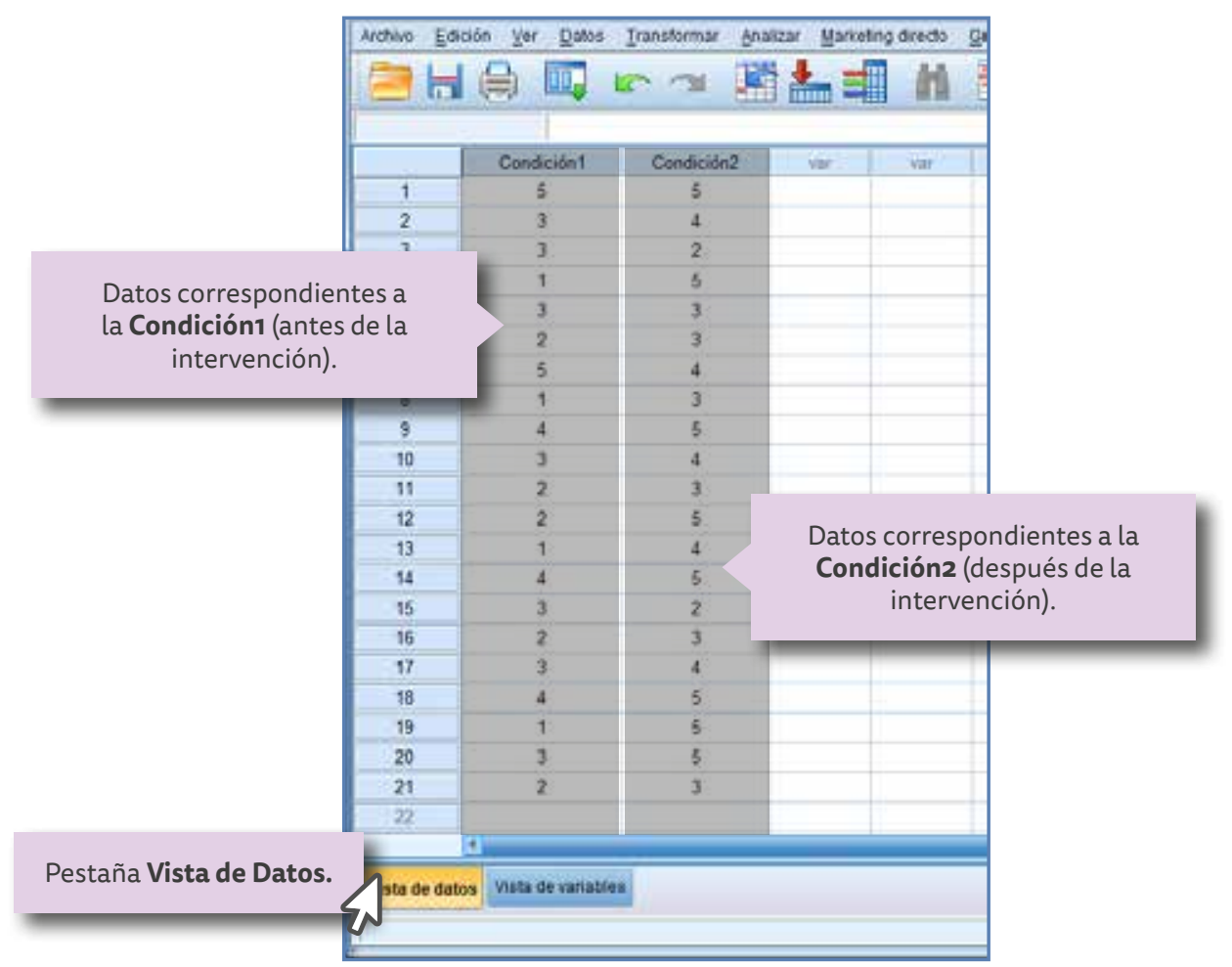

Figura 14. Valores ingresados de las variables "Condición 1 y Condición 2". 
Una vez que se han introducido las características de las dos variables se procede a ingresar los valores correspondientes. Para esto es necesario hacer clic en la pestaña Vista de datos que se encuentra en la parte inferior de la tabla. En la primera columna aparece el encabezado con el título de la variable Condición1, es aquí donde se deben introducir los datos ya sea de forma manual o copiarlos de la tabla correspondiente (antes de la intervención) ocupando las primeras 21 casillas.

Una vez introducidos los datos de la primera columna se procede a introducir los datos de la variable Condición2 en la segunda columna, ocupando las primeras 21 casillas (después de la intervención), quedando como se muestra en la Figura 14.

El SPSS permite ver los atributos de las variables en lugar de simples números como se muestran en la Figura 14. Para lograr esto es necesario ir a la opción de Etiquetas de valor y hacer clic, como se muestra en la Figura 15.

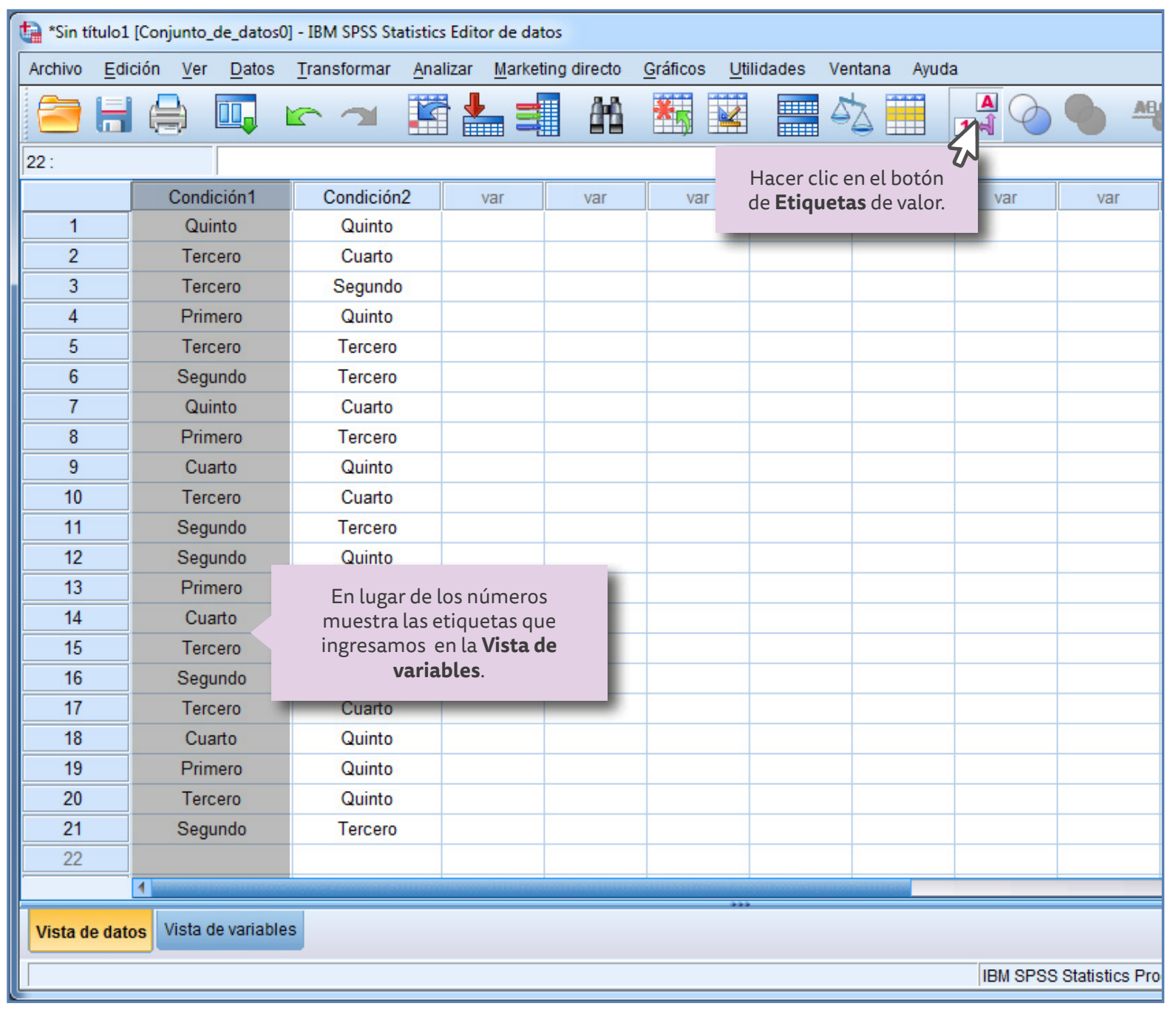

Figura 15. Opción de Etiquetas de valor que muestra la Vista de variables.

Hasta aquí se muestra el procedimiento de las generalidades del uso del programa SPSS, las particularidades se irán mostrando conforme se analicen las diferentes pruebas estadísticas, existiendo variaciones de acuerdo al tipo de cálculos que se requieren para su análisis, así como la forma de introducir los diferentes tipos de datos. 


\section{PARTE V \\ ¿Cuándo utilizar las pruebas no paramétricas?}





\section{Capítulo 5}

\section{Prueba Wilcoxon (muestras relacionadas)}

La prueba Wilcoxon se debe utilizar para diseños relacionados cuando las dos condiciones se aplican a los mismos participantes y los datos deben ser ordinales.

Ejemplo 80. Se trata de aceptar o rechazar la siguiente hipótesis de investigación:

$\mathrm{Hi}$ : Si los alumnos participan en la estrategia denominada "los juegos matemáticos" para agilizar la solución de problemas en Matemáticas, entonces éstos los resolverán en menor tiempo.

\subsection{Estado situacional}

El investigador pretende conocer si con la estrategia de "los juegos matemáticos" los alumnos mejoran el tiempo empleado para la solución de problemas. Por lo que implementó como instrumento de recolección de datos una escala para medir estos tiempos de la siguiente manera:

¿Con qué frecuencia entrega el alumno los problemas de Matemáticas a tiempo?

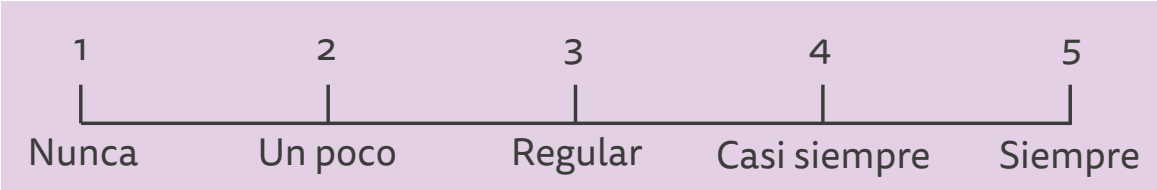

Este instrumento es aplicado a un grupo de 21 alumnos de segundo de secundaria, inicialmente como un diagnóstico para determinar el estado inicial antes de la intervención estratégica; todo el grupo participó activamente en ésta.

El tiempo máximo que se dio para resolver cinco problemas fue de 50 minutos, con un grado de dificultad medio; una vez concluida la intervención se volvió a aplicar el instrumento obteniendo los resultados que se muestran en la Tabla 10.

\subsection{Explicación}

La prueba Wilcoxon consiste en comparar el número de categorías con signo positivo y negativo bajo las dos condiciones. Se calculan las diferencias de los resultados por cada participante. Si las diferencias positivas y negativas son aproximadamente las mismas, entonces éstas pueden ser aleatorias entre las condiciones como lo establece la hipótesis nula. Para descartar a la hipótesis nula y aceptar la de investigación debe existir un predominio de categorías positivas o negativas en la dirección esperada. Si existen resultados obtenidos por alguno de los participantes que sean iguales en las dos condiciones no deben ser incluidos en el análisis puesto que una diferencia de o (cero) no tiene signo (Greene y D'oliveira, 2006). 
Tabla 10. Resultados de la agilidad para resolver problemas de matemáticas con y sin la estrategia "los juegos matemáticos".

\begin{tabular}{|c|c|c|c|c|c|c|c|}
\hline № & $\begin{array}{l}\text { Condición } \\
1 \text { sin } \\
\text { estrategia }\end{array}$ & $\begin{array}{l}\text { Condición } \\
2 \text { con } \\
\text { estrategia }\end{array}$ & $\begin{array}{l}\text { Diferencia } \\
\text { (d) }\end{array}$ & $\begin{array}{l}\text { Ordenación } \\
\text { de } \\
\text { diferencias }\end{array}$ & $\begin{array}{c}\text { Clasificación } \\
\text { de } \\
\text { diferencias }\end{array}$ & $\begin{array}{l}\text { Categorias } \\
\text { de signo } \\
\text { positivo }\end{array}$ & $\begin{array}{c}\text { Categorias } \\
\text { de signo } \\
\text { negativo }\end{array}$ \\
\hline 1 & 5 & 5 & 0 & 0 & No hay & -- & -- \\
\hline 2 & 3 & 4 & -1 & 1 & 7 & & -7 \\
\hline 3 & 3 & 2 & +1 & 2 & 7 & +7 & \\
\hline 4 & 1 & 5 & -4 & 18 & 18.5 & & -18.5 \\
\hline 5 & 3 & 3 & 0 & 0 & No hay & -- & -- \\
\hline 6 & 2 & 3 & -1 & 3 & 7 & & -7 \\
\hline 7 & 5 & 4 & +1 & 4 & 7 & +7 & \\
\hline 8 & 1 & 3 & -2 & 14 & 14.5 & & -14.5 \\
\hline 9 & 4 & 5 & -1 & 5 & 7 & & -7 \\
\hline 10 & 3 & 4 & -1 & 6 & 7 & & -7 \\
\hline 11 & 2 & 3 & -1 & 7 & 7 & & -7 \\
\hline 12 & 2 & 5 & -3 & 16 & 16.5 & & -16.6 \\
\hline 13 & 1 & 4 & -3 & 17 & 16.5 & & -16.5 \\
\hline 14 & 4 & 5 & -1 & 8 & 7 & & -7 \\
\hline 15 & 3 & 2 & +1 & 9 & 7 & +7 & \\
\hline 16 & 2 & 3 & -1 & 10 & 7 & & -7 \\
\hline 17 & 3 & 4 & -1 & 11 & 7 & & -7 \\
\hline 18 & 4 & 5 & -1 & 12 & 7 & & -7 \\
\hline 19 & 1 & 5 & -4 & 19 & 18.5 & & -18.5 \\
\hline 20 & 3 & 5 & -2 & 15 & 14.5 & & -14.5 \\
\hline 21 & 2 & 3 & -1 & 13 & 7 & & -7 \\
\hline Media & 2.714 & 3.904 & & & $\sum$ (Sumas) & +21 & -169 \\
\hline
\end{tabular}

De acuerdo a lo anterior, la prueba Wilcoxon para muestras relacionadas debe cumplir con los siguientes requisitos:

- Deben existir dos condiciones experimentales (antes y después) con una variable.

- Las dos condiciones se deben aplicar a los mismos participantes.

- Los datos numéricos deben ser ordinales.

- Son pruebas no paramétricas ya que son adecuadas para realizar análisis de datos numéricos ordinales.

\subsection{Procedimiento para determinar el valor de $W$}

1. Calcular la diferencia (d), restando la Condición 1 a la Condición 2, por cada uno de los participantes, anotando los signos correspondientes (positivo o negativo). Observar la columna Diferencia (d) en la Tabla 10.

2. Ordenar las diferencias designando el 1 al valor de la menor categoría ignorando los signos y omitiendo los valores que no tienen diferencia (o) y designar el valor máximo al número de mayor categoría, en este caso corresponde al -4 con el número de ordenamiento 19, note que son 21 datos pero dos no son tomados en cuenta por no existir diferencia (participantes 1 y 5).

3. Calcular y llenar la columna de las categorías de las diferencias, siguiendo el procedimiento recomendado en el Capítulo 4. Ejemplo: en número 1 de las diferencias aparece 13 veces y conforme va apareciendo se le designa un orden que va del 1 al 13, por lo tanto para determinar el valor de la categoría que le corresponde se suman el número de orden y se divide entre su total quedando como sigue: 


$$
(1+2+3+4+5+6+7+8+9+10+11+12+13) / 13=7
$$

Por lo tanto a todos los 1 les corresponde la Categoría 7, siguiendo este proceso se deben calcular los valores correspondientes a los otros valores de las diferencias.

4. Aplicar el signo de la columna Diferencias (d) a las categorías de la columna de Clasificación de diferencias y elaborar dos columnas más, una con las categorías de signo positivo y otra con las de signo negativo.

5. Calcular la suma de las columnas de categorías con signo positivo y la de signo negativo, se puede observar en la Tabla 10 que los valores encontrados son:

Total de categorías positivas $=+21$

Total de categorías negativas $=-169$

El total de categorías menor corresponde al valor de $W=21$.

6. Calcular el número de participantes sin contar a los que tuvieron resultados iguales (diferencia = 0), $N=21-2=19$.

7. Buscar la significación. En la Tabla B en el Apéndice D, contiene las posibilidades para comprobar hipótesis unilaterales y bilaterales, en este caso el total de la diferencia de las categorías menores $W=21$ debe ser igual o menor que los valores que se encuentran en la Tabla B y para un valor de $N=19$ se encontró que:

$$
W_{\text {calculado }}=21<W_{\text {tabla }}=32 \text { para un nivel de significación } \rho<0.005
$$

Observando en la parte superior de la Tabla $B$, se puede ver que para una prueba unilateral el nivel de significación es $\rho<0.005$, este valor está por debajo de la probabilidad que proponen los investigadores en educación como máximo valor aceptable, esto es $\rho<0.05$, entonces se puede rechazar la hipótesis nula y aceptar la de investigación. Definitivamente sí existe una diferencia significativa entre los alumnos referente a la agilidad (velocidad) para resolver los problemas de matemáticas antes y después de aplicar la estrategia denominada "los juegos matemáticos".

\subsection{Prueba Wilcoxon utilizando el programa SPSS}

El programa SPSS para esta prueba permite determinar el nivel de significación comparándolo con el nivel mínimo utilizado por los investigadores en educación que corresponde a $\rho<0.05$ si el que se determina mediante el proceso del programa resulta mayor que este valor, entonces se puede decir que las diferencias de los resultados son causados por variables aleatorias y se debe aceptar la hipótesis nula, pero si el valor es menor entonces las diferencias son significativas y se debe rechazar la hipótesis nula y aceptar la hipótesis de investigación.

El primer paso consiste en otorgar las propiedades a las variables; una vez abierto el programa como se indica en el Capítulo 4, antes de introducir los datos, es necesario definir las variables y otorgarle las características para su presentación en la tabla, para esto se requiere hacer un clic en la pestaña Vista de variables. En este caso las acciones indispensables para obtener los resultados correctos son:

a. Designar los nombres de las variables. Para realizar esto es necesario presionar la ceja de Vista de variables, y en seguida teclear el nombre de cada variable, primero en la columna Nombre (primera) y la fila 1, la palabra Condición1, la cual debe ir sin espacio entre la palabra y el número debido a que el programa no reconoce caracteres vacíos; segundo en la columna Nombre pero ahora en la fila 2, escribir Condiciónz. 
b. Definir el tipo de medida que se realizó. Debido a que los datos son ordinales se requiere que en la columna Medida selecciones la opción Ordinal.

El programa preselecciona el tipo de variables como numérico; para darle presentación a los datos se pueden realizar las siguientes operaciones (pero no es necesario): definir la Anchura (2) y cantidad de decimales (0) requeridos y la Alineación (centrado).

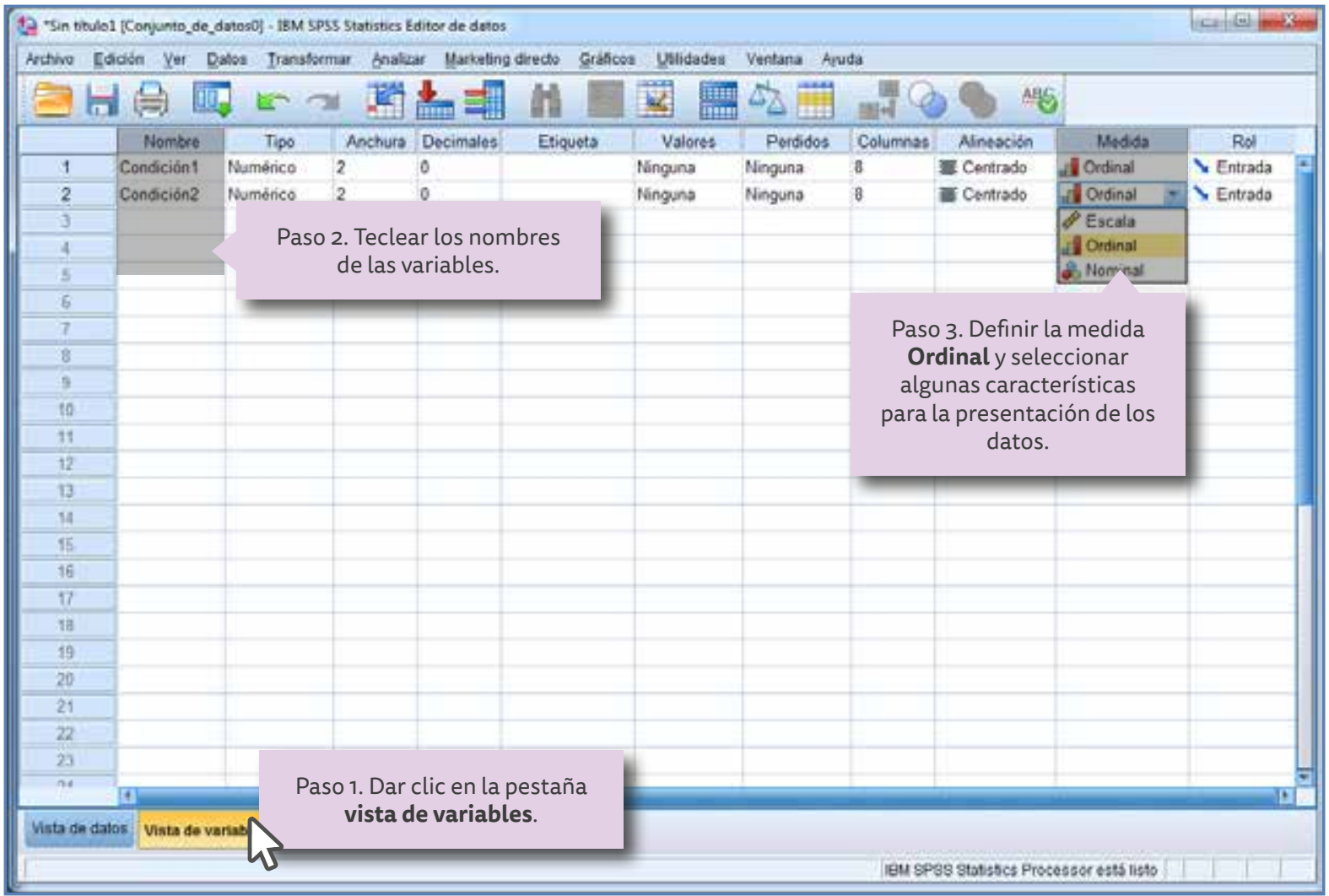

Figura 16. Designación de variables y sus características.

En la Figura 16 se observan estos pasos, así como la ubicación de cada variable y las propuestas de opciones para la definición y presentación de las variables.

\section{Cuadro 9. Variables seleccionadas.}

Designación de variables para la prueba Wilcoxon (relacionada).

Nombre: Condición1

Tipo: Numérico

Anchura: 2

Decimales: 0

Etiqueta: Nada

Valores: Ninguno

Perdidos: Ninguno

Columnas: 8

Alineación: Centrado

Medida: Ordinal

Rol: Entrada
Nombre: Condición2

Tipo: Numérico

Anchura: 2

Decimales: 0

Etiqueta: Nada

Valores: Ninguno

Perdidos: Ninguno

Columnas: 8

Alineación: Centrado

Medida: Ordinal

Rol: Entrada 
Una vez designados los nombres de las variables y sus características (Ver Cuadro 9) se procede a introducir los datos en la tabla, para llevar a cabo esto debe hacerse un clic en la pestaña Vista de datos e introducir los datos correspondientes a cada variable, como ya se mencionó en el Capítulo 4; los datos se pueden introducir uno por uno tecleándolos o bien importarlos (seleccionándolos, copiar y pegar) de la tabla en donde se encuentran ubicados y pegarlos dentro de esta tabla.

En la Figura 17 se observa cómo quedan los datos siguiendo cualquiera de los procedimientos y de acuerdo a las características seleccionadas anteriormente.

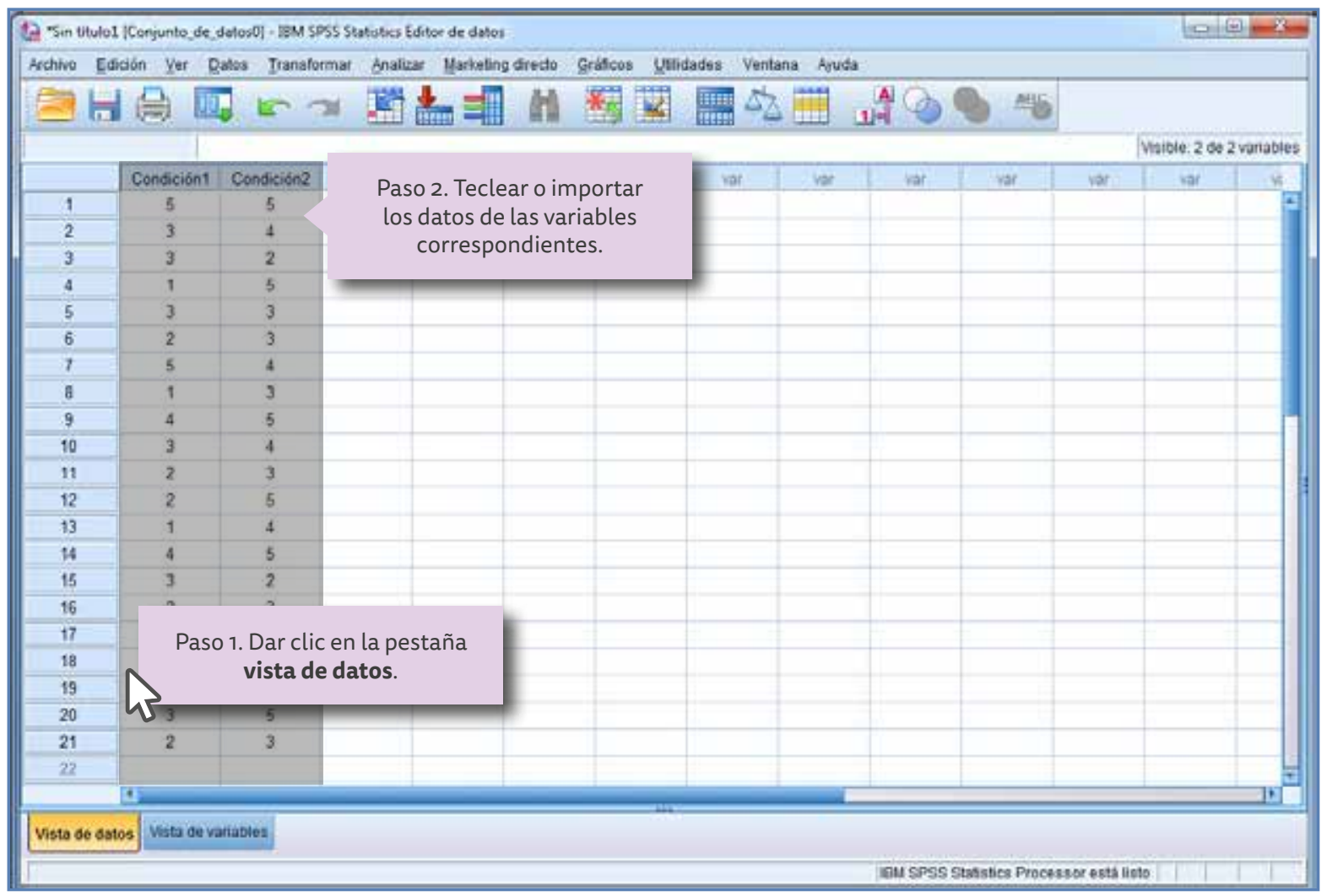

Figura 17. Presentación de los datos arrojados por los participantes en la estrategia "los juegos matemáticos".

Una vez que los datos se encuentran en la tabla, se procede a realizar la prueba; para hacerlo es necesario dar un clic en la pestaña ubicada en la barra superior designada como Analizar, en seguida aparece un cuadro de diálogo, en el cual se debe seleccionar la línea que indica Pruebas no paramétricas, por pertenecer precisamente la prueba Wilcoxon a este tipo. Al ubicar el apuntador del ratón en esta opción, se presenta a la derecha otro cuadro de diálogo con cuatro opciones, seleccionando la opción Cuadros de diálogo antiguos y se selecciona la opción $\mathbf{2}$ muestras relacionadas (que corresponden al presente problema) y se hace clic con el ratón (Ver Figura 18).

Al hacer clic con el ratón aparece la ventana de la Figura 19 en la cual se muestran las variables del lado izquierdo, Condición1 y Condición2, éstas deben ser trasladadas a la ventana que dice Contrastar pares; la forma de hacerlo es seleccionar con un clic la variable deseada (Condición1) y hacer clic en la flecha que se ubica entre las dos ventanas, repitiendo esta operación para la Variable 2 (Condición2). Se observa que el programa preselecciona el tipo de prueba Wilcoxon.

Note que la opción Aceptar no está habilitada hasta que se ha formado el par 1; el programa no permite ir al siguiente paso mientras estén incompletos los datos. 


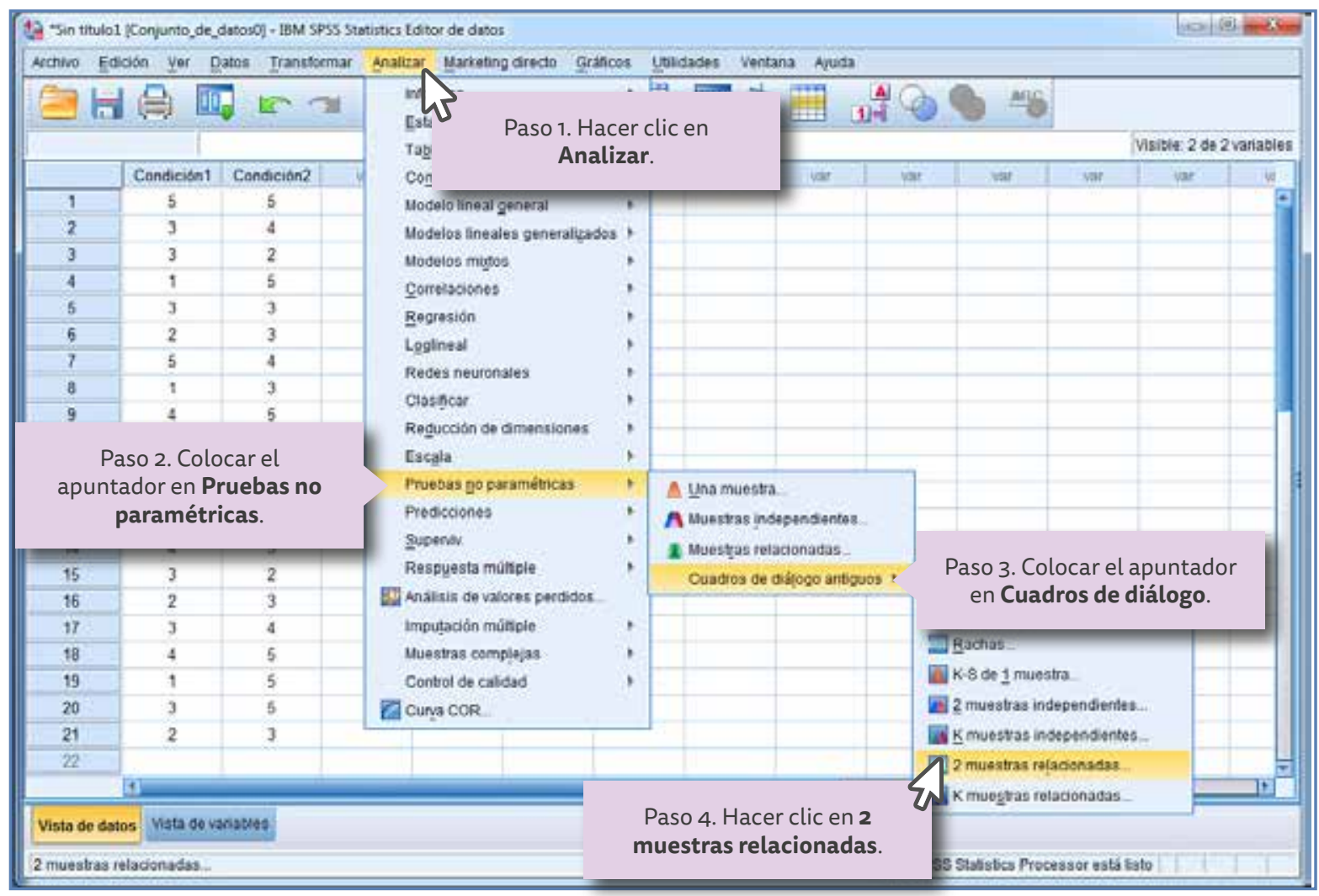

Figura 18. Cuadros de diálogo para seleccionar la prueba no paramétrica de dos muestras relacionadas.

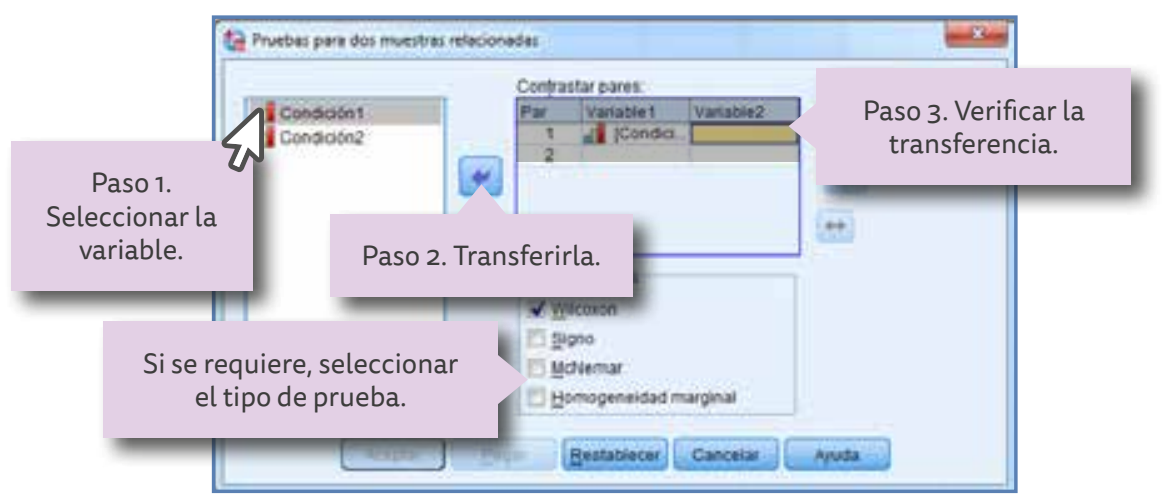

Figura 19. Pasos para ingresar las variables al programa SPSS.

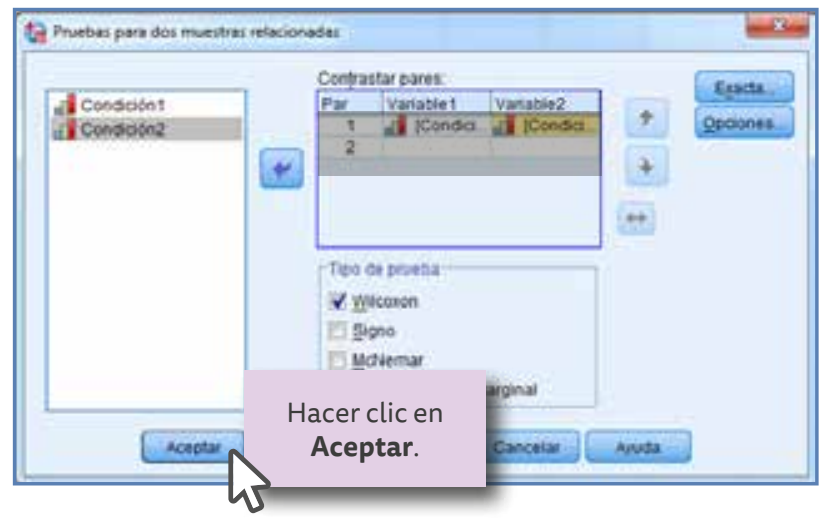

Figura 20. Pasos para ejecutar el programa SPSS para que realice los cálculos requeridos. 
Cuadro 10. Resultados obtenidos con el programa SPSS para la prueba no paramétrica Wilcoxon para dos muestras relacionadas.

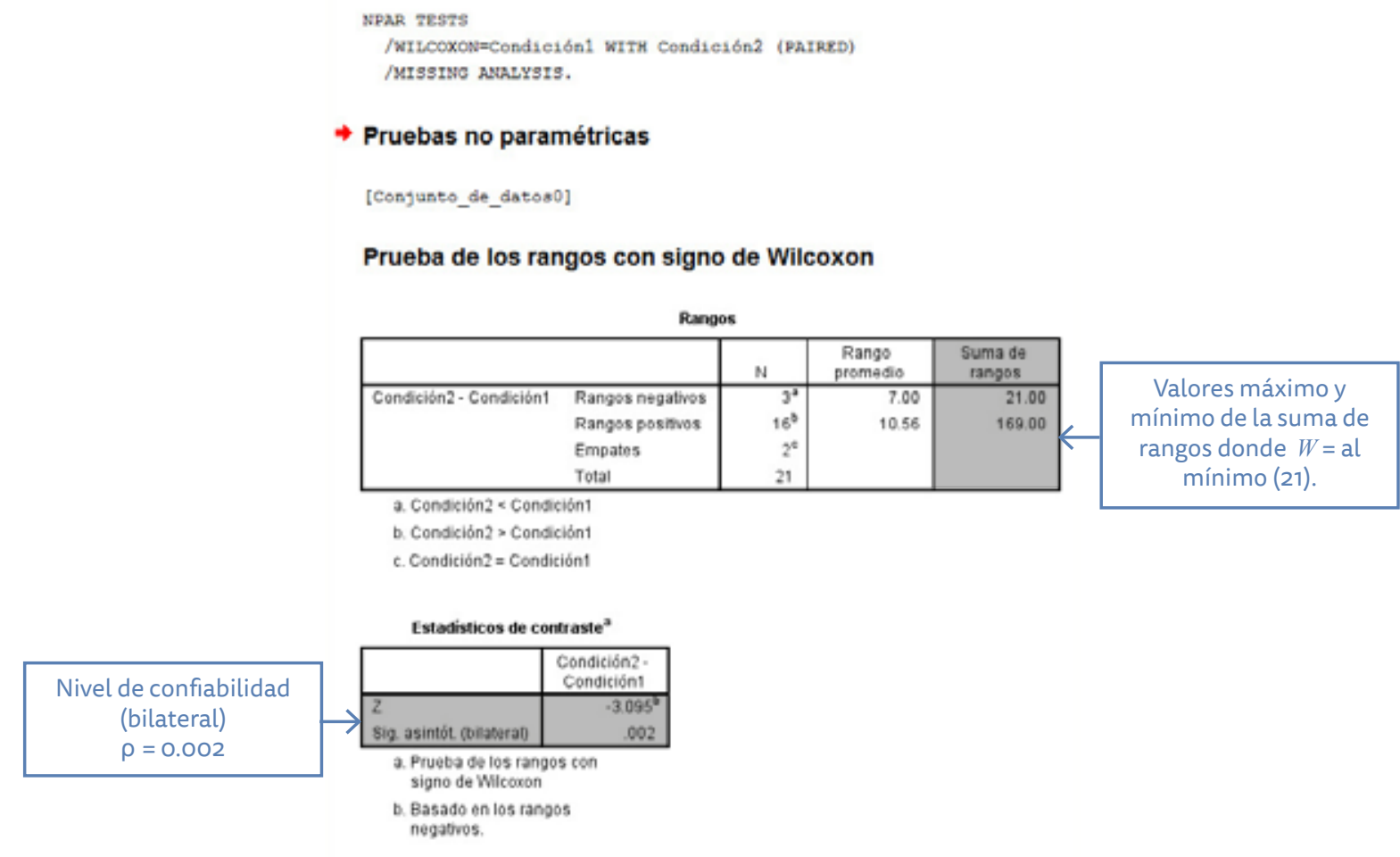

El siguiente paso es hacer clic en el botón Aceptar; después de esta acción aparecen los resultados que se muestran en el Cuadro 10.

En el Cuadro 10 se observan los valores de la suma de rangos que coincide con los del cálculo realizado en el apartado anterior (21 para el mínimo y 169 para el máximo), y se obtiene también el valor del nivel de significación [Significación asintótica (bilateral)] $\rho<0.002$.

$$
\text { Entonces se puede concluir que } \rho_{\text {encontrada }} 0.002<\rho_{\text {aceptada }} 0.05
$$

Es decir, el valor encontrado 0.002 es menor que el mínimo aceptable por los investigadores en educación (0.05), lo que significa que los resultados de la diferencia no son aleatorios

Hi: Si los alumnos participan en la estrategia denominada "los juegos matemáticos" para agilizar la solución de problemas en Matemáticas, entonces éstos los resolverán en menor tiempo.

puesto que existe una diferencia significativa, por lo que se puede rechazar la hipótesis nula y aceptar la hipótesis de investigación. 



\section{Capítulo 6}

\section{Prueba Mann-Whitney (para muestras independientes)}

La prueba Mann-Whitney se utiliza en diseños no relacionados o independientes, es decir, cuando la Condición 1 se aplica a un grupo de participantes diferente al de la Condición 2, los datos en este caso deben ser ordinales.

Ejemplo 81. Se trata de aceptar o rechazar la siguiente hipótesis de investigación: $\mathrm{Hi}$ : Si a un grupo de participantes se les da a leer un libro digital que contiene enlaces que le permiten ampliar los conceptos de su contenido, éstos comprenderán un mayor número de conceptos que un grupo de participantes que leyeron el mismo libro impreso en papel.

\subsection{Estado situacional}

El investigador pretende conocer si los participantes que utilizaron el libro digital reconocen e interpretan un mayor número de conceptos que los participantes que utilizaron el libro impreso en papel. Por lo que implementa como instrumento de recolección de datos una escala para medir el número de conceptos identificados de la siguiente manera:

¿Cuántos de los 10 conceptos que se le presentaron identificaron los participantes después de haber leído el libro?

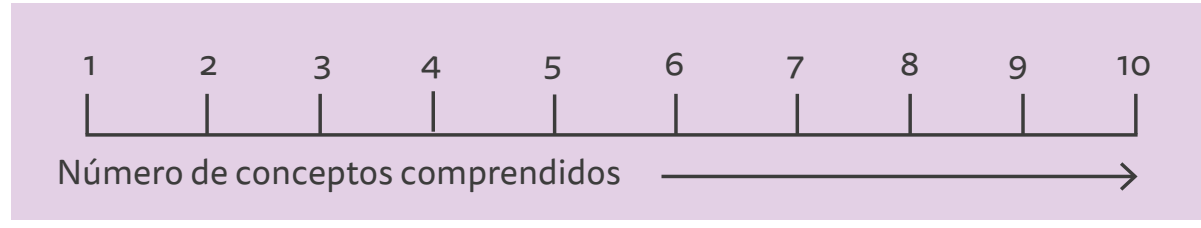

Este instrumento es aplicado a un grupo de 38 alumnos de sexto de primaria, 20 alumnos que leyeron el libro impreso en papel (Condición 1) y 18 alumnos que utilizaron el libro digital (Condición 2).

El tiempo máximo que se dio para identificar y definir los conceptos fue de 30 minutos, solicitándoles que los describieran con sus propias palabras, pues el objetivo es la comprensión (no la memorización), los resultados obtenidos después de aplicar el instrumento se muestran en la Tabla 11. 
Tabla 11. Resultados obtenidos después de realizar las lecturas impresas y digitales.

\begin{tabular}{|c|c|c|c|c|c|c|}
\hline $\begin{array}{l}\text { Número de } \\
\text { participante }\end{array}$ & $\begin{array}{l}\text { Condición } \\
1 \text { (Libro de } \\
\text { papel) }\end{array}$ & $\begin{array}{l}\text { Ordenación } \\
\text { (conjunta) }\end{array}$ & $\begin{array}{l}\text { Designación } \\
\text { de } \\
\text { categorías }\end{array}$ & $\begin{array}{l}\text { Condición } \\
2 \text { (Libro } \\
\text { digital) }\end{array}$ & $\begin{array}{l}\text { Ordenación } \\
\text { (conjunta) }\end{array}$ & $\begin{array}{l}\text { Designación } \\
\text { de } \\
\text { categorías }\end{array}$ \\
\hline 1 & 5 & 9 & 10.5 & 8 & 27 & 27 \\
\hline 2 & 2 & 1 & 1 & 9 & 31 & 32.5 \\
\hline 3 & 10 & 35 & 36.5 & 7 & 21 & 21.5 \\
\hline 4 & 3 & 2 & 4 & 10 & 36 & 36.5 \\
\hline 5 & 8 & 24 & 27 & 5 & 12 & 10.5 \\
\hline 6 & 4 & 7 & 7.5 & 6 & 18 & 16 \\
\hline 7 & 5 & 10 & 10.5 & 3 & 6 & 4 \\
\hline 8 & 4 & 8 & 7.5 & 9 & 32 & 32.5 \\
\hline 9 & 6 & 13 & 16 & 7 & 22 & 21.5 \\
\hline 10 & 3 & 3 & 4 & 9 & 33 & 32.5 \\
\hline 11 & 5 & 11 & 10.5 & 9 & 34 & 32.5 \\
\hline 12 & 6 & 14 & 16 & 8 & 28 & 27 \\
\hline 13 & 3 & 4 & 4 & 10 & 37 & 36.5 \\
\hline 14 & 7 & 20 & 21.5 & 6 & 19 & 16 \\
\hline 15 & 8 & 25 & 27 & 8 & 29 & 27 \\
\hline 16 & 6 & 15 & 16 & 7 & 23 & 21.5 \\
\hline 17 & 6 & 16 & 16 & 10 & 38 & 36.5 \\
\hline 18 & 8 & 26 & 27 & 8 & 30 & 27 \\
\hline 19 & 3 & 5 & 4 & & & \\
\hline \multirow[t]{2}{*}{20} & 6 & 17 & 16 & & & \\
\hline & $\bar{x}_{1}=5.4$ & & $T_{1}=282.5$ & $\bar{x}_{2}=7.72$ & & $T_{2}=458.5$ \\
\hline
\end{tabular}

\subsection{Explicación}

La prueba Mann-Whitney consiste en comparar los totales de las categorías correspondientes a las dos condiciones a partir de la clasificación conjunta. Si hay aproximadamente las mismas categorías para las dos condiciones, entonces las diferencias entre las correlaciones clasificadas son aleatorias y se debe aceptar la hipótesis nula. Pero si hay predominio significativo para una de las condiciones en la dirección esperada, esta diferencia significativa entre los totales de las categorías para las dos condiciones permiten rechazar la hipótesis nula y aceptar la hipótesis de investigación (Greene y D'oliveira, 2006).

De acuerdo a lo anterior la prueba Mann-Whitney para muestras independientes debe cumplir con los siguientes requisitos:

- Deben existir dos condiciones experimentales (una por grupo) con una variable.

- Las dos condiciones se deben aplicar a diferentes participantes.

- Los datos numéricos deben ser ordinales.

- Son pruebas no paramétricas ya que son las adecuadas para realizar análisis de datos numéricos ordinales.

\subsection{Procedimiento para determinar el valor de $U$}

1. Ordenar todos los resultados de los dos grupos juntos, como si fuera una sola serie de ordenamiento. Asignando el orden 1 al resultado menor y el 38 al mayor de acuerdo al orden en que aparecen en la tabla 11, llenando las columnas denominadas ordenación (conjunta).

2. Convertir el número de orden en categorías y llenar las columnas correspondientes a la designación de categorías. Hay que recordar que es necesario calcular las categorías de 
acuerdo a los números que se repiten sumando su orden y dividiéndolo en el número de valores repetidos, por ejemplo, en este caso el número menor es el 2 al cual le corresponde el número de orden 1, pero hay cinco valores de 3, cuyo orden será $2,3,4,5$ y 6, entonces su categoría corresponde a $(2+3+4+5+6) / 5=4$, esto es, todos los valores 3 tienen la Categoría 4.

3. Calcular el total de categorías de cada condición sumando los valores en cada caso de las categorías correspondientes, como se muestra en la Tabla 11, donde:

$$
T_{1}=282.5 \text { y } T_{2}=458.5
$$

4. Calcular el valor de $U$ utilizando la fórmula siguiente:

Sustituyendo:

$$
U_{1}=n_{1} n_{2}+\frac{n_{1}\left(n_{1}+1\right)}{2}-T_{1}
$$

Donde:

$$
U_{1}=(20 \times 18)+\frac{20(20+1)}{2}-282.5=\mathbf{2 8 7 . 5}
$$

$$
\begin{aligned}
& n_{1}=\text { número de participantes para la Condición } 1 . \\
& n_{2}=\text { número de participantes para la Condición } 2 . \\
& T_{1}=\text { total de categorías para la Condición } 1 .
\end{aligned}
$$

5. Sustituir los valores de $U_{1}, n_{1}$ y $n_{2}$ en la siguiente fórmula calculando $U_{2}$ :

Sustituyendo:

$$
U_{2}=n_{1} n_{2}-U_{1}
$$

$$
U_{2}=(20 \times 18)-287.5=72.5
$$

El valor de $U$ será el menor de $U_{1}$ y $U_{2}$, entonces:

$$
U=72.5
$$

6. Buscar la significación de $U$ en la Tabla $C$ Apéndice $D$. En las tablas $C_{1}$ y $C_{2}$ se encuentran las probabilidades para comprobar la hipótesis unilaterales y bilaterales. En la Tabla $\mathrm{C}_{1}$ se utiliza para un nivel de significación de $\rho<0.05$ conteniendo las probabilidades para una hipótesis unilateral y la Tabla $\mathrm{C}_{2}$ contiene las probabilidades para una hipótesis unilateral para un nivel de significación de $\rho<0.01$ y para una hipótesis bilateral con $\rho<0.02$. Para rechazar la hipótesis nula y aceptar la hipótesis de investigación el valor de $U$ debe ser igual o menor a los valores de la Tabla C.

Para utilizar la Tabla C, el número de participantes de la Condición $1\left(n_{1}=20\right)$ se encuentra localizado en la fila superior mientras que el número de participantes de la Condición 2 $\left(n_{2}=18\right)$ se localiza en la columna de la izquierda, éstas son las coordenadas en donde se interceptan estos valores; se localiza el $U_{\text {tabla }}$ que en este caso es igual a $U_{\text {tabla }}=100$ en la Tabla $C_{2}$, y el valor calculado es $U=72.5$, siendo este último menor, por lo que se rechaza la hipótesis nula y se acepta la hipótesis de investigación unilateral con un nivel de significación de $p<0.01$. 


$$
U=72.5<U_{\text {tabla }}=100 \text {, para un nivel de significación } \rho<0.01
$$

Como hipótesis unilateral el nivel de significación es $\rho<0.01$, este valor está por debajo de la probabilidad que proponen los investigadores en educación como máximo valor aceptable, esto es $\rho<0.05$, entonces se puede rechazar la hipótesis nula y aceptar la de investigación. Definitivamente sí existe una diferencia significativa entre los participantes con lectura impresa en papel y la lectura digital.

\subsection{Prueba Mann-Whitney utilizando el programa SPSS}

Se inicia este proceso otorgando las propiedades a las variables, una vez abierto el programa como se indica en el Capítulo 4; antes de introducir los datos, es necesario definir las variables y designarle las características para su presentación en la tabla, para esto se requiere hacer un clic en la pestaña Vista de variables.

Cuando se trata de muestras no relacionadas o independientes, los valores de los datos obtenidos se deben colocar en una misma columna como la primera variable, la que se designará como condiciones 1 y 2, la segunda variable se designa como agrupación, en donde se especifica cuáles son los datos de la columna 1 que corresponden a la Condición 1 (Grupo 1), y cuales a la Condición 2 (Grupo 2).

En este caso se teclea en el primer espacio para nombre, el nombre de la primera variable Condiciones1y2, recordando que no debe haber espacios vacíos entre los caracteres, aquí se deben anotar las dos condiciones, es decir, los datos obtenidos por los participantes de la lectura en papel (referencia), y en seguida a los participantes de la lectura digital (experimental).

El siguiente paso es introducir el nombre de la segunda variable en el espacio 2 de la columna nombre, datos denominados con el término de Agrupación (variable de agrupación); en este caso sólo se utilizan dos valores 1 para indicar que se refiere a los datos correspondientes al Grupo 1, que realizó la lectura en papel y el número 2 para el Grupo 2, que sí realizó la lectura digital.

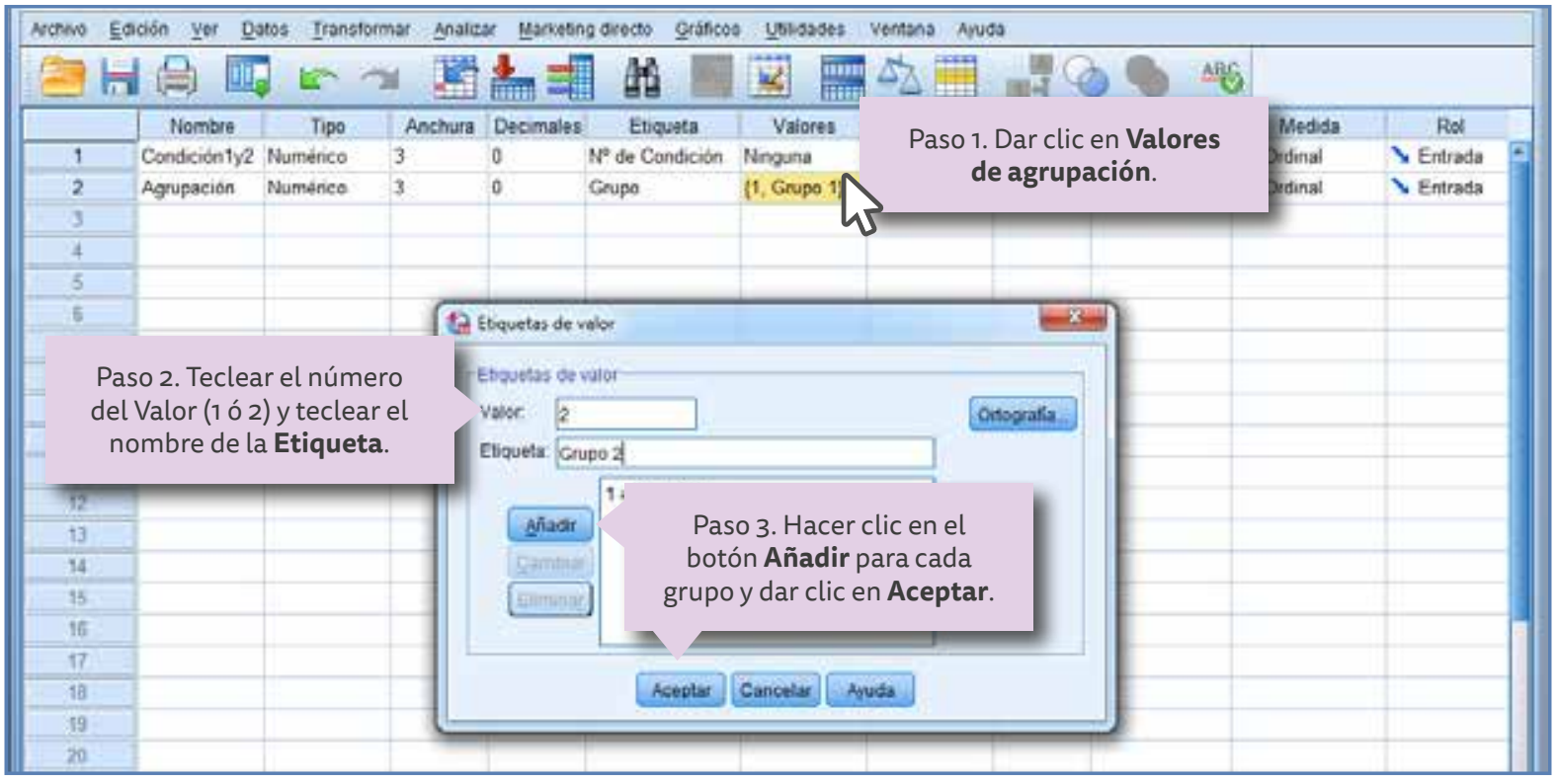

Figura 21. Ventana de diálogo para etiquetar los valores de agrupación. 
Para designar las etiquetas de valor, es decir, definir la ubicación de los grupos dentro de la tabla, en la línea de agrupación y columna valores se hace clic con el apuntador y aparece un cuadro de diálogo, en la ventana Valores se coloca el número del grupo (1 para el primer grupo, Condición 1) y la ventana Etiqueta el nombre con que se etiqueta al grupo (Grupo 1) se hace clic en el botón Añadir y los datos se transfieren a la ventana inferior, se repite este paso para registrar los valores para la Condición 2. Las características seleccionadas para la presentación de las variables así como los nombres de éstas, se pueden observar en la Figura 22.

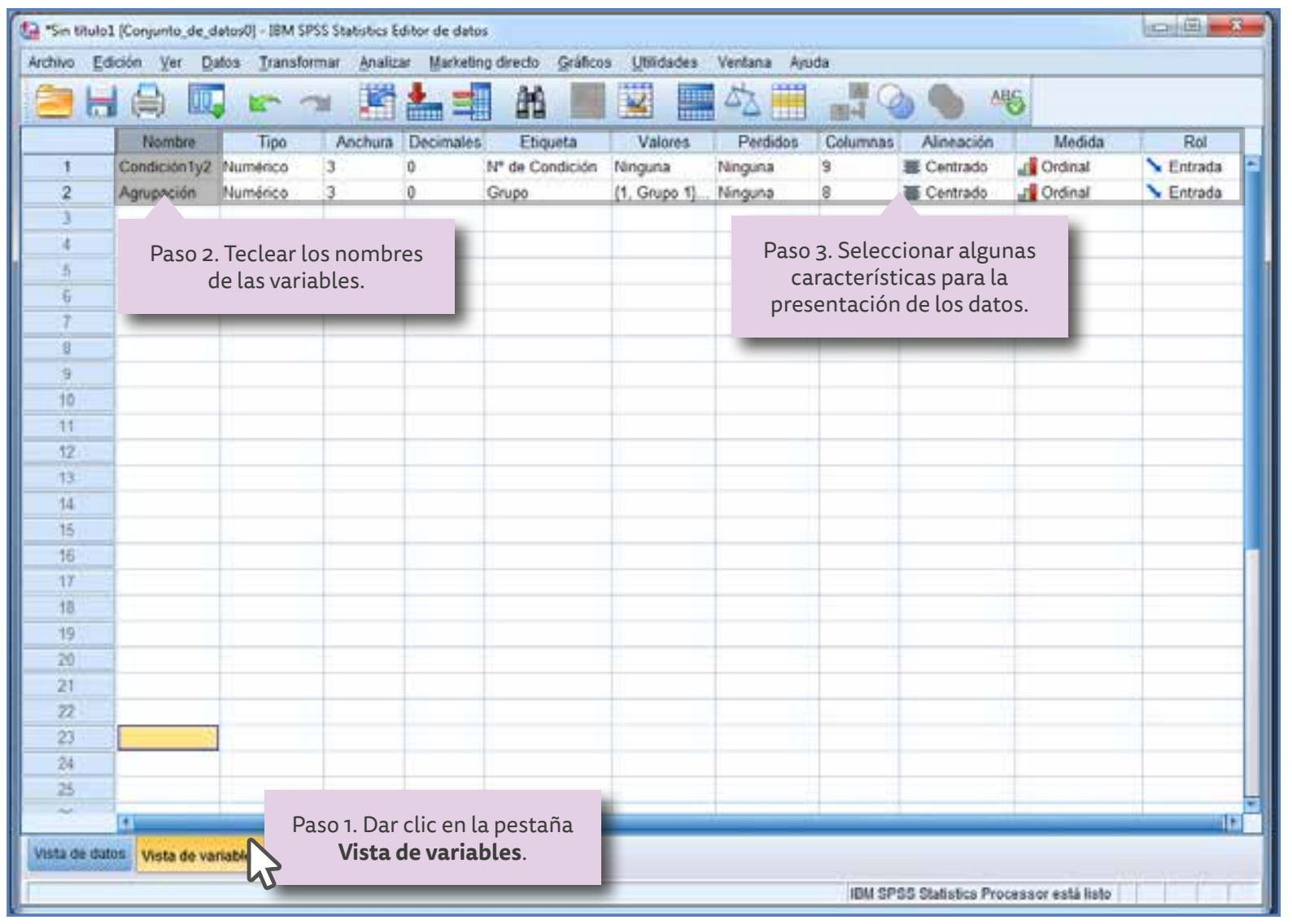

Figura 22. Designación de nombre de las variables y características de presentación para la prueba de comprensión.

Las variables seleccionadas para este ejemplo se observan en el siguiente cuadro:

Cuadro 11. Designación de variables para la prueba Mann-Whitney (independiente).

\begin{tabular}{l|l}
\hline Nombre: Condición1y2 & Nombre: Agrupación \\
\hline Tipo: Numérico & Tipo: Numérico \\
\hline Anchura: 3 & Anchura: 3 \\
\hline Decimales: 0 & Decimales: 0 \\
\hline Etiqueta: Nada & Etiqueta: Nada \\
\hline Valores: Ninguno & Valores: 1 . Grupo 1 y 2. Grupo 2 \\
\hline Perdidos: Ninguno & Perdidos: Ninguno \\
\hline Columnas: 8 & Columnas: 8 \\
\hline Alineación: Centrado & Alineación: Centrado \\
\hline Medida: Ordinal & Medida: Ordinal \\
\hline Rol: Entrada & Rol: Entrada \\
\hline
\end{tabular}


Una vez designados los nombres de las variables y sus características se procede a introducir los datos en la tabla, para llevar a cabo esto se da un clic en la pestaña Vista de datos y se introducen los datos de la siguiente forma:

1. En la columna 1 (Condición1y2) se introducen los valores de los datos obtenidos por el grupo de la Condición 1 y en seguida se introducen los datos de la Condición 2.

2. En la columna 2 (Agrupación) se introduce el valor de 1 para todos los datos que correspondan a la Condición 1, y el valor de 2 para los datos correspondientes a la Condición 2.

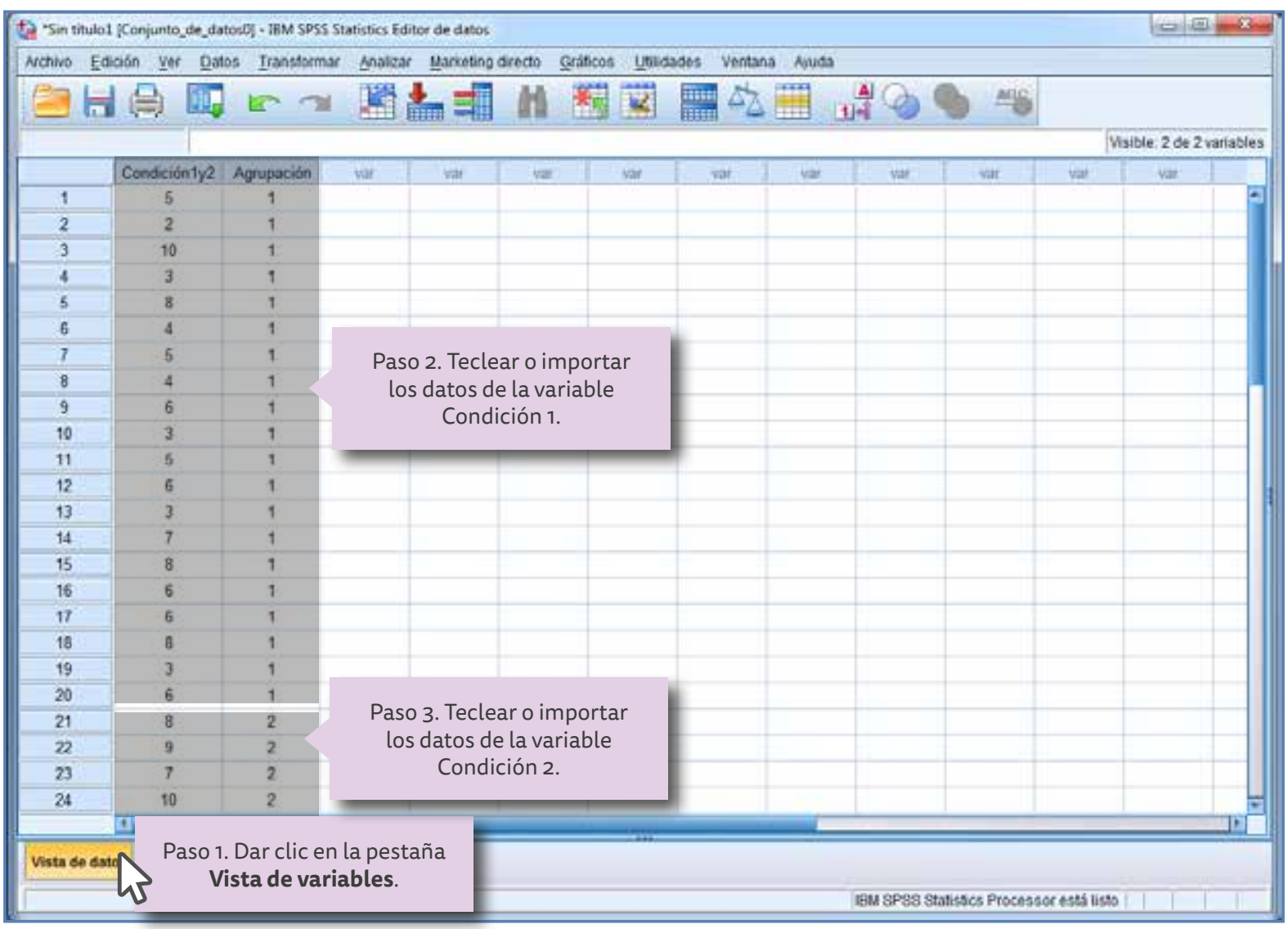

Figura 23. Presentación de los datos arrojados por los participantes en las estrategias de "lectura".

En la Figura 23 se observa cómo deben quedar los datos siguiendo los procedimientos mencionados y de acuerdo a las características seleccionadas en los pasos anteriores.

Otra manera de verificar si los datos coinciden con los grupos es activando la etiqueta de Valores de agrupación, que al programar las características se etiquetan como $1=$ Grupo 1 y el 2 = Grupo 2, mostrándose como se puede observar en la Figura 24.

Después de introducir los datos en la tabla, se procede a realizar la prueba, para hacerlo es necesario dar un clic en la pestaña ubicada en la barra superior designada como Analizar, en seguida aparece un cuadro de diálogo, en el cual se selecciona la línea que indica Pruebas no paramétricas, por pertenecer precisamente la prueba Mann-Whitney a este tipo.

Al ubicar el apuntador del ratón en esta opción se presenta a la derecha otro cuadro de diálogo con cuatro opciones, seleccionando la que corresponde a Cuadro de diálogos antiguo aparecen otras opciones y se selecciona $\mathbf{2}$ muestras independientes (que corresponden al presente problema) y se hace clic con el ratón. 


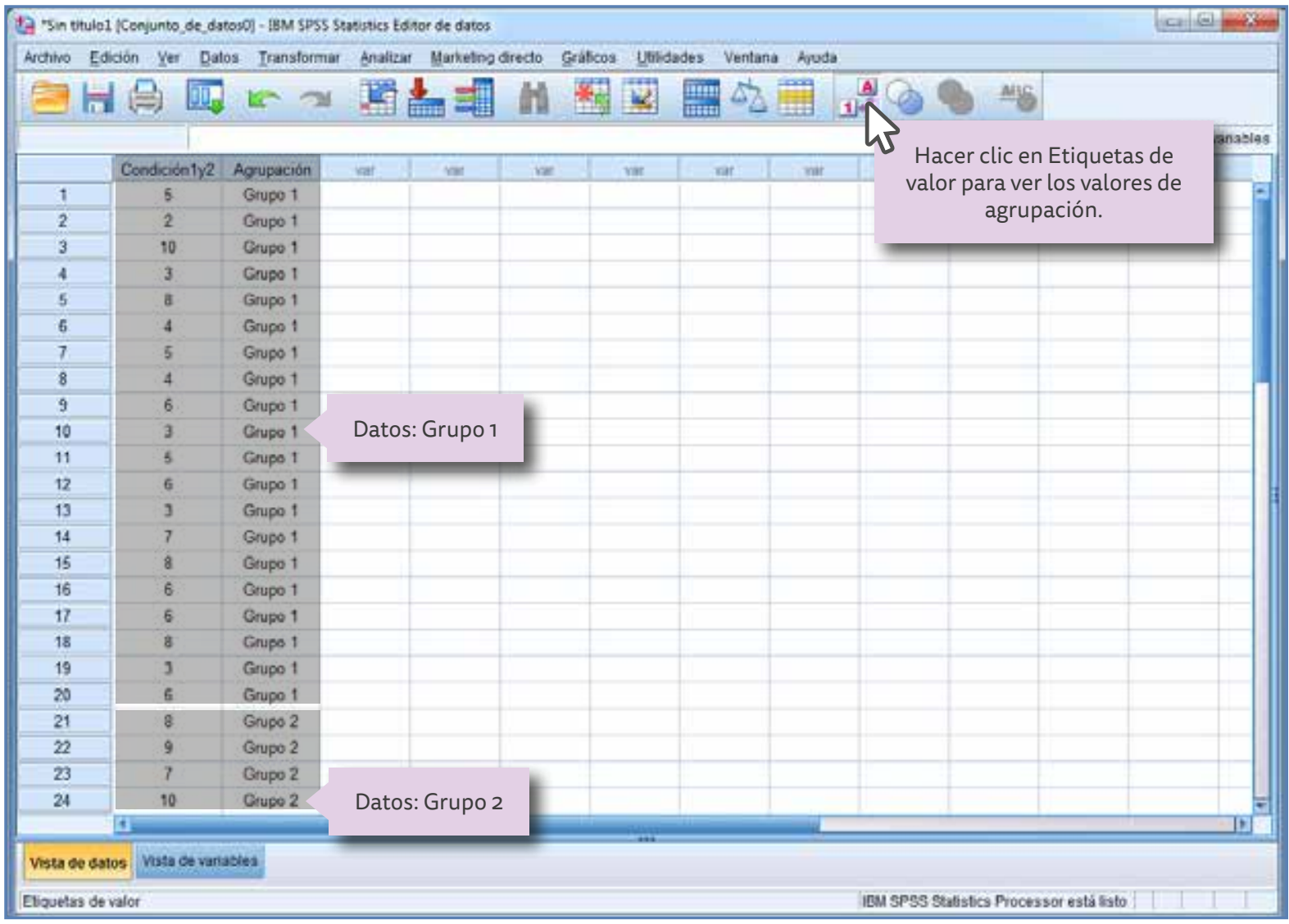

Figura 24. Presentación de los datos activando las etiquetas de valor.

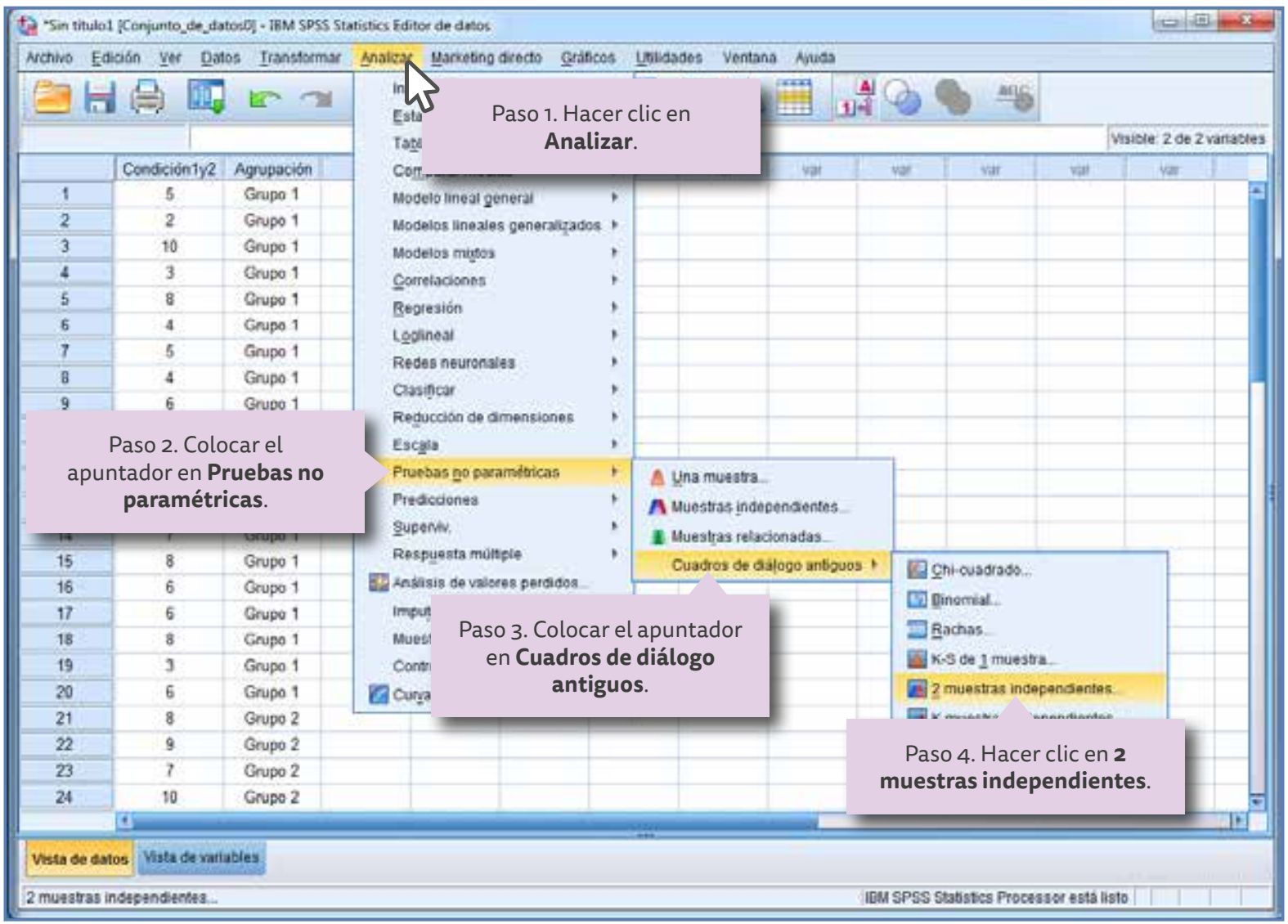

Figura 25. Cuadros de diálogo para seleccionar la prueba no paramétrica de dos muestras independientes. 
Al hacer clic con el ratón aparece la ventana de la Figura 26, la cual muestra las variables del lado izquierdo, Condición1y2 y Agrupación; la primera debe ser trasladada a la ventana que dice Lista contrastar variables, la forma de hacerlo es seleccionar con un clic la variable deseada (Condición1y2) y hacer clic en la flecha superior que se ubica entre las dos ventanas.

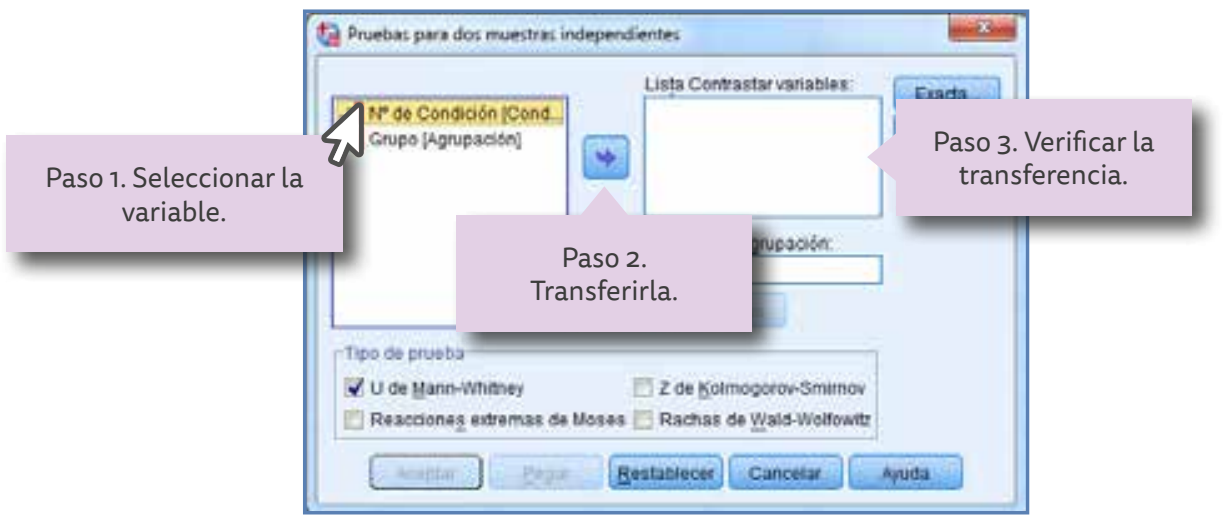

Figura 26. Pasos para ingresar las variables № de condición al programa SPSS.

Para trasladar la otra variable (agrupación) se hace clic en la flecha inferior que se encuentra entre las ventanas y se traslada a la ventana designada como Variables de agrupación, se observa que el programa preselecciona el tipo de prueba $U$ de Mann-Whitney (Figura 27).

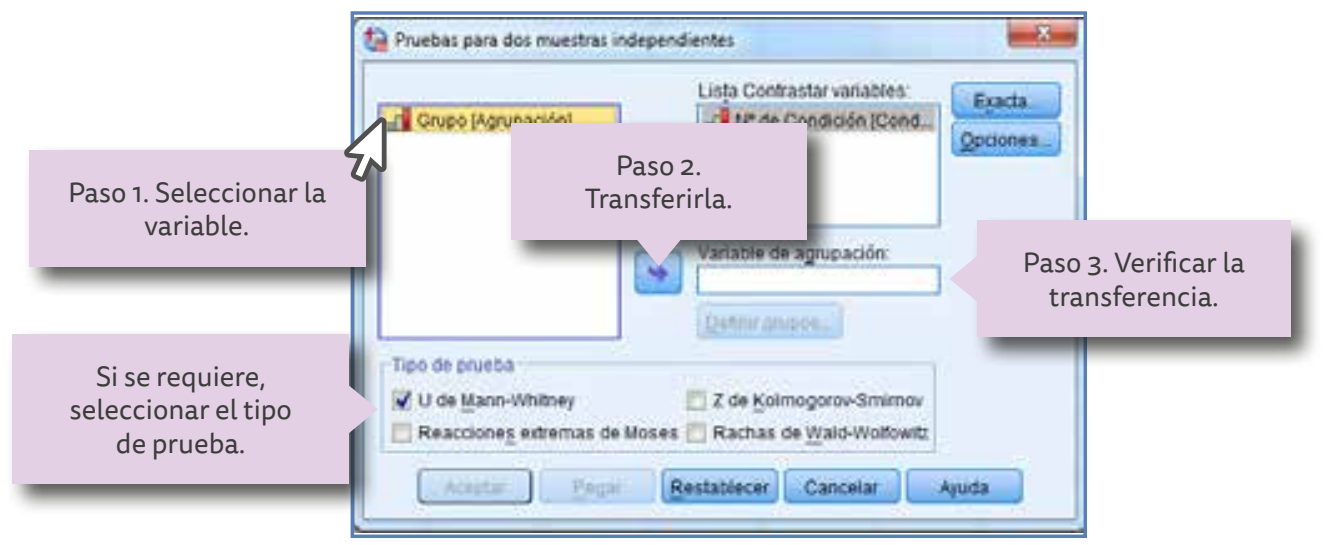

Figura 27. Pasos para ingresar las variables Agrupación al programa SPSS.

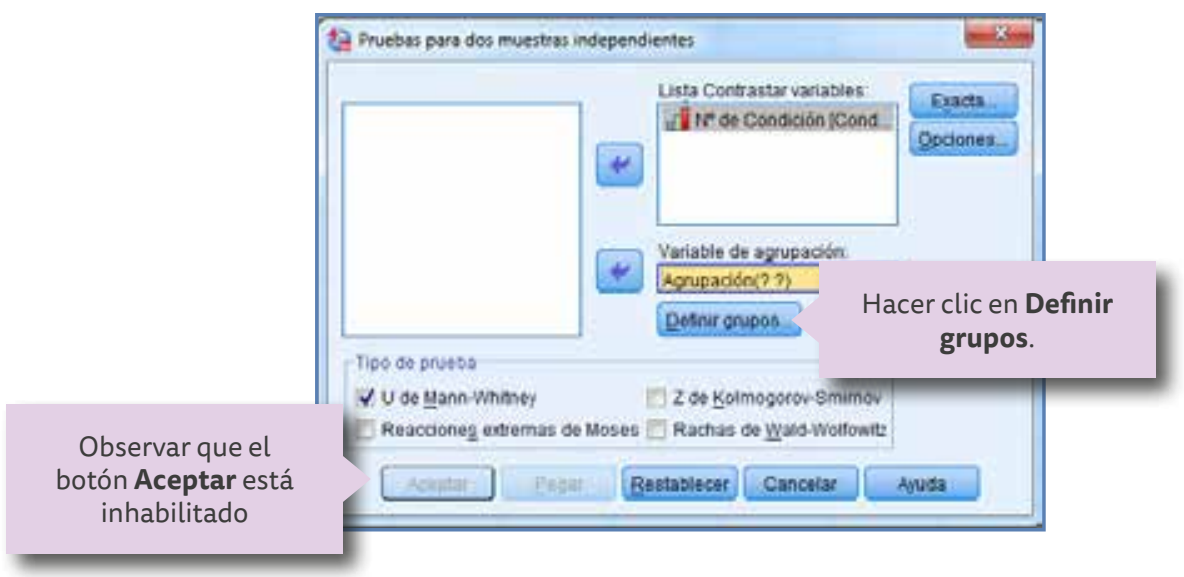

Figura 28. Actividad para definir los grupos paso 1. 
Se observa que el programa aún no habilita el botón de Aceptar (Figura 28), está esperando que se definan los grupos de acuerdo a la columna de agrupación; para hacer esto se requiere dar clic en el botón que se encuentra debajo de la ventana de Variable de agrupación, el cual especifica Definir grupos y aparece una subventana en donde se teclea el número 1 para el Grupo 1 y el 2 para el Grupo 2, finalmente se da clic en el botón Continuar (Figura 29).

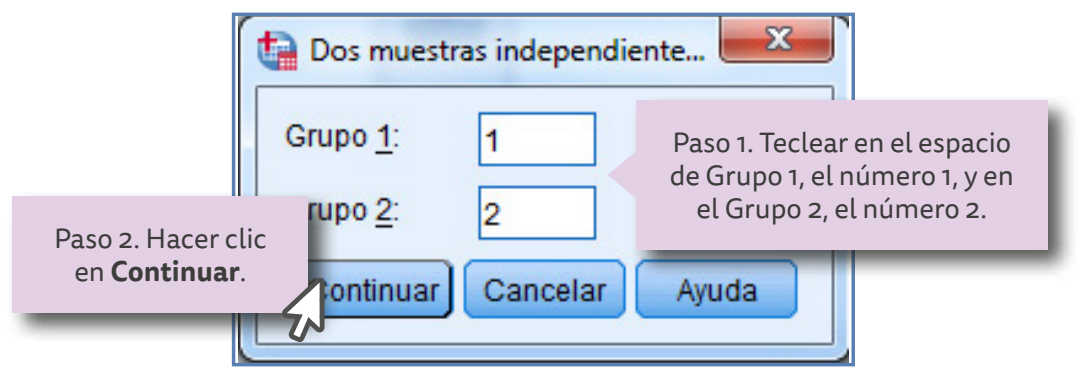

Figura 29. Actividad para definir los grupos paso 2.

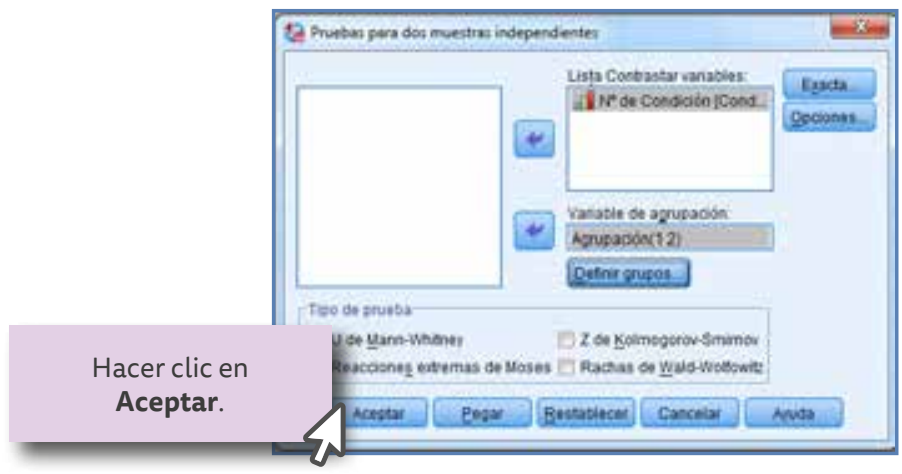

Figura 30. Paso para ejecutar el programa SPSS para que realice los cálculos requeridos.

Se observa que una vez hecho este proceso ya se encuentra habilitado el botón Aceptar, se da clic en éste y aparecen los resultados que se muestran en el Cuadro 12, en el cual se observan los valores de la suma de rangos que coinciden con los del cálculo realizado en el apartado anterior (282.5 para el Grupo 1 y 458.5 para el Grupo 2) así como el valor de $U$ de Mann-Whitney, $U=72.5$, y se obtiene también el valor del nivel de significación [Significación asintótica (unilateral)] $\rho=0.001$.

$$
\text { Entonces se puede concluir que } \rho \text { encontrada } 0.001<\rho \text { aceptada } 0.05
$$

Es decir, el valor encontrado 0.001 es menor que el mínimo aceptable por los investigadores en educación (0.05), lo que significa que los resultados de la diferencia no son aleatorios puesto que existe una diferencia significativa, por lo que se puede rechazar la hipótesis nula y aceptar la hipótesis de investigación.

Hi: Si a un grupo de participantes se les da a leer un libro digital que contiene enlaces que le permiten ampliar los conceptos de su contenido, éstos comprenderán un mayor número de conceptos que un grupo de participantes que leyeron el mismo libro impreso en papel. 
Cuadro 12. Resultados obtenidos con el programa SPSS para la prueba no paramétrica Mann-Whitney para dos muestras independientes.

NPAR TESTS

$/ \mathrm{M}-\mathrm{W}=$ Condieibn1y 2 BY Agrupacion $\left(\begin{array}{ll}1 & 2\end{array}\right)$

/MTSSTNG ANALYSTS.

+ Pruebas no paramétricas

[Conjunto_de_datos0]

Prueba de Mann-Whitney

\begin{tabular}{|ll|r|r|r|}
\multicolumn{1}{|c}{ Rangos } \\
\hline & Grupo & N & $\begin{array}{c}\text { Rango } \\
\text { promedio }\end{array}$ & $\begin{array}{c}\text { Suma de } \\
\text { rangos }\end{array}$ \\
\hline$N^{*}$ de Condición & Grupo 1 & 20 & 14.13 & 28250 \\
& Grup0 2 & 18 & 25.47 & 458.50 \\
& Total & 36 & & \\
\hline
\end{tabular}

Fstadisticos de contraste ${ }^{3}$

La $U$ de Mann-Whitney es igual a la del valor calculado con la fórmula.

\begin{tabular}{|c|c|c|}
\hline & $\begin{array}{c}\mathrm{N}^{*} \text { de } \\
\text { Condición }\end{array}$ & \\
\hline U de Mann-Whitney & 72.500 & \\
\hline $\begin{array}{l}\text { W de Wilcoxon } \\
z\end{array}$ & $\begin{array}{r}202.500 \\
-3.173\end{array}$ & \\
\hline $\begin{array}{l}\text { Sig. asintót. (bilateral) } \\
\text { Sig, exacta [2*(Sig. } \\
\text { uniliateral)] }\end{array}$ & $\begin{array}{l}.002 \\
.001^{\circ}\end{array}$ & $\begin{array}{c}\text { Nivel de confiabilidad bilateral y } \\
\text { unilateral. }\end{array}$ \\
\hline
\end{tabular}

a. Variable de agrupación Grupo

b. No corregidos para los empates. 


\section{Capítulo 7}

\section{Prueba Friedman (muestras relacionadas)}

La prueba Friedman se debe utilizar para diseños relacionados cuando tres o más condiciones se aplican a los mismos participantes y los datos deben ser ordinales.

Ejemplo 82. Se trata de aceptar o rechazar la siguiente hipótesis de investigación:

Hi: Si los alumnos escriben palabras poco comunes en un dictado, entonces tendrán más errores ortográficos que si utilizaran palabras muy comunes.

\subsection{Estado situacional}

El investigador desea saber si el uso de diferentes tipos de palabras al ser dictadas influye en la capacidad de los participantes para utilizar correctamente las reglas de ortografía, por lo que en una primera intervención (Condición 1) les dicta 20 palabras muy poco comunes, después de una semana vuelve a dictarles 20 palabras poco comunes (Condición 2), para finalmente una semana después, dictarles 20 palabras comunes (Condición 3). La variable dependiente consistió en el número de palabras escritas correctamente en cada uno de los dictados, los resultados se pueden observar en la Tabla 12.

Tabla 12. Resultados obtenidos por los participantes en los tres dictados con respecto a las reglas de ortografía.

\begin{tabular}{|c|c|c|c|c|c|c|c|c|c|}
\hline 일 $\frac{\stackrel{d}{\frac{8}{2}}}{\frac{0}{2}}$ & 롱 & 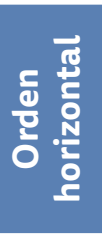 & 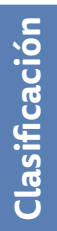 & 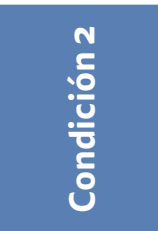 & 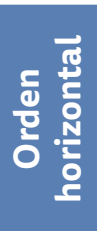 & $\begin{array}{l}\frac{5}{0} \\
\frac{8}{8} \\
\frac{8}{0} \\
\frac{0}{0} \\
\end{array}$ & $\begin{array}{l}\text { m } \\
: \frac{5}{0} \\
\frac{.0}{0} \\
\frac{0}{0}\end{array}$ & 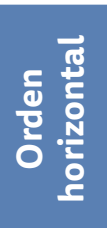 & 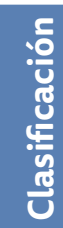 \\
\hline 1 & 15 & 1 & 1.5 & 15 & 2 & 1.5 & 18 & 3 & 3 \\
\hline 2 & 10 & 1 & 1 & 12 & 2 & 2 & 17 & 3 & 3 \\
\hline 3 & 13 & 1 & 1 & 15 & 2 & 2 & 19 & 3 & 3 \\
\hline 4 & 12 & 2 & 2 & 10 & 1 & 1 & 15 & 3 & 3 \\
\hline 5 & 12 & 1 & 1 & 13 & 2 & 2 & 15 & 3 & 3 \\
\hline 6 & 11 & 1 & 1 & 12 & 2 & 2 & 13 & 3 & 3 \\
\hline 7 & 9 & 1 & 1 & 10 & 2 & 2 & 13 & 3 & 3 \\
\hline 8 & 12 & 1 & 1 & 14 & 2 & 2 & 16 & 3 & 3 \\
\hline 9 & 11 & 1 & 1 & 16 & 2 & 2 & 19 & 3 & 3 \\
\hline 10 & 16 & 1 & 1 & 19 & 2 & 2 & 20 & 3 & 3 \\
\hline 11 & 14 & 1 & 1 & 17 & 2 & 2.5 & 17 & 3 & 2.5 \\
\hline 12 & 14 & 1 & 1.5 & 14 & 2 & 1.5 & 15 & 3 & 3 \\
\hline \multicolumn{2}{|c|}{$\Sigma_{1}=149$} & \multicolumn{2}{|c|}{$T_{1}=14$} & $\Sigma_{2}=167$ & \multicolumn{2}{|c|}{$T_{2}=22.5$} & $\Sigma_{3}=197$ & \multicolumn{2}{|c|}{$T_{3}=35.5$} \\
\hline \multicolumn{2}{|c|}{$\bar{x}_{1}=12.42$} & \multicolumn{2}{|c|}{ Prom. $=1.17$} & $\bar{x}_{2}=13.92$ & \multicolumn{2}{|c|}{ Prom. $=1.88$} & $\bar{x}_{3}=16.42$ & \multicolumn{2}{|c|}{ Prom. $=2.96$} \\
\hline
\end{tabular}


Se trabajó con el Grupo C de quinto grado de primaria que constó de 12 alumnos, se aplicaron los dictados los lunes, con el primer tema de Español, a las dos horas de iniciar labores, procurando que ya se encontrara el grupo completo.

Se observa en la Tabla 12 que el ordenamiento se realiza por alumno de manera horizontal, dando orden a sus tres intervenciones de menor a mayor. En la siguiente columna son clasificados, designándoles el mismo valor del ordenamiento, si algún dato se repitió entonces se le asigna la media de los valores del orden asignado.

Un ejemplo de lo anterior es el observado en el alumno 1, el cual obtuvo el mismo resultado en las condiciones 1 y 2, con 15 puntos y en la Condición 3 obtuvo 18 por lo que el orden es 1 (Condición 1), 2 (Condición 2) y 3 (Condición 3), por lo tanto, para determinar el valor de las categorías 1 y 2 , se procede a determinar el promedio de su posición en el orden, esto es $(1+2) / 2=1.5$.

\subsection{Explicación}

La prueba Friedman consiste en comparar los totales de las categorías correspondientes a las tres condiciones a partir de la clasificación horizontal. Si hay aproximadamente las mismas categorías para las tres condiciones, entonces las diferencias entre las correlaciones clasificadas son aleatorias y se debe aceptar la hipótesis nula. Pero si hay predominio significativo para una de las condiciones, esta diferencia significativa entre los totales de las categorías para las tres condiciones permiten rechazar la hipótesis nula y aceptar la hipótesis de investigación (Greene y D'oliveira, 2006).

De acuerdo a lo anterior la prueba Friedman para muestras relacionadas debe cumplir con los siguientes requisitos:

- Deben existir tres condiciones experimentales (antes, intermedia y después) con una variable.

- Las tres condiciones se deben aplicar a los mismos participantes.

- Los datos numéricos deben ser ordinales.

- Son pruebas no paramétricas ya que son las adecuadas para realizar análisis de datos numéricos ordinales.

\subsection{Procedimiento para determinar el valor de $X^{2} r^{\circ}$}

1. Ordenar los resultados de cada fila en sentido horizontal por cada uno de los participantes por separado. Asignando el 1 al resultado menor, 2 al siguiente y 3 al mayor.

2. Designar las categorías en cada fila horizontal a cada uno de los participantes, relacionando las que se requieran, por ejemplo: los alumnos 1 y 11 con 1.5 y 2.5 respectivamente.

3. Calcular el total de categorías para cada condición:

$$
T_{1}=14, T_{2}=22.5 \text { y } T_{3}=35.5
$$

4. Calcular el valor de $X^{2}{ }_{r}$ utilizando la siguiente fórmula:

$$
X_{r}^{2}=\left[\frac{12}{N C(C+1)} \Sigma T^{2}\right]-3 N(C+1)
$$


Donde:

$$
\begin{aligned}
& C=\text { número de condiciones }=3 \\
& N=\text { número de participantes }=12 \\
& \sum T^{2}=\text { suma del cuadrado de los totales }=T^{2}{ }_{1}+T^{2}{ }_{2}+T^{2} \\
& X^{2}{ }_{r}=\text { símbolo de la prueba estadística "Chi erre cuadrada" }
\end{aligned}
$$

Reemplazando los datos en la ecuación se obtiene:

$$
\begin{gathered}
\sum T^{2}=(14)^{2}+(22.5)^{2}+(35.5)^{2}=(196)+(506.25)+(1260.25)=1962.5 \\
X_{r}^{2}=\left[\frac{12}{(12)(3)(3+1)}(1962.5)\right]-[3(12)(3+1)]=163.54-144=19.54
\end{gathered}
$$

5. Determinar el número de grados de libertad restando 1 al número de condiciones:

$$
g l=C-1=3-1=2
$$

6. Buscar la significación de $X_{r}^{2}$ en la Tabla D o E del Apéndice D.

Tabla D: se debe utilizar para un máximo de nueve participantes, contiene una lista de todas las probabilidades para cualquier valor calculado de $X_{r}{ }_{r}$, solo utiliza los valores que incluyen un nivel de significación aceptado como válido $(\rho<0.05)$, encontrándose en la parte inferior de la lista de probabilidades. El valor calculado de $X^{2}{ }_{r}$ debe ser igual o mayor que los valores que aparecen en la tabla para descartar la hipótesis nula y aceptar la de investigación para niveles de significación aceptables $(\rho<0.05)$.

Tabla E: se debe utilizar para más de nueve participantes, ésta es una tabla estadística más general, conocida como Chi cuadrado. Para consultar las probabilidades se utilizan los grados de libertad $g l=C-1$. Considerando que en este ejemplo el número de participantes es mayor que nueve $(N=12)$, se utilizará esta tabla.

En la Tabla E se observan los grados de libertad $g l=2$, en donde el valor calculado 19.54 es mayor que el valor 13.82 para $\rho<0.001$.

$$
\begin{gathered}
X^{2}{ }_{r \text {-calculado }}=19.54 \text { (es mayor que) }>X^{2}{ }_{r \text {-tabla }}=13.82 \\
\text { para un nivel de significación de } \rho<0.001
\end{gathered}
$$

El nivel de significación es $\rho<0.001$, que está por debajo de la probabilidad que proponen los investigadores en educación como máximo valor aceptable, esto es $\rho<0.05$, entonces se puede rechazar la hipótesis nula y aceptar la de investigación. Definitivamente si los participantes utilizan palabras más comunes tendrán menos faltas de ortografía que si utilizan palabras rebuscadas o poco comunes.

\subsection{Prueba Friedman utilizando el programa SPSS}

El programa SPSS para esta prueba permite determinar el nivel de significación comparándolo con el nivel mínimo utilizado por los investigadores en educación que corresponde a $\rho<0.05$. Si el que se determine mediante el proceso del programa resulta mayor que este valor, entonces se puede decir que las diferencias de los resultados son causados por variables 
aleatorias y se debe aceptar la hipótesis nula, pero si el valor es menor entonces las diferencias son significativas y se debe rechazar la hipótesis nula y aceptar la hipótesis de investigación.

El primer paso consiste en otorgar las propiedades a las variables, una vez abierto el programa, antes de introducir los datos, es necesario definir las variables y otorgar las características para su presentación en la tabla, para lo cual se requiere hacer clic en la pestaña Vista de variables. En este caso las acciones indispensables para obtener los resultados correctos son:

a. Designar los nombres de las variables. Para realizarlo es necesario presionar la ceja de Vista de variables, y en seguida teclear el nombre de cada una, primero en la columna Nombre (primera) y la fila 1, la palabra Condición1, que debe ir sin espacio entre la palabra y el número debido a que el programa no reconoce caracteres vacíos; segundo en la columna Nombre pero ahora en la fila 2, escribir Condición2 y en la fila 3 Condición3.

b. Definir el tipo de medida que se realizó. Debido a que los datos son ordinales se requiere que en la columna Medida se seleccione la opción Ordinal.

El programa preselecciona el tipo de variables como numérico, para darle presentación a los datos se puede realizar las siguientes operaciones (pero no es necesario): definir la Anchura (2) y cantidad de Decimales (o) requeridos y la Alineación (centrado).

En la Figura 31 se observan estos pasos, así como la ubicación de cada variable y las propuestas de opciones para la definición y presentación de las mismas.

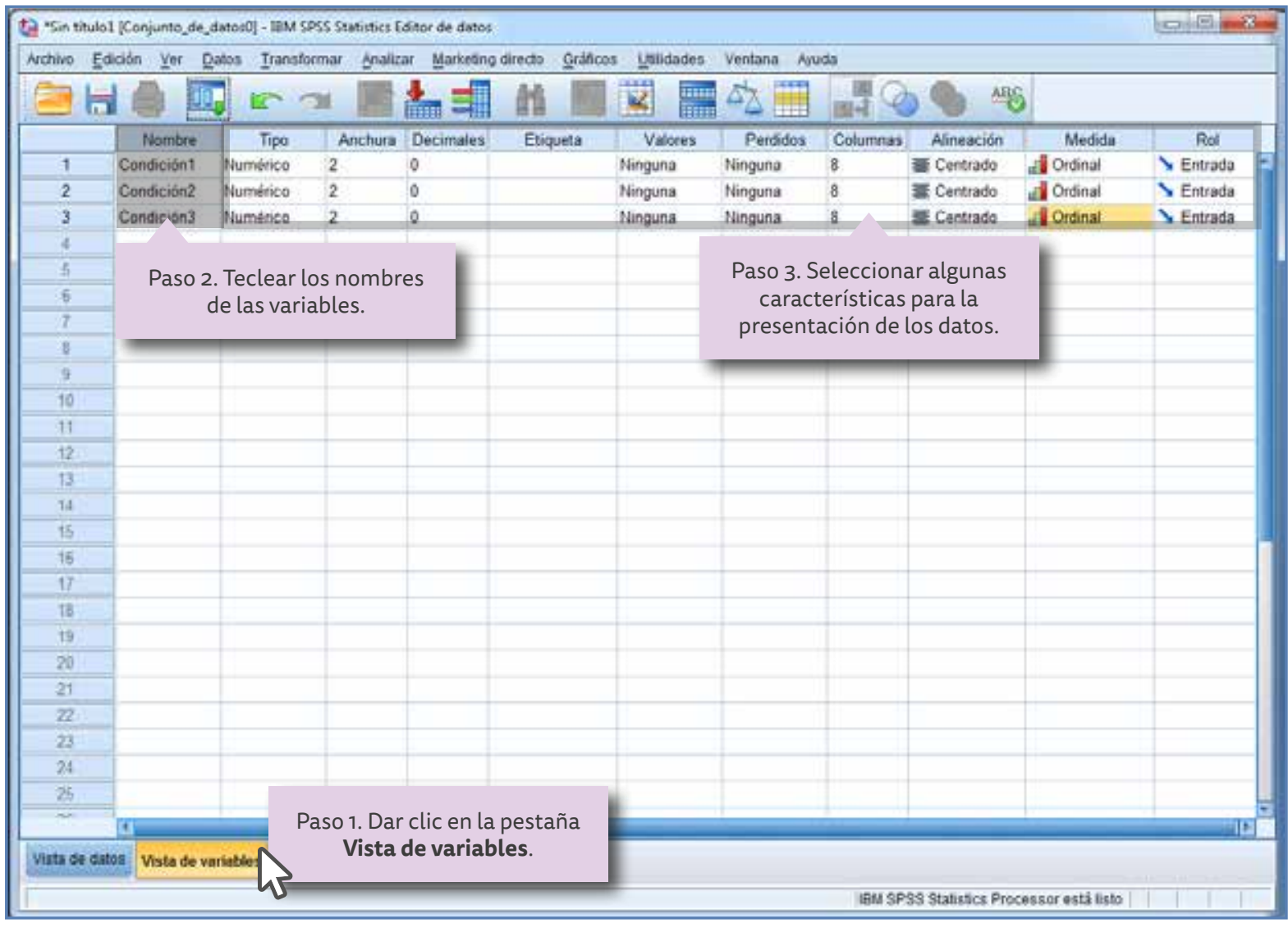

Figura 31. Designación de variables y sus características.

Las variables seleccionadas en este ejemplo se observan en el siguiente cuadro: 
Cuadro 13. Designación de variables para la prueba Friedman (relacionada).

\begin{tabular}{l|l|l|}
\hline Nombre: Condición1 & Nombre: Condición2 & Nombre: Condición3 \\
\hline Tipo: Numérico & Tipo: Numérico & Tipo: Numérico \\
\hline Anchura: 2 & Anchura: 2 & Anchura: 2 \\
\hline Decimales: 0 & Decimales: 0 & Decimales: 0 \\
\hline Etiqueta: Nada & Etiqueta: Nada & Etiqueta: Nada \\
\hline Valores: Ninguno & Valores: Ninguno & Valores: Ninguno \\
\hline Perdidos: Ninguno & Perdidos: Ninguno & Perdidos: Ninguno \\
\hline Columnas: 8 & Columnas: 8 & Columnas: 8 \\
\hline Alineación: Centrado & Alineación: Centrado & Alineación: Centrado \\
\hline Medida: Ordinal & Medida: Ordinal & Medida: Ordinal \\
\hline Rol: Entrada & Rol: Entrada & Rol: Entrada
\end{tabular}

Una vez designados los nombres de las variables y sus características, se introducen los datos en la tabla; para llevar a cabo esto es necesario dar un clic en la pestaña Vista de datos, e introducir los datos correspondientes a cada variable, los datos se pueden introducir uno por uno, tecleándolos o bien importarlos (seleccionar, copiar y pegar) de la tabla en donde se encuentran ubicados y pegarlos dentro de esta tabla.

En la Figura 32 se observa como quedan los datos siguiendo cualquiera de los procedimientos mencionados y de acuerdo a las características seleccionadas en los pasos anteriores.

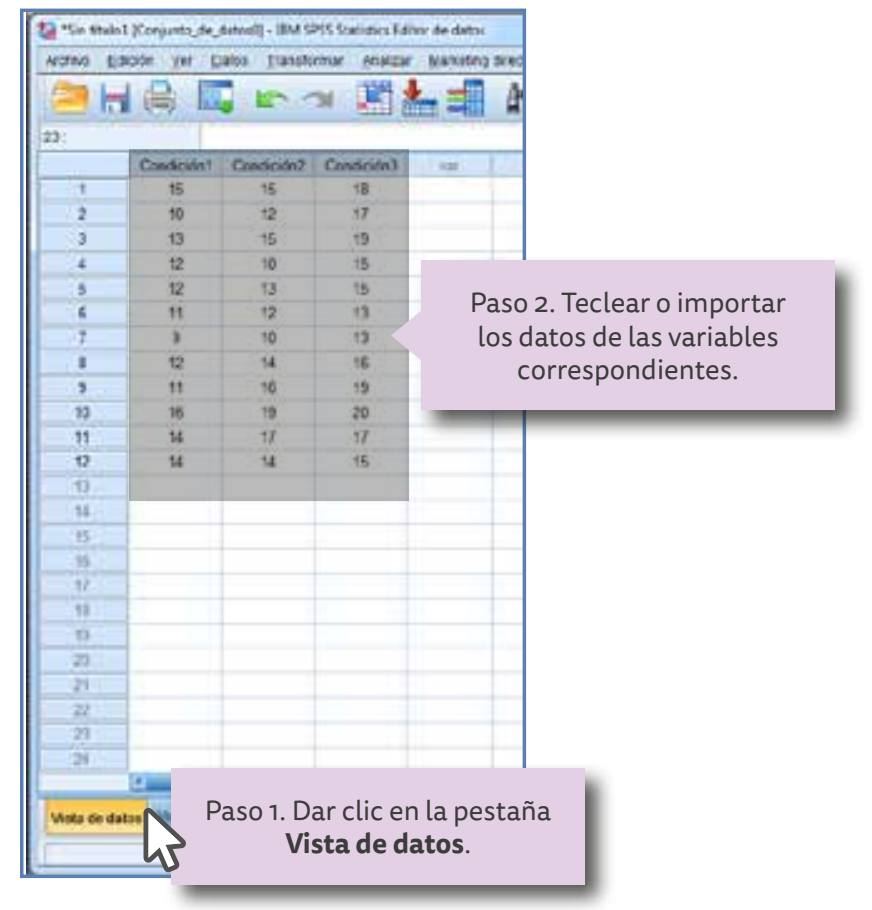

Figura 32. Presentación de los datos arrojados por los participantes en la estrategia "los tres dictados".

Una vez que los datos se encuentran en la tabla, se realiza la prueba, para hacerlo es necesario dar un clic en la pestaña ubicada en la barra superior designada como Analizar, en seguida aparece un cuadro de diálogo, se selecciona la línea que indica Pruebas no paramétricas, por pertenecer precisamente la prueba Friedman a este tipo; al ubicar el 
apuntador del ratón en esta opción se presenta a la derecha otro cuadro de diálogo con cuatro opciones, se selecciona Cuadros de diálogo antiguos, aparece otras opciones y se selecciona $\mathbf{K}$ muestras relacionadas (que corresponden a tres o más muestras relacionadas) y se hace clic.

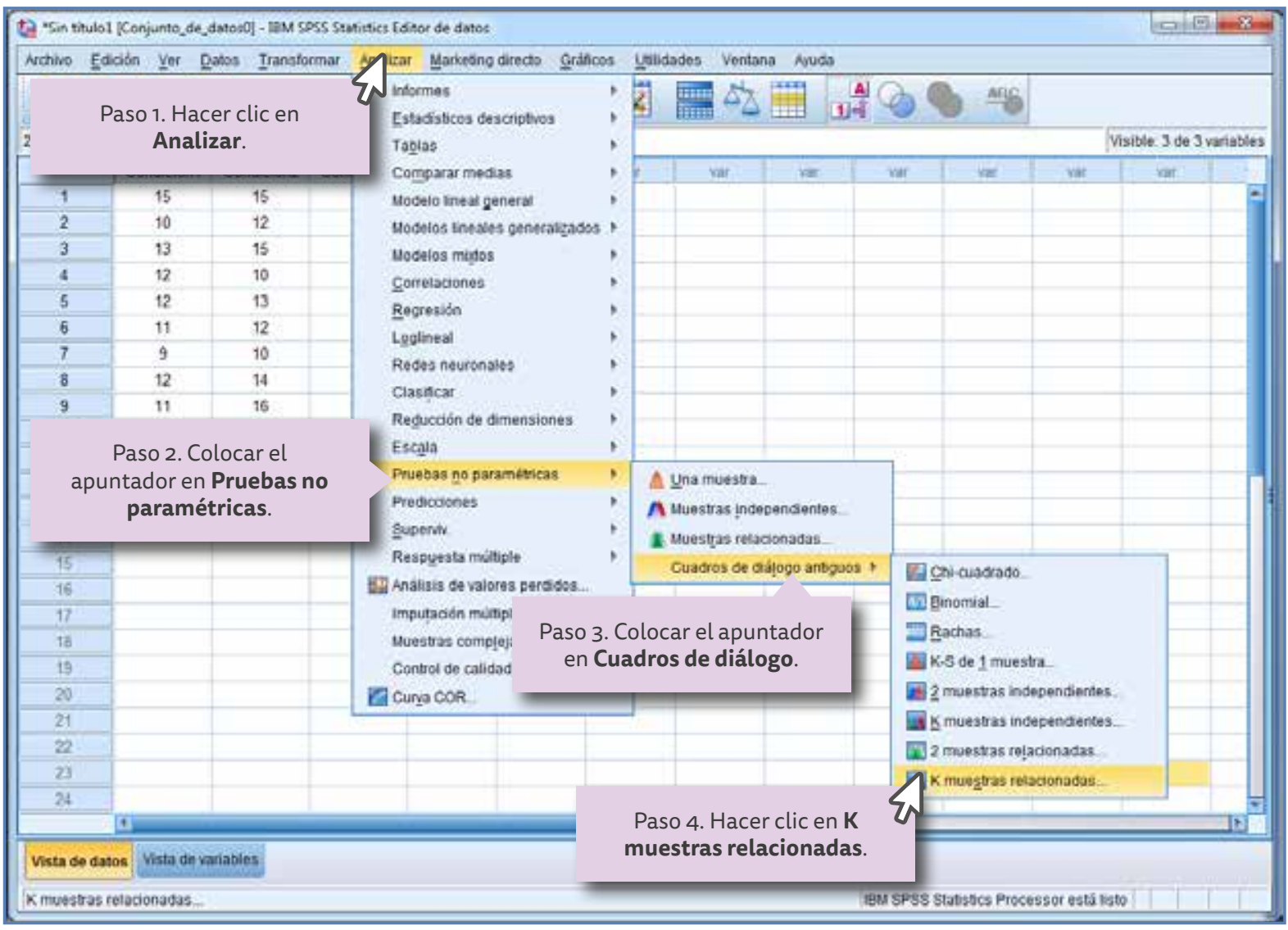

Figura 33. Cuadros de diálogo para seleccionar la prueba no paramétrica de K muestras relacionadas.

Al hacer clic con el ratón aparece la ventana de la Figura 34, en la cual se muestran las variables del lado izquierdo, Condición1, Condición2 y Condición3, las cuales deben ser trasladadas a la ventana que dice Variables de contraste. La forma de hacerlo es seleccionar con un clic la variable deseada (Condición1) y dar un clic en la flecha que se ubica entre las dos ventanas, repitiendo esta operación para la variable 2 y 3 (Condición2 y Condición3). También se observa que el programa preselecciona el tipo de prueba Friedman.

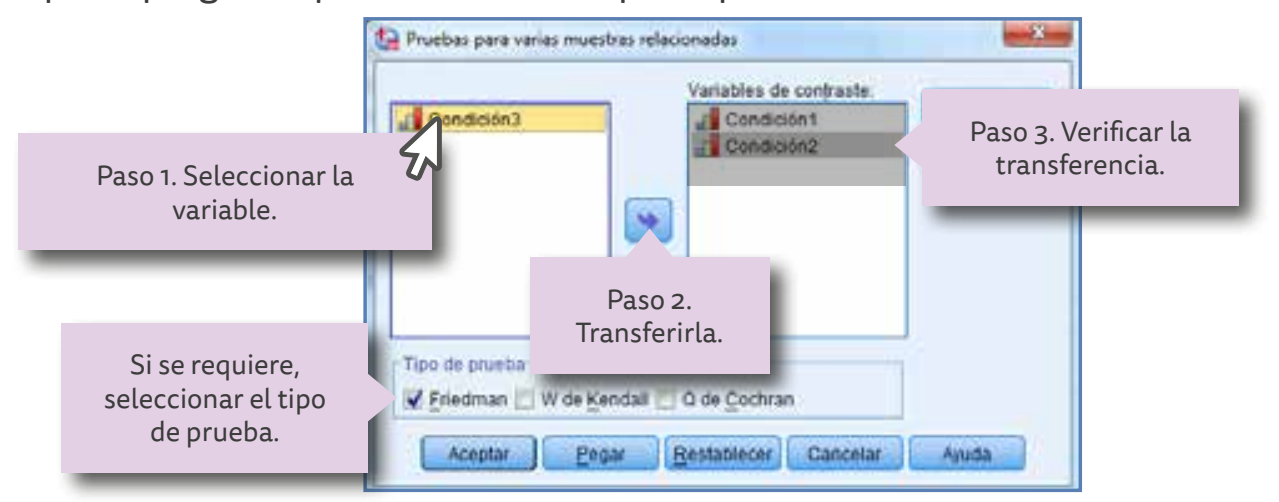

Figura 34. Transferencia de las variables Condición 1, 2 y 3 para procesar los datos con el programa SPSS. 
Con la finalidad de que los resultados muestren los datos de los estadísticos descriptivos como son los valores de la media, es necesario activar con el apuntador el botón que indica Estadísticos (ver Figura 35), al momento de hacer clic aparece un cuadro de diálogo en donde es necesario activar la opción Descriptivos colocando el apuntador en la pequeña ventana y dando clic; al realizar esta acción aparece una palomita que indica que se seleccionó. Una vez seleccionado se activa el botón Continuar (ver Figura 36), con el apuntador y dando clic se regresa al cuadro de diálogo anterior.

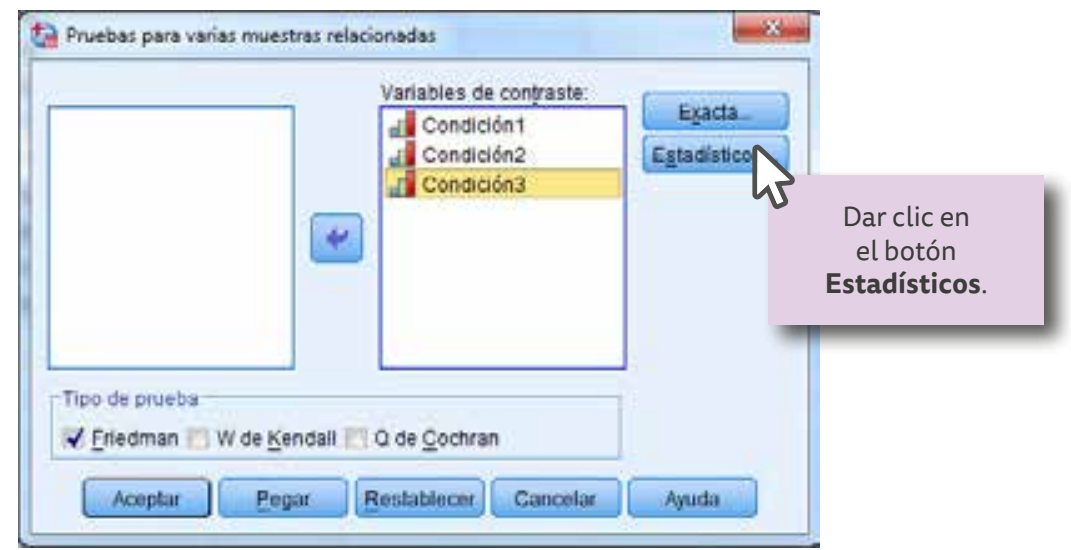

Figura 35. Proceso para entrar al cuadro de diálogo para que el programa muestre los datos estadísticos de la media de cada condición.

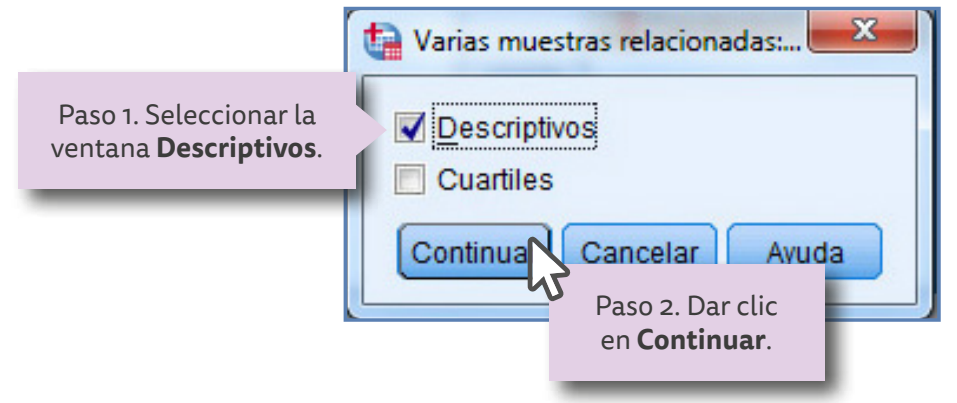

Figura 36. Proceso para que el programa muestre los la tabla de estadísticos descriptivos.

Para calcular el valor del nivel de significación exacto (ver Figura 37), se debe activar el botón Exacta, y aparece el cuadro de diálogo que se muestra en la Figura 38; , colocando el apuntador y dando clic se selecciona la opción Exacta, después se activa el botón Continuary regresa al cuadro de diálogo anterior.

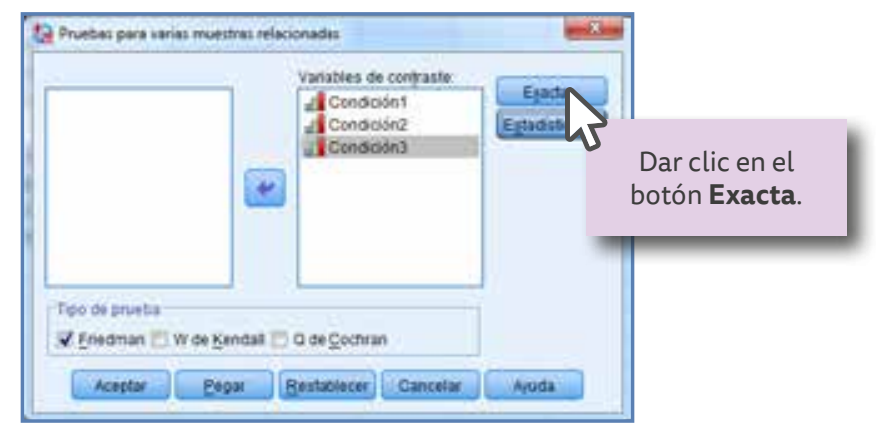

Figura 37. Proceso para entrar al cuadro de diálogo para calcular el nivel de significación unilateral (exacto). 


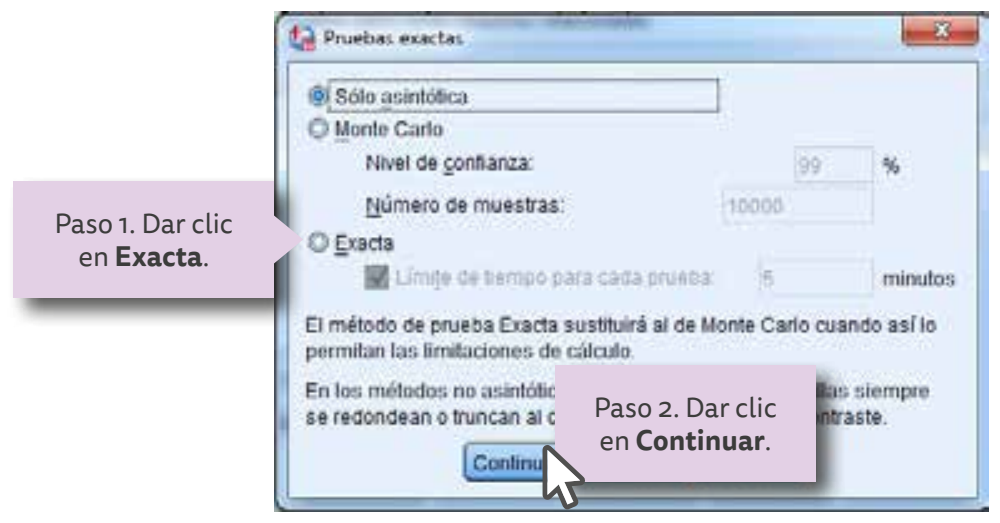

Figura 38. Proceso para calcular el nivel de significación unilateral (exacto).

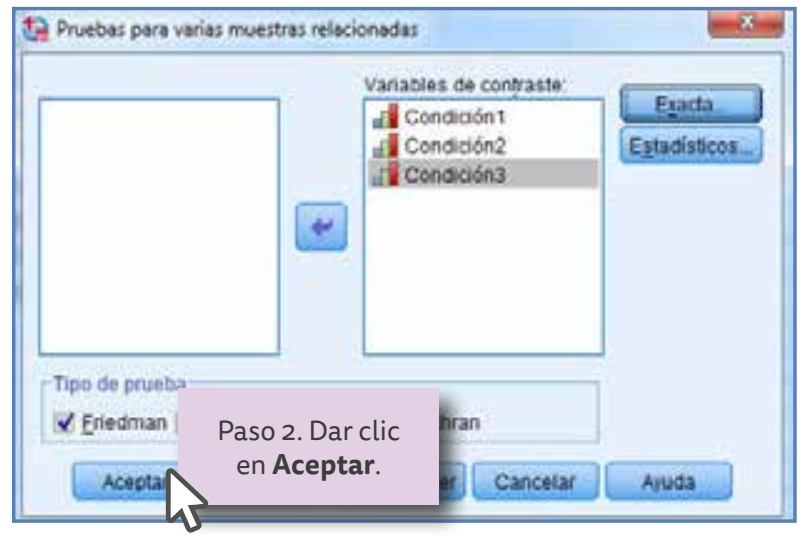

Figura 39. Paso para ejecutar el programa SPSS para que realice los cálculos requeridos.

Una vez realizadas estas acciones el programa queda listo para arrojar los resultados, al activar el botón Aceptar se obtienen los resultados que se muestran en el Cuadro 14.

En el cuadro se pueden observar los valores de las medias de cada condición, que coinciden con los del cálculo realizado en el apartado anterior. El valor del nivel de significación [Significación asintótica] $\rho<0.000$.

$$
\text { Entonces se puede concluir que } \rho_{\text {encontrada }} 0.000<\rho_{\text {aceptada }} 0.05
$$

Es decir, el valor encontrado es 0.000 es menor que el mínimo aceptable por los investigadores en educación (0.05), lo que significa que los resultados de la diferencia no son aleatorios puesto que existe una diferencia significativa, es así que se puede rechazar la hipótesis nula y aceptar la hipótesis de investigación.

Ver Resultados obtenidos con el programa SPSS para la prueba no paramétrica Friedman para tres muestras relacionadas en Cuadro 14.

El valor de $X^{2}$ calculado por medio del programa es ligeramente mayor que el valor calculado utilizando la fórmula, esto puede deberse a que el programa SPSS calcula el valor exacto de Chi-cuadrado $\left(X^{2}\right)$.

$$
X_{r \text {-calculado }}^{2}=19.54 \text { y } X^{2} \text { SPSS }=20.84
$$


Cuadro 14. Resultados obtenidos con el programa SPSS para la prueba no paramétrica Friedman para tres muestras relacionadas.

STPRR TzSTS

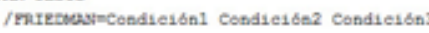

/statrstics sescarpatves

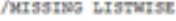

/NETHOONEXACT TMER(5).

$\rightarrow$ Pruebas no paramétricas

[Congunto_de_datoso]

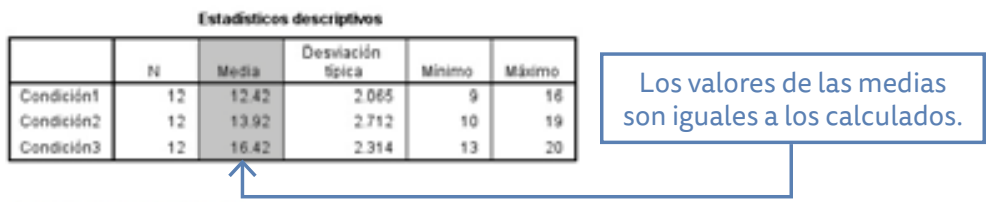

Prueba de Friedman

\begin{tabular}{|c|c|c|c|}
\hline \multicolumn{2}{|c|}{ Ranges } & & \\
\hline & $\begin{array}{l}\text { Rango } \\
\text { promengdio }\end{array}$ & & \multirow{4}{*}{$\begin{array}{l}\text { Los valores del promedio de } \\
\text { las clasificaciones } \\
\text { son iguales. }\end{array}$} \\
\hline Condicisnt & 1,17 & $K$ & \\
\hline Cenacisn? & 1.10 & & \\
\hline Condicien 3 & 2.96 & & \\
\hline
\end{tabular}

El nivel de significación bilateral y unilateral.

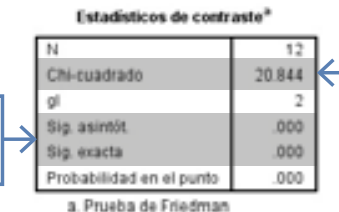

Hi: Si los alumnos escriben palabras poco comunes en un dictado, entonces éstos tendrán más errores ortográficos que si escriben palabras comunes. 



\section{Capítulo 8}

\section{Pruebas Kruskal-Wallis (muestras independientes)}

La prueba Kruskal-Wallis se utiliza para diseños no relacionados o independientes, es decir, cuando la Condición 1 se aplica a un grupo de participantes diferente a los de las condiciones 2 y 3 , los datos en este caso deben ser ordinales.

Ejemplo 83. Se trata de aceptar o rechazar la siguiente hipótesis de investigación:

$\mathrm{Hi}$ : Si a un grupo de participantes se les da a leer un libro que contiene un gran número de ejemplos de solución de problemas de matemáticas, estos participantes resolverán un mayor número de problemas que otros grupos de participantes que leyeron libros con pocos o ningún ejemplo.

\subsection{Estado situacional}

El investigador pretende conocer si el número de ejemplos para la solución de problemas de matemáticas contenidos en un texto influye en la capacidad de los participantes para resolver problemas de este tipo. Su estrategia consistió en seleccionar tres grupos de participantes; al primero le proporcionó un texto con muchos ejemplos, al segundo le proporcionó un texto con pocos ejemplos y al tercero grupo un texto que no contiene ejemplos.

Una vez analizados los textos se sometió a los tres grupos a una olimpiada de matemáticas, en la cual deben resolver 10 problemas con igual grado de dificultad entre ellos, el tiempo estimado fue de 40 minutos por lo que se les otorgó un tiempo de 60 minutos para que los resolvieran, se tomaron como datos el número de problemas resueltos por cada uno de los participantes.

Los grupos seleccionados fueron de $2^{\circ}$ grado de secundaria, integrados de la siguiente forma: Grupo H con 17 participantes, Grupo I con 20 participantes y el Grupo J con 16 participantes. La olimpiada se realizó en el gimnasio, a las 10:00 am en la misma fecha; se permitió utilizar calculadora científica. Los resultados obtenidos se muestran en la Tabla 13.

\subsection{Explicación}

La prueba Kruskal-Wallis consiste en comparar los totales de las categorías correspondientes a las tres condiciones a partir de la clasificación conjunta. Si hay aproximadamente las mismas categorías para las tres condiciones, entonces las diferencias entre las correlaciones clasificadas son aleatorias y se debe aceptar la hipótesis nula. Pero si hay predominio significativo para una de las condiciones en la dirección esperada, esta diferencia significativa entre los totales de las categorías para las dos condiciones permite rechazar la hipótesis nula y aceptar la hipótesis de investigación (Greene y D’oliveira, 2006). 
Tabla 13. Resultados obtenidos en la olimpiada de matemáticas por los participantes experimentales.

\begin{tabular}{|c|c|c|c|c|c|c|c|c|c|}
\hline 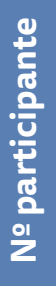 & 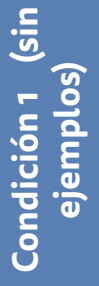 & 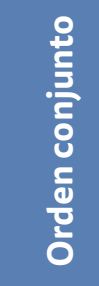 & 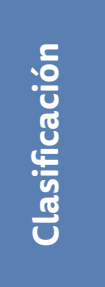 & 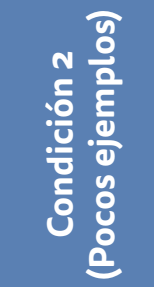 & 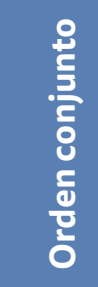 & 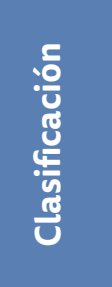 & 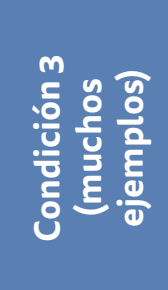 & 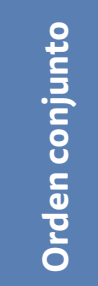 & 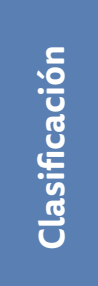 \\
\hline 1 & 6 & 20 & 25.5 & 7 & 33 & 36 & 9 & 48 & 48 \\
\hline 2 & 5 & 11 & 15 & 6 & 23 & 25.5 & 8 & 43 & 43 \\
\hline 3 & 7 & 32 & 36 & 7 & 34 & 36 & 10 & 52 & 52 \\
\hline 4 & 3 & 1 & 3 & 6 & 24 & 25.5 & 7 & 37 & 36 \\
\hline 5 & 5 & 12 & 15 & 5 & 16 & 15 & 6 & 30 & 25.5 \\
\hline 6 & 3 & 2 & 3 & 4 & 10 & 8 & 5 & 19 & 15 \\
\hline 7 & 4 & 6 & 8 & 5 & 17 & 15 & 7 & 38 & 36 \\
\hline 8 & 8 & 41 & 43 & 6 & 25 & 25.5 & 6 & 31 & 25.5 \\
\hline 9 & 4 & 7 & 8 & 9 & 46 & 48 & 9 & 49 & 48 \\
\hline 10 & 6 & 21 & 25.5 & 7 & 35 & 36 & 10 & 53 & 52 \\
\hline 11 & 5 & 13 & 15 & 6 & 26 & 25.5 & 7 & 39 & 36 \\
\hline 12 & 6 & 22 & 25.5 & 5 & 14 & 15 & 3 & 5 & 3 \\
\hline 13 & 3 & 3 & 3 & 3 & 4 & 3 & 8 & 44 & 43 \\
\hline 14 & 4 & 8 & 8 & 6 & 27 & 25.5 & 9 & 50 & 48 \\
\hline 15 & 5 & 14 & 15 & 6 & 28 & 25.5 & 7 & 40 & 36 \\
\hline 16 & 4 & 9 & 8 & 6 & 29 & 25.5 & 8 & 45 & 43 \\
\hline 17 & 5 & 15 & 15 & 7 & 36 & 36 & & & \\
\hline 18 & & & & 9 & 47 & 48 & & & \\
\hline 19 & & & & 8 & 42 & 43 & & & \\
\hline 20 & & & & 10 & 51 & 52 & & & \\
\hline \multicolumn{2}{|c|}{$\Sigma_{1}=83$} & \multicolumn{2}{|c|}{$T_{1}=271.5$} & $\Sigma_{2}=128$ & \multicolumn{2}{|c|}{$T_{2}=569.5$} & $\Sigma_{3}=119$ & \multicolumn{2}{|c|}{$T_{3}=590$} \\
\hline \multicolumn{2}{|c|}{$\bar{x}_{1}=4.9$} & \multicolumn{2}{|c|}{ Promedio 15.97} & $\bar{x}_{2}=6.4$ & \multicolumn{2}{|c|}{ Promedio 28.47} & $\bar{x}_{3}=7.44$ & \multicolumn{2}{|c|}{ Promedio 36.87} \\
\hline
\end{tabular}

De acuerdo a lo anterior la prueba Kruskal-Wallis para muestras independientes debe cumplir con los siguientes requisitos:

- Deben existir tres condiciones experimentales (una por grupo) con una variable.

- Las tres condiciones se deben aplicar a diferentes participantes.

- Los datos numéricos deben ser ordinales.

- Son pruebas no paramétricas ya que son las adecuadas para realizar análisis de datos numéricos ordinales.

\subsection{Procedimiento para determinar el valor de $H$}

1. Ordenar los resultados de los tres grupos juntos, como si fuera una sola serie de ordenamiento. Asignando el orden 1 al resultado menor y el 53 al mayor, de acuerdo al orden en que aparecen en la Tabla 13, llenando las columnas denominadas ordenación (conjunta).

2. Convertir el número de orden en categorías y llenar las columnas correspondientes a la designación de categorías. Hay que recordar que es necesario calcular las categorías de acuerdo a los números que se repiten, sumando su orden y dividiéndolo en el número de valores repetidos, por ejemplo, en este caso el número menor es el 3 al cual le corresponde el número de orden 1, pero hay cinco valores de 3, cuyo orden será 1, 2, 3, 4 y 5, entonces su categoría corresponde a $(1+2+3+4+5) / 5=3$, es decir, todos los valores 3 tienen la Categoría 3. 
3. Calcular el total de categorías de cada condición sumando los valores en cada caso de las categorías correspondientes, como se muestra en la Tabla 13, donde:

$$
T_{1}=271.5, T_{2}=569.5 \text { y } T_{3}=590
$$

4. Calcular el valor de $H$ utilizando la fórmula siguiente:

$$
H=\left[\frac{12}{N(N+1)} \sum \frac{T^{2}}{n}\right]-3(N+1)
$$

Donde:

$n_{1}=$ número de participantes para la Condición 1 (17).

$n_{2}=$ número de participantes para la Condición 2 (20).

$n_{3}=$ número de participantes para la Condición 3 (16).

$\sum \frac{T^{2}}{n}=$ suma de los cuadrados de los totales de categorías

para cada condición dividida entre el número de

participantes para esa condición.

$N=$ número total de participantes (53).

Calcular el valor de:

$$
\begin{gathered}
\sum \frac{T^{2}}{n}=\frac{T_{1}^{2}}{n_{1}}+\frac{T_{2}^{2}}{n_{2}}+\frac{T_{3}^{2}}{n_{3}} \\
\sum \frac{T^{2}}{n}=\frac{(271.5)^{2}}{17}+\frac{(569.5)^{2}}{20}+\frac{(590)^{2}}{16} \\
\sum \frac{T^{2}}{n}=4336.01+16216.51+21756.25=42308.77
\end{gathered}
$$

Sustituir los valores en la fórmula de $H$ :

$$
\begin{gathered}
H=\left[\frac{12}{N(N+1)} \sum \frac{T^{2}}{n}\right]-3(N+1) \\
H=\left[\frac{12}{53(53+1)}(42308.77)\right]-3(53+1) \\
H=[(0.0042)(42308.77)]-163=14.69
\end{gathered}
$$

5. Calcular los grados de libertad restando 1 al número de condiciones.

$$
g l=C-1=3-1=2
$$

6. Buscar el nivel de significación de $H$ en las tablas $F$ y $E$ del Apéndice D.

Tabla F: se debe utilizar para un máximo de cinco participantes, en esta tabla se debe buscar el tamaño de los grupos de los experimentos. En este ejemplo el tamaño de los grupos es $n_{1}=17, n_{2}=20$ y $n_{3}=16$, generalmente se ordenan de mayor a menor, por lo que la combinación de tamaños en este ejemplo sería 20, 17, 16.

El valor de $H$ calculado debe ser igual o mayor que los valores que aparecen en las tablas. La primera columna de cada serie de tamaños de los grupos contiene los valores de $H$ y 
la siguiente contiene los niveles de probabilidad asociada con cada valor de $H$. En este ejemplo no es posible utilizar esta tabla puesto que el número de participantes excede al valor de cinco.

Tabla E: se debe utilizar para más de cinco participantes, ésta es una tabla estadística más general, conocida como Chi cuadrado; para consultar las probabilidades se utilizan los grados de libertad $g l=C-1$. Considerando que en este ejemplo el número de participantes es mayor a cinco $(N=53)$ se utiliza esta tabla.

En la Tabla E se observan los grados de libertad $g l=2$, en donde el valor calculado 14.69 es mayor que el valor 13.82 para $\rho=0.001$.

$$
\begin{gathered}
X^{2}{ }_{r \text {-calculado }}=14.69 \text { (es mayor que) }>X^{2}{ }_{r \text {-tabla }}=13.82 \\
\text { para un nivel de significación de } \rho<0.001
\end{gathered}
$$

El nivel de significación es $\rho=0.001$, por debajo de la probabilidad que proponen los investigadores en educación como máximo valor aceptable, es decir, $\rho<0.05$, entonces se puede rechazar la hipótesis nula y aceptar la de investigación. Definitivamente si los participantes utilizan el libro con mayor número de ejemplos resuelven más problemas de matemáticas correctamente que los alumnos que utilizan los libros con pocos o ningún ejemplo.

\subsection{Prueba Kruskal-Wallis utilizando el programa SPSS}

Se inicia este proceso otorgando las propiedades a las variables, una vez abierto el programa, antes de introducir los datos es necesario definir las variables y designar las características para su presentación en la tabla, para lo cual se requiere hacer un clic en la pestaña Vista de variables (Ver Figura 41).

Cuando se trata de muestras no relacionadas o independientes los valores de los datos obtenidos se deben colocar en una misma columna como la primera variable la que se designará como Condiciones 1, 2 y 3 ; y la segunda variable se designa como Agrupación en donde se especifica cuáles son los datos de la columna 1 que corresponden a la Condición 1 (Grupo 1), Condición 2 (Grupo 2) y Condición 3 (Grupo 3).

En este caso se teclea en el primer espacio para Nombre, la primera variable Condiciones1a3, recodando que no debe haber espacios vacíos entre los caracteres, aquí se deben anotar las tres condiciones, es decir, los datos obtenidos por los participantes de la lectura de textos sin ejemplos, en seguida la lectura de textos con pocos ejemplos y finalmente los participantes de la lectura de textos con muchos ejemplos.

El siguiente paso es introducir el nombre de la segunda variable en el espacio 2 de la columna nombre, los datos se denominan con el término de Agrupación (variable de agrupación) en este caso se utilizan tres valores: 1 para indicar que se refiere a los datos correspondientes al Grupo 1 (sin ejemplos), el número 2 para el Grupo 2 (con pocos ejemplos), y por último el número 3 para el Grupo 3 (con muchos ejemplos).

Para designar las Etiquetas de valor, es decir, definir la ubicación de los grupos dentro de la tabla, en la línea de agrupación y columna valores se da clic con el apuntador y aparece un cuadro de diálogo, en la ventana Valor (Figura 40) se coloca el número del grupo (1 para el primer grupo, Condición 1) y la ventana Etiqueta el nombre con que se etiqueta al grupo (Grupo 1), se da clic en el botón Añadir y los datos se transfieren a la ventana inferior; se repiten estos pasos para registrar los valores para las condiciones 2 y 3. 


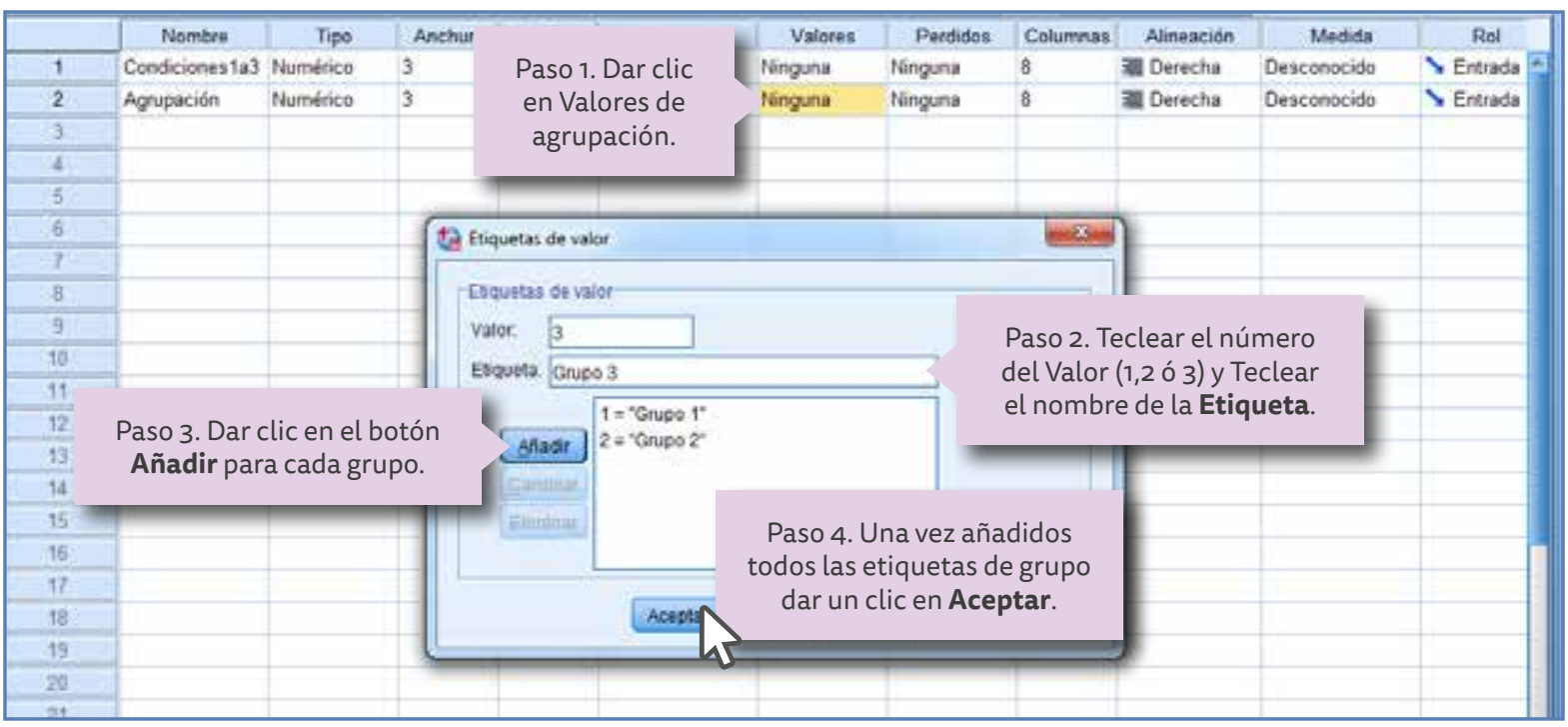

Figura 40. Ventana de diálogo para etiquetar los valores de agrupación.

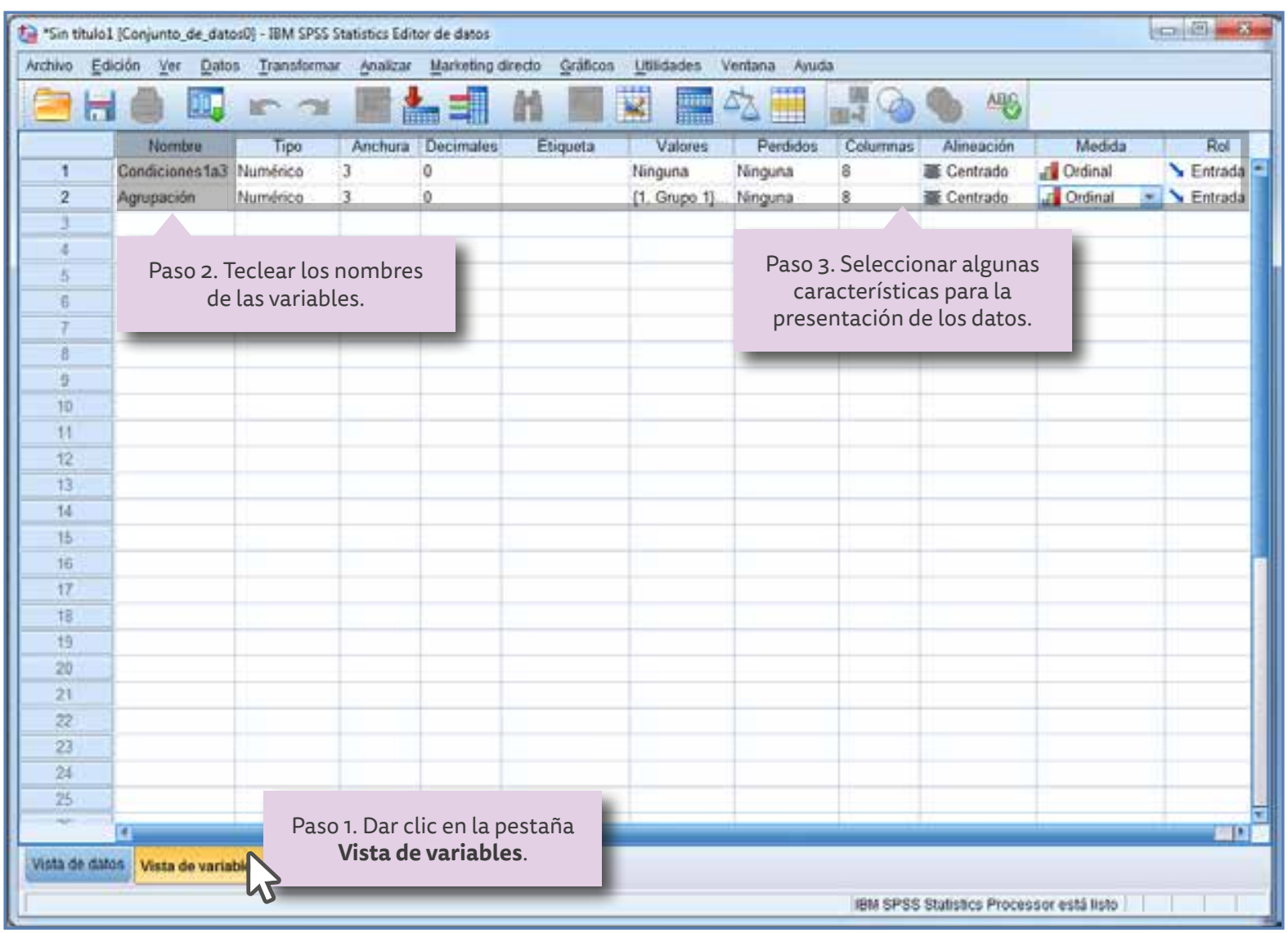

Figura 41. Designación del nombre de las variables y características de presentación para la prueba de matemáticas.

Las características seleccionadas para la presentación de las variables, así como los nombres de éstas, se observan en la Figura 41.

Una vez designados los nombres de las variables y sus características se procede a introducir los datos en la tabla; para llevar a cabo ésto es necesario dar un clic en la pestaña Vista de datos, e introducir los datos de la siguiente manera: 
1. En la columna 1 (Condición1a3) se introducen los valores de los datos obtenidos por el grupo de la Condición 1, en seguida se introducen los datos de la Condición 2 y por último se introducen los datos de la Condición 3.

2. En la columna dos (Agrupación) se introduce el valor de 1 para todos los datos que correspondan a la Condición 1, el valor de 2 para los datos correspondientes a la Condición 2 y por último el valor de 3 para los datos correspondientes a la Condición 3.

En el siguiente cuadro se observan las variables seleccionadas en este ejemplo:

Cuadro 15. Designación de variables para la prueba Kruskal-Wallis (independiente).

\begin{tabular}{l|l|}
\hline Nombre: Condición1a3 & Nombre: Agrupación \\
\hline Tipo: Numérico & Tipo: Numérico \\
\hline Anchura: 3 & Anchura: 3 \\
\hline Decimales: 0 & Decimales: o \\
\hline Etiqueta: Nada & Etiqueta: Nada \\
\hline Valores: Ninguno & Valores: 1 . Grupo 1, 2. Grupo 2 y 3. Grupo 3 \\
\hline Perdidos: Ninguno & Perdidos: Ninguno \\
\hline Columnas: 8 & Columnas: 8 \\
\hline Alineación: Centrado & Alineación: Centrado \\
\hline Medida: Ordinal & Medida: Ordinal \\
\hline Roll: Entrada & Roll: Entrada \\
\hline
\end{tabular}

En la Figura 42 se observa cómo deben quedar los datos siguiendo los procedimientos mencionados y de acuerdo a las características seleccionadas en los pasos anteriores.

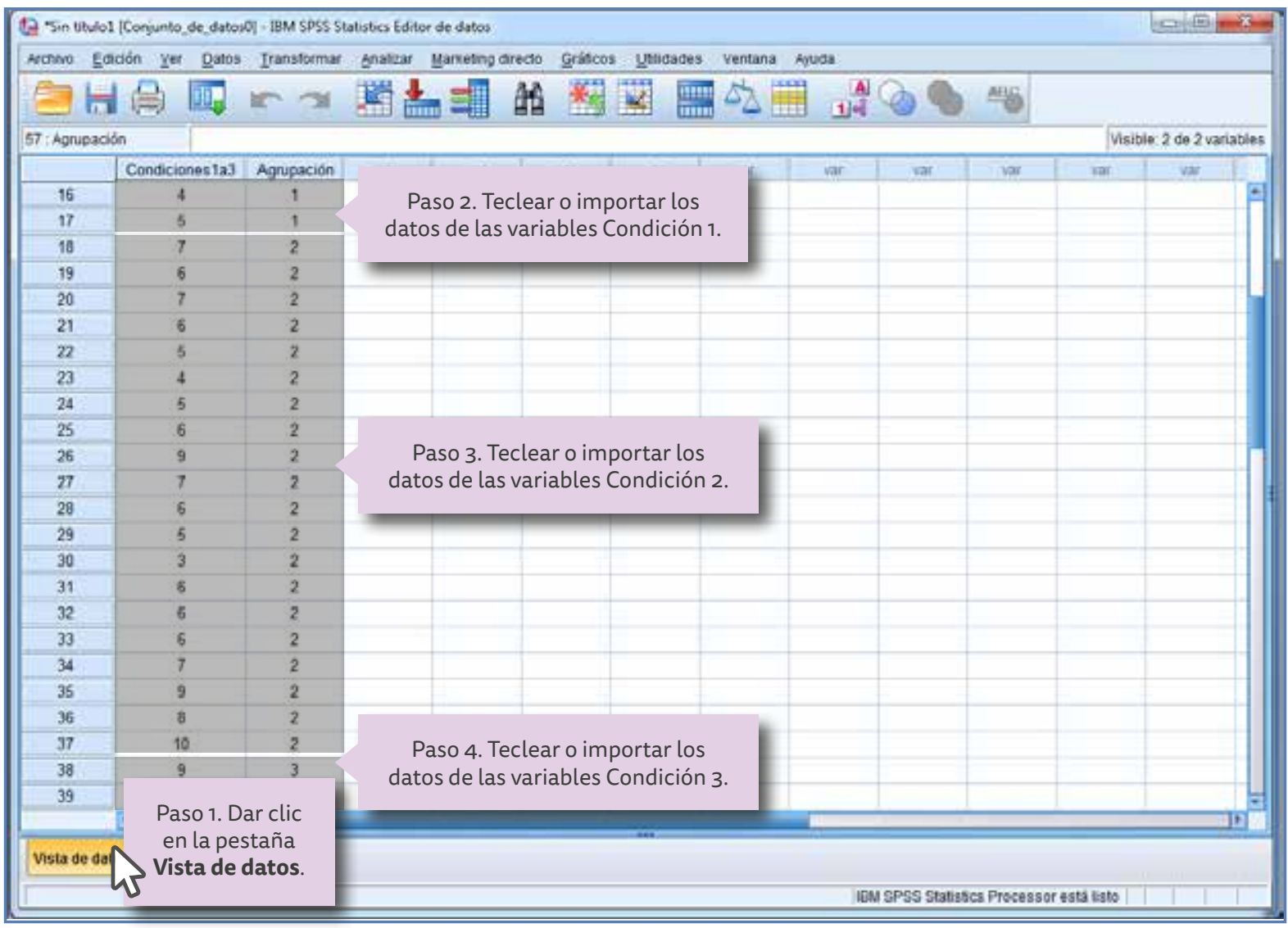

Figura 42. Presentación de los datos arrojados por los participantes en las estratégias de matemáticas. 


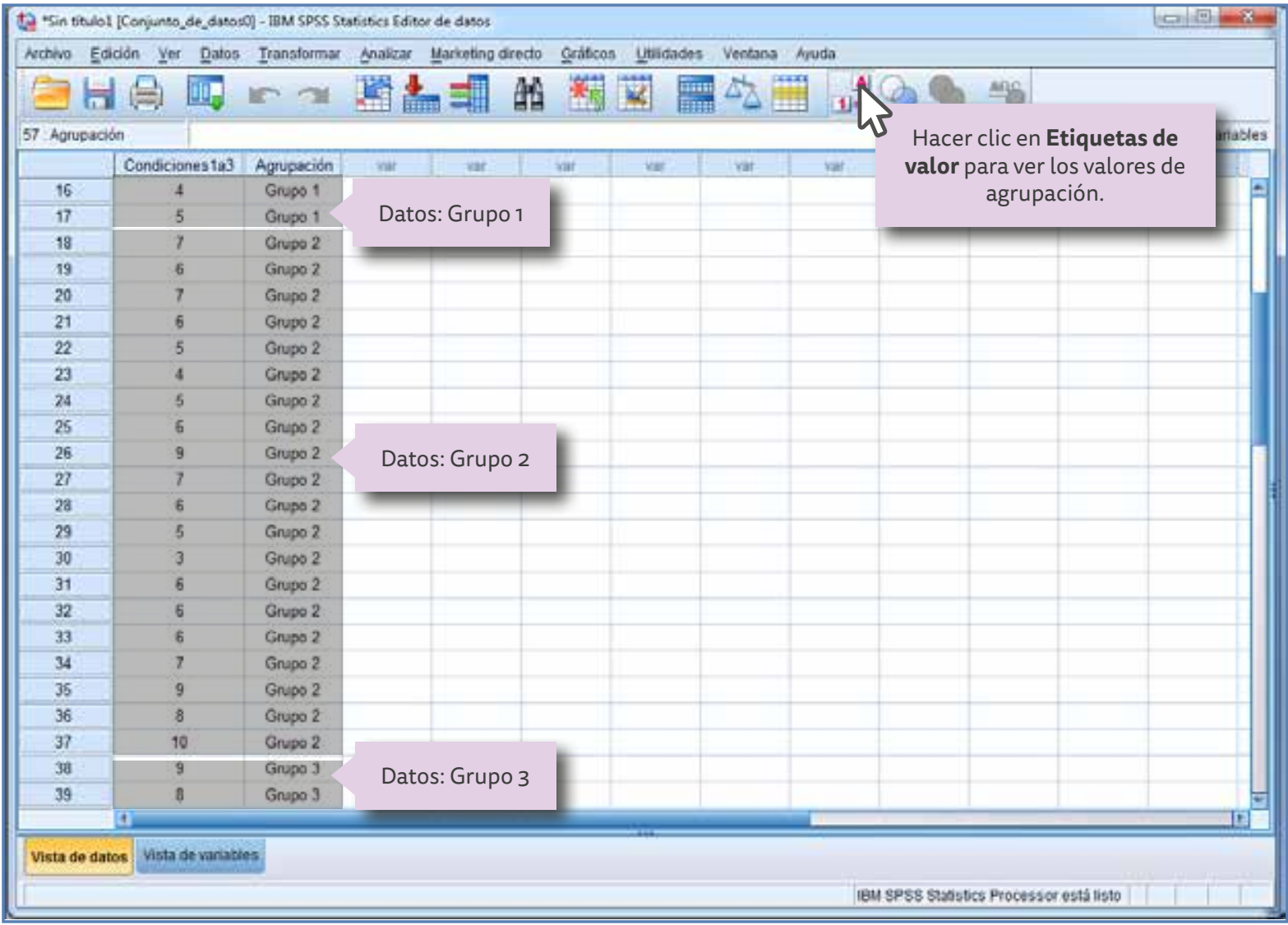

Figura 43. Presentación de los datos activando las etiquetas de valor.

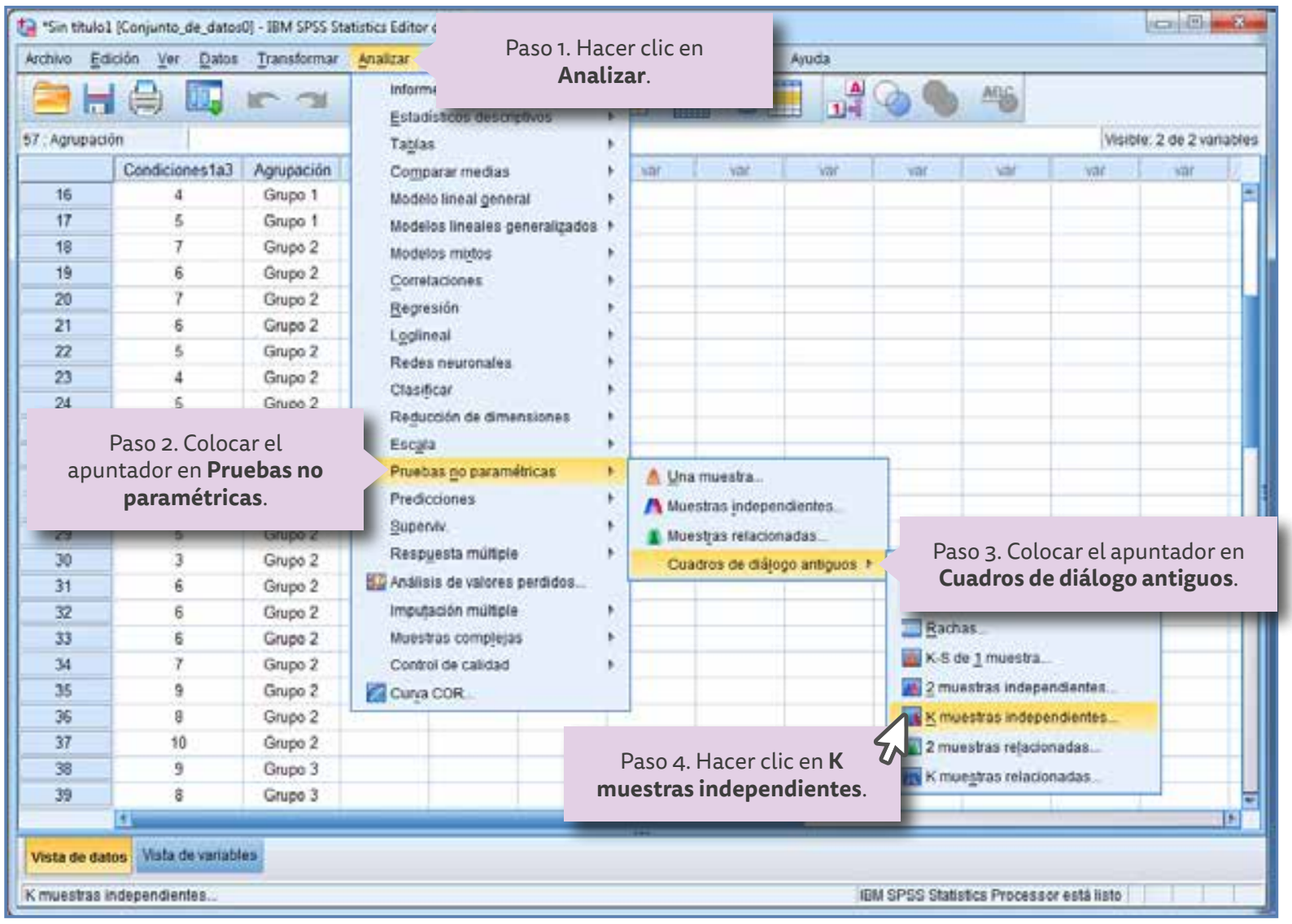

Figura 44. Cuadros de diálogo para seleccionar la prueba no paramétrica de dos muestras independientes. 
Otra manera de verificar si los datos coinciden con los grupos es activando la etiqueta de valores de agrupación; las cuales al programar las características se etiquetaron como $1=$ Grupo 1, 2 = Grupo 2 y el 3 = Grupo 3, mostrándose como se puede observar en la Figura 43.

Después de introducir los datos en la tabla, se realiza la prueba (Figura 44), para hacerlo es necesario dar un clic en la pestaña ubicada en la barra superior designada como Analizar, en seguida aparece un cuadro de diálogo, en el cual se selecciona la línea que indica Pruebas no paramétricas, por pertenecer precisamente la prueba Kruskal-Wallis a este tipo.

Al ubicar el apuntador del ratón en esta opción se presenta a la derecha otro cuadro de diálogo con cuatro opciones, se selecciona la que corresponde colocando el apuntador en Cuadros de diálogo antiguos y aparecen otras opciones, se selecciona $\mathbf{K}$ muestras independientes (las cuales corresponden al presente problema) dando clic con el ratón.

Después de estas acciones aparece la ventana de la Figura 45, la cual muestra las variables del lado izquierdo, Condición1a3 y Agrupación, la primera debe ser trasladada a la ventana que dice Lista contrastar variables; la forma de hacerlo es seleccionar con un clic la variable deseada (Condición1a3) y dar clic en la flecha que se ubica entre las dos ventanas.

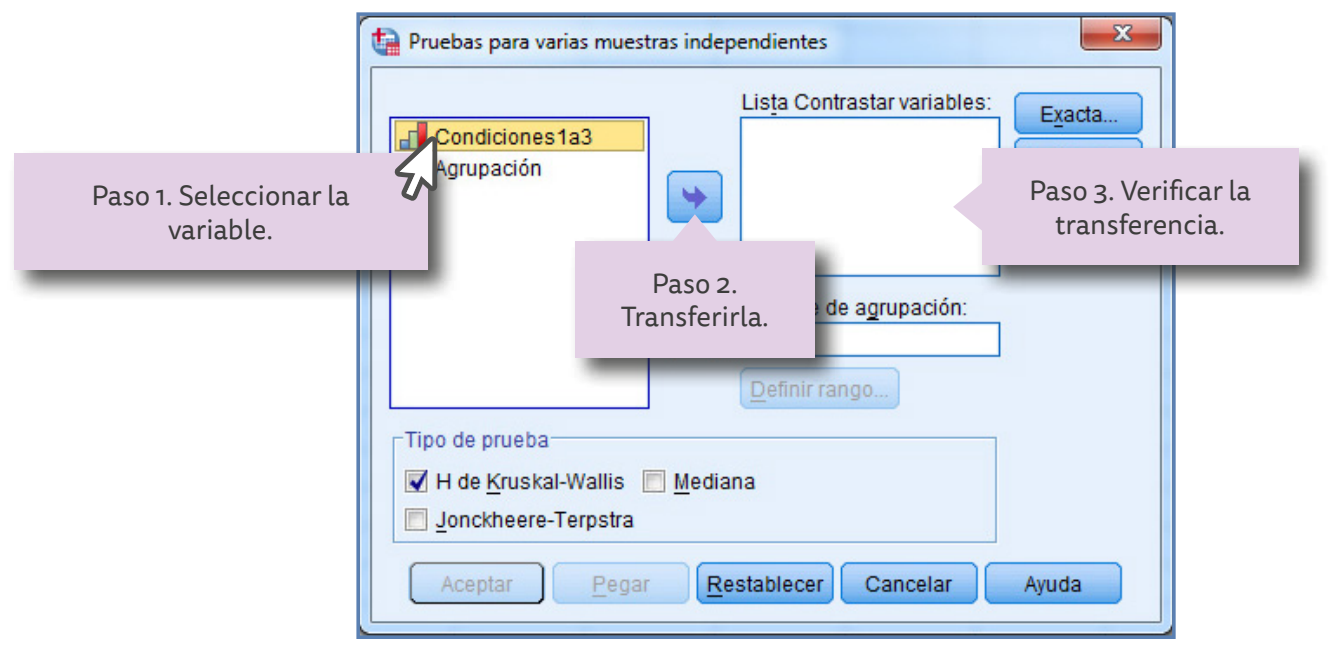

Figura 45. Pasos para ingresar las variables condiciones a la lista contrastar variables al programa SPSS.

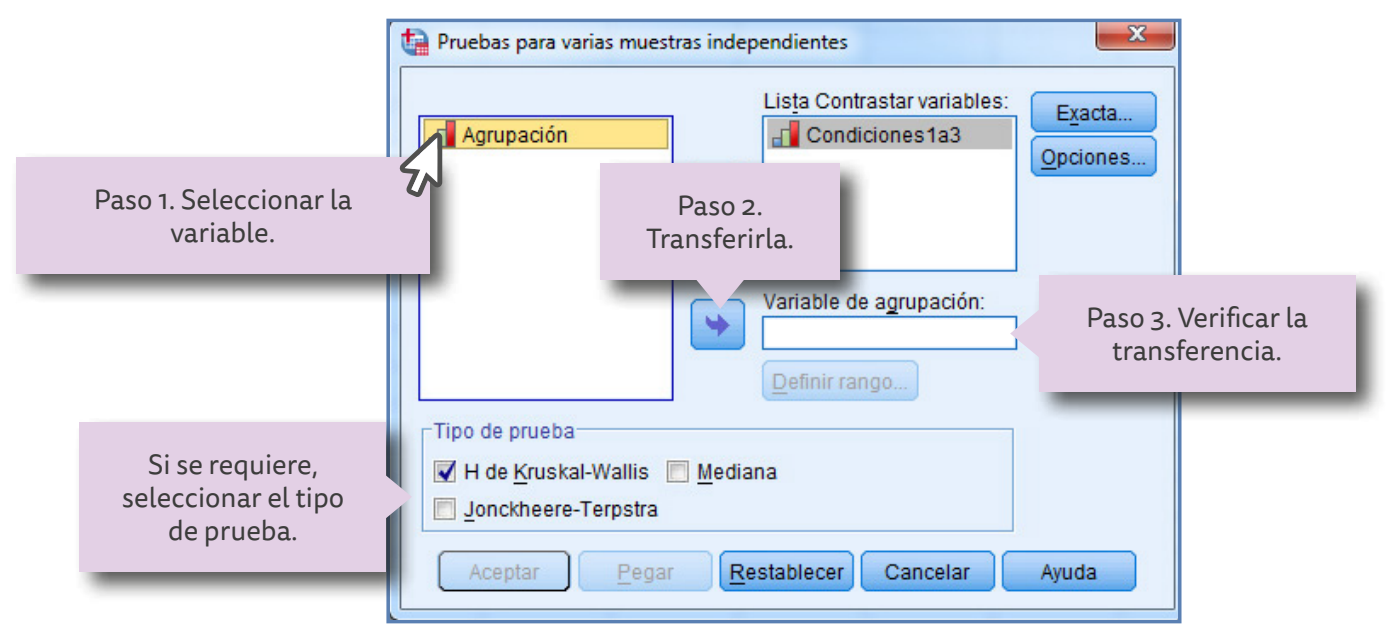

Figura 46. Pasos para ingresar las variables Agrupación al programa SPSS. 
Para trasladar la otra variable (agrupación) se da un clic en la flecha que se encuentra entre las ventanas y se traslada a la ventana designada como Variables de agrupación; se observa que el programa preselecciona el tipo de prueba $\mathrm{H}$ de Kruskal-Wallis (Figura 46).

Para que en los resultados se muestren los datos de los estadísticos descriptivos es necesario activar con el apuntador el botón que indica Opciones (ver Figura 47), al momento de dar clic se muestra un cuadro de diálogo en el cual es necesario activar la opción Descriptivos, colocando el apuntador en la pequeña ventana y dando clic; al efectuar esta acción aparece una palomita que indica que se seleccionó.

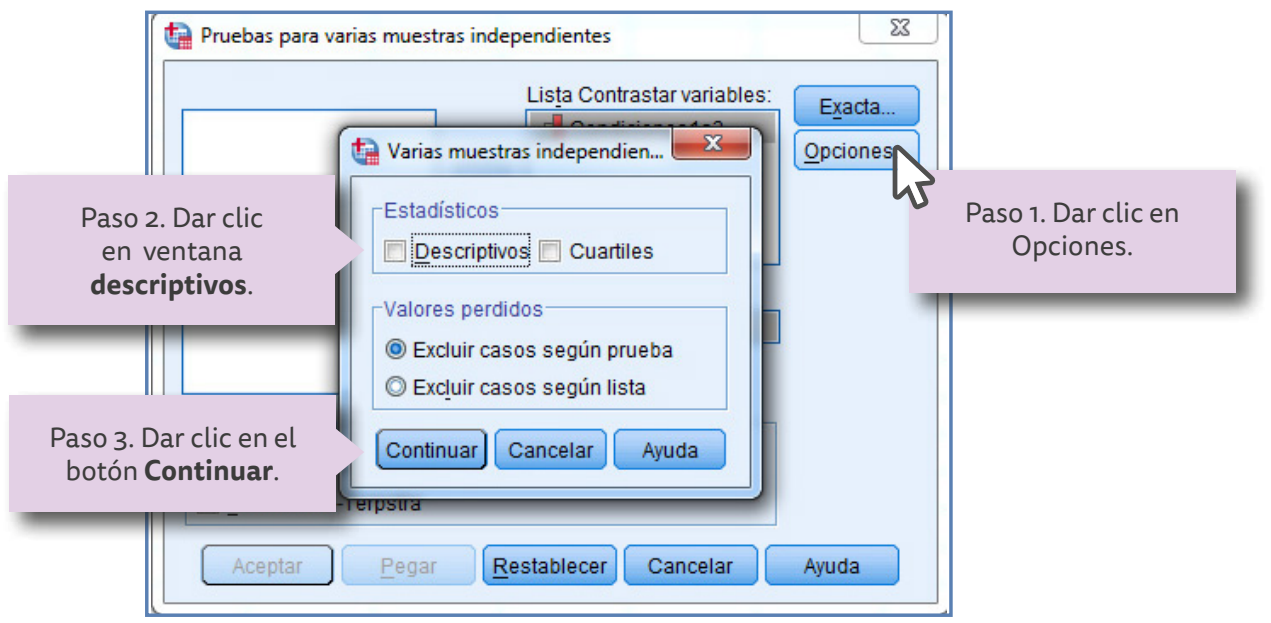

Figura 47. Proceso para que el programa muestre la tabla de estadísticos descriptivos.

Después de esta acción se activa el botón Continuar, con el apuntador y dando clic se regresa al cuadro de diálogo anterior.

Se puede observar que el programa aún no habilita el botón de Aceptar (Figura 48), está esperando que se definan los grupos de acuerdo a la columna de agrupación, para hacer esto se requiere dar clic en el botón que se encuentra debajo de la ventana de Variable de agrupación, el cual especifica Definir rango y aparece una sub ventana en donde se teclea el número 1 para el mínimo y el 3 para el máximo, finalmente se da clic en el botón Continuar.

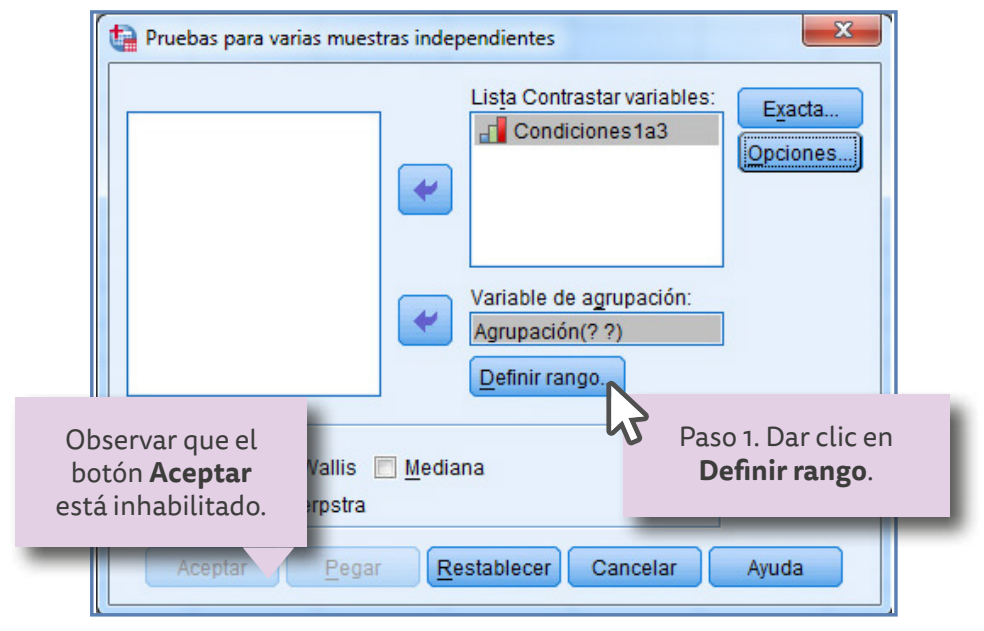

Figura 48. Actividad para definir los grupos paso 1.

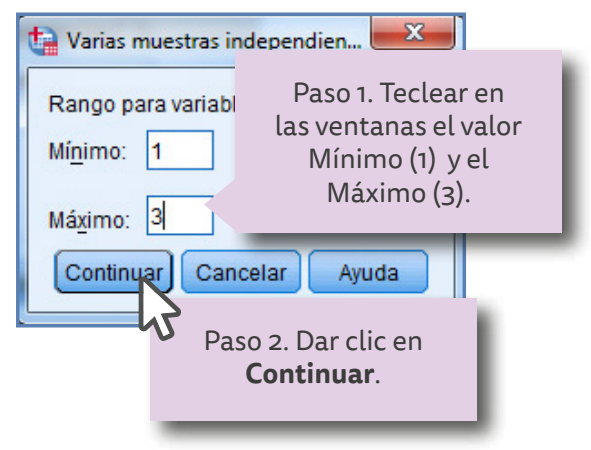

Figura 49. Actividad para definir los grupos paso 2.

Una vez realizado este proceso se habilita el botón Aceptar (ver Figura 50), se da clic en este botón y aparecen los resultados que se muestran en el Cuadro 16. 


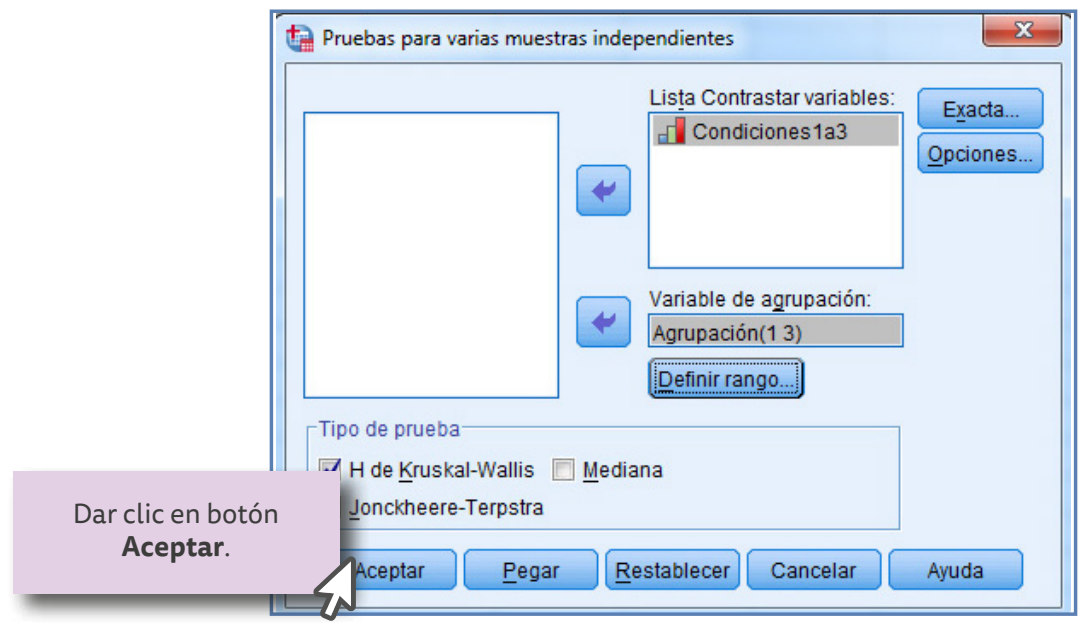

Figura 50. Paso para ejecutar el programa SPSS para que realice los cálculos requeridos.

En el cuadro 16 se observan los valores de los promedios de las clasificaciones por condición, los cuales coinciden con los del cálculo realizado en el apartado anterior (Rango promedio). El valor del nivel de significación [Significación asintótica] $\rho<0.000$.

$$
\text { Entonces se puede concluir que } \rho_{\text {encontrada }} 0.000<\rho_{\text {aceptada }} 0.05
$$

Es decir, el valor encontrado es 0.000 que es menor que el mínimo aceptable por los investigadores en educación (0.05), lo que significa que los resultados de la diferencia no son aleatorios puesto que existe una diferencia significativa, por lo que se puede rechazar la hipótesis nula y aceptar la hipótesis de investigación.

Cuadro 16. Resultados obtenidos con el programa SPSS para la prueba no paramétrica Kruskal-Wallis para dos muestras independientes.

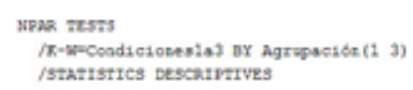

\begin{tabular}{|c|c|c|c|c|c|}
\hline \multicolumn{6}{|c|}{ Estassticos descriphens } \\
\hline & N & Media & $\begin{array}{c}\text { Despiation } \\
\text { toika }\end{array}$ & Ninimo & Nabimo \\
\hline Conditionat1s) & 53 & 6.21 & 1.920 & 3 & 10 \\
\hline Avupasión & 53 & 1.98 & .795 & 1 & 3 \\
\hline
\end{tabular}

Prueba de Kruskal-Wallis
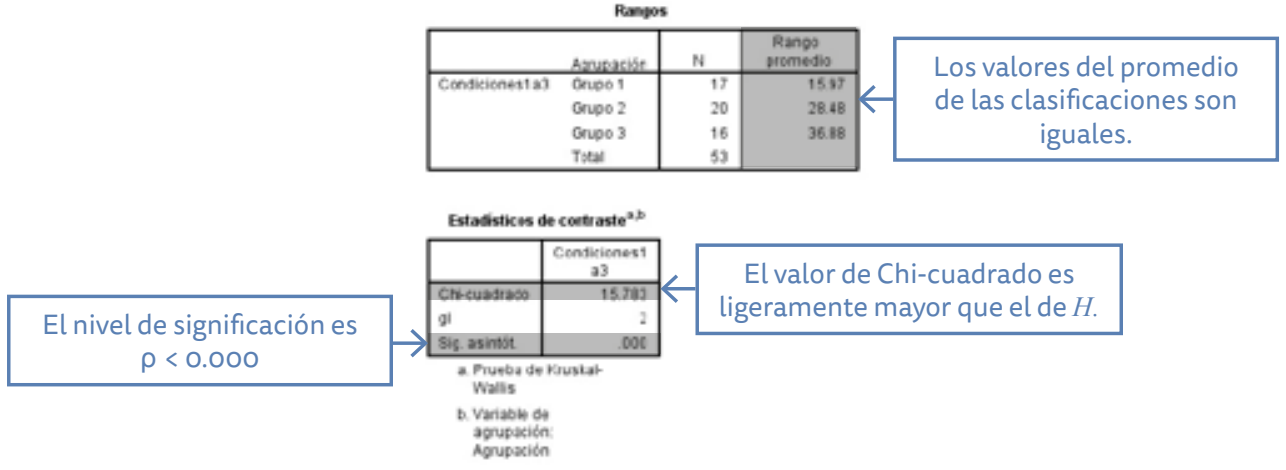
Hi: Si a un grupo de participantes se les da a leer un libro que contiene un gran número de ejemplos de solución de problemas de matemáticas, estos participantes resolverán un mayor número de problemas que otros grupos de participantes que leyeron libros con pocos o ningún ejemplo.

El valor de $X^{2}$ calculado por medio del programa es ligeramente mayor que el valor calculado utilizando de $H$ la fórmula, esto se puede deber a que el programa SPSS calcula el valor exacto de Chi-cuadrado $\left(X^{2}\right)$.

$$
H_{\text {calculado }}=14.69 \text { y } X^{2} \text { SPSS }=15.783
$$





\section{PARTE VI \\ ¿Cuándo utilizar las pruebas paramétricas?}





\section{Capítulo 9}

\section{Prueba $t$ (muestras relacionadas)}

La prueba $t$ se debe utilizar para diseños relacionados cuando dos condiciones se aplican a los mismos participantes y los datos corresponden a la escala de intervalo.

Ejemplo 84. Se trata de aceptar o rechazar la siguiente hipótesis de investigación:

$\mathrm{Hi}$ : Si se aplican las dinámicas grupales-vivenciales como refuerzo en la materia de Seminario de Aprendizaje y Desarrollo, los alumnos del primer semestre del bachillerato comprenderán mejor los contenidos.

\subsection{Estado situacional}

El investigador desea saber si el uso de dinámicas grupales-vivenciales influye en la comprensión de contenidos de los participantes de manera significativa, por lo que en una primera intervención (Condición 1) se les aplicó un examen de conocimientos de diagnóstico para establecer las condiciones iniciales del grupo experimental $\left(x_{\mathrm{e}}\right)$, después de utilizar las dinámicas grupales-vivenciales, se aplicó un examen de verificación (Condición 2). La variable independiente consistió en utilizar dinámicas grupales-vivenciales, y la variable dependiente en la comprensión de mayor número de conceptos.

Se seleccionó al grupo de 1ํ A de bachillerato, conformado con 30 alumnos, al cual se le aplicó un examen diagnóstico antes, con el tema "la autoestima" y otro de verificación después, cuyo tema fue "el aprendizaje académico y su instrumentación en el aprendizaje".

En la Tabla 14 se muestran los resultados obtenidos del examen diagnóstico (antes), del examen posterior (después) y el desarrollo del análisis estadístico utilizado. Se calcula el valor para la prueba de media $t$ relacionada.

\subsection{Explicación}

La prueba $t$ para muestras relacionadas. El concepto de muestras relacionadas se refiere a que los mismos participantes son sometidos a dos condiciones, es decir, antes de la intervención y después de la misma, generando dos resultados por participante. La varianza esperada se determina por medio de la suma de las diferencias entre los resultados correspondientes a las dos condiciones (Greene y D'oliveira, 2006).

La varianza pronosticada entre las dos condiciones se expresa como una proporción de la varianza total. Si el valor de la varianza debido a las diferencias pronosticadas es relativamente grande con respecto al de la varianza total, se puede rechazar la hipótesis nula y aceptar la de investigación. Esta prueba también recibe el nombre de prueba $t$ pareada y se calcula de acuerdo a pares de resultados relacionados. 
Tabla 14. Puntajes obtenidos en la evaluación previa y posterior a la aplicación de las dinámicas grupales del grupo experimental.

\begin{tabular}{|c|c|c|c|c|}
\hline \multirow{2}{*}{$\begin{array}{l}\text { Número } \\
\text { Sujetos }\end{array}$} & Antes & Después & Diferencia & Diferencia 2 \\
\hline & $x_{\mathrm{e} 1}$ & $x_{\mathrm{e} 2}$ & $d=x_{\mathrm{e} 2}-x_{\mathrm{e} 1}$ & $d^{2}$ \\
\hline 1 & 8.36 & 10 & 1.64 & 2.69 \\
\hline 2 & 8.36 & 10 & 1.64 & 2.69 \\
\hline 3 & 6.92 & 9.36 & 2.44 & 5.95 \\
\hline 4 & 6.92 & 9.36 & 2.44 & 5.95 \\
\hline 5 & 5.48 & 7.92 & 2.44 & 5.95 \\
\hline 6 & 6.92 & 9.36 & 2.44 & 5.95 \\
\hline 7 & 3.32 & 5.76 & 2.44 & 5.95 \\
\hline 8 & 8.36 & 10 & 1.64 & 2.69 \\
\hline 9 & 4.4 & 7.92 & 3.52 & 12.39 \\
\hline 10 & 7.64 & 10 & 2.36 & 5.57 \\
\hline 11 & 5.48 & 8.64 & 3.16 & 9.98 \\
\hline 12 & 4.76 & 7.92 & 3.16 & 9.98 \\
\hline 13 & 4.76 & 9.36 & 4.6 & 21.16 \\
\hline 14 & 6.92 & 10 & 3.08 & 9.48 \\
\hline 15 & 6.2 & 9.36 & 3.16 & 9.98 \\
\hline 16 & 6.92 & 9.36 & 2.44 & 5.95 \\
\hline 17 & 5.76 & 7.92 & 2.16 & 4.66 \\
\hline 18 & 3.32 & 6.48 & 3.16 & 9.98 \\
\hline 19 & 2.6 & 7.2 & 4.6 & 21.16 \\
\hline 20 & 4.3 & 7.2 & 2.9 & 8.41 \\
\hline 21 & 5.48 & 9.36 & 3.88 & 15.05 \\
\hline 22 & 7.64 & 9.36 & 1.72 & 2.96 \\
\hline 23 & 8.36 & 9.36 & 1 & 1 \\
\hline 24 & 8.36 & 9.36 & 1 & 1 \\
\hline 25 & 6.92 & 7.92 & 1 & 1 \\
\hline 26 & 10 & 10 & 0 & 0 \\
\hline 27 & 8.64 & 8.64 & 0 & 0 \\
\hline 28 & 5.76 & 5.76 & 0 & 0 \\
\hline 29 & 9.36 & 7.92 & -1.44 & 2.07 \\
\hline 30 & 9.36 & 8.64 & -0.72 & 0.52 \\
\hline Suma & $\sum x_{1}=197.58$ & $\Sigma x_{2}=259.44$ & $\Sigma d=61.86$ & $\Sigma d^{2}=190.12$ \\
\hline Media & $\bar{x}_{1}=6.58$ & $\bar{x}_{2}=8.62$ & & \\
\hline
\end{tabular}

Los datos que se utilizan en esta prueba deben de ser de intervalo, esto significa que son de valor numérico y la distancia o intervalo entre sus valores debe ser igual. Por ejemplo, un examen de conocimientos en el que cada reactivo tiene el mismo valor, si son 10 reactivos cada uno vale 1, es decir, si se obtienen 8 aciertos la calificación es de 8, pero si fueran 20 reactivos cada uno valdría 0.5 , es decir, si tuviera 8 aciertos la calificación sería igual a 4 . En los dos casos la distancia o intervalo entre los valores es constante: 1 para 10 reactivos y 0.5 para 20.

El concepto de intervención consiste en que los sujetos participantes sean sometidos a un proceso pedagógico que rompa con los convencionalismos de las estrategias pedagógicas tradicionales, ya sean éstas de enseñanza o aprendizaje, utilizado por el maestro para propiciar que el alumno establezca contacto con los saberes de una manera significativa. Ejemplo de lo anterior puede ser utilizar juegos matemáticos para que el alumno desarrolle sus habilidades en esta disciplina o, como en el ejemplo que se trata en este ejercicio, utilizar dinámicas grupales-vivenciales. 
De acuerdo a lo anterior, la prueba $t$ para muestras relacionadas debe cumplir con los siguientes requisitos:

- Deben existir dos condiciones experimentales (antes y después) con una variable.

- Las dos condiciones se deben aplicar a los mismos participantes.

- Los datos numéricos deben ser de intervalo.

- Son pruebas paramétricas ya que son adecuadas para realizar análisis de datos numéricos de intervalo.

9.3 Procedimiento para determinar el valor de $t$ (relacionada)

1. Calcular las diferencias entre los resultados de los participantes, para lo cual se requiere restar a los valores de los resultados de la Condición 2, los valores de los resultados obtenidos en la Condición 1, elaborando la columna d.

$$
d=x e_{2}-x e_{1}
$$

2. Calcular la suma de las diferencias, tomando en cuenta los signos positivos y negativos.

$$
\sum d=61.86
$$

3. Calcular el cuadrado de las diferencias y elaborar la columna $\mathrm{d}^{2}$.

4. Sumar los cuadrados de las diferencias.

$$
\sum d^{2}=190.12
$$

5. Calcular el valor de $t$ utilizando la siguiente fórmula:

$$
t=\frac{\sum d}{\sqrt{\frac{N \sum \mathrm{d}^{2}-\left(\sum \mathrm{d}\right)^{2}}{N-1}}}
$$

Donde:

$N=$ número total de participantes $=30$

$\sum d^{2}=$ suma del cuadrado de las diferencias $=190.12$

$\sum d=$ suma de las diferencias $=61.86$

$\left(\sum d\right)^{2}=$ cuadrado de la suma de las diferencias $=(61.86)^{2}$

Sustituyendo los valores:

$$
\begin{gathered}
t=\frac{61.8}{\sqrt{\frac{\left(30(190.12)-(61.86)^{2}\right.}{30-1}}} \\
t=7.686
\end{gathered}
$$


6. Calcular el valor de los grados de libertad.

$$
g l=N-1=30-1=29
$$

7. Buscar el nivel de significación de la prueba $t$ (relacionada) en la Tabla G del Apéndice D.

La Tabla G contiene las probabilidades correspondientes a los valores de $t$ para dos condiciones ya sea relacionada o independiente. El valor de $t$ calculado debe ser igual o mayor que los valores que aparecen en la Tabla $\mathrm{G}$.

Para encontrar el valor de $t$ se debe buscar en la primer columna los grados de libertad $(g l=29)$ en donde el valor calculado 7.689 es mayor que el valor 3.659 para $\rho<0.0005$, para una hipótesis unilateral.

$$
\begin{gathered}
t_{\text {calculado }}=7.686 \text { (es mayor que) }>t_{\text {tabla }}=3.659 \\
\text { para un nivel de significación de } \rho<0.0005
\end{gathered}
$$

El nivel de significación es $\rho<0.0005$, que está por debajo de la probabilidad que proponen los investigadores en educación como máximo valor aceptable esto es $\rho<0.05$, entonces se puede rechazar la hipótesis nula y aceptar la de investigación.

Al utilizar las dinámicas grupales-vivenciales, los participantes obtuvieron mayor puntaje en la evaluación posterior que en la evaluación diagnóstica de manera significativa y no aleatoria.

\subsection{Prueba $t$ (relacionada) utilizando el programa SPSS}

El programa SPSS para esta prueba permite determinar el nivel de significación comparándolo con el nivel mínimo utilizado por los investigadores en educación que corresponde a $\rho<0.05$, si el que se determina mediante el proceso del programa resulta mayor que este valor, entonces se puede decir que las diferencias de los resultados son causados por variables aleatorias y se debe aceptar la hipótesis nula, pero si el valor es menor entonces las diferencias son significativas, se debe rechazar la hipótesis nula y aceptar la hipótesis de investigación.

El primer paso consiste en otorgarle las propiedades a las variables, una vez abierto el programa, antes de introducir los datos, es necesario definir las variables y otorgar las características para su presentación en la tabla, para esto se requiere dar un clic en la pestaña Vista de variables. En este caso las acciones indispensables para obtener los resultados correctos son:

a. Designar los nombres de las variables. Para realizar esto es necesario presionar la ceja de Vista de variables, y en seguida teclear el nombre de cada variable, primero en la columna Nombre (primera) y la fila 1, la palabra Condición1, debe ir sin espacio entre la palabra y el número debido a que el programa no reconoce caracteres vacíos, segundo en la columna Nombre pero ahora en la fila 2, escribir Condición2.

b. Definir el tipo de medida que se utilizó. Debido a que los datos son de intervalo se requiere que en la columna Medida selecciones la opción Escala.

El programa preselecciona el tipo de variables como numérico, para darle presentación a los datos se pueden realizar las siguientes operaciones (pero no es necesario): definir la Anchura (4) y cantidad de Decimales (2) requeridos y la Alineación (centrado).

En la Figura 51 se observan estos pasos así como la ubicación de cada variable y las opciones para la definición y presentación de las variables. 


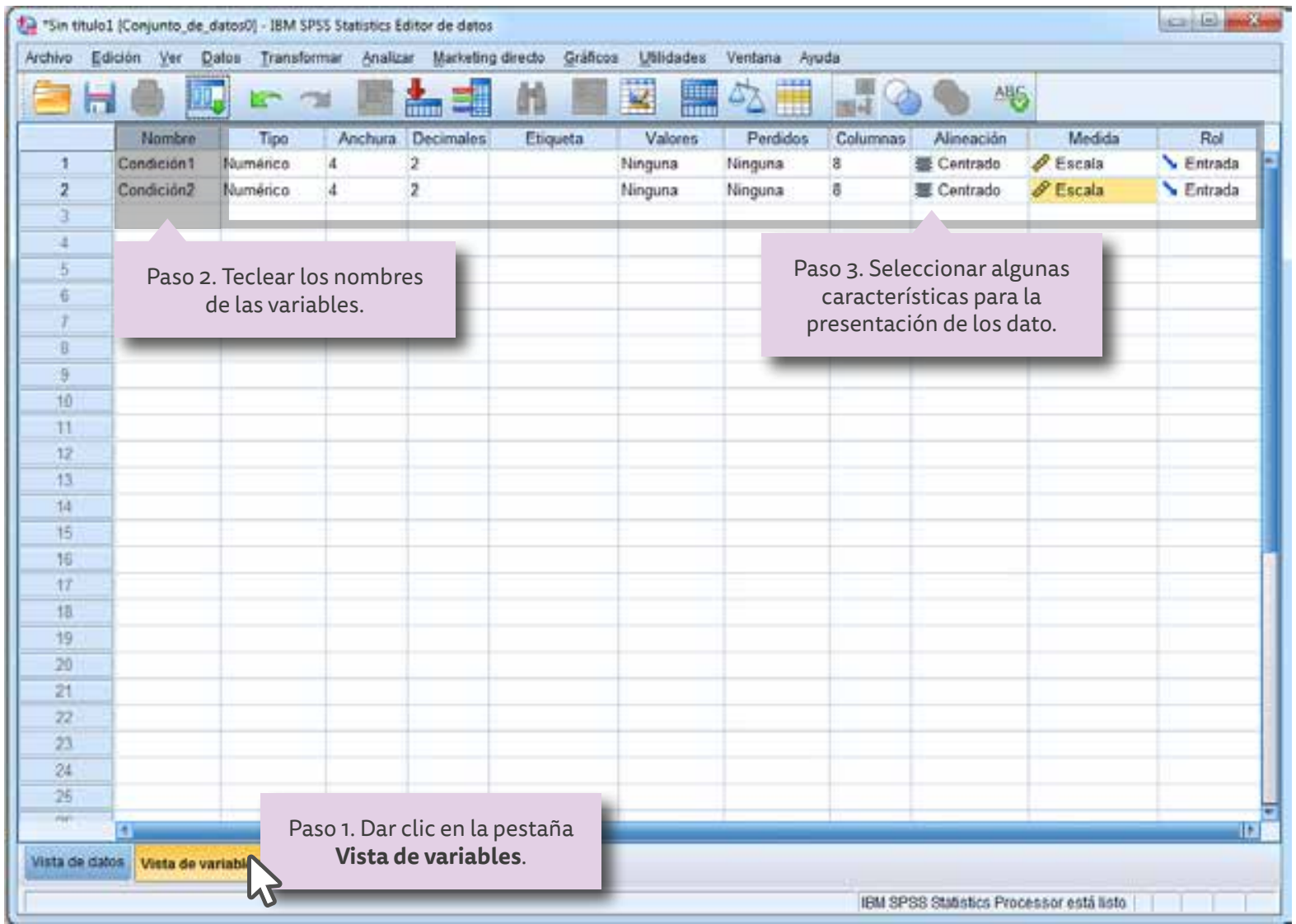

Figura 51. Designación de variables y sus características para la prueba t (relacionada).

Una vez designados los nombres de las variables y sus características se procede a introducir los datos en la tabla; para llevar a cabo esto es necesario dar un clic en la pestaña Vista de datos, e introducir los datos correspondientes a cada variable, los cuales se pueden introducir uno por uno tecleándolos o bien importarlos (seleccionar, copiar y pegar) de la tabla en donde se encuentran ubicados y pegarlos dentro de esta tabla.

Las variables seleccionadas en este ejemplo se observan en el siguiente cuadro:

Cuadro 17. Designación de variables para la prueba $t$ (relacionada).

\begin{tabular}{|l|l|}
\hline Nombre: Condición1 & Nombre: Condición2 \\
\hline Tipo: Numérico & Tipo: Numérico \\
\hline Anchura: 4 & Anchura: 4 \\
\hline Decimales: 2 & Decimales: 2 \\
\hline Etiqueta: Nada & Etiqueta: Nada \\
\hline Valores: Ninguno & Valores: Ninguno \\
\hline Perdidos: Ninguno & Perdidos: Ninguno \\
\hline Columnas: 8 & Columnas: 8 \\
\hline Alineación: Centrado & Alineación: Centrado \\
\hline Medida: Escala & Medida: Escala \\
\hline Rol: Entrada & Rol: Entrada \\
\hline
\end{tabular}

En la Figura 52 se observa cómo quedan los datos siguiendo cualquiera de los procedimientos mencionados y de acuerdo a las características seleccionadas en los pasos anteriores. 


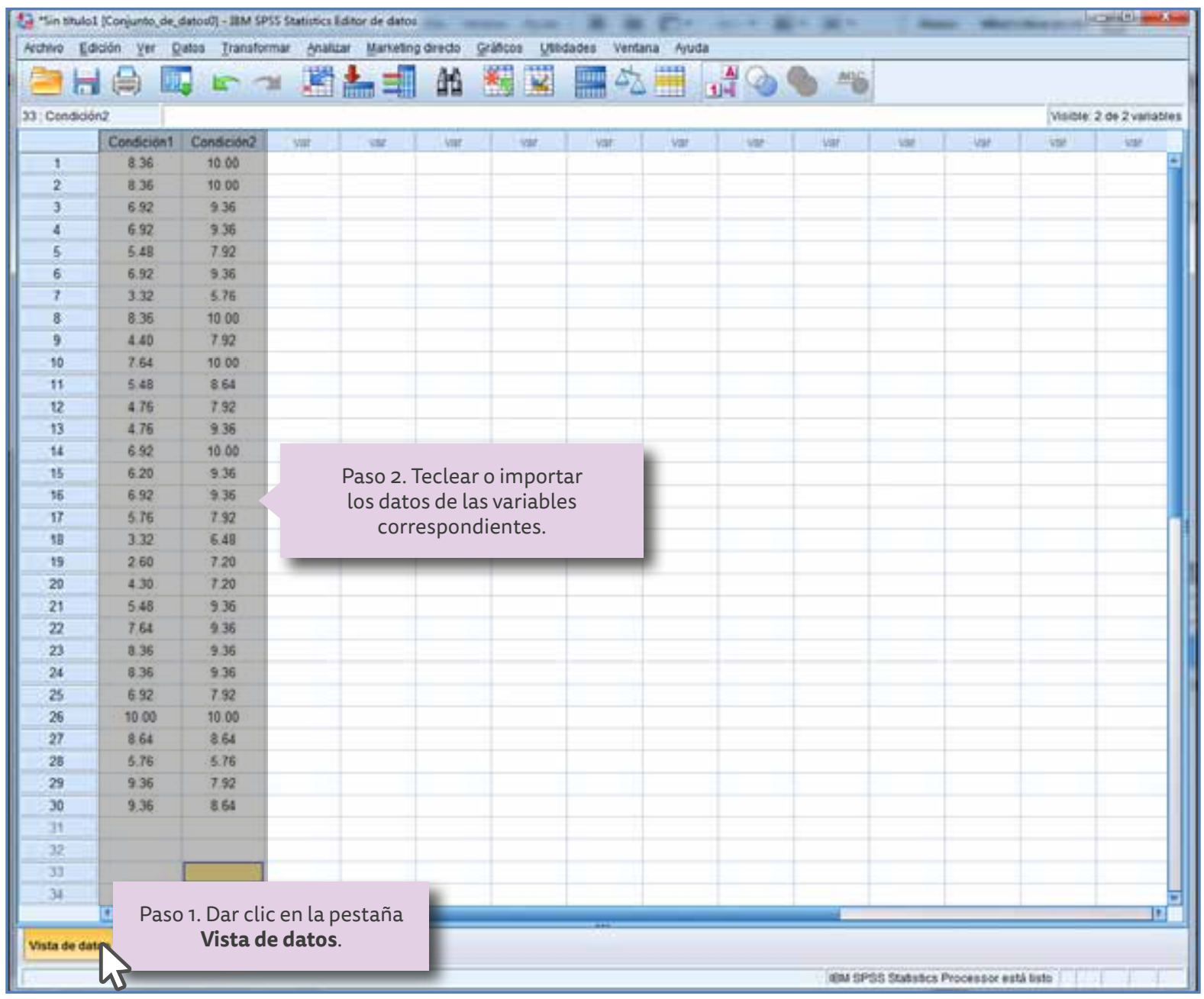

Figura 52. Presentación de los datos arrojados por los participantes en la estrategia "dinámicas grupalesvivenciales".

Una vez que los datos se encuentran en la tabla, se realiza la prueba (Figura 53), para hacerlo es necesario dar un clic en la pestaña ubicada en la barra superior designada como Analizar, en seguida aparece un cuadro de diálogo, en el que se selecciona la línea que indica Comparar medias, por pertenecer precisamente la prueba $t$ (relacionada) a este tipo; al ubicar el apuntador del ratón en esta opción se presenta a la derecha otro cuadro de diálogo, se selecciona Prueba $t$ para muestras relacionadas (que son las que corresponden a dos muestras relacionadas) y se da clic con el ratón.

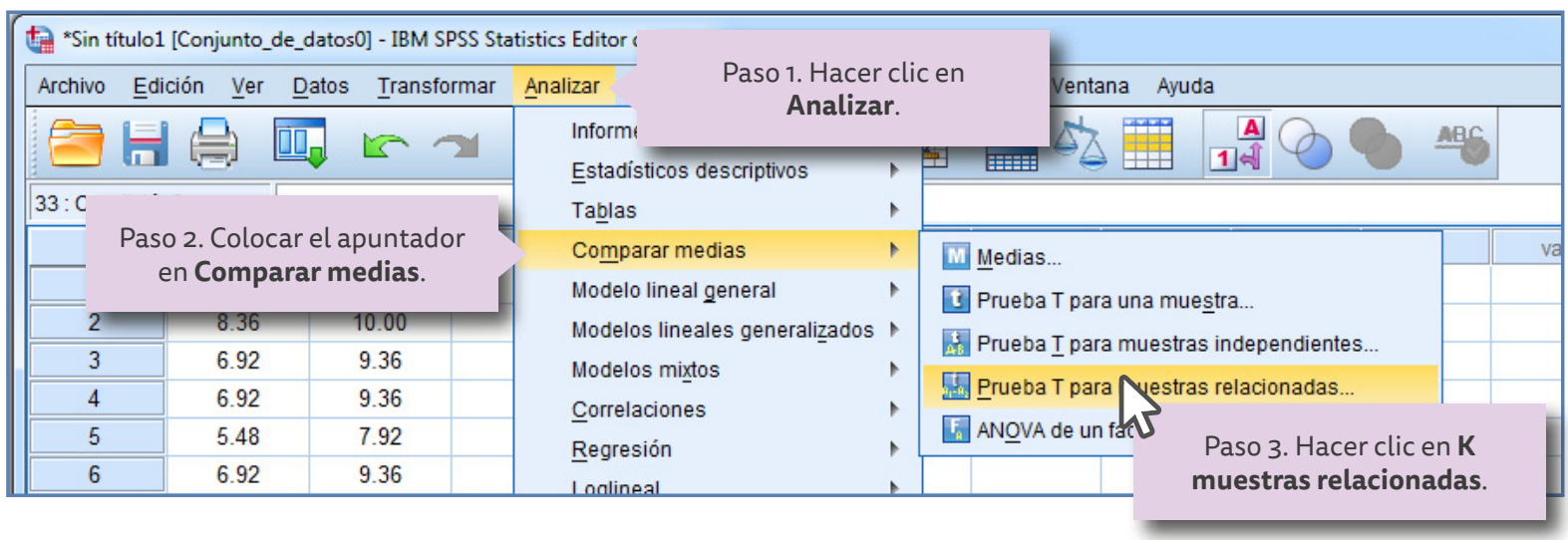

Figura 53. Cuadros de diálogo para seleccionar la prueba paramétrica de dos muestras relacionadas. 
Al realizar esta última acción aparece la ventana de la Figura 54, en la cual se muestran las variables del lado izquierdo, Condición1 y Condición2, éstas deben ser trasladadas a la ventana que dice Variables emparejadas; la forma de hacerlo es seleccionando con un clic la variable deseada (Condición1) y después dar un clic en la flecha que se ubica entre las dos ventanas, repitiendo esta operación para la variable 2 (Condición2).

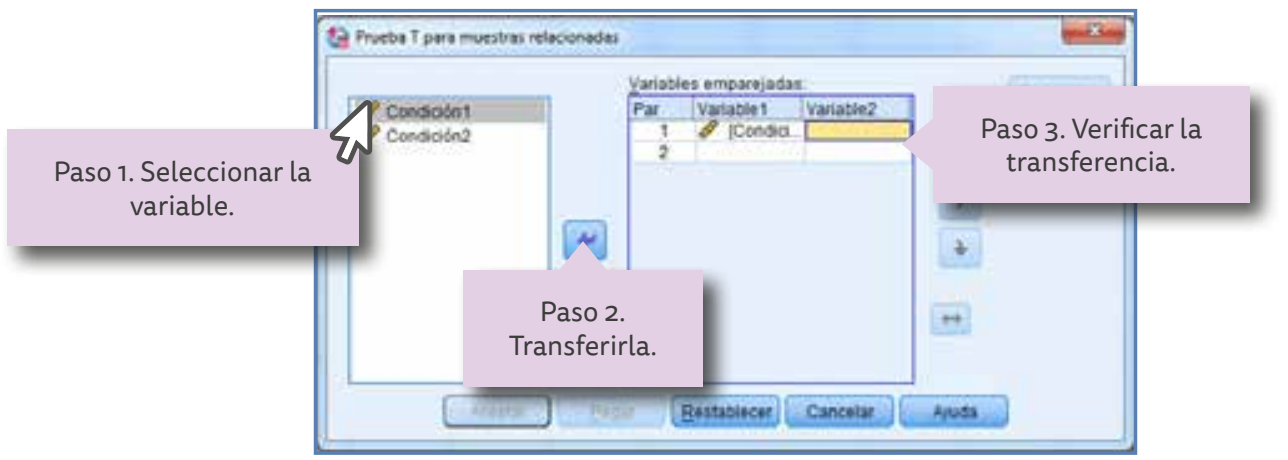

Figura 54. Transferencia de la variable Condición 1 para procesar los datos con el programa SPSS.

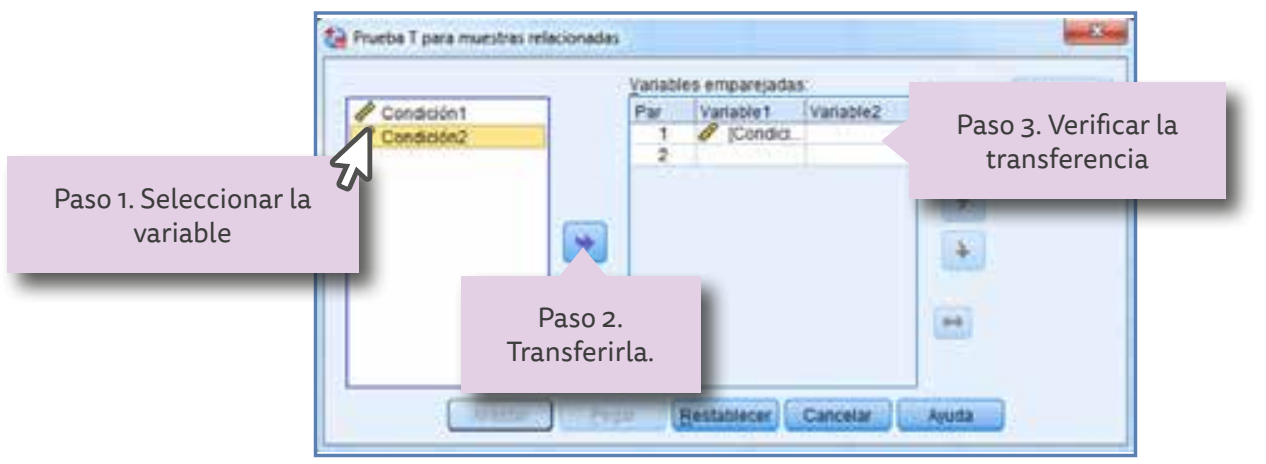

Figura 55. Transferencia de la variable Condición 2 para procesar los datos con el programa SPSS.

Una vez realizadas estas acciones el programa queda listo para arrojar los resultados, al activar el botón Aceptar (Figura 56) se obtienen los resultados que se muestran en el Cuadro 18.

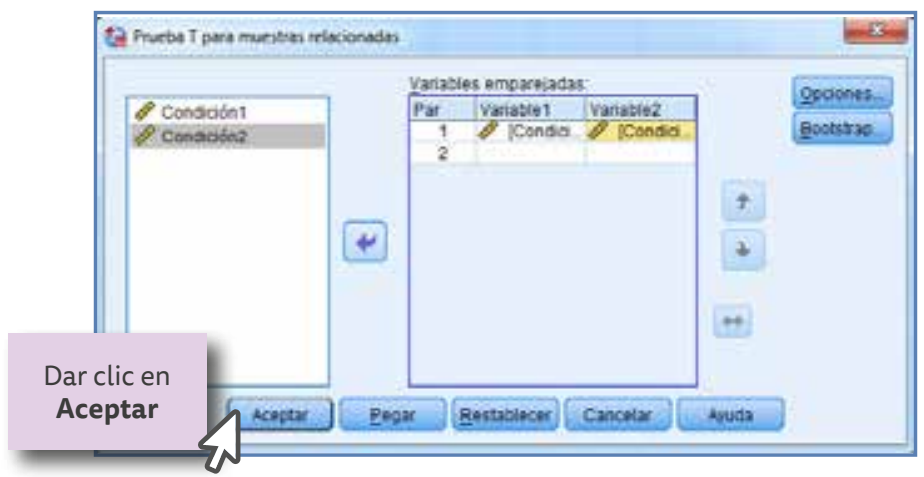

Figura 56. Paso para ejecutar el programa SPSS para que realice los cálculos requeridos para la prueba t (relacionada).

En el cuadro 18 se observan los valores de las medias de cada condición, que coincide con los del cálculo realizado en el apartado anterior. El valor del nivel de significación [Significación asintótica] $\rho<0.000$.

Entonces se puede concluir que $\rho_{\text {encontrada }} 0.000<\rho_{\text {aceptada }} 0.05$ 
Es decir, el valor encontrado 0.000 es menor que el mínimo aceptable por los investigadores en educación (0.05), lo que significa que los resultados de la diferencia no son aleatorios puesto que existe una diferencia significativa, por lo que se puede rechazar la hipótesis nula y aceptar la hipótesis de investigación.

Hi: Si se aplican las dinámicas grupales-vivenciales como refuerzo en la materia de Seminario de Aprendizaje y Desarrollo, los alumnos del primer semestre del bachillerato comprenderán mejor los contenidos.

También se puede observar que el valor de $t$ calculado por medio del programa es igual que el valor calculado utilizando la fórmula.

$$
t_{\text {calculado }}=7.686 \text { y } t_{\text {SPSS }}=7.686
$$

Cuadro 18. Resultados obtenidos con el programa SPSS para la prueba paramétrica $t$ (relacionada) para dos muestras relacionadas.

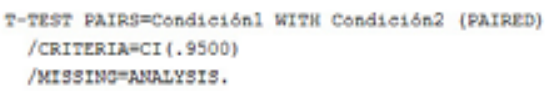

\section{$\rightarrow$ Prueba T}

[Conjuate_de_datea0]

\begin{tabular}{|c|c|c|c|c|c|c|}
\hline & & Media & $N$ & $\begin{array}{c}\text { Desviakion } \\
\text { 5p }\end{array}$ & $\begin{array}{c}\text { Errortia, de la } \\
\text { media }\end{array}$ & \multirow{3}{*}{$\begin{array}{l}\text { Los valores de las medias } \\
\text { son iguales a los calculados. }\end{array}$} \\
\hline \multirow[t]{2}{*}{$P_{2 \times 1}$} & Conditid́n1 & 6.5860 & 30 & 193844 & 35391 & \\
\hline & Condieion 2 & 9.6400 & 30 & 1.24200 & 22690 & \\
\hline
\end{tabular}

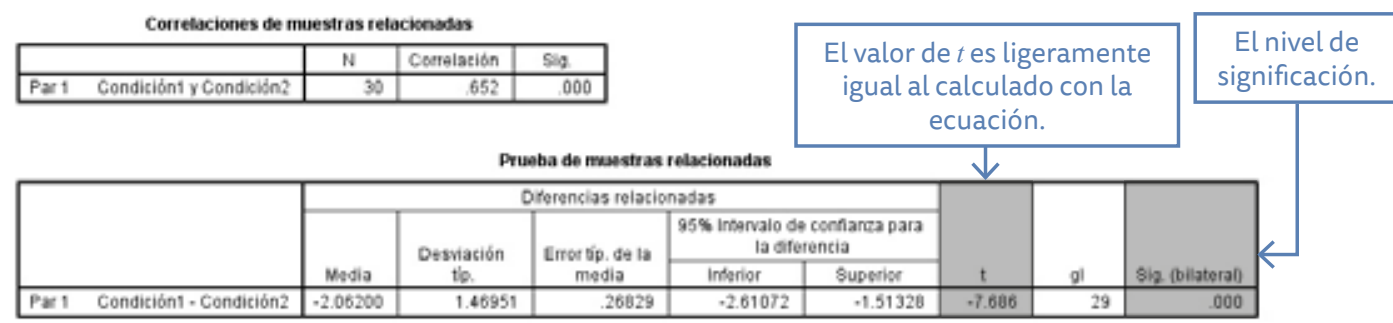




\section{Capítulo 10}

10. Prueba $t$ (para muestras independientes)

La prueba $t$ (para muestras independientes) se utiliza en diseños no relacionados o independientes, es decir, cuando la Condición 1 se aplica a un grupo de participantes diferente al de la Condición 2; los datos en este caso deben pertenecer a la escala de intervalo.

Ejemplo 85. Se trata de aceptar o rechazar la siguiente hipótesis de investigación: $\mathrm{Hi}$ : Si en uno de los grupos se realiza el aprendizaje por medio de la utilización de videos interactivos entonces éste retiene mayor cantidad de conocimientos que el grupo que lo hace utilizando videos de la manera tradicional.

\subsection{Estado situacional}

El investigador desea saber si el uso de un video interactivo influye en la retención de conocimiento de los participantes de manera significativa con respecto a la proyección de un video tradicional; se utilizó un grupo al que se le proyectó el video interactivo (Condición 1) y otro grupo para ver la proyección tradicional (Condición 2). El video interactivo consiste en incluir dentro del video una serie de preguntas que el alumno debe responder con los conocimientos que posee, en seguida presenta la información y de nuevo propone las preguntas para que las responda con los conocimientos nuevos, su principio se basa en el aprendizaje significativo.

Se seleccionaron dos grupos con 30 participantes cada uno de $5^{\circ}$ grado de primaria con el tema de palancas de primer orden, al grupo de referencia ( $\left.5^{\circ} \mathrm{A}\right)$, se le proyectó el video con sólo la información, mientras que al grupo experimental (5ㄷ C), se le proyectó el video interactivo; en ambos casos se realizó una plenaria para comentar el contenido del video, posterior a la proyección se les aplicó a los participantes una prueba objetiva con 20 reactivos de opción múltiple y correlación. En la Tabla 15 se muestran los resultados obtenidos por los participantes en las dos condiciones.

\subsection{Explicación}

La prueba $t$ (para muestras independientes) tiene su fundamento en la comparación de las medias de los resultados para los dos grupos a los que se les aplican diferentes condiciones, también es conocida como prueba $t$ independiente, es decir, la varianza esperada se calcula como la diferencia entre las medias de las dos condiciones (Greene y D'oliveira, 2006).

La varianza esperada se expresa como una proporción de la varianza total. Si la diferencia entre la varianza esperada es reducida con respecto a la varianza total en los resultados, debido a las diferencias pronosticadas entre las variaciones, éstas serían diferencias aleatorias y no significativas, por lo tanto, se debe aceptar la hipótesis nula. 
En caso contrario si estas diferencias son significativas entonces se puede rechazar la hipótesis nula y aceptar la hipótesis de investigación.

Tabla 15. Análisis comparativo entren el grupo de referencia y el experimental después de la intervención.

\begin{tabular}{|c|c|c|c|c|}
\hline $\begin{array}{l}\text { Número } \\
\text { Sujetos }\end{array}$ & $\begin{array}{l}\text { Referencia } \\
\text { Condición } 1\end{array}$ & $\begin{array}{l}\text { Experimental } \\
\text { Condición } 2\end{array}$ & $\begin{array}{l}\text { Cuadrados } \\
\text { de } x_{r}\end{array}$ & $\begin{array}{l}\text { Cuadrados } \\
\text { de } x_{e}\end{array}$ \\
\hline$n$ & $\mathrm{x}_{r}$ & $x_{e}$ & $\left(x_{r}\right)^{2}$ & $\left(x_{e}\right)^{2}$ \\
\hline 2 & 5 & 8 & 25 & 64 \\
\hline 3 & 6 & 7 & 36 & 49 \\
\hline 4 & 7 & 10 & 49 & 100 \\
\hline 5 & 7 & 8 & 49 & 64 \\
\hline 6 & 5 & 7 & 25 & 49 \\
\hline 7 & 5 & 10 & 25 & 100 \\
\hline 8 & 4 & 10 & 16 & 100 \\
\hline 9 & 7 & 10 & 49 & 100 \\
\hline 10 & 7 & 10 & 49 & 100 \\
\hline 11 & 5 & 8 & 25 & 64 \\
\hline 12 & 8 & 8 & 64 & 64 \\
\hline 13 & 5 & 7 & 25 & 49 \\
\hline 14 & 6 & 6 & 36 & 36 \\
\hline 15 & 3 & 6 & 9 & 36 \\
\hline 16 & 4 & 7 & 16 & 49 \\
\hline 17 & 5 & 10 & 25 & 100 \\
\hline 18 & 8 & 8 & 64 & 64 \\
\hline 19 & 8 & 8 & 64 & 64 \\
\hline 20 & 6 & 7 & 36 & 49 \\
\hline 21 & 6 & 10 & 36 & 100 \\
\hline 22 & 3 & 10 & 9 & 100 \\
\hline 23 & 3 & 7 & 9 & 49 \\
\hline 24 & 6 & 7 & 36 & 49 \\
\hline 25 & 7 & 8 & 49 & 64 \\
\hline 26 & 2 & 8 & 4 & 64 \\
\hline 27 & 6 & 8 & 36 & 64 \\
\hline 28 & 6 & 8 & 36 & 64 \\
\hline 29 & 7 & 5 & 49 & 25 \\
\hline 30 & 7 & 9 & 49 & 81 \\
\hline Suma & $\sum x_{r}=174$ & $\sum x_{e}=243$ & $\Sigma\left(x_{r}\right)^{2}=1100$ & $\Sigma\left(x_{e}\right)^{2}=2025$ \\
\hline Medias & $\bar{x}_{1}=5.8$ & $\bar{x}_{2}=8.1$ & & \\
\hline
\end{tabular}

Los datos que se utilizan en esta prueba deben ser de intervalo, esto significa que son de valor numérico y la distancia o intervalo entre sus valores debe ser igual. De acuerdo a lo anterior la prueba $t$ para muestras independientes debe cumplir con los siguientes requisitos:

- Deben existir dos condiciones experimentales (una por grupo) con una variable.

- Las dos condiciones se deben aplicar a diferentes participantes.

- Los datos numéricos deben ser de intervalo.

- Son pruebas paramétricas ya que son adecuadas para realizar análisis de datos numéricos de intervalo. 
10.3 Procedimiento para determinar el valor de $t$ (independiente)

1. Calcular la suma de los resultados para cada condición y elevarlos al cuadrado.

$$
\begin{aligned}
\sum x_{r} & =174 & \left(\sum x_{r}\right)^{2} & =(174)^{2}=30276 \\
\sum x_{\mathrm{e}} & =243 & \left(\sum x_{\mathrm{e}}\right)^{2} & =(243)^{2}=59049
\end{aligned}
$$

2. Calcular la media para cada condición.

$$
\begin{aligned}
& \bar{x}_{1}=174 / 30=5.8 \\
& \bar{x}_{2}=243 / 30=8.1
\end{aligned}
$$

3. Calcular el cuadrado de los resultados para cada condición y llenar las columnas $\left(x_{r}\right)^{2}$ y $\left(x_{\mathrm{e}}\right)^{2}$.

4. Sumar por separado los cuadrados para cada condición.

$$
\begin{aligned}
& \sum\left(x_{r}\right)^{2}=1100 \\
& \Sigma\left(x_{\mathrm{e}}\right)^{2}=2025
\end{aligned}
$$

5. Calcular el valor de $t$ utilizando la siguiente fórmula.

$$
t=\frac{\overline{\mathrm{x}}_{1}-\overline{\mathrm{x}}_{2}}{\sqrt{\frac{\left[\sum x_{e}^{2}-\frac{\left(\sum x_{e}\right)^{2}}{n_{e}}\right]+\left[\sum x_{r}{ }^{2}-\frac{\left(\sum x_{r}\right)^{2}}{n_{r}}\right]}{\left(n_{e}-1\right)+\left(n_{r}-1\right)}\left(\frac{1}{n_{e}}\right)+\left(\frac{1}{n_{r}}\right)}}
$$

Más general.

$$
t=\frac{\overline{\mathrm{x}}_{1}-\overline{\mathrm{x}}_{2}}{\sqrt{\frac{\left[\sum x_{1}^{2}-\frac{\left(\sum x_{1}\right)^{2}}{n_{1}}\right]+\left[\sum x_{2}{ }^{2}-\frac{\left(\sum x_{2}\right)^{2}}{n_{2}}\right]}{\left(n_{1}-1\right)+\left(n_{2}-1\right)}\left(\frac{1}{n_{1}}\right)+\left(\frac{1}{n_{2}}\right)}}
$$

Donde:

$\overline{\mathrm{x}}_{1}=$ valor de la media para la Condición 1 (5.8).

$\bar{x}_{2}=$ valor de la media para la Condición 2 (8.1).

$\sum\left(x_{\mathrm{r}}\right)^{2}=$ valor de la suma de los cuadrados de la Condición 1 (1100).

$\Sigma\left(x_{\mathrm{e}}\right)^{2}=$ valor de la suma de los cuadrados de la Condición 2 (2025).

$\left(\sum x_{r}\right)^{2}=$ valor de la suma de la Condición 1 elevado al cuadrado (30276).

$\left(\sum x_{\mathrm{e}}\right)^{2}=$ valor de la suma de la Condición 2 elevado al cuadrado (59049). 
$n_{1}=$ número de participantes en la Condición 1 (30).

$n_{2}=$ número de participantes en la Condición 2 (30).

Sustituyendo valores:

$$
t=\frac{5.8-8.1}{\sqrt{\frac{\left[1100-\frac{30276}{30}\right]+\left[2025-\frac{59049}{30}\right]}{(30-1)+(30-1)}\left(\frac{1}{30}\right)+\left(\frac{1}{30}\right)}}
$$

Se encuentra un valor de:

$$
t=5.586
$$

Nota: El signo positivo o negativo del resultado de restar las medias es irrelevante $\left(\bar{x}_{1}-\bar{x}_{2}\right)$. Al consultar el valor de $t$ en las tablas se toma el valor absoluto.

6. Calcular los grados de libertad restando 1 al número de participantes para cada condición y sumar los resultados obtenidos.

$$
n_{1}-1=29 \text { y } n_{2}-1=29 \text {, entonces los grados de libertad son } g l=58
$$

7. Buscar el nivel de significación de la prueba $t$ (independiente) en la Tabla G del Apéndice D.

La Tabla G contiene las probabilidades correspondientes de los valores de $t$ para dos condiciones ya sea relacionada o independiente. El valor de $t$ calculado debe ser igual o mayor que los valores que aparecen en la Tabla G.

Para encontrar el valor de $t$ se debe buscar en la primer columna los grados de libertad $(g l=58)$ en donde el valor calculado 5.586 es mayor que el valor 3.551 para $\rho<0.0005$ para una hipótesis unilateral. Nota: en la tabla no hay valor de $g l=58$ por lo que se toma el inmediato inferior esto es $g l=40$.

$$
\begin{gathered}
t_{\text {calculado }}=5.586 \text { (es mayor que) }>t_{\text {tabla }}=3.551 \\
\text { para un nivel de significación de } \rho<0.0005
\end{gathered}
$$

El nivel de significación es $\rho<0.0005$, está por debajo de la probabilidad que proponen los investigadores en educación como máximo valor aceptable, esto es $\rho<0.05$, entonces se puede rechazar la hipótesis nula y aceptar la de investigación.

Al utilizar video interactivo, los participantes obtuvieron mayor puntaje en la evaluación que los participantes que utilizaron el video tradicional de manera significativa y no aleatoria. 
10.4 Prueba $t$ (independiente) utilizando el programa SPSS

Se inicia este proceso otorgando las propiedades a las variables, una vez abierto el programa como se indica en el Capítulo 4, antes de introducir los datos, es necesario definir las variables y designarle las características para su presentación en la tabla, para esto se requiere dar un clic en la pestaña Vista de variables (Ver Figura 58).

Cuando se trata de muestras no relacionadas o independientes los valores de los datos obtenidos se deben colocar en una misma columna como la primera variable, la que se designará como Condiciones 1 a 2 y la segunda variable se designa como Agrupación en donde se especifica cuáles son los datos de la columna 1 que corresponden a la Condición 1 (grupo de referencia), y cuales a la Condición 2 (Grupo experimental).

En este caso se teclea en el primer espacio para Nombre, el de la primera variable Condiciones1a2, recordando que no deben haber espacios vacíos entre los caracteres, aquí se deben anotar las dos condiciones, es decir, los datos obtenidos por los participantes con el video tradicional (referencia), y en seguida a los participantes con el video interactivo (experimental).

El siguiente paso es introducir el Nombre de la segunda variable en el espacio 2 de la columna nombre, los datos de la segunda variable que se denominan con el término de Agrupación (variable de agrupación) en este caso, sólo se utilizan dos valores: 1 para indicar que se refiere a los datos correspondientes al Grupo 1, que utilizó el video tradicional y el número 2 para el Grupo 2, que utilizó el video interactivo.

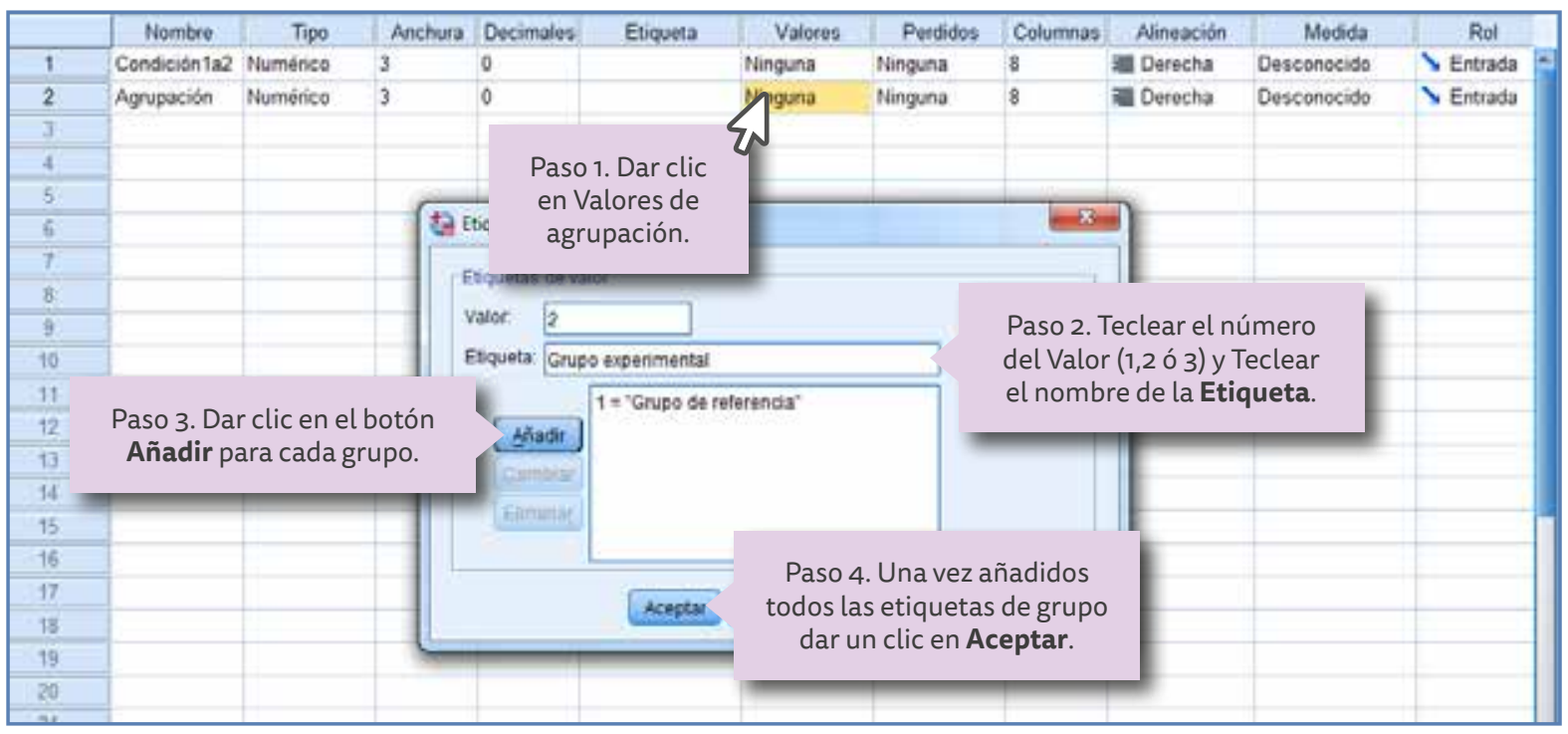

Figura 57. Ventana de diálogo para etiquetar los valores de agrupación.

Para designar las Etiquetas de valor, esto es, definir la ubicación de los grupos dentro de la tabla, en la línea de agrupación y columna valores se da clic con el apuntador y aparece un cuadro de diálogo (Figura 57, en la ventana Valor se coloca el número del grupo (1 para el primer grupo, Condición 1) y la ventana etiqueta el nombre con que se designa al grupo (Grupo de referencia) se da clic en el botón Añadir y los datos se transfieren a la ventana inferior, se repite este paso para registrar los valores para la Condición 2 (Grupo experimental). Las características seleccionadas para la presentación de las variables así como los nombres de éstas se pueden observar en la Figura 58. 


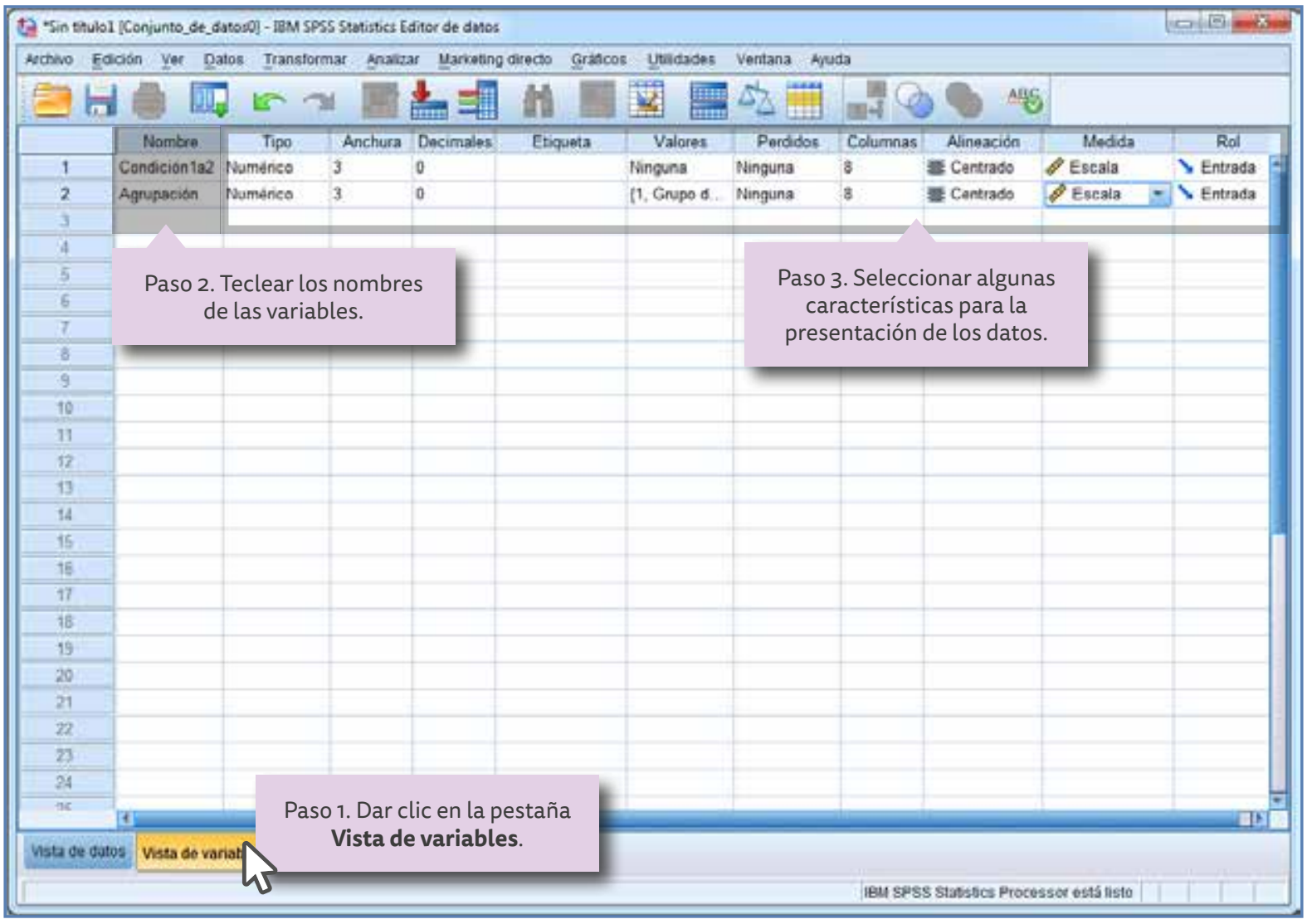

Figura 58. Designación de nombre de las variables y características de presentación para la prueba $t$ (independiente).

Una vez designados los nombres de las variables y sus características se introducen los datos en la tabla; para llevar a cabo esto es necesario dar clic en la pestaña Vista de datos, e introducirlos de la siguiente manera:

1. En la columna 1 (Condición1a2) se introducen los valores de los datos obtenidos por el grupo de la Condición 1 y en seguida se introducen los datos de la Condición 2.

2. En la columna dos (Agrupación) se introduce el valor de 1 para todos los datos que correspondan a la Condición 1, y el valor de 2 para los datos correspondientes a la Condición 2.

En el siguiente cuadro se observan las variables seleccionadas en este ejemplo:

Cuadro 19. Designación de variables para la prueba $t$ (relacionada).

\section{Nombre: Condición1a2}

Tipo: Numérico

Anchura: 3

Decimales: 0

Etiqueta: Nada

Valores: Ninguno

Perdidos: Ninguno

Columnas: 8

Alineación: Centrado

Medida: Escala

Rol: Entrada

\section{Nombre: Agrupación}

Tipo: Numérico

Anchura: 3

Decimales: 0

Etiqueta: Nada

Valores: 1. Grupo de referencia y

2. Grupo experimental

Perdidos: Ninguno

Columnas: 8

Alineación: Centrado

Medida: Escala

Rol: Entrada 


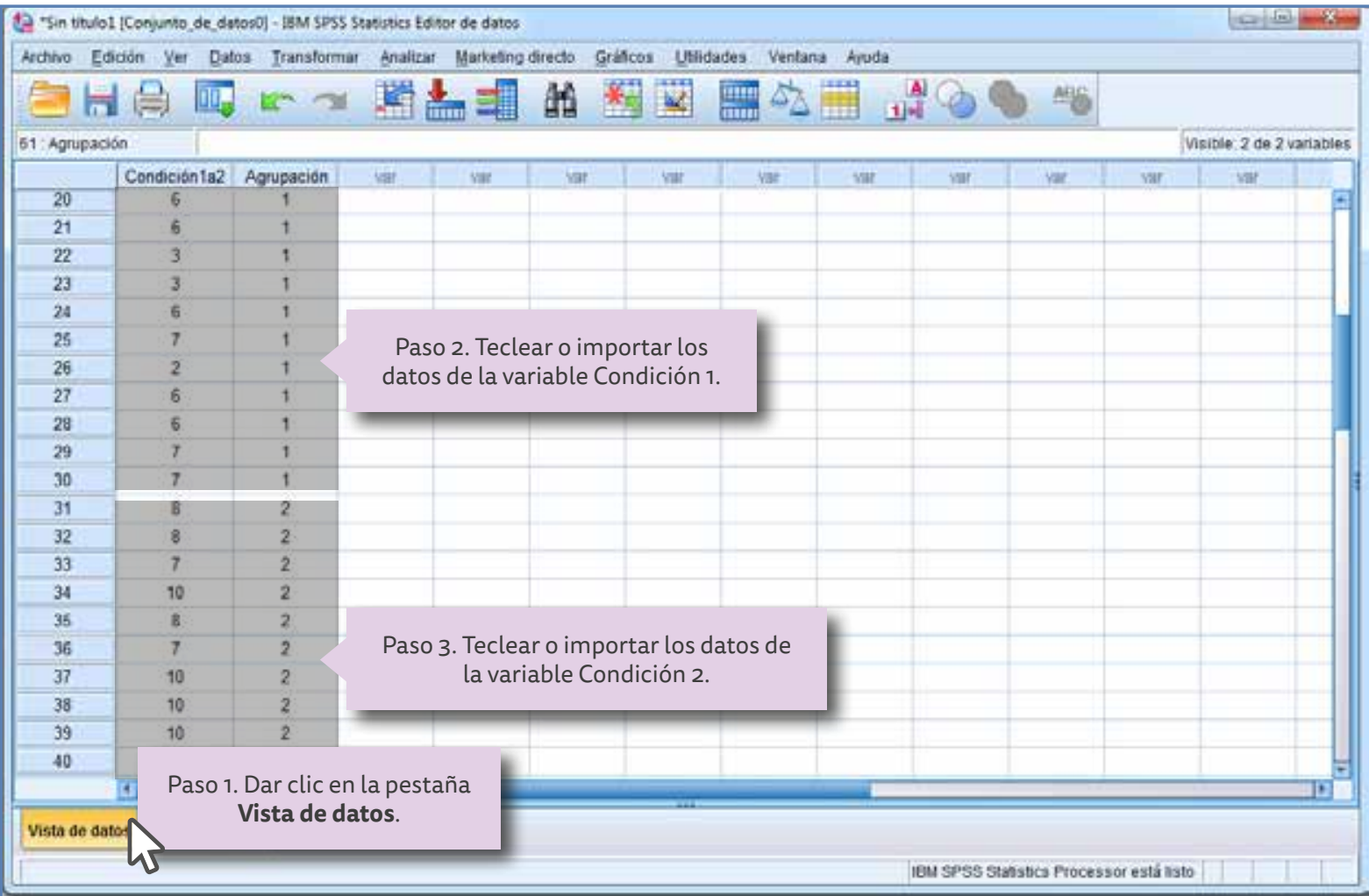

Figura 59. Presentación de los datos arrojados por los participantes en las proyecciones de los videos tradicional e interactivo.

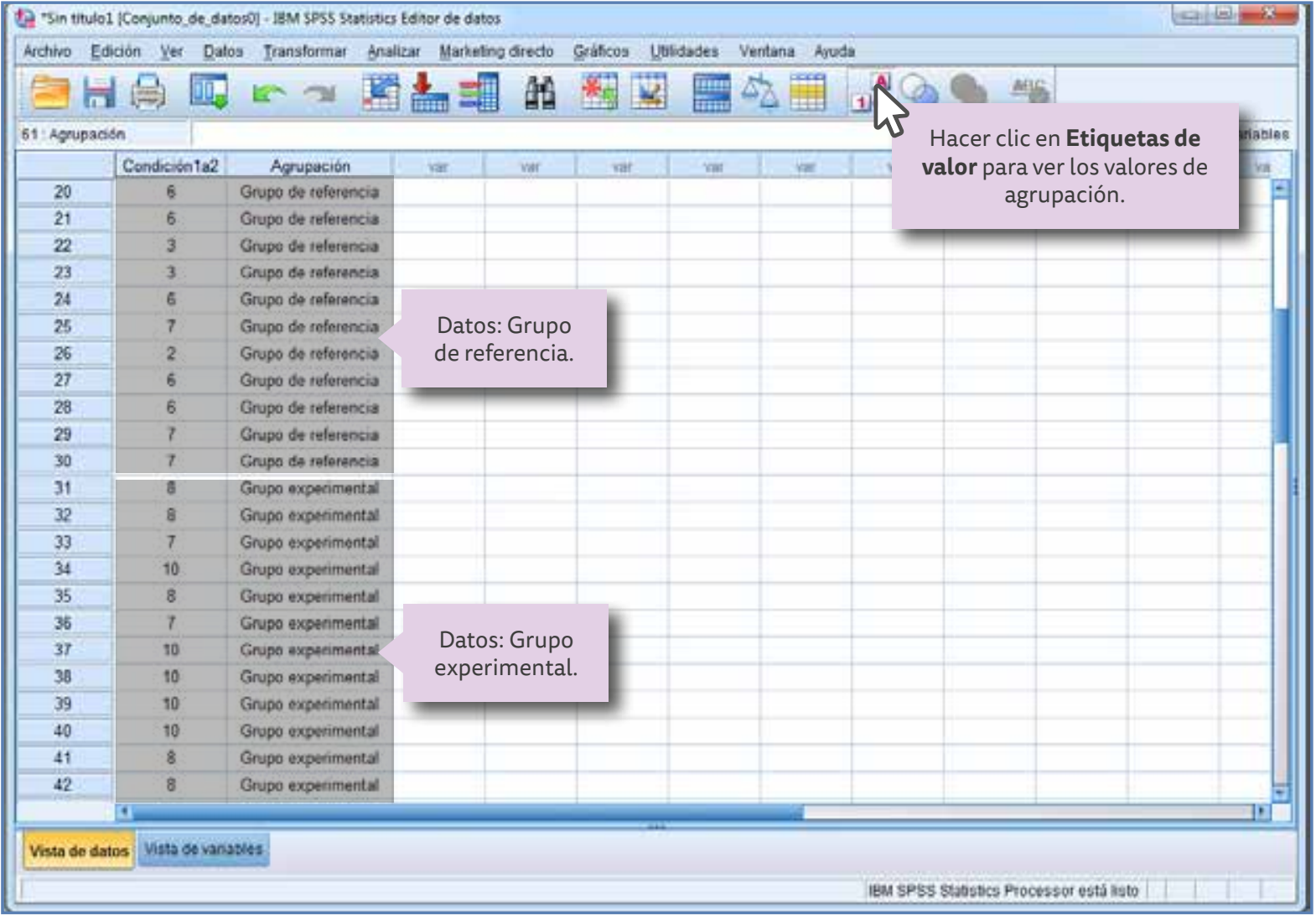

Figura 60. Presentación de los datos activando las etiquetas de valor. 
En la Figura 59 se observa cómo deben quedar los datos siguiendo los procedimientos mencionados y de acuerdo a las características seleccionadas en los pasos anteriores.

Otra manera de verificar si los datos coinciden con los grupos es activando la Etiqueta de valores de agrupación en donde al programar las características se etiquetaron como $\mathbf{1}=$ Grupo de referencia y el $\mathbf{2}$ = Grupo experimental, mostrándose como observa en la Figura 60.

Una vez que los datos se encuentran en la tabla, se realiza la prueba (Figura 61); para hacerlo es necesario dar un clic en la pestaña ubicada en la barra superior designada como Analizar, en seguida aparece un cuadro de diálogo, en el cual se selecciona la línea que indica Comparar medias, por pertenecer precisamente la Prueba $t$ (independiente) a este tipo; al ubicar el apuntador del ratón en esta opción se presenta a la derecha otro cuadro de diálogo, se selecciona Prueba $\boldsymbol{t}$ para muestras independientes que son las que corresponden a dos muestras no relacionadas y se da clic con el ratón.

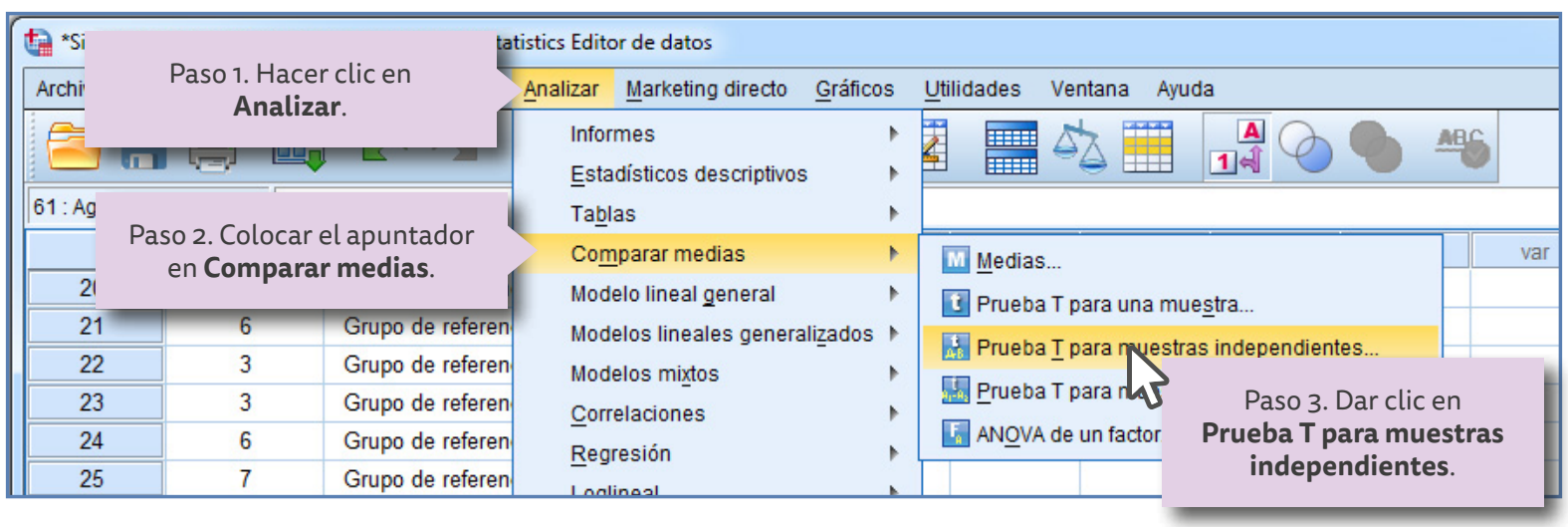

Figura 61. Cuadros de diálogo para seleccionar la prueba paramétrica de dos muestra independientes.

Al realizar esta última acción aparece la ventana de la Figura 62, en la cual se muestran las variables del lado izquierdo, Codición1a2 y Agrupación, la primera debe ser trasladada a la ventana que dice Variables para contrastar; la forma de hacerlo es seleccionar con un clic la variable deseada (Condición1a2) y se da un clic en la flecha superior que se ubica entre las dos ventanas.

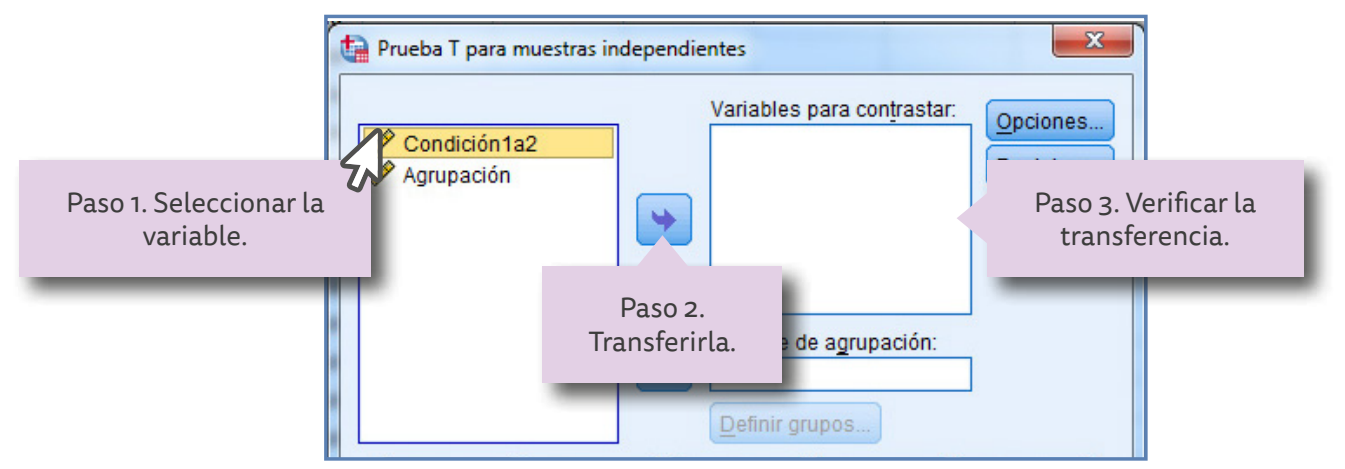

Figura 62. Pasos para ingresar las variables número de condición al programa SPSS.

Para trasladar la otra variable (agrupación) se debe seleccionar y dar un clic en la flecha inferior que se encuentra entre las ventanas y se traslada a la ventana designada como Variables de agrupación (Figura 63). 


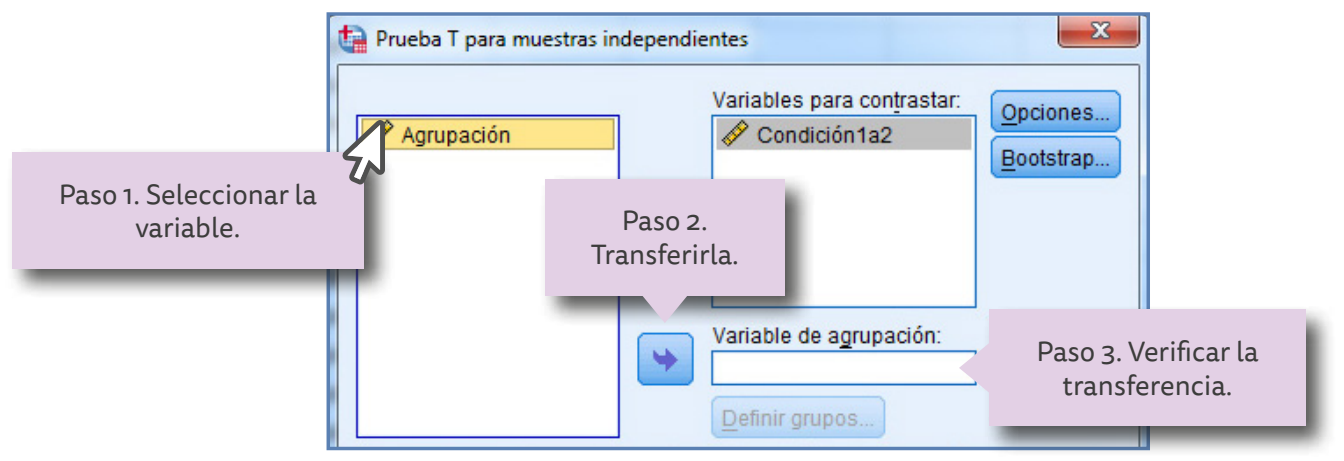

Figura 63. Pasos para ingresar las variables Agrupación al programa SPSS.

Se puede observar que el programa aún no habilita el botón Aceptar (Figura 64), está esperando que se definan los grupos de acuerdo a la columna de agrupación, para hacerlo se requiere dar clic en el botón que se encuentra debajo de la ventana de Variable de agrupación, el cual especifica Definir grupos y aparece una sub ventana en la cual se teclea el número 1 para el grupo de referencia y el 2 para el grupo experimental; finalmente se da clic en el botón

\section{Continuar.}

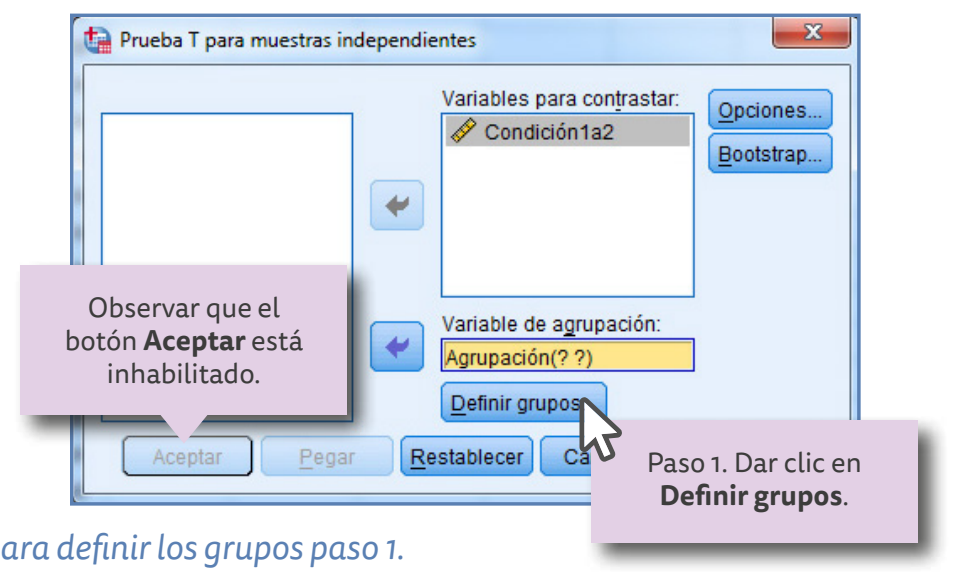

Figura 64. Actividad para definir los grupos paso 1.

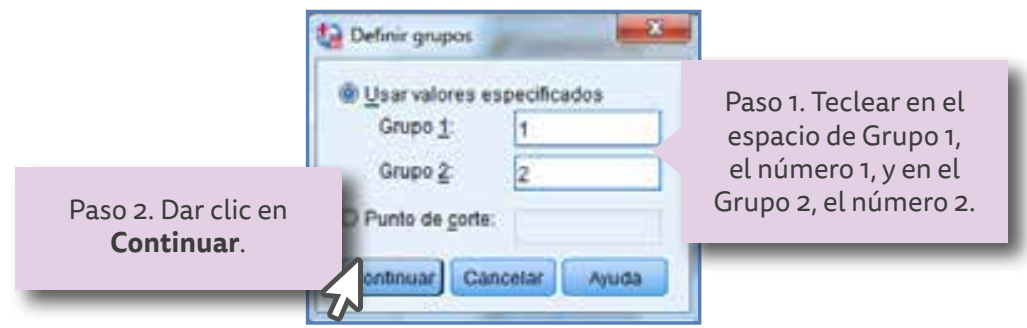

Figura 65. Actividad para definir los grupos paso 2.

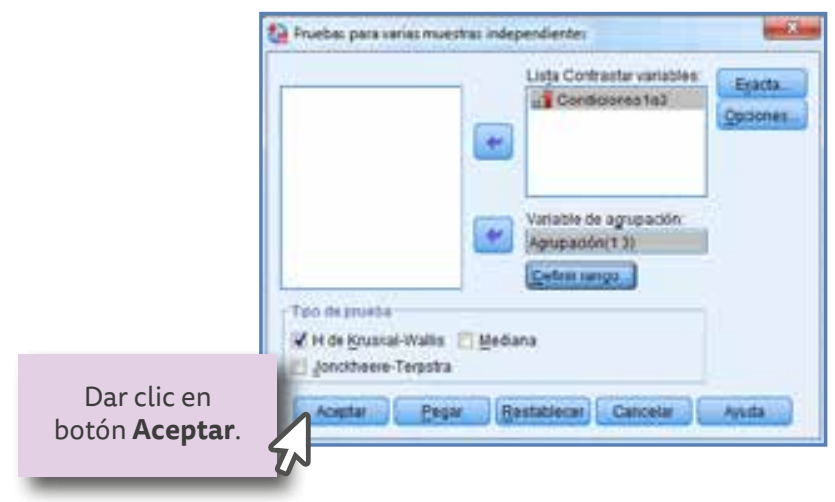

Figura 66. Paso para ejecutar el programa SPSS para que realice los cálculos requeridos. 
Una vez realizadas estas acciones el programa queda listo para arrojar los resultados, al activar el botón Aceptar (Figura 66) se obtienen los resultados que se muestran en el Cuadro 20 , en el que se observan los valores de las medias de cada condición, que coinciden con los del cálculo realizado en el apartado anterior. El valor del nivel de significación [Significación asintótica] $\rho<0.000$.

$$
\text { Entonces se puede concluir que } \rho \text { encontrada } 0.000<\rho_{\text {aceptada }} 0.05
$$

Es decir, el valor encontrado es 0.000 que es menor que el mínimo aceptable por los investigadores en educación (0.05), lo que significa que los resultados de la diferencia no son aleatorios puesto que existe una diferencia significativa, por lo que se puede rechazar la hipótesis nula y aceptar la hipótesis de investigación.

También se observa que el valor de $t$ calculado por medio del programa es igual que el valor calculado utilizando la fórmula.

$$
t_{\text {calculado }}=5.586 \text { y } t_{\text {SPSS }}=5.586
$$

Hi: Si en uno de los grupos se realiza el aprendizaje por medio de la utilización de videos interactivos entonces éste retiene mayor cantidad de conocimientos que el grupo que lo hace utilizando videos de la manera tradicional.

Cuadro 20. Resultados obtenidos con el programa SPSS para la prueba paramétrica $t$ (independiente) para dos muestras no relacionadas.

7-7tsz GROOFS-Agrupación (12)

/Mrssmo-aralysis

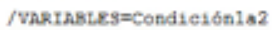

/CRITERIA=CI (.95) .

\section{$\rightarrow$ Prueba T}

[Congunto_de_dstos 0]

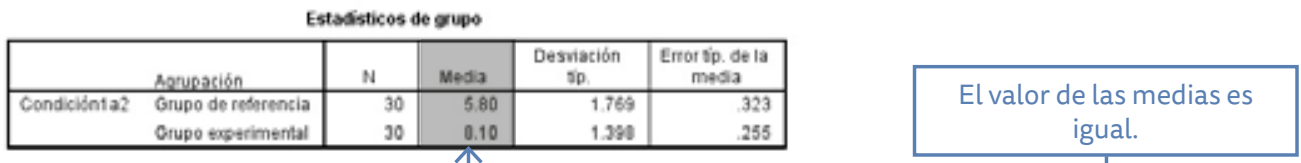

\begin{tabular}{|c|c|c|c|c|c|c|c|c|c|c|}
\hline & & \multicolumn{2}{|c|}{$\begin{array}{l}\text { Prueba de Levene para is } \\
\text { igualdad de variancas }\end{array}$} & \multicolumn{7}{|c|}{ Pruaba Tpara la igualdad de medias } \\
\hline & & \multirow[b]{2}{*}{$\mathrm{F}$} & \multirow[b]{2}{*}{$\operatorname{sig}$} & \multirow[b]{2}{*}{$t$} & \multirow[b]{2}{*}{ gl } & \multirow[b]{2}{*}{ Sig (bilateral) } & \multirow{2}{*}{$\begin{array}{c}\text { Diferencia de } \\
\text { medias }\end{array}$} & \multirow{2}{*}{$\begin{array}{c}\text { Emor tip. de ia } \\
\text { difterentia }\end{array}$} & \multicolumn{2}{|c|}{$\begin{array}{c}958 \text { Intervals de tonfiarea para } \\
\text { la dikeentia }\end{array}$} \\
\hline & & & & & & & & & Inferiot & Supetion \\
\hline \multirow[t]{2}{*}{ Condiciónlaz } & $\begin{array}{l}\text { 3e han asumiso } \\
\text { variancas iguases }\end{array}$ & \multirow[t]{2}{*}{1.309} & \multirow[t]{2}{*}{.243} & .5506 & 58 & .000 & -2.300 & .412 & -3.124 & -1.476 \\
\hline & $\begin{array}{l}\text { No se han asumido } \\
\text { variancas igualas }\end{array}$ & & & -5506 & 55.057 & .000 & -2.300 & .412 & -3.125 & -1.475 \\
\hline
\end{tabular}

Prueba de muestras independentes

La $\boldsymbol{t}$ (independiente) es igual a la del valor calculado con la fórmula.
Nivel de confiabilidad $\rho<0.000$ 


\section{Capítulo 11}

11. Prueba ANOVA Unifactorial (muestras relacionadas)

La prueba ANOVA Unifactorial (relacionada) se utiliza en diseños relacionados cuando tres o más condiciones se aplican a los mismos participantes y los datos pertenecen a la escala de intervalo.

Ejemplo 86. Se trata de aceptar o rechazar la siguiente hipótesis de investigación: Hi: Si se utiliza el video como refuerzo en la materia de Física, los alumnos de sexto grado de primaria retendrán mejor el conocimiento, más aún si el video es interactivo.

\subsection{Estado situacional}

El investigador desea saber si el uso de diferentes tipos de videos influyen en la retención de los conocimientos de los participantes de manera significativa, por lo que en una primera intervención (Condición 1) se les aplicó un examen diagnóstico de conocimientos para establecer las condiciones iniciales del grupo experimental en donde no se utilizó algún video. Para la Condición2 de recibir la lección en el salón de clases se les proyectó un video convencional para reforzar los conocimientos y se aplicó un examen de verificación. Para la Condición 3, además de la clase expositiva se reforzó ésta con la proyección de un video interactivo.

El video interactivo dentro de su contenido plantea al alumno una serie de interrogantes que debe responder con los conocimientos adquiridos en clase y en seguida presenta la información correspondiente, solicitando al alumno que de acuerdo a lo que respondió inicialmente y la información presentada replantee las respuestas dadas para posteriormente discutirlas en sesión plenaria. La variable independiente consistió en utilizar diferentes tipos de videos para reforzar los conocimientos de los participantes y la variable dependiente en la retención de mayor número de conceptos.

Se seleccionó al grupo de 6 C de primaria, conformado por 16 alumnos, a quienes se les aplicó un examen diagnóstico, con el tema "palancas de primer orden", otro examen después de reforzar el contenido teórico con la proyección de un video referente al contenido de "palancas de segundo orden", para concluir con un examen más para el tema de "palancas de tercer orden" que fue reforzado con la proyección del video interactivo. En la Tabla 16 se muestran los resultados obtenidos en estos tres exámenes y el desarrollo del análisis estadístico utilizado. Se calcula el valor para la prueba de media ANOVA Unifactorial (relacionada). 
Tabla 16. Puntajes obtenidos en las tres evaluaciones de acuerdo a la utilización de los videos en el grupo experimental.

\begin{tabular}{|c|c|c|c|c|c|c|c|c|}
\hline $\begin{array}{c}\text { № de } \\
\text { participante }\end{array}$ & $\begin{array}{l}\text { Condición } 1 \\
\text { Sin video }\end{array}$ & $X_{1}^{2}$ & $\begin{array}{l}\text { Condición } \\
2 \text { video } \\
\text { tradicional }\end{array}$ & $X_{2}^{2}$ & $\begin{array}{l}\text { Condición } \\
3 \text { Video } \\
\text { interactivo }\end{array}$ & $X_{3}^{2}$ & $\begin{array}{c}T_{S} \text { Total } \\
\text { general } \\
\text { participantes }\end{array}$ & $T_{\mathrm{s}}^{2}$ \\
\hline 1 & 5 & 25 & 5 & 25 & 7 & 49 & 17 & 289 \\
\hline 2 & 6 & 36 & 6 & 36 & 7 & 49 & 19 & 361 \\
\hline 3 & 4 & 16 & 5 & 25 & 10 & 100 & 19 & 361 \\
\hline 4 & 6 & 36 & 9 & 81 & 9 & 81 & 24 & 576 \\
\hline 5 & 5 & 25 & 9 & 81 & 10 & 100 & 24 & 576 \\
\hline 6 & 4 & 16 & 6 & 36 & 9 & 81 & 19 & 361 \\
\hline 7 & 4 & 16 & 9 & 81 & 10 & 100 & 23 & 529 \\
\hline 8 & 6 & 36 & 6 & 36 & 9 & 81 & 21 & 441 \\
\hline 9 & 4 & 16 & 5 & 25 & 7 & 49 & 16 & 256 \\
\hline 10 & 3 & 9 & 6 & 36 & 9 & 81 & 18 & 324 \\
\hline 11 & 5 & 25 & 8 & 64 & 9 & 81 & 22 & 484 \\
\hline 12 & 4 & 16 & 8 & 64 & 10 & 100 & 22 & 484 \\
\hline 13 & 6 & 36 & 5 & 25 & 7 & 49 & 18 & 324 \\
\hline 14 & 3 & 9 & 5 & 25 & 8 & 64 & 16 & 256 \\
\hline 15 & 5 & 25 & 8 & 64 & 9 & 81 & 22 & 484 \\
\hline 16 & 6 & 36 & 6 & 36 & 8 & 64 & 20 & 400 \\
\hline$\Sigma=$ & 76 & 378 & 106 & 740 & 138 & 1210 & 320 & 6506 \\
\hline Media = & 4.75 & & 6.625 & & 8.625 & & & \\
\hline
\end{tabular}

\subsection{Explicación}

La prueba ANOVA Unifactorial (relacionada) calcula la varianza entre los tres resultados de cada participante, ya que éstos se encuentran relacionados. Las diferencias entre estos resultados permiten tener una base para el cálculo de la varianza ocasionada por participante.

En este caso se pueden calcular los siguientes tipos de varianza (Greene y D'oliveira, 2006):

a. Varianza esperada. Se origina por las diferencias pronosticadas entre condiciones.

b. Varianza individual. Se origina por las diferencias entre los resultados en relación a cada participante.

c. Varianza de error. Se origina por variables irrelevantes.

d. Varianza total. Incluye todos los tipos de varianzas anteriores.

La finalidad de ANOVA es comparar ratios de varianza. La variable independiente del uso del video (sin video, video convencional y video interactivo) representa las diferencias pronosticadas entre las tres condiciones (varianza esperada). La predicción afirma que la varianza esperada debe ser relativamente elevada en comparación con la varianza de error causada por las variables irrelevantes.

Es decir, para aceptar la hipótesis de investigación, el ratio (relación) entre la varianza esperada y la varianza de error debe ser relativamente grande, mientras que el ratio (relación) de la varianza individual y la varianza de error no debe representar una diferencia significativa. El término de ANOVA Unifactorial se refiere a que sólo hay una variable independiente para analizar.

De acuerdo a lo anterior la prueba ANOVA para muestras relacionadas debe cumplir con los siguientes requisitos:

- Deben existir tres o más condiciones experimentales con una variable independiente.

- Las tres condiciones se deben aplicar a los mismos participantes.

- Los datos numéricos deben ser de intervalo.

- Son pruebas paramétricas, adecuadas para realizar análisis de datos numéricos de intervalo. 
11.3 Procedimiento para determinar el valor de ANOVA Unifactorial (relacionada).

Los cálculos numéricos se realizan con datos en escala de intervalo, calculando el ratio (relación) entre la varianza esperada y la varianza de error.

1. Calcular el valor de la varianza esperada $S C_{\text {esp }}$

$$
S C_{\text {esp }}=\frac{\sum\left(X_{T}\right)^{2}}{n}-\frac{\left(\sum x\right)^{2}}{N}
$$

Donde:

$\Sigma\left(X_{T}\right)^{2}=$ suma de los cuadrados de los totales para cada condición.

$\Sigma T^{2}{ }_{s}=$ suma de los cuadrados de los totales para cada participante.

$n=$ número de participantes.

$c=$ número de condiciones.

$N=$ número de resultados.

$\left(\Sigma T_{S}\right)^{2}=$ cuadrado del total general.

$\frac{\left(\sum T_{\mathrm{S}}\right)^{2}}{N}=$ constante que se debe restar a todas las sumas de cuadrados.

$\sum x^{2}=$ suma de cada uno de los resultados elevados al cuadrado.

Entonces de acuerdo a los datos de la tabla calcular:

$$
\begin{gathered}
\sum\left(X_{T}\right)^{2}=\sum\left(X_{1}\right)^{2}+\sum\left(X_{2}\right)^{2}+\sum\left(X_{3}\right)^{2} \\
\sum\left(X_{T}\right)^{2}=(76)^{2}+(106)^{2}+(138)^{2}=36056 \\
\sum\left(X_{T}\right)^{2}=6506 \\
n=16 \\
c=3 \\
N=(16) 3=48 \\
\frac{\left(\sum T_{S}\right)^{2}=(320)^{2}=102400}{\left.N T_{S}\right)^{2}}=\frac{(102400)}{48}=2133.33 \\
\sum x^{2}=\sum x_{1}{ }^{2}+\sum x_{2}{ }^{2}+\sum x_{3}{ }^{2}=378+740+1210=2328
\end{gathered}
$$

Sustituir en la ecuación se encuentra:

$$
S C_{\text {esp }}=\frac{\sum\left(X_{T}\right)^{2}}{n}-\frac{\left(\sum T_{S}\right)^{2}}{N}=\frac{(36056)}{16}-2133.33=120.17
$$


2. Calcular el valor de varianza individual $S C_{\text {ind }}$

$$
S C_{\text {ind }}=\frac{\sum T_{S}^{2}}{C}-\frac{\left(\sum T_{\mathrm{s}}\right)^{2}}{N}=\frac{(6506)}{3}-2133.33=35.33
$$

3. Calcular el valor de varianza total $S C_{\text {tot }}$

$$
S C_{\text {tot }}=\sum x^{2}-\frac{\left(\Sigma T_{s}\right)^{2}}{N}=2328-2133.33=194.67
$$

4. Calcular el valor de varianza de error $S C_{\text {error }}$

$$
\begin{gathered}
S C_{\text {error }}=S C_{\text {tot }}-S C_{\text {esp }}-S C_{\text {ind }} \\
S C_{\text {error }}=194.67-120.17-35.33=39.17
\end{gathered}
$$

5. Calcular los grados de libertad.

$$
\begin{aligned}
& g l_{\text {esp }}=\text { número de condiciones }-1=\mathrm{c}-1 \\
& g l_{\text {ind }}=\text { número de sujetos }-1=n-1 \\
& g l_{\text {tot }}=\text { número de resultados }-1=N-1 \\
& g l_{\text {error }}=g l_{\text {tot }}-g l_{\text {esp }}-g l_{\text {ind }}
\end{aligned}
$$

Donde:

$$
\begin{aligned}
& g l_{\text {esp }}=3-1=2 \\
& g l_{\text {ind }}=16-1=15 \\
& g l_{\text {tot }}=48-1=47 \\
& g l_{\text {error }}=47-2-15=30
\end{aligned}
$$

6. Dividir cada $S C$ entre los $g l$ para obtener el valor de los cuadrados medios $M C$.

$$
\begin{gathered}
M C_{\text {esp }}=\frac{S C_{\text {esp }}}{g l_{\text {esp }}}=\frac{120.17}{2}=60.085 \\
M C_{\text {ind }}=\frac{S C_{\text {ind }}}{g l_{\text {ind }}}=\frac{35.33}{15}=2.355 \\
M C_{\text {error }}=\frac{S C_{\text {error }}}{g l_{\text {error }}}=\frac{39.17}{30}=1.305
\end{gathered}
$$

7. Calcular el valor de $F$ ratio para $M C_{\text {esp }}$ y $M C_{\text {ind }}$ con relación a $M C_{\text {error }}$, asignar el número de $g l$ adecuado para las $F$ ratios:

$$
\begin{array}{ll}
F \text { ratio para } \mathrm{MC}_{\text {esp }}=\frac{M C_{\text {esp }}}{M C_{\text {error }}} & F_{2,30}=60.085 / 1.305=45.042 \\
F \text { ratio para } \mathrm{MC}_{\text {ind }}=\frac{M C_{\text {ind }}}{M C_{\text {error }}} & F_{15,30}=2.355 / 1.305=1.804
\end{array}
$$


8. Buscar el nivel de significación de $F$ en la Tabla $H$ del Apéndice D.

Para la prueba ANOVA se utilizan las tablas $\mathrm{H}$ (1) que contiene los valores para $\rho<0.05$ y $\mathrm{H}$ (2) que contiene los valores para $\rho<0.01$ ( $\rho$ es el valor del nivel de significación). El valor calculado $F$ debe ser igual o mayor que el valor crítico que se muestra en las tablas, para poder aceptar la hipótesis de investigación.

Para localizar el valor de la $F$ de la tabla se debe utilizar los valores de los grados de libertad $(\mathrm{gl})$ para la varianza esperada, la varianza de error y la varianza individual, en este ejem-

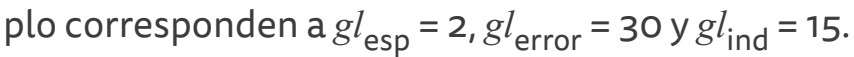

Para $F_{2,30}$ se localiza el valor de $g l_{\text {esp }}=2$ en la Tabla $H$, se ubica éste en la fila superior $\left(v_{1}\right)$ y para el valor de $g l$ error $=30$ se ubica éste en la primera columna de la izquierda $\left(v_{2}\right)$, donde se interceptan los dos puntos se localiza el valor crítico de $F_{\text {Tabla }}=5.39$ en la Tabla H (2). El valor calculado $F_{2,30}=45.042$ es mayor que 5.39 por lo tanto, se puede rechazar la hipótesis nula y aceptar la hipótesis de investigación con un nivel de significación de $\rho<0.01$.

$$
\begin{gathered}
F_{2,30}=45.042 \text { (es mayor que) }>F_{\text {tabla }}=5.39 \\
\text { con un nivel de significación de } \rho<0.01
\end{gathered}
$$

El nivel de significación $\rho<0.01$, está por debajo de la probabilidad que proponen los investigadores en educación como máximo valor aceptable, esto es $\rho<0.05$, entonces se puede rechazar la hipótesis nula y aceptar la de investigación.

Al utilizar el video como refuerzo, los participantes obtuvieron mayor puntaje en las evaluaciones posteriores que en la evaluación diagnóstico de manera significativa y no aleatoria.

En lo que se refiere a la relación de la varianza individual $F_{15,30}=1.804$, es usual que los resultados de cada participante no sean una fuente de varianza significativa, siguiendo los pasos indicados en el párrafo anterior para $F_{15,30}$ se localiza el valor de $g l_{\text {ind }}=15$ en la Tabla $H$ (1), se ubica éste en la fila superior $\left(v_{1}\right)$, en la tabla se observa que no hay un valor para 15 sólo hay 120 24, en este caso se selecciona el valor de 12 para garantizar que el valor de 15 se encuentra por debajo de este valor y para el valor de $g l_{\text {error }}=30$ se ubica éste en la primera columna de la izquierda $\left(v_{2}\right)$, donde se interceptan los dos puntos se localiza el valor crítico de $F_{\text {tabla }}=2.09$, en donde $F_{15,30}=1.804$ es menor que el encontrado en la tabla, por lo que las diferencias entre los participantes no son significativas.

$$
\begin{gathered}
F_{15,30}=1.804 \text { (es menor que) }<F_{\text {tabla }}=2.09 \\
\text { para un nivel de significación de } \rho<0.05
\end{gathered}
$$

\subsection{Prueba ANOVA Unifactorial (relacionada) utilizando el programa SPSS}

El programa SPSS en esta prueba determina el nivel de significación comparándolo con el nivel mínimo utilizado por los investigadores en educación que corresponde a $\rho<0.05$, si el que se determina mediante el proceso del programa resulta mayor que este valor, entonces se puede decir que las diferencias en los resultados son causados por variables aleatorias y se debe aceptar la hipótesis nula, pero si el valor es menor entonces las diferencias son significativas y se debe rechazar la hipótesis nula y aceptar la hipótesis de investigación.

El primer paso consiste en otorgar propiedades a las variables, una vez abierto el programa, antes de introducir los datos, es necesario definir las variables y otorgar las características para su presentación en la tabla, para esto se requiere dar clic en la pestaña Vista de variables. 
En el caso de la prueba ANOVA cuando se trata de muestras relacionadas o independientes los valores de los datos obtenidos se deben colocar en una misma columna como la primera variable, la que se designará como Condiciones1az y la segunda variable se designa como Agrupación en donde se especifica cuáles son los datos de la columna 1 que corresponden a la Condición 1 (sin video), Condición 2 (con video tradicional) y Condición 3 (con video interactivo).

En este caso se teclea en el primer espacio para Nombre, el nombre de la primera variable Condiciones1a3, recordando que no debe haber espacios vacíos entre los caracteres, se deben anotar las tres condiciones, es decir, los datos obtenidos por los participantes sin video, con video tradicional y por último con el video interactivo.

El siguiente paso es introducir el nombre de la segunda variable en el espacio 2 de la columna Nombre, los datos de la segunda variable que se denominan con el término de Agrupación (variable de agrupación) en este caso se utilizan tres valores: 1 para indicar que se refiere a los datos correspondientes a la Condición 1 (sin video), 2 para la Condición 2 (video tradicional) y el 3 para la Condición 3 (video interactivo).

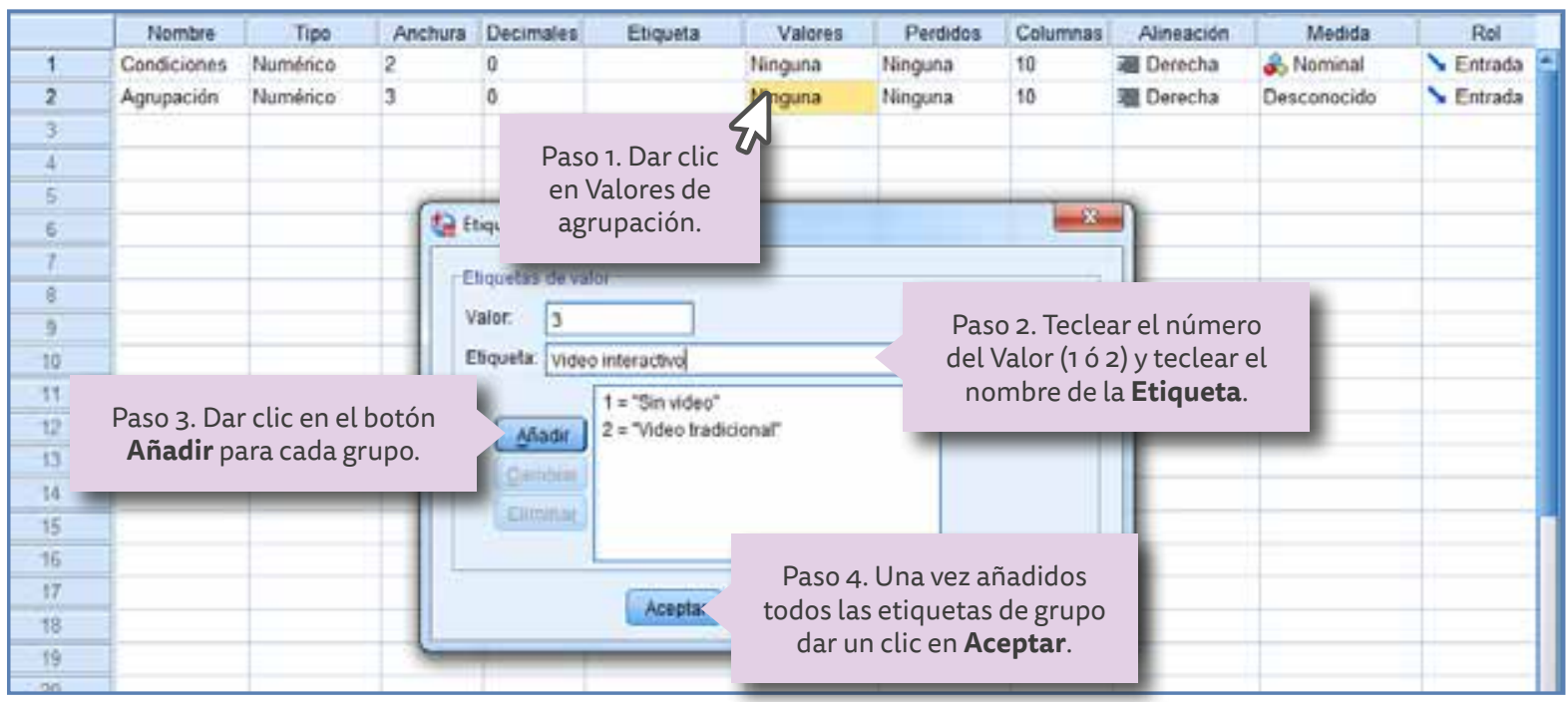

Figura 67. Ventana de diálogo para etiquetar los valores de agrupación.

Para designar las Etiquetas de valor, es decir, definir la ubicación de los grupos dentro de la tabla, en la línea de Agrupación y columna Valores se hace clic con el apuntador y aparece un cuadro de diálogo (Figura 67), en la ventana Valor se coloca el número del grupo (1 para la Condición 1) y la ventana etiqueta el nombre con que se etiqueta al grupo (Sin video), se da clic en el botón Añadir y los datos se transfieren a la ventana inferior, se repite este paso para registrar los valores para la condiciones 2 (Video tradicional) y 3 (Video interactivo). Las características seleccionadas para la presentación de las variables así como los nombres de éstas se pueden encontrar en la Figura 68.

Una vez designados los nombres de las variables y sus características se introducen los datos en la tabla; para llevar a cabo esto es necesario dar clic en la pestaña Vista de datos, e introducir los datos de la siguiente manera:

1. En la columna 1 (Condición1a3) se introducen los valores de los datos obtenidos por el grupo de la Condición 1 y en seguida se introducen los datos de la Condición 2, para concluir introduciendo los datos de la Condición 3.

2. En la columna dos (Agrupación) se introduce el valor de 1 para todos los datos que correspondan a sin video (Condición 1), el valor de 2 para los datos correspondientes a Video tradicional (Condición 2) y el valor 3 para Video interactivo (Condición 3). 
En el siguiente cuadro se observan las variables seleccionadas en este ejemplo:

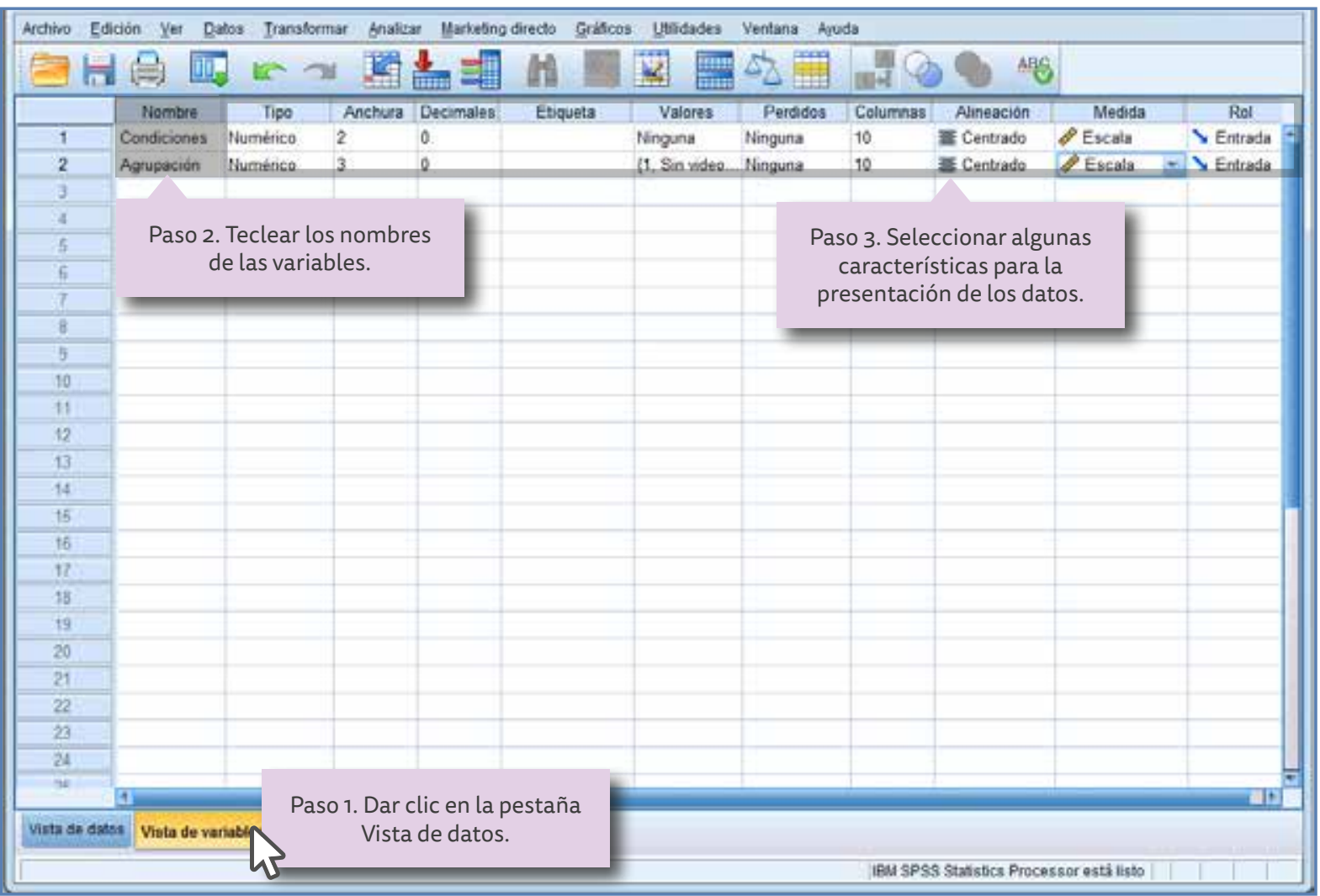

Figura 68. Designación de nombre de las variables y características de presentación para la prueba ANOVA Unifactorial (relacionada).

Cuadro 21. Designación de variables para la prueba ANOVA Unifactorial (relacionada).

Nombre: Condición1a3

Tipo: Numérico

Anchura: 2

Decimales: 0

Etiqueta: Nada

Valores: Ninguno

Perdidos: Ninguno

Columnas: 10

Alineación: Centrado

Medida: Escala

Rol: Entrada
Nombre: Agrupación

Tipo: Numérico

Anchura: 2

Decimales: 0

Etiqueta: Nada

Valores: 1. Sin video

2. Video tradicional

3. Video interactivo

Perdidos: Ninguno

Columnas: 10

Alineación: Centrado

Medida: Escala

Rol: Entrada

En la Figura 69 se observa cómo deben quedar los datos siguiendo los procedimientos mencionados y de acuerdo a las características seleccionadas en los pasos anteriores.

Otra manera de verificar si los datos coinciden con los grupos es activando la etiqueta de valores de agrupación en donde al programar las características se etiquetaron como $1=\operatorname{Sin}$ video, 2 = Video tradicional y el 3 = Video interactivo, mostrándose como se puede observar en la Figura 70. 


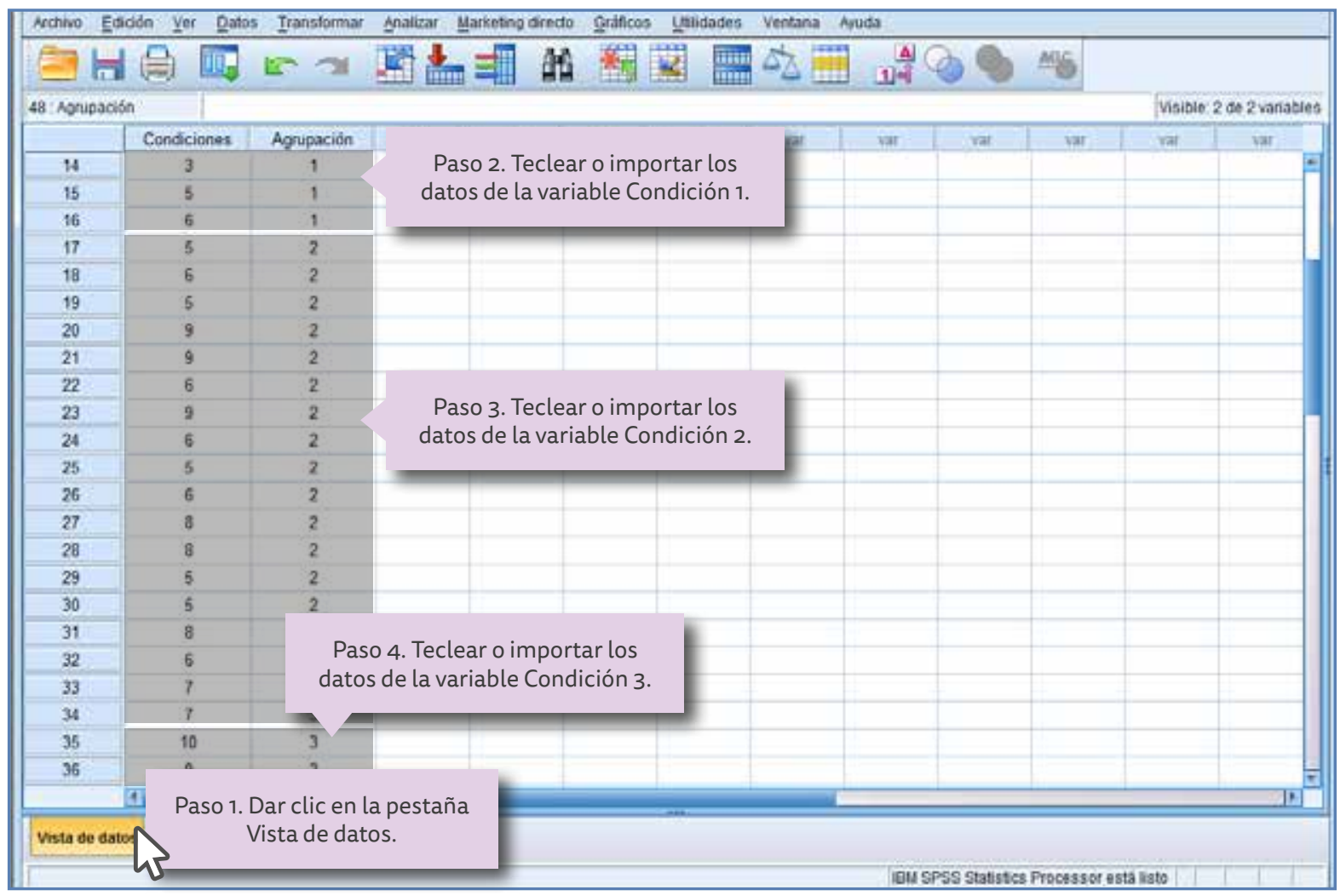

Figura 69. Presentación de los datos arrojados por los participantes en las tres condiciones: sin video, con video tradicional $y$ con video interactivo.

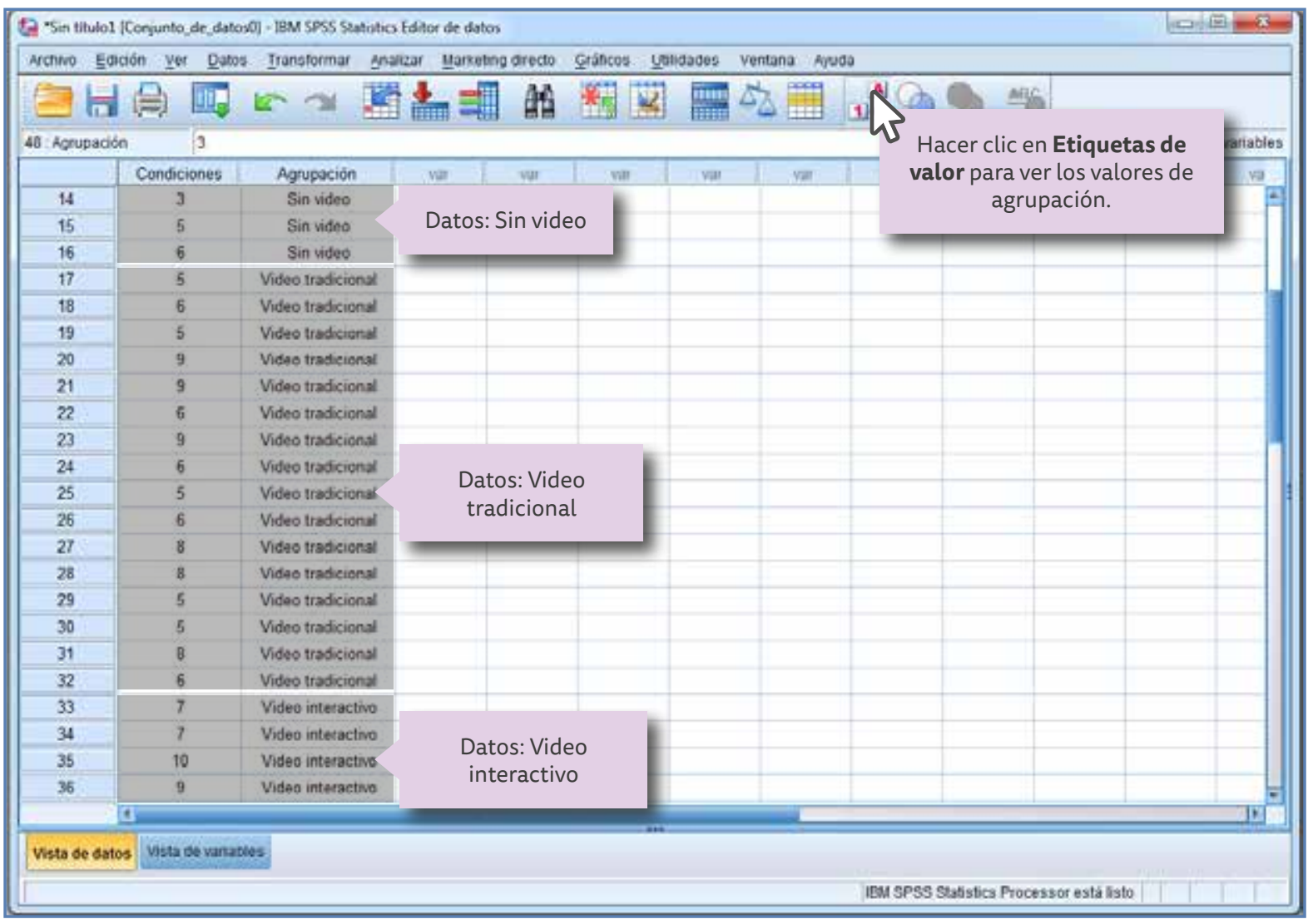

Figura 70. Presentación de los datos activando las etiquetas de valor. 
Una vez que los datos se encuentran en la tabla, se realiza la prueba (Figura 71); para hacerlo es necesario dar clic en la pestaña ubicada en la barra superior designada como Analizar, en seguida aparece un cuadro de diálogo en el cual se selecciona la línea que indica Comparar medias, por pertenecer precisamente la prueba ANOVA a este tipo; al ubicar el apuntador del ratón en esta opción se presenta a la derecha otro cuadro de diálogo, se selecciona ANOVA de un factor (que son las que corresponden a tres muestras o más relacionadas) y se da clic

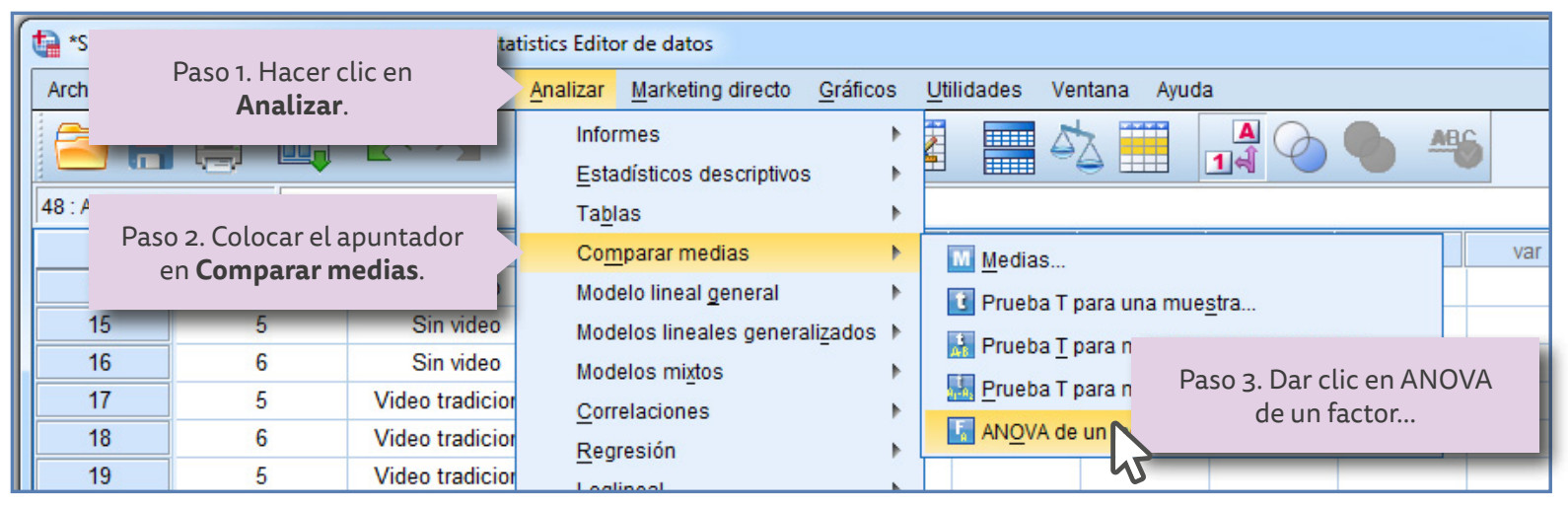

Figura 71. Cuadro de diálogo para seleccionar la prueba paramétrica de tres muestras relacionadas.

Aparece la ventana de la Figura 72 en la cual se muestran las variables del lado izquierdo, Condiciones1a3 y Agrupación, la primera debe ser trasladada a la ventana que dice Variables para contrastar; la forma de hacerlo es seleccionando la variable deseada (Condiciones1az) y después dar clic en la flecha superior que se ubica entre las dos ventanas.

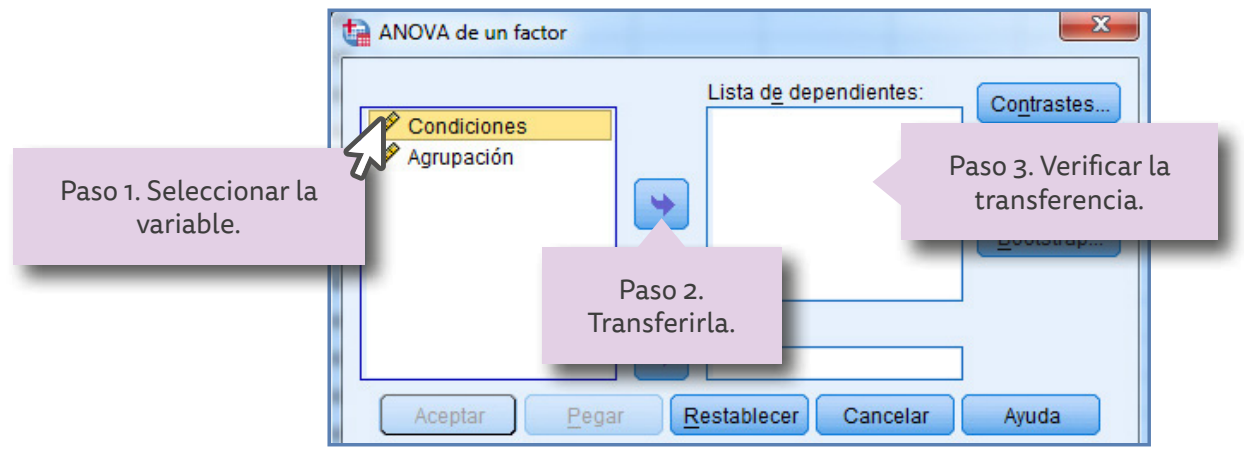

Figura 72. Pasos para ingresar la variable Condicionestaz al programa SPSS.

Para trasladar la otra variable (Agrupación) debes seleccionarla, dar clic en la flecha inferior que se encuentra entre las ventanas y se traslada a la ventana designada como Factor (Figura 73).

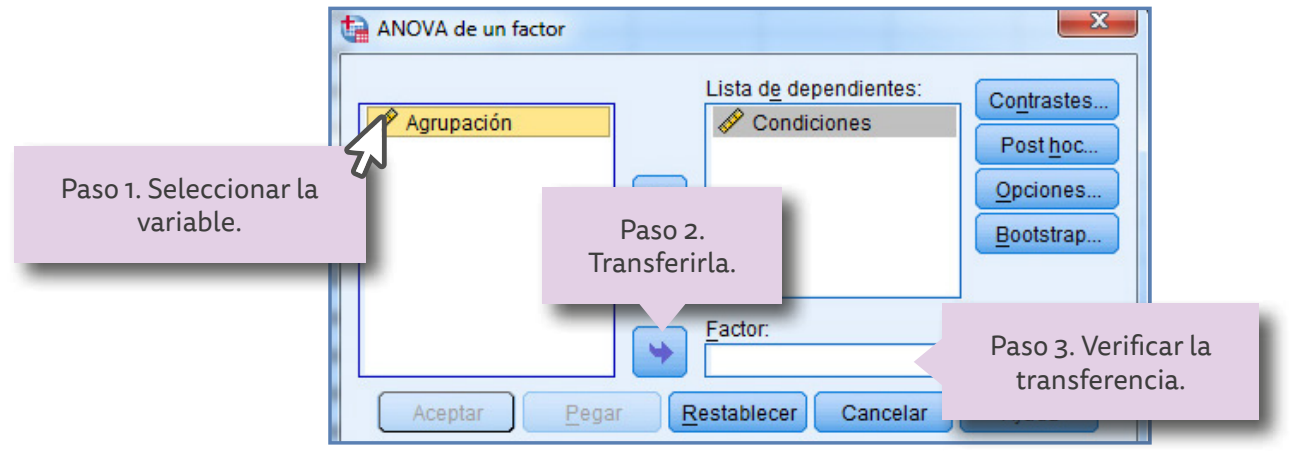

Figura 73. Pasos para ingresar la variable Agrupación al programa SPSS. 


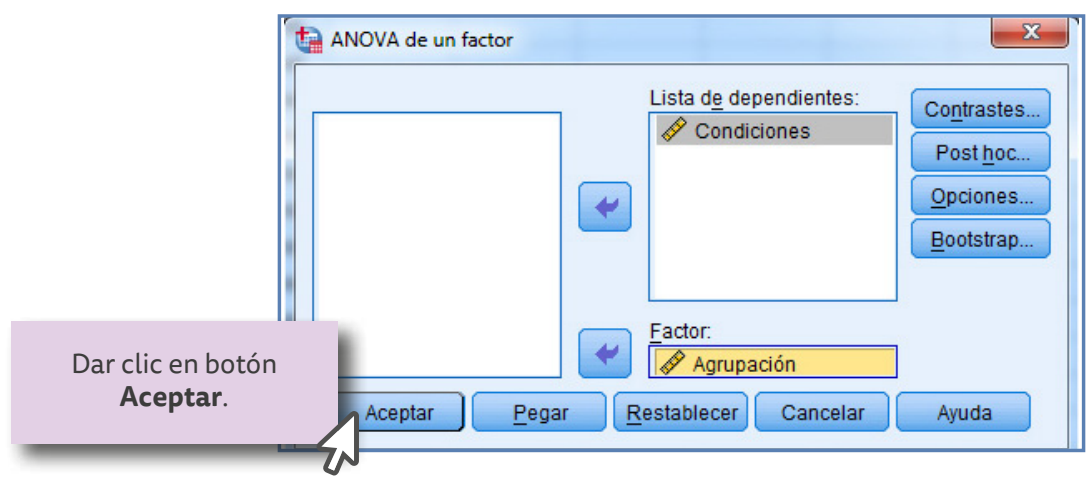

Figura 74. Paso para ejecutar el programa SPSS para que realice los cálculos requeridos.

Una vez realizadas estas acciones el programa queda listo para arrojar los resultados, al activar el botón Aceptar (Figura 74) se obtienen los resultados que se muestran en el siguiente cuadro.

Cuadro 22. Resultados obtenidos con el programa SPSS para la prueba paramétrica ANOVA Unifactorial para tres muestras relacionadas.

ONEWAY Condiciones BY Agrupación

/MISSING ANALYSIS.

$\Rightarrow$ ANOVA de un factor

[Conjunto_de_datos0]

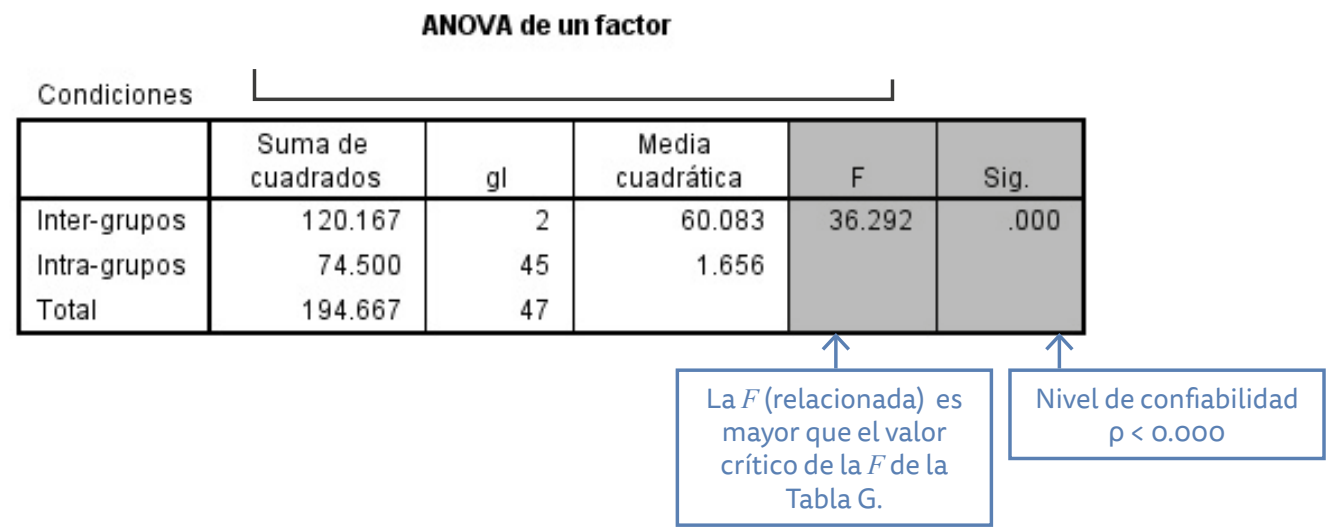

En el cuadro se puede observar el valor del nivel de significación [Significación asintótica] $\rho<0.000$.

$$
\text { Entonces se puede concluir que } \rho_{\text {encontrada }} 0.000<\rho_{\text {aceptada }} 0.05
$$

Esto es, el valor encontrado 0.000 es menor que el mínimo aceptable por los investigadores en educación (0.05), lo que significa que los resultados de la diferencia no son aleatorios puesto que existe una diferencia significativa, por lo que se puede rechazar la hipótesis nula y aceptar la hipótesis de investigación.

También se puede observar que el valor de $F$ calculado por medio del programa es mayor que el valor crítico de la Tabla $\mathrm{H}(2)$ para $\rho<0.01$. 
$F=36.292$ (es mayor que) $>F_{\text {tabla }}=5.39$ para un nivel de significación de $\rho<0.01$

Hi: Si se utiliza el video como refuerzo en la materia de Física, los alumnos de sexto grado de primaria retendrán mejor el conocimiento, más aún si el video es interactivo. 



\section{Capítulo 12}

12. Prueba ANOVA Unifactorial (muestras independientes)

La prueba ANOVA Unifactorial (no relacionada) se debe utilizar para diseños independientes cuando tres o más condiciones se aplican a los distintos participantes y los datos pertenecen a la escala de intervalo.

Ejemplo 87. Se trata de aceptar o rechazar la siguiente hipótesis de investigación: Hi: Si se utilizan prácticas de laboratorio como refuerzo en la materia de Química, los alumnos de tercero de secundaria retendrán mejor el conocimiento, más aún si son prácticas constructivistas.

\subsection{Estado situacional}

El investigador desea saber si el uso de diferentes tipos de prácticas de laboratorio influyen en la retención de los conocimientos de los participantes de manera significativa, para tal efecto se seleccionan tres grupos de tercero de secundaria bajo las siguientes condiciones: Grupo "A" sin práctica de laboratorio, Grupo "B" con práctica proporcionada por la Academia y Grupo "C" con una práctica constructivista.

La práctica constructivista otorga al alumno un papel activo en la selección de la teoría o teorías que se pretenden comprobar, los objetivos que se persiguen, el desarrollo de la misma y la presentación de resultados y conclusiones. Se debe hacer en equipo y siguiendo una guía proporcionada por el maestro que le permita construirla y al mismo tiempo descubrir conocimientos nuevos. El Grupo A está constituido por 20 alumnos, el Grupo B por 18 y el Grupo C por 19, en todos los casos se terminó de ver el mismo tema, y se les aplicó una prueba objetiva con 10 reactivos de opción múltiple.

En la Tabla 17 se muestran los resultados obtenidos después de aplicar la prueba objetiva y el desarrollo del análisis estadístico utilizado. Se calcula el valor para la prueba de media ANOVA Unifactorial (independiente).

\subsection{Explicación}

La prueba ANOVA Unifactorial (independiente) se basa en calcular la varianza en experimentos de tres o más condiciones, en donde cada condición se aplica a grupos de participantes distintos que son expuestos a una sola de las condiciones. Es por esto que los resultados se deben tratar como resultados independientes de participantes distintos. En este caso se pueden calcular los siguientes tipos de varianza (Greene y D'oliveira, 2006): 
a. Varianza esperada. Se origina por las diferencias pronosticadas entre condiciones.

b. Varianza de error. Se origina por variables irrelevantes.

c. Varianza total. Incluye todos los tipos de varianzas anteriores.

Tabla 17. Puntajes obtenidos por los grupos participantes de acuerdo a las condiciones establecidas por el investigador.

\begin{tabular}{|c|c|c|c|c|c|c|}
\hline $\begin{array}{c}\text { № de } \\
\text { participante }\end{array}$ & $\begin{array}{l}\text { Condición } 1 \\
\text { (Grupo A) } \\
\text { Sin práctica }\end{array}$ & $X_{1}^{2}$ & $\begin{array}{c}\text { Condición } 2 \\
\text { (Grupo B) Práctica } \\
\text { académica }\end{array}$ & $X_{2}^{2}$ & $\begin{array}{c}\text { Condición } 3 \\
\text { (Grupo C) Práctica } \\
\text { constructivista }\end{array}$ & $X_{3}^{2}$ \\
\hline 1 & 6 & 36 & 7 & 49 & 9 & 81 \\
\hline 2 & 6 & 36 & 7 & 49 & 9 & 81 \\
\hline 3 & 4 & 16 & 6 & 36 & 3 & 9 \\
\hline 4 & 3 & 9 & 7 & 49 & 7 & 49 \\
\hline 5 & 5 & 25 & 8 & 64 & 9 & 81 \\
\hline 6 & 6 & 36 & 7 & 49 & 9 & 81 \\
\hline 7 & 3 & 9 & 8 & 64 & 8 & 64 \\
\hline 8 & 5 & 25 & 9 & 81 & 9 & 81 \\
\hline 9 & 7 & 49 & 5 & 25 & 6 & 36 \\
\hline 10 & 5 & 25 & 6 & 36 & 9 & 81 \\
\hline 11 & 3 & 9 & 4 & 16 & 8 & 64 \\
\hline 12 & 6 & 36 & 6 & 36 & 6 & 36 \\
\hline 13 & 5 & 25 & 4 & 16 & 10 & 100 \\
\hline 14 & 7 & 49 & 8 & 64 & 6 & 36 \\
\hline 15 & 3 & 9 & 7 & 49 & 9 & 81 \\
\hline 16 & 6 & 36 & 8 & 64 & 9 & 81 \\
\hline 17 & 5 & 25 & 9 & 81 & 8 & 64 \\
\hline 18 & 5 & 25 & 8 & 64 & 9 & 81 \\
\hline 19 & 6 & 36 & & & 7 & 49 \\
\hline 20 & 7 & 49 & & & & \\
\hline$\Sigma=$ & 96 & $\begin{array}{c}\sum X_{1}^{2}= \\
565\end{array}$ & 124 & $\begin{array}{c}\Sigma X_{2}^{2}= \\
892\end{array}$ & 150 & $\begin{array}{c}\sum X_{3}^{2}= \\
1236\end{array}$ \\
\hline Media & 5.15 & & 6.89 & & 7.89 & \\
\hline
\end{tabular}

La finalidad de ANOVA es comparar ratios de varianza. La variable independiente del uso de la práctica (sin práctica, práctica académica y práctica constructivista) representa las diferencias pronosticadas entre las tres condiciones (varianza esperada). La predicción afirma que la varianza esperada debe ser relativamente elevada en comparación con la varianza de error causada por las variables irrelevantes.

Es decir, para aceptar la hipótesis de investigación el ratio (relación) entre la varianza esperada y la varianza de error debe ser relativamente grande. El término de ANOVA Unifactorial se refiere a que sólo hay una variable independiente para analizar.

De acuerdo a lo anterior la prueba ANOVA para muestras relacionadas debe cumplir con los siguientes requisitos:

- Deben existir tres o más condiciones experimentales con una variable.

- Las tres condiciones se deben aplicar a distintos participantes.

- Los datos numéricos deben ser de intervalo.

- Son pruebas paramétricas, adecuadas para realizar análisis de datos numéricos de intervalo. 
12.3 Procedimiento para determinar el valor de ANOVA Unifactorial (independiente).

Los cálculos numéricos se realizan con datos que pertenecen a una escala de intervalo, calculando el ratio (relación) entre la varianza esperada y la varianza de error.

1. Calcular el valor de $S C_{\text {esp. }}$

$$
S C_{\text {esp }}=\frac{\Sigma T^{2}}{n}-\frac{(\Sigma x)^{2}}{N}=\frac{\Sigma T_{1}^{2}}{n_{1}}+\frac{\Sigma T_{2}^{2}}{n_{2}}+\frac{\Sigma T_{3}^{2}}{n_{3}}-\frac{\left(\Sigma x^{2}\right)}{N}
$$

Donde:

$\Sigma T^{2}=$ suma de los cuadrados de los totales para cada condición.

$n=$ número de participante en cada grupo.

$N$ = número de resultados.

$(\Sigma x)^{2}=$ cuadrado del total general.

$\frac{(\Sigma X)^{2}}{N}=$ constante que se debe restar a todas las sumas de cuadrados.

$\Sigma \mathrm{x}^{2}=$ suma de cada uno de los resultados elevados al cuadrado.

Entonces, de acuerdo a los datos de la tabla calcular:

$$
\begin{gathered}
\frac{\sum T^{2}}{n}=\frac{(90)^{2}}{20}+\frac{(124)^{2}}{18}+\frac{(150)^{2}}{19}=2499.23 \\
n_{1}=20, n_{2}=18 \text { y } n_{3}=19 \\
N=20+18+19=57 \\
\left(\sum \mathrm{x}\right)^{2}=(96+124+150)^{2}=136900 \\
\frac{\left(\sum \mathrm{x}\right)^{2}}{N}=(136900) / 57=2401.75 \\
\sum \mathrm{x}^{2}=\sum \mathrm{x}_{1}{ }^{2}+\sum \mathrm{x}_{2}{ }^{2}+\sum \mathrm{x}_{3}{ }^{2}=565+892+1236=2693
\end{gathered}
$$

Al sustituir en la ecuación se encuentra:

$$
S C_{\mathrm{esp}}=\frac{\sum T^{2}}{n}-\frac{\left(\sum \mathrm{x}\right)^{2}}{N}=2499.23-2401.75=97.48
$$

2. Calcular el valor de $S C_{\text {tot }}$ :

$$
S C_{\text {tot }}=\sum x^{2}-\frac{(\Sigma x)^{2}}{N}=2693-2401.75=291.25
$$

3. Calcular el valor de $S C_{\text {error: }}$

$$
\begin{gathered}
S C_{\text {error }}=S C_{\text {tot }}-S C_{\text {esp }} \\
S C_{\text {error }}=291.25-97.48=139.77
\end{gathered}
$$


4. Calcular los grados de libertad.

Donde:

$$
\begin{aligned}
& g l_{\text {esp }}=\text { número de condiciones }-1=c-1 \\
& g l_{\text {tot }}=\text { número de resultados }-1=N-1 \\
& g l_{\text {error }}=g l_{\text {tot }}-g l_{\text {esp }}
\end{aligned}
$$

$$
\begin{aligned}
& g l_{\text {esp }}=3-1=2 \\
& g l_{\text {tot }}=57-1=56 \\
& g l_{\text {error }}=56-2=54
\end{aligned}
$$

5. Dividir cada $S C$ entre los $g l$ para obtener el valor de $M C$

$$
\begin{gathered}
M C_{\text {esp }}=\frac{S C_{\text {esp }}}{g l_{\text {esp }}}=\frac{(97.48)}{2}=48.74 \\
M C_{\text {error }}=\frac{S C_{\text {error }}}{g l_{\text {error }}}=\frac{(139.77)}{54}=2.588
\end{gathered}
$$

6. Calcular el valor de $F$ ratio para $M C_{\text {esp }}$ con relación a $M C_{\text {error }}$ asignar el número de $g l$ adecuado para las $F$ ratios:

$$
\begin{gathered}
F \text { ratio para } M C_{\text {esp }}=\frac{M C_{\text {esp }}}{M C_{\text {error }}} \\
F_{2,54}=\frac{48.74}{2.58}=18.83
\end{gathered}
$$

7. Buscar el nivel de significación de $F$ en la Tabla $H$ del Apéndice $D$.

Para la prueba ANOVA se utilizan las tablas $\mathrm{H}$ (1) que contiene los valores para $\rho<0.05$ y $\mathrm{H}$ (2) que contiene los valores para $\rho<0.01$ ( $\rho$ es el valor del nivel de significación). El valor calculado $F$ debe ser igual o mayor que el valor crítico que se muestra en las tablas para poder aceptar la hipótesis de investigación.

Para localizar el valor de la $F$ de la tabla se debe utilizar los valores de los grados de libertad $g l$ para la varianza esperada, la varianza de error y la varianza individual, en este ejemplo corresponden a $g l_{\text {esp }}=2$, y $g l_{\text {error }}=54$.

Para $F_{2,54}$ se localiza el valor de $g l_{\text {esp }}=2$ en la Tabla $H$, se ubica éste en la fila superior $\left(v_{1}\right)$ y para el valor de $g l_{\text {error }}=54$ se ubica éste en la primera columna de la izquierda $\left(v_{2}\right)$, donde se interceptan los dos puntos se localiza el valor crítico de $F_{\text {Tabla }}=5.18$ en la Tabla H (2). El valor calculado $F_{2,54}=18.83$ es mayor que 5.18 por lo tanto se puede rechazar la hipótesis nula y aceptar la hipótesis de investigación para un nivel de significación de $\rho<0.01$. Se puede observar que en la tabla no se encuentra el valor para $g l_{\text {error }}=54$, en este caso se utiliza el inmediato inferior que es el valor de 40 para garantizar que el valor de 54 se encuentra por debajo de este valor:

$$
F_{2,54}=18.83 \text { (es mayor que) }>F_{\text {tabla }}=5.18 \text { para un nivel de significación de } \rho<0.01
$$


El nivel de significación $\rho<0.01$, está por debajo de la probabilidad que proponen los investigadores en educación como máximo valor aceptable, esto es $\rho<0.05$, entonces se puede rechazar la hipótesis nula y aceptar la de investigación.

Al utilizar la práctica de laboratorio como refuerzo, los participantes del Grupo C obtuvieron el mayor puntaje que los otros grupos.

La prueba ANOVA solo indica que existe una diferencia significativa en la relación entre las varianzas pero para determinar el sentido se pueden observar los valores de las medias en la Tabla 17 en donde se observa que el Grupo A (sin práctica de laboratorio) es el que obtuvo la media más baja.

\subsection{Prueba ANOVA Unifactorial (independiente) utilizando el programa SPSS}

El programa SPSS para esta prueba permite determinar el nivel de significación comparándolo con el nivel mínimo utilizado por los investigadores en educación que corresponde a $\rho<0.05$; si el valor que se determine mediante el proceso del programa resulta mayor que éste, entonces se puede decir que las diferencias de los resultados son causados por variables aleatorias y se debe aceptar la hipótesis nula, pero si el valor es menor entonces las diferencias son significativas y se debe rechazar la hipótesis nula y aceptar la de investigación.

El primer paso consiste en otorgarle las propiedades a las variables, una vez abierto el programa, antes de introducir los datos, es necesario definir las variables y otorgar las características para su presentación en la tabla, para esto se requiere dar un clic en la pestaña Vista de variables (Ver Figura 76).

En el caso de la prueba ANOVA cuando se trata de muestras relacionadas o independientes, los valores de los datos obtenidos se deben colocar en una misma columna como la primera variable, la que se designará como Condiciones 1 a 3 y la segunda variable se designa como Agrupación en donde se especifica cuáles son los datos de la columna 1 que corresponden a la Condición 1 (sin práctica), Condición 2 (con práctica académica) y Condición 3 (práctica constructivista).

En este caso se teclea en el primer espacio, el Nombre de la primera variable Condiciones1a3, recordando que no debe haber espacios vacíos entre los caracteres, se deben anotar las tres condiciones, es decir, los datos obtenidos por los participantes sin video, con video tradicional y por último con el video interactivo.

El siguiente paso es introducir el nombre de la segunda variable en el espacio 2 de la columna Nombre, los datos de la segunda variable que se denominan con el término de Agrupación (variable de agrupación), en este caso se utilizan tres valores: 1 para indicar que se refiere a los datos correspondientes a la Condición 1 (sin práctica), 2 para la Condición 2 (práctica académica) y el 3 para la Condición 3 (práctica constructivista).

Para designar las Etiquetas de valor, esto es, definir la ubicación de los grupos dentro de la tabla (Figura 75), en la línea de Agrupación y columna Valores se hace clic con el apuntadory aparece un cuadro de diálogo, en la ventana Valor se coloca el número del grupo (1 para la Condición 1) y la ventana Etiqueta el nombre con que se etiqueta al grupo (Sin práctica), se da clic en el botón Añadir y los datos se transfieren a la ventana inferior, se repite este paso para registrar los valores para la condiciones 2 (Práctica académica) y 3 (Práctica constructivista). Las características seleccionadas para la presentación de las variables así como los nombres de éstas, se pueden observar en la Figura 76. 


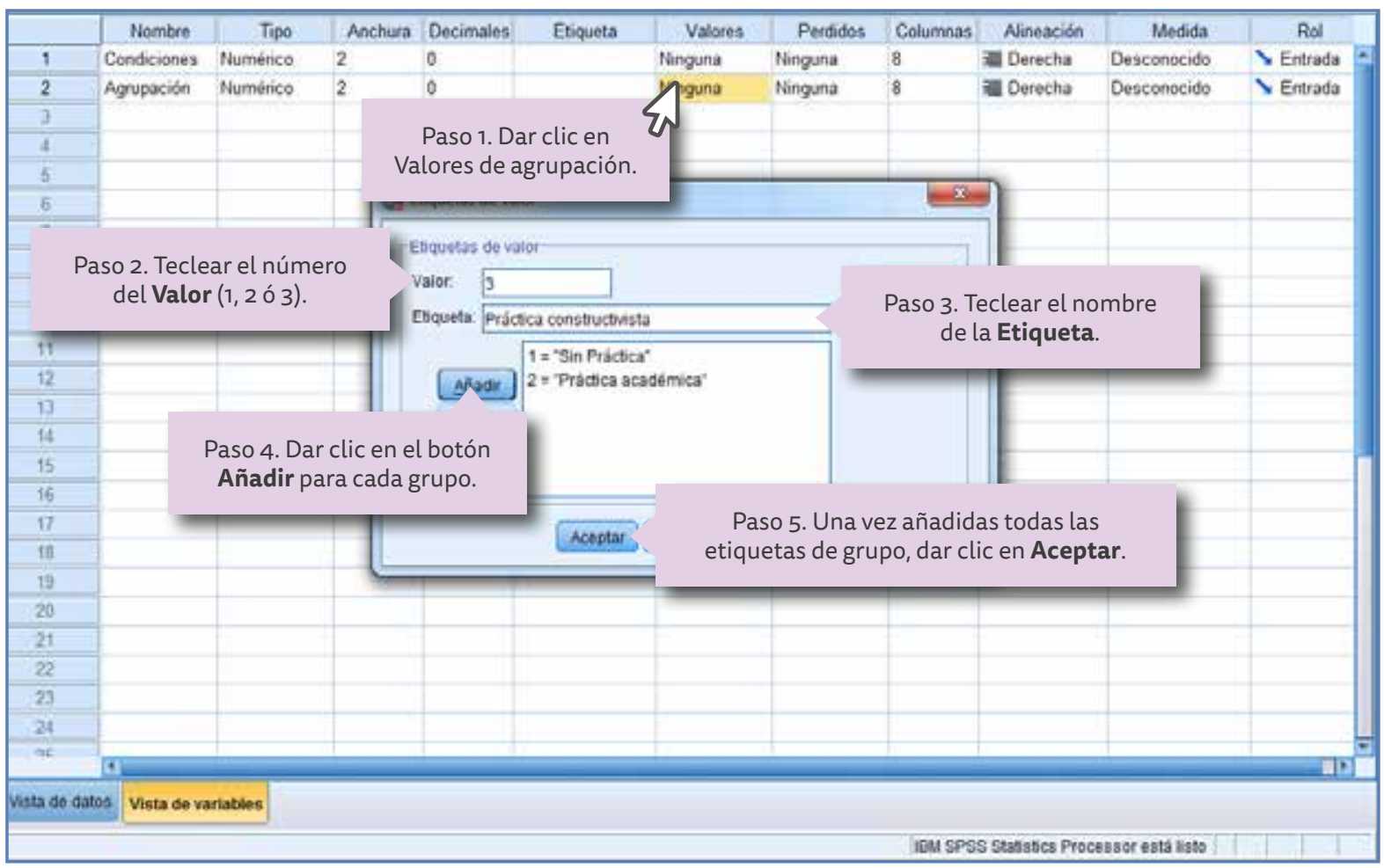

Figura 75. Ventana de diálogo para etiquetar los valores de agrupación.

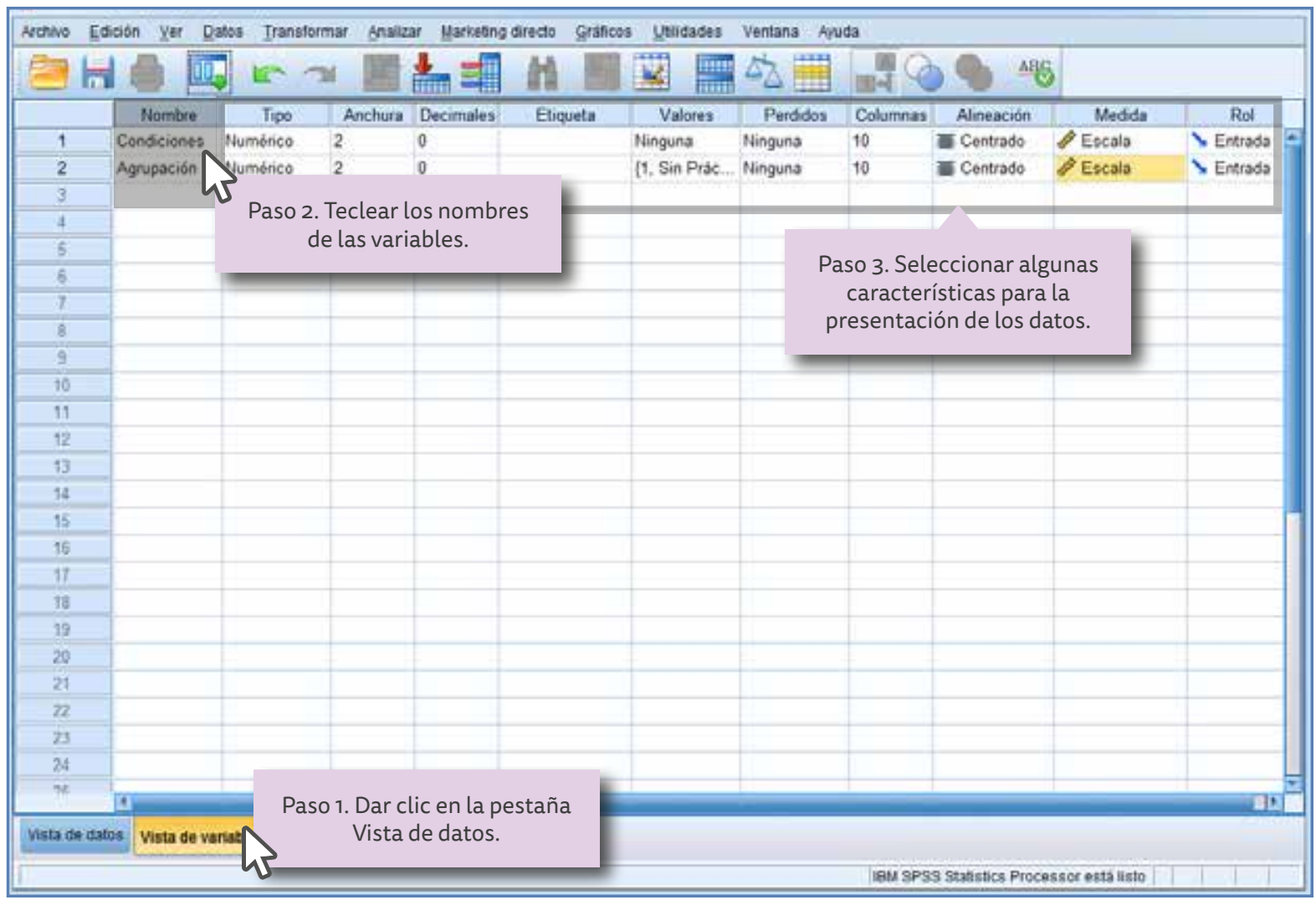

Figura 76. Designación de nombre de las variables y características de presentación para la prueba ANOVA Unifactorial (independiente).

Una vez designados los nombres de las variables y sus características se introducen los datos en la tabla; para llevar a cabo esto es necesario dar clic en la pestaña Vista de datos, e introducir los datos de la siguiente manera utilizando el Cuadro 23. 
Cuadro 23. Designación de variables para la prueba ANOVA Unifactorial (no relacionada).

Nombre: Condición1a3

Tipo: Numérico

Anchura: 2

Decimales: 0

Etiqueta: Nada

Valores: Ninguno

Perdidos: Ninguno

Columnas: 10

Alineación: Centrado

Medida: Escala

Rol: Entrada

\section{Nombre: Agrupación}

Tipo: Numérico

Anchura: 2

Decimales: 0

Etiqueta: Nada

Valores: 1 . Sin práctica

2. Práctica académica

3. Práctica constructivista

Perdidos: Ninguno

Columnas: 10

Alineación: Centrado

Medida: Escala

Rol: Entrada

1. En la columna 1 (Condición1a3) se introducen los valores de los datos obtenidos por los grupos: (Grupo A) Condición 1 y en seguida se introducen los datos de la Condición 2 (Grupo B), para concluir introduciendo los datos de la Condición 3 (Grupo C).

2. En la columna 2 (Agrupación) se introduce el valor de 1 para todos los datos que correspondan a sin práctica (Condición 1), el valor de 2 para los datos correspondientes a la práctica académica (Condición 2) y el valor 3 para la práctica constructivista (Condición 3).

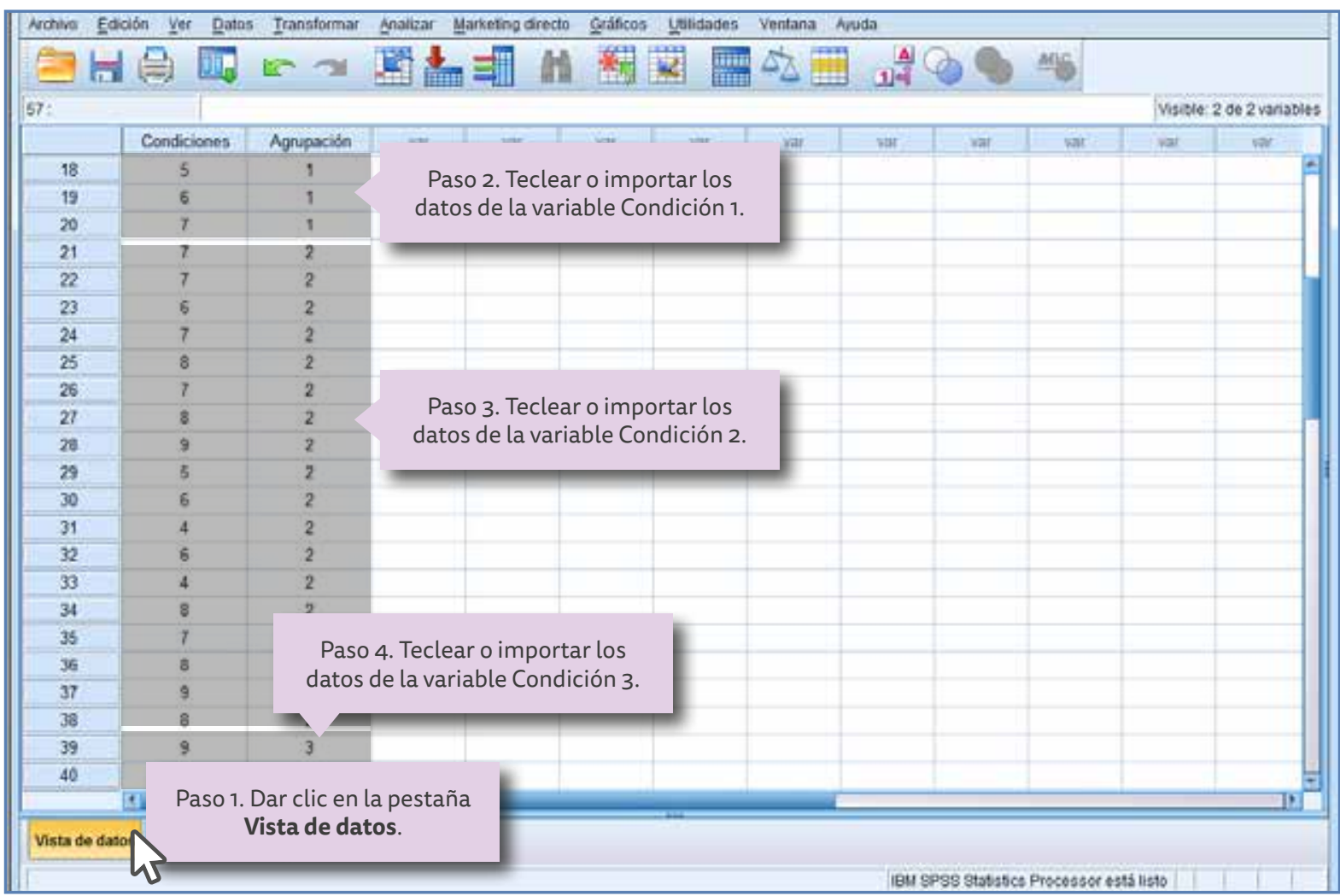

Figura 77. Presentación de los datos arrojados por los participantes en las tres condiciones.

Otra manera de verificar si los datos coinciden con los grupos es activando las Etiquetas de valor de agrupación en donde al programar las características se etiquetaron como 1 = Sin práctica, 2 = Práctica académica y el 3 = Práctica constructivista (Ver Figura 78). 


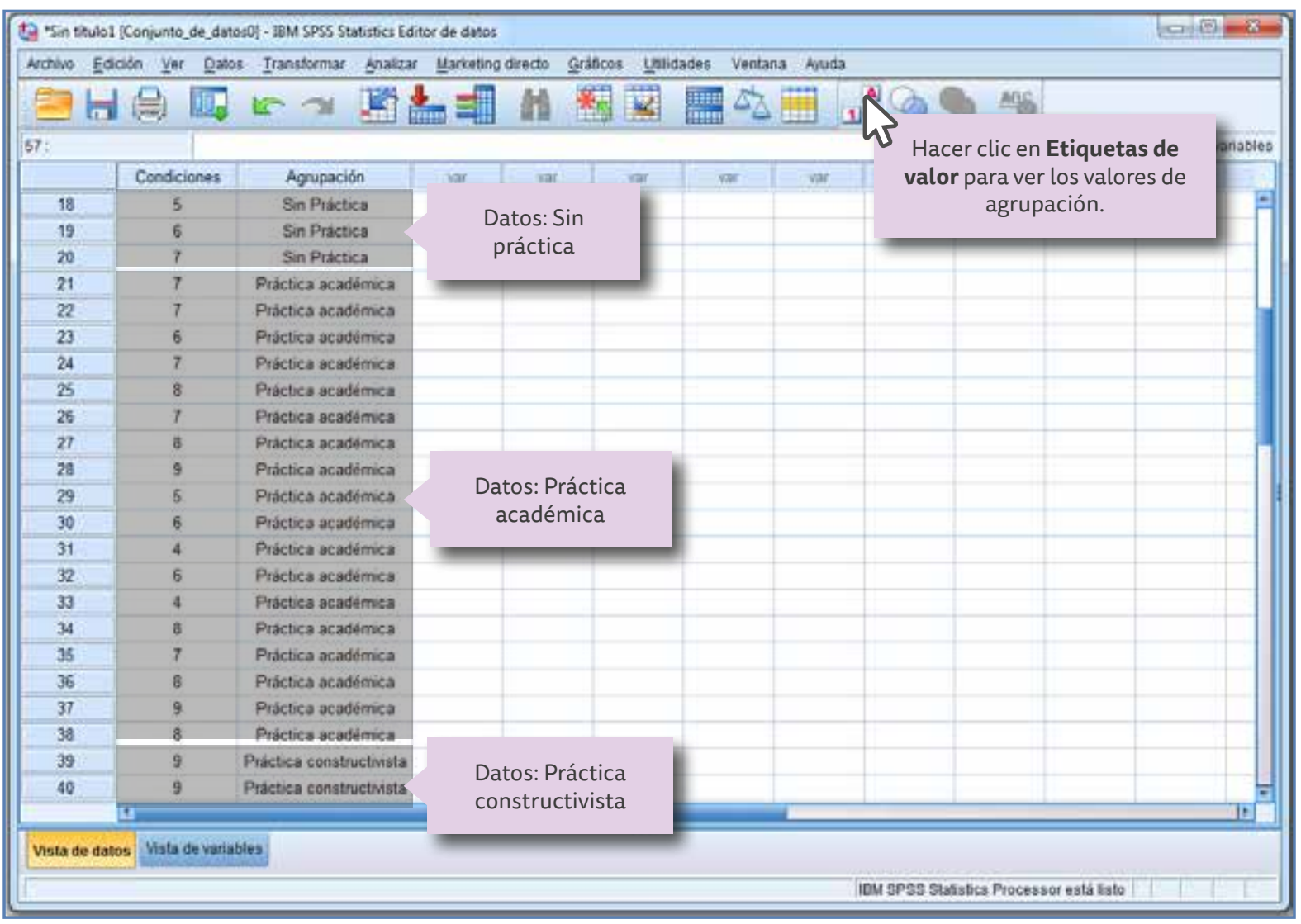

Figura 78. Presentación de los datos activando las etiquetas de valor.

Una vez que los datos se encuentran en la tabla, se realiza la prueba (Figura 79); para hacerlo es necesario dar clicen la pestaña ubicada en la barra superior designada como Analizar, en seguida aparece un cuadro de diálogo, en donde se selecciona la línea que indica Comparar medias, por pertenecer precisamente la prueba ANOVA a este tipo; al ubicar el apuntador del ratón en esta opción se presenta a la derecha otro cuadro de diálogo, se selecciona ANOVA de un factor (que son las que corresponden a tres muestras o más independientes) y se da clic.

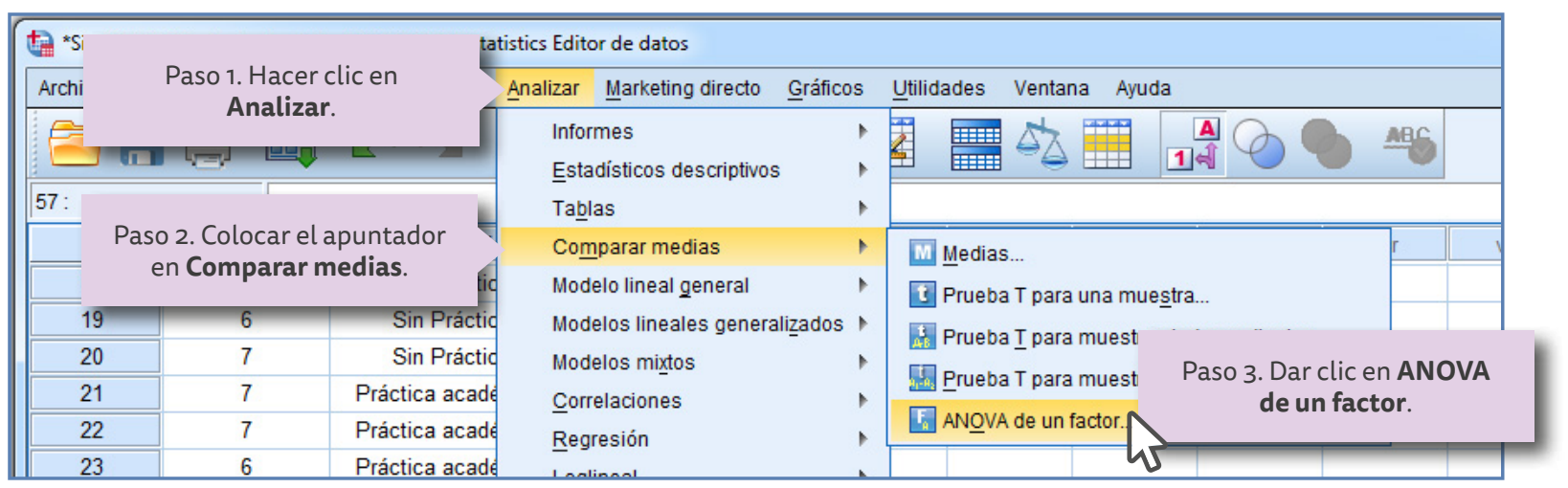

Figura 79. Cuadro de diálogo para seleccionar la prueba paramétrica de tres muestras independientes.

Una vez realizado lo anterior, aparece la ventana de la Figura 80 en la cual se muestran las variables de lado izquierdo, Condiciones1az y Agrupación, la primera debe ser trasladada a la ventana que dice; la forma de hacerlo es seleccionando la variable deseada (Condiciones1a3) y después dar un clic en la flecha superior que se ubica entre las dos ventanas. 


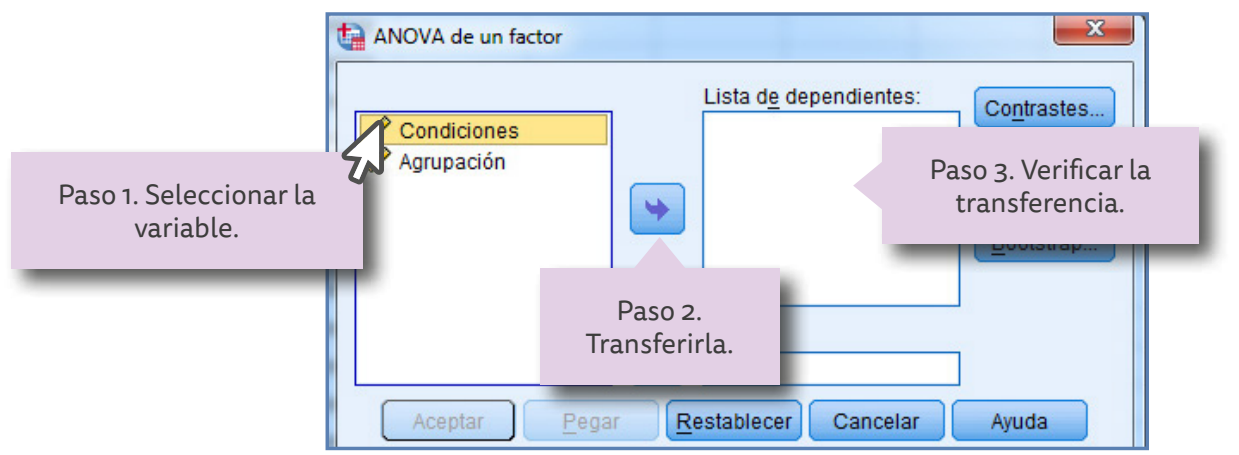

Figura 80. Pasos para ingresar las variables Condicionesiaz al programa SPSS.

Para trasladar la otra variable (Agrupación) debe ser seleccionada, se da un clic en la flecha inferior que se encuentra entre las ventanas y se traslada a la ventana designada como Factor (Figura 81).

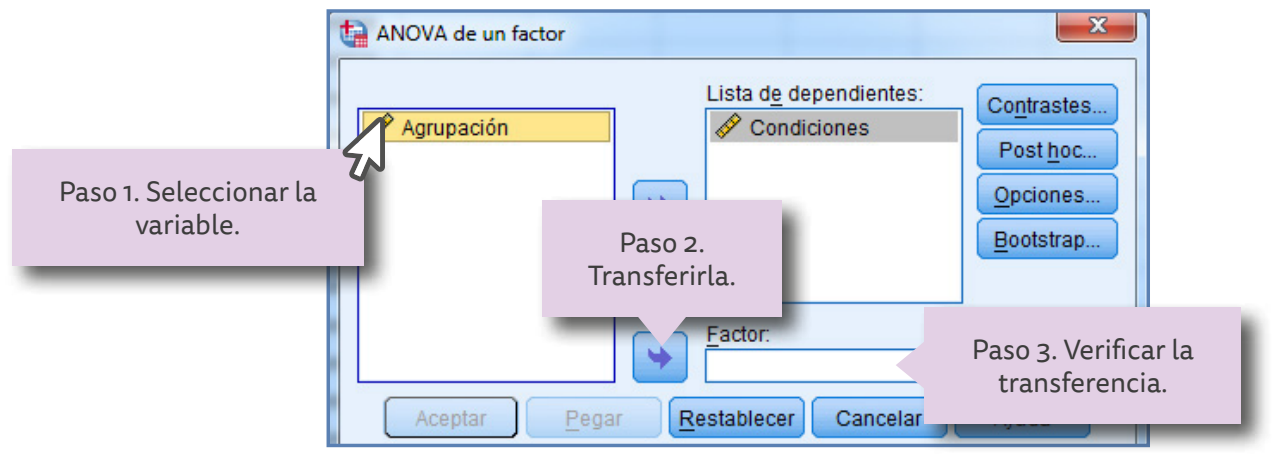

Figura 81. Pasos para ingresar las variables Agrupación al programa SPSS.

Una vez realizadas estas acciones el programa queda listo para arrojar los resultados; al activar el botón Aceptar (Figura 82) se obtienen los resultados que se muestran en el Cuadro 24.

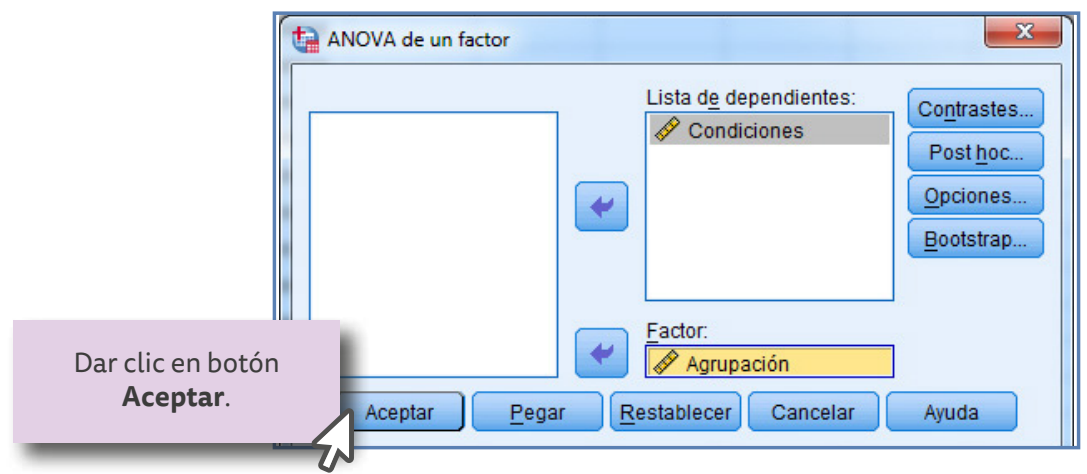

Figura 82. Paso para ejecutar el programa SPSS para que realice los cálculos requeridos.

En el cuadro se puede observar el valor del nivel de significación [Significación asintótica] $\rho<0.000$.

$$
\text { Entonces se puede concluir que } \rho \text { encontrada } 0.000<\rho_{\text {aceptada }} 0.05
$$

Esto es, el valor encontrado 0.000 es menor que el mínimo aceptable por los investigadores en educación (0.05), lo que significa que los resultados de la diferencia no son aleatorios puesto que existe una diferencia significativa, por lo que se puede rechazar la hipótesis nula y aceptar la hipótesis de investigación. 
Cuadro 24. Resultados obtenidos con el programa SPSS para la prueba paramétrica ANOVA Unifactorial para tres muestras independientes.

ONEWAY Condicionesla3 BY Agrupación

/MISSING ANALYSIS.

\section{ANOVA de un factor}

[Conjunto_de_datos0]

ANOVA de un factor

Condiciones1a3

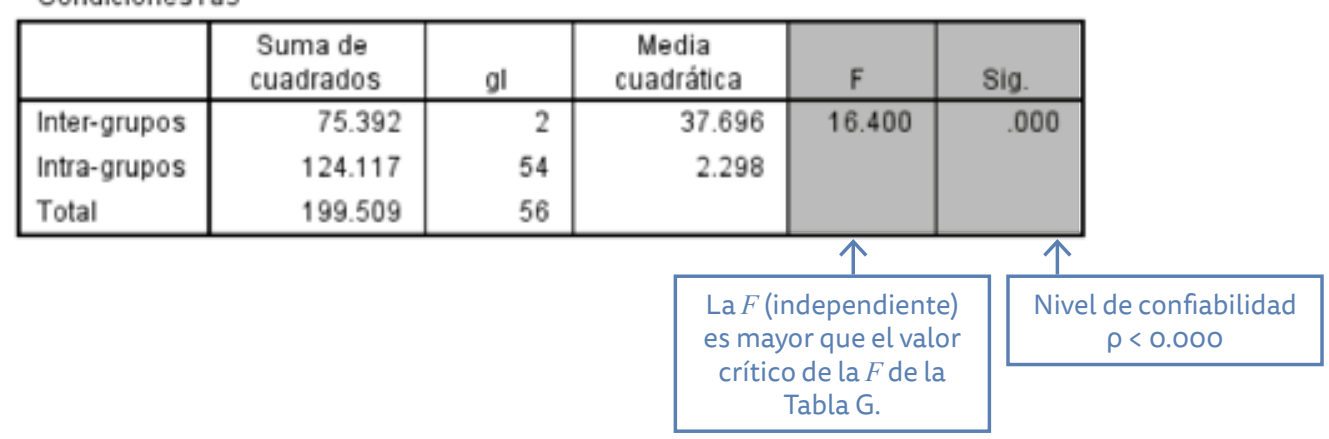

También se puede observar que el valor de $F$ calculado por medio del programa es mayor que el valor crítico de la Tabla $\mathrm{H}(2)$ para $\rho<0.01$.

$$
F=16.4 \text { (es mayor que) }>F_{\text {tabla }}=5.18 \text { para un nivel de significación de } \rho<0.01
$$

Hi: Si se utilizan prácticas de laboratorio como refuerzo en la materia de Química, los alumnos de tercero de secundaria retendrán mejor el conocimiento, más aún si son prácticas constructivistas. 


\section{Capítulo 13}

13. Prueba ANOVA Bifactorial (muestras relacionadas)

La prueba ANOVA Bifactorial (relacionada) se debe utilizar para diseños relacionados cuando dos variables independientes se aplican a los mismos participantes y los datos pertenecen a la escala de intervalo. Estas variables, independientes a su vez, presentan dos o más condiciones.

Ejemplo 88. Se trata de aceptar o rechazar la siguiente hipótesis de investigación:

$\mathrm{Hi}$ : Si se utiliza en los enunciados diferentes tipos de datos (simulados abstractos o experimentales reales) y grados de complejidad (sencillos o complejos) en los ejercicios de matemáticas, los alumnos de segundo grado de secundaria retendrán mejor el conocimiento, si los datos se obtienen de sus experiencias o vivencias, con menor grado de complejidad en su enunciado.

\subsection{Estado situacional}

El investigador desea saber si el uso de diferentes tipos de datos (Variable 1) influye en la retención de los conocimientos de los participantes de manera significativa, por otro lado desea determinar si el grado de complejidad (Variable 2) facilita esta retención en los alumnos de matemáticas de segundo grado de secundaria. El investigador propone realizar un experimento en donde la Variable 1 es una comparación que presenta datos simulados abstractos obtenidos de fuentes teóricas y por otro lado, datos experimentales reales obtenidos de las experiencias y vivencias de los participantes; en lo que se refiere a la Variable 2 se trata de comparar el grado de complejidad de los enunciados de los problemas clasificándolos en sencillos y complejos.

Como instrumento de recolección de datos se elaboraron series de problemas con las características mencionadas en el párrafo anterior, quedando de la siguiente manera:

- 20 problemas con datos simulados abstractos distribuidos como sigue: 10 problemas sencillos y 10 problemas complejos.

- 20 problemas con datos experimentales reales distribuidos como sigue: 10 problemas sencillos y 10 problemas complejos.

En las actividades se presentan, contextos considerados familiares a los participantes, con el propósito de que ponga en juego sus conocimientos previos. En este aspecto se busca promover un acercamiento intuitivo a los objetos matemáticos antes de establecer su presentación formal, desde la perspectiva disciplinar.

En la Tabla 18 se muestran los resultados obtenidos por los 13 alumnos del Grupo A de segundo grado de secundaria en la solución de problemas de matemáticas. 
Tabla 18. Puntajes obtenidos por los grupos participantes de acuerdo a las condiciones establecidas por el investigador.

\begin{tabular}{|c|c|c|c|c|}
\hline \multirow{2}{*}{$\begin{array}{c}\text { Mismos } \\
\text { Participantes }\end{array}$} & \multicolumn{2}{|c|}{$A_{1}$ Datos simulados, abstractos } & \multicolumn{2}{|c|}{$\mathrm{A}_{2}$ Datos experimentales, reales } \\
\hline & $\begin{array}{l}\text { B, Problemas } \\
\text { sencillos }\end{array}$ & $\begin{array}{c}\text { B }_{2} \text { Problemas } \\
\text { complejos }\end{array}$ & $\begin{array}{l}\text { B Problemas } \\
\text { sencillos }\end{array}$ & $\begin{array}{c}\text { B }_{2} \text { Problemas } \\
\text { complejos }\end{array}$ \\
\hline 1 & 7 & 5 & 7 & 5 \\
\hline 2 & 8 & 6 & 7 & 6 \\
\hline 3 & 6 & 4 & 10 & 5 \\
\hline 4 & 6 & 6 & 9 & 9 \\
\hline 5 & 7 & 5 & 7 & 9 \\
\hline 6 & 8 & 3 & 9 & 6 \\
\hline 7 & 5 & 4 & 9 & 5 \\
\hline 8 & 7 & 6 & 7 & 6 \\
\hline 9 & 7 & 4 & 8 & 8 \\
\hline 10 & 6 & 1 & 9 & 5 \\
\hline 11 & 6 & 5 & 8 & 6 \\
\hline 12 & 5 & 4 & 9 & 6 \\
\hline 13 & 4 & 6 & 10 & 8 \\
\hline Media = & 6.30 & 4.53 & 8.38 & 6.46 \\
\hline
\end{tabular}

\subsection{Explicación}

La prueba ANOVA Bifactorial (relacionada) se basa en comparar los ratios de varianza entre los resultados de cada participante ya que éstos se encuentran relacionados. Las diferencias entre estos resultados permiten tener una base para el cálculo de la varianza ocasionada por participante. En este caso se pueden calcular los siguientes tipos de varianza (Greene y D'oliveira, 2006):

- Varianza esperada. Se origina entre las condiciones para la Variable A, la Variable B y la interacción entre ambas.

- Varianza individual. Se origina por las diferencias entre los resultados en relación a cada participante bajo las dos condiciones correspondientes a las variables $\mathrm{A}$ y $\mathrm{B}$.

- Varianza de error. Se origina por los resultados debidos a variables irrelevantes.

- Varianza total. Incluye todos los tipos de varianzas anteriores.

La finalidad de ANOVA Bifactorial es comparar ratios de varianza. Las variables independientes $A$ y $B$ representan las diferencias pronosticadas entre las condiciones (varianzas esperadas). La predicción afirma que las varianzas esperadas deben ser relativamente elevadas en comparación con la varianza de error causada por las variables irrelevantes.

Es decir, para aceptar la hipótesis de investigación, el ratio (relación) entre las varianzas esperadas y la varianza de error debe ser relativamente grande mientras que el ratio (relación) de la varianza individual y la varianza de error no debe representar una diferencia significativa. El término de ANOVA Bifactorial se refiere a que hay dos variables independientes para analizar.

De acuerdo a lo anterior la prueba ANOVA para muestras relacionadas debe cumplir con los siguientes requisitos:

- Deben existir dos o más condiciones experimentales con dos variables independientes.

- Las condiciones se deben aplicar a los mismos participantes.

- Los datos numéricos deben ser de intervalo.

- Son pruebas paramétricas, adecuadas para realizar análisis de datos numéricos de intervalo. 


\subsection{Procedimiento para determinar el valor de ANOVA Bifactorial (relacionada).}

En este caso para ANOVA bifactorial existen varias fuentes de varianza e interrelaciones, por lo que es necesario distribuir los datos de la Tabla 18 en tres tablas que representan las combinaciones de las posibles interacciones, esto es, la interacción entre A y B; la interacción entre A y los sujetos (S) y la interacción entre B y los sujetos (S).

1. Elaborar las tablas de interacciones.

a. Tabla de interacciones entre A y B.

1. Para elaborar la Tabla 19 se agrupan en casillas todos los valores que tienen correspondencia con los valores de los participantes, por ejemplo:

En la casilla $A_{1} B_{1}$ se colocan los valores obtenidos por los trece participantes en las condiciones de "datos simulados abstractos" y que "resuelven problemas sencillos".

2. En la siguiente casilla (columna $T_{\mathrm{A} 1 \mathrm{~B}}$ ) se calculan los totales sumando los trece resultados.

$$
T_{\mathrm{A} 1 \mathrm{~B}}=7+8+6+6+7+8+5+7+7+6+6+5+4=82
$$

3. Se calculan los totales de resultados para las dos condiciones de la Variable A y se anotan en la parte inferior de la tabla.

4. Se calculan los totales de resultados para las dos condiciones de la Variable B y se anotan en la parte derecha de la tabla.

5. Se suman los totales y se obtiene un total general que debe coincidir tanto con la suma de $A$, como con la de $B$.

Tabla 19. Interacciones entre A y B.

\begin{tabular}{|c|c|c|c|c|c|}
\hline & $\mathbf{A}_{1}$ & $T_{\text {A1B }}$ & $\mathbf{A}_{2}$ & $T_{\text {A2B }}$ & $T_{\text {B }}$ \\
\hline $\mathbf{B}_{1}$ & $\begin{array}{c}7,8,6,6,7,8,5, \\
7,7,6,6,5,4\end{array}$ & 82 & $\begin{array}{c}7,7,10,9,7,9, \\
9,7,8,9,8,9,10\end{array}$ & 109 & 191 \\
\hline $\mathbf{B}_{\mathbf{2}}$ & $\begin{array}{c}5,6,4,6,5,3,4 \\
6,4,7,5,4,6\end{array}$ & 59 & $\begin{array}{c}5,6,5,9,9,6,5, \\
6,8,5,6,6,8\end{array}$ & 84 & 143 \\
\hline$T_{\mathbf{A}}$ & & 141 & & 193 & 334 \\
\hline
\end{tabular}

b. Tabla de interacciones entre A y S.

1. En este caso se muestran los resultados relacionados por cada sujeto (S) bajo las dos condiciones de la Variable A (Tabla 20).

2. Los resultados relacionados para cada sujeto se suman dando los totales para $S$ que se anotan en la columna $T_{\mathrm{A}_{1} \mathrm{~S}}$ para la Variable $\mathrm{A}_{1}$.

$$
T_{\mathrm{A} 1 \mathrm{~S} 1}=7+5=12
$$

3. Elaborar la columna $T_{\mathrm{A}_{1} \mathrm{~S}}{ }^{2}$ elevando al cuadrado los valores de $T_{\mathrm{A} 1 \mathrm{~S}}$.

4. Repetir los dos pasos anteriores para la Variable $A_{2}$.

5. Sumar los valores de las variables $A_{1}$ y $A_{2}$ y anotar los totales en la columna $T_{\mathrm{AS}}$.

$$
T_{\mathrm{AS} 1}=T_{\mathrm{A} 1 \mathrm{~S} 1}+T_{\mathrm{A} 2 \mathrm{~S} 1}=12+12=24
$$

6. Elaborar la columna $\mathrm{T}_{\mathrm{AS}}{ }^{2}$ elevando al cuadrado los valores de $T_{\mathrm{AS}}$.

7. Realizar la suma de todas las columnas para obtener sus valores de sumatoria $(\Sigma)$.

Nota: Se puede observar que los valores de los totales de A son los mismos que en la Tabla 18 al igual que el total general. 
Tabla 20. Interacciones entre A y S.

\begin{tabular}{|c|c|c|c|c|c|c|c|c|}
\hline & $\mathbf{A}_{1}$ & $T_{\text {A1S }}$ & $T_{\text {A1S }} \mathbf{2}$ & $\mathbf{A}_{\mathbf{2}}$ & $T_{\text {A2S }}$ & $T_{\text {A2S }}{ }^{2}$ & $T_{\text {AS }}$ & $T_{\text {AS }}{ }^{2}$ \\
\hline $\mathrm{S}_{1}$ & 7,5 & 12 & 144 & 7,5 & 12 & 144 & 24 & 576 \\
\hline $\mathrm{S}_{2}$ & 8,6 & 14 & 196 & 7,6 & 13 & 169 & 27 & 729 \\
\hline $\mathrm{S}_{3}$ & 6,4 & 10 & 100 & 10,5 & 15 & 225 & 25 & 625 \\
\hline $\mathrm{S}_{4}$ & 6,6 & 12 & 144 & 9,9 & 18 & 324 & 30 & 900 \\
\hline $\mathrm{S}_{5}$ & 7,5 & 12 & 144 & 7,9 & 16 & 256 & 28 & 784 \\
\hline $\mathrm{S}_{6}$ & 8,3 & 11 & 121 & 9,6 & 15 & 225 & 26 & 676 \\
\hline $\mathrm{S}_{7}$ & 5,4 & 9 & 81 & 9,5 & 14 & 196 & 23 & 529 \\
\hline $\mathrm{S}_{8}$ & 7,6 & 13 & 169 & 7,6 & 13 & 169 & 26 & 676 \\
\hline $\mathrm{S}_{9}$ & 7,4 & 11 & 121 & 8,8 & 16 & 256 & 27 & 729 \\
\hline $\mathrm{S}_{10}$ & 6,1 & 7 & 49 & 9,5 & 14 & 196 & 21 & 441 \\
\hline $\mathrm{S}_{11}$ & 6,5 & 11 & 121 & 8,6 & 14 & 196 & 25 & 625 \\
\hline $\mathrm{S}_{12}$ & 5,4 & 9 & 81 & 8,6 & 15 & 225 & 24 & 576 \\
\hline $\mathrm{S}_{13}$ & 4,6 & 10 & 100 & 10,8 & 18 & 324 & 28 & 784 \\
\hline $\mathbf{\Sigma}$ & & 141 & 1571 & & 193 & 2905 & 334 & $\mathbf{8 6 5 0}$ \\
\hline
\end{tabular}

c. Tabla de interacciones entre B y S.

1. En este caso se muestran los resultados relacionados por cada sujeto (S) bajo las dos condiciones de la Variable B (Tabla 21).

Tabla 21. Interacciones entre B y S.

\begin{tabular}{|c|c|c|c|c|c|c|c|c|}
\hline & $B_{1}$ & $T_{B 1 S}$ & $T_{B 1 S^{2}}$ & $B_{2}$ & $T_{\mathrm{B} 2 \mathrm{~S}}$ & $T_{\mathrm{B} 2 \mathrm{~S}^{2}}$ & $T_{\mathrm{BS}}$ & $T_{\mathrm{BS}^{2}}$ \\
\hline $\mathrm{S}_{1}$ & 7,7 & 14 & 196 & 5,5 & 10 & 100 & 24 & 576 \\
\hline $\mathrm{S}_{2}$ & 8,7 & 15 & 225 & 6,6 & 12 & 144 & 27 & 729 \\
\hline $\mathrm{S}_{3}$ & 6,10 & 16 & 256 & 4,5 & 9 & 81 & 25 & 625 \\
\hline $\mathrm{S}_{4}$ & 6,9 & 15 & 225 & 6,9 & 15 & 225 & 30 & 900 \\
\hline $\mathrm{S}_{5}$ & 7,7 & 14 & 196 & 5,9 & 14 & 196 & 28 & 784 \\
\hline $\mathrm{S}_{6}$ & 8,9 & 17 & 289 & 3,6 & 9 & 81 & 26 & 676 \\
\hline $\mathrm{S}_{7}$ & 5,9 & 14 & 196 & 4,5 & 9 & 81 & 23 & 529 \\
\hline $\mathrm{S}_{8}$ & 7,7 & 14 & 196 & 6,6 & 12 & 144 & 26 & 676 \\
\hline $\mathrm{S}_{9}$ & 7,8 & 15 & 225 & 4,8 & 12 & 144 & 27 & 729 \\
\hline$S_{10}$ & 6,9 & 15 & 225 & 1,5 & 6 & 36 & 21 & 441 \\
\hline$S_{11}$ & 6,8 & 14 & 196 & 5,6 & 11 & 121 & 25 & 625 \\
\hline$S_{12}$ & 5,9 & 14 & 196 & 4,6 & 10 & 100 & 24 & 576 \\
\hline$S_{13}$ & 4,10 & 14 & 196 & 6,8 & 14 & 196 & 28 & 784 \\
\hline$\Sigma$ & & 191 & 2817 & & 143 & 1649 & 334 & 8650 \\
\hline
\end{tabular}

2. Los resultados relacionados para cada participante se suman dando los totales para $S$ que se anotan en la columna $T_{B_{1} S}$ para la Variable $B_{1}$.

$$
T_{\mathrm{B} 1 \mathrm{~S} 1}=7+7=14
$$

3. Elaborar la columna $T_{\mathrm{B} 1 \mathrm{~S}}{ }^{2}$ elevando al cuadrado los valores de $T_{\mathrm{B} 1 \mathrm{~S}}$.

4. Repetir los dos pasos anteriores para la Variable $B_{2}$.

5. Sumar los valores de las variables $\mathrm{B}_{1}$ y $\mathrm{B}_{2}$ y anotar los totales en la columna $T_{\mathrm{BS}}$.

$$
T_{\mathrm{BS} 1}=T_{\mathrm{B} 1 \mathrm{~S} 1}+T_{\mathrm{B} 2 \mathrm{~S} 1}=14+10=24
$$

6. Elaborar la columna $T_{\mathrm{BS}}{ }^{2}$ elevando al cuadrado los valores de $T_{\mathrm{BS}}$.

7. Realizar la suma de todas las columnas para obtener sus valores de sumatoria $(\Sigma)$. 
Nota: Se puede observar que los valores de los totales de B son los mismos que en la Tabla 18 al igual que el total general.

En resumen se determinan los siguientes valores de los datos:

$\Sigma T_{\mathrm{A}}^{2}=$ suma de los cuadrados de los totales de A en la Tabla 19.

$\Sigma T_{\mathrm{B}}^{2}=$ suma de los cuadrados de los totales de B en la Tabla 19.

$\sum T_{\mathrm{AB}}{ }^{2}=$ suma de los cuadrados de los totales de $\mathrm{AB}$ para cada valor de TAB en la Tabla 19.

$\Sigma T_{\mathrm{S}}{ }^{2}=$ suma de los cuadrados de los totales para cada sujeto en la Tabla 20 ó 21.

$\sum T_{\mathrm{AS}}{ }^{2}=$ suma de los cuadrados de los totales para AS.

$\sum T_{\mathrm{BS}}{ }^{2}=$ Suma de los cuadrados de los totales para BS.

$n=$ número de participantes.

$a=$ número de condiciones para la Variable $\mathrm{A}$.

$b=$ número de condiciones para la Variable $\mathrm{B}$.

$N=$ número total de resultados.

$\left(\sum x\right)^{2}=$ cuadrado del total general.

$\frac{\left(\sum x\right)^{2}}{N}=$ constante que se debe restar a todas las sumas de cuadrados.

$\sum x^{2}=$ suma de cada uno de los resultados elevados al cuadrado.

Entonces de acuerdo a los datos de la tabla calcular:

$$
\begin{aligned}
& \sum T_{A}^{2}=(141)^{2}+(193)^{2}=(19881)+(37249)=57130 \\
& \sum T_{\mathrm{B}}^{2}=(191)^{2}+(143)^{2}=(36481)+(20449)=56930 \\
& \sum T_{\mathrm{AB}}^{2}=\left(T_{\mathrm{A} 1 \mathrm{~B} 1}\right)^{2}+\left(T_{\mathrm{A} 1 \mathrm{~B} 2}\right)^{2}+\left(T_{\mathrm{A} 2 \mathrm{~B} 1}\right)^{2}+\left(T_{\mathrm{A} 2 \mathrm{~B} 2}\right)^{2}= \\
& \sum T_{\mathrm{AB}}^{2}=(82)^{2}+(59)^{2}+(109)^{2}+(84)^{2}= \\
& \sum T_{\mathrm{AB}}{ }^{2}=(6724)+(3481)+(11881)+(7056)=29142 \\
& \Sigma T_{\mathrm{S}}^{2}=8650 \\
& \sum T_{\mathrm{AS}^{2}}=\sum T_{\mathrm{A} 1 \mathrm{~S}^{2}}+\sum T_{\mathrm{A} 2 \mathrm{~S}^{2}}=1571+2905=4476 \\
& \sum T_{\mathrm{BS}^{2}}=\sum T_{\mathrm{B} 1 S^{2}}+\sum T_{\mathrm{B} 2 \mathrm{~S}^{2}}=2817+1649=4466 \\
& n=13 \\
& a=2 \\
& b=2 \\
& N=(13) 4=52
\end{aligned}
$$




$$
\begin{aligned}
& \left(\sum x\right)^{2}=(334)^{2}=111556 \\
& \frac{\left(\sum x\right)^{2}}{N}=\frac{111556}{52}=2145.3
\end{aligned}
$$

Para determinar el valor de $\sum x^{2}$ como son muchos los valores de los resultados encontrados ( $\mathrm{x}$ ) es conveniente realizar el cálculo elaborando la Tabla 22.

$$
\sum x^{2}=\sum x_{1}{ }^{2}+\sum x_{2}{ }^{2}+\sum x_{3}{ }^{2}+\sum x_{4}{ }^{2}=534+293+929+570=2326
$$

2. Calcular el valor de la varianza esperada para $A, S C_{A}$.

$$
S C_{\mathrm{A}}=\frac{\sum T_{\mathrm{A}}^{2}}{n \mathrm{~b}}-\frac{(\Sigma \mathrm{x})^{2}}{N}=\frac{57130}{(13)(2)}-2145.3=52
$$

\begin{tabular}{|c|c|c|c|c|c|c|c|c|}
\hline \multicolumn{9}{|c|}{$x^{2}$ Cuadrado de Resultados } \\
\hline & $x_{1}$ & $x_{1}^{2}$ & $x_{2}$ & $x_{2}^{2}$ & $x_{3}$ & $x_{3}^{2}$ & $x_{4}$ & $x_{4}^{2}$ \\
\hline $\mathrm{S}_{1}$ & 7 & 49 & 5 & 25 & 7 & 49 & 5 & 25 \\
\hline $\mathrm{S}_{12}$ & 8 & 64 & 6 & 36 & 7 & 49 & 6 & 36 \\
\hline $\mathrm{S}_{3}$ & 6 & 36 & 4 & 16 & 10 & 100 & 5 & 25 \\
\hline $\mathrm{S}_{4}$ & 6 & 36 & 6 & 36 & 9 & 81 & 9 & 81 \\
\hline $\mathrm{S}_{5}$ & 7 & 49 & 5 & 25 & 7 & 49 & 9 & 81 \\
\hline $\mathrm{S}_{6}$ & 8 & 64 & 3 & 9 & 9 & 81 & 6 & 36 \\
\hline $\mathrm{S}_{7}$ & 5 & 25 & 4 & 16 & 9 & 81 & 5 & 25 \\
\hline $\mathrm{S}_{8}$ & 7 & 49 & 6 & 36 & 7 & 49 & 6 & 36 \\
\hline $\mathrm{S}_{9}$ & 7 & 49 & 4 & 16 & 8 & 64 & 8 & 64 \\
\hline $\mathrm{S}_{10}$ & 6 & 36 & 1 & 1 & 9 & 81 & 5 & 25 \\
\hline$S_{11}$ & 6 & 36 & 5 & 25 & 8 & 64 & 6 & 36 \\
\hline $\mathrm{S}_{12}$ & 5 & 25 & 4 & 16 & 9 & 81 & 6 & 36 \\
\hline $\mathrm{S}_{13}$ & 4 & 16 & 6 & 36 & 10 & 100 & 8 & 64 \\
\hline$\Sigma$ & \multicolumn{2}{|c|}{$\sum x_{1}^{2}=534$} & \multicolumn{2}{|c|}{$\sum x_{2}^{2}=293$} & \multicolumn{2}{|c|}{$\sum x_{3}^{2}=929$} & \multicolumn{2}{|c|}{$\sum x_{4}^{2}=570$} \\
\hline
\end{tabular}

3. Calcular el valor de la varianza esperada para $\mathrm{B}, S C_{\mathrm{B}}$.

$$
S C_{\mathrm{B}}=\frac{\sum \mathrm{x} T_{\mathrm{B}}^{2}}{n \mathrm{a}}-\frac{\left(\sum \mathrm{x}\right)^{2}}{N}=\frac{56930}{(13)(2)}-2145.3=44.31
$$

Tabla 22. Cálculo de los valores de los resultados elevados al cuadrado.

4. Calcular el valor de la varianza individual, $S C_{\mathrm{S}}$.

$$
S C_{\mathrm{S}}=\frac{\sum T_{\mathrm{S}}^{2}}{\mathrm{ab}}-\frac{\left(\sum \mathrm{x}\right)^{2}}{N}=\frac{8650}{(2)(2)}-2145.3=17.2
$$


5. Calcular el valor de la varianza de la interacción entre $A$ y $B, S C_{A B}$.

$$
\begin{gathered}
S C_{\mathrm{AB}}=\frac{\sum T_{\mathrm{AB}}^{2}}{n}-\frac{\left(\sum \mathrm{x}\right)^{2}}{N}-S C_{\mathrm{A}}-S C_{\mathrm{B}}= \\
S C_{\mathrm{AB}}=\frac{29142}{13}-2145.3-52-44.31=0.082
\end{gathered}
$$

6. Calcular el valor de la varianza de error entre $\mathrm{A}$ y $\mathrm{S}, \mathrm{SC}_{\mathrm{AS}}$.

$$
\begin{gathered}
S C_{\mathrm{AS}}=\frac{\sum T_{\mathrm{AS}}^{2}}{\mathrm{~b}}-\frac{\left(\sum \mathrm{x}\right)^{2}}{N}-S C_{\mathrm{A}}-S C_{\mathrm{S}}= \\
S C_{\mathrm{AS}}=\frac{4476}{2}-2145.3-52-17.2= \\
S C_{\mathrm{AS}}=(2238)-2145.3-69.2=23.5
\end{gathered}
$$

7. Calcular el valor de la varianza de error entre $\mathrm{B}$ y $\mathrm{S}, S C_{\mathrm{BS}}$.

$$
\begin{gathered}
S C_{\mathrm{BS}}=\frac{\sum T_{\mathrm{BS}}^{2}}{\mathrm{a}}-\frac{\left(\sum \mathrm{x}\right)^{2}}{N}-S C_{\mathrm{B}}-S C_{\mathrm{S}}= \\
S C_{\mathrm{BS}}=\frac{4466}{2}-2145.3-44.31-17.2= \\
S C_{\mathrm{BS}}=(2233)-2145.3-61.51=26.19
\end{gathered}
$$

8. Calcular el valor de la varianza total $S C_{\text {tot }}$.

$$
S C_{\text {tot }}=\sum \mathrm{x}^{2}-\frac{\left(\sum \mathrm{x}\right)^{2}}{N}=2326-2145.3=180.7
$$

9. Calcular el valor de la varianza de error $S C_{\mathrm{ABS}}$.

$$
\begin{gathered}
S C_{\mathrm{ABS}}=S C_{\text {tot }}-S C_{\mathrm{A}}-S C_{\mathrm{B}}-S C_{\mathrm{S}}-S C_{\mathrm{AB}}-S C_{\mathrm{AS}}-S C_{\mathrm{BS}} \\
S C_{\mathrm{ABS}}=180.7-52-44.31-17.2-0.082-23.5-26.19=17.418
\end{gathered}
$$

10. Calcular los grados de libertad donde:

$$
\begin{aligned}
& g l_{\mathrm{A}}=\text { número de condiciones } \mathrm{A}-1 \\
& g l_{\mathrm{B}}=\text { número de condiciones } \mathrm{B}-1 \\
& g l_{\mathrm{S}}=\text { número de sujetos } \mathrm{S}-1 \\
& g l_{\mathrm{AB}}=\left(g l_{\mathrm{A}}\right)\left(g l_{\mathrm{B}}\right) \\
& g l_{\mathrm{AS}}=\left(g l_{\mathrm{A}}\right)\left(g l_{\mathrm{S}}\right) \\
& g l_{\mathrm{BS}}=\left(g l_{\mathrm{B}}\right)\left(g l_{\mathrm{S}}\right) \\
& g l_{\mathrm{ABS}}=\left(g l_{\mathrm{A}}\right)\left(g l_{\mathrm{B}}\right)\left(g l_{\mathrm{S}}\right) \\
& g l_{\text {tot }}=\text { número de resultados } N-1
\end{aligned}
$$




$$
\begin{aligned}
& g l_{\mathrm{A}}=\mathrm{A}-1=2-1=1 \\
& g l_{\mathrm{B}}=\mathrm{B}-1=2-1=1 \\
& g l_{\mathrm{S}}=\mathrm{S}-1=13-1=12 \\
& g l_{\mathrm{AB}}=(1)(1)=1 \\
& g l_{\mathrm{AS}}=(1)(12)=12 \\
& g l_{\mathrm{BS}}=(1)(12)=12 \\
& g l_{\mathrm{ABS}}=(1)(1)(12)=12 \\
& g l_{\text {tot }}=N-1=52-1=51
\end{aligned}
$$

11. Dividir cada $S C$ entre los $g l$ para obtener el valor de los cuadrados medios $M C$.

$$
\begin{gathered}
M C_{\mathrm{A}}=\frac{\mathrm{SC}_{\mathrm{A}}}{g l_{\mathrm{A}}}=\frac{52}{1}=52 \\
M C_{\mathrm{B}}=\frac{\mathrm{SC}_{\mathrm{B}}}{g l_{\mathrm{B}}}=\frac{44.31}{1}=44.31 \\
M C_{\mathrm{S}}=\frac{\mathrm{S} C_{\mathrm{S}}}{g l_{\mathrm{S}}}=\frac{17.2}{12}=1.43 \\
M C_{\mathrm{AB}}=\frac{\mathrm{S} C_{\mathrm{AB}}}{g l_{\mathrm{AB}}}=\frac{0.082}{1}=0.082 \\
M C_{\mathrm{AS}}=\frac{\mathrm{SC}}{g l_{\mathrm{AS}}}=\frac{23.5}{12}=1.958 \\
M C_{\mathrm{BS}}=\frac{\mathrm{SC} C_{\mathrm{BS}}}{g l_{\mathrm{BS}}}=\frac{26.19}{12}=2.18 \\
M C_{\mathrm{ABS}}=\frac{\mathrm{SC}_{\mathrm{ABS}}}{g l_{\mathrm{ABS}}}=\frac{(17.418)}{12}=1.45 \\
M C_{\text {tot }}=\frac{\mathrm{SC} \text { tot }}{g l_{\text {tot }}}=\frac{180.7}{51}=3.54
\end{gathered}
$$

12. Calcular el valor de $F$ ratio para $M C_{\mathrm{A}^{\prime}} M C_{\mathrm{B}^{\prime}} M C_{\mathrm{AB}}$, $\mathrm{y} M C_{\mathrm{S}}$ y asignar el número de $g l$ adecuado para las $F$ ratios:

$$
\begin{array}{ll}
F \text { ratio para } M C_{\mathrm{A}}=\frac{M C_{A}}{M C_{A S}} & F_{\mathrm{A}(1,12)}=\frac{52}{1.958}=26.55 \\
F \text { ratio para } M C_{\mathrm{B}}=\frac{M C_{\mathrm{B}}}{M C_{\mathrm{BS}}} & F_{\mathrm{B}(1,12)}=\frac{44.31}{2.18}=20.32 \\
F \text { ratio para } M C_{\mathrm{AB}}=\frac{\mathrm{MC}_{\mathrm{AB}}}{\mathrm{MC}_{\mathrm{ABS}}} & F_{\mathrm{AB}(1,12)}=\frac{0.082}{1.45}=0.056 \\
F \text { ratio para } M C_{\mathrm{S}}=\frac{M C_{\mathrm{S}}}{M C_{\mathrm{ABS}}} & F_{\mathrm{S}(12,12)}=\frac{1.43}{1.45}=0.986
\end{array}
$$


13. Buscar el nivel de significación de $F$ en la Tabla $H$ del Apéndice $D$.

Para la prueba ANOVA se utilizan las tablas $\mathrm{H}(1)$ que contiene los valores para $\rho<0.05$ y $\mathrm{H}$ (2) que contiene los valores para $\rho<0.01$ ( $\rho$ es el valor del nivel de significación). El valor calculado $F$ debe ser igual o mayor que el valor crítico que se muestra en las tablas, para poder aceptar la hipótesis de investigación.

Para localizar el valor de la $F$ de la tabla se utilizan los valores de los grados de libertad $g l$ para las tres varianzas esperadas entre condiciones $A, B, A B$, la varianza individual y la varianza de error; en este ejemplo corresponden a $g l_{\mathrm{A}}=1, g l_{\mathrm{AS}}=12 ; g l_{\mathrm{B}}=1, g l_{\mathrm{BS}}=12 ; g l_{\mathrm{AB}}=1$, $g l_{\mathrm{ABS}}=12$. Se puede observar que todos los valores críticos que se deben buscar se encuentran en los mismos grados de libertad esto es $F_{1,12}$.

Para $F_{1,12}$ se localiza el valor de $g l_{\text {esp }}=1$ en la Tabla $H$, se ubica éste en la fila superior $\left(v_{1}\right)$ y para el valor de $g l_{\text {error }}=12$ se ubica éste en la primera columna de la izquierda $\left(v_{2}\right)$, donde se interceptan los dos puntos se localiza el valor crítico de $F_{\text {tabla }}=4.75$ en la Tabla $\mathrm{H}$ (1) para $\rho<0.05$ y en la Tabla $\mathrm{H}(2)$ el valor crítico corresponde a $F_{1,12}=9.33$ para $\rho<0.01$. Comparando los valores calculados con el valor crítico de la tabla se puede observar que para un nivel de significación de $\rho<0.01$.

$$
\begin{gathered}
F_{\mathrm{A}(1,12)}=26.55 \text { (es mayor que) }>F_{\text {tabla }}=9.33 \text { para un nivel de significación de } \rho<0.01 \\
F_{\mathrm{B}(1,12)}=20.32 \text { (es mayor que) }>F_{\text {tabla }}=9.33 \text { para un nivel de significación de } \rho<0.01 \\
F_{\mathrm{AB}(1,12)}=0.056 \text { (es menor que) }<F_{\text {tabla }}=9.33 \text { para un nivel de significación de } \rho<0.01
\end{gathered}
$$

El nivel de significación $\rho<0.01$ está por debajo de la probabilidad que proponen los investigadores en educación como máximo valor aceptable, esto es $\rho<0.05$, entonces se puede rechazar la hipótesis nula y aceptar la de investigación en los casos de las variables $A$ y $B$, mas no en el caso de la intercepción donde el valor encontrado es muy pequeño $\left(F_{\mathrm{AB}(1,12)}=0.056\right)$ por lo que se acepta la hipótesis nula y se rechaza la de investigación.

En lo que se refiere a la relación de la varianza individual $F_{\mathrm{S}(12,12)}=0.986$, es usual que los resultados de cada participante no sean una fuente de varianza significativa, siguiendo los pasos indicados en el párrafo anterior para $F_{\mathrm{S}(12,12)}$ se localiza el valor de $g l_{S}=12$ en la Tabla $\mathrm{H}(1)$, se ubica éste en la fila superior $\left(v_{1}\right)$ y para el valor de $g l_{\mathrm{ABS}}=12$ se ubica éste en la primera columna de la izquierda $\left(v_{2}\right)$, en donde se interceptan los dos puntos se localiza el valor crítico de $F_{\text {Tabla }}=2.69$, en donde $F_{12,12}=0.986$ es menor que el encontrado en la tabla, por lo que las diferencias entre los participantes no son significativas.

$$
F_{12,12}=0.986 \text { (es menor que) }<F_{\text {tabla }}=2.69 \text { para un nivel de significación de } \rho<0.05
$$

Se puede afirmar entonces que los alumnos de segundo grado de secundaria retendrán mejor el conocimiento si los datos se obtienen de sus experiencias o vivencias (Variable A), con menor grado de complejidad en su enunciado (Variable B) y la ausencia de interacción significativa entre las dos variables ( $\mathrm{A}$ y B), así como de los resultados relacionados de cada participante. 


\subsection{Prueba ANOVA Bifactorial (relacionada) utilizando el programa SPSS}

El programa SPSS para esta prueba permite determinar el nivel de significación comparándolo con el nivel mínimo utilizado por los investigadores en educación que corresponde a $\rho<0.05$, si el que se determina mediante el proceso del programa resulta mayor que este valor, entonces se puede decir que las diferencias de los resultados son causadas por variables aleatorias y se debe aceptar la hipótesis nula, pero si el valor es menor entonces las diferencias son significativas, por lo tanto se debe rechazar la hipótesis nula y aceptar la hipótesis de investigación.

El primer paso consiste en otorgarle las propiedades a las variables, una vez abierto el programa, antes de introducir los datos, es necesario definir las variables y otorgar las características para su presentación en la tabla, para esto se requiere hacer un clic en la pestaña Vista de variables (Ver Figura 83).

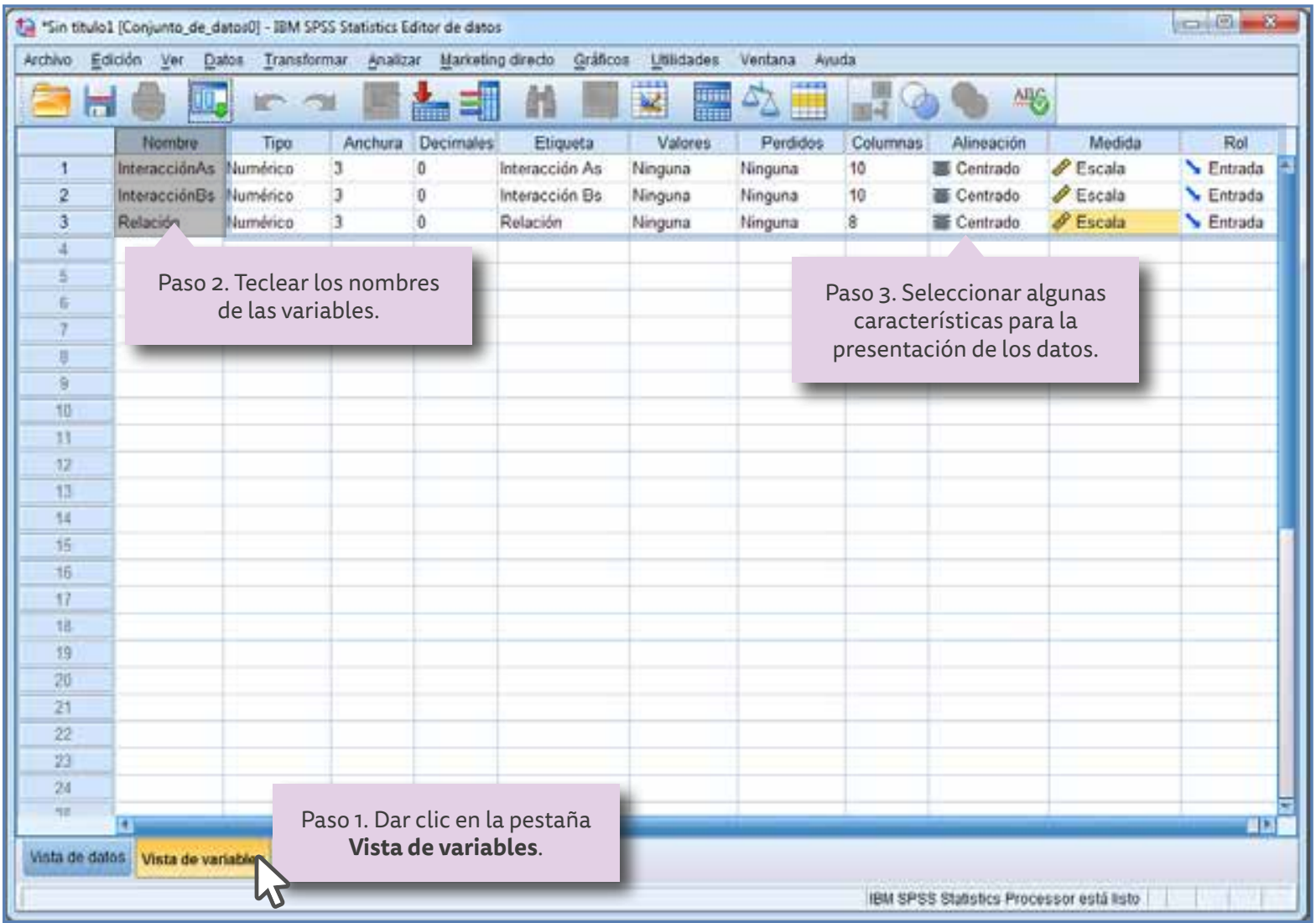

Figura 83. Designación de nombre de las variables y características de presentación para la prueba ANOVA Bifactorial (relacionada).

En el caso de la prueba ANOVA Bifactorial cuando se trata de muestras relacionadas o independientes los valores de los datos obtenidos se deben colocar en una misma columna por cada variable (A y B) que en este caso se les designará como Interacción As (variable Asujeto) e Interacción Bs (variable Bsujeto) y la tercera columna se denomina como Relación en donde se especifica cuáles son los datos de la columna 1 y 2 que corresponden a las Condiciones 1 y 2.

En este caso se teclea en el primer espacio (ver Figura 83), el Nombre de la primera variable InteracciónAs, recordando que no debe haber espacios vacíos entre los caracteres, aquí se deben anotar las dos condiciones que se muestran en la Tabla 20, primero los correspondientes a $A_{1}$ en donde se encuentran ubicados dos resultados obtenidos por cada sujeto, y se completa con la columna $A_{2}$ obteniéndose un total de 52 datos (26 por cada columna). 
El nombre de la segunda variable InteracciónBs corresponde a los obtenidos en la Tabla 21, se debe seguir el mismo proceso que el empleado en la variable InteracciónAs pero ahora con los datos de $\mathrm{B}_{1}$ y $\mathrm{B}_{2}$.

El siguiente paso es introducir el nombre de la tercer columna en el espacio 3 de la columna Nombre, los datos de la tercer columna que se denominan con el término de Relación (variable de agrupación), en este caso se utilizan dos valores: 1 para indicar que se refiere a los datos correspondientes a la Condición $1\left(A_{1}\right.$ y $\left.B_{1}\right)$, y el 2 para la Condición $2\left(A_{2}\right.$ y $\left.B_{2}\right)$.

Una vez designados los nombres de las variables y sus características se procede a introducir los datos en la tabla, para llevar a cabo esto es necesario dar un clic en la pestaña Vista de datos, e introducir los datos (ver Figura 84) de la siguiente manera:

- En la columna uno (InteracciónAs) se introducen los valores de los datos obtenidos por el grupo en la Tabla 20, primero los de la columna $A_{1}$ seguidos por los de la columna $A_{2}$.

- En la columna dos (InteracciónBs) se introducen los valores de los datos obtenidos por el grupo en la Tabla 21, primero los de la columna $B_{1}$ seguidos por los de la columna $B_{2}$.

- En la columna tres (Relación) se introduce el valor de 1 para todos los datos que correspondan a la condición $\left(A_{1}\right.$ y $\left.B_{1}\right)$, el valor de 2 para los datos correspondientes a la Condición 2 $\left(A_{2}\right.$ y $\left.B_{2}\right)$.

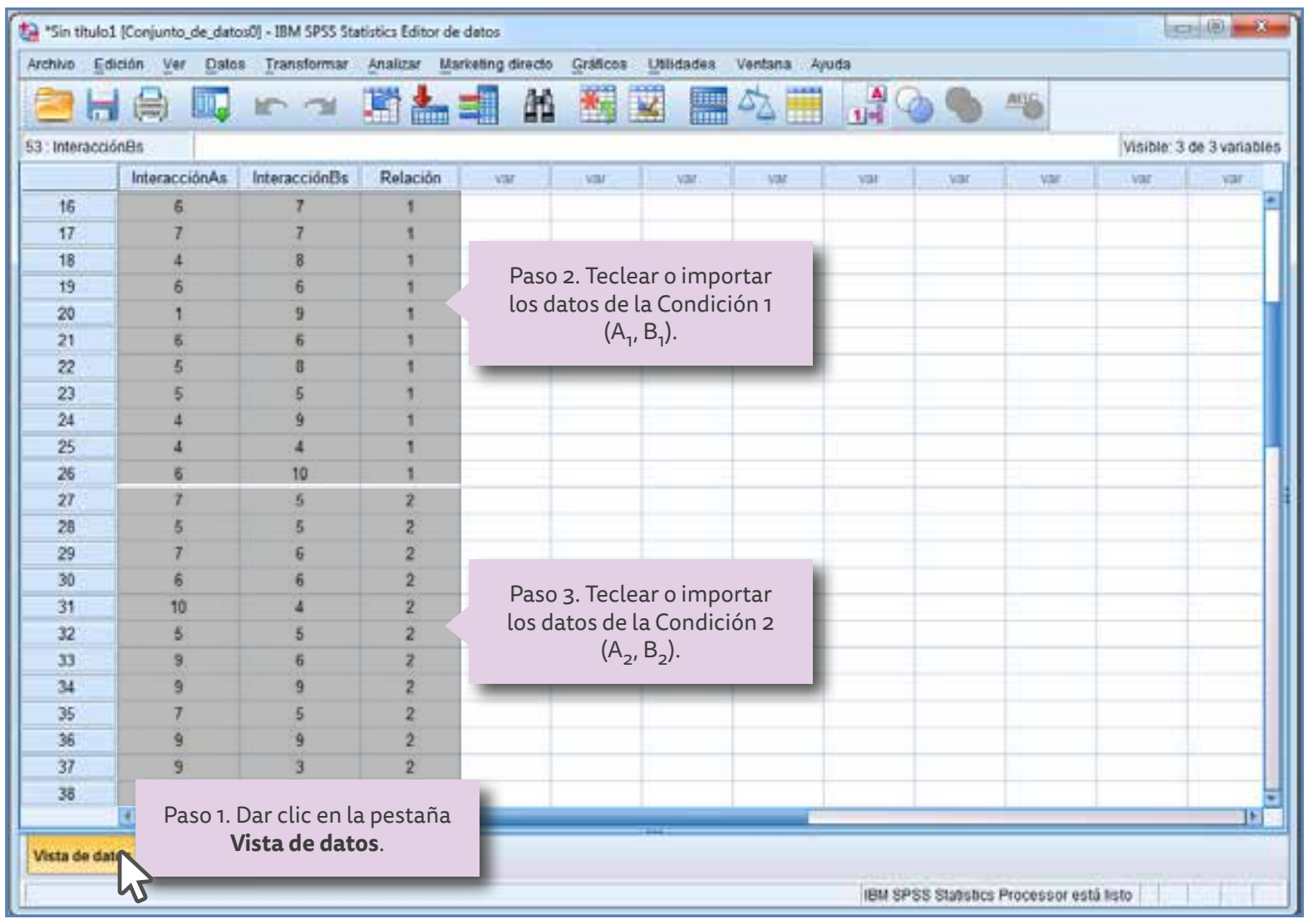

Figura 84. Presentación de los datos arrojados por los participantes.

En el siguiente cuadro se observan las variables seleccionadas en este ejemplo: 
Cuadro 25. Designación de variables para la prueba ANOVA bifacorial (relacionada).

Nombre: InteracciónAs

Tipo: Numérico

Anchura: 3

Decimales: 0

Etiqueta: InteracciónAs

Valores: Ninguno

Perdidos: Ninguno

Columnas: 10

Alineación: Centrado

Medida: Escala

Rol: Entrada

\section{Nombre: InteracciónBs}

Tipo: Numérico

Anchura: 3

Decimales: 0

Etiqueta: InteracciónBs

Valores: Ninguno

Perdidos: Ninguno

Columnas: 10

Alineación: Centrado

Medida: Escala

Rol: Entrada
Nombre: Relación

Tipo: Numérico

Anchura: 3

Decimales: 0

Etiqueta: Relación

Valores: Ninguno

Perdidos: Ninguno

Columnas: 8

Alineación: Centrado

Medida: Escala

Rol: Entrada

Una vez que los datos se encuentran en la tabla, se realiza la prueba, para hacerlo es necesario dar un clic en la pestaña ubicada en la barra superior designada como Analizar, en seguida aparece un cuadro de diálogo, en el cual se selecciona la línea que indica Modelo Lineal General, en este caso no se selecciona comparar medias debido a que el programa SPSS no tiene la opción de ANOVA Bifactorial por lo que se recurre a un proceso general para obtener una buena aproximación de los resultados requeridos; al ubicar el apuntador del ratón en esta opción se presenta a la derecha otro cuadro de diálogo y se selecciona Multivariante (que son las que corresponden a dos variables independientes o más), posteriormente, dar clic con el ratón.

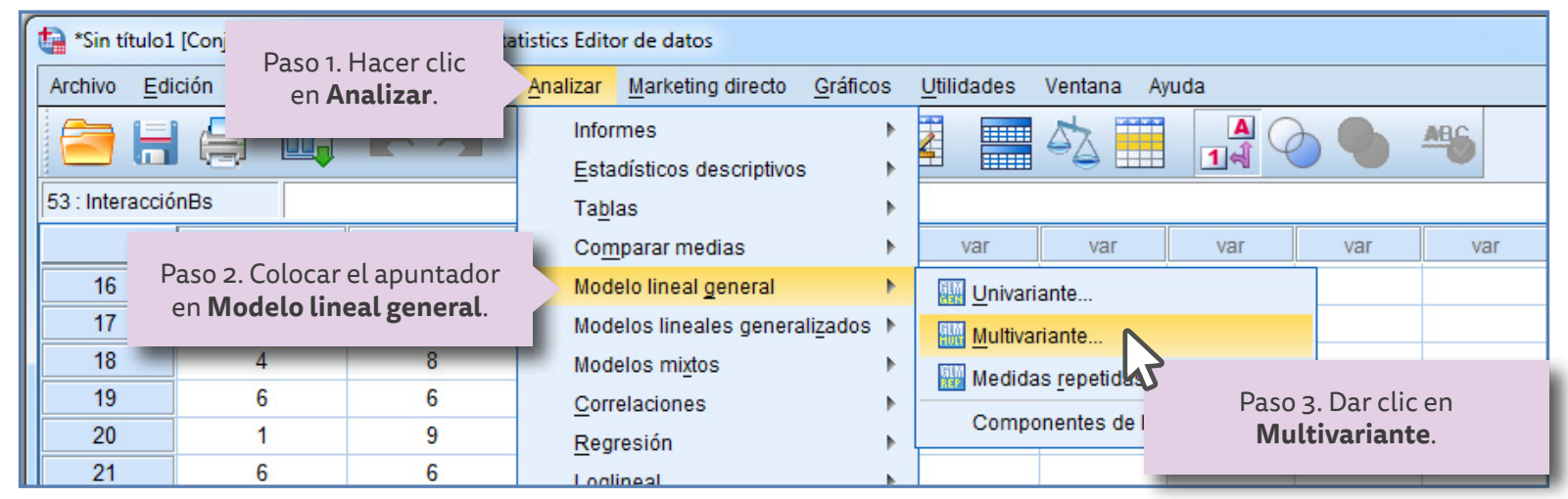

Figura 85. Cuadros de diálogo para seleccionar la prueba paramétrica de dos variables independientes para muestras relacionadas.

Aparece entonces otra ventana (ver Figura 86) donde se muestran las variables del lado izquierdo, InteracciónAs, InteracciónBs y Relación, las dos primeras deben ser trasladadas a la ventana que dice Variables dependientes; la forma de hacerlo es seleccionando con un clic la variable deseada (InteracciónAs) y después en la flecha superior que se ubica entre las dos ventanas. Se repite este proceso para la variable siguiente (InteracciónBs).

Para trasladar la otra variable (Relación) se debe seleccionar y dar clic en la flecha inferior que se encuentra entre las ventanas y se traslada a la ventana designada como Factores fijos (Figura 87). 


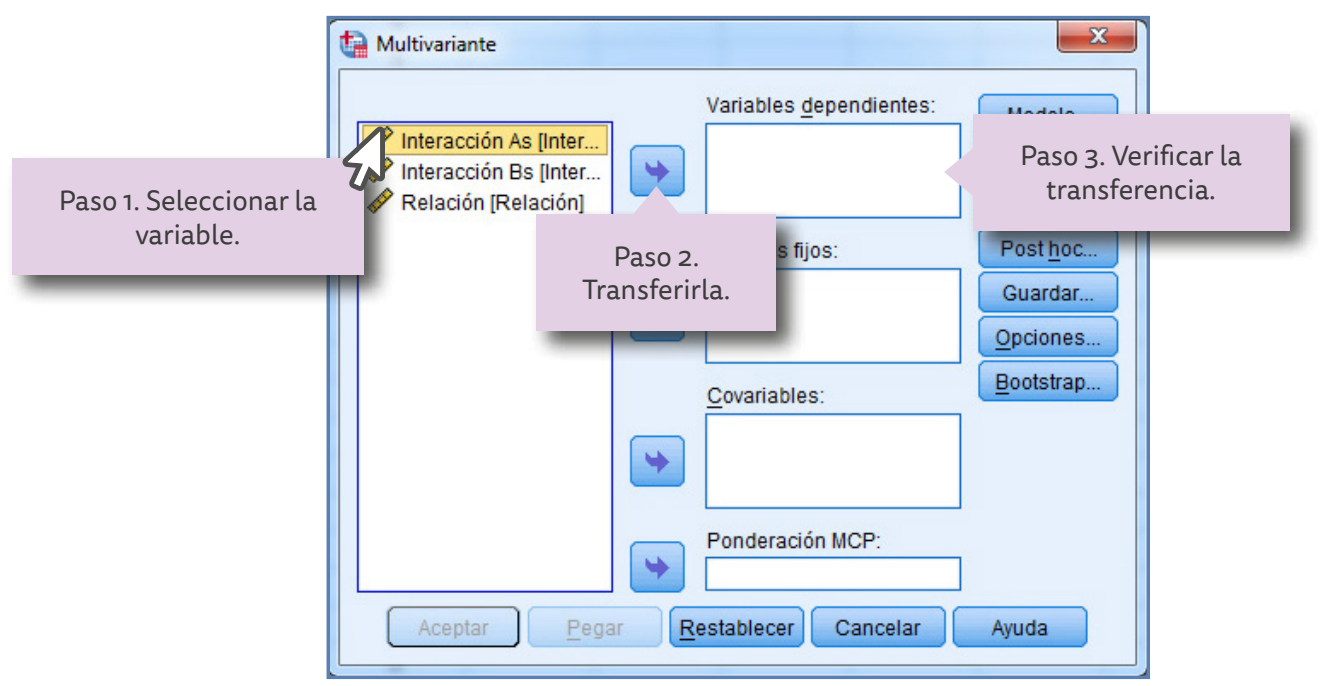

Figura 86. Paso para ingresar las variables Interacción Asy Bs al programa SPSS.

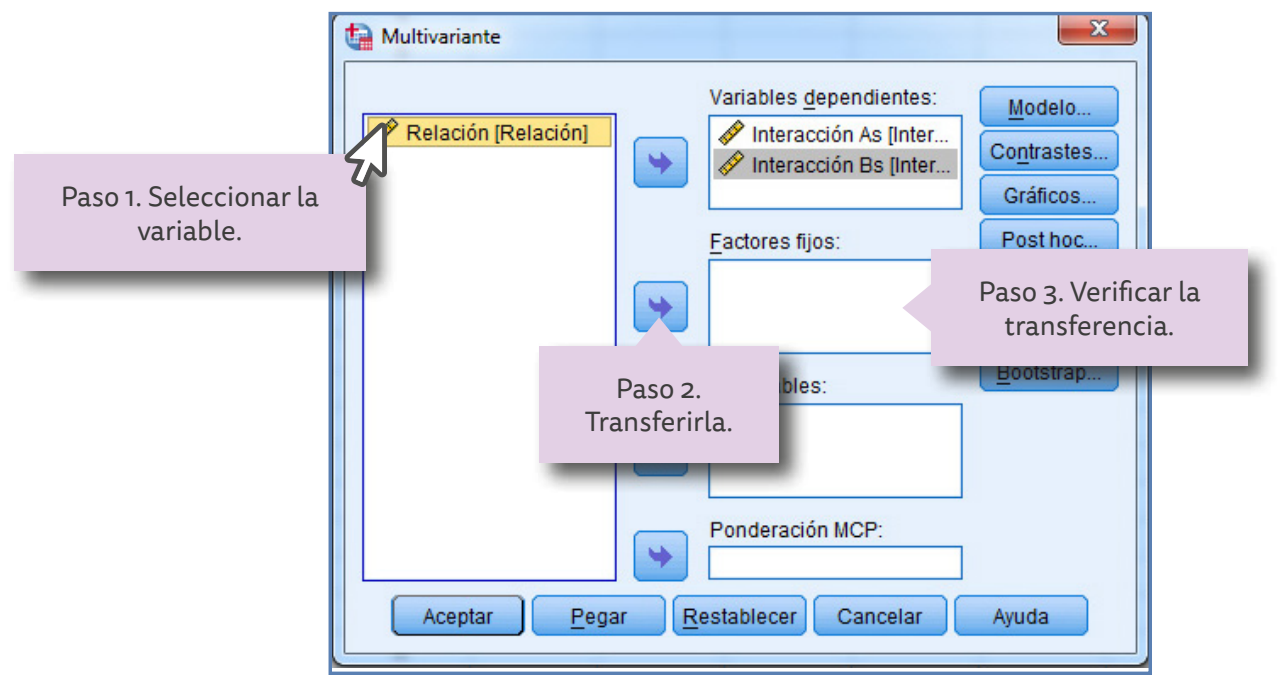

Figura 87. Pasos para ingresar las variables Relación al programa SPSS.

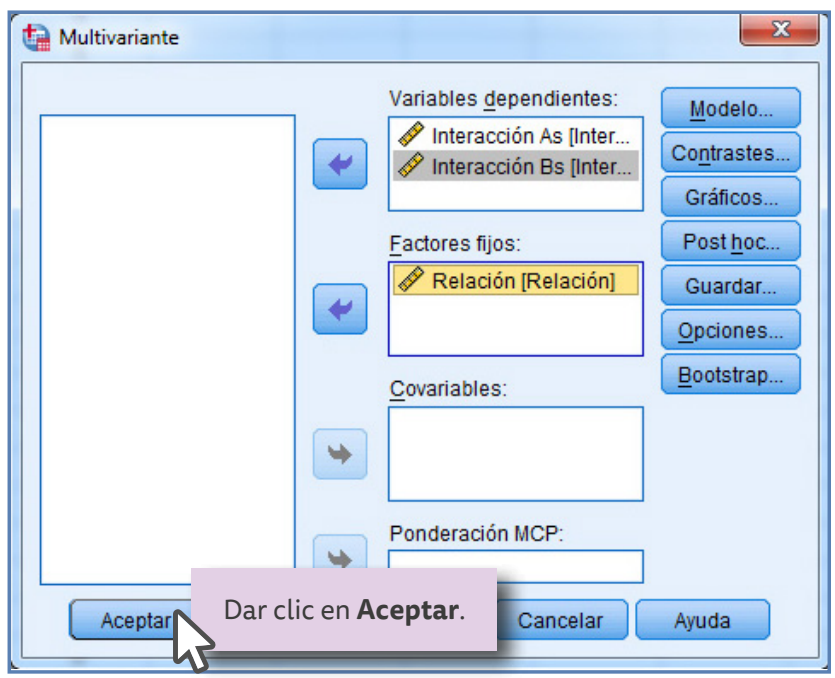

Figura 88. Paso para ejecutar el programa SPSS para que realice los cálculos requeridos. 
Una vez realizado lo anterior, el programa queda listo para arrojar los resultados, al activar el botón Aceptar (Figura 88) se obtienen los resultados que se muestran en el cuadro 26 , en el cual se observa el valor del nivel de significación [Significación asintótica] $\rho<0.000$.

$$
\text { Entonces se puede concluir que } \rho_{\text {encontrada }} 0.000<\rho_{\text {aceptada }} 0.05
$$

Esto es, el valor encontrado 0.000 es menor que el mínimo aceptable por los investigadores en educación (0.05), lo que significa que los resultados de la diferencia no son aleatorios puesto que existe una diferencia significativa, por lo que se puede rechazar la hipótesis nula y aceptar la hipótesis de investigación.

\section{Cuadro 26. Resultados obtenidos con el programa SPSS para la prueba paramétrica ANOVA} Bifactorial para muestras relacionadas utilizando el procedimiento Multivariante.

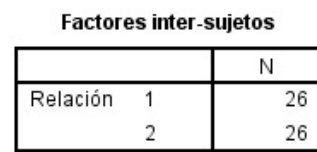

\begin{tabular}{|ll|r|r|r|r|r|}
\hline \multicolumn{1}{|c|}{ Contrastes multivariados $^{\mathrm{a}}$} \\
\hline \multirow{3}{*}{ Efecto } & & \multicolumn{1}{c|}{ Valor } & \multicolumn{1}{c|}{$\mathrm{F}$} & $\begin{array}{c}\text { Gl de la } \\
\text { hipótesis }\end{array}$ & Gl del error & \multicolumn{1}{c|}{ Sig. } \\
\hline Intersección & Traza de Pillai & .974 & $907.564^{\mathrm{b}}$ & 2.000 & 49.000 & .000 \\
& Lambda de Wilks & .026 & $907.564^{\mathrm{b}}$ & 2.000 & 49.000 & .000 \\
& Traza de Hotelling & 37.043 & $907.564^{\mathrm{b}}$ & 2.000 & 49.000 & .000 \\
& Raiz mayor de Roy & 37.043 & $907.564^{\mathrm{b}}$ & 2.000 & 49.000 & .000 \\
\hline Relación & Traza de Pillai & .391 & $15.762^{\mathrm{b}}$ & 2.000 & 49.000 & .000 \\
& Lambda de Wilks & .609 & $15.762^{\mathrm{b}}$ & 2.000 & 49.000 & .000 \\
& Traza de Hotelling & .643 & $15.762^{\mathrm{b}}$ & 2.000 & 49.000 & .000 \\
& Raiz mayor de Roy & .643 & $15.762^{\mathrm{b}}$ & 2.000 & 49.000 & .000 \\
\hline
\end{tabular}

a. Diseño: Intersección + Relación

b. Estadístico exacto

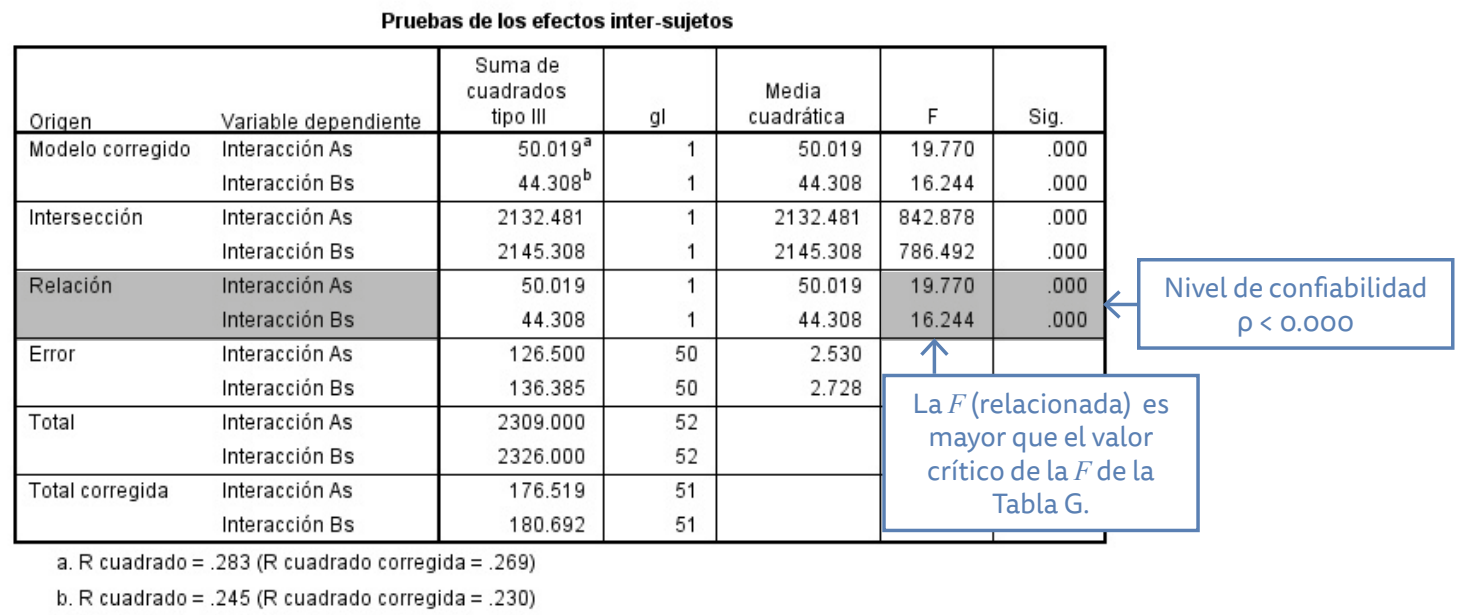

También se observa que el valor de $F$ calculado por medio del programa es mayor que el valor crítico de la Tabla $\mathrm{H}$ (2) para $\rho<0.01$.

$$
\begin{gathered}
F_{\mathrm{A}(1,12)}=19.77 \text { (es mayor que) }>F_{\text {Tabla }}=9.33 \text { para un nivel de significación de } \rho<0.01 \\
F_{\mathrm{B}(1,12)}=16.244 \text { (es mayor que) }>F_{\text {Tabla }}=9.33 \text { para un nivel de significación de } \rho<0.01
\end{gathered}
$$


Hi: Si se utiliza en los enunciados diferentes tipos de datos (simulados abstractos o experimentales reales) y grados de complejidad (sencillos o complejos) en los ejercicios de matemáticas, los alumnos de segundo grado de secundaria retendrán mejor el conocimiento, si los datos se obtienen de sus experiencias o vivencias, con menor grado de complejidad en su enunciado.

\subsection{Comprobación de interacciones por medio de gráficas}

Los datos gráficos representan una forma para determinar si existe interacción entre las dos variables. Para confirmar si existe interacción, el procedimiento utilizado consiste en trazar líneas que conecten los valores de las medias obtenidas para las variables $A_{1}$ y $A_{2}$ en su interacción con las variables $B_{1}$ y $B_{2}$, esto es:

- $A_{1}$ que corresponde a trabajar con datos simulados, abstractos para las dos condiciones de $\mathrm{B}_{1}$ "Problemas sencillos" y $\mathrm{B}_{2}$ "Problemas complejos" $\mathrm{y}$

- $A_{2}$ que corresponde a trabajar con datos experimentales, reales para las dos condiciones de $B_{1}$ "Problemas sencillos" y $B_{2}$ "Problemas complejos".

Si las pendientes se mantienen iguales significa que no hay indicios de interacción entre las dos variables, lo que expresa que en las dos condiciones el grupo muestra los mismos niveles de mejora debido al tipo de problemas resueltos.

Por otro lado, si los valores de las pendientes son diferentes significa que es muy probable que exista una interacción entre las variables como consecuencia de un efecto causado por una variable sobre la otra.

\subsection{Elaboración de las gráficas por medio del programa SPSS}

El primer paso consiste en introducir los nombres de los datos que se han de introducir por lo que es necesario abrir el programa y seleccionar la pestaña Vista de variables, se coloca en la primera columna estos nombres MediasA1, MediasA2 y VariablesB1yB2 en los tres espacios correspondientes a la columna Nombre y en seguida se procede a introducir las características correspondientes a cada uno de éstos, quedando las variables como se muestra en la Figura 89. En el siguiente cuadro se observan las variables seleccionadas en este ejemplo:

Cuadro 27. Designación de variables para la prueba ANOVA Bifactorial (relacionada).

\begin{tabular}{l|l|l|}
\hline Nombre: MediasA1 & Nombre: MediasA2 & Nombre: VariablesB1yB2 \\
\hline Tipo: Numérico & Tipo: Numérico & Tipo: Numérico \\
\hline Anchura: 4 & Anchura: 4 & Anchura: 3 \\
\hline $\begin{array}{l}\text { Decimales: } 2 \\
\text { Etiqueta: Datos simulados, } \\
\text { abstractos }\end{array}$ & $\begin{array}{l}\text { Decimales: } 2 \\
\text { Etiqueta: Datos experimentales, } \\
\text { reales }\end{array}$ & $\begin{array}{l}\text { Decimales: } 0 \\
\text { Etiqueta: Ninguna }\end{array}$ \\
\hline Valores: Ninguno & Valores: Ninguno & $\begin{array}{l}\text { Valores: 1. B problemas sencillos } \\
\text { 2. B } 2 \text { Problemas complejos }\end{array}$ \\
\hline Perdidos: Ninguno & Perdidos: Ninguno & Perdidos: Ninguno \\
\hline Columnas: 8 & Columnas: 8 & Columnas: 8 \\
\hline $\begin{array}{l}\text { Alineación: Centrado } \\
\text { Medida: Escala }\end{array}$ & Alineación: Centrado & Alineación: Centrado \\
\hline Rol: Entrada & Medida: Escala & Medida: Escala \\
\hline
\end{tabular}




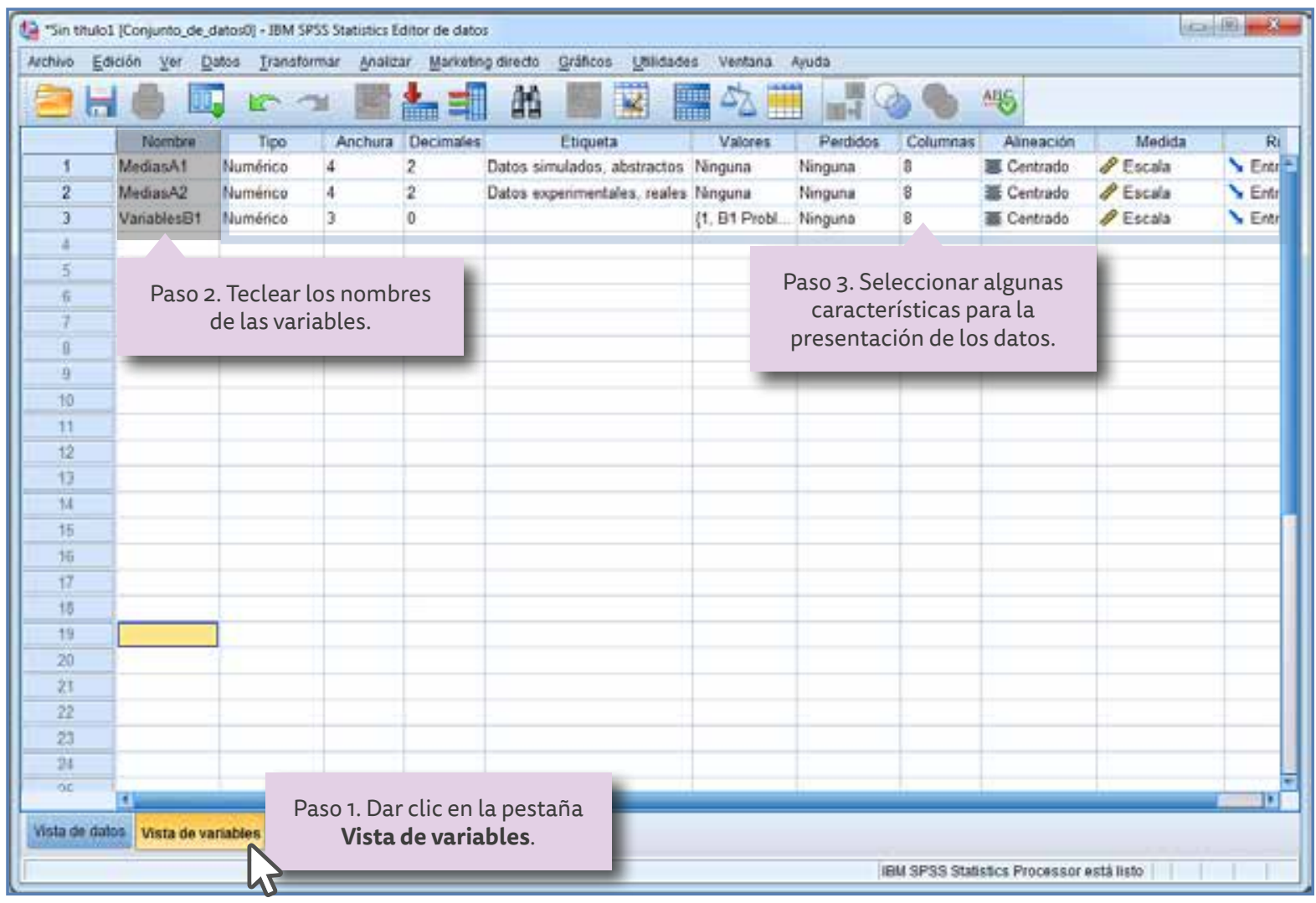

Figura 89. Designación de nombre de las variables y características de presentación para la elaboración de las gráficas.

Una vez designados los nombres de las variables y sus características, se introducen los datos en la tabla, para llevar a cabo esto es necesario dar un clic en la pestaña Vista de datos, e introducirlos (ver Figura 90) de la siguiente manera:

- En la columna uno (MediasA1) se introducen los valores las medias para la Variable $A_{1}$ esto es $B_{1}=6.30$ y $B_{2}=4.53$ (Tabla 18 ).

- En la columna dos (MediasA2) se introducen los valores las medias para la Variable $A_{2}$ esto es $B_{1}=8.36$ y $B_{2}=6.46$.

- En la columna tres (Relación) se introduce el valor de 1 para todos los datos que correspondan a la condición $\left(B_{1}\right)$, el valor de 2 para los datos correspondientes a la Condición $2\left(B_{2}\right)$.

Una vez que los datos se encuentran en la tabla se realiza la gráfica, para hacerlo es necesario dar clic en la pestaña ubicada en la barra superior designada como Gráficos, en seguida aparece un cuadro de diálogo en el cual se selecciona la línea que indica Cuadro de diálogo antiguo y en seguida el tipo de gráfica que se desea utilizar, en este caso Líneas (Figura 91).

Con el clic se activa una ventana y se selecciona la opción Múltiple, después la opción Resúmenes para distintas variables, finalmente se da clic en el botón Definir (Figura 92).

Al dar clic en Definir aparece otra ventana (Figura 93) en la cual es necesario trasladar los datos simulados, abstractos, experimentales y reales a la ventana designada como Las líneas representan; se seleccionan estos datos y trasladan con la flecha correspondiente. Una vez realizado esto se trasladan las variables B1 y B2 (Figura 94) a la ventana designada como Eje de categorías, seleccionando las variables y trasladándolas con la flecha correspondiente.

Una vez transferidos los datos se da clic en Aceptar (Figura 95) y se genera la Gráfica 15 , en la cual el tipo de problemas sencillos y complejos se representan en el eje horizontal y las líneas representan los datos simulados, abstractos y los datos experimentales, reales. 


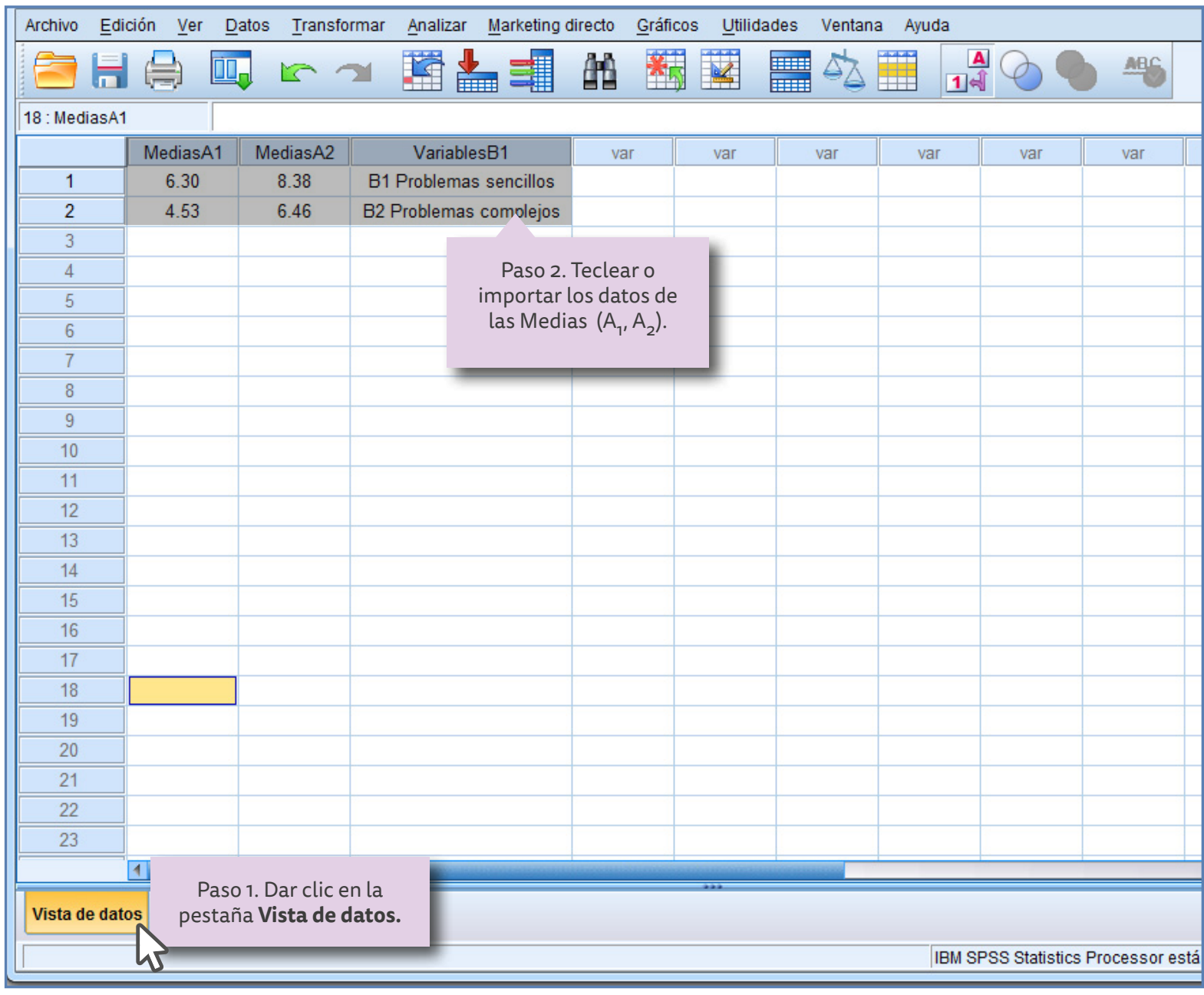

Figura 90. Presentación de los valores de las medias correspondientes.

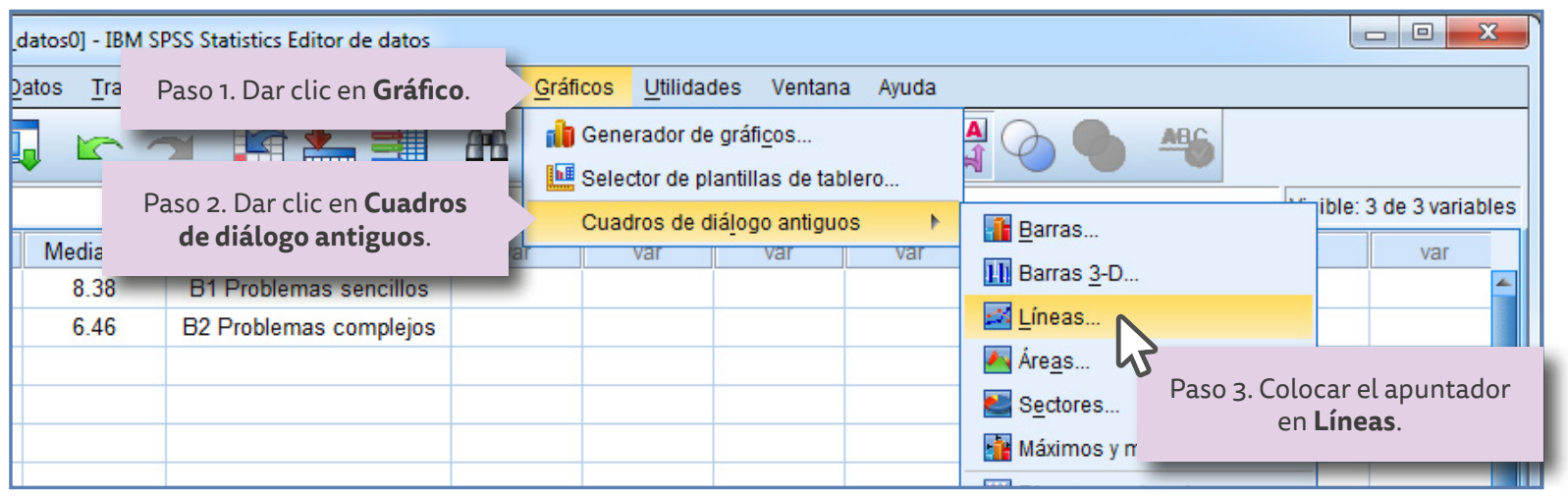

Figura 91. Cuadros de diálogo para seleccionar la prueba paramétrica de dos variables independientes para muestras relacionadas. 


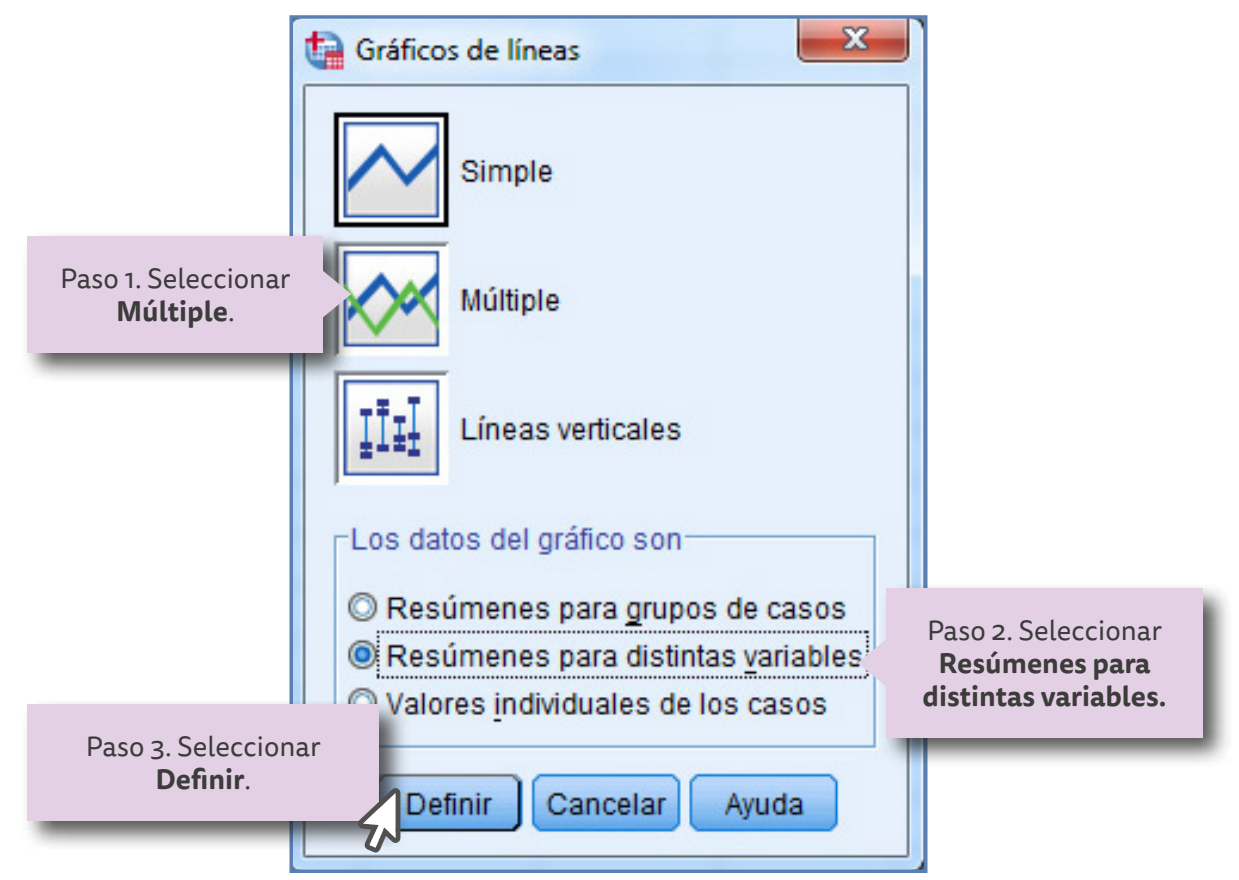

Figura 92. Cuadros de diálogo para seleccionar el tipo de gráficas que se desean representar.

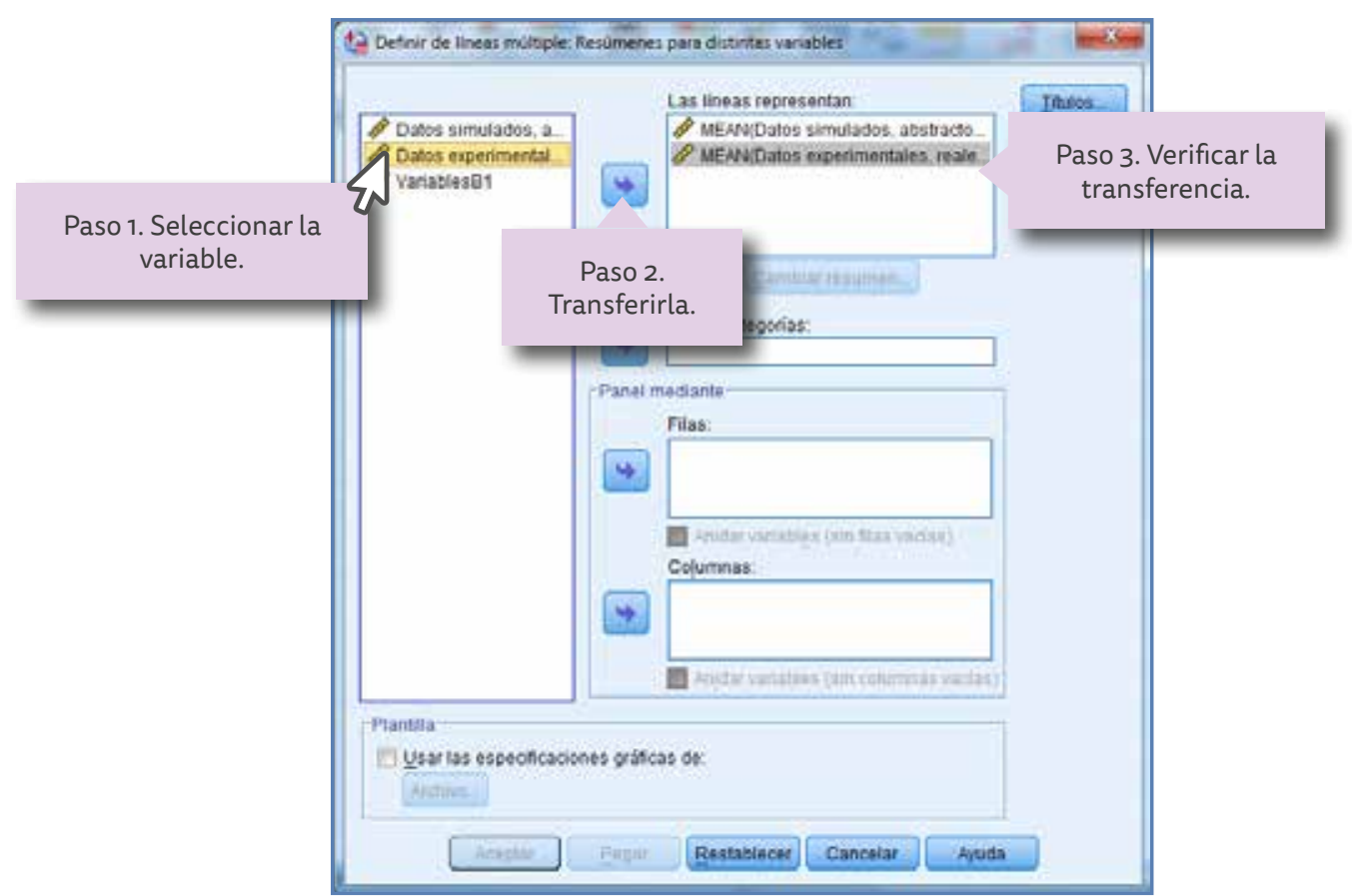

Figura 93. Cuadros de diálogo para definir los parámetros para graficar las líneas que representan.

Las líneas paralelas de los valores medios de los resultados indican que los datos experimentales, reales fueron superiores a los datos simulados, abstractos.

Por otro lado los valores de las pendientes de las líneas indican que no existe interacción entre las dos variables del tipo de datos y los tipos de problemas, ya que ninguna variable tiene efecto sobre la otra (ver Gráfica 15). 


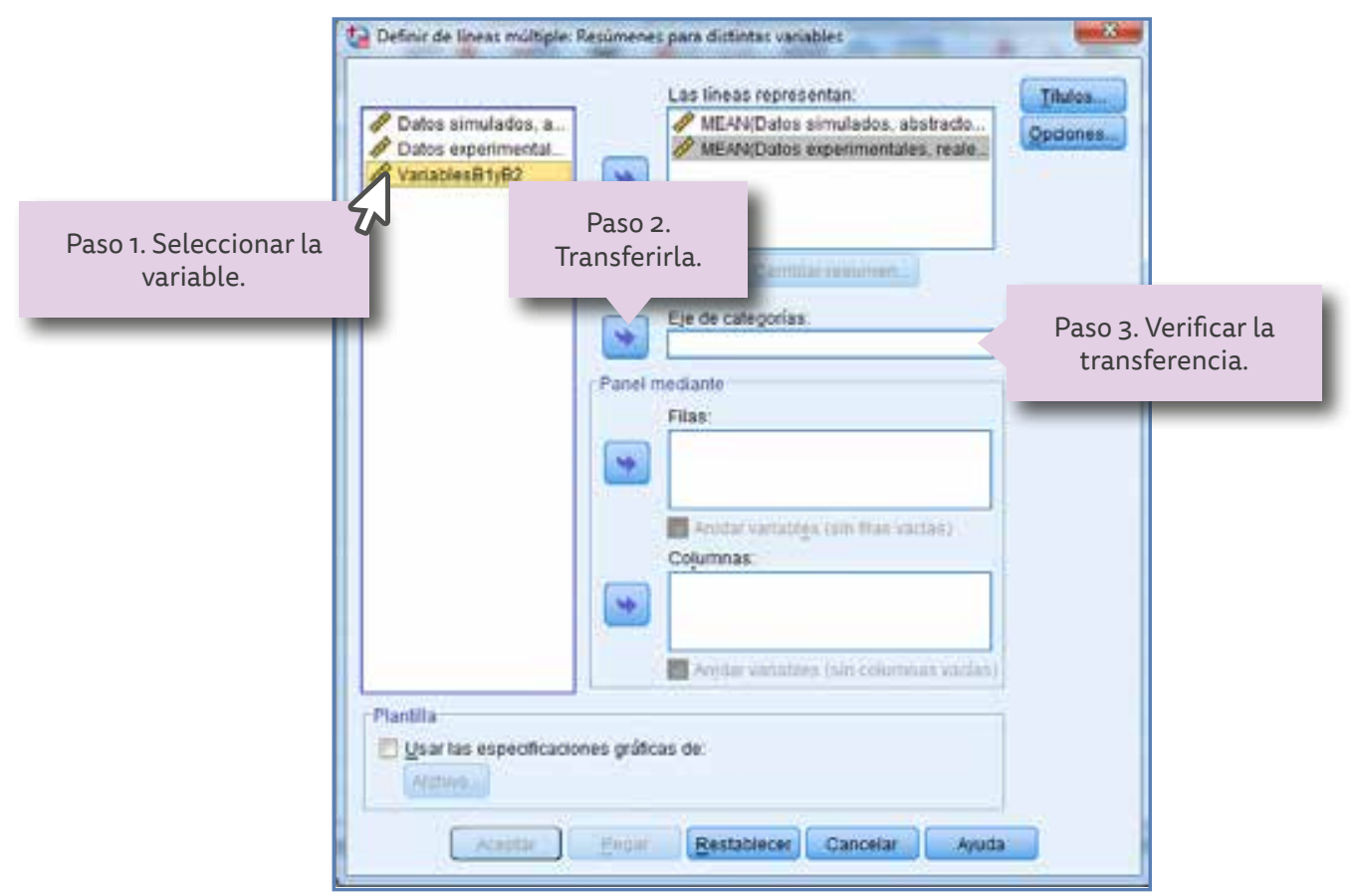

Figura 94. Cuadros de diálogo para definir los parámetros para graficar el Eje de categorías.

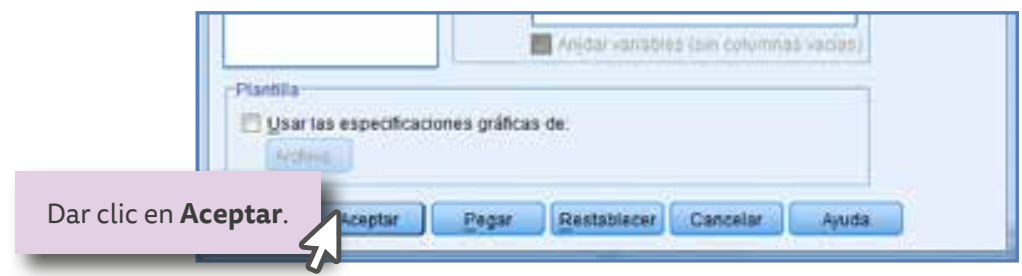

Figura 95. Cuadros de diálogo para generar la gráfica.

Gráfica 15. Gráfica 2 X 2 para ANOVA Bifactorial para muestras relacionadas.

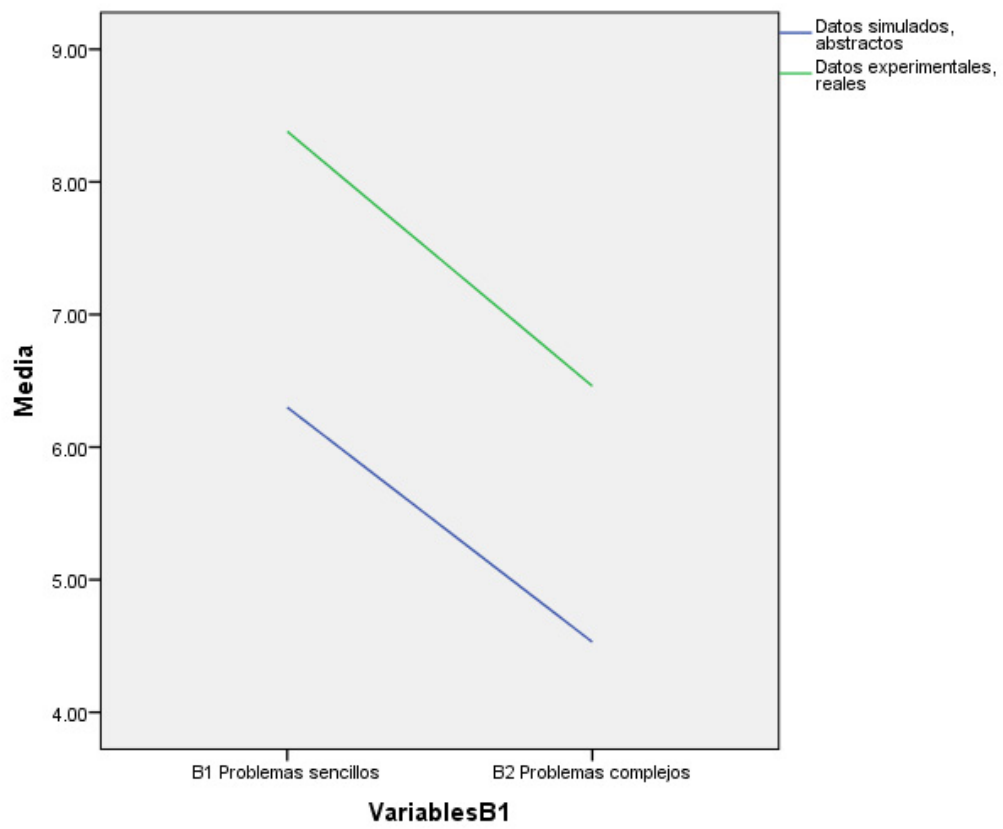





\section{Capítulo 14}

\section{Prueba ANOVA Bifactorial (muestras independientes)}

Este tipo de prueba se debe utilizar cuando cada condición es aplicada a sujetos (participantes) distintos, se tienen dos variables independientes y los datos deben pertenecer a la escala de intervalo. Estas variables independientes a su vez presentan dos o más condiciones.

Ejemplo 89. Se trata de aceptar o rechazar la siguiente hipótesis de investigación: $\mathrm{Hi}$ : Si se utilizan diferentes frecuencias de retroalimentación (Continua e intermitente) y distintos procedimientos (tradicional y constructivista) durante la realización de experimentos en la materia de Física, los alumnos de primer grado de secundaria retendrán mejor el conocimiento, si la frecuencia de retroalimentación es intermitente y el experimento es de corte constructivista.

\subsection{Estado situacional}

El investigador desea saber si el uso de diferentes frecuencias de retroalimentación durante la realización de algún tipo de experimento (Variable 1) influye en la retención de los conocimientos de los participantes de manera significativa; por otro lado desea determinar si el tipo de experimento (Variable 2) facilita esta retención en los alumnos de Física de primer grado de secundaria. El investigador propone realizar un experimento en donde la Variable 1, la frecuencia de retroalimentación se presenta a dos grupos de manera continua de acuerdo al procedimiento tradicional, o por intervalos, señalando sólo los contenidos que se deben significar por medio de la discusión grupal, y por otro lado (Variable 2) los experimentos deben ser de dos tipos:

a. El primero siguiendo el proceso experimental tradicional, donde el alumno cuenta con un formato preestablecido que le indica los pasos a seguir y los experimentos a realizar.

b. El segundo proceso experimental es de corte Constructivista, donde el alumno debe realizar la teoría que soporte su experimento, así como elaborar los pasos para la realización del experimento e inferir sus propios objetivos, procedimiento y conclusiones.

Como instrumento de recolección de datos se elaboró una prueba objetiva con 10 reactivos sobre el tema que se experimentó, es decir, la teoría electromagnética, y fueron aplicados a los cuatro grupos obteniéndose los resultados que se muestran en la Tabla 23. 
Tabla 23. Puntajes obtenidos por los grupos participantes de acuerdo a las condiciones establecidas por el investigador.

\begin{tabular}{|c|c|c|c|c|}
\hline \multirow{2}{*}{$\begin{array}{c}\text { Distintos } \\
\text { Participantes }\end{array}$} & \multicolumn{2}{|c|}{$\mathbf{A}_{\mathbf{1}}$ Retroalimentación continua } & \multicolumn{2}{|c|}{$\mathbf{A}_{\mathbf{2}}$ Retroalimentación intermitente } \\
\cline { 2 - 5 } & $\begin{array}{c}\mathbf{B}_{\mathbf{1}} \text { Experimento } \\
\text { tradicional }\end{array}$ & $\begin{array}{c}\mathbf{B}_{\mathbf{2}} \text { Experimento } \\
\text { constructivista }\end{array}$ & $\begin{array}{c}\mathbf{B}_{\mathbf{1}} \text { Experimento } \\
\text { tradicional }\end{array}$ & $\begin{array}{c}\mathbf{B}_{\mathbf{2}} \text { Experimento } \\
\text { constructivista }\end{array}$ \\
\hline 1 & 7 & 9 & 7 & 8 \\
\hline 2 & 5 & 6 & 7 & 8 \\
\hline 3 & 7 & 6 & 6 & 6 \\
\hline 4 & 6 & 5 & 7 & 9 \\
\hline 5 & 2 & 7 & 8 & 8 \\
\hline 6 & 6 & 7 & 7 & 7 \\
\hline 7 & 4 & 6 & 8 & 9 \\
\hline 8 & 6 & 7 & 9 & 5 \\
\hline 9 & 6 & 7 & 5 & 8 \\
\hline 10 & 3 & 8 & 6 & 7 \\
\hline 11 & 6 & 6 & 4 & 6 \\
\hline 12 & 5 & 8 & 6 & 6 \\
\hline 13 & 7 & 6 & 8 & 8 \\
\hline 14 & 7 & 6 & 7 & $\mathbf{7 . 4 2}$ \\
\hline Media & 5.50 & 6.71 & 6.78 & \\
\hline
\end{tabular}

\subsection{Explicación}

Para ANOVA Bifactorial cuando existen dos variables independientes se pueden calcular cinco tipos de varianza (Greene y D'oliveira, 2006):

a. La Varianza entre las condiciones de la Variable A (pronosticada).

b. La Varianza entre las condiciones de la Variable B (pronosticada).

c. La Varianza debida a la interacción entre $A$ y $B$ (pronosticada), indicada como $A \times B$.

d. La Varianza de error causada por variables irrelevantes (por ejemplo las diferencias entre participantes).

e. La Varianza total que incluye todas las fuentes de varianza antes mencionadas.

La ANOVA Bifactorial para muestras independientes tiene como objetivo comparar ratios de varianza, esto es, la varianza entre las condiciones para las variables $A$ y $B$ así como su intercepción $(A \times B)$ que representa la varianza entre las condiciones pronosticadas. La varianza de error se representa por las diferencias entre los resultados debidas a variables irrelevantes.

La predicción afirma que las varianzas deben ser relativamente elevadas en comparación con la varianza de error causada por las variables irrelevantes. Esto es, para aceptar la hipótesis de investigación, el ratio (relación) entre las varianzas y la varianza de error debe ser relativamente grande.

\subsection{Procedimiento para determinar el valor de ANOVA Bifactorial (independiente)}

En este caso para ANOVA Bifactorial para muestras independientes existen varias fuentes de varianza e interrelaciones, por lo que es necesario distribuir los datos de la Tabla 23 en una tabla que representa las combinaciones de las posibles interacciones entre A y $B$.

1. Elaborar la tabla de interacciones entre A y B.

Para elaborar la Tabla 23 se agrupan en casillas todos los valores que tienen correspondencia con los valores de los participantes, por ejemplo:

a. En la casilla $\mathrm{A} 1 \mathrm{~B} 1$ se colocan los valores obtenidos por los catorce participantes en las condiciones de "retroalimentación continua" y el "experimento tradicional". 
b. En la siguiente casilla (columna $T_{\mathrm{A} 1 \mathrm{~B}}$ ) se calculan los totales sumando los trece resultados.

$$
T_{\mathrm{A} 1 \mathrm{~B} 1}=7+5+7+6+2+6+4+6+6+3+6+5+7+7=77
$$

c. Se calculan los totales de resultados para las dos condiciones de la Variable A y se anotan en la parte inferior de la tabla.

d. Se calculan los totales de resultados para las dos condiciones de la Variable B y se anotan en la parte derecha de la tabla.

e. Se suman estos totales y se obtiene un total general que debe coincidir tanto con la suma de A, como con la de B.

Tabla 24. Interacciones entre A y B.

\begin{tabular}{|c|c|c|c|c|c|}
\hline & $A_{1}$ & $T_{\mathrm{A} 1 \mathrm{~B}}$ & $A_{2}$ & $T_{\mathrm{A} 2 \mathrm{~B}}$ & $T_{\mathrm{B}}$ \\
\hline$B_{1}$ & $\begin{array}{l}7,5,7,6,2,6,4 \\
6,6,3,6,5,7,7\end{array}$ & 77 & $\begin{array}{l}7,7,6,7,8,7,8, \\
9,5,6,4,6,8,7\end{array}$ & 95 & 172 \\
\hline$B_{2}$ & $\begin{array}{l}9,6,6,5,7,7,6 \\
7,7,8,6,8,6,6\end{array}$ & 94 & $\begin{array}{l}8,8,6,9,8,7,9 \\
5,8,7,6,6,9,8\end{array}$ & 104 & 198 \\
\hline$T_{\mathrm{A}}$ & & 171 & & 199 & 370 \\
\hline
\end{tabular}

En resumen se determinan los siguientes valores de los datos:

$\sum T_{\mathrm{A}}^{2}=$ suma de los cuadrados de los totales de A en la Tabla 24.

$\Sigma T_{\mathrm{B}}^{2}=$ suma de los cuadrados de los totales de B en la Tabla 24.

$\Sigma T_{A B}{ }^{2}=$ suma de los cuadrados de los totales de $A B$ para cada valor de $T_{A B}$ en la Tabla 24.

$n=$ número de participantes.

$a=$ número de condiciones para la Variable $\mathrm{A}$.

$b=$ número de condiciones para la Variable $\mathrm{B}$.

$N=$ número total de resultados.

$\left(\sum x\right)^{2}=$ cuadrado del total general.

$\frac{\left(\sum \mathrm{x}\right)^{2}}{N}=$ constante que se debe restar a todas las sumas de cuadrados.

$\sum \mathrm{x}^{2}=$ suma de cada uno de los resultados elevados al cuadrado.

Entonces de acuerdo a los datos de la tabla, calcular:

$$
\begin{gathered}
\sum T_{\mathrm{A}}^{2}=(171)^{2}+(199)^{2}=(29241)+(39601)=68842 \\
\sum T_{\mathrm{B}}^{2}=(172)^{2}+(198)^{2}=(29584)+(39204)=68788 \\
\sum T_{\mathrm{AB}}^{2}=\left(T_{\mathrm{A} 1 \mathrm{~B} 1}\right)^{2}+\left(T_{\mathrm{A} 1 \mathrm{~B} 2}\right)^{2}+\left(T_{\mathrm{A} 2 \mathrm{~B} 1}\right)^{2}+\left(T_{\mathrm{A} 2 \mathrm{~B} 2}\right)^{2}= \\
\sum T_{\mathrm{AB}}{ }^{2}=(77)^{2}+(94)^{2}+(95)^{2}+(104)^{2}= \\
\sum T_{\mathrm{AB}}{ }^{2}=(5929)+(8836)+(9025)+(10816)=34606
\end{gathered}
$$




$$
\begin{gathered}
n=14 \\
a=2 \\
b=2 \\
N=(14) 4=56 \\
\left(\sum x\right)^{2}=(370)^{2}=136900 \\
\frac{\left(\sum x\right)^{2}}{N}=\frac{136900}{56}=2444.64
\end{gathered}
$$

Para determinar el valor de $\sum x^{2}$, como son muchos los valores de los resultados encontrados $(x)$ es conveniente realizar el cálculo elaborando la Tabla 25.

$$
\sum x^{2}=\sum x_{1}{ }^{2}+\sum x_{2}{ }^{2}+\sum x_{3}{ }^{2}+\sum x_{4}{ }^{2}=453+646+667+729=2558
$$

2. Calcular el valor de la varianza esperada para $A, S C_{A}$.

$$
S C_{\mathrm{A}}=\frac{\sum T_{\mathrm{A}}^{2}}{n \mathrm{~b}}-\frac{\left(\sum \mathrm{x}\right)^{2}}{N}=\frac{68842}{(14)(2)}-2444.64=14
$$

3. Calcular el valor de la varianza esperada para $\mathrm{B}, S C_{\mathrm{B}}$.

$$
S C_{\mathrm{B}}=\frac{\sum \mathrm{x} T_{\mathrm{B}}^{2}}{n \mathrm{a}}-\frac{\left(\sum \mathrm{x}\right)^{2}}{N}=\frac{68788}{(14)(2)}-2444.64=12.07
$$

4. Calcular el valor de la varianza $A \times B, S C_{A B}$.

$$
\begin{gathered}
S C_{\mathrm{AB}}=\frac{\sum T_{\mathrm{AB}}^{2}}{n}-\frac{\left(\sum \mathrm{x}\right)^{2}}{N}-S C_{\mathrm{A}}-S C_{\mathrm{B}}= \\
S C_{\mathrm{AB}}=\frac{34606}{14}-2444.64-14-12.07=1.147
\end{gathered}
$$

5. Calcular el valor de la varianza total $S C_{\text {tot }}$.

$$
S C_{\text {tot }}=\sum x^{2}-\frac{\left(\sum x\right)^{2}}{N}=2558-2444.64=113.36
$$


Tabla 25. Cálculo de los valores de los resultados elevados al cuadrado.

\begin{tabular}{|c|c|c|c|c|c|c|c|c|}
\hline \multicolumn{9}{|c|}{$x^{2}$ Cuadrado de Resultados } \\
\hline & $x_{1}$ & $x_{1}^{2}$ & $x_{2}$ & $x_{2}^{2}$ & $x_{3}$ & $x_{3}^{2}$ & $x_{4}$ & $x_{4}^{2}$ \\
\hline $\mathrm{S}_{1}$ & 7 & 49 & 9 & 81 & 7 & 49 & 8 & 64 \\
\hline $\mathrm{S}_{2}$ & 5 & 25 & 6 & 36 & 7 & 49 & 8 & 64 \\
\hline $\mathrm{S}_{3}$ & 7 & 49 & 6 & 36 & 6 & 36 & 6 & 36 \\
\hline $\mathrm{S}_{4}$ & 6 & 36 & 5 & 25 & 7 & 49 & 9 & 81 \\
\hline $\mathrm{S}_{5}$ & 2 & 4 & 7 & 49 & 8 & 64 & 8 & 64 \\
\hline $\mathrm{S}_{6}$ & 6 & 36 & 7 & 49 & 7 & 49 & 7 & 47 \\
\hline $\mathrm{S}_{7}$ & 4 & 16 & 6 & 36 & 8 & 64 & 9 & 81 \\
\hline $\mathrm{S}_{8}$ & 6 & 36 & 7 & 49 & 9 & 81 & 5 & 25 \\
\hline $\mathrm{S}_{9}$ & 6 & 36 & 7 & 49 & 5 & 25 & 8 & 64 \\
\hline $\mathrm{S}_{10}$ & 3 & 9 & 8 & 64 & 6 & 36 & 7 & 49 \\
\hline$S_{11}$ & 6 & 36 & 6 & 36 & 4 & 16 & 6 & 36 \\
\hline$S_{12}$ & 5 & 25 & 8 & 64 & 6 & 36 & 6 & 36 \\
\hline $\mathrm{S}_{13}$ & 7 & 47 & 6 & 36 & 8 & 64 & 9 & 81 \\
\hline $\mathrm{S}_{14}$ & 7 & 49 & 6 & 36 & 7 & 49 & 8 & 64 \\
\hline$\Sigma$ & \multicolumn{2}{|c|}{$\sum x_{1}^{2}=453$} & \multicolumn{2}{|c|}{$\sum x_{2}^{2}=646$} & \multicolumn{2}{|c|}{$\sum x_{3}^{2}=667$} & \multicolumn{2}{|c|}{$\sum x_{4}^{2}=729$} \\
\hline
\end{tabular}

6. Calcular el valor de la varianza de error $S C_{\text {error }}$

$$
\begin{gathered}
S C_{\text {error }}=S C_{\text {tot }}-S C_{\mathrm{A}}-S C_{\mathrm{B}}-S C_{\mathrm{AB}} \\
S C_{\text {error }}=113.36-14-12.07-1.47=85.82
\end{gathered}
$$

7. Calcular los grados de libertad donde:

$$
\begin{aligned}
& g l_{\mathrm{A}}=\text { número de condiciones } \mathrm{A}-1 \\
& g l_{\mathrm{B}}=\text { número de condiciones } \mathrm{B}-1 \\
& g l_{\mathrm{AB}}=\left(g l_{\mathrm{A}}\right)\left(g l_{\mathrm{B}}\right) \\
& g l_{\text {tot }}=\text { número de resultados } N-1 \\
& g l_{\text {error }}=g l_{\text {tot }}-g l_{\mathrm{A}}-g l_{\mathrm{B}}-g l_{\mathrm{AB}}
\end{aligned}
$$

$$
\begin{aligned}
& g l_{\mathrm{A}}=\mathrm{A}-1=2-1=1 \\
& g l_{\mathrm{B}}=\mathrm{B}-1=2-1=1 \\
& g l_{\mathrm{AB}}=(1)(1)=1 \\
& g l_{\text {tot }}=N-1=56-1=55 \\
& g l_{\text {error }}=55-1-1-1=52
\end{aligned}
$$

8. Dividir cada $S C$ entre los $g l$ para obtener el valor de los cuadrados medios $M C$.

$$
\begin{gathered}
M C_{\mathrm{A}}=\frac{\mathrm{SC}_{\mathrm{A}}}{g l_{\mathrm{A}}}=\frac{14}{1}=14 \\
M C_{\mathrm{B}}=\frac{S C_{\mathrm{B}}}{g l_{\mathrm{B}}}=\frac{12.07}{1}=12.07
\end{gathered}
$$




$$
\begin{gathered}
M C_{\mathrm{AB}}=\frac{\mathrm{SC}_{\mathrm{AB}}}{g l_{\mathrm{AB}}}=\frac{1.147}{1}=1.147 \\
M C_{\text {error }}=\frac{\mathrm{SC}_{\text {error }}}{g l_{\text {error }}}=\frac{85.82}{52}=1.65 \\
M C_{\text {tot }}=\frac{S C_{\text {tot }}}{g l_{\text {tot }}}=\frac{113.36}{55}=2.06
\end{gathered}
$$

9. Calcular el valor de $F$ ratio para $M C_{\mathrm{A}}, M C_{\mathrm{B}}, M C_{\mathrm{AB}}$, y $M C_{\mathrm{S}}$, con respecto a $M C_{\text {error }}$ y asignar el número de $g l$ adecuado para las $F$ ratios:

$$
\begin{array}{ll}
F \text { ratio para } M C_{\mathrm{A}}=\frac{M C_{\mathrm{A}}}{\mathrm{MC} C_{\text {error }}} & F_{1,52}=\frac{14}{1.65}=8.48 \\
F \text { ratio para } M C_{\mathrm{B}}=\frac{M C_{\mathrm{B}}}{M C_{\text {error }}} & F_{1,52}=\frac{12.07}{1.65}=7.31 \\
F \text { ratio para } M C_{\mathrm{AB}}=\frac{M C_{\mathrm{AB}}}{M C_{\mathrm{error}}} & F_{1,52}=\frac{1.147}{1.65}=0.056
\end{array}
$$

10. Buscar el nivel de significación de $F$ en la Tabla $H$ del Apéndice D.

Para la prueba ANOVA se utilizan las tablas: $\mathrm{H}(1)$ que contiene los valores para $\rho<0.05$ y H (2) que contiene los valores para $\rho<0.01$ ( $\rho$ es el valor del nivel de significación). El valor calculado $F$ debe ser igual o mayor que el valor crítico que se muestra en las tablas, para poder aceptar la hipótesis de investigación.

Para localizar el valor de la $F$ de la tabla de debe utilizar los valores de los grados de libertad gl para las tres varianzas entre condiciones $A, B, A B$, y la varianza de error, en este ejemplo corresponden $a g l_{A}=1, g l_{B}=1, g l_{A B}=1, g l_{\text {error }}=52$. Se puede observar que todos los valores críticos que se deben buscar, se encuentran en los mismos grados de libertad esto es $F_{1,52}$.

Para $F_{1,52}$ se localiza el valor de $g l=1$ para A, B y AB en la Tabla $\mathrm{H}$, se ubica éste en la fila superior $\left(v_{1}\right)$ y para el valor de $g l_{\text {error }}=52$ se ubica éste en la primera columna de la izquier$\mathrm{da}\left(\mathrm{v}_{2}\right)$, en donde se interceptan los dos puntos se localiza el valor crítico. Se puede observar que en la tabla no se encuentra el valor de 52 solo hay 40060 por lo que se debe tomar el menor para garantizar que esté por debajo de este valor critico obteniéndose para $v_{2}=40$, $F_{\text {tabla }}=4.08$ en la Tabla $\mathrm{H}$ (1) para $\rho<0.05$ y en la Tabla $\mathrm{H}(2)$ el valor crítico corresponde a $F_{1,52}=7.31$ para $\rho<0.01$. Comparando los valores calculados con el valor crítico de la tabla se puede observar que para un nivel de significación de $\rho<0.01$.

$$
\begin{gathered}
F_{\mathrm{A}(1,52)}=8.48 \text { (es mayor que) }>F_{\text {tabla }}=7.31 \text { para un nivel de significación de } \rho<0.01 \\
F_{\mathrm{B}(1,52)}=7.31 \text { (es igual) }=F_{\text {tabla }}=7.31 \text { para un nivel de significación de } \rho<0.01 \\
F_{\mathrm{AB}(1,52)}=0.056 \text { (es menor que) }<F_{\text {tabla }}=7.31 \text { para un nivel de significación de } \rho<0.01
\end{gathered}
$$


El nivel de significación es $\rho<0.01$, está por debajo de la probabilidad que proponen los investigadores en educación como máximo valor aceptable esto es $\rho<0.05$, entonces se puede rechazar la hipótesis nula y aceptar la de investigación en los casos de las variables $A$ y $B$, más no en el caso de la intercepción en donde el valor encontrado es muy pequeño $\left(F_{\mathrm{AB}(1,52)}=0.056\right)$ por lo que en este caso se acepta la hipótesis nula y se rechaza la de investigación.

\subsection{Prueba ANOVA Bifactorial (independiente) utilizando el programa SPSS}

El programa SPSS para esta prueba permite determinar el nivel de significación comparándolo con el nivel mínimo utilizado por los investigadores en educación que corresponde a $\rho<0.05$, si el que se determina mediante el proceso del programa resulta mayor que este valor, entonces se puede decir que las diferencias de los resultados son causados por variables aleatorias y se debe aceptar la hipótesis nula, pero si el valor es menor entonces las diferencias son significativas y se debe rechazar la hipótesis nula y aceptar la hipótesis de investigación.

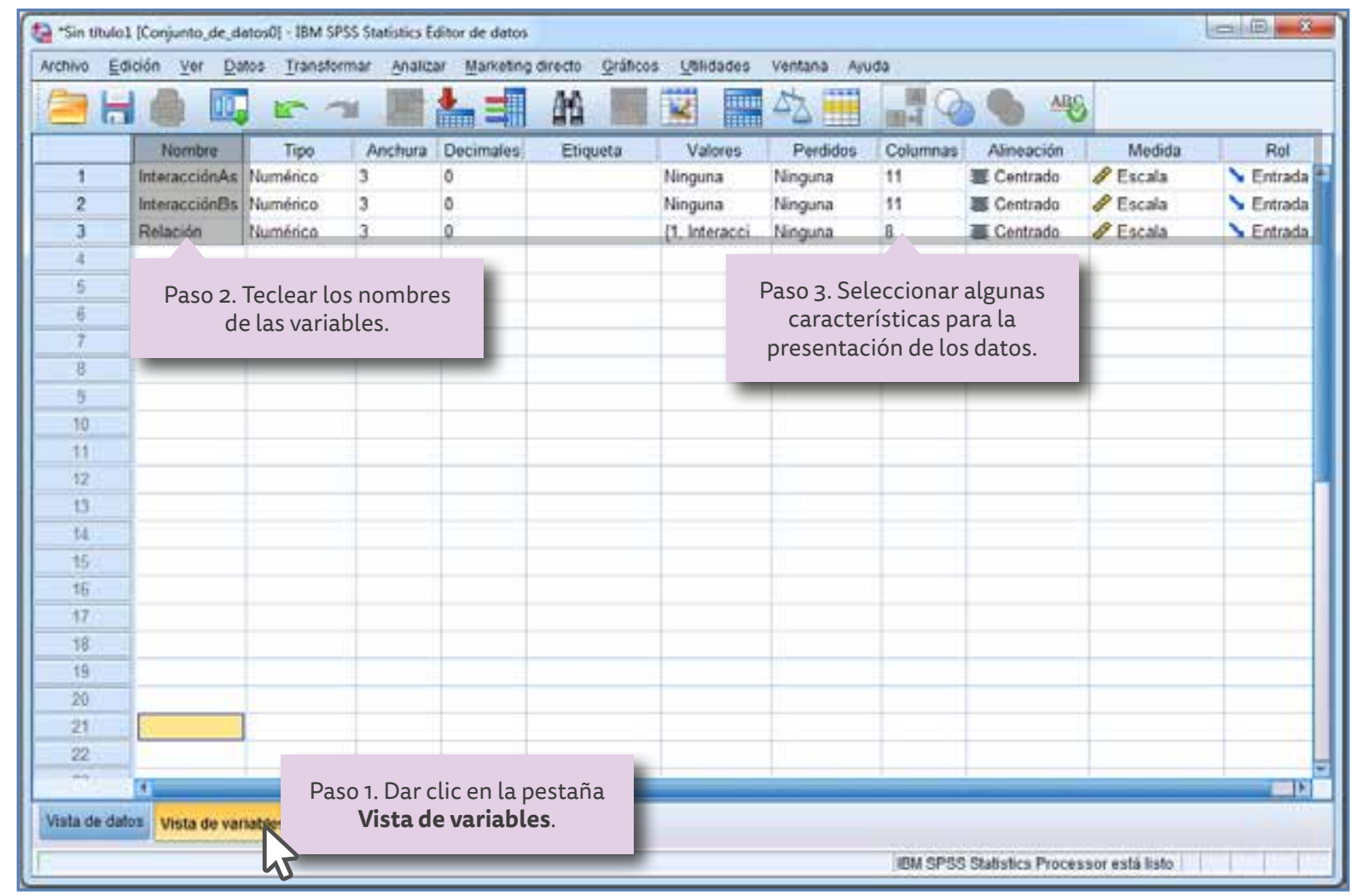

Figura 96. Designación de nombre de las variables y características de presentación para la prueba ANOVA Bifactorial (independiente).

El primer paso consiste en otorgarle las propiedades a las variables, una vez abierto el programa y antes de introducir los datos, es necesario definir las variables y otorgarle las características para su presentación en la tabla, para lo cual se requiere dar clic en la pestaña Vista de variables.

En el caso de la prueba ANOVA Bifactorial cuando se trata de muestras relacionadas o independientes los valores de los datos obtenidos se deben colocar en una misma columna por cada variable ( $\mathrm{A}$ y $B$ ) que en este caso se les designará como InteracciónAs (variable Asujeto) e InteracciónBs (variable Bsujeto) y la tercera columna se denomina como Relación en donde se especifica cuáles son los datos de la columna 1 y 2 que corresponden a las condiciones 1 y 2. 
En este caso se teclea en el primer espacio para Nombre (ver Figura 96), el de la primera variable InteracciónAs, recordando que no debe haber espacios vacíos entre los caracteres, se deben anotar las dos condiciones que se muestran en la Tabla 24, colocando primero los correspondientes a $A_{1}$ en donde se encuentran ubicados los resultados obtenidos por cada sujeto, y se completa con la columna $A_{2}$ obteniéndose un total de 52 datos ( 26 por cada columna).

El nombre de la segunda variable InteracciónBs corresponden a los obtenidos en la Tabla 24, se debe seguir el mismo proceso que para la variable InteracciónAs pero ahora con los datos de $\mathrm{B}_{1}$ y $\mathrm{B}_{2}$.

El siguiente paso es introducir el nombre de la tercer columna en el espacio 3 de la columna Nombre, los cuales se denominan con el término de Relación (variable de agrupación) en este caso se utilizan dos valores 1 para indicar que se refiere a los datos correspondientes a la Condición $1\left(A_{1}\right.$ y $\left.B_{1}\right)$, y el 2 para la Condición $2\left(A_{2}\right.$ y $\left.B_{2}\right)$.

Una vez designados los nombres de las variables y sus características se procede a introducir los datos en la tabla; para llevar a cabo esto es necesario dar clic en la pestaña Vista de datos e introducirlos (ver Figura 97) de la siguiente manera:

- En la columna uno (InteracciónAs) se introducen los valores de los datos obtenidos por el grupo en la Tabla 24, primero los correspondientes al valor de $A_{1}\left(A_{1} B_{1}\right.$ y $\left.A_{1} B_{2}\right)$ seguidos por los correspondientes al valor de $A_{2}\left(A_{2} B_{1}\right.$ y $\left.A_{2} B_{2}\right)$.

- En la columna dos (InteracciónBs) se introducen los valores de los datos obtenidos por el grupo en la Tabla 24, primero los correspondientes al valor de $B_{1}\left(B_{1} A_{1}\right.$ y $\left.B_{1} A_{2}\right)$ seguidos por los correspondientes al valor de $B_{2}\left(B_{2} A_{1}\right.$ y $\left.B_{2} A_{2}\right)$.

- En la columna tres (Relación) se introduce el valor de 1 para todos los datos que correspondan a la condición $\left(A_{1}\right.$ y $\left.B_{1}\right)$, el valor de 2 para los datos correspondientes a la Condición 2 $\left(A_{2}\right.$ y $\left.B_{2}\right)$.

En el siguiente cuadro se observan las variables seleccionadas en este ejemplo:

Cuadro 28. Designación de variables para la prueba ANOVA Bifactorial (no relacionada).

\begin{tabular}{l|l|l}
\hline Nombre: InteracciónAs & Nombre: InteracciónBs & Nombre: Relación \\
\hline Tipo: Numérico & Tipo: Numérico & Tipo: Numérico \\
\hline $\begin{array}{l}\text { Anchura: 3 } \\
\text { Decimales: } 0\end{array}$ & Anchura: 3 & Anchura: 3 \\
\hline Etiqueta: Ninguna & Decimales: 0 & Decimales: o \\
\hline Valores: Ninguno & Etiqueta: Ninguna & Etiqueta: 1 Interacción A1, B1 \\
\hline Perdidos: Ninguno & Valores: Ninguno & Valores: Ninguno \\
\hline Columnas: 8 & Perdidos: Ninguno & Perdidos: Ninguno \\
\hline Alineación: Centrado & Columnas: 8 & Columnas: 8 \\
\hline Medida: Escala & Alineación: Centrado & Alineación: Centrado \\
\hline Rol: Entrada & Medida: Escala & Medida: Escala \\
\hline & Rol: Entrada & Rol: Entrada
\end{tabular}

Una vez que los datos se encuentran en la tabla, se realiza la prueba; para hacerlo es necesario dar clic en la pestaña ubicada en la barra superior designada como Analizar, en seguida aparece un cuadro de diálogo, en la cual se selecciona la línea que indica Modelo lineal general, en este caso no se selecciona comparar medias debido a que el programa SPSS no tiene la opción de ANOVA Bifactorial por lo que se recurre a un proceso general para obtener una buena aproximación de los resultados requeridos; al ubicar el apuntador del ratón en esta opción se presenta a la derecha otro cuadro de diálogo, se selecciona Multivariante (que son las que corresponden a dos variables independientes o más) y se da clic con el ratón (Ver Figura 98). 


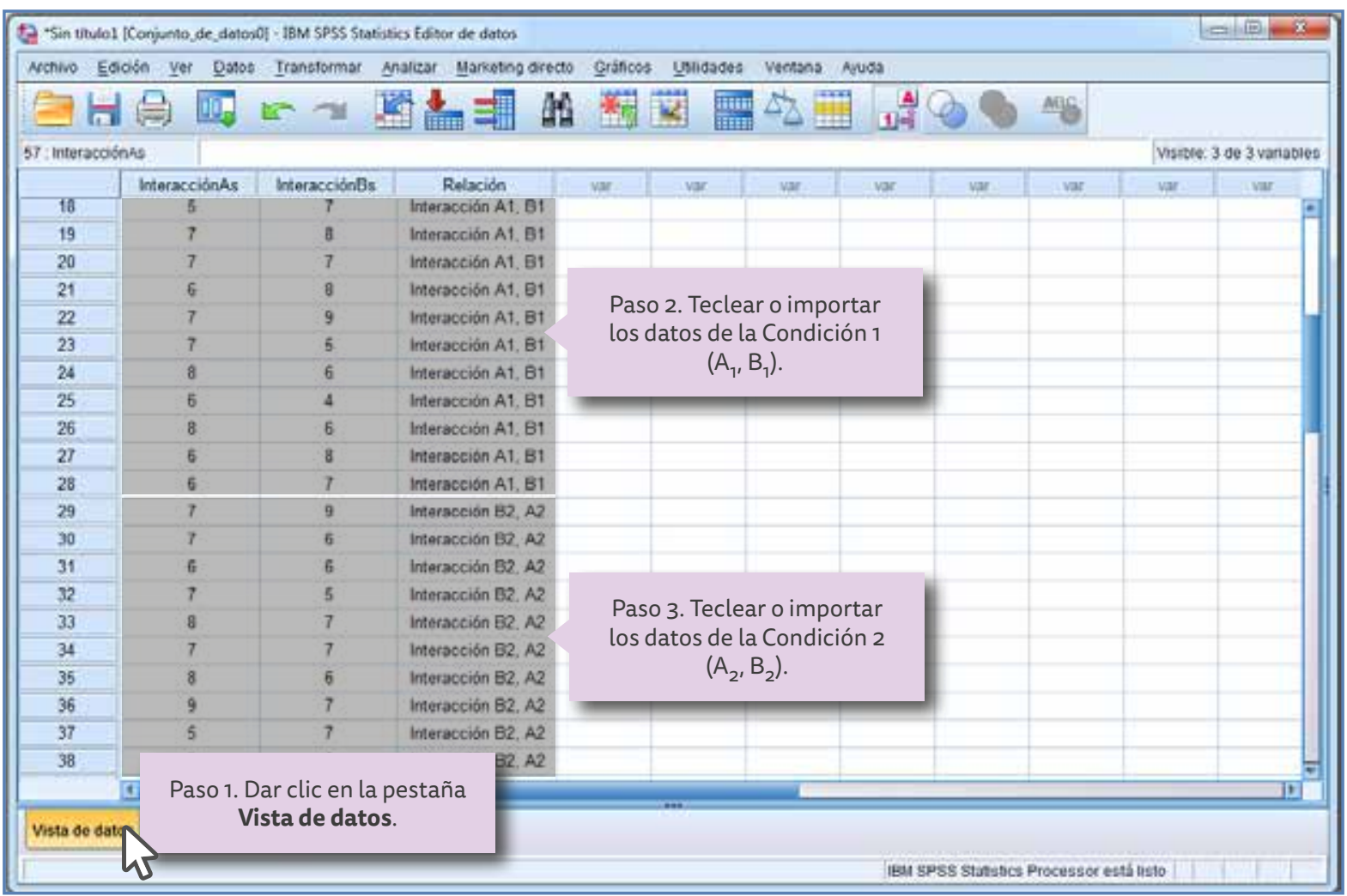

Figura 97. Presentación de los datos arrojados por los participantes.

\begin{tabular}{|r|l|l|l|l|l|l|l|}
\hline Archivo & Paso 1. Dar clic en \\
\hline
\end{tabular}

Figura 98. Cuadros de diálogo para seleccionar la prueba paramétrica de dos variables independientes para muestras no relacionadas.

Aparecerá una ventana (ver Figura 99) en la cual se muestran las variables del lado izquierdo, InteracciónAs, InteracciónBs y Relación; las dos primeras deben ser trasladadas a la ventana que dice Variables dependientes; la forma de hacerlo es seleccionando con un clic la variable deseada (InteracciónAs) y después en la flecha superior que se ubica entre las dos ventanas. Se repite este proceso para la variable siguiente (InteracciónBs). 


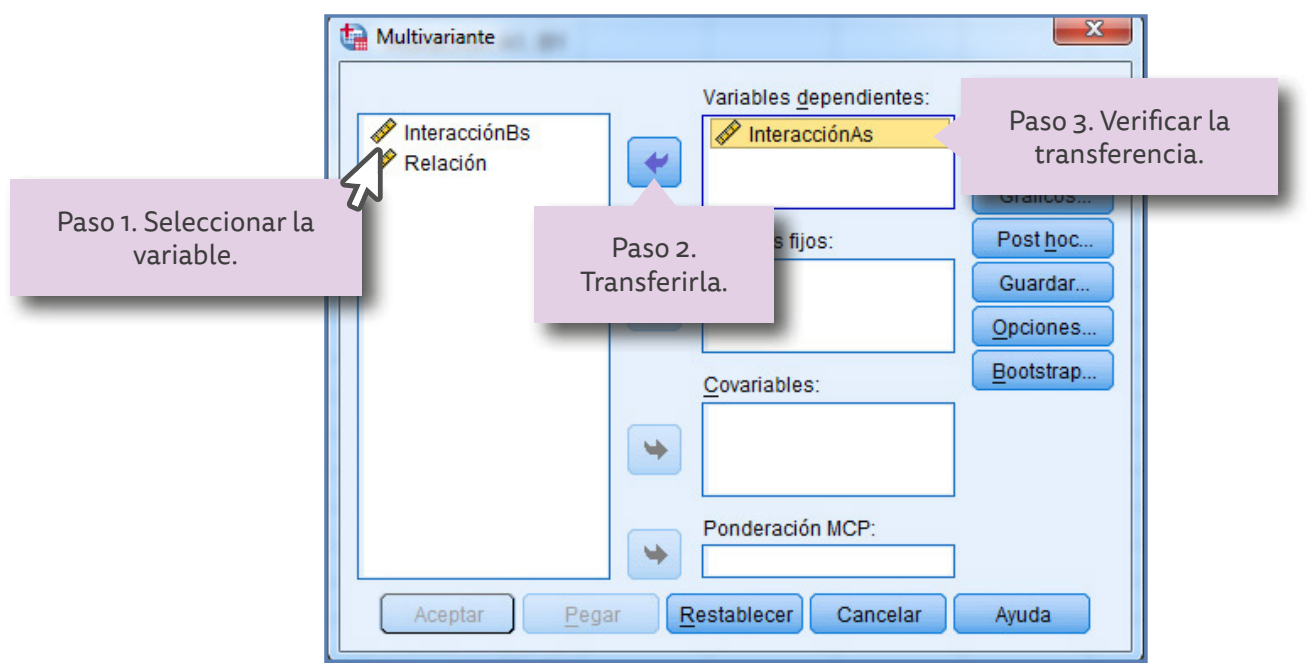

Figura 99. Paso para ingresar las variables Interacción Asy Bs al programa SPSS.

Para trasladar la otra variable (Relación) se selecciona y se da un clic en la flecha inferior que se encuentra entre las ventanas, después se traslada a la ventana designada como Factores fijos.

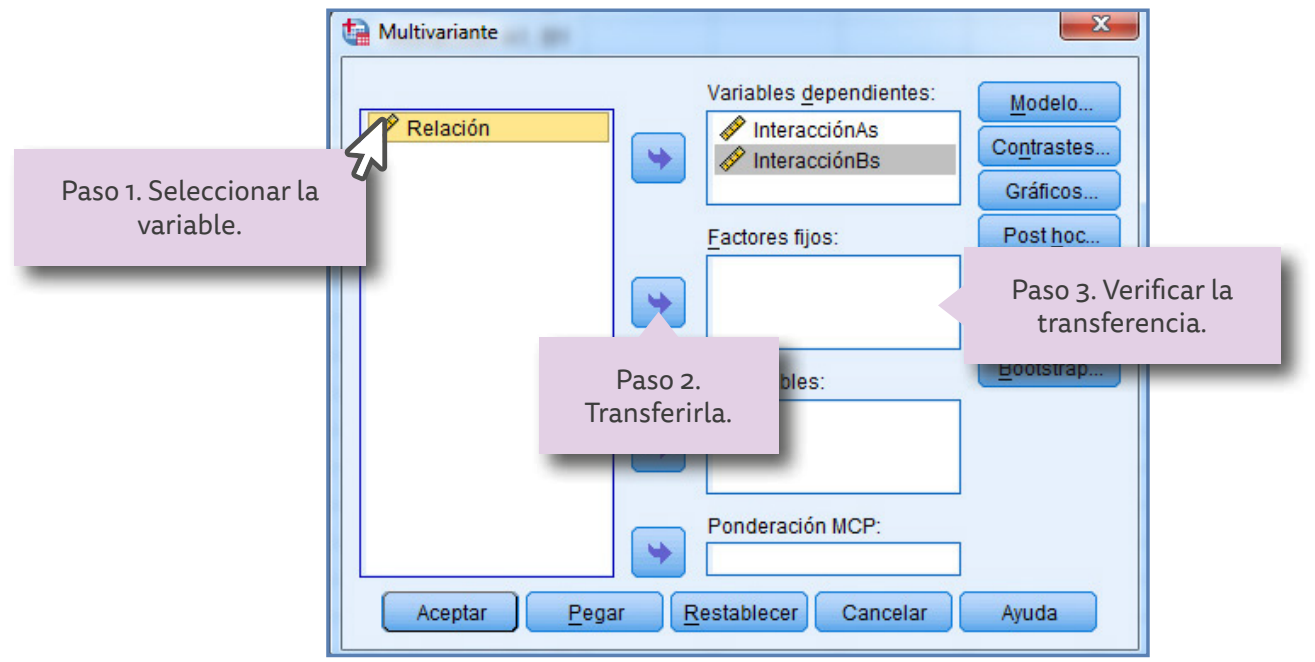

Figura 100. Pasos para ingresar las variables Relación al programa SPSS.

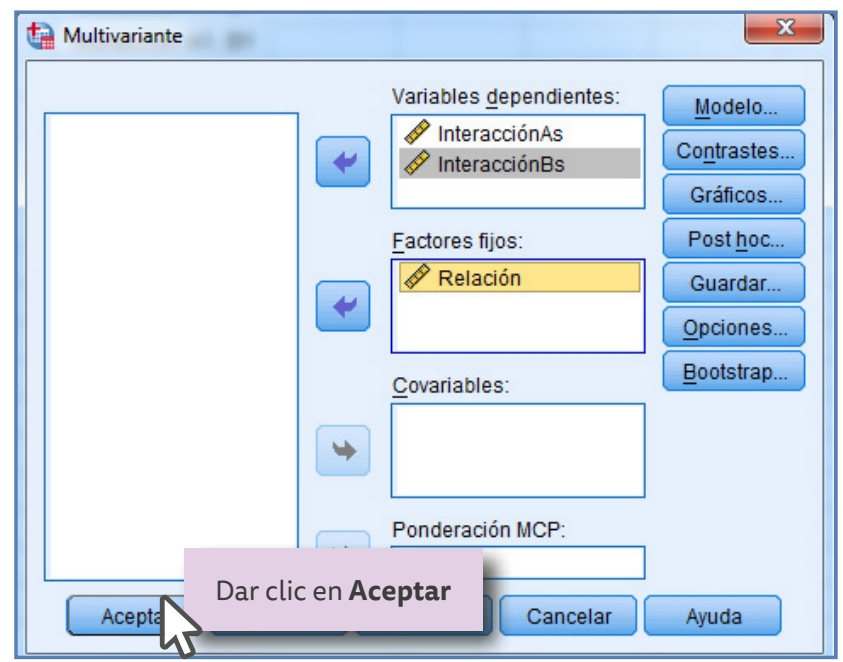

Figura 101. Pasos para ejecutar el programa SPSS para que realice los cálculos requeridos. 
Efectuadas estas acciones, el programa queda listo para arrojar los resultados, al activar el botón Aceptar (Figura 101) se obtienen los resultados que se muestran en el Cuadro 29, en el cual se observa el valor del nivel de significación [Significación asintótica] para As es $\rho<0.009$ y para Bs es $\rho<0.016$.

$$
\text { Se puede concluir que } \rho_{\text {encontrada }} \text { As } 0.009<\text { Bs } 0.016<\rho_{\text {aceptada }} 0.05
$$

Es decir, los valores encontrados son menores que el mínimo aceptable por los investigadores en educación (0.05), lo que significa que los resultados de la diferencia no son aleatorios puesto que existe una diferencia significativa, por lo que se puede rechazar la hipótesis nula y aceptar la hipótesis de investigación.

También se puede observar que el valor de $F$ calculado por medio del programa es mayor que el valor crítico de la Tabla $\mathrm{H}(1)$ para $\rho<0.05$.

$$
\begin{aligned}
& F_{\mathrm{A}(1,52)}=7.314 \text { (es mayor que) }>F_{\text {Tabla }}=4.08 \text { para un nivel de significación de } \rho<0.05 \\
& F_{\mathrm{B}(1,52)}=6.191 \text { (es mayor que) }>F_{\text {Tabla }}=4.08 \text { para un nivel de significación de } \rho<0.05
\end{aligned}
$$

\begin{tabular}{|c|c|c|c|}
\hline \multicolumn{4}{|c|}{ Factores inter-sujetos } \\
\hline & & $\begin{array}{c}\text { Etiqueta del } \\
\text { valor }\end{array}$ & $\mathrm{N}$ \\
\hline Relación & 1 & $\begin{array}{l}\text { Interacción } \\
\text { A1, B1 }\end{array}$ & 28 \\
\hline & 2 & $\begin{array}{l}\text { Interacción } \\
\text { B2, A2 }\end{array}$ & 28 \\
\hline
\end{tabular}

Cuadro 29. Resultados obtenidos con el programa SPSS para la prueba paramétrica ANOVA Bifactorial para muestras no relacionadas utilizando el procedimiento Multivariante.

\begin{tabular}{|ll|r|r|r|r|r|}
\multicolumn{8}{|c|}{ Contrastes multivariados $^{\mathrm{a}}$} \\
\hline \multirow{3}{*}{ Efecto } & & \multicolumn{1}{|c|}{ Valor } & \multicolumn{1}{c|}{$\mathrm{F}$} & $\begin{array}{c}\text { Gl de la } \\
\text { hipótesis }\end{array}$ & Gl del error & \multicolumn{1}{c|}{ Sig. } \\
\hline Intersección & Traza de Pillai & .966 & $763.705^{\mathrm{b}}$ & 2.000 & 53.000 & .000 \\
& Lambda de Wilks & .034 & $763.705^{\mathrm{b}}$ & 2.000 & 53.000 & .000 \\
& Traza de Hotelling & 28.819 & $763.705^{\mathrm{b}}$ & 2.000 & 53.000 & .000 \\
& Raiz mayor de Roy & 28.819 & $763.705^{\mathrm{b}}$ & 2.000 & 53.000 & .000 \\
\hline Relación & Traza de Pillai & .134 & $4.099^{\mathrm{b}}$ & 2.000 & 53.000 & .022 \\
& Lambda de Wilks & .866 & $4.099^{\mathrm{b}}$ & 2.000 & 53.000 & .022 \\
& Traza de Hotelling & .155 & $4.099^{\mathrm{b}}$ & 2.000 & 53.000 & .022 \\
& Raiz mayor de Roy & .155 & $4.099^{\mathrm{b}}$ & 2.000 & 53.000 & .022 \\
\hline
\end{tabular}

a. Diseño: Intersección + Relación

b. Estadístico exacto

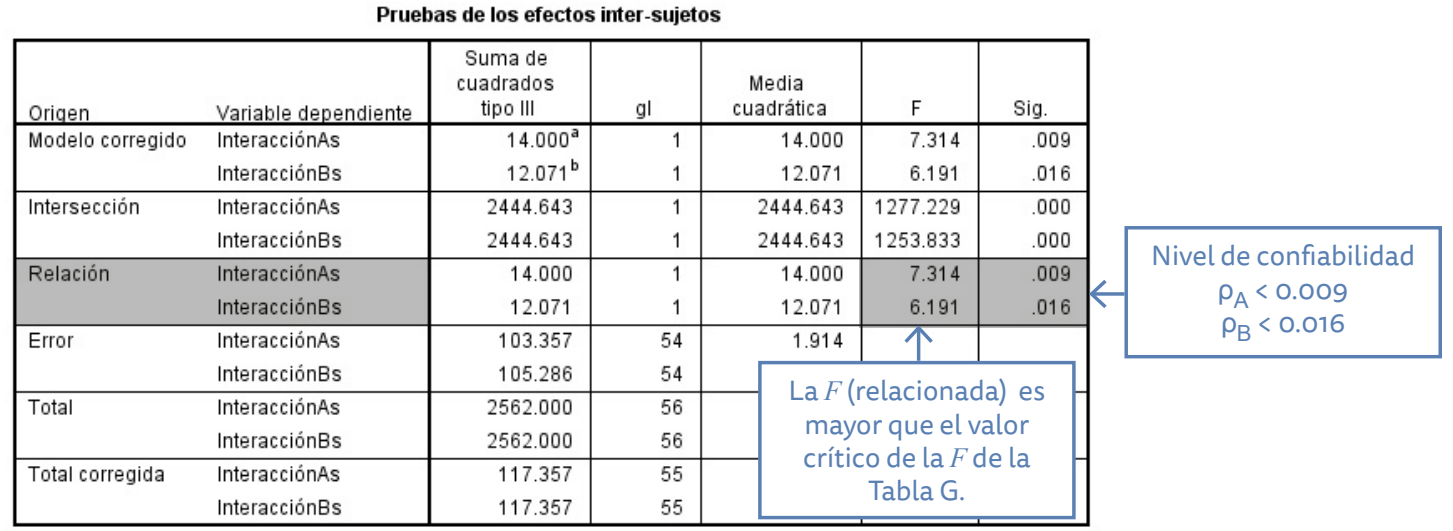

a. $\mathrm{R}$ cuadrado $=.119$ ( $\mathrm{R}$ cuadrado corregida $=.103)$

b. $\mathrm{R}$ cuadrado $=.103$ ( $\mathrm{R}$ cuadrado corregida $=.086$ ) 
Hi: Si se utilizan diferentes frecuencias de retroalimentación (continua e intermitente) y distintos procedimientos (tradicional y constructivista) durante la realización de experimentos en la materia de Física, los alumnos de primer grado de secundaria retendrán mejor el conocimiento, si la frecuencia de retroalimentación es intermitente y el experimento es de corte constructivista.

\subsection{Comprobación de interacciones por medio de gráficas}

Los datos gráficos representan una forma para determinar si existe interacción entre las dos variables. Para confirmarla se lleva a cabo un procedimiento que consiste en trazar líneas que conecten los valores de las medias obtenidas para las variables $A_{1}$ y $A_{2}$ en su interacción con las variables $B_{1}$ y $B_{2}$, esto es:

- $A_{1}$ que corresponde a trabajar con retroalimentación continua para las dos condiciones de $\mathrm{B}_{1}$ "Experimentos tradicionales" y $\mathrm{B}_{2}$ "Experimentos constructivistas" $\mathrm{y}$

- $\quad A_{2}$ que corresponde a trabajar con retroalimentación intermitente para las dos condiciones de $\mathrm{B}_{1}$ "Experimentos tradicionales" y $\mathrm{B}_{2}$ "Experimentos constructivistas".

Si las pendientes se mantienen iguales significa que no hay indicios de interacción entre las dos variables lo que significa que en las dos condiciones el grupo muestra los mismos niveles de mejora debido al tipo de problemas resueltos.

Por otro lado, si los valores de las pendientes son diferentes significa que es muy probable que exista una interacción entre las variables como consecuencia de un efecto causado por una variable sobre la otra.

\subsection{Elaboración de las gráficas por medio del programa SPSS}

El primer paso consiste en introducir los nombres de los datos, se abre el programa y se selecciona la pestaña Vista de variables, se coloca en la primer columna estos nombres MediasA1, MediasA2 y VariablesB1yB2 en los tres espacios correspondientes a la columna Nombre y en seguida se procede a introducir las características correspondientes a cada uno de estos (ver Figura 102).

Una vez designados los nombres de las variables y sus características se introducen los datos en la tabla; para llevar a cabo esto se requiere dar clic en la pestaña Vista de datos e introducirlos (ver Figura 103) de la siguiente manera:

- En la columna uno (MediasA1) se introducen los valores de las medias para la Variable $A_{1}$ esto es $B_{1}=5.50$ y $B_{2}=6.71$ (Tabla 23).

- En la columna uno (MediasA2) se introducen los valores de las medias para la Variable $A_{2}$ esto es $B_{1}=6.78$ y $B_{2}=7.42$.

- En la columna tres (VariablesB1yB2) se introduce el valor de 1 para todos los datos que correspondan a la condición $\left(B_{1}\right)$, el valor de 2 para los datos correspondientes a la Condición $2\left(B_{2}\right)$.

Una vez que los datos se encuentran en la tabla se realiza la gráfica, para hacerlo es necesario dar clic en la pestaña ubicada en la barra superior designada como Gráficos, en seguida aparece un cuadro de diálogo, en la cual se selecciona la línea que indica Cuadro de diálogo antiguo, y en seguida el tipo de gráfica que se desea utilizar, en este caso Líneas y se da clic con el ratón (Ver Figura 104). 


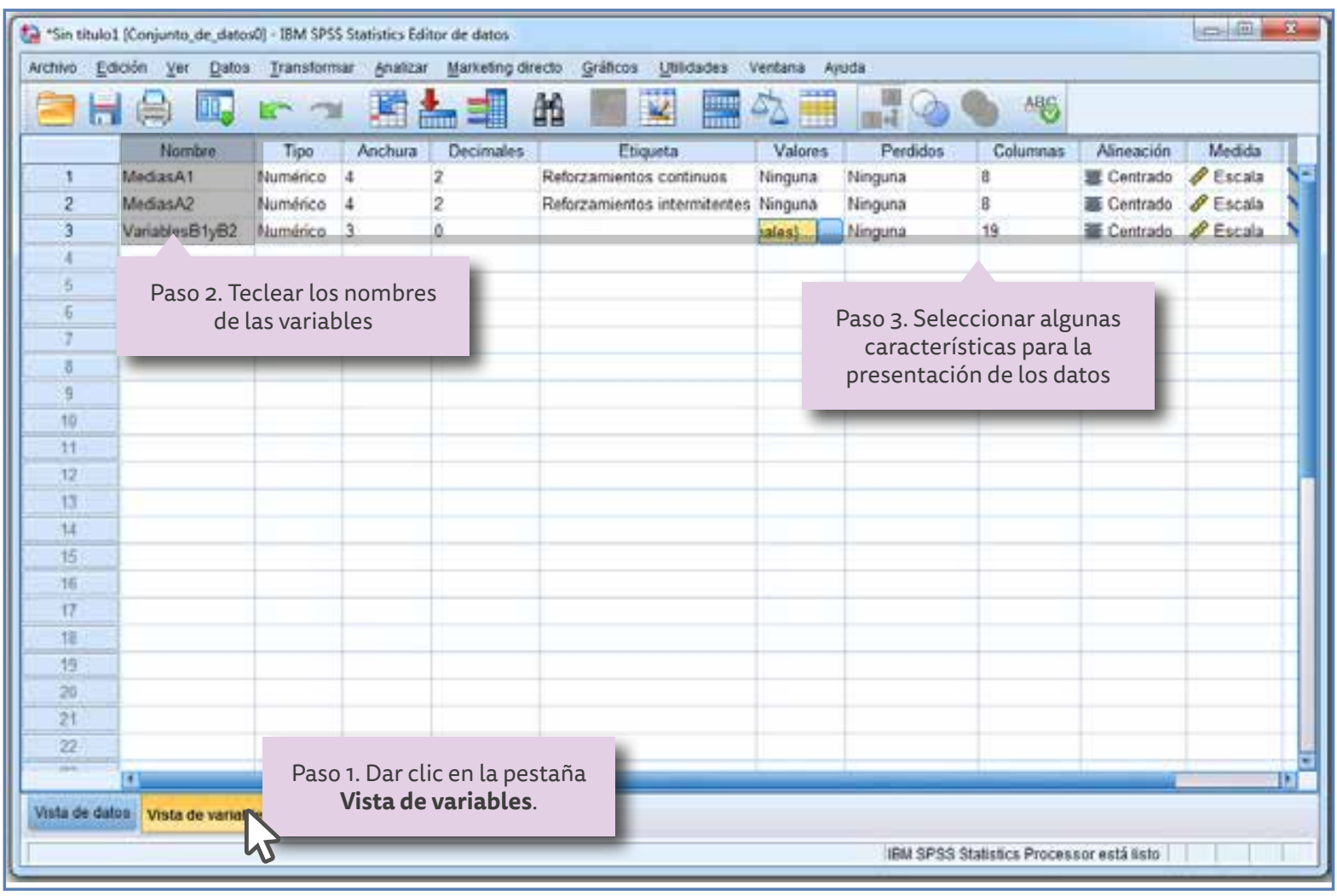

Figura 102. Designación de nombre de las variables y características de presentación para la elaboración de las gráficas.

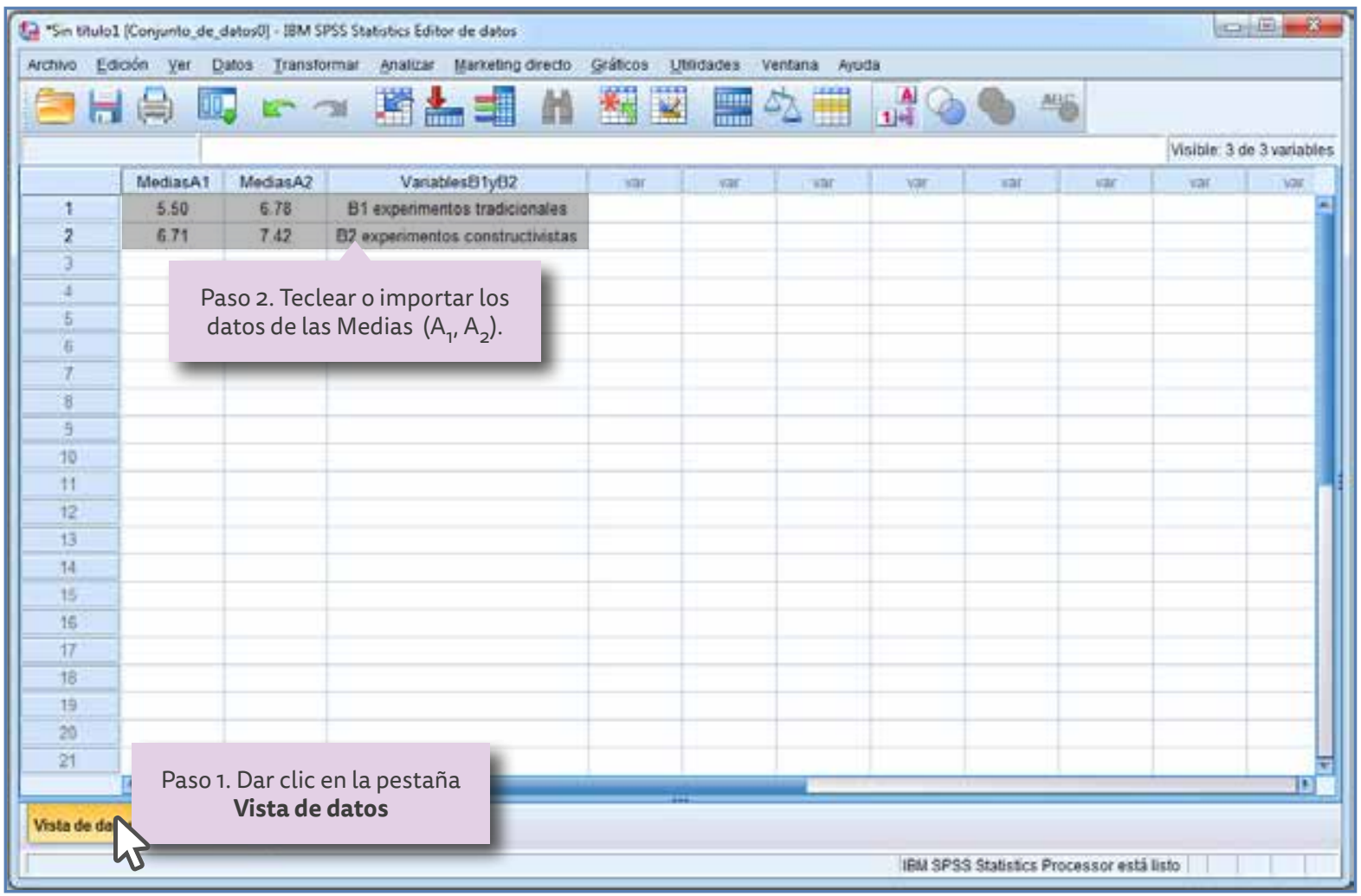

Figura 103. Presentación de los valores de las medias correspondientes. 


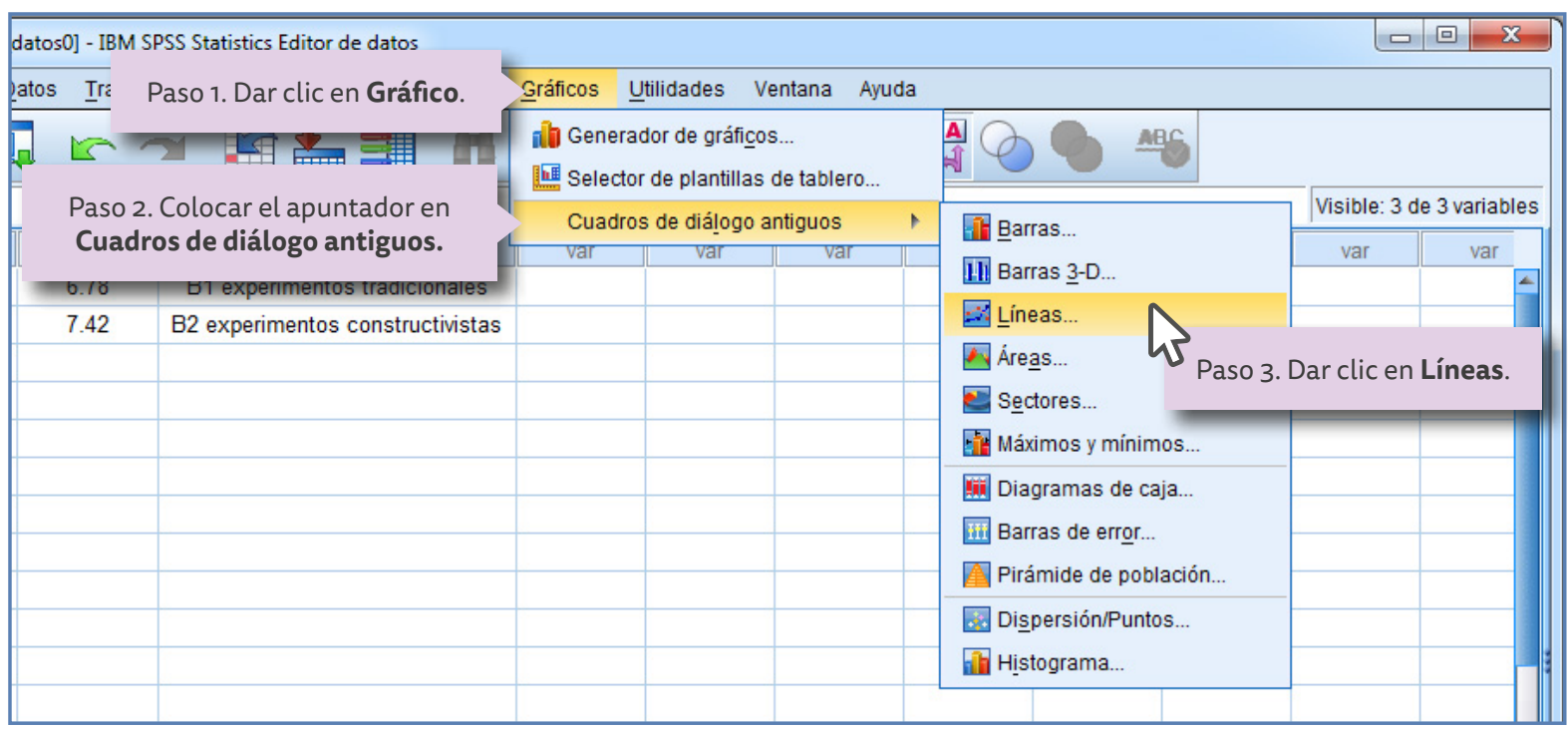

Figura 104. Cuadros de diálogo para seleccionar la prueba paramétrica de dos variables independientes para muestras no relacionadas.

Con el clic se activa una ventana en la que es necesario seleccionar la opción Múltiple y activar el botón de selección Resúmenes para distintas variables para finalmente dar clic en Definir.

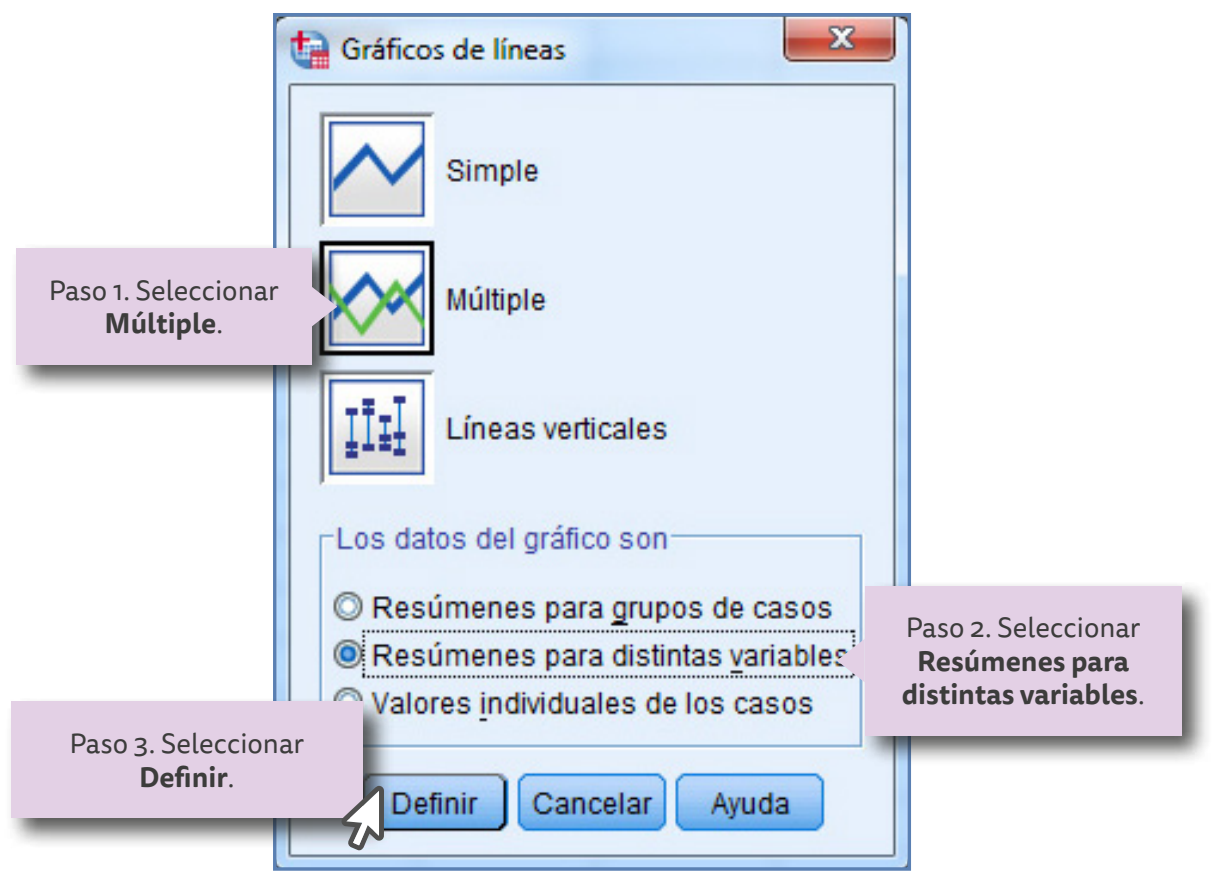

Figura 105. Cuadros de diálogo para seleccionar el tipo de gráficas que se desean representar.

Al realizar esta última acción aparece otra ventana en la que es necesario trasladar los datos simulados, abstractos y los datos experimentales, reales a la ventana denominada Las líneas representan, se seleccionan y trasladan con la flecha correspondiente; una vez realizado esto se trasladan las variablesB1yB2 a la ventana designada como Eje de categorías, se seleccionan las variables y se trasladan con la flecha correspondiente (Figura 106). 


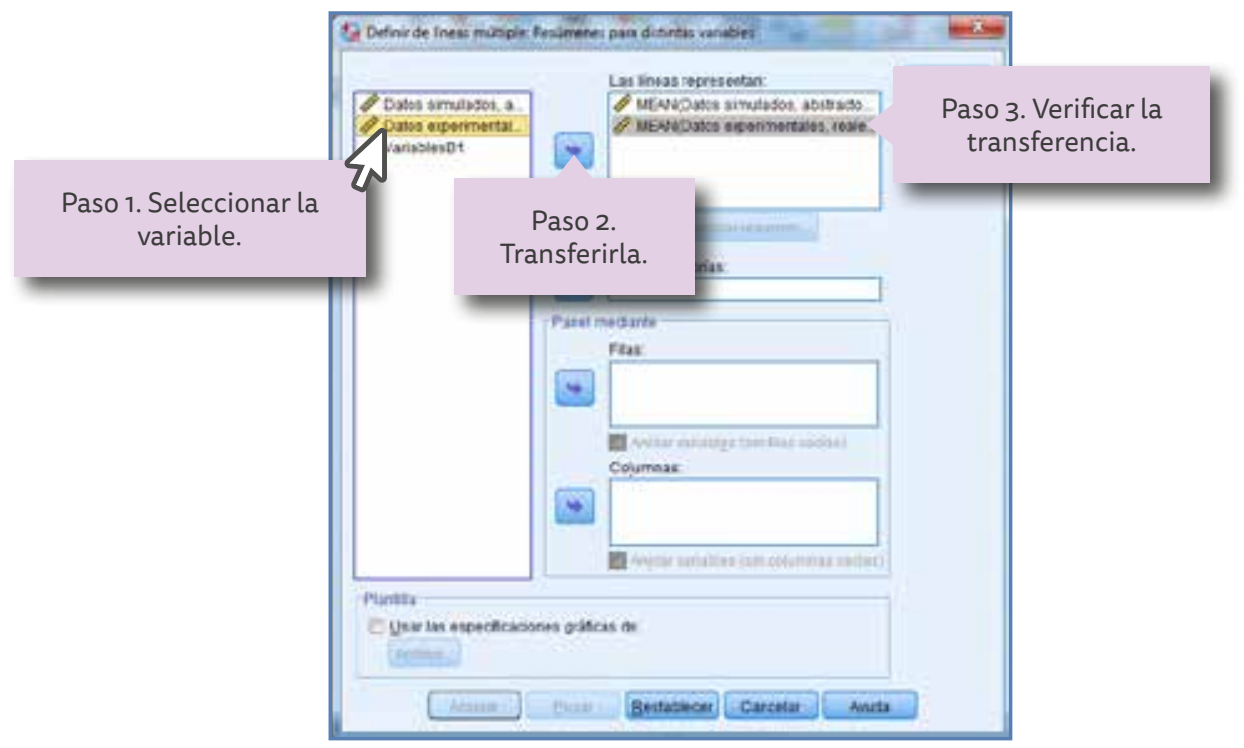

Figura 106. Cuadros de diálogo para definir los parámetros para graficar las líneas que representan.

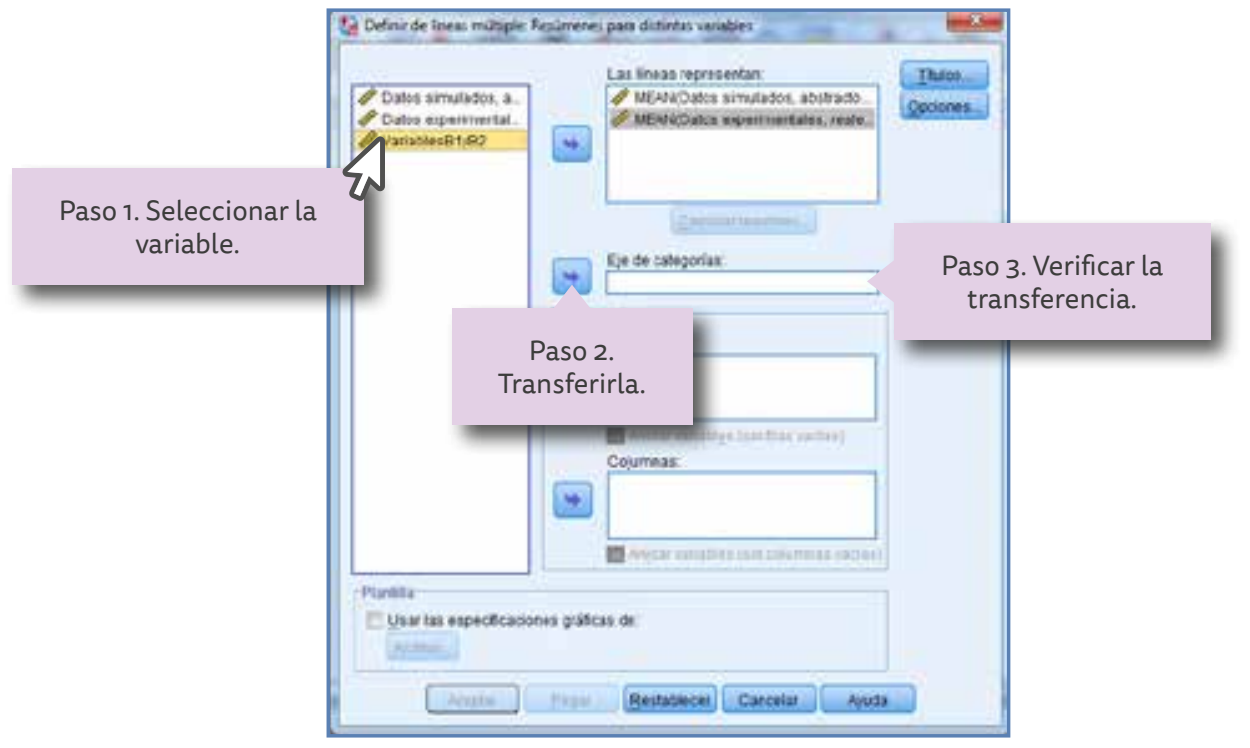

Figura 107. Cuadros de diálogo para definir los parámetros para graficar el Eje de categorías.

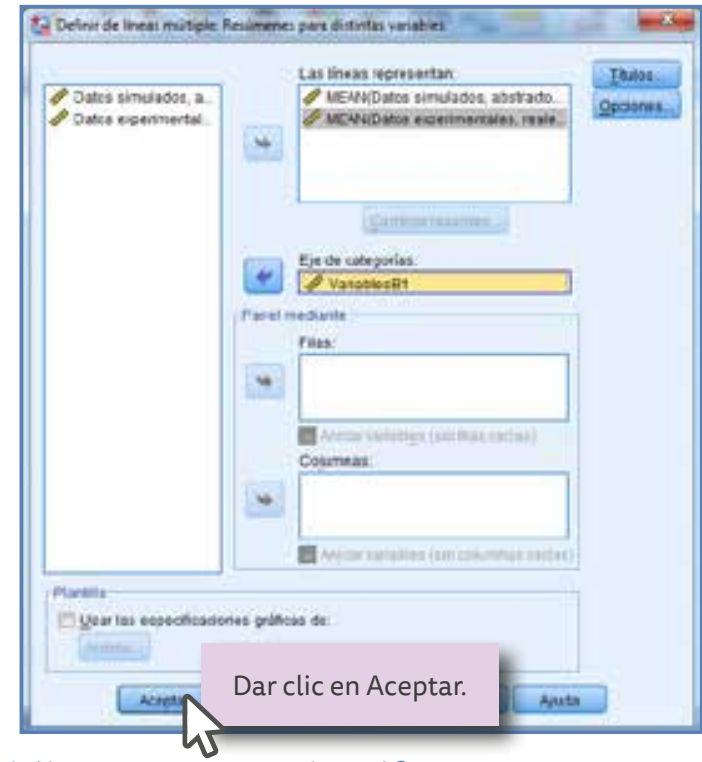

Figura 108. Cuadros de diálogo para generar la gráfica. 
En el siguiente cuadro se observan las variables seleccionadas en este ejemplo:

Cuadro 30. Designación de variables para la prueba ANOVA Bifactorial (no relacionada).

\begin{tabular}{l|l|l|}
\hline Nombre: MediasA1 & Nombre: MediasA2 & Nombre: VariablesB1yB2 \\
\hline Tipo: Numérico & Tipo: Numérico & Tipo: Numérico \\
\hline Anchura: 4 & Anchura: 4 & Anchura:3 \\
\hline $\begin{array}{l}\text { Decimales: } 2 \\
\text { Etiqueta: } \text { Reforzamiento } \\
\text { continuo }\end{array}$ & $\begin{array}{l}\text { Decimales: } 2 \\
\text { Etiqueta: } \text { Reforzamiento } \\
\text { intermitente }\end{array}$ & $\begin{array}{l}\text { Decimales: } 0 \\
\text { Etiqueta: Ninguna }\end{array}$ \\
\hline $\begin{array}{l}\text { Valores: Ninguno } \\
\text { Perdidos: Ninguno }\end{array}$ & Valores: Ninguno & $\begin{array}{l}\text { Valores: } 1 . \text { B1 Experimento tradicional } \\
\text { 2. B2 Experimento Constructivista }\end{array}$ \\
\hline Columnas: 8 & Perdidos: Ninguno & Perdidos: Ninguno \\
\hline Alineación: Centrado & Columnas: 8 & Columnas: 8 \\
\hline Medida: Escala & Alineación: Centrado & Alineación: Centrado \\
\hline Rol: Entrada & Medida: Escala & Medida: Escala \\
\hline & Rol: Entrada & Rol: Entrada
\end{tabular}

En la Gráfica 16 el tipo de experimento (tradicional y constructivista) se representa en el eje horizontal y las líneas representan el tipo de retroalimentación (continua e intermitente). Las líneas de los valores medios de los resultados de la retención del conocimiento para la retroalimentación intermitente fue superior a la retroalimentación continua.

Por otro lado, los valores de las pendientes de las líneas indican una cierta tendencia de interacción entre las dos variables (frecuencia, retroalimentación y tipo de experimento), con una baja probabilidad de que una variable tiene efecto sobre la otra a causa de la diferencia en las pendientes.

\section{Gráfica 16. Gráfica $2 \times 2$ para ANOVABifactorial para muestras independientes.}

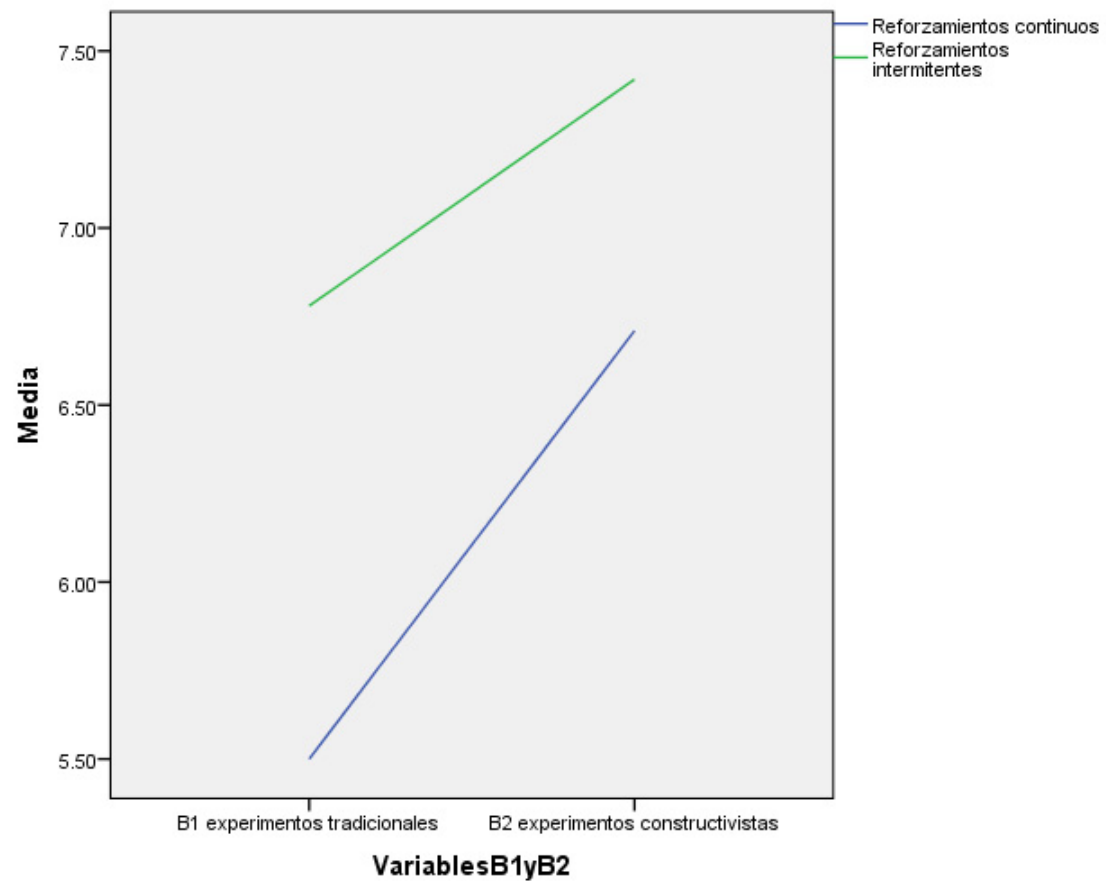




\section{PARTE VII \\ ¿Cómo relacionar las variables?}





\section{Capítulo 15}

15. Prueba de Chi-Cuadrado

La prueba Chi-cuadrado no analiza los resultados, en este caso, las dos variables se representan como categorías y los datos son nominales. Es decir, la medida del comportamiento de los participantes sometidos a estas variables se determina por las categorías que se les asignen.

Ejemplo 90. Se trata de aceptar o rechazar la siguiente hipótesis de investigación: Hi: Si los alumnos participan en un programa de formación de usuarios de la biblioteca, entonces conocerán un mayor número de servicios que ofrece la biblioteca con relación a los alumnos que no participan.

\subsection{Estado situacional}

Los aspectos que motivaron a realizar esta investigación en el nivel universitario, tuvieron origen al observar las dificultades a las que se enfrentan los usuarios de la biblioteca, principalmente los estudiantes, debido a la falta de conocimientos y habilidades en el proceso de obtención de la información, independientemente de la licenciatura que cursen.

Se aplicó un examen diagnóstico en el cual los resultados obtenidos pusieron de manifiesto que los estudiantes ingresan al nivel de licenciatura con escaso o nulo conocimiento de los servicios ofrecidos en las bibliotecas y más de una biblioteca especializada, como es el caso de las bibliotecas universitarias, así como también el poco conocimiento de las habilidades informativas y el desconocimiento de las Tecnologías de la Información y la Comunicación (TIC) aplicadas en el uso y manejo bibliotecario.

En este caso se trata de determinar si los participantes tienen más facilidad de utilizar los servicios de la biblioteca cuando participan dentro de un programa de capacitación. Por ejemplo, observar cuántos servicios que ofrece la biblioteca conoce el participante con y sin la capacitación.

Se seleccionaron 60 participantes, 31 estudiantes conformaron el grupo experimental y 29 estudiantes conformaron el grupo de referencia, sólo el grupo experimental participó en el proceso de capacitación bibliotecnológica; el grupo de referencia siguió utilizando los servicios de la biblioteca en forma cotidiana.

Se elaboró la encuesta para comprobar si existen diferencias significativas referente a los conocimientos sobre el uso y las habilidades informativas requeridas para desenvolverse con eficiencia dentro de la biblioteca, entre el grupo experimental y el de referencia. 


\section{Cuadro 31. Pregunta 1 de la encuesta dirigida a usuarios de la biblioteca.}

1. ¿Del listado siguiente, qué servicios conoces que ofrece la biblioteca?

- Circulación (préstamo externo de libros y expedición de credenciales).

- Referencia (orientación básica y especializada a usuarios).

- Préstamo de computadoras de procesadores de palabras e Internet.

- Publicaciones periódicas (préstamo de revistas, periódicos y disco compactos).

- Colecciones especiales.

- Catálogo Local del Centro Universitario al que ingresó.

- Catálogo Público en línea que incluye el acervo de las bibliotecas de todos los Centros Universitarios.

Ninguna

1 a 3

4 a 6 Todos

Para comprobar la hipótesis particular de este ejemplo sólo se van a analizar las respuestas a la pregunta 1, designándole un valor numérico a cada opción de respuesta de la siguiente manera:

Tabla 26. Relación del número de opción con el valor asignado de la pregunta 1.

\section{1. ¿Del listado siguiente, qué servicios conoces que ofrece la biblioteca?}

Número de opción

Ninguno

De 1 a 3

De 4 a 6

Todos
Número asignado

1

2

3

4

Los principales recursos didácticos que se propusieron a emplear fueron los medios impresos como:

- Trípticos. Contienen las guías sobre los servicios, horarios, planos de localización y reglamentos; señalización que permite identificar fácilmente al usuario las áreas constitutivas de la biblioteca;

- Charlas informativas y el establecimiento de visitas guiadas;

- Presentación de los servicios como parte del Curso de inducción que obligadamente reciben los alumnos de primer ingreso.

En la Tabla 27 se muestran los resultados obtenidos de la aplicación de la encuesta y la designación correspondiente a cada una de las opciones de acuerdo a la codificación de la Tabla 26.

\subsection{Explicación}

Las frecuencias esperadas se calculan teniendo en cuenta los totales relevantes que reflejan los porcentajes de los 29 estudiantes de referencia y los 31 estudiantes del grupo experimental, de los que se esperaría que estuvieran dentro de una de las cuatro opciones de categorías del número de servicios que conoce, si fuera igual de probable que todos los estudiantes estuvieran dentro de las cuatro categorías (Greene y D'oliveira, 2006).

Las frecuencias esperadas se comparan con las hipótesis nulas de frecuencias esperadas y si son significativamente distintas las primeras de las segundas se puede descartar la hipótesis nula.

Como se mencionó al inicio de este capítulo sólo se puede utilizar cuando se asignan categorías a los participantes y los datos son nominales, ya que sólo analiza categorías, no resultados. 
Tabla 27. Relación de respuestas a la pregunta 1 (Grupo experimental y de referencia).

\begin{tabular}{|c|c|c|c|c|}
\hline № & $\begin{array}{c}\text { Grupo de } \\
\text { Referencia opción }\end{array}$ & $\begin{array}{c}\text { Grupo } \\
\text { Experimental } \\
\text { opción }\end{array}$ & $\begin{array}{c}\text { Grupo de } \\
\text { Referencia } \\
\text { designación }\end{array}$ & $\begin{array}{c}\text { Grupo } \\
\text { Experimental } \\
\text { designación }\end{array}$ \\
\hline 1 & ninguno & ninguno & 1 & 1 \\
\hline 2 & ninguno & ninguno & 1 & 1 \\
\hline 3 & ninguno & ninguno & 1 & 1 \\
\hline 4 & ninguno & de 1 a 3 & 1 & 2 \\
\hline 5 & ninguno & de 1 a 3 & 1 & 2 \\
\hline 6 & ninguno & de 1 a 3 & 1 & 2 \\
\hline 7 & ninguno & de 1 a 3 & 1 & 2 \\
\hline 8 & ninguno & de 1 a 3 & 1 & 2 \\
\hline 9 & ninguno & de 4 a 6 & 1 & 3 \\
\hline 10 & ninguno & de 4 a 6 & 1 & 3 \\
\hline 11 & de 1 a 3 & de 4 a 6 & 2 & 3 \\
\hline 12 & de 1 a 3 & de 4 a 6 & 2 & 3 \\
\hline 13 & de 1 a 3 & de 4 a 6 & 2 & 3 \\
\hline 14 & de 1 a 3 & de 4 a 6 & 2 & 3 \\
\hline 15 & de 1 a 3 & de 4 a 6 & 2 & 3 \\
\hline 16 & de 1 a 3 & de 4 a 6 & 2 & 3 \\
\hline 17 & de 1 a 3 & de 4 a 6 & 2 & 3 \\
\hline 18 & de 4 a 6 & de 4 a 6 & 3 & 3 \\
\hline 19 & de 4 a 6 & de 4 a 6 & 3 & 3 \\
\hline 20 & de 4 a 6 & de 4 a 6 & 3 & 3 \\
\hline 21 & de 4 a 6 & todos & 3 & 4 \\
\hline 22 & de 4 a 6 & todos & 3 & 4 \\
\hline 23 & de 4 a 6 & todos & 3 & 4 \\
\hline 24 & de 4 a 6 & todos & 3 & 4 \\
\hline 25 & de 4 a 6 & todos & 3 & 4 \\
\hline 26 & de 4 a 6 & todos & 3 & 4 \\
\hline 27 & todos & todos & 4 & 4 \\
\hline 28 & todos & todos & 4 & 4 \\
\hline 29 & todos & todos & 4 & 4 \\
\hline 30 & & todos & & 4 \\
\hline 31 & & todos & & 4 \\
\hline
\end{tabular}

En la prueba de Chi-cuadrado basta con contar el número de participantes que conocen un determinado número de servicios y los que no los conocen. El número de participantes 
en cada categoría es la medida relevante, a esta medida se le conoce como datos nominales. Esta es la diferencia con los resultados que se usan en otros tipos de investigación. El término "nominal" indica que este tipo de medición solo puede asignar una etiqueta o nombre a las categorías.

En este experimento las etiquetas (nombre) asignadas a las categorías de acuerdo a la pregunta 1 de la encuesta comparativa, son las siguientes:

a. Variable A: Capacitación.

- Categoría 1: Con capacitación.

- Categoría 2: Sin capacitación.

b. Variable B: Número de Servicios que conoce.

- Categoría 1: Ninguno

- Categoría 2: de 1 a 3

- Categoría 3: de 4 a 6

- Categoría 4: Todos

Debido a que los datos se miden como el número de participantes en cada categoría, a los datos nominales también se les conoce como categóricos.

\subsection{Procedimiento para determinar el valor Chi-Cuadrado}

1. Clasificar con los datos de la Tabla 27 el número de servicios que conoce, de acuerdo a las cuatro categorías, y elaborar la tabla de categorías cruzadas que se muestra en la Tabla 28.

Tabla 28. Relación de respuestas a la pregunta 1: ¿Del listado siguiente, qué servicios conoces que ofrece la biblioteca?

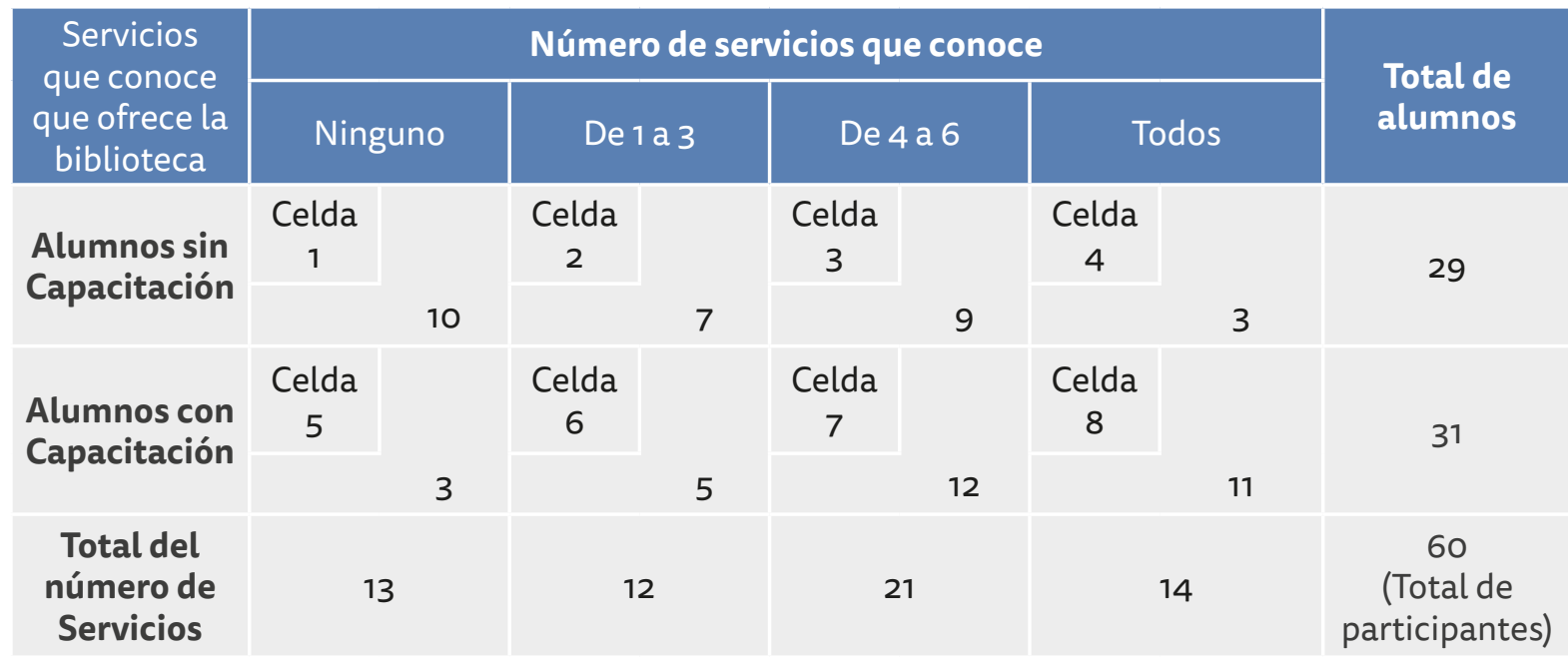

En la tabla anterior se observa que:

- Las cuatro opciones del número de servicios que conoce el estudiante aparecen en la parte superior de la tabla.

- Los dos grupos, el experimental (con capacitación) y el de referencia (sin capacitación) aparecen en la parte izquierda de la tabla.

- Muestra el número de estudiantes que se asignaron a cada una de las cuatro categorías de "opción de servicios".

- Contiene ocho celdas, dos para los grupos de estudiantes y cuatro para el número de servicios que conoce que ofrece la biblioteca $(2 \times 4)$. Numerándose en un recuadro (Celda 1, Celda 2, etc.). 
- En cada celda se indica el número de estudiantes correspondiente a cada categoría. Por ejemplo, en la Celda 1, hay 10 estudiantes sin capacitación, mientras que en la Celda 5, hay tres alumnos con capacitación, que ningún servicio de la biblioteca conocen.

- Estos números se conocen como frecuencias observadas, esto es, el número de cada celda representa la frecuencia de como se clasifica el número de estudiantes en cada una de las cuatro categorías del número de servicios que conoce.

- Los totales de los cuatro números de servicios que conoce se muestran en la parte inferior de la tabla y el total para los dos grupos de estudiantes en la parte derecha.

- En la intercepción de la parte inferior y la derecha de la tabla aparece el total de todos los participantes que es igual a 60, éste resulta de 29 de referencia (sin capacitación) y 31 del experimental (con capacitación).

Las frecuencias observadas de las dos categorías de estudiantes que indicaron las categorías del número de servicios que conoce, se localizan en la Tabla 29. Éstas deben ser comparadas con las frecuencias esperadas, las cuales representan a la hipótesis nula y se calculan sin considerar la posibilidad de que exista una relación entre las dos categorías.

2. Determinar las frecuencias observadas en cada una de las celdas, en este caso se tienen 8 celdas que se numeran del 1 al 8 , entonces se encontraron los siguientes valores:

$$
\begin{aligned}
& \mathrm{O}_{1}=10 \\
& \mathrm{O}_{2}=7 \\
& \mathrm{O}_{3}=9 \\
& \mathrm{O}_{4}=3 \\
& \mathrm{O}_{5}=3 \\
& \mathrm{O}_{6}=5 \\
& \mathrm{O}_{7}=12 \\
& \mathrm{O}_{8}=11
\end{aligned}
$$

3. Calcular las frecuencias esperadas $(E)$ para las celdas 1 a 8 de acuerdo a la Tabla 28 , multiplicando los totales marginales relevantes para cada celda y dividiendo la cifra resultante entre el número total de participantes.

$$
\begin{aligned}
& E_{1}=\frac{(13)(29)}{60}=6.28 \\
& E_{2}=\frac{(12)(29)}{60}=5.80 \\
& E_{3}=\frac{(21)(29)}{60}=10.15 \\
& E_{4}=\frac{(14)(29)}{60}=6.76 \\
& E_{5}=\frac{(13)(31)}{60}=6.71 \\
& E_{6}=\frac{(12)(31)}{60}=6.20 \\
& E_{7}=\frac{(21)(31)}{60}=10.85 \\
& E_{8}=\frac{(14)(31)}{60}=7.23
\end{aligned}
$$


4. Determinar el valor de Chi cuadrado $\left(X^{2}\right)$ usando la siguiente fórmula:

$$
X^{2}=\sum \frac{(O-E)^{2}}{E}
$$

Se pueden reemplazar los datos en la fórmula siguiente:

$$
\begin{gathered}
X^{2}=\frac{\left(O_{1}-E_{1}\right)^{2}}{E_{1}}+\frac{\left(O_{2}-E_{2}\right)^{2}}{E_{2}}+\frac{\left(O_{3}-E_{3}\right)^{2}}{E_{3}}+\frac{\left(O_{4}-E_{4}\right)^{2}}{E_{4}}+\frac{\left(O_{5}-E_{5}\right)^{2}}{E_{5}}+ \\
\frac{\left(O_{6}-E_{6}\right)^{2}}{E_{6}}+\frac{\left(O_{7}-E_{7}\right)^{2}}{E_{7}}+\frac{\left(O_{8}-E_{8}\right)^{2}}{E_{8}} \\
X^{2}=\frac{(10-6.28)^{2}}{6.28}+\frac{(7-5.8)^{2}}{5.8}+\frac{(9-10.15)^{2}}{10.15}+\frac{(3-6.77)^{2}}{6.77}+\frac{(3-6.71)^{2}}{6.71}+ \\
\frac{(5-6.2)^{2}}{6.2}+\frac{(12-10.85)^{2}}{10.85}+\frac{(11-7.23)^{2}}{7.23}=9.049
\end{gathered}
$$

O realizar los cálculos por partes como se muestra en la Tabla 29.

Tabla 29. Cálculo de Chi-cuadrado por partes.

\begin{tabular}{|c|c|c|c|}
\hline$O$ & $E$ & $(O-E)^{2}$ & $\frac{(O-E)^{2}}{E}$ \\
\hline 10 & 6.28 & 13.84 & 2.203 \\
\hline 7 & 5.8 & 1.44 & 0.248 \\
\hline 9 & 10.15 & 1.32 & 0.130 \\
\hline 3 & 6.77 & 14.21 & 2.099 \\
\hline 3 & 6.71 & 13.76 & 2.051 \\
\hline 12 & 6.2 & 1.44 & 0.232 \\
\hline 11 & 10.85 & 1.32 & 0.121 \\
\hline & 7.23 & 14.21 & 1.965 \\
\hline
\end{tabular}

5. Calcular los grados de libertad:

Donde:

$$
\begin{aligned}
& c=\text { número de columnas }=4 \\
& r=\text { número de filas }=2 \\
& g l=\text { grados de libertad }=(c-1)(r-1)
\end{aligned}
$$

Entonces:

$$
\begin{aligned}
& g l=(c-1)(r-1) \\
& g l=(4-1)(2-1)=3
\end{aligned}
$$


6. Determinar significación de Chi cuadrado $\left(X^{2}\right)$.

En la Tabla E del Apéndice D se encuentran los valores críticos de Chi-cuadrado, el valor calculado debe ser mayor que los valores encontrados en esta tabla, para encontrar este valor se localiza la fila correspondiente a los grados de libertad, para este caso $g l=3$. El valor crítico para un nivel de significación $\rho<0.05$ es $X^{2}=7.82$.

El valor calculado para Chi cuadrado es $X_{\text {calculada }}^{2} 9.049$, como el valor es mayor que el valor crítico de $X^{2}{ }_{\text {tabla }}=7.82$ se puede rechazar la hipótesis nula y se acepta la de investigación, lo que significa que los alumnos que participaron en el programa de formación de usuarios de la información mostraron una diferencia significativa ya que los estudiantes del grupo experimental conocen un mayor número de servicios que ofrece la biblioteca que los alumnos del grupo de referencia.

$$
\begin{gathered}
X_{\text {calculada }}^{2}=9.049>X^{2} \text { tabla }=7.82 \\
\text { Para un nivel de significación } \rho<0.05
\end{gathered}
$$

Al capacitar a los usuarios de la biblioteca los participantes conocieron los servicios que ofrece la misma, no sucediendo así con los que no participaron.

\subsection{Prueba de Chi cuadrado con el programa SPSS}

El programa SPSS para esta prueba permite determinar el nivel de significación comparándolo con el nivel mínimo utilizado por los investigadores en educación que corresponde a $\rho<0.05$ si el que se determine mediante el proceso del programa resulta mayor que este valor, entonces se puede decir que las diferencias de los resultados son causados por variables aleatorias y se debe aceptar la hipótesis nula, pero si el valor es menor entonces las diferencias son significativas y se debe rechazar la hipótesis nula y aceptar la hipótesis de investigación.

El primer paso consiste en otorgarle las propiedades a las variables, una vez abierto el programa y antes de introducir los datos, es necesario definir las variables y otorgar las características para su presentación en la tabla, para esto se requiere dar clic en la pestaña Vista de variables. En este caso las acciones indispensables para obtener los resultados correctos son: a. Designar los nombres de las variables (Figura 111). Para realizar esto es necesario presionar la ceja de Vista de variables, y en seguida teclear el nombre de cada variable, primero en la columna Nombre (primera) y la fila 1, la palabra Opción, debe ir sin espacio entre las letras debido a que el programa no reconoce caracteres vacíos, segundo en la columna Nombre pero ahora en la fila 2, escribir Grupo.

b. Definir el tipo de medida que se realizó. Debido a que los datos son nominales se requiere que en la columna Medida selecciones la opción Nominal.

El programa preselecciona el tipo de variables como numérico, para darle presentación a los datos se pueden realizar las siguientes operaciones (pero no es necesario): definir la Anchura (3) y cantidad de Decimales (0) requeridos y la Alineación (centrado).

Para este ejemplo es conveniente recordar el uso de la opción Valores en la cual se combinan números con palabras, los que permitirán identificar los atributos o características de los números asignados a cada opción como se puede observar en la tabla de los datos (Tabla 18). Para realizar este proceso se da clic en la casilla donde aparece la palabra Ninguna en la opción Valores como se observa en la Figura 109, en la que aparece el cuadro de diálogo designado como Etiquetas de valor. 


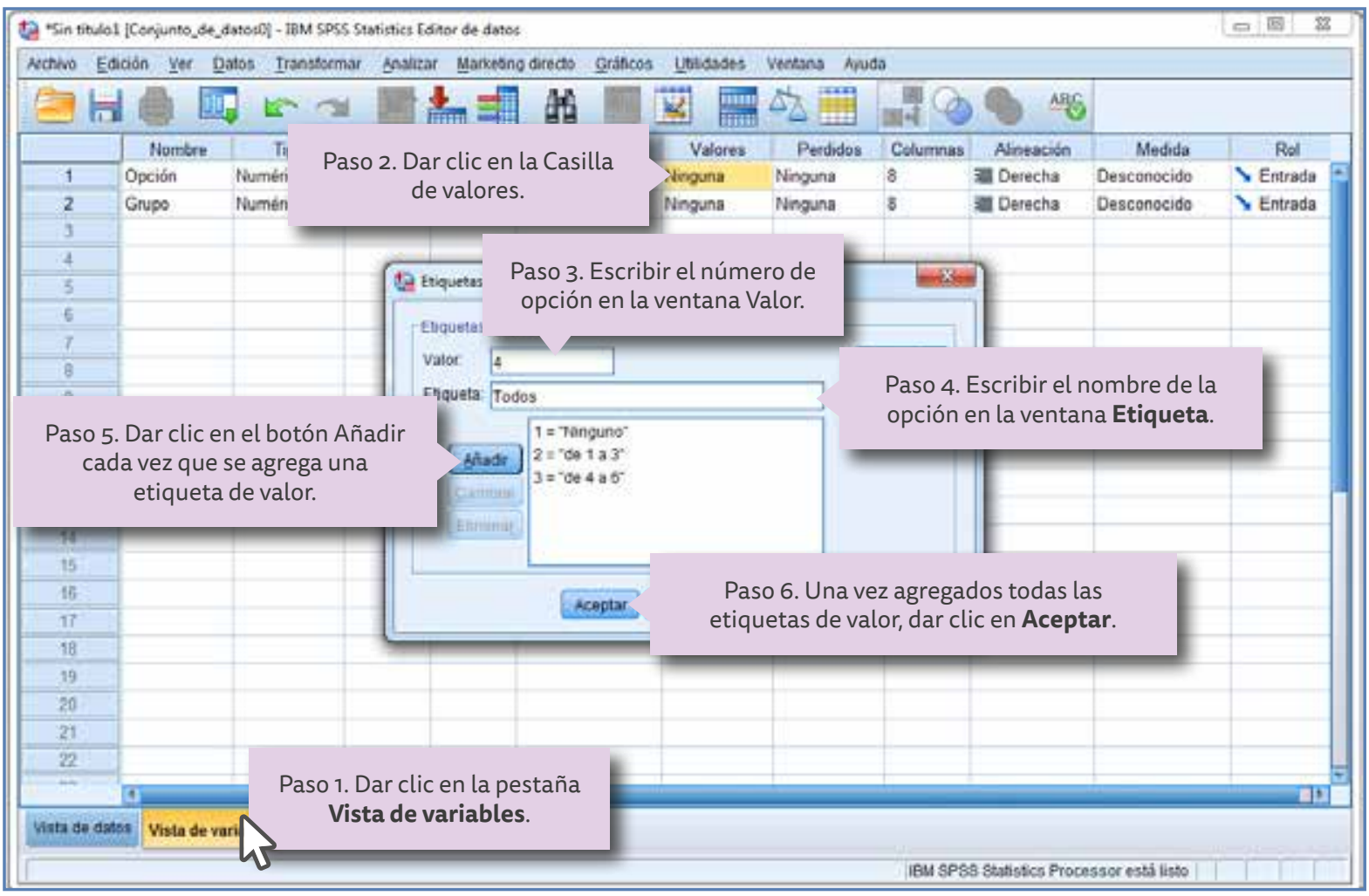

Figura 109. Cuadro de diálogo para designar la correspondencia de los números con sus atributos a la variable Opción.

En el cuadro de diálogo se codifican los números con sus atributos, en este caso para la variable Opción se designan de acuerdo a la tabla de datos de la siguiente manera:

- Número $1=$ "ninguno"

- Número 2 = "de 1 a 3"

- Número $3=$ "de 4 a 6"

- Número 4 = "todos"

Se anota el número en la ventana denominada Valor (4) y el atributo en la ventana Etiqueta (Todos), para ingresar todos los datos se presiona el botón Añadir. Una vez que se han incluido todos los valores se da clic en el botón Aceptar.

Siguiendo este proceso se otorgan los valores y atributos a la variable Grupo como se observa en la Figura 110.

En la Figura 111 se observa la designación de las variables y sus características, indicando la ubicación de cada variable y las propuestas de opciones para la definición y presentación de las variables.

Una vez que se han introducido las características de las dos variables se ingresan los valores correspondientes. Para esto es necesario dar clic en la pestaña Vista de datos que se encuentra en la parte inferior de la tabla. En la primera columna aparece el encabezado con el título de la variable Opción, que es donde se introducen los datos, ya sea de forma manual o copiarlos de la Tabla 27, primero los del Grupo 1 (sin capacitación) ocupando las primeras 29 casillas, en esa misma columna se introducen los datos correspondientes al Grupo 2 (con capacitación) en las siguientes 31 casillas. 


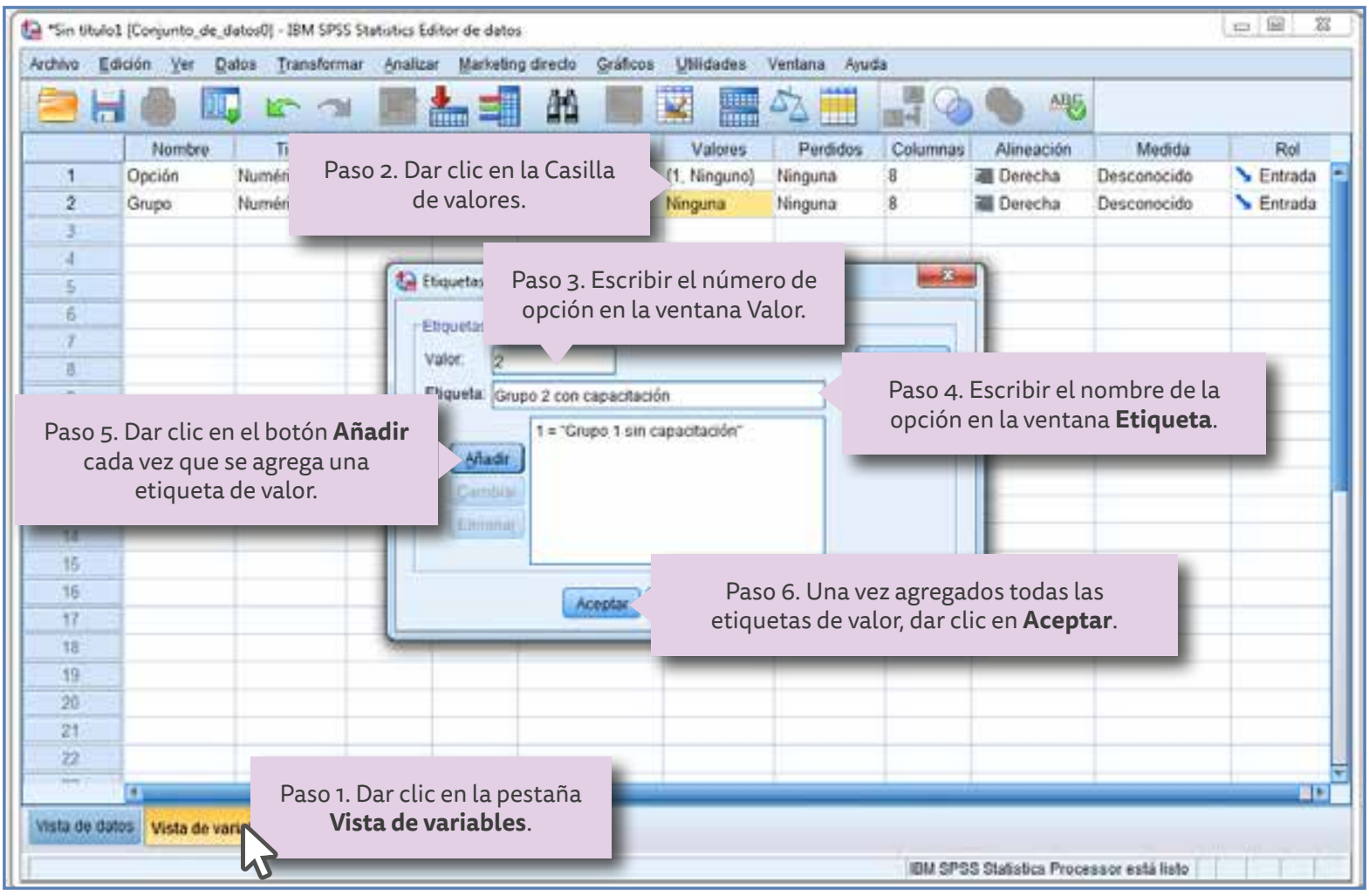

Figura 110. Cuadro de diálogo para designar la correspondencia de los números con sus atributos a la variable Grupo.

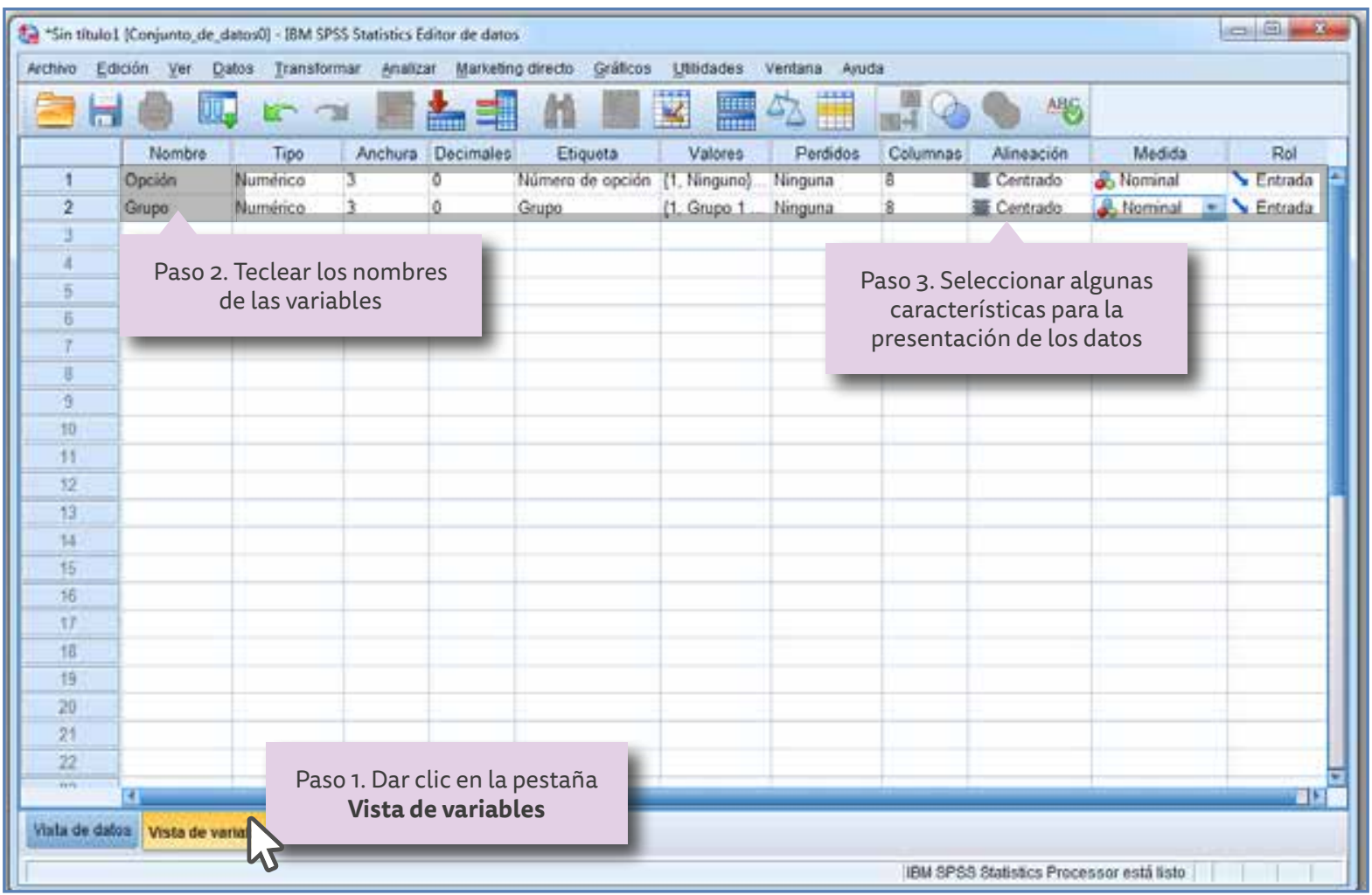

Figura 111. Designación de variables y sus características para la prueba Chi cuadrado. 
En el siguiente cuadro se observan las variables seleccionadas en este ejemplo:

Cuadro 32. Designación de variables para la prueba Chi cuadrada (relacionada).

Nombre: Opción

Tipo: Numérico

Anchura: 3

Decimales: 0

Etiqueta: Número de opción

Valores: $1=$ Ninguno

$2=\operatorname{de} 1 \mathrm{a} 3$

$3=$ de 4 a 6

$4=$ Todos

Perdidos: Ninguno

Columnas: 8

Alineación: Centrado

Medida: Nominal

Rol: Entrada
Nombre: Grupo

Tipo: Numérico

Anchura: 3

Decimales: 0

Etiqueta: Grupo

Valor: $1=$ Grupo 1 sin capacitación

2 = Grupo 2 con capacitación

Perdidos: Ninguno

Columnas: 8

Alineación: Centrado

Medida: Nominal

Rol: Entrada

Una vez introducidos los datos (ver Tabla 27) de la primera columna, se introducen los datos de la variable Grupo en la segunda columna, esto es, se designa el número 1 a los datos correspondientes al Grupo 1 colocando un 1 en las primeras 29 casillas y el número 2 en las casillas restantes que corresponden al Grupo 2, como se muestra en la Figura 112.

EI SPSS permite ver los atributos de las variables en lugar de simples números como se muestran en la Figura 112. Para lograr esto es necesario ir a la opción de Etiquetas de valor y dar clic, como se muestra en la Figura 113.

Otra característica de la función de Etiquetas de valor es que si a cualquiera de los atributos se le da un clic con el botón izquierdo del ratón, despliega una ventana que muestra las opciones que se tienen para dicha variable.

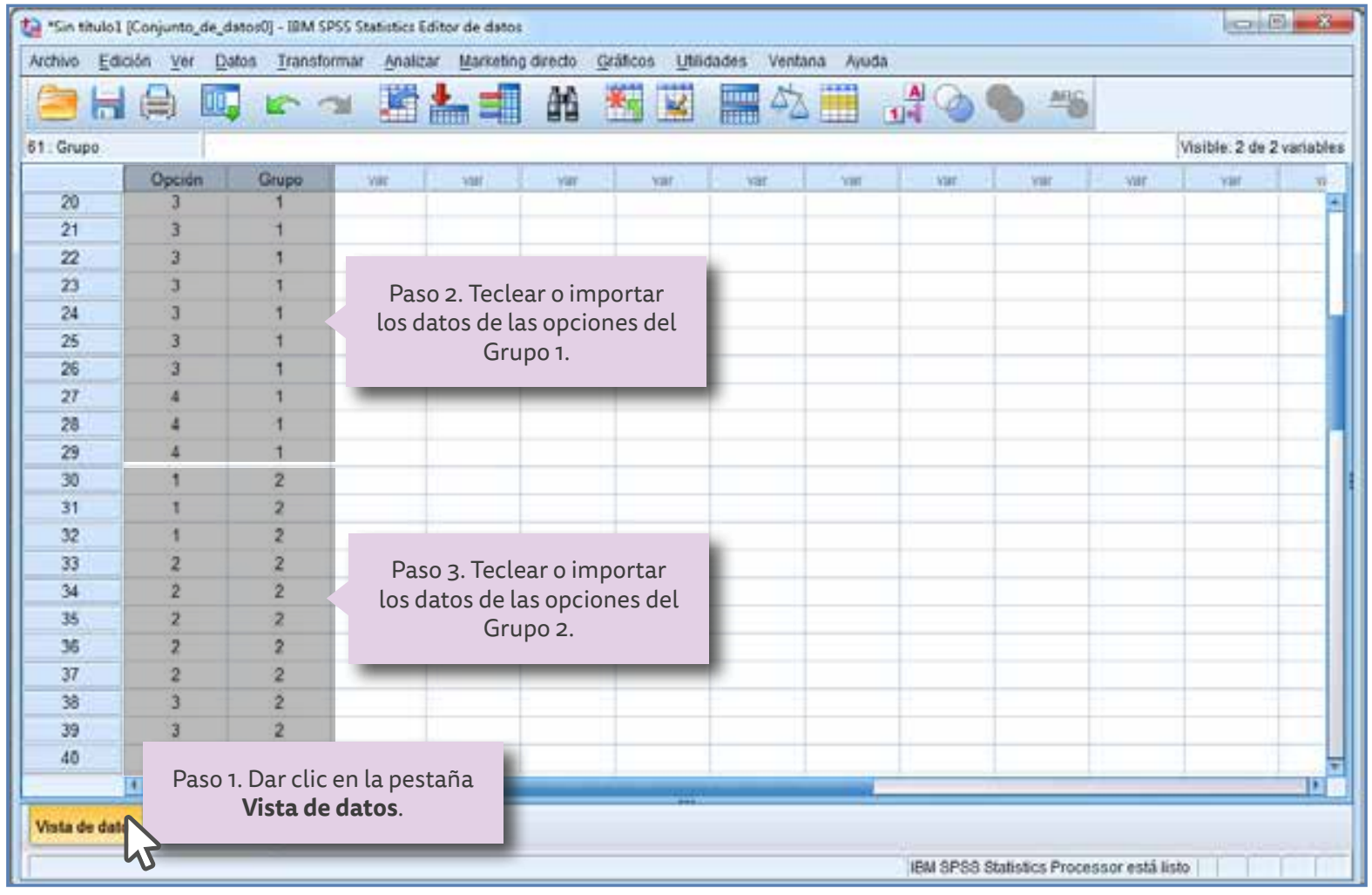

Figura 112. Valores ingresados de las variables "Opción"y "Grupo". 


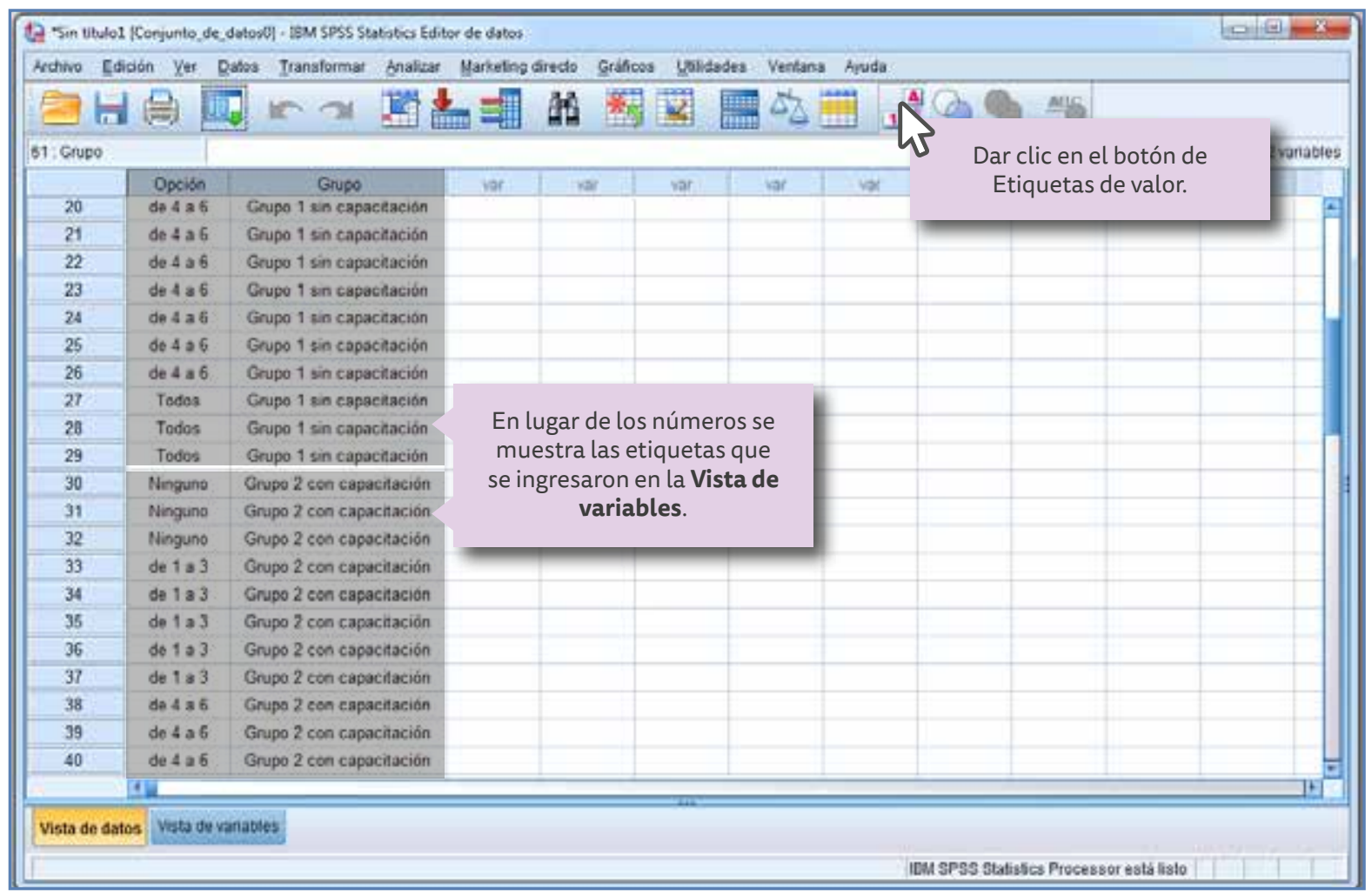

Figura 113. Opción de Etiquetas de valor que muestra la Vista de variables.

En la Figura 114 se puede observar que en la variable Opción se da un clic en el primero de los atributos presentando las opciones completas que se tienen en éste.

Una vez que se han introducido los datos y las características de las variables es necesario comparar las dos variables entre sí, así como los grupos en cuestión; para determinar si existe una diferencia significativa entre ellos es conveniente realizar un análisis de la tabulación cruzada de datos. Los pasos a seguir para realizar una tabulación cruzada en SPSS, consisten en: seleccionar en la Barra de Menú Principal la opción Analizar, colocar el apuntador en Estadísticos descriptivos y seleccionar la opción Tablas de contingencia como se observa en la Figura 115.

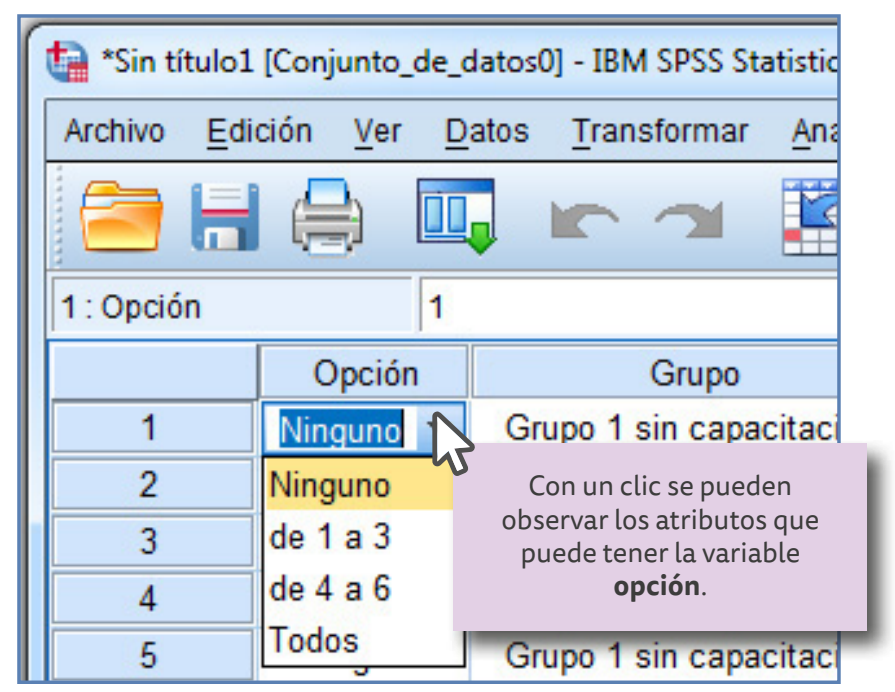

Figura 114. Listado de atributos que tiene la variable "opción". 


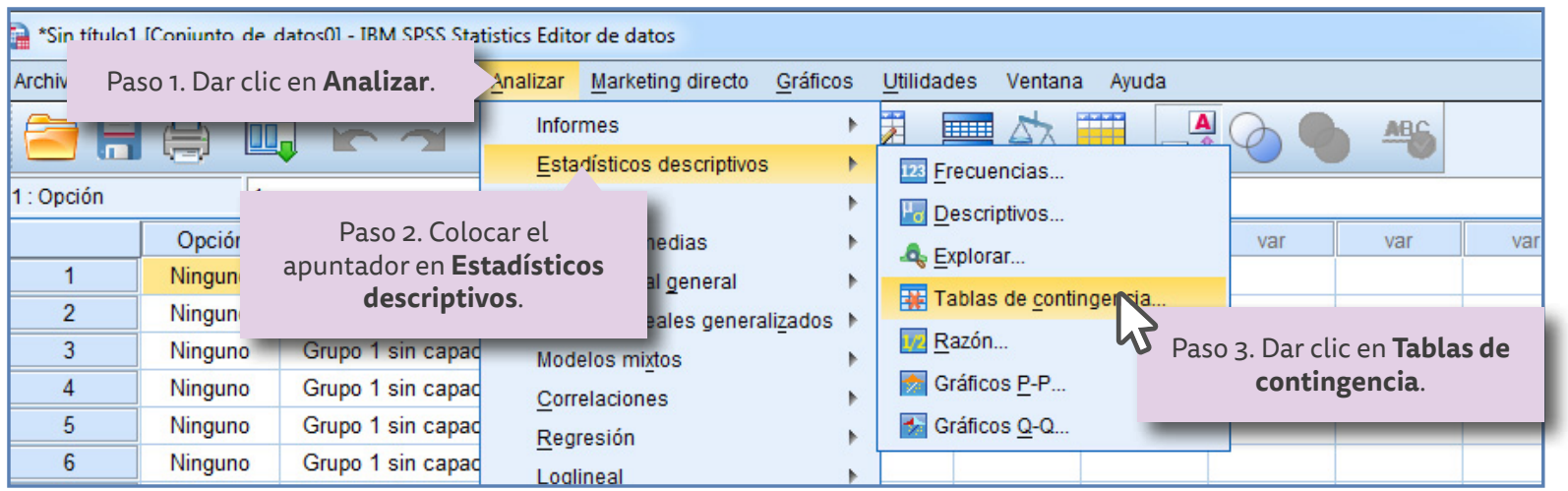

Figura 115. Pasos para realizar la prueba del análisis de tabulación cruzada de datos.

Al dar clic en la opción de Tablas de contingencia se presenta el cuadro de diálogo mostrado en la Figura 116, en el cual se exponen las opciones de análisis. Para seleccionar la variable que se desee introducir como fila se selecciona con el cursor y se presiona el botón correspondiente a Filas. Para tener coincidencia con la tabla realizada en el cálculo matemático (Tabla 27) se selecciona como "Filas" la variable Número de opción, pero igual se puede seleccionar la variable Grupo (esto sólo afecta al orden en la tabla).

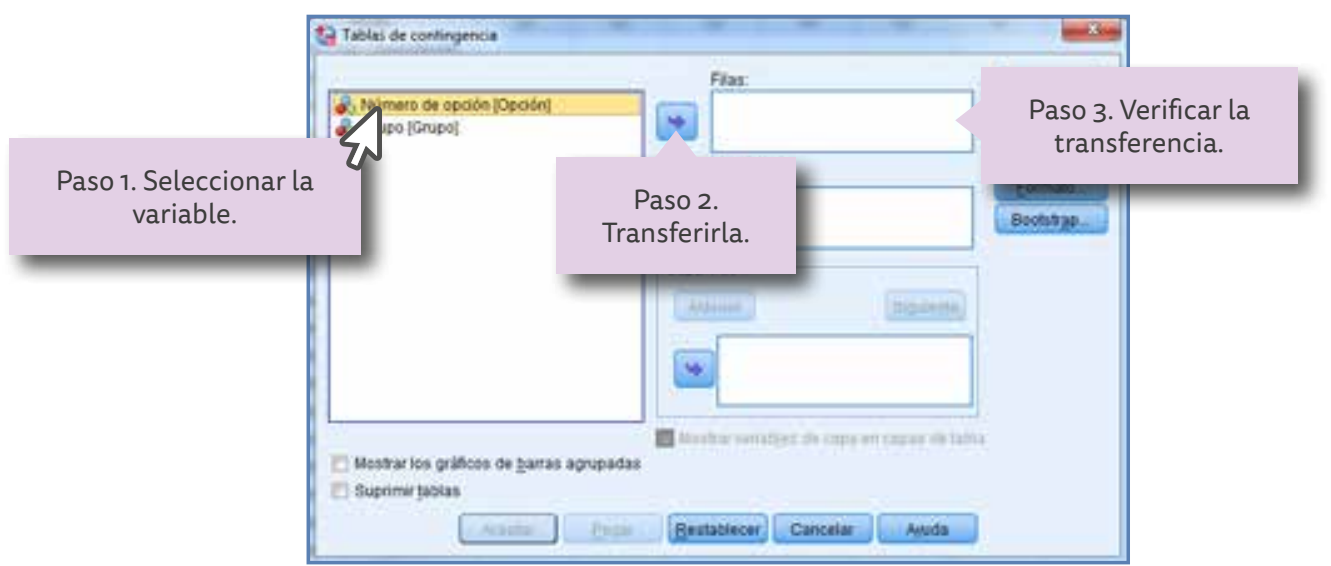

Figura 116. Cuadro de diálogo de tablas de contingencia para ingresar el número de Opción.

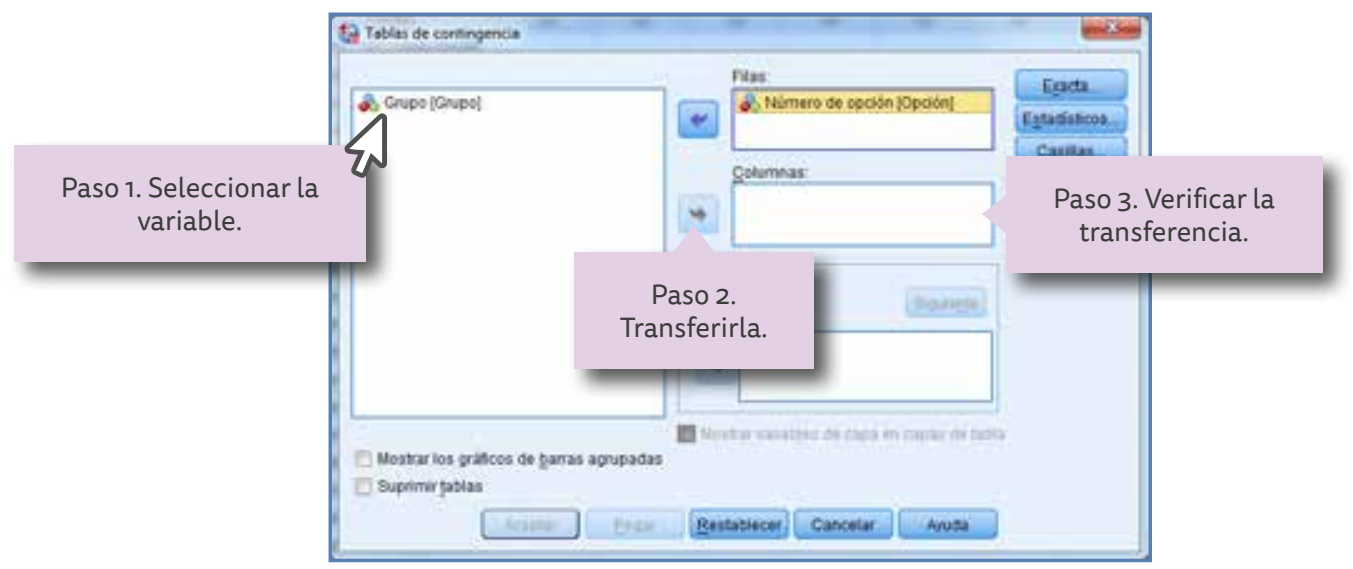

Figura 117. Cuadro de diálogo de tablas de contingencia para ingresar el número de Grupo.

Siguiendo el mismo procedimiento se selecciona la variable Grupo y se hace clic en el botón de Columnas, seleccionando de esta forma la variable Grupo como columna. 
Después de elegir las variables (Opción y Grupo) y su posición dentro de la tabla (filas y columnas) es necesario configurar las características que se deseen para este análisis. Para realizar esto se selecciona el botón Estadísticos (Figura 118); en esta opción se pueden calcular muchos indicadores, tales como: Chi-cuadrado, Correlaciones, Variables (Nominales y Ordinales), Nominal por intervalo (coeficiente Eta), Índice de Kappa, Coeficiente de riesgo, Coeficiente de McNemar, y los estadísticos de Cochran y de Mantel-Haenszel (ver Figura 119). En este caso solo se selecciona el estadístico Chi-cuadrado aplicando un clic en la casilla correspondiente y pulsando el botón Continuar.

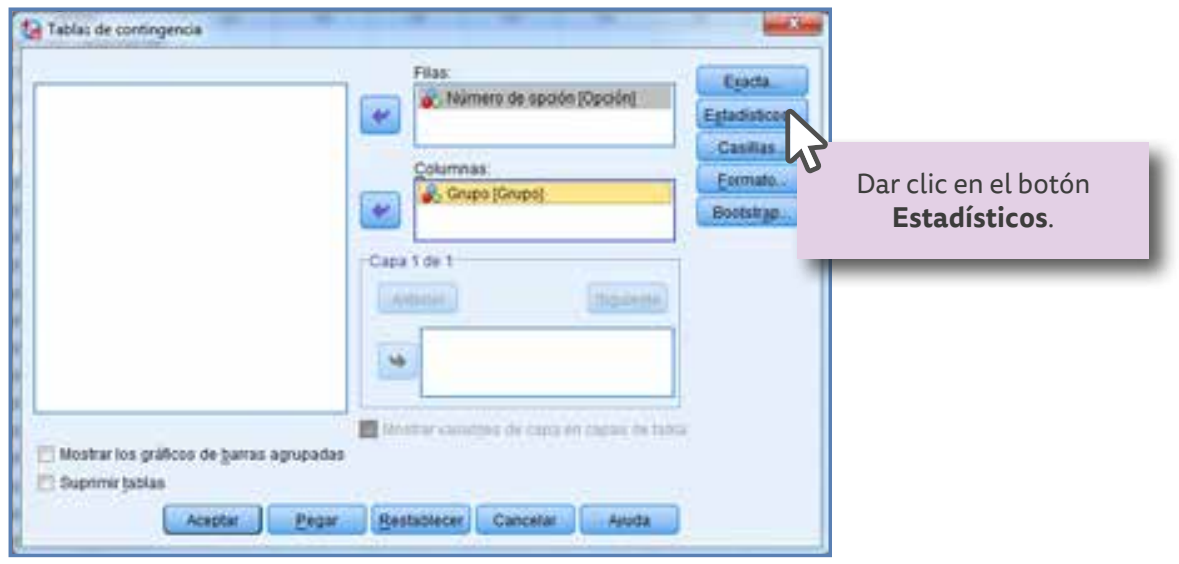

Figura 118. Cuadro de diálogo de tablas de contingencia para ingresar a Estadísticos.

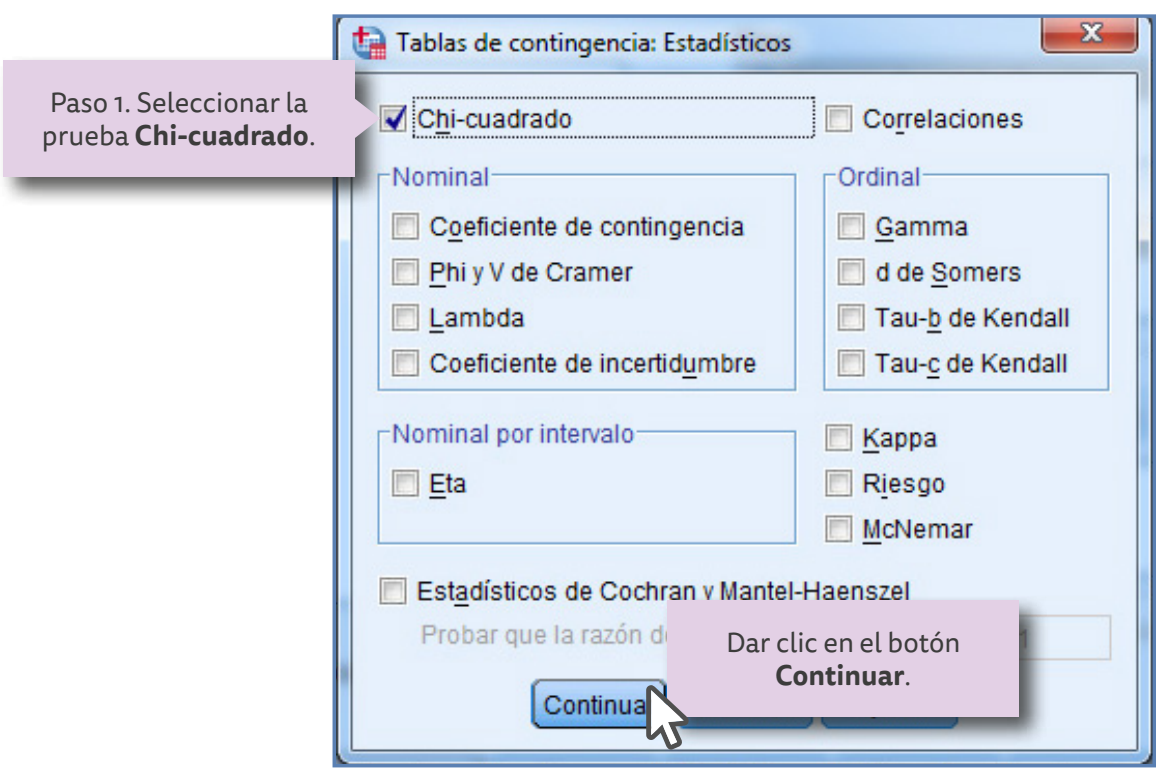

Figura 119. Recuadro correspondiente a la tabla de contingencia en la opción "Estadísticos".

Si se desea que se muestre la gráfica, seleccionar la opción Mostrar gráficos de barras agrupadas (Figura 120). Dar clic en el botón Aceptar y con esto aparece el Cuadro 33. 


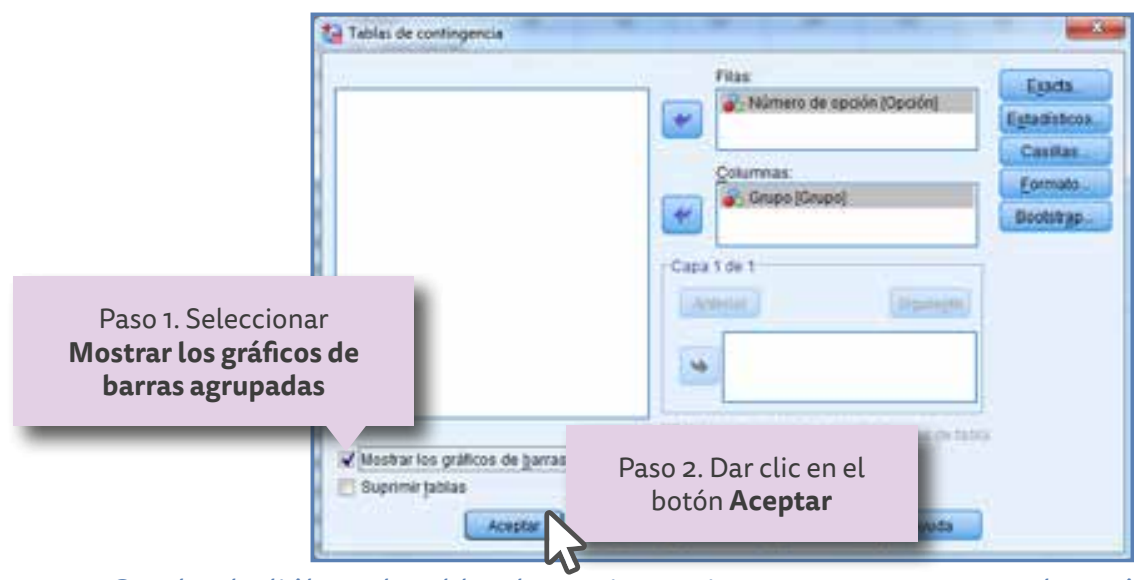

Figura120. Cuadro de diálogo de tablas de contingencia para quesemuestren los gráficos de barras agrupadas.

En el Cuadro 33 se observa que aparece el título Tablas de contingencia y presenta un resumen de los casos y la tabla de contingencia entre las variables que se seleccionaron, Grupo (Grupo 1 y 2) y Opción (Número de opción). Si se compara esta tabla con la que se elaboró en el análisis matemático se puede apreciar que es la misma (Tabla 28). Resulta por lo tanto interesante realizar "cruces de variables", de las principales que se tengan en las investigaciones que se realicen, a través de las tablas de contingencia.

Cuadro 33. Visor de resultados o visor SPSS de las tablas de contingencias.

$\rightarrow$ Tablas de contingencia

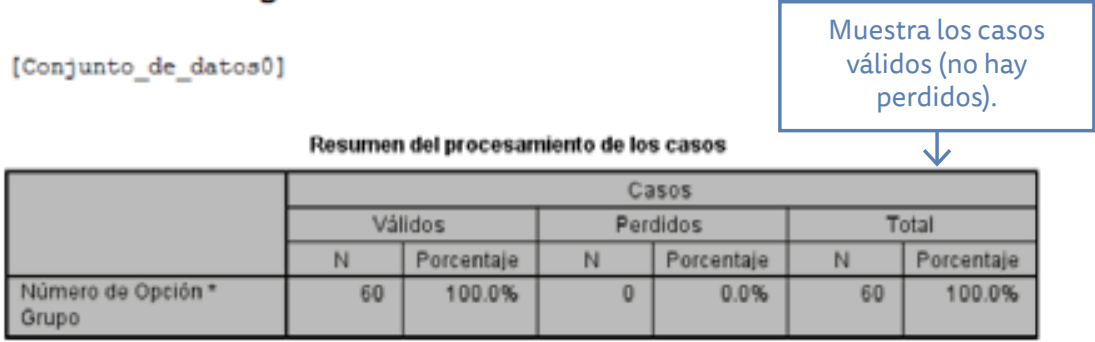

Tabla de contingencia Nümero de Opción " Grupo
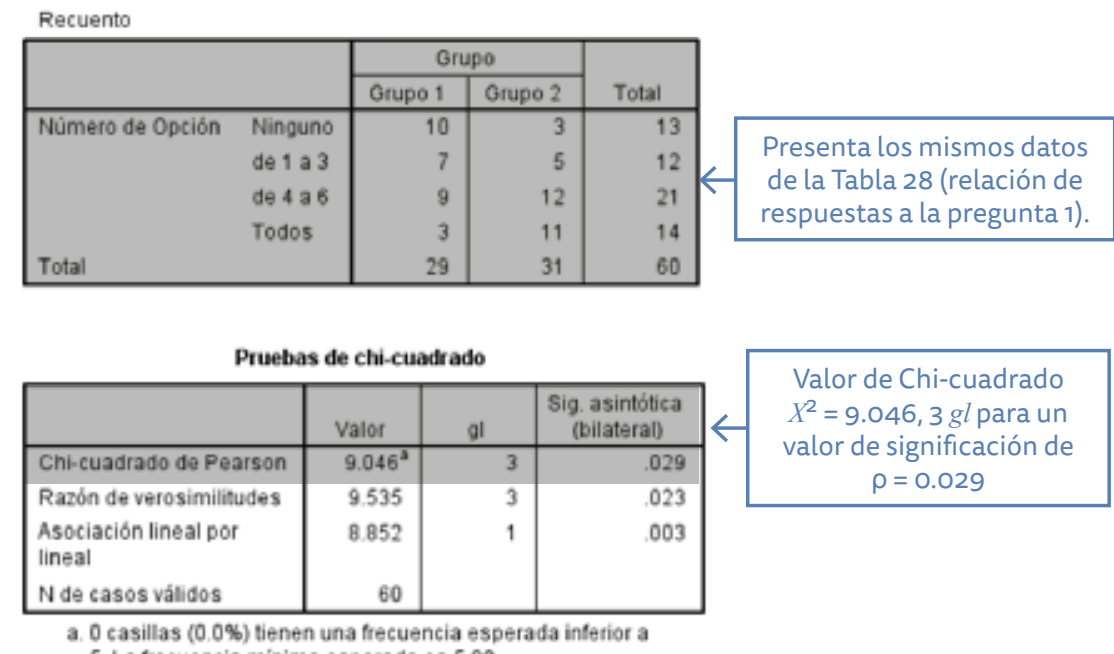

Valor de Chi-cuadrado

$X^{2}=9.046,3 \mathrm{gl}$ para un valor de significación de $\rho=0.029$ 
También se puede observar los resultados de las pruebas de Chi cuadrado, en donde el valor del coeficiente de Chi-cuadrado de Pearson es de 9.046, con tres grados de libertad ( $\mathrm{gl}$ ) y con un nivel de significancia asintótica (bilateral) de $\rho=0.029$ que está por debajo del esperado (0.05). Esto es, se tiene un nivel de confianza del $(1-\rho)(100)=(1-0.029)(100)=97.1 \%$. Como se puede observar el programa SPSS permite obtener el nivel de confianza más exacto mientras que el análisis matemático solo indica que está por encima del $95 \%$.

En el Cuadro 33 se observa el valor del nivel de significación [Significación asintótica] $\rho<0.029$.

\section{Entonces se puede concluir que $\rho_{\text {encontrada }} 0.029<\rho_{\text {aceptada }} 0.05$}

Esto es, el valor encontrado 0.029 es menor que el mínimo aceptable por los investigadores en educación (0.05), lo que significa que los resultados de la diferencia no son aleatorios puesto que existe una diferencia significativa, por lo que se puede rechazar la hipótesis nula y aceptar la hipótesis de investigación.

También se puede observar que el valor de $X^{2}$ (Chi-cuadrado) calculado por medio del programa es prácticamente igual que el valor calculado utilizando la fórmula.

$$
X_{\text {calculado }}^{2}=9.049 \mathrm{y} X^{2} \text { SPSS }=9.046
$$

Entonces se acepta la hipótesis de investigación y se puede afirmar:

Hi: Si los alumnos participan en un programa de formación de usuarios de la biblioteca, entonces conocerán un mayor número de servicios que ofrece la biblioteca con relación a los alumnos que no participan.

Gráfica 17. Representación gráfica la tabla de contingencia "Número de opción”, "Grupo”.

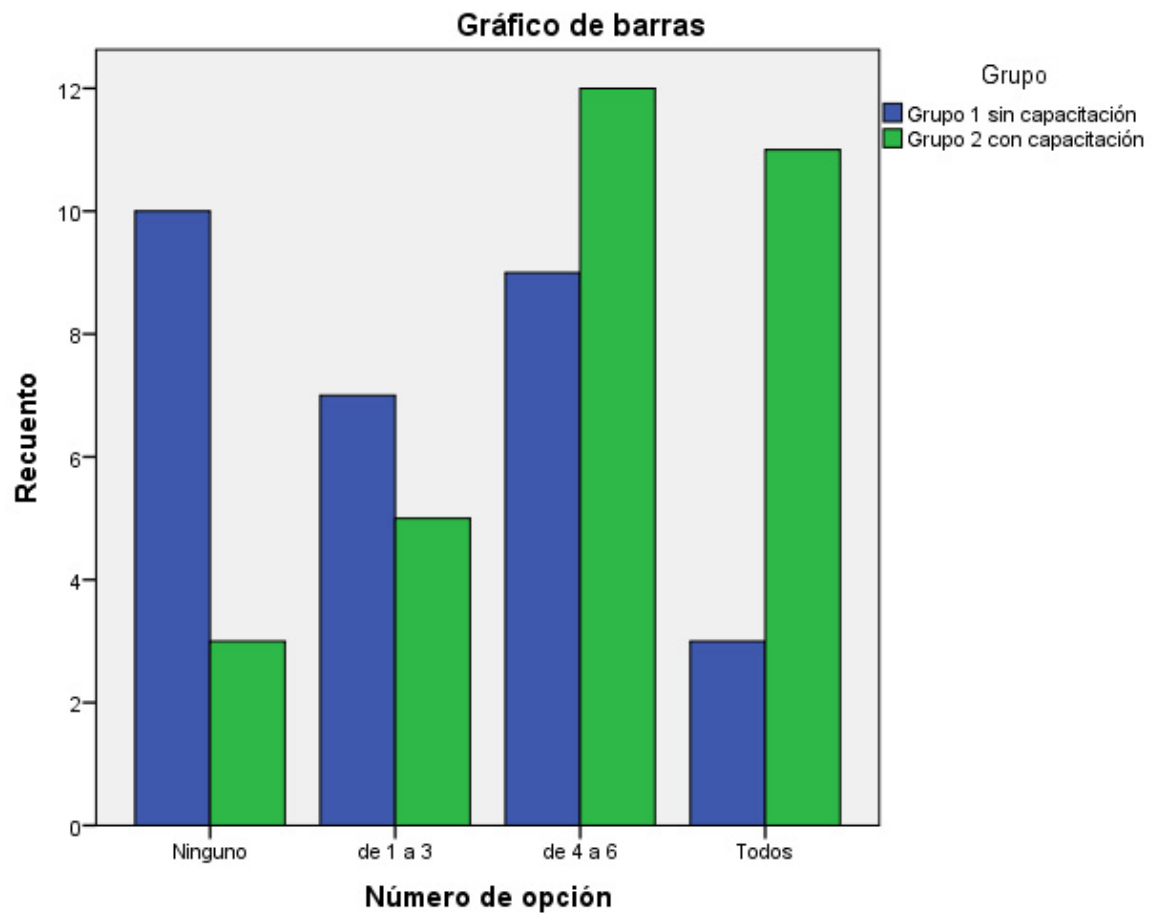





\section{Capítulo 16}

\section{Coeficiente de correlación para datos de intervalo momento-producto de Pearson}

La correlación momento-producto de Pearson permite determinar si existe una relación recíproca entre dos variables, se debe de utilizar cuando existe una correlación entre los resultados y los datos pertenecen a la escala de intervalo.

Ejemplo 91. Se trata de aceptar o rechazar la siguiente hipótesis de investigación:

Hi: La predicción supone que los resultados obtenidos por los alumnos de Medicina como promedio obtenido en el bachillerato tiene una correlación positiva con el promedio del primer semestre cursado.

\subsection{Estado situacional}

Los aspectos que motivaron a realizar esta investigación en el nivel universitario, tuvieron su origen en determinar si la exigencia de un promedio mínimo obtenido por el aspirante durante su estancia en el bachillerato se justifica ante los lineamientos que se requieren para no fracasar durante el proceso que demanda el aspirante a médico.

Por lo general los promedios de las evaluaciones reflejan los hábitos de estudio; es sabido que un estudiante que obtiene un buen promedio es un alumno dedicado al estudio, sin embargo, las calificaciones no reflejan sólo el conocimiento adquirido sino también las habilidades con que cuenta, es por esto que no se considera adecuado comparar el promedio del bachillerato con el examen de admisión, que es el otro requisito necesario para ser admitido en esta carrera y que generalmente requiere de un nivel de valor menor que el obtenido en el promedio, por otra parte, los valores obtenidos en los promedios involucran diferentes tipos de evaluaciones y evaluadores que le suman un valor agregado a éstos.

En este caso se trata de determinar si existe una correlación positiva entre los promedios obtenidos por los participantes al concluir el primer semestre de la licenciatura y el correspondiente a su certificado de bachillerato (preparatoria). Se trata de una hipótesis unilateral ya que predice una correlación positiva entre las variables: promedio del primer semestre y el del bachillerato.

Se seleccionaron 30 estudiantes que conformaron el único grupo que cursó el primer semestre de la licenciatura en Medicina, es importante resaltar que es el mismo número de estudiantes que fueron admitidos, lo que significa que no existieron deserciones ni reprobados durante el semestre.

En la Tabla 30 se muestran los resultados obtenidos en este proceso, la suma de los resultados para las dos variables y se agregan las siguientes columnas: 
- Multiplicación de los resultados obtenidos por cada uno de los participantes para las dos variables $(X$ y $Y$ ) y la suma de estos productos, representando la varianza esperada entre las variables $X$ y $Y$.

- Cuadrado de $X\left(X^{2}\right)$ se muestran los resultados del cálculo del cuadrado de cada uno de los resultados de $X$ y la suma de estos cuadrados*.

- Cuadrado de $Y\left(Y^{2}\right)$ se muestran los resultados del cálculo del cuadrado de cada uno de los resultados de $Y$ y la suma de estos cuadrados*.

* Nota: Estas sumas de cuadrados representan la varianza total.

\subsection{Explicación}

En la correlación de Pearson se trata de comprobar si los resultados de una variable se relacionan con los resultados de la otra. Las correlaciones se miden en términos de coeficientes de correlación que pueden adquirir valores que representan correlaciones (Greene y D'oliveira, 2006):

- Nula, en donde el valor del coeficiente de correlación es igual a cero, existiendo una total ausencia de correlación.

- Positiva, en donde el valor del coeficiente de correlación se encuentra entre los valores arriba de cero hasta +1 , en donde el 1 representa una correlación positiva perfecta. Esto significa que las dos variables se mueven en la misma dirección, si una aumenta la otra también.

- Negativa, en donde el valor del coeficiente de correlación se encuentra entre los valores abajo de cero hasta -1, en donde el -1 representa una correlación negativa perfecta. Esto significa que las dos variables se mueven en la dirección opuesta, si una aumenta la otra disminuye.

En la mayoría de los casos los valores de correlación se encuentran entre los valores extremos +1 (positiva), - 1 (negativa) y cero (ausencia de correlación). En otras palabras, mientras más se aleje el coeficiente de correlación del valor de cero, existe una correlación más significativa.

La principal característica de los diseños correlacionales es que las dos variables se representan como un continuo de resultados, lo que implica que se consideren a éstos como datos de intervalo. Si se estudia un número muy elevado de sujetos, una correlación baja puede resultar significativa.

La correlación se determina por medio del ratio (relación) entre la varianza esperada en los resultados y la varianza total. Si el valor del ratio es bajo se tiene que aceptar la hipótesis nula, por el contrario si es alto, se rechaza la hipótesis nula, y se acepta la hipótesis de investigación. El ratio se representa por medio de la letra $r$.

\subsection{Procedimiento para determinar el valor del ratio $r$}

1. Multiplicar los resultados de la variable $X$ por los resultados de la variable $Y,(X Y)$ hasta completar la Tabla 30.

2. Calcular el cuadrado de cada uno de los resultados para la variable $X_{1}\left(X^{2}\right)$ hasta completar la Tabla 30.

3. Calcular el cuadrado de cada uno de los resultados para la variable $Y_{,}\left(Y^{2}\right)$ hasta completar la Tabla 30. 
Tabla 30. Relación de evaluaciones correspondientes a la carrera de Medicina.

\begin{tabular}{|c|c|c|c|c|c|}
\hline № & $\begin{array}{l}\text { Variable } X \\
\text { Promedio del } \\
\text { Bachillerato }\end{array}$ & $\begin{array}{c}\text { Variable } Y \\
\text { Promedio 1er } \\
\text { semestre }\end{array}$ & $X Y$ & $X^{2}$ & $y^{2}$ \\
\hline 1 & 95.3 & 98.5 & 9387.05 & 9082.09 & 9702.25 \\
\hline 2 & 93.41 & 97.1 & 9070.111 & 8725.4281 & 9428.41 \\
\hline 3 & 89 & 93.33 & 8306.37 & 7921 & 8710.4889 \\
\hline 4 & 94.56 & 96 & 9077.76 & 8941.5936 & 9216 \\
\hline 5 & 94.43 & 96 & 9065.28 & 8917.0249 & 9216 \\
\hline 6 & 95.71 & 89.6 & 8575.616 & 9160.4041 & 8028.16 \\
\hline 7 & 94.94 & 87.38 & 8295.8572 & 9013.6036 & 7635.2644 \\
\hline 8 & 90.84 & 94.9 & 8620.716 & 8251.9056 & 9006.01 \\
\hline 9 & 92.3 & 92.8 & 8565.44 & 8519.29 & 8611.84 \\
\hline 10 & 89 & 95.33 & 8484.37 & 7921 & 9087.8089 \\
\hline 11 & 98 & 97 & 9506 & 9604 & 9409 \\
\hline 12 & 98 & 94.33 & 9244.34 & 9604 & 8898.1489 \\
\hline 13 & 82 & 84.89 & 6960.98 & 6724 & 7206.3121 \\
\hline 14 & 96.53 & 94.6 & 9131.738 & 9318.0409 & 8949.16 \\
\hline 15 & 97 & 95.89 & 9301.33 & 9409 & 9194.8921 \\
\hline 16 & 100 & 97 & 9700 & 10000 & 9409 \\
\hline 17 & 96 & 96.3 & 9244.8 & 9216 & 9273.69 \\
\hline 18 & 91.6 & 89.67 & 8213.772 & 8390.56 & 8040.7089 \\
\hline 19 & 94.12 & 90.33 & 8501.8596 & 8858.5744 & 8159.5089 \\
\hline 20 & 95 & 88.4 & 8398 & 9025 & 7814.56 \\
\hline 21 & 91.22 & 92.33 & 8422.3426 & 8321.0884 & 8524.8289 \\
\hline 22 & 81.23 & 89.32 & 7255.4636 & 6598.3129 & 7978.0624 \\
\hline 23 & 88.38 & 84.51 & 7468.9938 & 7811.0244 & 7141.9401 \\
\hline 24 & 93.58 & 94.48 & 8841.4384 & 8757.2164 & 8926.4704 \\
\hline 25 & 91.46 & 94 & 8597.24 & 8364.9316 & 8836 \\
\hline 26 & 93.02 & 92.8 & 8632.256 & 8652.7204 & 8611.84 \\
\hline 27 & 95.92 & 94.3 & 9045.256 & 9200.6464 & 8892.49 \\
\hline 28 & 97.02 & 97.45 & 9454.599 & 9412.8804 & 9496.5025 \\
\hline 29 & 95.58 & 96.2 & 9194.796 & 9135.5364 & 9254.44 \\
\hline 30 & 97.28 & 87.56 & 8517.8368 & 9463.3984 & 7666.7536 \\
\hline $\begin{array}{l}\sum= \\
\text { Total }\end{array}$ & $\begin{array}{c}\sum X= \\
2802.43\end{array}$ & $\begin{array}{c}\sum Y= \\
2792.3\end{array}$ & $\begin{array}{c}\sum(X Y)= \\
261081.612\end{array}$ & $\begin{array}{c}\sum X^{2}= \\
262320.271\end{array}$ & $\begin{array}{c}\sum Y^{2}= \\
260326.541\end{array}$ \\
\hline
\end{tabular}


4. Calcular el valor del Coeficiente de correlación de Pearson $r$, utilizando la siguiente fórmula:

$$
r=\frac{N\left(\sum \mathrm{xy}\right)-\left(\sum \mathrm{x}\right)\left(\sum \mathrm{y}\right)}{\sqrt{\left[N \sum \mathrm{x}^{2}-\left(\sum \mathrm{x}\right)^{2}\right]\left[N \sum \mathrm{y}^{2}-\left(\sum \mathrm{y}\right)^{2}\right]}}
$$

Donde:

$$
\begin{aligned}
& r=\text { coeficiente de correlación de Pearson } \\
& N=\text { número de participantes }=30 \\
& \sum(\mathrm{xy})=\text { suma del producto de } \mathrm{x} y=261081.612 \\
& \sum \mathrm{x}=\text { suma de la variable } \mathrm{x}=2802.43 \\
& \sum \mathrm{y}=\text { suma de la variable } \mathrm{y}=2792.3 \\
& \left(\sum \mathrm{x}\right)^{2}=\text { cuadrados totales para } \mathrm{x}=(2802.43)^{2}=7853613.9 \\
& \left(\sum \mathrm{y}\right)^{2}=\text { cuadrados totales para } \mathrm{y}=(2792.3)^{2}=7796939.29 \\
& \sum \mathrm{x}^{2}=\text { suma de } \mathrm{x} \text { elevada al cuadrado }=262320.271 \\
& \sum \mathrm{y}^{2}=\text { suma de } y \text { elevada al cuadrado }=260326.541
\end{aligned}
$$

Sustituyendo:

$$
\begin{gathered}
r=\frac{30(261081.612)-(2802.43)(2792.3)}{\sqrt{\left[30(262320.271)-(2802.43)^{2}\right]\left[30(260326.541)-(2792.3)^{2}\right]}} \\
r=\frac{7223.071}{\sqrt{[15994.2251][12856.94]}} \\
r=\frac{7223.071}{14340.04158}=0.503699
\end{gathered}
$$

5. Calcular los grados de libertad, el número de participantes menos 2.

$$
g l=N-2=30-2=28
$$

Nota: Si los grados de libertad no se encuentran en la tabla, se debe utilizar el siguiente inferior, en este ejemplo se toma el valor de $g l=25$.

6. Significación de $r$ para la correlación de Pearson.

En la Tabla I del Apéndice D, se encuentran los valores críticos de $r$ para la correlación de Pearson, el valor calculado debe ser mayor que los valores encontrados en esta tabla, para encontrar este valor se localiza la fila correspondiente a los grados de libertad, para este caso $g l=28$. El valor crítico para un nivel de significación $\rho=0.01$ es $r=0.4869$.

El valor calculado para $r_{\text {calculada }}=0.503699$, es mayor que el valor crítico de $r_{\text {tabla }}=0.4869$, por lo que se puede rechazar la hipótesis nula y se acepta la de trabajo, esto significa que sí existe una correlación positiva entre el promedio del primer semestre y el promedio del bachillerato de los estudiantes de la licenciatura en Medicina.

$$
r_{\text {calculada }}=0.503699>r_{\text {tabla }}=0.4869 \text { Para un nivel de significación } \rho<0.01
$$




\subsection{Prueba de Correlación de Pearson con el programa SPSS}

El programa SPSS para esta prueba permite determinar el nivel de significación comparándolo con el nivel mínimo utilizado por los investigadores en educación que corresponde a $\rho<0.05$, si el que se determine mediante el proceso del programa resulta mayor que este valor, entonces se puede decir que las diferencias de los resultados son causados por variables aleatorias y se debe aceptar la hipótesis nula, pero si el valor es menor entonces las diferencias son significativas y se debe rechazar la hipótesis nula y aceptar la hipótesis de investigación.

El primer paso consiste en otorgarle las propiedades a las variables, una vez abierto el programa y antes de introducir los datos, es necesario definir las variables y otorgarle las características para su presentación en la tabla, para esto se requiere dar un clic en la pestaña Vista de variables. En este caso las acciones indispensables para obtener los resultados correctos son:

- Designar los nombres de las variables. Para realizar esto es necesario presionar la ceja de Vista de variables, y en seguida teclear el nombre de cada variable, primero en la columna Nombre (primera) y la fila 1, la palabra Prom1erSemestre, debe ir sin espacio entre la palabra y el número debido a que el programa no reconoce caracteres vacíos, segundo en la columna Nombre pero ahora en la fila 2, escribir PromBachillerato.

- Definir el tipo de medida que se realizó. Debido a que los datos son de intervalo se requiere que en la columna Medida se seleccione la opción Escala.

El programa preselecciona el tipo de variables como numérico, para darle presentación a los datos se pueden realizar las siguientes operaciones (pero no es necesario): definir la Anchura (5) y cantidad de Decimales (2) requeridos y la Alineación (centrado).

En la Figura 121 se observan estos pasos, así como la ubicación de cada variable y las propuestas de opciones para la definición y presentación de éstas.

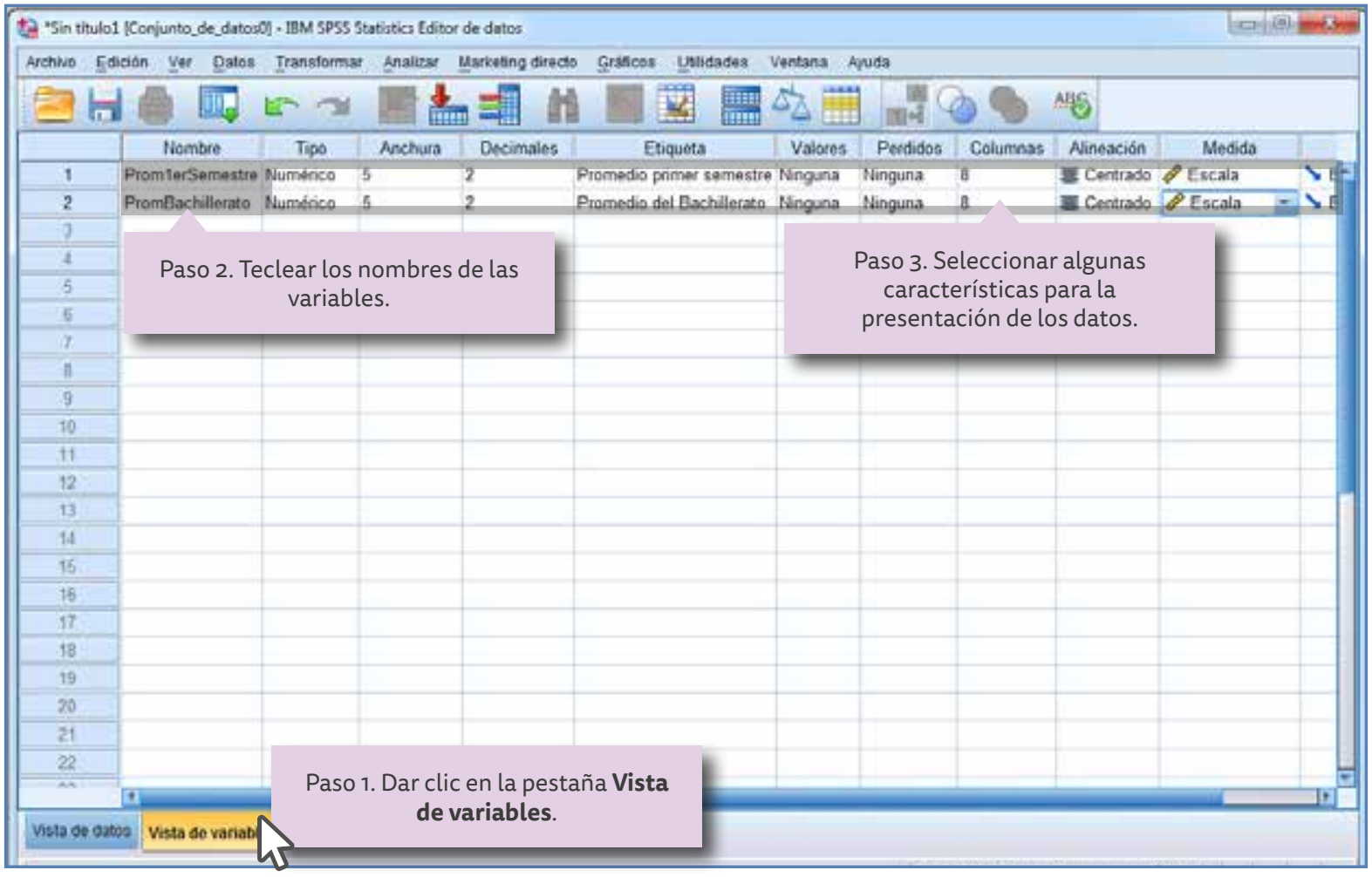

Figura 121. Designación de variables y sus características para la prueba r correlación de Pearson. 
Una vez designados los nombres de las variables y sus características se introducen los datos en la tabla, para llevar a cabo esto es necesario dar un clic en la pestaña Vista de datos, e introducir los datos correspondientes a cada variable, éstos pueden introducirse uno por uno tecleándolos o bien importarlos (seleccionar, copiar y pegar) de la Tabla 30 en donde se encuentran ubicados y pegarlos dentro de esta tabla.

En el siguiente cuadro se observan las variables seleccionadas en este ejemplo:

Cuadro 34. Designación de variables para la prueba de Correlación.

\section{Nombre: Prom1erSemestre}

Tipo: Numérico

Anchura: 5

Decimales: 2

Etiqueta: Promedio primer semestre

Valores: Ninguno

Perdidos: Ninguno

Columnas: 8

Alineación: Centrado

Medida: Escala

Rol: Entrada

\section{Nombre: PromBachillerato}

Tipo: Numérico

Anchura: 5

Decimales: 2

Etiqueta: Promedio del Bachillerato

Valores: Ninguno

Perdidos: Ninguno

Columnas: 8

Alineación: Centrado

Medida: Escala

Rol: Entrada

En la Figura 122 se observa como quedan los datos, siguiendo cualquiera de los procedimientos mencionados y de acuerdo a las características seleccionadas en los pasos previos.

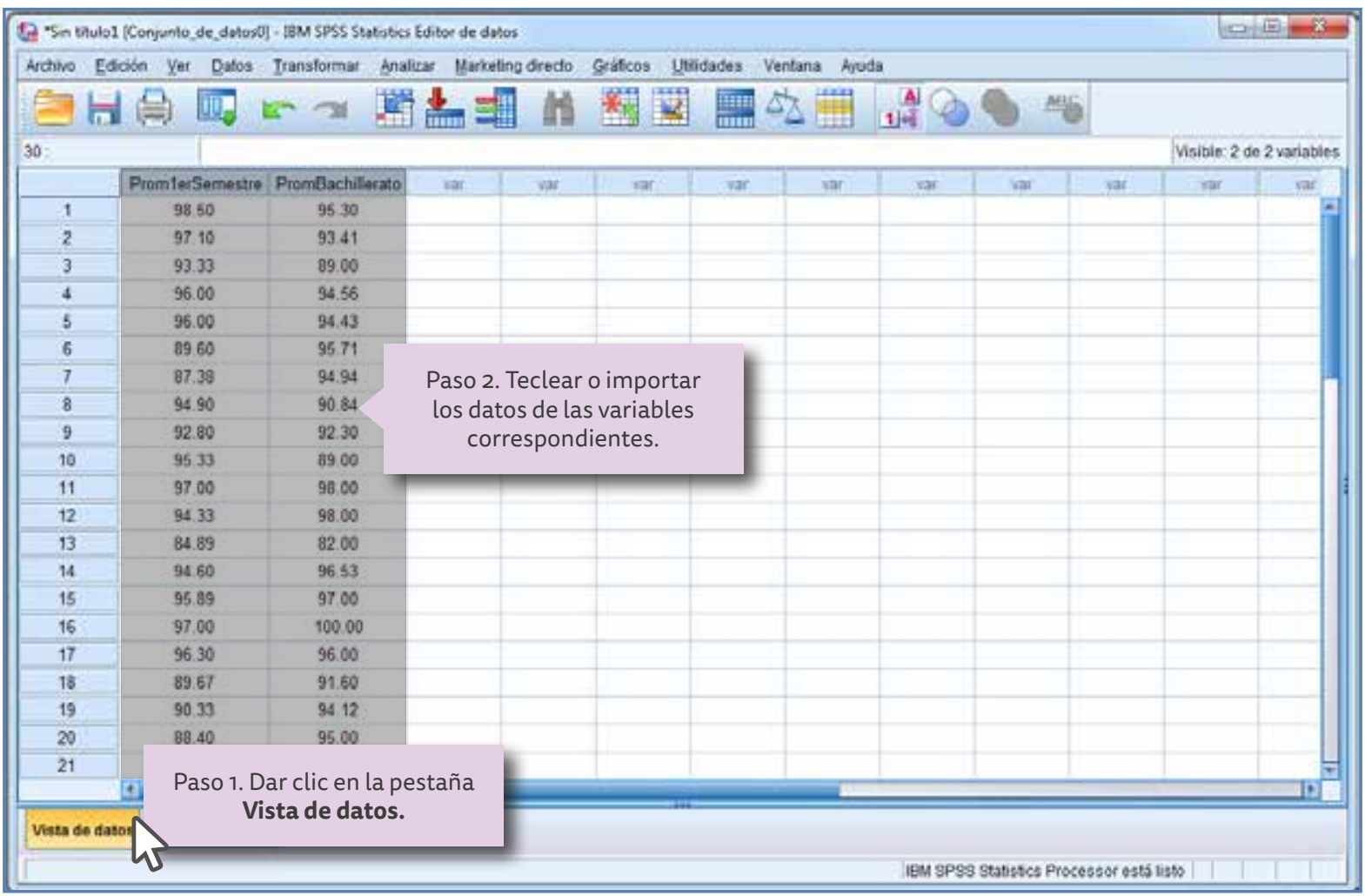

Figura 122. Presentación de los Promedios del Primer Semestrey los Promedios del Bachillerato.

Una vez que los datos se encuentran en la tabla, se realiza la prueba (Figura 123), para hacerlo es necesario dar un clic en la pestaña ubicada en la barra superior designada como Analizar, en seguida aparece un cuadro de diálogo, en donde se selecciona la línea que indica 
Correlaciones, al ubicar el apuntador del ratón en esta opción se presenta a la derecha otro cuadro de diálogo, se selecciona Bivariadas (que son las que corresponden a dos variables) y se da clic con el ratón.

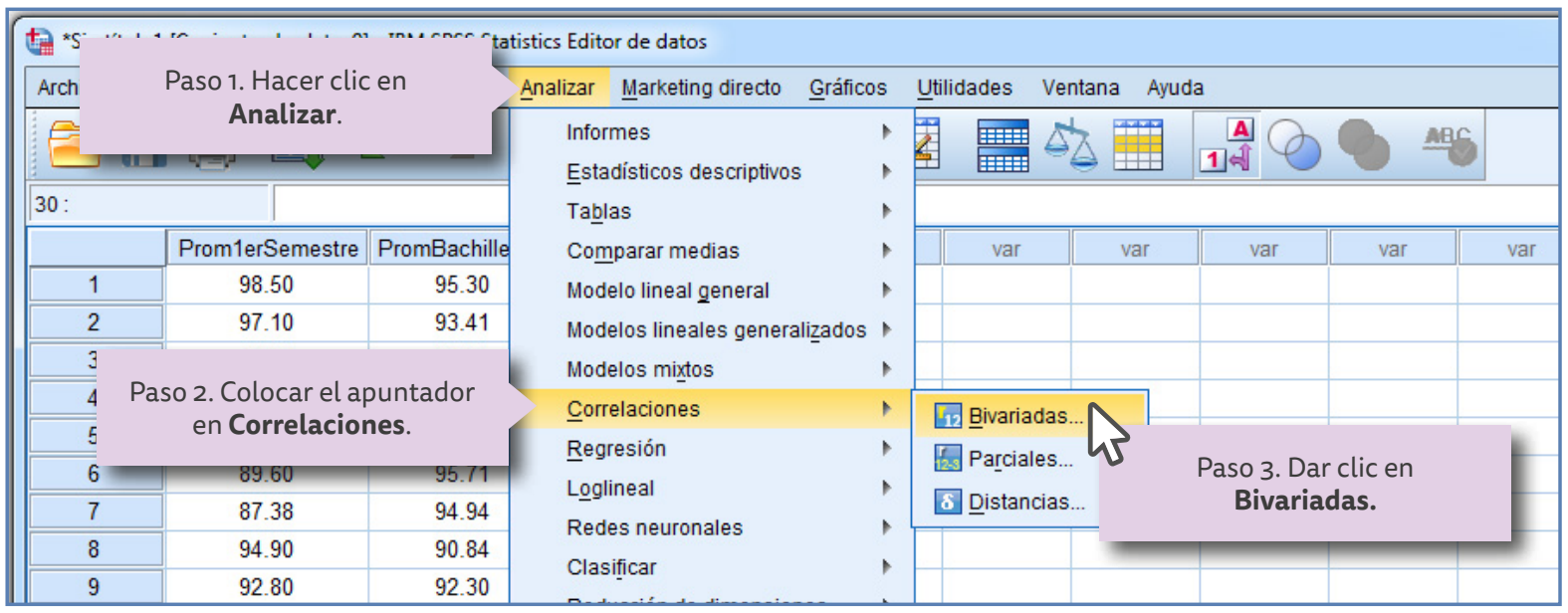

Figura 123. Cuadros de diálogo para seleccionar la prueba r correlación de Pearson.

Aparece inmediatamente la ventana de la Figura 124, en la cual se muestran las variables del lado izquierdo, Promedio primer Semestre y Promedio del Bachillerato, éstas deben ser trasladadas a la ventana que dice Variables; la forma de hacerlo es seleccionando con un clic la variable deseada (Promedio primer Semestre) y se da un clic en la flecha que se ubica entre las dos ventanas, repitiendo esta operación para la otra variable (Promedio del Bachillerato).

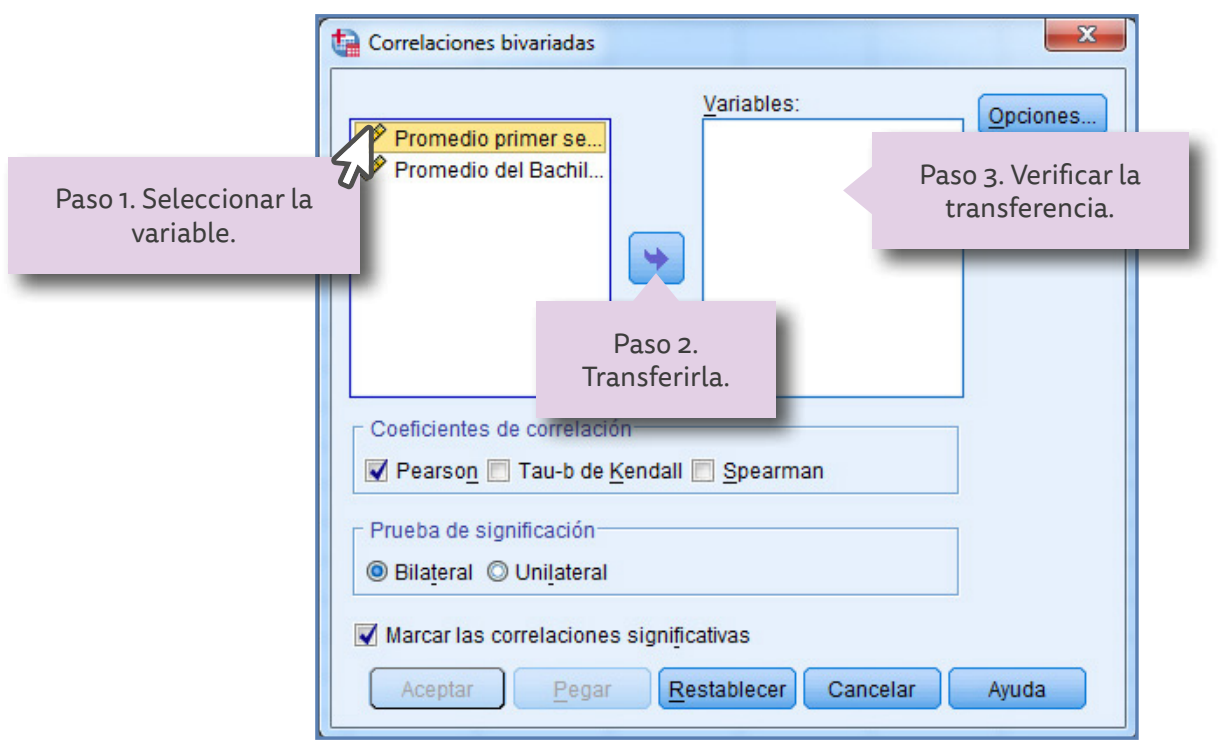

Figura 124. Transferencia de la variable Promedio primer Semestre para procesar los datos con el programa SPSS.

Se debe seleccionar el tipo de prueba que se requiere activando con el ratón donde se indica el Coeficiente de correlación y la ventana correspondiente a Pearson (Figura 125). Si se desea que en los resultados del programa se muestren los valores de las medias y desviaciones típicas, se debe dar clic en el botón Opciones y aparece el cuadro de diálogo que se muestra en la Figura 126, se selecciona la opción Medias y desviaciones típicas y en seguida dar clic en el botón Continuar. 


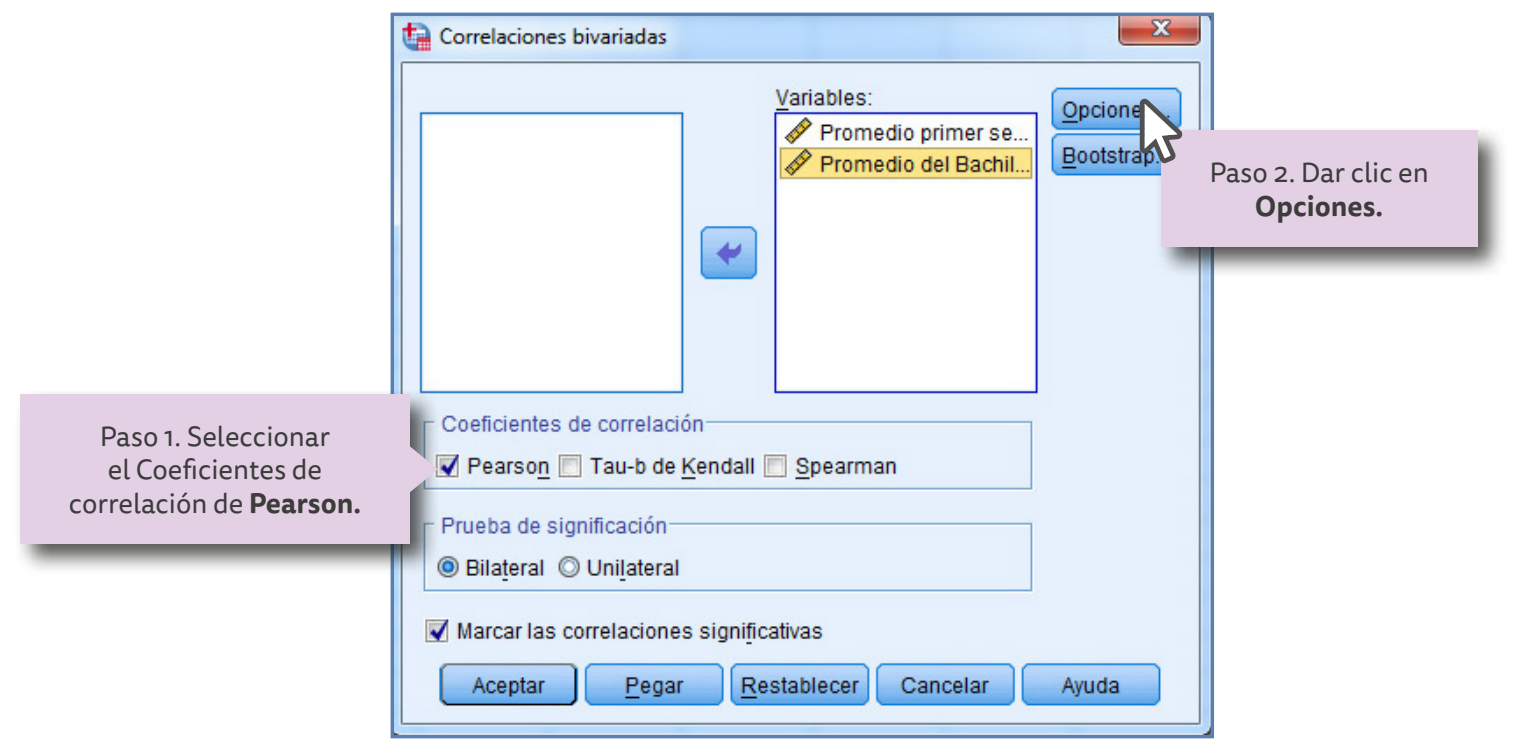

Figura 125. Paso para abrir laventana de diálogoy las opciones para incluir las variables mediasy desviaciones típicas.

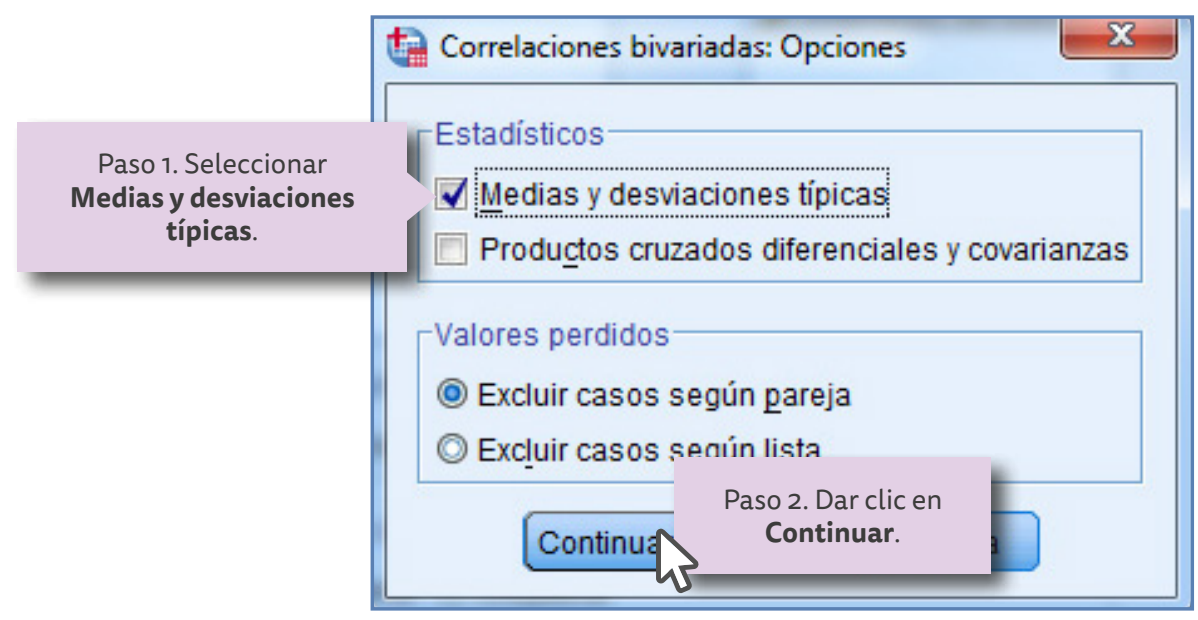

Figura 126. Paso para ejecutar el programa para que realice los cálculos requeridos para determinar los valores de las medias y desviaciones típicas.

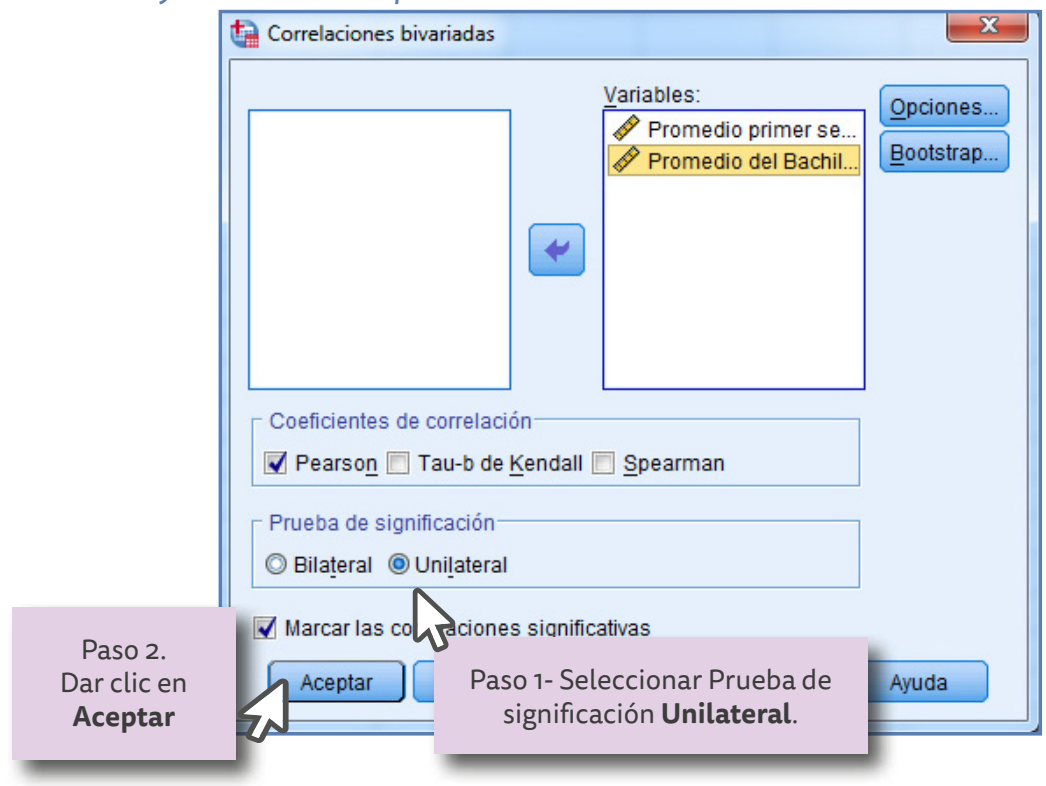

Figura 127. Paso para ejecutar el programa SPSS para que realice los cálculos requeridos para la prueba $r$ correlación de Pearson. 
Es importante recordar que se trata de una hipótesis unilateral puesto que se busca una correlación positiva de acuerdo a la propuesta de la investigación, es decir, no se busca solo la correlación (que puede ser positiva, negativa o nula) pues sería en tal caso una hipótesis bilateral. Debido a esto se debe seleccionar con un clic la opción Unilateral. Una vez realizadas estas acciones el programa queda listo para arrojar los resultados, al activar el botón Aceptar se obtienen los resultados que se muestran en el Cuadro 35.

En el cuadro se pueden observar los valores de las medias de cada condición así como las desviaciones típicas. El valor del nivel de significación [Significación asintótica] $\rho<0.002$.

$$
\text { Entonces se puede concluir que } \rho_{\text {encontrada }} 0.002<\rho_{\text {aceptada }} 0.05
$$

Esto es, el valor encontrado 0.002 es menor que el mínimo aceptable por los investigadores en educación (0.05), lo que significa que los resultados de la diferencia no son aleatorios puesto que existe una diferencia significativa, por lo que se rechaza la hipótesis nula y se acepta la hipótesis de investigación.

También se observa que el valor de $r$ calculado por medio del programa es prácticamente igual que el valor calculado utilizando la fórmula.

$$
r_{\text {calculado }}=0.503699 \mathrm{y} r_{\text {SPSS }}=0.504
$$

Hi: La predicción supone que los resultados obtenidos por los alumnos de Medicina como promedio obtenidos en el bachillerato tienen una correlación positiva con los promedios del primer semestre cursado.

Cuadro 35. Resultados obtenidos con el programa SPSS para la prueba r correlación de Pearson.

\section{$\Rightarrow$ Correlaciones}
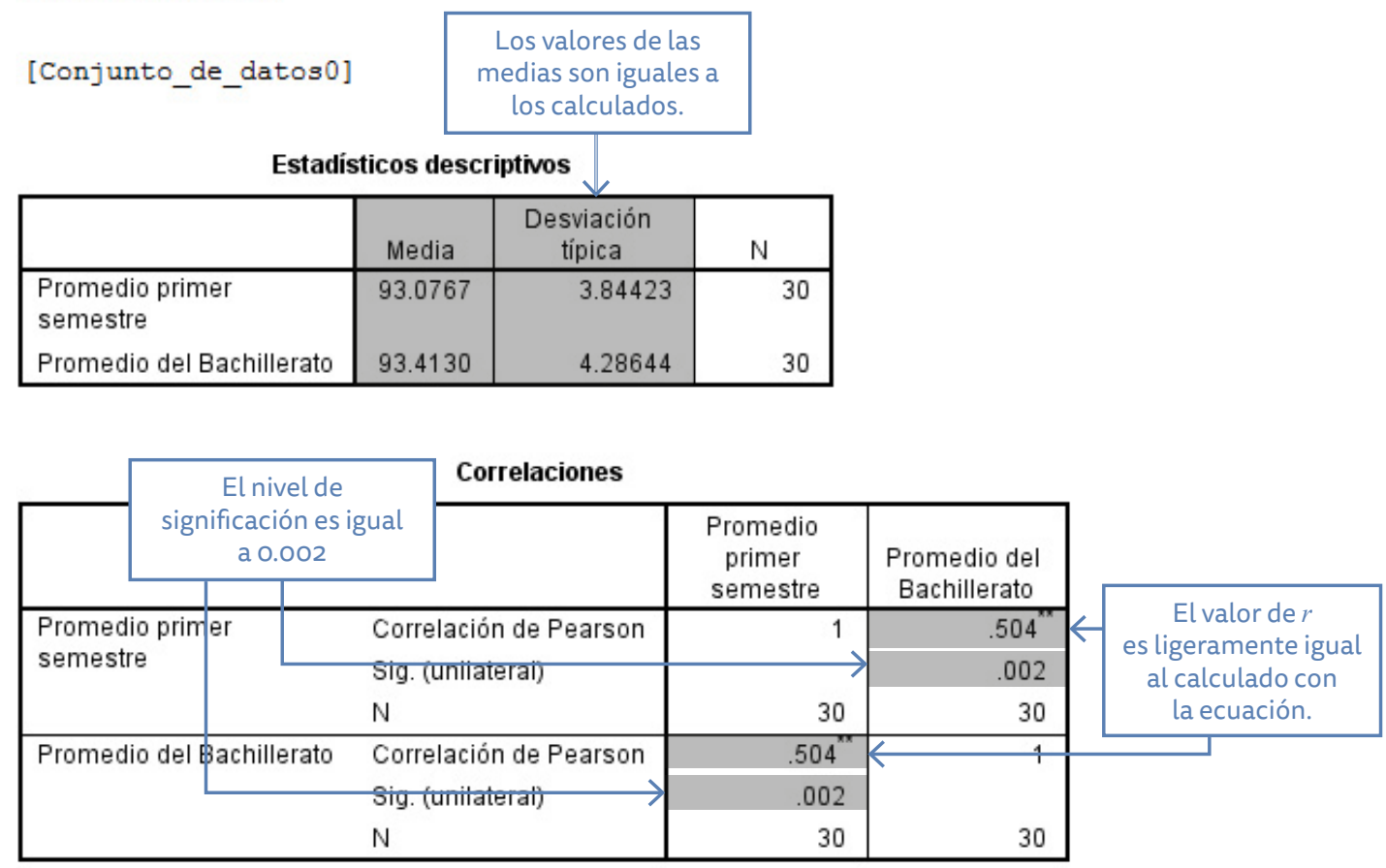

**. La correlación es significante al nivel 0,01 (unilateral). 



\section{Capítulo 17}

17. Coeficiente de correlación para datos ordinales de Spearman $\left(r_{s}\right)$ La correlación para datos ordinales permite determinar si existe una relación recíproca entre dos variables, se sugiere utilizar cuando existe una correlación entre los resultados y los datos son ordinales. Estos datos se colocan por rangos ordenados en relación a la presencia de una determinada característica.

Ejemplo 92. Se trata de aceptar o rechazar la siguiente hipótesis de investigación:

Hi: La predicción supone que la frecuencia con que participan alumnos en el salón de clase tiene una correlación positiva con las calificaciones obtenidas.

\subsection{Estado situacional}

Se pretende encontrar el grado de asociación que existe entre la frecuencia con que participan los alumnos de 5 grado de primaria durante la clase correspondiente al tema "La Guerra de Reforma" y los resultados del examen aplicado específicamente sobre ese tema, la muestra es igual a 18 alumnos.

Por medio de la observación se registró el número de veces que participó cada uno de los alumnos; la clase se desarrolló de manera que se propiciara la participación mediante comentarios, preguntas y observaciones por parte de los alumnos y el maestro; se le designó el valor de 1 , al alumno que reunió la menor cantidad de intervenciones, hasta llegar al valor de orden 18 que correspondió al alumno que participó un mayor número de veces.

Los resultados se emparejaron con las calificaciones obtenidas, éstas se ordenaron de acuerdo al valor obtenido otorgándole el valor más bajo (1) a la calificación más baja, hasta otorgar el valor 18 a la calificación mayor, quedando como se muestra en la Tabla 31.

\subsection{Explicación}

El coeficiente de correlación de rangos de Spearman rho, se debe utilizar con una o dos variables de escala ordinal. La rho de Spearman es en realidad el coeficiente de correlación lineal $r$ de Pearson, solo que se aplica a datos que satisfacen los requisitos de una escala ordinal (Greene y D'oliveira, 2006). 
Tabla 31. Resultados obtenidos por los alumnos del grupo de $5^{\circ}$ A, de acuerdo a su participación en clase y la calificación del examen aplicado.

\begin{tabular}{|c|c|c|c|c|c|c|}
\hline $\begin{array}{l}\text { Número } \\
\text { de } \\
\text { Alumno }\end{array}$ & $\begin{array}{c}\text { Participación } \\
\text { en clase }(X)\end{array}$ & Calificación & $\begin{array}{l}\text { Posición de } \\
\text { calificación }\end{array}$ & $\begin{array}{l}\text { Rango } \\
(I)\end{array}$ & $D=X-Y$ & $D^{2}=(X-Y)^{2}$ \\
\hline 1 & 18 & 91 & 17 & 17 & 1 & 1 \\
\hline 2 & 17 & 84 & 15 & 14 & 3 & 9 \\
\hline 3 & 16 & 92 & 18 & 18 & -2 & 4 \\
\hline 4 & 15 & 86 & 16 & 16 & -1 & 1 \\
\hline 5 & 14 & 84 & 14 & 14 & 0 & 0 \\
\hline 6 & 13 & 82 & 11 & 11 & 2 & 4 \\
\hline 7 & 12 & 83 & 12 & 12 & 0 & 0 \\
\hline 8 & 11 & 84 & 13 & 14 & -3 & 9 \\
\hline 9 & 10 & 76 & 6 & 5.5 & 3.5 & 12.25 \\
\hline 10 & 9 & 78 & 9 & 9 & 0 & 0 \\
\hline 11 & 8 & 81 & 10 & 10 & -2 & 4 \\
\hline 12 & 7 & 77 & 8 & 7.5 & -0.5 & 0.25 \\
\hline 13 & 6 & 74 & 4 & 4 & 2 & 4 \\
\hline 14 & 5 & 76 & 5 & 5.5 & -0.5 & 0.25 \\
\hline 15 & 4 & 72 & 3 & 3 & 1 & 1 \\
\hline 16 & 3 & 70 & $2^{\#}$ & 1.5 & 1.5 & 2.25 \\
\hline 17 & 2 & 77 & 7 & 7.5 & -5.5 & 30.25 \\
\hline 18 & 1 & 70 & $1^{\#}$ & 1.5 & -0.5 & 0.25 \\
\hline$N=18$ & \multicolumn{6}{|c|}{$\sum D^{2}=82.5$} \\
\hline
\end{tabular}

De la misma manera que la correlación $r$ de Pearson, con esta prueba se trata de comprobar si los resultados de una variable se relacionan con los resultados de la otra. Las correlaciones se miden en términos de coeficientes que pueden adquirir valores que representan correlaciones:

- Nula, en donde el valor del coeficiente de correlación es igual a cero, existiendo una total ausencia de correlación.

- Positiva, en donde el valor del coeficiente de correlación se encuentra entre los valores arriba de cero hasta +1 , en donde el 1 representa una correlación positiva perfecta. Esto significa que las dos variables se mueven en la misma dirección, si una aumenta la otra también.

- Negativa, en donde el valor del coeficiente de correlación se encuentra entre los valores abajo de cero hasta -1, en donde el -1 representa una correlación negativa perfecta. Esto significa que las dos variables se mueven en la dirección opuesta, si una aumenta la otra disminuye.

Los valores de correlación entonces en la mayoría de los casos se encuentran entre los valores extremos + 1 (positiva), - 1 (negativa) y cero (ausencia de correlación). 
En otras palabras, mientras más se aleje el coeficiente de correlación del valor de cero, existe una correlación más significativa. La ecuación para determinar el valor de $r_{\mathrm{s}}$ cuando no existen o existen unos cuantos empates, con respecto al número de parejas de datos es:

$$
r_{\mathrm{s}}=1-\frac{6 \sum D^{2}}{N\left(N^{2}-1\right)}
$$

Donde:

$r_{\mathrm{s}}=$ coeficiente de correlación para rangos ordenados.

$D=$ diferencia de rangos entre las variables $X, Y$.

$N=$ número total de casos.

\subsection{Procedimiento para determinar el valor de $r_{\mathrm{s}}$}

1. Colocar por rangos a los participantes sobre las variables $X, Y$. Colocando por rangos a los alumnos por su participación en relación a la $X$, asignando el rango de 1 al alumno que participó menos y el rango de 18 al alumno que participó más.

2. Colocar por rangos a los alumnos en términos de $Y$, la calificación obtenida en el examen. Se puede observar que se tienen casos de rangos empatados.

3. Resolver los casos empatados. En la vida real no es siempre posible colocar a los participantes por rangos ordenados evitando los empates, este caso no es la excepción ya que resulta difícil que más de alguno de los alumnos obtenga la misma calificación que otro dependiendo del número de aciertos en el examen.

Se observa en la Tabla 31 que existen valores empatados en los resultados de las calificaciones, como es el caso del alumno 18 y el 16 que ocupan las dos primeras posiciones de la calificación para el puntaje de calificación 70, en estos casos es necesario determinar la posición exacta, sumando las posiciones de calificación empatadas y dividiendo entre el número de empates, obteniendo el rango promedio, esto es:

$$
\frac{\text { Suma de posiciones de calificación empatadas }}{\text { Número de empates }}=\frac{1+2}{2}=1.5
$$

Siguiendo este procedimiento se encuentra la posición para los puntajes de calificación 76, 77 y 84, quedando como sigue:

$$
\begin{gathered}
\text { 76) } \frac{5+6}{2}=5.5 \\
\text { 77) } \frac{7+8}{2}=7.5 \\
\text { 84) } \frac{13+14+15}{3}=14
\end{gathered}
$$

Estos resultados se sustituyen en la columna del rango, quedando como se muestra en la Tabla 31.

4. Encontrar las diferencias entre los rangos $X$ e $Y$, donde $D=X-Y$, hasta completar la tabla.

5. Elevar al cuadrado estas diferencias, $D^{2}=(X-Y)^{2}$, hasta completar la tabla.

6. Obtener la suma de los cuadrados de las diferencias $\Sigma D^{2}$.

7. Sustituir los resultados en la fórmula para el coeficiente de correlación para rangos ordenados de Spearman. 


$$
r_{\mathrm{S}}=1-\frac{6 \sum \mathrm{D}^{2}}{N\left(N^{2}-1\right)}
$$

Donde:

$$
\begin{aligned}
& N=18 \text { y } D^{2}=86.25 \\
& r_{\mathrm{S}}=1-\frac{6(82.5)}{18\left(18^{2}-1\right)}=1-\frac{495}{5814}=0.91
\end{aligned}
$$

8. Comparar el coeficiente de correlación por rangos ordenados obtenido con el valor correspondiente al de la Tabla J del Apéndice $D$.

En la Tabla J del anexo se encuentran los valores críticos de $r$ para la correlación por rangos ordenados, el valor calculado debe ser mayor que los valores encontrados en esta tabla, para encontrar este valor se localiza la fila correspondiente a $N$, para este caso $N=18$. El valor crítico para un nivel de significación $\rho=0.01$ es $r_{\mathrm{s}}=0.625$.

El valor calculado para $r_{\mathrm{s} \text { calculada }}=0.91$, como el valor es mayor que el valor crítico de $r_{\text {s tabla }}=0.625$ se puede rechazar la hipótesis nula y se acepta la de trabajo lo que significa que sí existe una correlación positiva entre la participación de los alumnos y la calificación del examen aplicado en los alumnos de 5 ㅇ A.

$$
r_{\text {s calculada }}=0.91>r_{\text {s tabla }}=0.625 \text { Para un nivel de significación } \rho<0.01
$$

17.4 Prueba del Coeficiente de correlación para datos ordinales de Spearman $\left(r_{s}\right)$ con el programa SPSS

El programa SPSS para esta prueba permite determinar el nivel de significación comparándolo con el nivel mínimo utilizado por los investigadores en educación que corresponde a $\rho<0.05$, si el que se determine mediante el proceso del programa resulta mayor que este valor, entonces se puede decir que las diferencias de los resultados son causadas por variables aleatorias y se debe aceptar la hipótesis nula, pero si el valor es menor entonces las diferencias son significativas y se debe rechazar la hipótesis nula y aceptar la hipótesis de investigación.

El primer paso consiste en otorgarle las propiedades a las variables, una vez abierto el programa y antes de introducir los datos, es necesario definir las variables y otorgarle las características para su presentación en la tabla, para esto se requiere dar un clic en la pestaña Vista de variables. En este caso las acciones indispensables para obtener los resultados correctos son:

- Designar los nombres de las variables. Para realizar esto es necesario presionar la ceja de Vista de variables, y en seguida teclear el nombre de cada variable, primero en la columna Nombre (primera) y la fila 1, la palabra VariableX, debe ir sin espacio entre la palabra debido a que el programa no reconoce caracteres vacíos, segundo en la columna Nombre pero ahora en la fila 2, escribir Calificación, por último en la fila tres escribir VariableY.

- Definir el tipo de medida que se realizó. En este ejemplo los datos para las variables X e $Y$ son ordinales por lo que se requiere que en la columna Medida se seleccione la opción Ordinal y los valores de los datos de Calificación son de intervalo, se requiere que en la columna Medida se seleccione la opción Escala. 
El programa preselecciona el tipo de variables como numérico, para darle presentación a los datos se pueden realizar las siguientes operaciones (pero no es necesario): definir la Anchura (8) y cantidad de Decimales (2) requeridos y la Alineación (centrado).

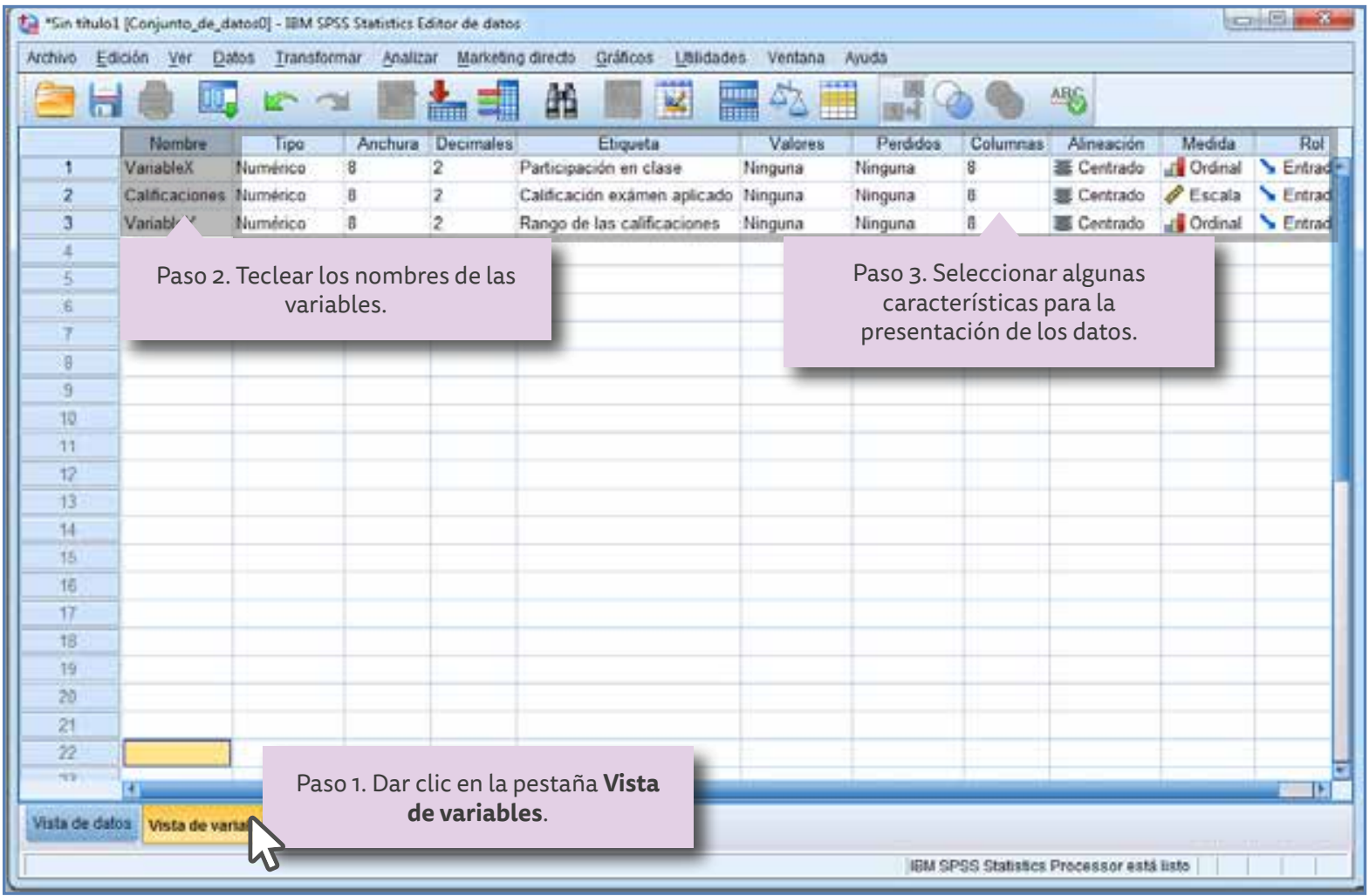

Figura 128. Designación de variables y sus características para la prueba $r_{s}$ correlación de Spearman.

En el siguiente cuadro se observan las variables seleccionadas en este ejemplo:

Cuadro 36. Designación de variables para la prueba de Correlación de Spearman.

\begin{tabular}{l|l|}
\hline Nombre: VariableX & Nombre: Calificaciones \\
\hline Tipo: Numérico & Tipo: Numérico \\
\hline Anchura: 8 & Anchura: 8 \\
\hline Decimales: 2 & Decimales: 2 \\
\hline Etiqueta: Participación en clase & $\begin{array}{l}\text { Etiqueta: Calificación examen } \\
\text { aplicado }\end{array}$ \\
\hline Valores: Ninguno & Valores: Ninguno \\
\hline Perdidos: Ninguno & Perdidos: Ninguno \\
\hline Columnas: 8 & Columnas: 8 \\
\hline Alineación: Centrado & Alineación: Centrado \\
\hline Medida: Ordinal & Medida: Escala \\
\hline Rol: Entrada & Rol: Entrada
\end{tabular}

Nombre: VariableY

Tipo: Numérico

Anchura: 8

Decimales: 2

Etiqueta: Rango de las calificaciones

Valores: Ninguno

Perdidos: Ninguno

Columnas: 8

Alineación: Centrado

Medida: Ordinal

Rol: Entrada

Una vez designados los nombres de las variables y sus características se introducen los datos en la tabla, para llevar a cabo esto se requiere dar clic en la pestaña Vista de datos, e introducir los datos correspondientes a cada variable, los datos se pueden introducir uno por uno tecleándolos o bien importarlos (seleccionar, copiar y pegar) de la Tabla 31, en donde se encuentran ubicados y pegarlos dentro de esta tabla. 
En realidad solo se requieren los datos de origen, que en este caso son el orden de frecuencias de participación en clase y las calificaciones, también se puede realizar el cálculo con el programa SPSS utilizando los datos del rango (Variable Y) en lugar de las calificaciones, obteniendo los mismos resultados.

En la Figura 129 se observa cómo quedan los datos siguiendo cualquiera de los procedimientos mencionados y de acuerdo a las características seleccionadas en los pasos anteriores.

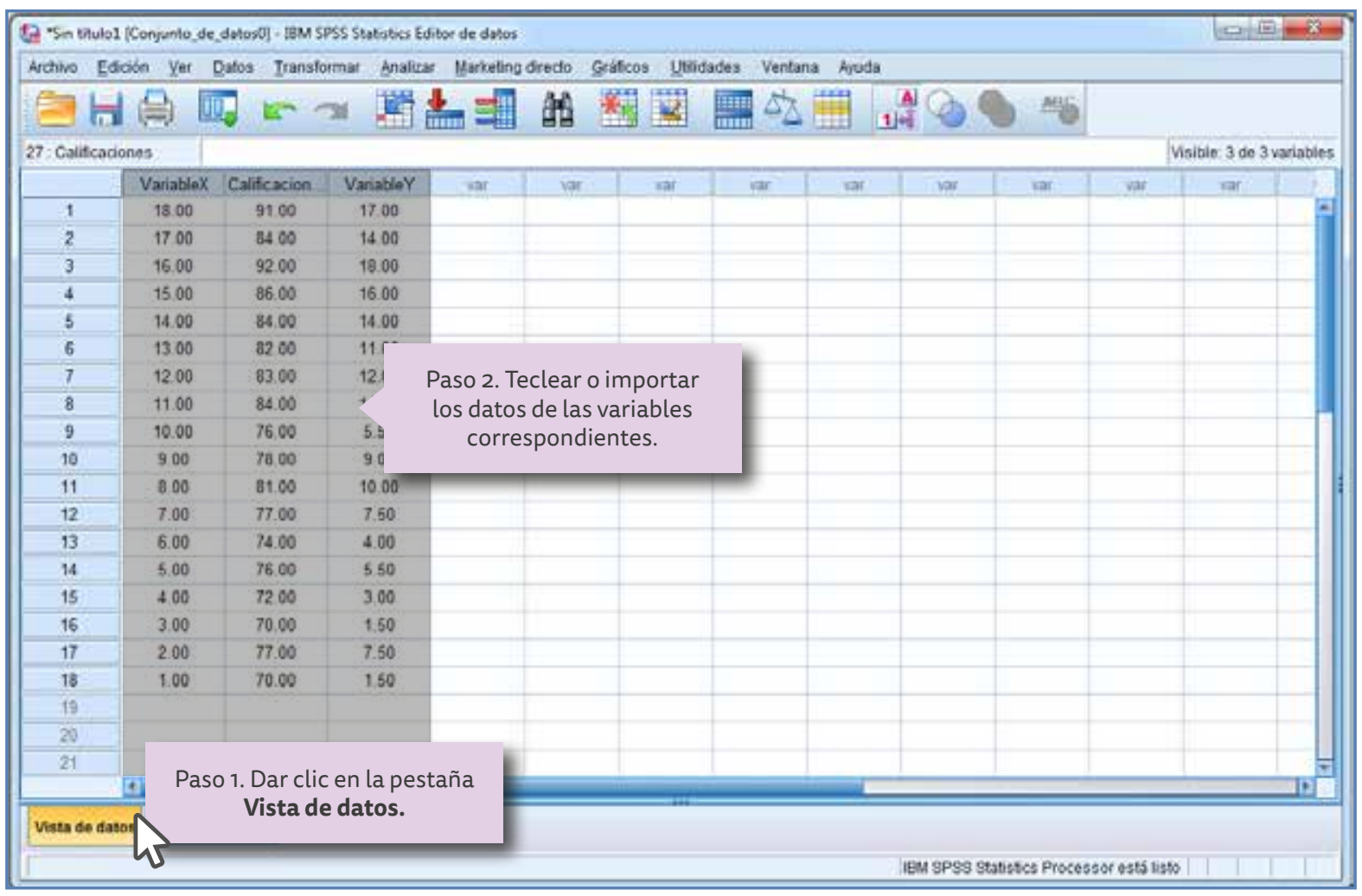

Figura 129. Presentación de la Variable X, las Calificaciones y la Variable Y.

Una vez que los datos se encuentran en la tabla se realiza la prueba (Figura 130), para hacerlo es necesario dar un clic en la pestaña ubicada en la barra superior designada como Analizar, en seguida aparece un cuadro de diálogo, en donde se selecciona la línea que indica Correlaciones, al ubicar el apuntador del ratón en esta opción se presenta a la derecha otro cuadro de diálogo, se selecciona Bivariadas (que son las que corresponden a dos variables) y se da clic con el ratón.

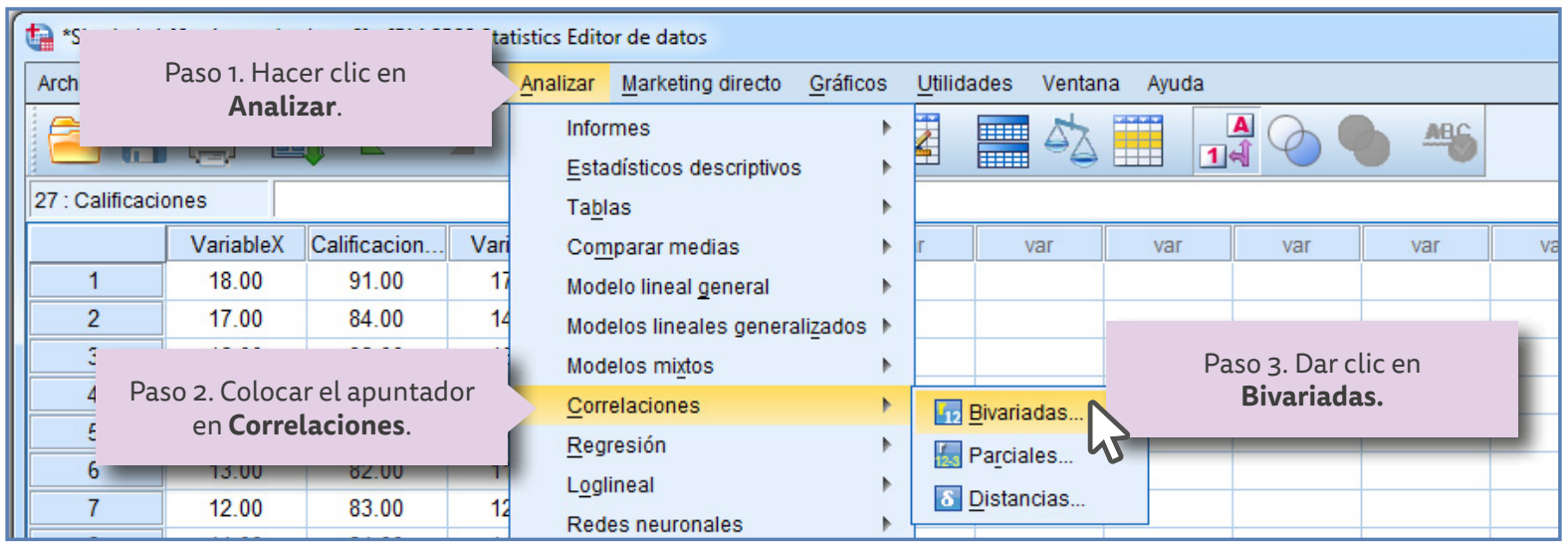

Figura 130. Cuadros de diálogo para seleccionar la prueba r correlación de Pearson. 
Aparece inmediatamente la ventana de la Figura 131 en donde se muestran las variables del lado izquierdo, VariableX (participación en clase), Calificaciones (calificación de examen aplicado) y VariableY (rango de calificaciónes), éstas deben ser trasladadas a la ventana que dice Variables, en este caso solo se seleccionan las dos primeras; la forma de hacerlo es seleccionando con un clic la variable (A) deseada (VariableX) y se da un clic en la flecha que se ubica entre las dos ventanas, repitiendo esta operación para la variable B (Calificaciones).

Se selecciona el tipo de prueba que se requiere activando con el ratón en donde indica el Coeficiente de correlación, la ventana correspondiente a Spearman (Deseleccionar Pearson).

Es importante recordar que se trata de una hipótesis unilateral puesto que se busca una correlación positiva de acuerdo a la propuesta de la investigación, esto es, no se busca solo la correlación (que puede ser positiva, negativa o nula) pues sería en tal caso una hipótesis bilateral. Debido a esto se debe seleccionar con un clic la opción Unilateral.

Una vez realizadas estas acciones el programa queda listo para arrojar los resultados, al activar el botón Aceptar (Figura 133) se obtienen los resultados que se muestran en el Cuadro 37.

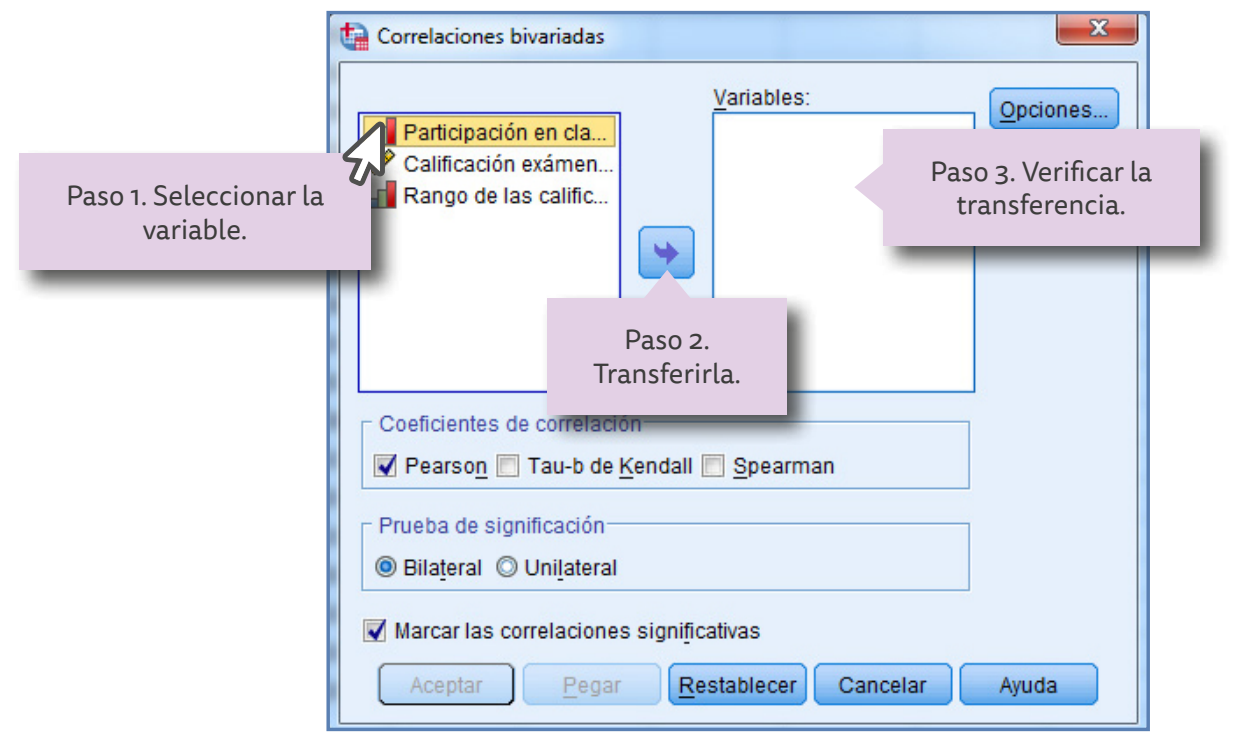

Figura 131. Transferencia de la VariableX (participación en clase) para procesar los datos con el programa SPSS.

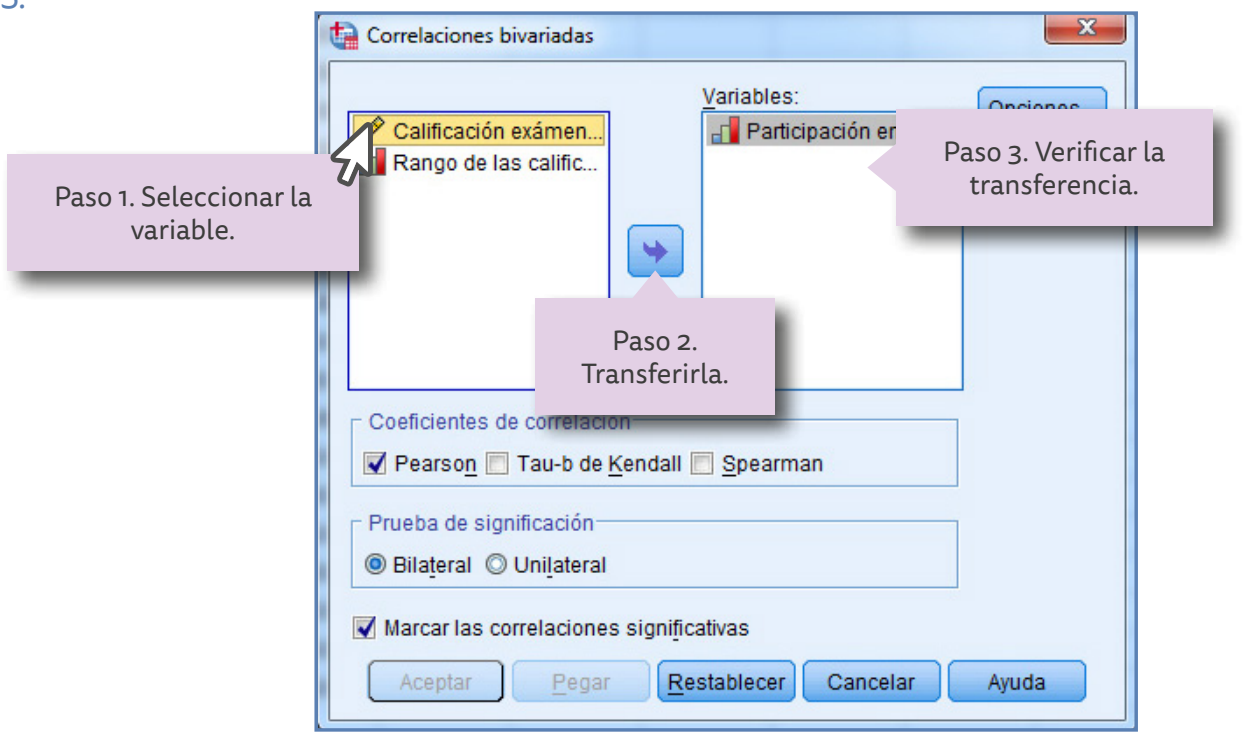

Figura 132. Transferencia de la variable Calificaciones (Calificación examen aplicado) para procesar los datos con el programa SPSS. 


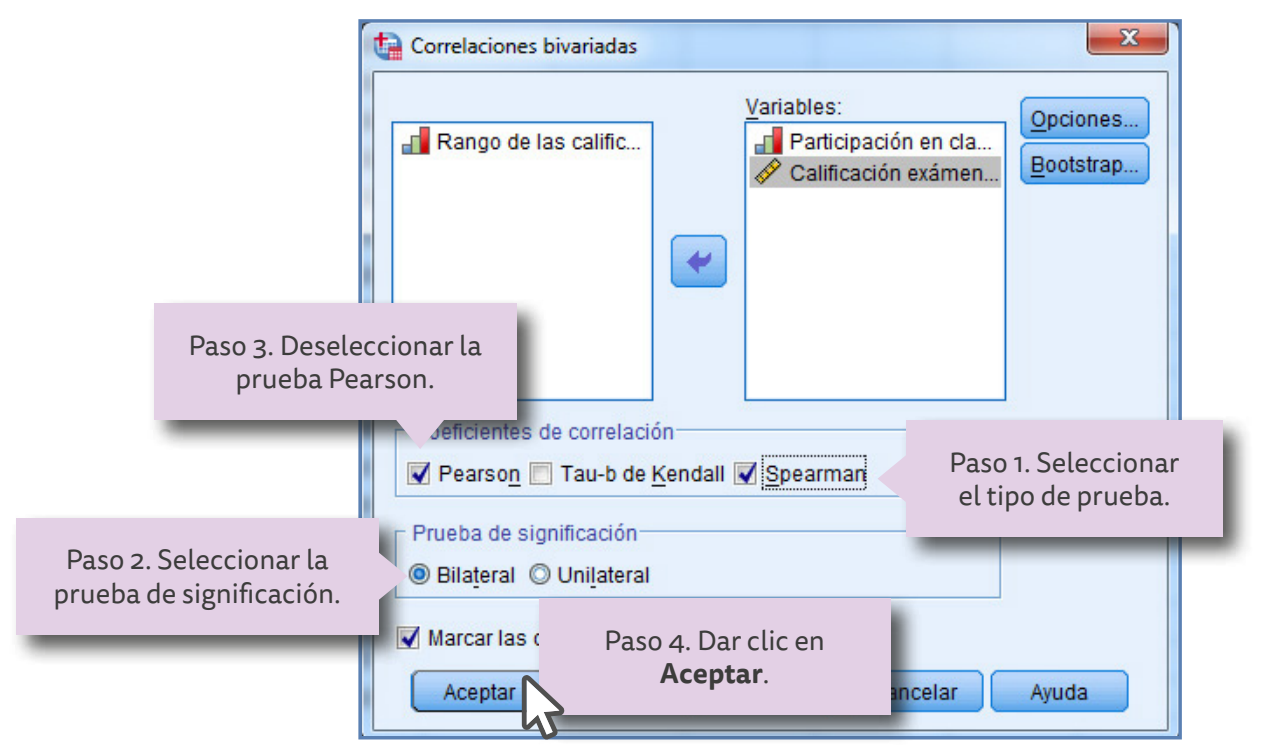

Figura 133. Paso para ejecutar el programa SPSS para que realice los cálculos requeridos para la prueba $r_{s}$ correlación de Spearman.

En el cuadro se pueden observar que el valor del nivel de significación [Significación asintótica] $\rho<0.000$.

$$
\text { Entonces se puede concluir que } \rho_{\text {encontrada }} 0.000<\rho_{\text {aceptada }} 0.05
$$

Esto es, el valor encontrado 0.000 es menor que el mínimo aceptable por los investigadores en educación (0.05), lo que significa que los resultados de la diferencia no son aleatorios puesto que existe una diferencia significativa, por lo que se puede rechazar la hipótesis nula y aceptar la hipótesis de investigación.

También se puede observar que el valor de $r_{s}$ calculado por medio del programa es bastante aproximado al valor calculado utilizando la fórmula.

$$
r_{\text {calculado }}=0.91 \text { y } r_{\text {SPSS }}=0.0 .9064
$$

El programa SPSS compara los datos con los de la Tabla J y valida la correlación con nivel de significación de $\rho=0.01$ siendo éste menor que el valor del nivel de significación aceptado por los investigadores $\rho_{\text {aceptada }} 0.05$.

Por lo tanto se acepta:

Hi: La predicción supone que la frecuencia con que participan alumnos en el salón de clase tiene una correlación positiva con las calificaciones obtenidas. 
Cuadro 37. Resultados obtenidos con el programa SPSS para la prueba $r_{s}$ correlación de Spearman.

$\Rightarrow$ Correlaciones no paramétricas

[Conjunto_de_datos0]

El valor de $r_{\mathrm{s}}$ es ligeramente igual al

calculado con la ecuación.

\begin{tabular}{|c|c|c|c|c|}
\hline \multicolumn{5}{|c|}{ Correlaciones } \\
\hline & & & $\begin{array}{c}\text { Participlación } \\
\text { en clase }\end{array}$ & $\begin{array}{l}\text { Calificación } \\
\text { exárnen } \\
\text { aplidado }\end{array}$ \\
\hline \multirow[t]{6}{*}{ Rho de Spearman } & \multirow[t]{3}{*}{ Participación en clase } & $\begin{array}{l}\text { Coeficiente de } \\
\text { correlación }\end{array}$ & \multirow[t]{2}{*}{1.000} & .906 \\
\hline & & Sig. (unilateral) & & .000 \\
\hline & & $\mathrm{N}$ & $\downarrow 18$ & 个 18 \\
\hline & \multirow[t]{3}{*}{$\begin{array}{l}\text { Calificación exámen } \\
\text { aplicado }\end{array}$} & $\begin{array}{l}\text { Coeficiente de } \\
\text { correlación }\end{array}$ & $.906^{\mathrm{m}}$ & \multirow[t]{2}{*}{1.000} \\
\hline & & Sig. (unilateral) & .000 & \\
\hline & & $\mathrm{N}$ & 个 18 & 18 \\
\hline \multicolumn{5}{|c|}{${ }^{\star \star}$. La correlación es significativa al nivel 0,01 (unilateral). } \\
\hline & & & \multicolumn{2}{|c|}{ El nivel de significación. } \\
\hline
\end{tabular}





\section{Capítulo 18}

\section{Análisis de regresión lineal simple}

La correlación entre dos variables tiene otra utilidad que permite predecir los valores de una Variable $\mathbf{Y}$ conociendo los valores de otra Variable $\boldsymbol{X}$. El análisis de regresión es una técnica que permite establecer esta predicción. Tanto la correlación como la regresión lineal se pueden representar por medio de gráficos conocidos como diagramas de dispersión.

En el caso de la correlación el interés se centra en saber si existe tal correlación entre las dos variables. La regresión lineal pretende ir más allá de la correlación entre las dos variables, en este caso, se pretende utilizar los resultados de una variable $(X)$ para predecir los resultados de la otra variable $(Y)$, a estas variables se les denomina:

- Variable explicativa o predictiva, es la que se selecciona para predecir los resultados de la otra variable, usualmente denominada por medio de la letra $X$.

- Variable explicada, es aquella en la cual los resultados se deben predecir, usualmente denominados por medio de la letra $Y$.

Para el ejemplo del capítulo anterior la variable explicativa representa los valores de los resultados obtenidos en los promedios del bachillerato $(X)$, que son utilizados para predecir los resultados obtenidos como promedios del primer semestre $(Y)$.

Diagramas de dispersión. Éstos permiten mostrar las relaciones entre las variables, son gráficos con una serie de puntos que representan los resultados de las variables, pueden representar una correlación entre los resultados o bien mostrar la relación entre la variable explicativa y la variable explicada pronosticada.

Ejemplo 93. Se trata de aceptar o rechazar la siguiente hipótesis de investigación: Hi: La predicción afirma que la variable explicativa siguiente: los promedios del bachillerato tienen un efecto sobre los resultados de la variable explicada, esto es, sobre los resultados obtenidos por los alumnos de la licenciatura en Medicina como promedio del primer semestre.

\subsection{Estado situacional}

Los aspectos que motivaron realizar esta investigación en el nivel universitario, tienen su origen en determinar si la exigencia de un promedio mínimo obtenido por el aspirante durante su estancia en el bachillerato, es un elemento suficiente para justificar la permanencia ante los lineamientos que se requieren para no fracasar durante el proceso de la licenciatura en Medicina.

En este caso se trata de determinar si la variable explicativa (promedios obtenidos por cada uno de los participantes al concluir el bachillerato) tienen efecto en el promedio del primer semestre, con una visión hacia el futuro, en lo referente a determinar la posibilidad de que 
todos los participantes concluyan favorablemente su licenciatura. Se trata de una hipótesis unilateral ya que predice un efecto positivo entre la variable explicativa $X$ y la explicada $Y$.

Con la finalidad de ir más allá de determinar solo la correlación de Pearson, se propone en este apartado continuar con el ejercicio presentado en el capítulo anterior, como primer paso determinar la correlación entre $X$ y la $Y$ por medio de los puntos generados por el diagrama de dispersión.

También se pretende identificar la línea imaginaria entre esos puntos como una línea de regresión, como una línea recta que se dibuja a través del diagrama de dispersión, que representa el mejor arreglo posible para realizar las predicciones de $X$ sobre $Y$.

\subsection{Explicación}

La regresión lineal consiste en una serie de procedimientos adecuados para predecir datos, suponiendo que existe una relación lineal entre las variables $X$ e $Y$. Si la relación no es lineal, la predicción no será muy precisa. Como consecuencia los supuestos que se deben de tomar en cuenta al realizar el análisis de la regresión lineal son (Greene y D’oliveira, 2006):

- La relación entre $X$ e $Y$ debe ser lineal, esta relación puede ser positiva o negativa pero nunca debe ser curvilínea.

- Se debe utilizar en sujetos en los que una de las variables es desconocida, en esta situación se debe inferir a la población o grupo por medio de una muestra aleatoria que se utiliza para determinar la línea de regresión.

- La ecuación de regresión lineal se utiliza solo para el rango de la variable en la cual se basa. Por ejemplo, si los valores oscilan entre 80 y 100 no se puede aplicar a valores menores de 80 o mayores de 100, ni en un rango de escala diferente, por ejemplo de 8 a 10.

- La línea de regresión se debe ajustar a los puntos de los datos de acuerdo con un criterio de mínimos cuadrados.

- Los errores de predicción se cuantifican calculando el error estándar de estimación, mientras menor sea este valor mayor será la confianza que se tendrá en la predicción.

Se trata de trazar una línea en el diagrama de dispersión que conecte los resultados de la variable explicativa $(X)$ y los resultados pronosticados para la variable $Y\left(Y^{\prime}\right)$, a esta línea se le conoce como línea de regresión que muestra la predicción de los resultados de $Y^{\prime}$ a partir de los valores de los resultados de $x$, mediante la ecuación de una recta que viene dada por la fórmula:

$$
Y^{\prime}=b_{y} X+a_{y}
$$

La pendiente de la línea de regresión representa la medida en que los resultados de $Y^{\prime}$ son predecibles a partir de los resultados de la variable explicativa $x$, para poder inferir los resultados pronosticados para $Y^{\prime}$ en la población o grupo partiendo de los resultados de $X$.

\subsection{Construcción de la recta de regresión por mínimos cuadrados}

Se trata de trazar la línea de regresión en el diagrama de dispersión que conecte los resultados de la variable explicativa $X$ y los resultados pronosticados para la variable $Y\left(Y^{\prime}\right)$. Esta línea muestra los resultados de $Y^{\prime}$ a partir de los resultados de $X$. La ecuación general de una recta se determina como sigue, pero en este contexto representa la línea de regresión, donde $a_{y}$ y $b_{y}$ se denominan constantes de regresión. 


$$
Y^{\prime}=b_{y} X+a_{y}
$$

Donde:

$Y^{\prime}=$ el valor calculado como predicción para $Y$.

$b_{y}=$ pendiente de la recta que minimiza los errores de predicción de $Y$.

$a_{y}=$ ordenada al origen de la recta que minimiza los errores de predicción de $Y$.

La constante de regresión $b_{y}$ se determina por medio de la siguiente ecuación:

$$
b_{y}=\frac{\sum X Y-\frac{\left(\sum X\right)\left(\sum Y\right)}{N}}{S C_{\mathrm{x}}}
$$

Donde:

$S C \mathrm{x}=$ suma de los cuadrados de los datos $X$.

$N=$ número de parejas de datos.

$\Sigma X Y=$ suma de los productos de cada par de $X$ e $Y$ (suma de productos cruzados).

$\Sigma X=$ suma de los valores de los datos de la variable $X$.

$\sum Y=$ suma de los valores de los datos de la variable $Y$.

$\sum x^{2}=$ suma de los valores de los datos de la variable y elevado al cuadrado.

Entonces:

$$
S C \mathrm{x}=\sum X^{2}-\frac{\left(\sum X\right)^{2}}{N}
$$

Sustituyendo se obtiene la ecuación para calcular la constante de regresión $b_{y}$ para predecir $Y$ dado por $X$ con los datos obtenidos en la tabla.

$$
b_{y}=\frac{\sum X Y-\frac{\left(\sum X\right)\left(\sum Y\right)}{N}}{\sum X^{2}-\frac{\left(\sum X\right)^{2}}{N}}
$$

La constante de regresión $a$ se determina por medio de la ecuación para calcular la constante de regresión $a_{y}$ para predecir $y$ dado por $X$ con los datos obtenidos en la tabla.

Donde:

$$
a_{y}=\overline{\mathrm{Y}}-b_{y} \overline{\mathrm{X}}
$$

$\bar{X}=$ media muestral de la distribución de la variable $X$
$\bar{Y}=$ media muestral de la distribución de la variable $Y$.

$$
\overline{\mathrm{X}}=\frac{\sum X}{N} \quad \overline{\mathrm{Y}}=\frac{\sum Y}{N}
$$


18.3.1 Procedimiento para determinar el valor del pronóstico $Y^{\prime}$ para la construcción de la recta de regresión por mínimos cuadrados

1. Elaborar la tabla para calcular los valores requeridos para determinar las constantes de regresión (Tabla 32).

2. Calcular la constante de regresión $b_{y}$ para predecir $Y$ dado por $X$ con los datos obtenidos en la tabla.

$$
\begin{gathered}
b_{y}=\frac{\sum X Y-\frac{\left(\sum X\right)\left(\sum Y\right)}{N}}{\sum X^{2}-\frac{(\Sigma X)^{2}}{N}}= \\
b_{y}=\frac{261081.52-\frac{(2802.43)(2792.30)}{30}}{262320.19-\frac{(2802.43)^{2}}{30}} \\
b_{y}=\frac{240.67}{533.05}=0.45
\end{gathered}
$$

3. Calcular los valores de las medias muestrales de la distribución de las variables $X$ e $Y$.

$$
\overline{\mathrm{X}}=\frac{\sum X}{N}=\frac{2802.43}{30}=93.41 \text { y } \overline{\mathrm{Y}}=\frac{\sum Y}{N}=\frac{2792.30}{30}=93.07
$$

4. Calcular la constante de regresión $a_{y}$ para predecir $Y$ dado por $X$ con los datos obtenidos en la Tabla 32.

$$
\begin{gathered}
a_{y}=\overline{\mathrm{Y}}-\mathrm{b}_{\mathrm{y}} \overline{\mathrm{X}}= \\
a_{y}=93.07-b_{y}(93.41)= \\
a_{y}=93.07-0.45(93.41)=51.03
\end{gathered}
$$

5. Sustituir en la ecuación de la recta las constantes de regresión:

$$
\begin{gathered}
Y^{\prime}=b_{y} X+a_{y} \\
Y^{\prime}=0.45 X+51.03
\end{gathered}
$$

6. Calcular los valores de $Y^{\prime}$ para los valores de $X$.

Ejemplo: Para el valor de $X_{1}=95.3$ sustituyendo en la ecuación

$$
Y_{1}^{\prime}=0.45(95.3)+51.03=93.91
$$


Tabla 32. Relación de los resultados obtenidos por la variable explicativa, explicada y la predictiva.

\begin{tabular}{|c|c|c|c|c|c|}
\hline $\begin{array}{c}\text { No } \\
\text { Alumno }\end{array}$ & $\begin{array}{c}\text { Variable } X \\
\text { Promedio del } \\
\text { Bachillerato }\end{array}$ & $\begin{array}{l}\text { Variable Y } \\
\text { Promedio 1er } \\
\text { semestre }\end{array}$ & $X Y$ & $x^{2}$ & $Y^{2}$ \\
\hline 1 & 95.30 & 98.50 & 9387.05 & 9082.09 & 9702.25 \\
\hline 2 & 93.41 & 97.10 & 9070.11 & 8725.42 & 9428.41 \\
\hline 3 & 89.00 & 93.33 & 8306.37 & 7921.00 & 8710.48 \\
\hline 4 & 94.56 & 96.00 & 9077.76 & 8941.59 & 9216.00 \\
\hline 5 & 94.43 & 96.00 & 9065.28 & 8917.02 & 9216.00 \\
\hline 6 & 95.71 & 89.60 & 8575.61 & 9160.40 & 8028.16 \\
\hline 7 & 94.94 & 87.38 & 8295.85 & 9013.60 & 7635.26 \\
\hline 8 & 90.84 & 94.90 & 8620.71 & 8251.90 & 9006.01 \\
\hline 9 & 92.30 & 92.80 & 8565.44 & 8519.29 & 8611.84 \\
\hline 10 & 89.00 & 95.33 & 8484.37 & 7921.00 & 9087.80 \\
\hline 11 & 98.00 & 97.00 & 9506.00 & 9604.00 & 9409.00 \\
\hline 12 & 98.00 & 94.33 & 9244.34 & 9604.00 & 8898.14 \\
\hline 13 & 82.00 & 84.89 & 6960.98 & 6724.00 & 7206.31 \\
\hline 14 & 96.53 & 94.60 & 9131.73 & 9318.04 & 8949.16 \\
\hline 15 & 97.00 & 95.89 & 9301.33 & 9409.00 & 9194.89 \\
\hline 16 & 100.00 & 97.00 & 9700.00 & 10000.00 & 9409.00 \\
\hline 17 & 96.00 & 96.30 & 9244.80 & 9216.00 & 9273.69 \\
\hline 18 & 91.60 & 89.67 & 8213.77 & 8390.56 & 8040.70 \\
\hline 19 & 94.12 & 90.33 & 8501.85 & 8858.57 & 8159.50 \\
\hline 20 & 95.00 & 88.40 & 8398.00 & 9025.00 & 7814.56 \\
\hline 21 & 91.22 & 92.33 & 8422.34 & 8321.08 & 8524.82 \\
\hline 22 & 81.23 & 89.32 & 7255.46 & 6598.31 & 7978.06 \\
\hline 23 & 88.38 & 84.51 & 7468.99 & 7811.02 & 7141.94 \\
\hline 24 & 93.58 & 94.48 & 8841.43 & 8757.21 & 8926.47 \\
\hline 25 & 91.46 & 94.00 & 8597.24 & 8364.93 & 8836.00 \\
\hline 26 & 93.02 & 92.80 & 8632.25 & 8652.72 & 8611.84 \\
\hline 27 & 95.92 & 94.30 & 9045.25 & 9200.64 & 8892.49 \\
\hline 28 & 97.02 & 97.45 & 9454.59 & 9412.88 & 9496.50 \\
\hline 29 & 95.58 & 96.20 & 9194.79 & 9135.53 & 9254.44 \\
\hline 30 & 97.28 & 87.56 & 8517.83 & 9463.39 & 7666.75 \\
\hline Suma & 2802.43 & 2792.30 & 261081.52 & 262320.19 & 260326.47 \\
\hline
\end{tabular}


18.4 Construcción de la recta de regresión utilizando el coeficiente de correlación.

Se traza la línea de regresión en el diagrama de dispersión que conecte los resultados de la variable explicativa $X$ y los resultados pronosticados para la variable $Y\left(Y^{\prime}\right)$. Esta línea muestra los resultados de $Y^{\prime}$ a partir de los resultados de $X$. Utilizando la ecuación de regresión se define la línea de regresión, ésta se representa por medio de la siguiente fórmula:

$$
Y^{\prime}=r\left(\frac{S_{y}}{S_{x}}\right) X-r\left(\frac{S_{y}}{S_{x}}\right) \overline{\mathrm{X}}+\overline{\mathrm{Y}}
$$

Donde:

$$
\begin{aligned}
& Y^{\prime}=\text { valor calculado como predicción para } Y \\
& r=\text { coeficiente de correlación de Pearson. } \\
& S_{y}=\text { desviación estándar muestral de la distribución de la variable } Y \text {. } \\
& S_{x}=\text { desviación estándar muestral de la distribución de la variable } X \text {. } \\
& X=\text { valor dado de } X \text {. } \\
& \bar{X}=\text { media muestral de la distribución de la variable } X . \\
& \bar{Y}=\text { media muestral de la distribución de la variable } Y .
\end{aligned}
$$

Esta ecuación corresponde a la fórmula matemática de una línea recta que representa el efecto de los resultados de la variable explicativa $X$, sobre los resultados pronosticados de $Y^{\prime}$. Esto es, la pendiente de la línea de regresión representa la medida en que los valores encontrados por $Y^{\prime}$ son predecibles como consecuencia de los resultados de la variable explicativa $X$.

Error residual. Este error se mide como la diferencia entre los resultados reales y los pronosticados por la línea de regresión, se pueden concebir como las desviaciones en los resultados respecto de los resultados pronosticados. El error es lo que queda después de haber considerado la varianza esperada. Estas desviaciones se determinan como la diferencia entre los valores de los resultados pronosticados $Y^{\prime}$ y los resultados reales de $Y$, esto es, el error residual que es igual, por lo tanto a $Y-Y^{\prime}$.

18.4.1 Procedimiento para determinar el valor del pronóstico $Y^{\prime}$ para la construcción de la recta de regresión utilizando el coeficiente de correlación

1. Encontrar el coeficiente de correlación de Pearson $r$, utilizando la siguiente fórmula (ver Tabla 30, Capítulo 16):

$$
r=\frac{N\left(\sum X Y\right)-\left(\sum X\right)\left(\sum Y\right)}{\sqrt{\left[N \sum X^{2}-\left(\sum X\right)^{2}\right]\left[N \sum Y^{2}-\left(\sum Y\right)^{2}\right]}}
$$

Donde:

$$
\begin{aligned}
& r=\text { coeficiente de correlación de Pearson } \\
& N=\text { número de participantes }=30 \\
& \sum(X Y)=\text { suma del producto de } X Y=261081.612 \\
& \sum X=\text { total para la variable } X=2802.43 \\
& \sum Y=\text { total para la variable } Y=2792.3
\end{aligned}
$$


$(\Sigma X)^{2}=$ cuadrados totales para $X=(2802.43)^{2}=7853613.9$

$(\Sigma Y)^{2}=$ cuadrados totales para $Y=(2792.3)^{2}=7796939.29$

$\Sigma X^{2}=$ suma de $X$ elevada al cuadrado $=262320.271$

$\Sigma Y^{2}=$ suma de $Y$ elevada al cuadrado $=260326.541$

Sustituyendo:

$$
\begin{gathered}
r=\frac{30(261081.612)-(2802.43)(2792.3)}{\sqrt{\left[30(262320.271)-(2802.43)^{2}\right]\left[30(260326.541)-(2792.3)^{2}\right]}} \\
r=\frac{7223.071}{\sqrt{[15994.2251][12856.94]}} \\
r=\frac{7223.071}{14340.04158}=0.503
\end{gathered}
$$

2. Calcular la media muestral para $X$ e $Y$.

$$
\begin{gathered}
\bar{X}=\frac{\sum X}{N} \quad \overline{\mathrm{Y}}=\frac{\sum Y}{N} \\
\overline{\mathrm{X}}=\frac{2802.43}{30}=93.41 \\
\overline{\mathrm{Y}}=\frac{2792.3}{30}=93.07
\end{gathered}
$$

3. Calcular la desviación estándar muestral para las variables $X$ e $Y$.

$$
\begin{aligned}
& S_{\mathrm{x}}=\sqrt{\frac{\sum X^{2}}{N}-\overline{\mathrm{X}}^{2}} \quad \mathrm{~S}_{\mathrm{y}}=\sqrt{\frac{\sum Y^{2}}{N}-\overline{\mathrm{Y}}^{2}} \\
& S_{\mathrm{x}}=\sqrt{\frac{262320.271}{30}-(93.414)^{2}}=4.22 \\
& S_{\mathrm{y}}=\sqrt{\frac{260326.541}{30}-(93.076)^{2}}=3.79
\end{aligned}
$$

4. Determinar la ecuación de regresión para encontrar la relación del valor de $Y^{\prime}$ en función del valor de $X$.

$$
\begin{gathered}
Y^{\prime}=r\left(\frac{S_{y}}{S_{x}}\right) X-r\left(\frac{S_{y}}{S_{x}}\right) \overline{\mathrm{X}}+\overline{\mathrm{Y}} \\
Y^{\prime}=0.503\left(\frac{3.79}{4.22}\right) X-0.503\left(\frac{3.79}{4.22}\right) 93.41+93.07 \\
Y^{\prime}=0.45 X+51.03
\end{gathered}
$$

5. Calcular los valores de $Y^{\prime}$ para los valores de $X$.

Ejemplo: Para el valor de $X_{1}=95.3$ sustituyendo en la ecuación

$$
Y^{\prime}{ }_{1}=0.45(95.3)+51.03=93.91
$$


Tabla 33. Relación de los resultados obtenidos por la variable explicativa, explicada y la predictiva.

\begin{tabular}{|c|c|c|c|}
\hline № Alumno & $\begin{array}{c}\text { Variable } X \\
\text { Promedio } \\
\text { del Bachillerato }\end{array}$ & $\begin{array}{c}\text { Variable } Y \\
\text { Promedio 1er semestre }\end{array}$ & $\begin{array}{c}\text { Variable } Y^{\prime \prime} \\
\text { Valor predictivo para } Y\end{array}$ \\
\hline 1 & 95.3 & 98.5 & 93.915 \\
\hline 2 & 93.41 & 97.1 & 93.0645 \\
\hline 3 & 89 & 93.33 & 91.08 \\
\hline 4 & 94.56 & 96 & 93.582 \\
\hline 5 & 94.43 & 96 & 93.5235 \\
\hline 6 & 95.71 & 89.6 & 94.0995 \\
\hline 7 & 94.94 & 87.38 & 93.753 \\
\hline 8 & 90.84 & 94.9 & 91.908 \\
\hline 9 & 92.3 & 92.8 & 92.565 \\
\hline 10 & 89 & 95.33 & 91.08 \\
\hline 11 & 98 & 97 & 95.13 \\
\hline 12 & 98 & 94.33 & 95.13 \\
\hline 13 & 82 & 84.89 & 87.93 \\
\hline 14 & 96.53 & 94.6 & 94.4685 \\
\hline 15 & 97 & 95.89 & 94.68 \\
\hline 16 & 100 & 97 & 96.03 \\
\hline 17 & 96 & 96.3 & 94.23 \\
\hline 18 & 91.6 & 89.67 & 92.25 \\
\hline 19 & 94.12 & 90.33 & 93.384 \\
\hline 20 & 95 & 88.4 & 93.78 \\
\hline 21 & 91.22 & 92.33 & 92.079 \\
\hline 22 & 81.23 & 89.32 & 87.5835 \\
\hline 23 & 88.38 & 84.51 & 90.801 \\
\hline 24 & 93.58 & 94.48 & 93.141 \\
\hline 25 & 91.46 & 94 & 92.187 \\
\hline 26 & 93.02 & 92.8 & 92.889 \\
\hline 27 & 95.92 & 94.3 & 94.194 \\
\hline 28 & 97.02 & 97.45 & 94.689 \\
\hline 29 & 95.58 & 96.2 & 94.041 \\
\hline 30 & 97.28 & 87.56 & 94.806 \\
\hline
\end{tabular}

6. Elaborar una tabla para los valores de $X, Y$ e $Y^{\prime}$, sustituyendo los valores de $X$ en la ecuación para completar la columna de $Y^{\prime}$, siguiendo el proceso del ejemplo del paso anterior. 
7. Elaborar la gráfica del diagrama de dispersión de los resultados de la variable explicativa, el promedio del bachillerato ( $X$ eje horizontal) y los resultados de la variable explicada, el promedio del primer semestre ( $Y$ eje vertical), con los datos de la Tabla 33.

8. Elaborar la gráfica de la línea de regresión conectada para la relación (promedio del bachillerato $-X$ eje horizontal-y los resultados de la variable predictiva) y el promedio del primer semestre ( $Y^{\prime}$ eje vertical).

Las gráficas se pueden elaborar utilizando papel especial (milimétrico) en donde se hacen coincidir los valores de las $X$ en el eje horizontal y los valores de $Y$ e $Y^{\prime}$ en el eje vertical para cada par de datos, esto es, $X_{1}$ con $Y_{1}$ para el caso del diagrama de dispersión y $X_{1}$ con $Y^{\prime}{ }_{1}$ para el caso de la línea de regresión. Ambos se pueden elaborar en una sola gráfica.

\subsection{Elaboración del gráfico utilizando el programa SPSS}

El programa SPSS para esta prueba permite realizar estos gráficos utilizando los pasos que se describen a continuación.

El primer paso consiste en otorgarle las propiedades a las variables, una vez abierto el programa y antes de introducir los datos, es necesario definir las variables y otorgarle las características para su presentación en la tabla, para esto se requiere dar un clic en la pestaña Vista de variables. En este caso las acciones indispensables para obtener los resultados correctos son:

- Designar los nombres de las variables. Para realizar esto es necesario presionar la ceja de Vista de variables, y en seguida teclear el nombre de cada variable, primero en la columna Nombre (primera) y la fila 1, la palabra VariableX, debe ir sin espacio entre la palabra variable y la $X$ debido a que el programa no reconoce caracteres vacíos, segundo en la columna Nombre pero ahora en la fila 2, escribir VariableY, y tercero en la columna Nombre fila 3 escribir VariableYprima.

- Definir el tipo de medida que se realizó. Debido a que los datos son continuos se requiere que en la columna Medida se seleccione la opción Escala.

El programa preselecciona el tipo de variables como numérico, para darle presentación a los datos se pueden realizar las siguientes operaciones (pero no es necesario): definir la Anchura (5) y cantidad de Decimales (2) requeridos y la Alineación (centrado).

Cuadro 38. Designación de variables para el análisis de regresión lineal.

\begin{tabular}{l|l|l|}
\hline Nombre: VariableX & Nombre: VariableY & Nombre: VariableYprima \\
\hline Tipo: Numérico & Tipo: Numérico & Tipo: Numérico \\
\hline Anchura: 5 & Anchura: 5 & Anchura: 5 \\
\hline Decimales: 2 & Decimales: 2 & Decimales: 2 \\
\hline Etiqueta: Variable X Explicativa & Etiqueta: Variable Y Explicada & Etiqueta: Variable Y' Predictiva \\
\hline Valores: Ninguno & Valores: Ninguno & Valores: Ninguno \\
\hline Perdidos: Ninguno & Perdidos: Ninguno & Perdidos: Ninguno \\
\hline Columnas: 8 & Columnas: 8 & Columnas: 8 \\
\hline Alineación: Centrado & Alineación: Centrado & Alineación: Centrado \\
\hline Medida: Escala & Medida: Escala & Medida: Escala \\
\hline Rol: Entrada & Rol: Entrada & Rol: Entrada
\end{tabular}


En la Figura 134 se observan estos pasos, así como la ubicación de cada variable y las propuestas de opciones para la definición y presentación de las variables.

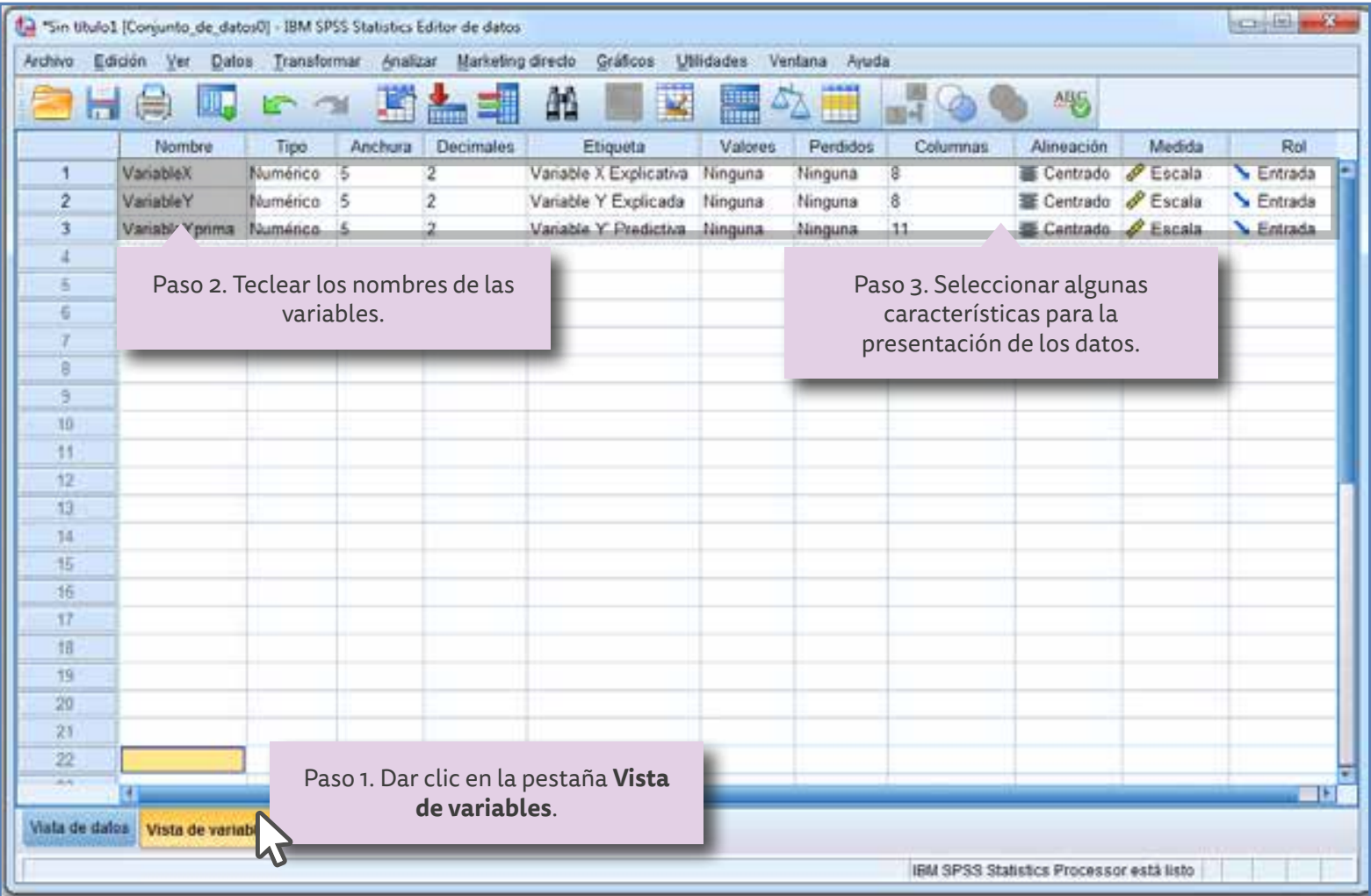

Figura 134. Designación de variables y sus características para el análisis de regresión lineal.

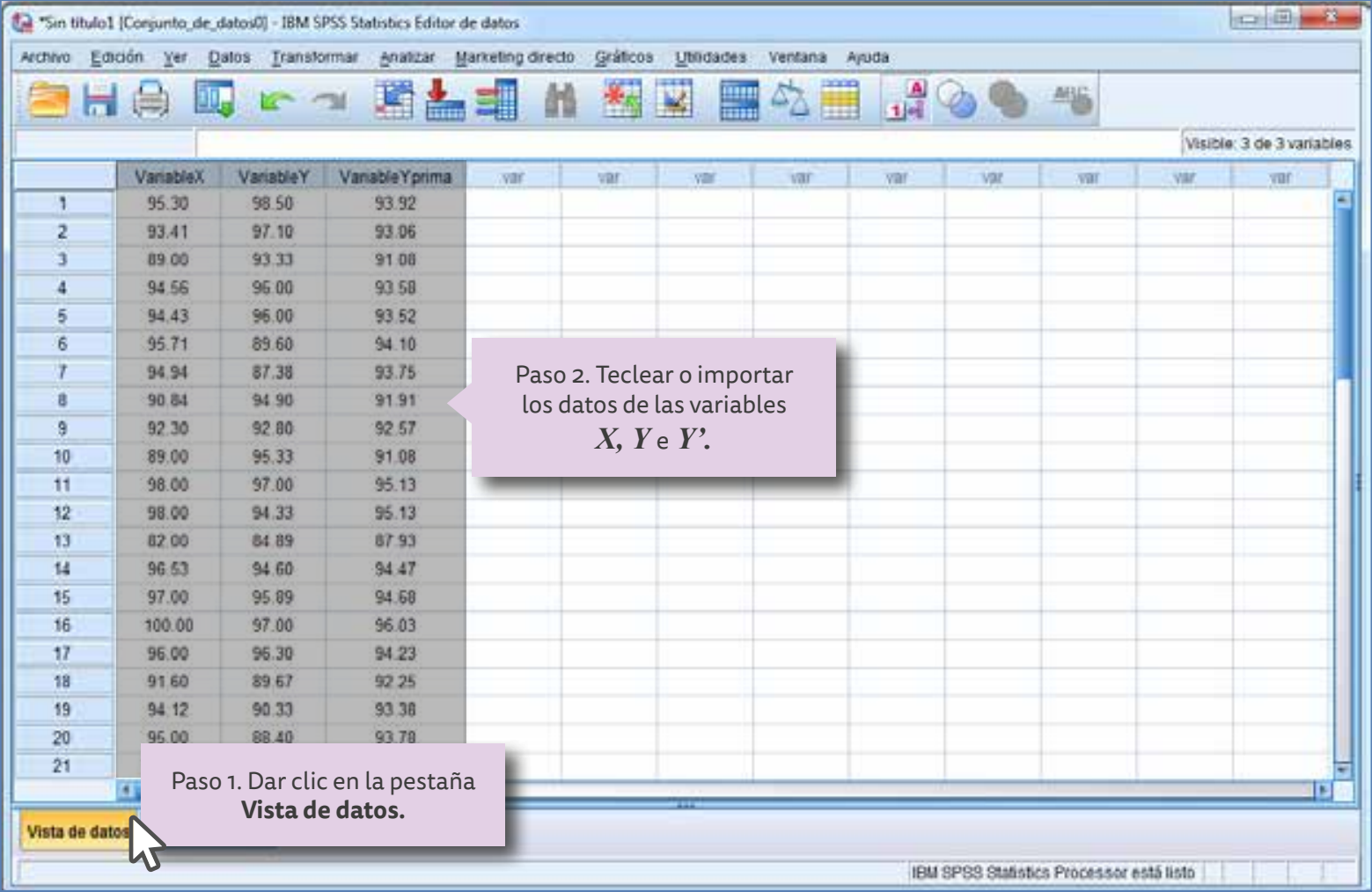

Figura 135. Presentación de las variables Explicativa $(X)$, Explicada $(Y)$ y Predictiva $\left(Y^{\prime}\right)$. 
Una vez designados los nombres de las variables y sus características se introducen los datos en la tabla; para llevar a cabo esto se requiere dar clic en la pestaña Vista de datos, e introducir los datos correspondientes a cada variable, éstos se pueden introducir uno por uno tecleándolos o bien importarlos (seleccionar, copiar y pegar) de la Tabla 33 en donde se encuentran ubicados y pegarlos dentro de esta tabla.

En la Figura 135 se observan cómo quedan los datos siguiendo cualquiera de los procedimientos mencionados y de acuerdo a las características seleccionadas en los pasos anteriores.

Una vez que los datos se encuentran en la tabla se realiza la prueba (Figura 136); para hacerlo es necesario dar un clic en la pestaña ubicada en la barra superior designada como Gráficos, en seguida aparece un cuadro de diálogo, se debe seleccionar la línea que indica Cuadros de diálogo antiguos, al ubicar el apuntador del ratón en esta opción se presenta a la derecha otro cuadro de diálogo y se selecciona Dispersión de puntos dando clic con el ratón.

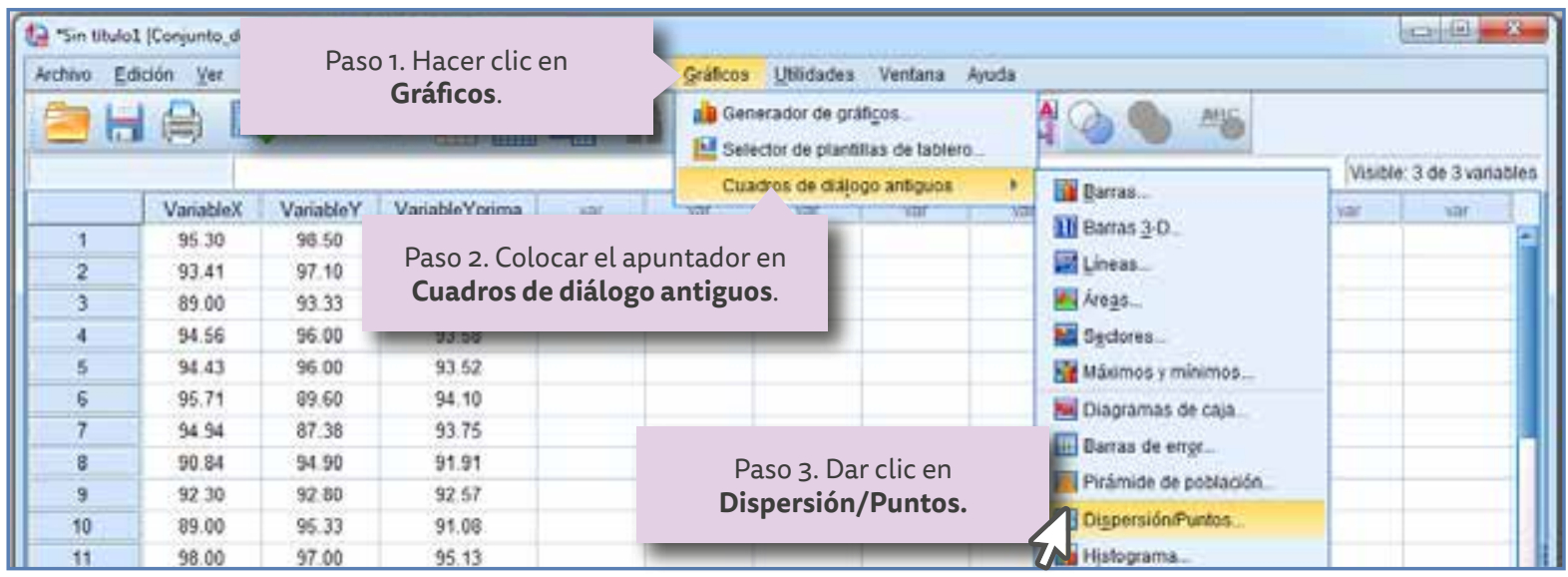

Figura 136. Cuadros de diálogo para seleccionar los gráficos de dispersión de puntos.

Aparece la ventana de la Figura 137 en la cual se muestran las opciones para la presentación del gráfico, en este caso se pretende que en un solo gráfico se presenten el diagrama de dispersión y la línea de regresión, por lo que se selecciona con un clic la opción Dispersión superpuesta, y se da clic en el botón Definir.

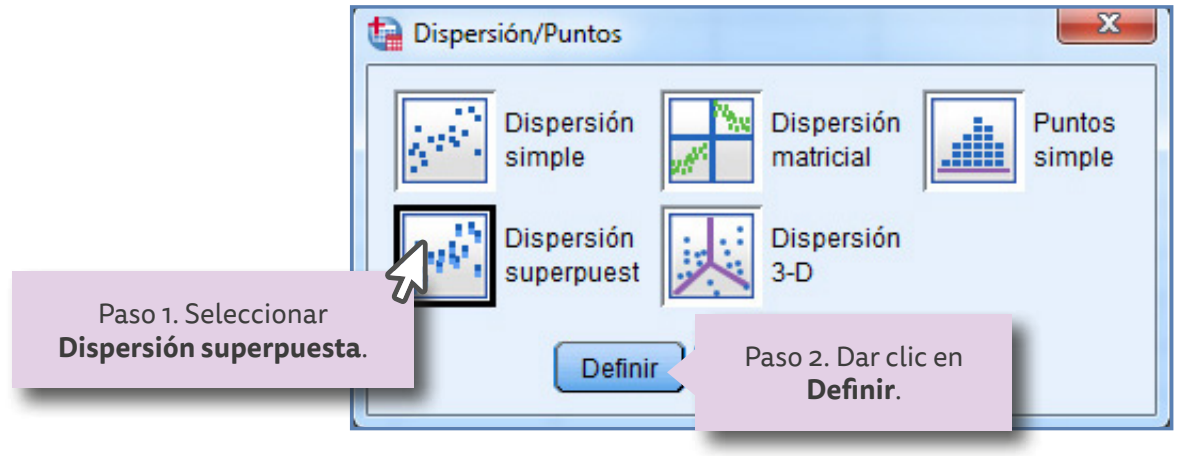

Figura 137. Selección del tipo de gráfico de dispersión de puntos que se desea utilizar.

Al hacer clic con el ratón aparece la ventana de la Figura 138 en la que se muestran las variables del lado izquierdo, Variable $\mathbf{X}$ explicativa, Variable $\mathbf{Y}$ explicada y Variable $\mathbf{Y}^{\prime}$ Predictiva, éstas deben ser trasladadas a la ventana que dice Pares Y-X; la forma de hacerlo es seleccionando con un clic la variable $(Y)$ deseada (Variable $Y$ Explicada) y después dar clic en 
la flecha que se ubica entre las dos ventanas, se transfiere al par 1, Variable $Y$. Se repite esta operación para la Variable $X$ (Variable $X$ explicativa), y es transferida al casillero par 1 Variable $X$. De esta manera queda formado el primer par de variables (Explicada $Y$ y Explicativa $X$ ).

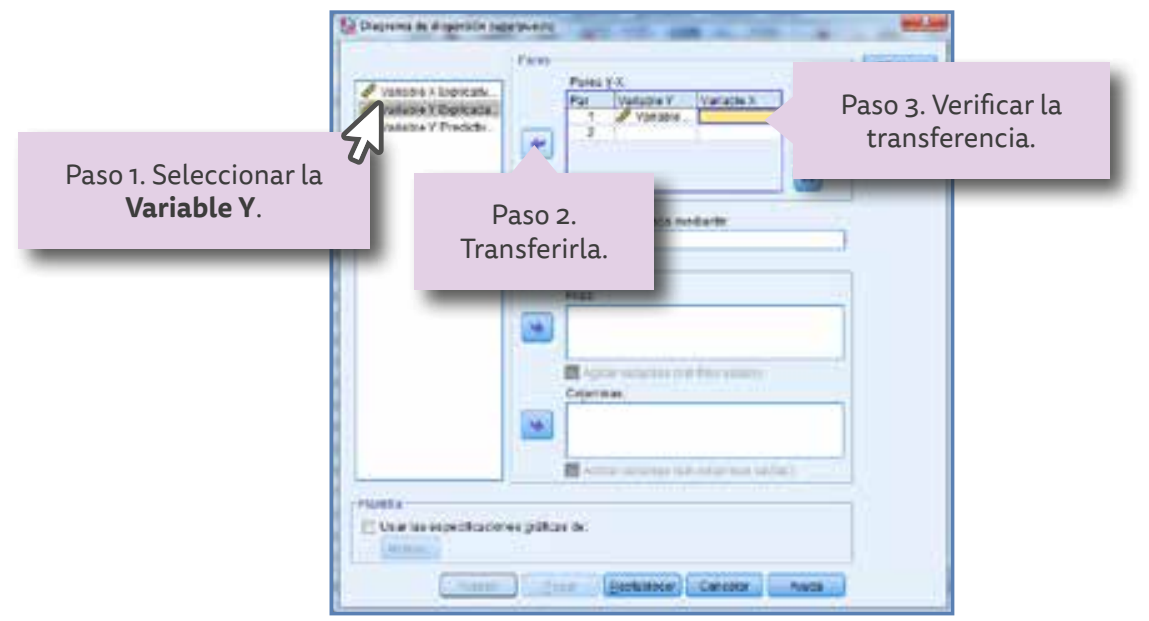

Figura 138. Transferencia de la variable Y Explicada al casillero par 1, Variable Y.

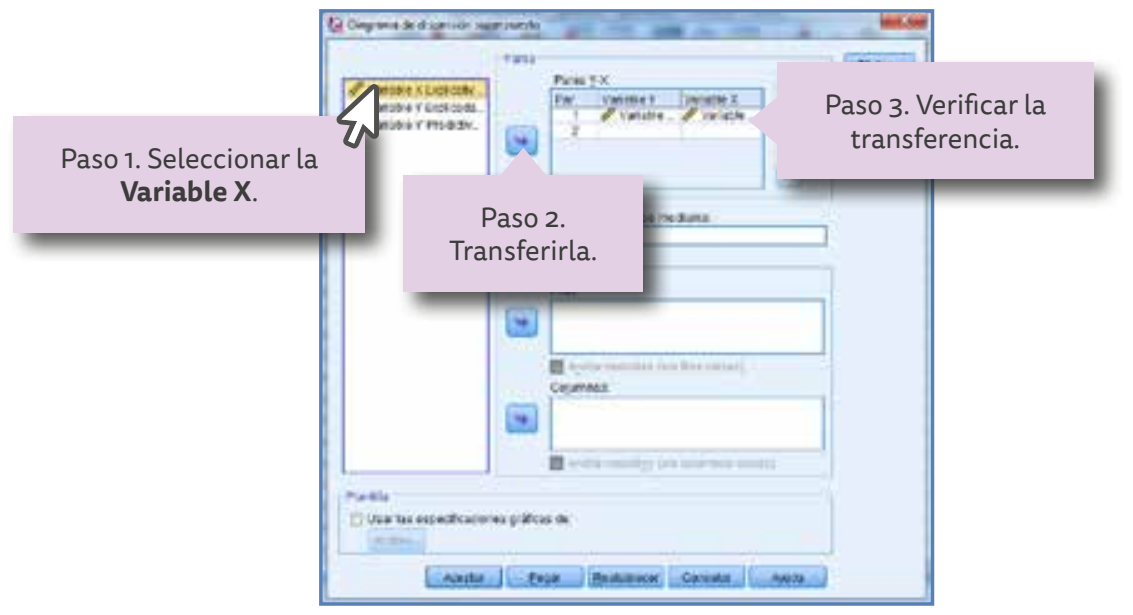

Figura 139. Transferencia de la variable X Explicativa al casillero par 1, Variable X.

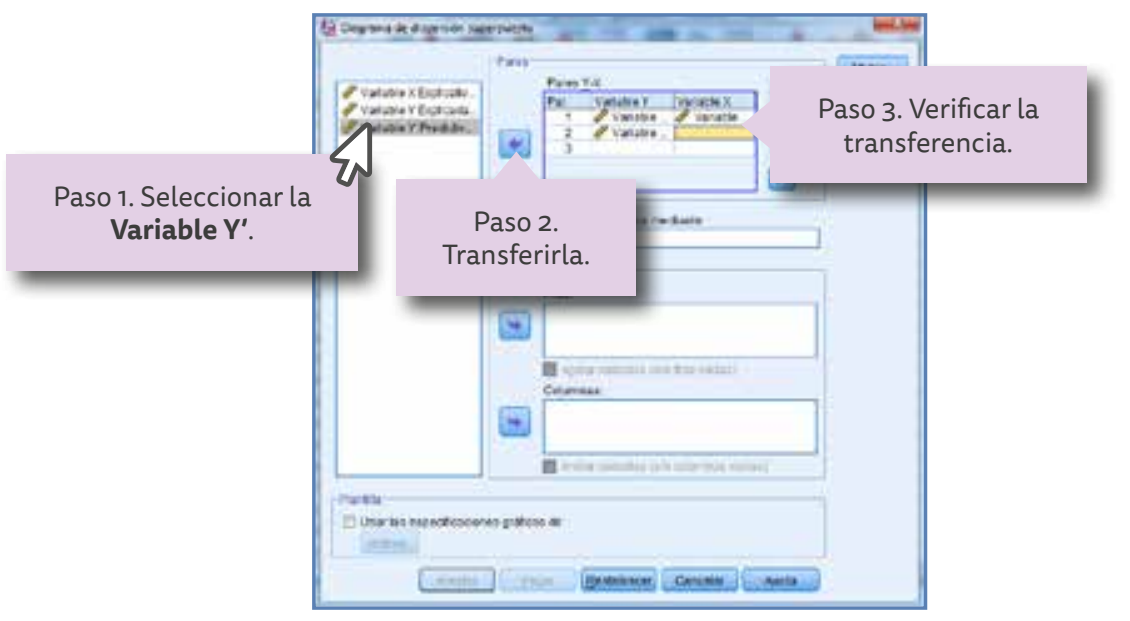

Figura 140. Transferencia de la variable Y' Predictiva al casillero par 2, Variable Y. 


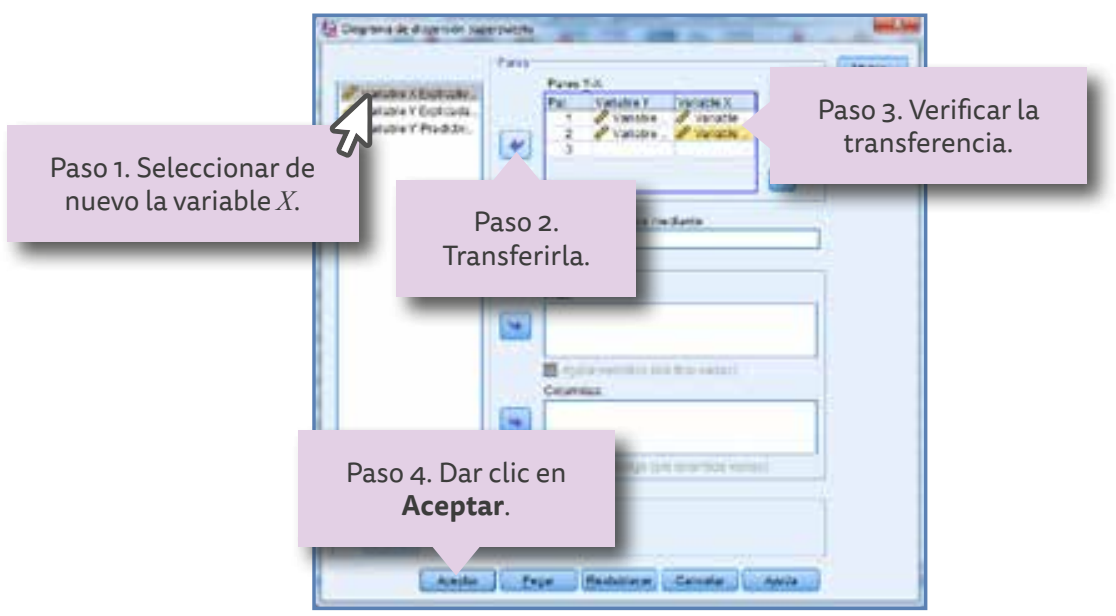

Figura 141. Transferencia de la variable X Predictiva al casillero par 2, Variable X.

Siguiendo el mismo procedimiento se transfiere la Variable $Y^{\prime}$, se selecciona y se envía al casillero par 2 (Figura 140), Variable $Y$, y se transfiere la Variable $X$ al casillero par 2, Variable $X$, recordando que esta variable $(X)$ es la misma para los dos gráficos.

Una vez realizados estas acciones, el programa queda listo para arrojar los resultados, al activar el botón Aceptar (Figura 141) se obtienen los resultados mostrados en la Gráfica 18.

Gráfica 18. Diagrama de dispersión y línea de regresión correspondientes a las variables Explicativa, Explicada y Predictiva.

\section{$\Rightarrow$ Gráfico}

[Conjunto_de_datos0]

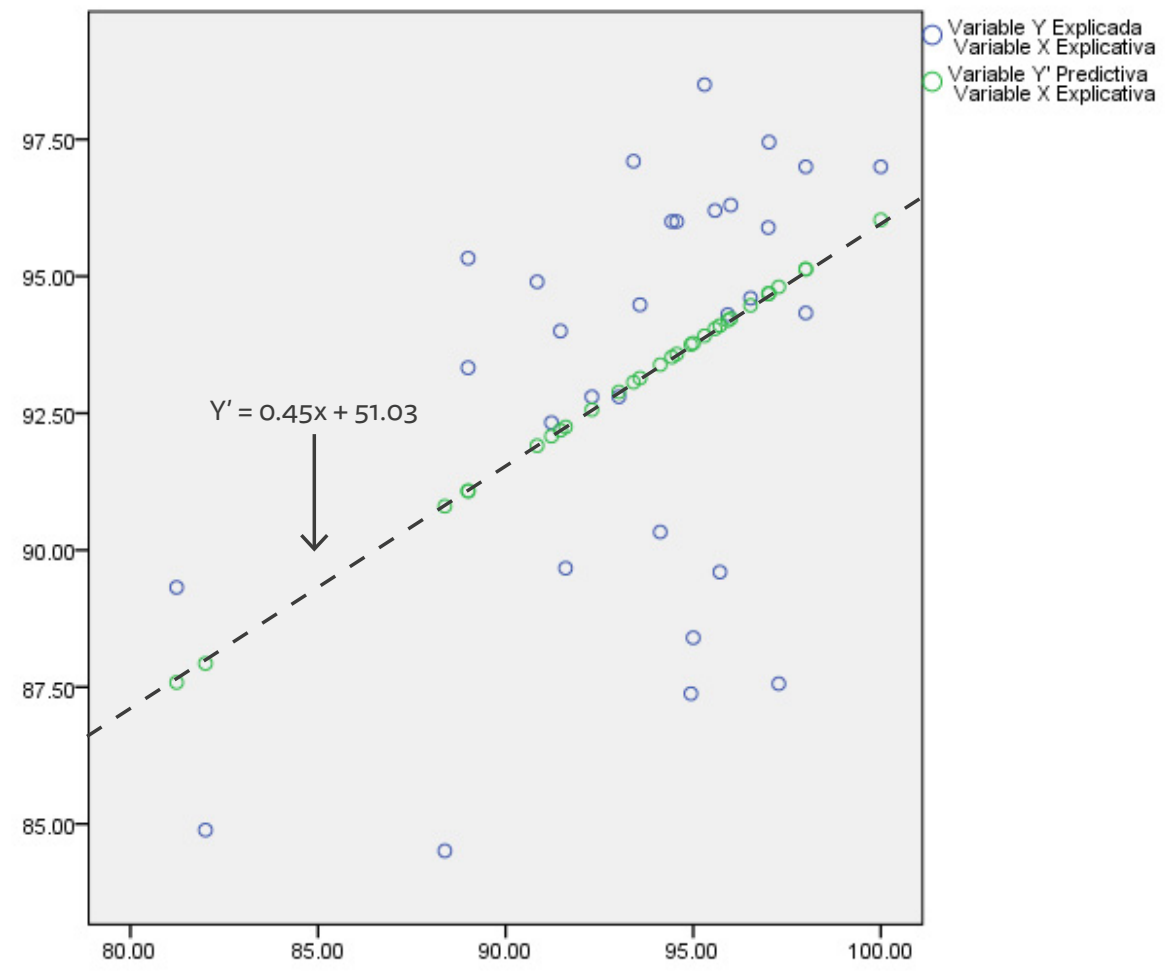


En la gráfica anterior se unieron los puntos correspondientes a la línea de regresión por medio de una línea punteada con la finalidad de definirla con mayor precisión. Se puede observar que existen algunas coincidencias entre los valores del diagrama de dispersión y la línea de regresión, esta última se encuentra ubicada en medio de la dispersión y su pendiente representa la medida en que los resultados $Y^{\prime}$ son predecibles a partir de los resultados de la variable explicativa $X$. Lo anterior permite inferir los resultados pronosticados para $Y^{\prime}$ a partir de los resultados de $X$, como se puede observar en la ecuación de regresión para este ejemplo:

$$
Y^{\prime}=0.45 x+51.03
$$

\subsection{El error estándar de la estimación}

Se puede observar que no todos los puntos que representan los resultados de los promedios coinciden con la línea de regresión, esto se debe a las diferencias que existen entre los participantes, es difícil esperar que todos los alumnos tuvieran exactamente la misma distribución de resultados del promedio del bachillerato y el del primer semestre.

El hecho de que la línea de regresión no coincida con todos los puntos indica que existe un cierto error entre los puntos que representan los resultados de los alumnos, esta relación entonces es imperfecta lo que puede representar que la predicción puede tener poca probabilidad de ser exacta. Esto significa que si el error es grande no se puede confiar en la predicción, como consecuencia para que ésta sea confiable, el error debe ser pequeño para poder tomar decisiones con ella.

La medición de errores de predicción implica calcular el error estándar de la estimación que es muy similar a la desviación estándar pues proporciona una medida de la desviación promedio de los errores de predicción en torno a la línea de regresión. Esta última se puede considerar como una estimación de la media de los valores de $X$ para cada valor de $X$.

En el error estándar de la estimación, la suma de los errores de predicción $\Sigma\left(Y-Y^{\prime}\right)$ es igual a o (por los signos positivos y negativos), es necesario elevarlos al cuadrado para obtener el promedio, sumando los valores elevados al cuadrado, dividiéndolos entre $N-2$ y calculando la raíz cuadrada del cociente, esto es:

$$
\mathrm{S}_{\mathrm{y} / \mathrm{x}}=\sqrt{\frac{\left(\Sigma\left(Y-Y^{\prime}\right)^{2}\right.}{N-2}}
$$

Que representa el error estándar de la estimación al predecir $Y$ dado $X$, es necesario dividir entre $N-2$ porque el cálculo del error estándar de la estimación implica el ajuste de los datos a una línea recta, estimando dos parámetros, la pendiente y la ordenada al origen, dejando las desviaciones en torno a la recta con $N-2$ grados de libertad.

En el caso de que no se desee tabular estas diferencias se puede utilizar la ecuación que se muestra a continuación:

$$
\mathrm{S}_{\mathrm{y} / \mathrm{x}}=\sqrt{\frac{\mathrm{SC}_{Y}-\frac{[\Sigma X Y-(\Sigma X)(\Sigma Y) / N]^{2}}{\mathrm{SC}_{X}}}{N-2}}
$$


Donde:

$S C_{\mathrm{x}}=$ suma de los cuadrados de los datos $X$.

$S C_{\mathrm{y}}=$ suma de los cuadrados de los datos $Y$.

$N=$ número de parejas de datos.

$\Sigma X Y=$ suma de los productos de cada par de $X$ e $Y$ (suma de productos cruzados).

$\Sigma X=$ suma de los valores de los datos de la variable $X$.

$\Sigma Y=$ suma de los valores de los datos de la variable $Y$.

Entonces:

$$
S C_{\mathrm{x}}=\sum X^{2}-\frac{(\Sigma X)^{2}}{N} \text { y } S C_{\mathrm{y}}=\sum Y^{2}-\frac{(\Sigma Y)^{2}}{N}
$$

18.6.1 Procedimiento para determinar el valor del error estándar de la estimación

De acuerdo a los párrafos anteriores se puede determinar este valor por medio de dos procedimientos:

a. La suma de los errores de predicción (tabulación).

b. El proceso matemático.

18.6.1.1 La suma de los cuadrados de las desviaciones (errores de predicción)

1. Calcular los valores de $Y-Y^{\prime}$ y elaborar la Tabla 34.

2. Elevar al cuadrado los resultados de $Y-Y^{\prime}$ y llenar la columna $\left(Y-Y^{\prime}\right)^{2}$.

3. Sustituir los valores en la ecuación:

$$
\begin{gathered}
S_{y / x}=\sqrt{\frac{\left(\sum\left(Y-Y^{\prime}\right)^{2}\right.}{N-2}} \\
S_{y / x}=\sqrt{\frac{321.35}{30-2}}=3.38
\end{gathered}
$$

\subsubsection{El Proceso matemático}

1. Calcular la suma de los cuadrados para los valores de $X$ e $Y$.

$$
\begin{gathered}
S C_{\mathrm{x}}=\sum X^{2}-\frac{\left(\sum X\right)^{2}}{N} \text { Sustituyendo los valores } \\
S C_{\mathrm{x}}=262320.19-\frac{(2802.43)^{2}}{30}=533.05 \\
S C_{\mathrm{y}}=\sum Y^{2}-\frac{\left(\sum Y\right)^{2}}{N} \text { Sustituyendo los valores } \\
S C_{\mathrm{y}}=260326.47-\frac{(2792.30)^{2}}{30}=428.49
\end{gathered}
$$


Tabla 34. Estimación de la suma de los errores de predicción $\left(Y-Y^{\prime}\right)^{2}$.

\begin{tabular}{|c|c|c|c|c|}
\hline № & $\begin{array}{l}\text { Variable } Y \\
\text { Promedio 1er } \\
\text { semestre }\end{array}$ & $\begin{array}{c}\text { Variable } Y^{\prime} \\
\text { Valor predictivo } \\
\text { para } Y\end{array}$ & $Y-Y^{\prime}$ & $\left(Y-Y^{\prime}\right)^{2}$ \\
\hline 1 & 98.5 & 93.9256 & 4.5744 & 20.88 \\
\hline 2 & 97.1 & 93.07132 & 4.02868 & 16.16 \\
\hline 3 & 93.33 & 91.078 & 2.252 & 5.06 \\
\hline 4 & 96 & 93.59112 & 2.36764 & 5.56 \\
\hline 5 & 96 & 93.53236 & 2.46764 & 6.05 \\
\hline 6 & 89.6 & 94.11092 & -4.51092 & 20.34 \\
\hline 7 & 87.38 & 93.76288 & -6.38288 & 40.70 \\
\hline 8 & 94.9 & 91.90968 & 2.99032 & 8.94 \\
\hline 9 & 92.8 & 92.5696 & 0.2304 & 0.05 \\
\hline 10 & 95.33 & 91.078 & 4.252 & 18.06 \\
\hline 11 & 97 & 95.146 & 1.854 & 3.42 \\
\hline 12 & 94.33 & 95.146 & -0.816 & 0.65 \\
\hline 13 & 84.89 & 87.914 & -3.024 & 9.12 \\
\hline 14 & 94.6 & 94.48156 & 0.11844 & 0.01 \\
\hline 15 & 95.89 & 94.694 & 1.196 & 3.84 \\
\hline 16 & 97 & 96.05 & 0.95 & 0.90 \\
\hline 17 & 96.3 & 94.242 & 2.058 & 4.20 \\
\hline 18 & 89.67 & 92.2532 & -2.5832 & 6.65 \\
\hline 19 & 90.33 & 93.39224 & -3.06224 & 9.36 \\
\hline 20 & 88.4 & 93.79 & -5.39 & 29.05 \\
\hline 21 & 92.33 & 92.08144 & 0.24856 & 0.05 \\
\hline 22 & 89.32 & 87.56596 & 1.75404 & 3.06 \\
\hline 23 & 84.51 & 90.79776 & -6.28776 & 39.43 \\
\hline 24 & 94.48 & 93.14816 & 1.33184 & 1.76 \\
\hline 25 & 94 & 92.18992 & 1.81008 & 3.27 \\
\hline 26 & 92.8 & 92.89504 & -0.09504 & 0.008 \\
\hline 27 & 94.3 & 94.20584 & 0.09416 & 0.008 \\
\hline 28 & 97.45 & 94.70304 & 2.74696 & 7.50 \\
\hline 29 & 96.2 & 94.05216 & 2.14784 & 4.57 \\
\hline \multirow[t]{2}{*}{30} & 87.56 & 94.82056 & -7.26056 & 52.70 \\
\hline & $\Sigma=2792.3$ & $\Sigma=2792.19836$ & $\Sigma=0.0604$ & $\Sigma=321.35$ \\
\hline
\end{tabular}


2. Sustituir los valores en la ecuación:

$$
\begin{aligned}
& \mathrm{S}_{\mathrm{y} / \mathrm{x}}=\sqrt{\frac{\mathrm{SC}_{Y}-\frac{[\Sigma X Y-(\Sigma X)(\Sigma Y) / N]^{2}}{\mathrm{SC}_{X}}}{N-2}} \\
& S_{y / x}=\sqrt{\frac{428.49-\frac{\left[\sum 261081.52-(2802.43)(2792.30) / 30\right]^{2}}{533.05}}{30-2}}=3.37
\end{aligned}
$$

Para este ejemplo el error estándar de estimación es igual a 3.37; este error cuantifica los errores de predicción, mientras mayor sea es menor la confianza y viceversa, mientras menor sea, es mayor la confianza. Se requiere suponer que la variabilidad de $Y$ permanece constante cuando se van sustituyendo cada uno de los datos de $X$ para aceptar la hipótesis de homosedasticidad, que supone que los datos dispersos se distribuyen uniformemente a lo largo de la línea de regresión.

Si esta hipótesis fuese válida y se construyeran dos rectas paralelas a la línea de regresión a las distancias de $\pm 1 \mathrm{~S}_{\mathrm{y} / \mathrm{x}^{\prime}} \pm 2 \mathrm{~S}_{\mathrm{y} / \mathrm{x}^{\prime}} \pm 3 \mathrm{~S}_{\mathrm{y} / \mathrm{x}^{\prime}}$ se tendría que aproximadamente el $68 \%$ de los datos se encontrarían entre la rectas $a \pm 1 S_{y / x}$, cerca del $85 \%$ de los datos se encontrarían entre $\pm 2 \mathrm{~S}_{\mathrm{y} / \mathrm{x}}$ y aproximadamente el $99 \%$ de los datos se encontrarían entre $\pm 3 \mathrm{~S}_{\mathrm{y} / \mathrm{x}}$.

Siguiendo con el ejemplo, en la Gráfica 19 se han trazado dos rectas punteadas paralelas a la línea de regresión correspondiente a los promedios del bachillerato y del primer semestre de Medicina, a una distancia de $\pm 1 \mathrm{~S}_{\mathrm{y} / \mathrm{x}}$, también se pueden observar los datos en la figura. De acuerdo a éstos, dentro del área limitada por las rectas punteadas se encuentra aproximadamente el $68 \%$ de los resultados, se puede observar que sólo 8 puntos se encuentran fuera del área, lo que significa que en el interior se tienen 22 puntos que divididos entre el total de los datos produce un porcentaje del $73 \%$.

Esta situación se puede deber al hecho de que el tamaño de la muestra $N$ no es muy grande, cuando $N$ aumenta, por lo general aumenta la coincidencia con el porcentaje correspondiente, para este caso del 68\% (Ver Gráfica 19).

\subsection{Prueba de Regresión Lineal utilizando el programa SPSS}

Un factor de interés consiste en determinar si las líneas de regresión son una predicción correcta de los resultados $Y^{\prime}$ con respecto a los observados $Y$, por otro lado, cómo saber si el error estándar de la estimación es suficientemente bajo para que la predicción sea más precisa.

Como se observa en el apartado 18.4 las desviaciones entre los valores de los resultados pronosticados $Y^{\prime}$ y los de los resultados reales que se obtienen mediante la suma de los cuadrados de las desviaciones, coinciden con la forma en que la prueba ANOVA calcula las sumas de los cuadrados como desviaciones (diferencias) entre las medias y los resultados.

En consecuencia es la prueba ANOVA la adecuada para calcular la significación de las predicciones teniendo como base las variables explicativas. La prueba ANOVA permite comprobar las varianzas que se producen en una regresión lineal, que integran la varianza total, éstas son:

- Varianza esperada en los resultados $Y$ con relación a los resultados pronosticados $Y^{\prime}$ partiendo de la variable explicativa $X$.

- Varianza del error estándar de estimación, como consecuencia de las diferencias no pronosticadas en los valores de los resultados $Y$ que no puede explicar la variable $X$. 
Gráfica 19. Línea de regresión para los promedios del Bachillerato y el primer semestre de Medicina, con rectas paralelas $1 \mathrm{~S}_{\mathrm{y} / \mathrm{x}}$ arriba y debajo de la línea de regresión.

$\Rightarrow$ Gráfico

[Conjunto_de_datos0]

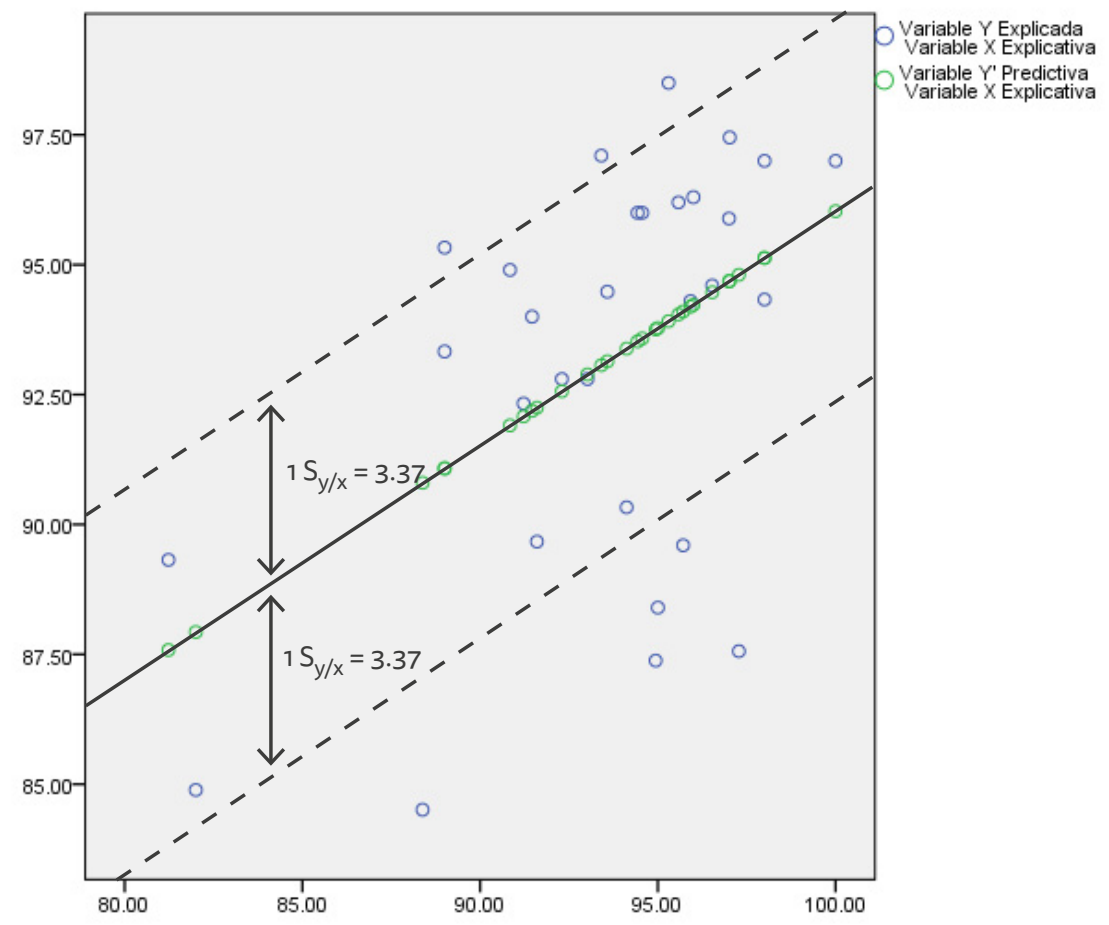

La suma de los cuadrados son calculados para cada fuente de varianza y se dividen entre el número de grados de libertad $g l$ correspondiente para determinar los cuadrados medios. El cuadrado medio pronosticado dividido por el cuadrado medio de error proporciona el valor de $F$ ratio.

Si la prueba ANOVA resulta significativa implica que el error estándar de estimación es lo suficientemente pequeño, refleja pocas desviaciones de la línea de regresión, permitiendo calcular una línea de regresión adecuada para minimizar las desviaciones, entonces se puede aceptar la hipótesis de investigación.

De manera contraria si los puntos están distribuidos de manera aleatoria, como establece la hipótesis nula, se vuelve imposible calcular una línea de regresión adecuada para minimizar las desviaciones y no se puede rechazar la hipótesis nula.

El primer paso consiste en otorgarle las propiedades a las variables, una vez abierto el programa y antes de introducir los datos, es necesario definir las variables y otorgarle las características para su presentación en la tabla, para esto se requiere dar un clic en la pestaña Vista de variables. Aquí las acciones indispensables para obtener resultados correctos son:

- Designar los nombres de las variables. Para realizar esto es necesario presionar la ceja de Vista de variables, y en seguida teclear el nombre de cada variable, primero en la columna Nombre (primera) y la fila 1, la palabra VariableX, debe ir sin espacio entre la palabra variable y la $x$ debido a que el programa no reconoce caracteres vacíos, segundo en la columna Nombre pero ahora en la fila 2, escribir VariableY.

- Definir el tipo de medida. Debido a que los datos son de intervalo se requiere que en la columna Medida selecciones la opción Escala. El programa preselecciona el tipo de varia- 
bles como numérico, para darle presentación a los datos se pueden realizar las siguientes operaciones (pero no es necesario): definir la Anchura (6) y cantidad de Decimales (2) requeridos y la Alineación (centrado).

En la Figura 142 se observan estos pasos así como la ubicación de cada variable y las propuestas de opciones para la definición y presentación de las variables.

Una vez designados los nombres de las variables y sus características se introducen los datos en la tabla; para llevar a cabo esto es necesario dar un clic en la pestaña Vista de datos, e introducir los datos correspondientes a cada variable, éstos se pueden introducir uno por uno tecleándolos o bien importarlos (seleccionar, copiar y pegar) de la Tabla 33 en donde se encuentran ubicados y pegarlos dentro de esta tabla.

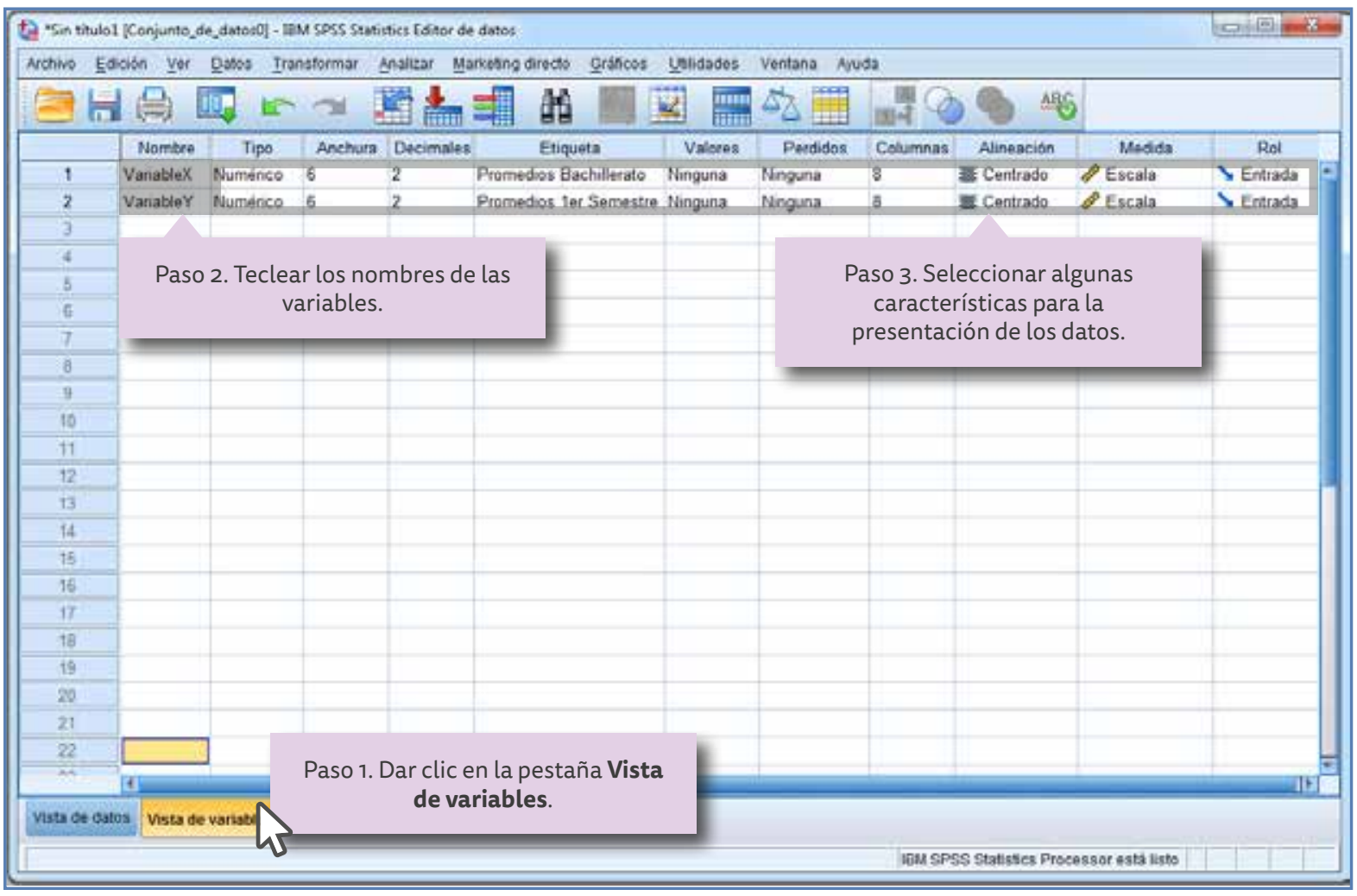

Figura 142. Designación de variables y sus características para la prueba de Regresión Lineal.

En el siguiente cuadro se observan las variables seleccionadas en este ejemplo:

Cuadro 39. Designación de variables para la prueba de Regresión Lineal.

\section{Nombre: VariableX}

Tipo: Numérico

Anchura: 6

Decimales: 2

Etiqueta: Promedio del Bachillerato

Valores: Ninguno

Perdidos: Ninguno

Columnas: 8

Alineación: Centrado

Medida: Escala

Rol: Entrada

\section{Nombre: VariableY}

Tipo: Numérico

Anchura: 6

Decimales: 2

Etiqueta: Promedio primer semestre

Valores: Ninguno

Perdidos: Ninguno

Columnas: 8

Alineación: Centrado

Medida: Escala

Rol: Entrada 
En la Figura 143 se observa cómo quedan los datos siguiendo cualquiera de los procedimientos mencionados y de acuerdo a las características seleccionadas en los pasos anteriores.

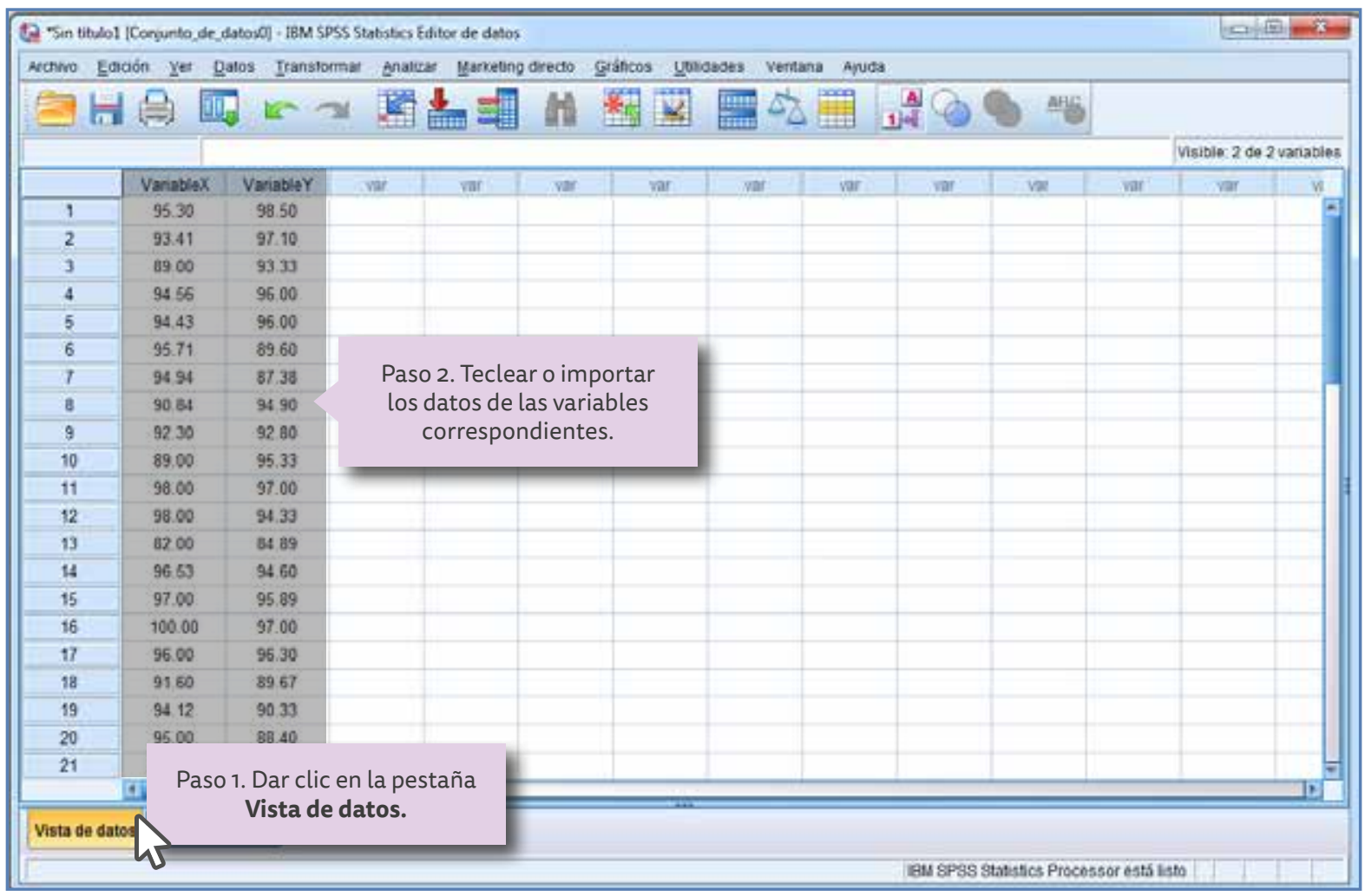

Figura 143. Presentación de las Variables Xy Y.

Una vez que los datos se encuentran en la tabla se realiza la prueba (Figura 144); para hacerlo es necesario dar un clic en la pestaña ubicada en la barra superior designada como Analizar, en seguida aparece un cuadro de diálogo, en el cual se selecciona la línea que indica Regresión, al ubicar el apuntador del ratón en esta opción se presenta a la derecha otro cuadro de diálogo, se selecciona Lineales (que son las que corresponden a dos variables), y se da un clic con el ratón.

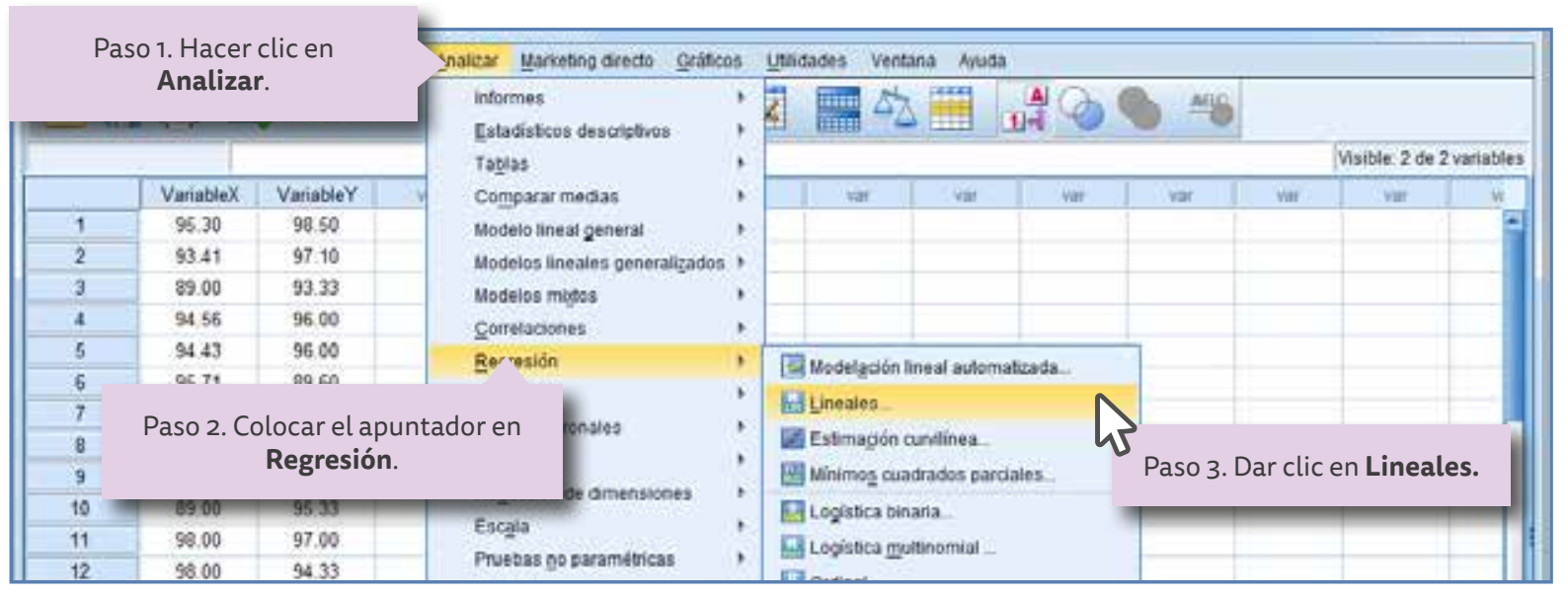

Figura 144. Cuadros de diálogo para seleccionar la prueba de regresión lineal. 
Aparece la ventana de la Figura 145, la cual muestra las variables del lado izquierdo (X, Promedio Bachillerato e Y, Promedio 1er Semestre), éstas deben ser trasladadas a la ventana que dice dependientes; la forma de hacerlo es seleccionando con un clic la variable dependiente (Variable Y) y dando un clic en la flecha que se ubica entre las dos ventanas, se traslada a la ventana Dependientes.

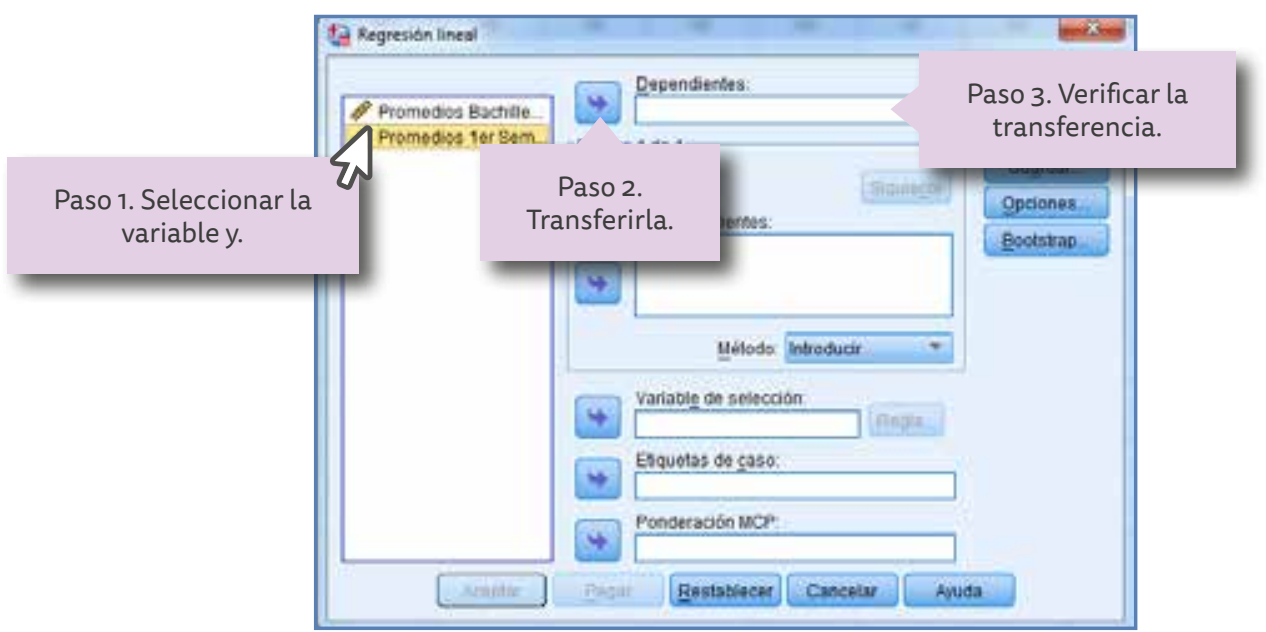

Figura 145. Transferencia de la variable Promedio primer Semestre o variable Y para procesar los datos con el programaSPSS.

Se selecciona la Variable independiente (Variable X) y se da un clic en la flecha que se ubica entre las dos ventanas, se traslada a la ventana Independientes (Figura 146).

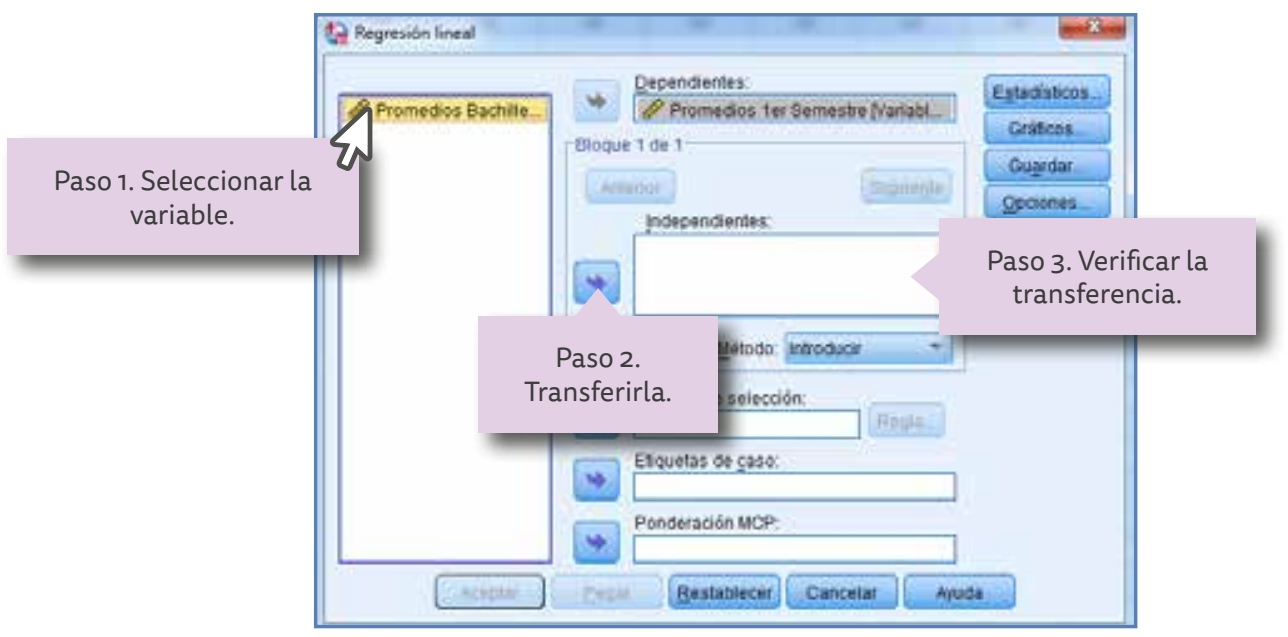

Figura 146. Transferencia de la variable Promedio Bachillerato para procesar los datos con el programaSPSS.

Una vez realizadas estas acciones el programa queda listo para arrojar los resultados, al activar el botón Aceptar (Figura 147) se obtienen los resultados que se muestran en el Cuadro 40, en el cual se observa que el valor típico de la estimación $\mathrm{S}_{\mathrm{y} / \mathrm{x}}$ es igual a 3.37973, bastante aproximado a los valores encontrados por los procedimientos utilizados en el cálculo.

El nivel de significación es $\rho_{\text {encontrada }}=0.005$ por lo que se puede concluir que:

$$
\rho_{\text {encontrada }} 0.005<\rho_{\text {aceptada }} 0.05
$$


Esto es, el valor encontrado 0.005 es menor que el mínimo aceptable por los investigadores en educación (0.05), lo que significa que los resultados de la diferencia no son aleatorios puesto que existe una diferencia significativa, por lo que se puede rechazar la hipótesis nula y aceptar la hipótesis de investigación.

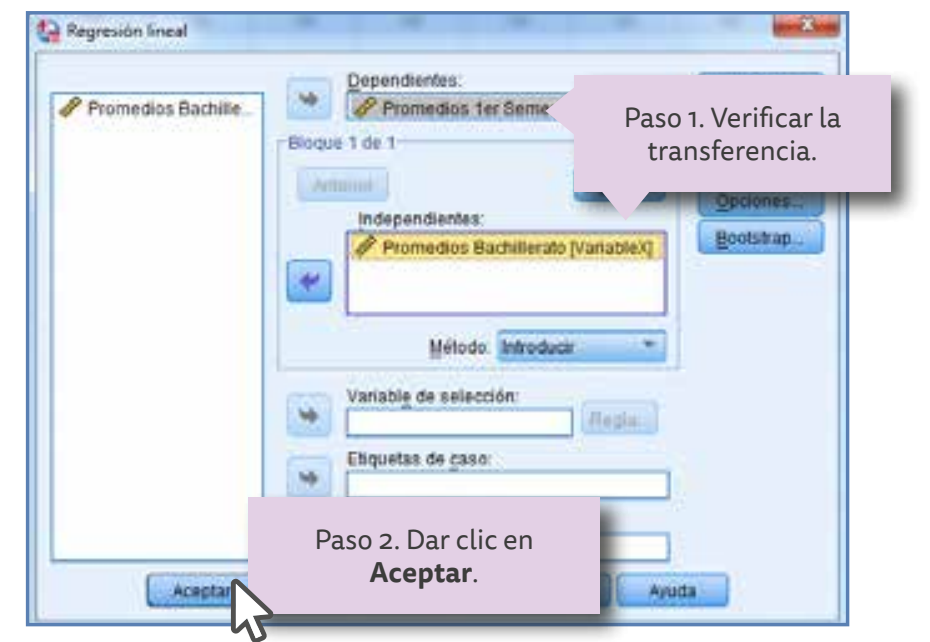

Figura 147. Paso para ejecutar el programa SPSS para que realice los cálculos requeridos para la prueba de Regresión Lineal.

También se observa que el valor de $F$ ratio es igual a 9.519 con un nivel de significación de $\rho_{\text {encontrada }}=0.005$ por lo que se puede rechazar la hipótesis nula y aceptar la hipótesis de investigación.

De acuerdo a los coeficientes arrojados por el programa SPSS se puede determinar la ecuación de la línea de regresión de la siguiente forma:

$$
Y^{\prime}=b_{\mathrm{y}} X+a_{\mathrm{y}}
$$

Donde:

Sustituyendo:

$$
b_{\mathrm{y}}=0.452 \text { y } a_{\mathrm{y}}=50.89
$$

$$
Y^{\prime}=0.452 X+50.89
$$

Que resulta una muy buena aproximación a la ecuación determinada en los cálculos realizados en este capítulo.

Prueba $\boldsymbol{t}$. Para comprobar la significación de cada uno de los coeficientes en relación con su propio error estándar, es recomendable utilizar las pruebas $t$. Se puede observar en la significación de la prueba $t$ mostrada en el Cuadro 40, que los coeficientes de las variables resultaron ser significativos, pues están por debajo del valor del nivel de significación $\rho_{\text {aceptada }}=0.05$, ya que $\rho_{\text {constante }}=0.001$ y $\rho_{\text {bachillerato }}=0.005$ se encuentran por debajo de $\rho_{\text {aceptada }}=0.05$, para que sea significativa. 


\section{Entonces:}

Hi: La predicción afirma la variable explicativa siguiente: los promedios del bachillerato tienen un efecto sobre los resultados de la variable explicada, esto es, sobre los resultados obtenidos por los alumnos de la licenciatura en Medicina como promedio del primer semestre.

\section{Cuadro 40. Resultados obtenidos con el programa SPSS para la prueba de Regresión} Lineal.

\section{$\Rightarrow$ Regresión}

[Conjunto_de_datos0]

Variables introducidas/eliminadas ${ }^{a}$

\begin{tabular}{|l|l|l|l|}
\hline Modelo & $\begin{array}{l}\text { Variables } \\
\text { introducidas }\end{array}$ & $\begin{array}{c}\text { Variables } \\
\text { eliminadas }\end{array}$ & Método \\
\hline 1 & $\begin{array}{l}\text { Promedios } \\
\text { Bachillerato }^{\text {b }}\end{array}$ & & Introducir \\
\hline
\end{tabular}

a. Variable dependiente: Promedios 1er Semestre

Existe coincidencia con

b. Todas las variables solicitadas introduc el error estándar de estimación $S_{y / x}=3.37$

\begin{tabular}{|l|c|r|r|c|}
\multicolumn{7}{|c|}{ Resumen del modelo } \\
\hline Modelo & $\mathrm{R}$ & R cuadrado & $\begin{array}{c}\text { R cuadrado } \\
\text { corregida }\end{array}$ & $\begin{array}{c}\text { Error típ. de la } \\
\text { estimación }\end{array}$ \\
\hline 1 & $.504^{\mathrm{a}}$ & .254 & .227 & 3.37973 \\
\hline
\end{tabular}

El valor de $F$ ratio valida la hipótesis de investigación a. Variables predictoras: (Constante), Promedios Bachillerato con un nivel de confianza de 0.005

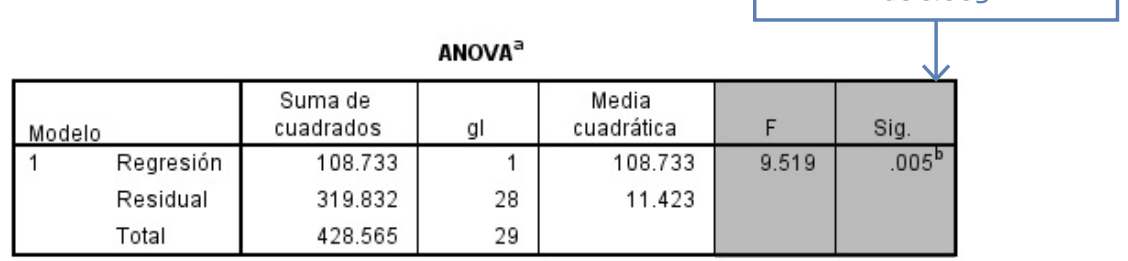

a. Variable dependiente: Promedios 1er Semestre

b. Variables predictoras: (Constante), Promedios Bachillerato

Coeficientes $^{a}$

\begin{tabular}{|c|c|c|c|c|c|}
\hline \multirow[b]{2}{*}{ Modelo } & \multicolumn{2}{|c|}{ Coeficientes no estandarizados } & \multirow{2}{*}{$\begin{array}{c}\text { Coeficientes } \\
\text { tipificados } \\
\text { Beta }\end{array}$} & \multirow[b]{2}{*}{$t$} & \multirow[b]{2}{*}{ Sig. } \\
\hline & $\mathrm{B}$ & Error típ. & & & \\
\hline $1 \quad$ (Constante) & 50.890 & 13.687 & & 3.718 & .001 \\
\hline Promedios Bachillerato & .452 & .146 & .504 & 3.085 & .005 \\
\hline \multicolumn{5}{|c|}{ a. Variable dépendiente: Promedios 1er Semestre } & \\
\hline $\begin{array}{l}\text { Los valores } a_{y}=50.89 y \\
\text { el valor de } b_{y}=0.452 \text { casi } \\
\text { igual al calculado. }\end{array}$ & & & & \multicolumn{2}{|c|}{$\begin{array}{c}\text { Prueba } t \text { para cada } \\
\text { coeficiente con relación a } \\
\text { su propio error. }\end{array}$} \\
\hline
\end{tabular}





\section{Capítulo 19}

\section{Análisis de regresión lineal múltiple}

La regresión lineal múltiple representa una extensión de la regresión simple cuando existen dos o más variables de predicción o explicativas. Al igual que en la regresión lineal simple las variables explicativas se representan por el símbolo $X$, por ejemplo, si se tienen tres variables explicativas se representan $X_{1}, X_{2}$, y $X_{3}$ y la variable explicada se indica con el símbolo $Y$.

El análisis de la regresión múltiple tiene como objetivo investigar en qué medida los resultados de las variables explicativas $X_{1}, X_{2}$, y $X_{3}$ permiten predecir los resultados de la variable $Y$.

Ejemplo 94. Se trata de aceptar o rechazar la siguiente hipótesis de investigación:

Hi: La predicción afirma que las tres variables explicativas siguientes: los promedios del bachillerato, la prueba de aptitud académica y la prueba de lectura, tienen un efecto sobre los resultados de la variable explicada, esto es, sobre los resultados obtenidos por los alumnos de la licenciatura en Enfermería como promedio del primer semestre.

\subsection{Estado situacional}

Los aspectos que motivaron a realizar esta investigación en el nivel universitario tienen origen en determinar si la exigencia de un promedio mínimo obtenido por el aspirante durante su estancia en el bachillerato, la prueba de aptitud académica y la prueba de lectura son elementos suficientes para justificar la permanencia ante los lineamientos que se requieren para no fracasar durante el proceso en la licenciatura en Enfermería.

En este caso se trata de determinar si las variables explicativas (los promedios obtenidos por cada uno de los participantes al concluir el bachillerato, las pruebas requeridas para la admisión del aspirante -aptitud académica y lectura-) tienen efecto en el promedio del primer semestre, con una visión hacia el futuro, en lo referente a determinar la posibilidad de que todos los participantes concluyan favorablemente su licenciatura. Se trata de una hipótesis unilateral ya que predice un efecto positivo entre las variables explicativas $X_{1}, X_{2} \ldots$ y la explicada $Y$.

Se seleccionaron 28 estudiantes que conformaron el único grupo que cursó el primer semestre de la licenciatura en Enfermería, es importante resaltar que es el mismo número de estudiantes que fueron admitidos, lo que significa que no hay deserciones ni reprobados durante el semestre. En la Tabla 35 se muestran los resultados obtenidos durante este proceso. 
Tabla 35. Relación de evaluaciones correspondientes a la Licenciatura en Enfermería.

\begin{tabular}{|c|c|c|c|c|}
\hline $\begin{array}{l}\text { Número del } \\
\text { Alumno }\end{array}$ & $\begin{array}{l}\text { Promedio 1er } \\
\text { Semestre }(\eta)\end{array}$ & $\begin{array}{c}\text { Promedio del } \\
\text { Bachillerato }\left(X_{1}\right)\end{array}$ & $\begin{array}{l}\text { Prueba Aptitud } \\
\text { Académica }\left(X_{2}\right)\end{array}$ & $\begin{array}{l}\text { Prueba de } \\
\text { Lectura }\left(X_{3}\right)\end{array}$ \\
\hline 1 & 89.50 & 90.07 & 62.77 & 70.00 \\
\hline 2 & 96.30 & 90.92 & 69.38 & 90.00 \\
\hline 3 & 88.00 & 81.28 & 68.33 & 60.00 \\
\hline 4 & 85.60 & 88.66 & 64.33 & 90.00 \\
\hline 5 & 90.10 & 85.89 & 65.55 & 80.00 \\
\hline 6 & 91.70 & 88.43 & 69.11 & 60.00 \\
\hline 7 & 92.20 & 93.20 & 72.27 & 50.00 \\
\hline 8 & 95.00 & 87.66 & 65.22 & 80.00 \\
\hline 9 & 86.50 & 83.41 & 64.88 & 60.00 \\
\hline 10 & 88.50 & 96.61 & 59.83 & 40.00 \\
\hline 11 & 90.33 & 82.94 & 64.11 & 50.00 \\
\hline 12 & 95.60 & 92.00 & 58.22 & 70.00 \\
\hline 13 & 95.90 & 88.00 & 79.55 & 50.00 \\
\hline 14 & 88.38 & 90.00 & 66.05 & 70.00 \\
\hline 15 & 89.09 & 87.00 & 53.00 & 70.00 \\
\hline 16 & 87.50 & 77.44 & 75.44 & 50.00 \\
\hline 17 & 93.70 & 92.00 & 67.05 & 100.00 \\
\hline ㅇ & 92.00 & 84.00 & 71.44 & 70.00 \\
\hline 19 & 91.11 & 97.00 & 56.38 & 40.00 \\
\hline 20 & 93.90 & 88.15 & 65.72 & 50.00 \\
\hline 21 & 86.80 & 94.00 & 56.00 & 70.00 \\
\hline 22 & 98.00 & 90.61 & 70.55 & 100.00 \\
\hline 23 & 83.00 & 84.58 & 66.66 & 60.00 \\
\hline 24 & 92.20 & 87.30 & 64.55 & 90.00 \\
\hline 25 & 90.10 & 88.46 & 60.16 & 40.00 \\
\hline 26 & 90.80 & 82.43 & 69.05 & 80.00 \\
\hline 27 & 91.67 & 85.51 & 71.66 & 70.00 \\
\hline 28 & 94.63 & 83.61 & 64.88 & 100.00 \\
\hline
\end{tabular}

19.2 Explicación

En la regresión múltiple se trata de predecir los efectos de variables explicativas sobre una variable explicada; las variables explicativas pueden ser continuas o categóricas, recordando que las continuas permanecen en una escala utilizando valores de intervalo o de escala, mientras que las variables categóricas pueden adquirir solo dos valores posibles: cursó o no el bachillerato. La variable explicada debe ser siempre una variable continua. 
La regresión múltiple consiste en primer lugar en determinar si la varianza de la regresión es significativamente mayor que la varianza debida al efecto del error estándar de predicción. Esto es, la varianza resultado del efecto de las variables explicativas sobre la variable pronosticada es mucho más grande que la varianza del efecto del error estándar de predicción (Greene y D'oliveira, 2006).

En segundo lugar se requiere determinar cómo contribuyen de manera relativa cada una de las variables explicadas sobre los resultados pronosticados de la variable explicada, el análisis de la regresión prueba cada variable explicativa y su propio error para comprobar la significación de cada variable explicada, utilizando la prueba $t$.

Si la varianza del error estándar de predicción es elevada, como afirma la hipótesis nula, entonces ésta se tiene que aceptar y rechazar la hipótesis de investigación.

\subsection{Procedimiento para determinar la ecuación de regresión múltiple}

La forma general de la ecuación de regresión múltiple para tres variables de predicción es:

$$
Y^{\prime}=b_{1} X_{1}+b_{2} X_{2}+b_{3} X_{3}+a
$$

Donde:

$$
\begin{aligned}
& Y^{\prime}=\text { predicción del valor } Y \\
& b_{1}=\text { coeficiente de la primera variable de predicción. } \\
& X_{1}=\text { primera variable de predicción. } \\
& b_{2}=\text { coeficiente de la segunda variable de predicción. } \\
& X_{2}=\text { segunda variable de predicción. } \\
& b_{3}=\text { coeficiente de la tercera variable de predicción. } \\
& X_{3}=\text { tercera variable de predicción. } \\
& a=\text { constante de predicción. }
\end{aligned}
$$

Esta ecuación es muy similar a la utilizada en la regresión simple, pero en este caso se han agregado dos variables de predicción y sus correspondientes coeficientes. Esta ecuación predice los resultados para $Y$ mediante el cálculo de las líneas de regresión para cada una de las tres variables explicativas, donde a representa un punto de corte común para estas tres variables.

En este caso el desarrollo matemático resulta muy complicado y los cálculos reales se realizan en una computadora, utilizando el programa SPSS.

\subsection{Análisis de regresión lineal múltiple con el programa SPSS}

El primer paso consiste en otorgarle las propiedades a las variables, una vez abierto el programa y antes de introducir los datos, es necesario definir las variables y otorgarle las características para su presentación en la tabla, para esto se requiere dar un clic en la pestaña Vista de variables. En este caso las acciones indispensables para obtener los resultados correctos son: - Designar los nombres de las variables. Para realizar esto es necesario presionar la ceja de Vista de variables, y en seguida teclear el nombre de cada variable, primero en la columna Nombre (primera) y la fila 1, la palabra VariableY, debe ir sin espacio entre la palabra variable y la y debido a que el programa no reconoce caracteres vacíos, segundo en la columna Nombre pero ahora en la fila 2, escribir VariableX1, y así respectivamente en la fila 3 escribir VariableX2 y en la fila 4 escribir VariableX3. 
- Definir el tipo de medida que se realizó. Debido a que los datos son de intervalo se requiere que en la columna Medida se seleccione la opción Escala. El programa preselecciona el tipo de variables como numérico, para darle presentación a los datos se pueden realizar las siguientes operaciones (pero no es necesario): definir la Anchura (8) y cantidad de Decimales (2) requeridos y la Alineación (centrado).

En la Figura 148 se observan estos pasos así como la ubicación de cada variable y las propuestas de opciones para la definición y presentación de las variables.

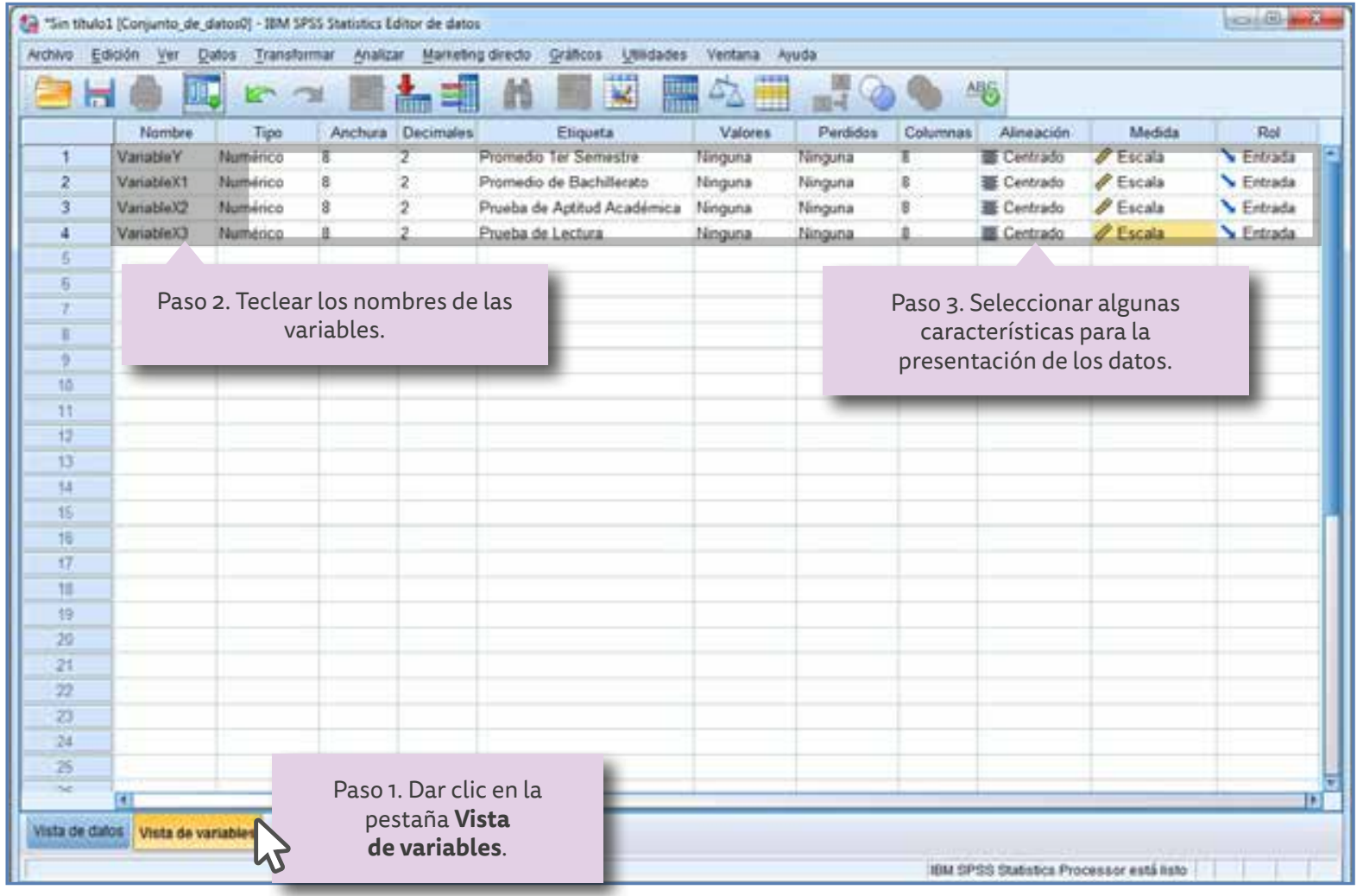

Figura 148. Designación de variables y sus características para la prueba de Regresión Lineal.

Una vez designados los nombres de las variables y sus características se introducen los datos en la tabla; para llevar a cabo esto es necesario dar un clic en la pestaña Vista de datos, e introducir los datos correspondientes a cada variable, éstos se pueden introducir uno por uno tecleándolos o bien importarlos (seleccionar, copiar y pegar) de la Tabla 35 en donde se encuentran ubicados y pegarlos dentro de esta tabla.

Cuadro 41. Designación de variables para la prueba de Regresión Múltiple.

\begin{tabular}{l|l|l|l|}
\hline Nombre: VariableY & Nombre: VariableX1 & Nombre: VariableX2 & Nombre: VariableX3 \\
\hline Tipo: Numérico & Tipo: Numérico & Tipo: Numérico & Tipo: Numérico \\
\hline $\begin{array}{l}\text { Anchura: } 8 \\
\text { Decimales: } 2\end{array}$ & Anchura: 8 & Anchura: 8 & Anchura: 8 \\
\hline Etiqueta: Promedio 1er & Eecimales: 2 & Decimales: 2 & Decimales: 2 \\
\hline Semestre & Bachillerato & Etiqueta: Prueba & Etiqueta: Prueba de \\
\hline Prueba de lectura & Valores: Ninguno & Valores: Ninguno & Valores: Ninguno \\
\hline Perdidos: Ninguno & Perdidos: Ninguno & Perdidos: Ninguno & Perdidos: Ninguno \\
\hline Columnas: 8 & Columnas: 8 & Columnas: 8 & Columnas: 8 \\
\hline Alineación: Centrado & Alineación: Centrado & Alineación: Centrado & Alineación: Centrado \\
Medida: Escala & Medida: Escala & Medida: Escala & Medida: Escala \\
\hline Rol: Entrada & Rol: Entrada & Rol: Entrada & Rol: Entrada
\end{tabular}


En la Figura 149 se observa cómo quedan los datos siguiendo cualquiera de los procedimientos mencionados y de acuerdo a las características seleccionadas en los pasos anteriores.

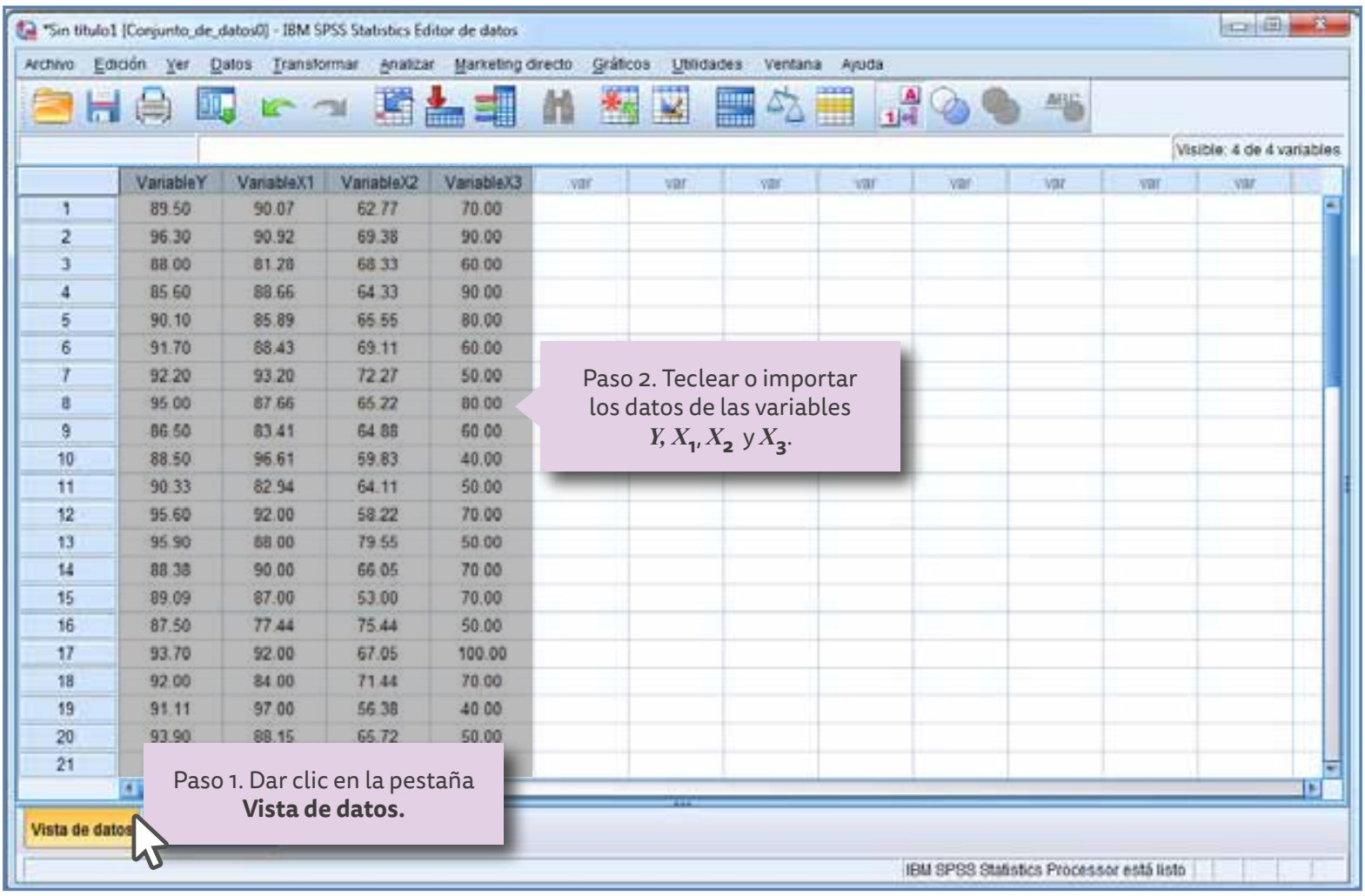

Figura 149. Presentación de las Variables $Y, X_{1}, X_{2} y X_{3}$

Una vez que los datos se encuentran en la tabla se realiza la prueba (Figura 150), para hacerlo es necesario dar un clic en la pestaña ubicada en la barra superior designada como Analizar, en seguida aparece un cuadro de diálogo, en donde se selecciona la línea que indica Regresión; al ubicar el apuntador del ratón en esta opción se presenta a la derecha otro cuadro de diálogo, se selecciona Lineales (que son las que corresponden a dos variables) y dar clic con el ratón.

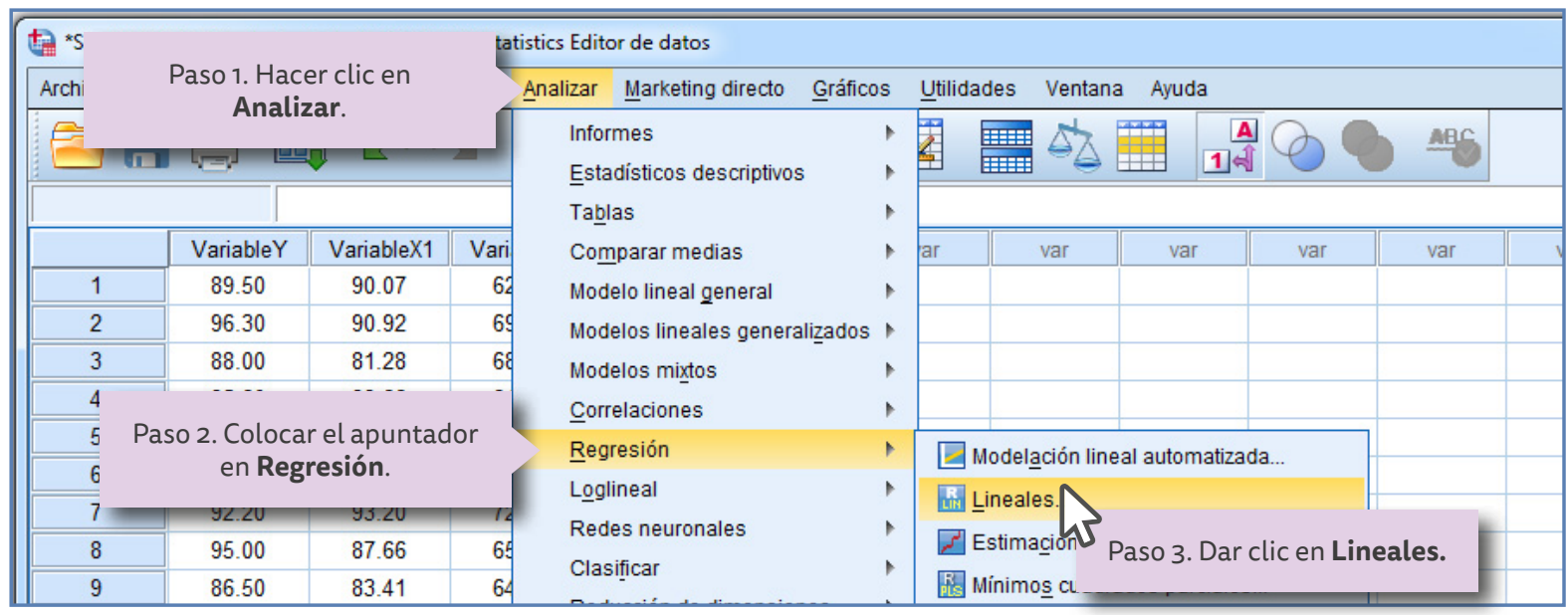

Figura 150. Cuadros de diálogo para seleccionar la prueba de regresión lineal.

Aparece la ventana de la Figura 151 en la que se muestran las variables del lado izquierdo: Promedio 1er Semestre $(Y)$, Promedio Bachillerato $\left(X_{1}\right)$, Prueba de Aptitud Académica $\left(X_{2}\right)$ 
y Prueba de lectura $\left(X_{3}\right)$, éstas deben ser trasladadas a la ventana que dice dependientes; la forma de hacerlo es seleccionando con un clic la variable dependiente (Variable Y) y dando un clic en la flecha que se ubica entre las dos ventanas se traslada a la ventana Dependientes.

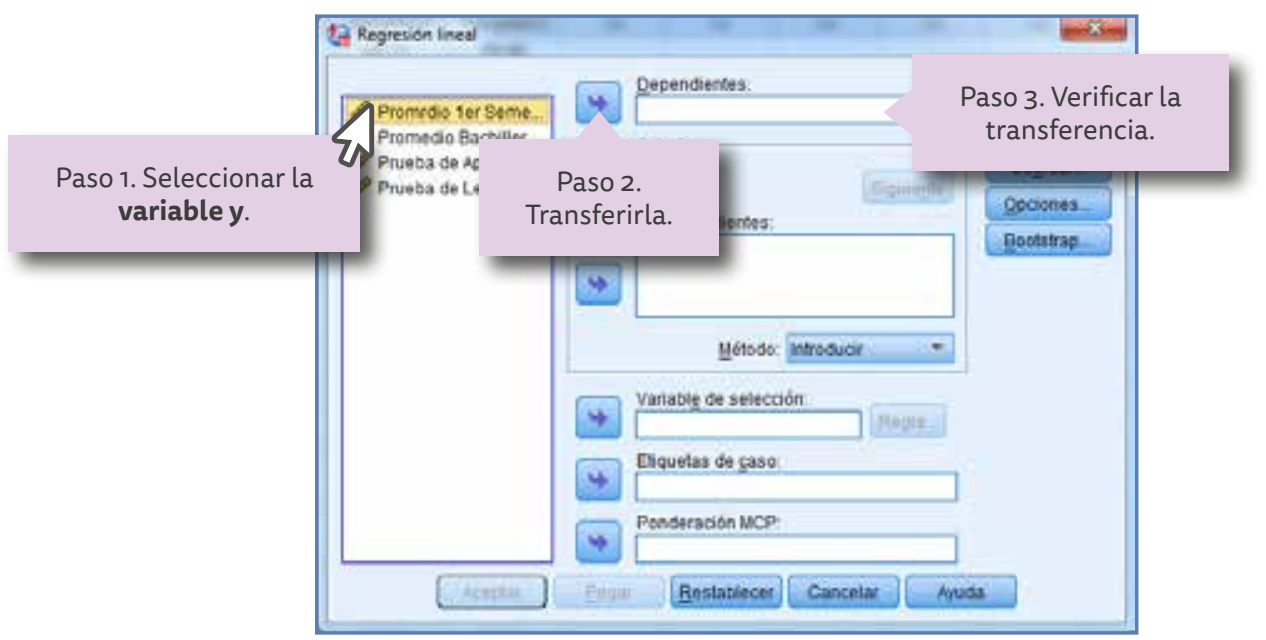

Figura 151. Transferencia de la variable Promedio primer Semestre para procesar los datos con el programa SPSS.

Se seleccionan las variables independientes $\left(X_{1}, X_{2}\right.$ y $\left.X_{3}\right)$ y se da un clic en la flecha que se ubica entre las dos ventanas, se trasladan a la ventana Independientes (Figura 152).

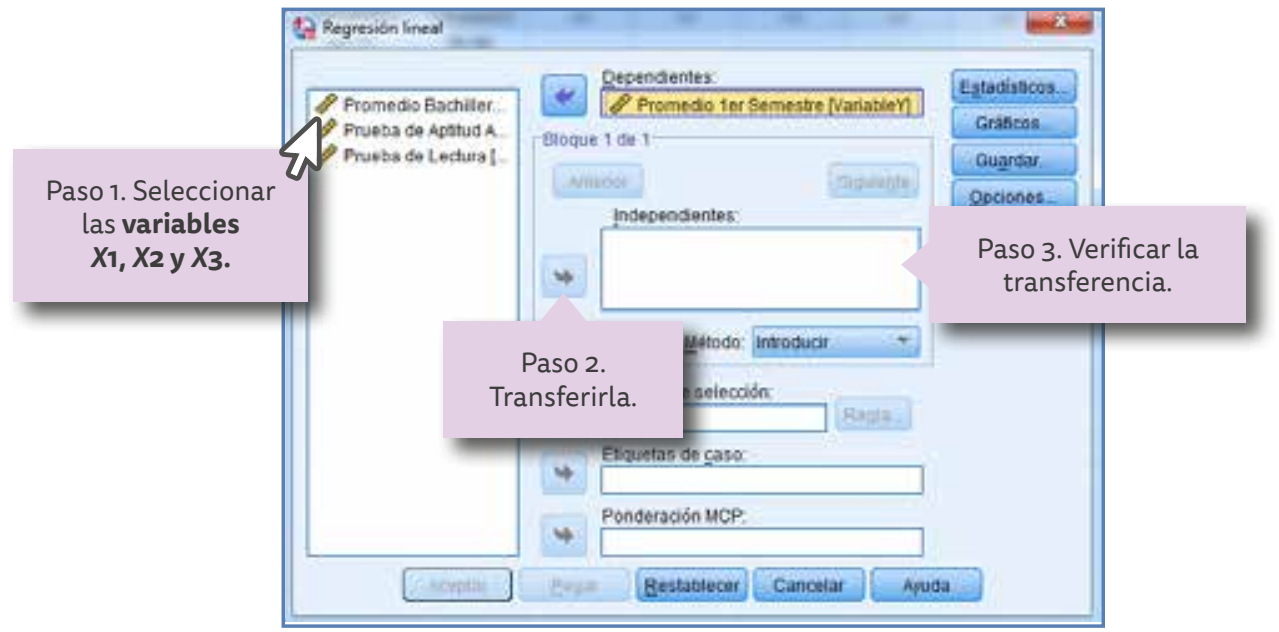

Figura 152. Transferencia de la variable Promedio Bachillerato para procesar los datos con el programa SPSS.

Una vez realizadas estas acciones el programa queda listo para arrojar los resultados, al activar el botón Aceptar (Figura 153) se obtienen los resultados que se muestran en el Cuadro 42, en el que se observa que el valor típico de la estimación $\mathrm{S}_{\mathrm{y} / \mathrm{x}}$ es igual a 3.10207.

El nivel de significación es $\rho_{\text {encontrada }}=0.02$ por lo que se puede concluir que:

$$
\rho_{\text {encontrada }} 0.02<\rho_{\text {aceptada }} 0.05
$$




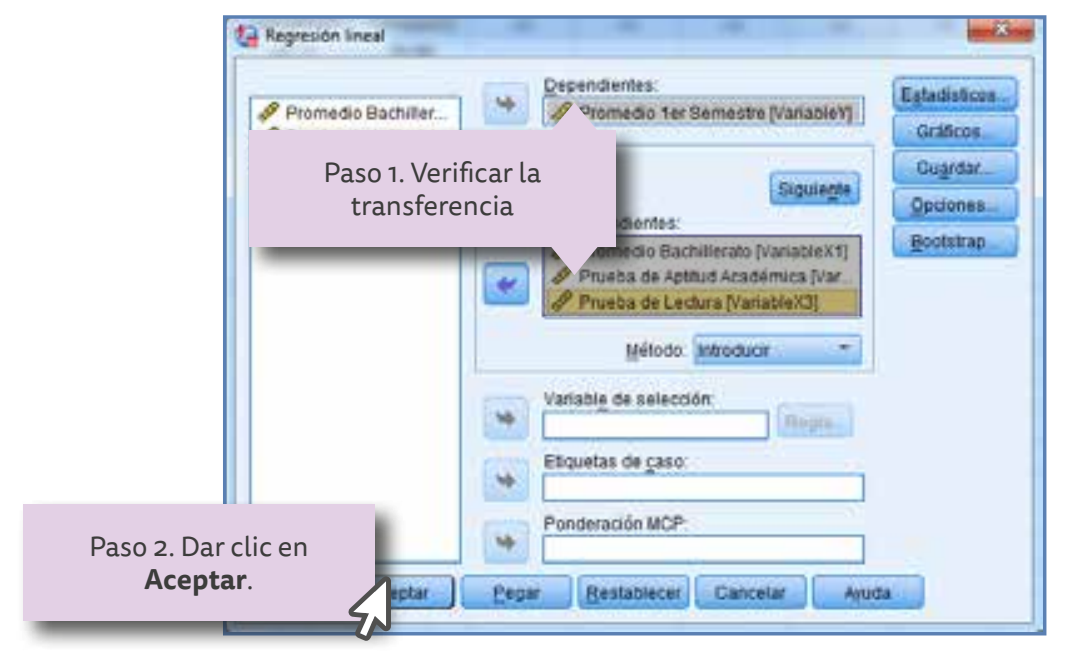

Figura 153. Paso para ejecutar el programa SPSS para que realice los cálculos requeridos para la prueba de Regresión Lineal.

Esto es, el valor encontrado 0.02 es menor que el mínimo aceptable por los investigadores en educación (0.05), lo que significa que los resultados de la diferencia no son aleatorios puesto que existe una diferencia significativa, por lo que se puede rechazar la hipótesis nula y aceptar la hipótesis de investigación.

También se puede observar que el valor de $F$ ratio es igual a 3.964 para un nivel de significación de $\rho_{\text {encontrada }}=0.02$, por lo que se puede rechazar la hipótesis nula y aceptar la hipótesis de investigación.

De acuerdo a los coeficientes arrojados por el programa SPSS se puede determinar la ecuación de la línea de regresión de la siguiente forma:

$$
Y^{\prime}=b_{1} x_{1}+b_{2} x_{2},+b_{3} x_{3}+a
$$

Donde:

$$
\begin{aligned}
b_{1}=0.344 \quad b_{2} & =0.263 \quad b_{3}=0.065 \\
\text { у } \quad a & =39.044
\end{aligned}
$$

Sustituyendo:

$$
Y^{\prime}=0.344 x_{1}+0.263 x_{2}, 0.065 x_{3}+39.044
$$

Prueba $t$. Para comparar cada una de las variables explicativas se debe comprobar la contribución de cada variable a la varianza total en los resultados de $Y$. Para comprobar la significación de cada uno de los coeficientes en relación con su propio error estándar, se utilizan las pruebas $t$, se puede observar en la significación de la prueba $t$ mostrada en el Cuadro 42, que la única variable que no resultó ser significativa fue la prueba de lectura pues no está por debajo del valor del nivel de significación $\rho_{\text {aceptada }} 0.05$, ya que $\rho_{\text {p. lectura }}=0.056$ debe ser menor que $\rho_{\text {aceptada }} 0.05$, para que sea significativa. 


\section{Entonces:}

Hi: La predicción supone que los resultados obtenidos por los alumnos de Enfermería como promedio obtenidos en el bachillerato tienen una correlación positiva con los promedios del primer semestre cursado.

\section{Cuadro 42. Resultados obtenidos con el programa SPSS para la prueba de Regresión} Lineal.

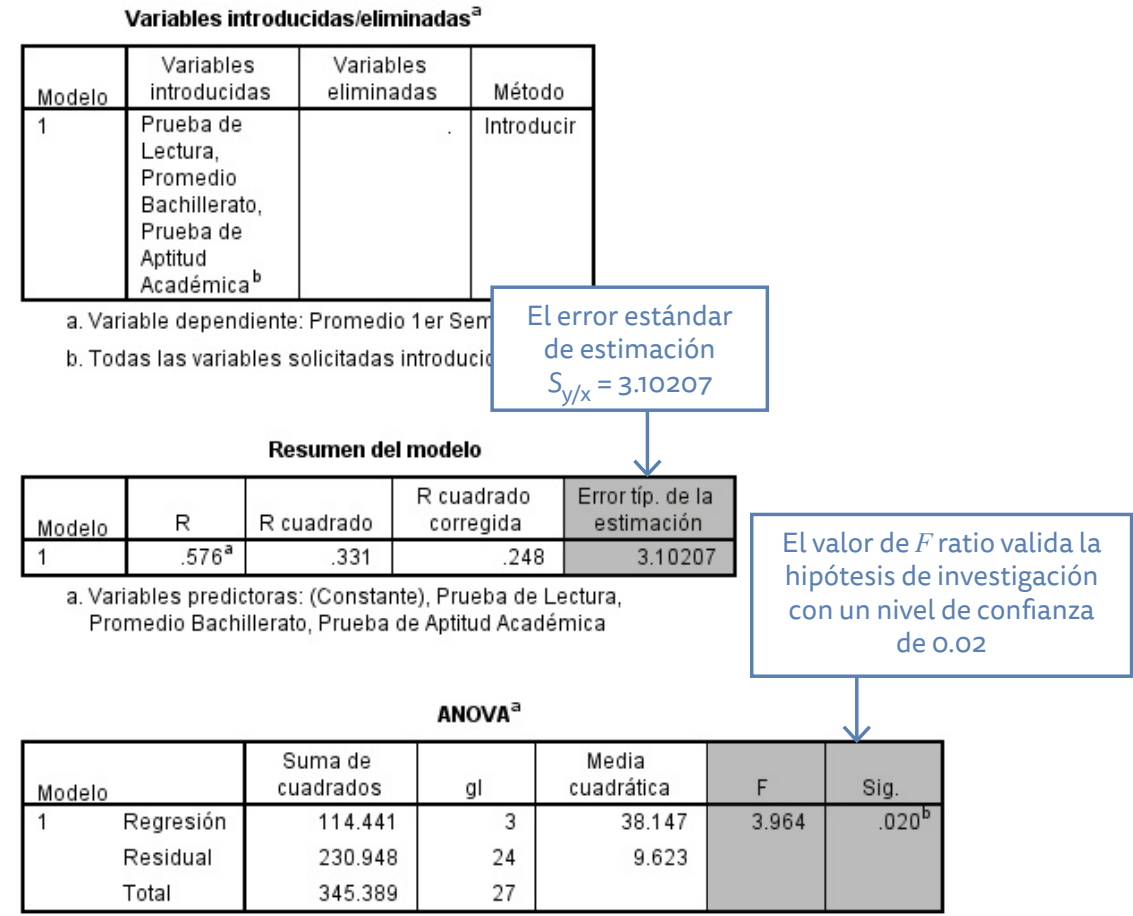

a. Variable dependiente: Promedio 1er Semestre

b. Variables predictoras: (Constante), Prueba de Lectura, Promedio Bachillerato, Prueba de Aptitud Académica

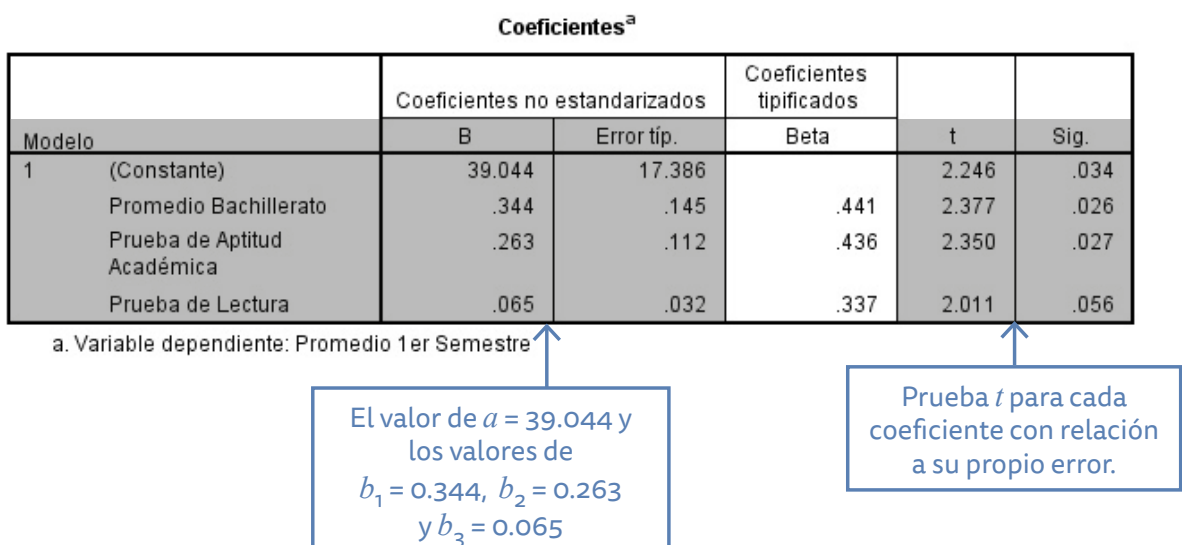


Apéndices

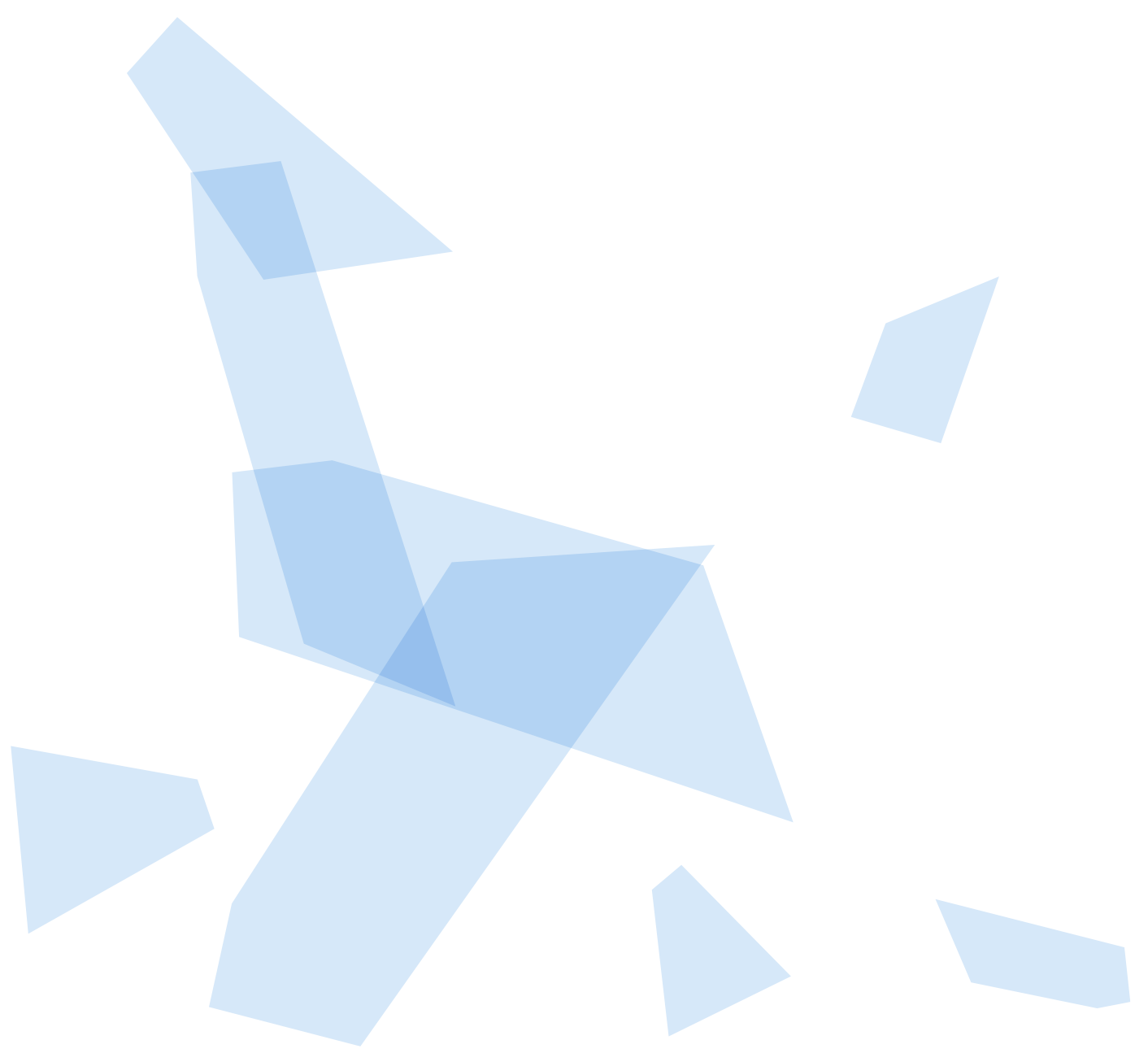



Ejemplo 1. ¿Qué está pasando?, ¿Cuál es el problema?

Posible respuesta: El procedimiento utilizado por el maestro para explicar, no es claro, al utilizarlo nuevamente sigue sin estar claro. Es por esta razón que los alumnos no comprenden.

Posible solución: El maestro debe de buscar otra manera para explicar en términos que los alumnos comprendan.

Ejemplo 2. ¿Qué está pasando?, ¿Cuál es el problema?

Posible respuesta: Miguel no presta atención al maestro por estar copiando lo que éste ha escrito en el pizarrón, posiblemente Miguel es lento para escribir y procesar la información.

Posible solución: El maestro debe dar tiempo a que Miguel termine de escribir, mediante el intercambio de comentarios con sus alumnos, y proceder a la explicación de la nueva información cuando Miguel esté atento.

Ejemplo 3. ¿Qué está pasando?, ¿Cuál es el problema?

Posible respuesta: los alumnos sólo aprenden a identificar los tipos de mapas pero no sus características y definición.

Posible solución: El maestro debe complementar el juego agregando al gritar las cartas estas características o la definición y luego nombrar el tipo de mapa, cerrando con cometarios.

Ejemplo 4. ¿Qué está pasando?, ¿Cuál es el problema?

Posible respuesta: Es posible que el maestro utilice el video de manera improvisada para cubrir el tiempo de la clase de historia, sin planear los momentos que se requieren en la técnica del uso del video.

Posible solución: El maestro debe de indicar al inicio de la proyección los objetivos que se persiguen, darles una guía de lo que se pretende observar, para que los alumnos tengan conciencia de lo que deben aprender, regular el tiempo para el cierre de la proyección comentar los hallazgos encontrados reafirmando de esta forma los conocimientos.

Ejemplo 5. ¿Qué está pasando?, ¿Cuál es el problema?

Posible respuesta: Posiblemente el número y tipo de respuestas no es adecuado para el tiempo del que se dispone para ser contestadas, no es adecuado improvisar la aplicación de los exámenes, éstos deben ser planeados y diseñados cuidadosamente en el momento de su aplicación.

Posible solución: Una prueba objetiva requiere menos tiempo para ser contestada y definitivamente se debe considerar la programación del examen con tiempo. 


\section{Ejemplo 6. ¿Qué está pasando?, ¿Cuál es el problema?}

Posible respuesta: La adversidad de no querer asistir a la escuela puede ser una señal de que el problema se encuentre ahí, y no en casa o el contexto, posiblemente se trate de un caso de bullying físico o psicológico por parte de algunos de sus compañeros.

Posible solución: El maestro debe observar el comportamiento de los alumno hacia Juanito y sus otros compañeros para detectar a los posibles agresores. Si los identifica proponer correctivos para evitar que vuelva a suceder.

Nota aclaratoria: éstos son solo ejemplos de problemas que pueden dar origen a una investigación educativa, las respuestas que dio el usuario del libro pueden ser correctas dentro de su contexto y experiencia frente al grupo dentro y fuera del salón de clase. Las respuestas aquí presentadas son de situaciones reales vividas por los autores de este libro. 
I. Coloque en el paréntesis una $\mathbf{V}$ si lo que se afirma es verdadero o una $\mathrm{F}$ si es falsa.

1. La señal moduladora debe ser alrededor del $30 \%$ de la potencia del amplificador ( ) de RF, si se modula en la salida de éste, con la finalidad de obtener una modulación correcta.

2. La retroalimentación en un circuito oscilador debe ser positiva para que la señal se ( ) mantenga estable.

3. Las ondas electromagnéticas reciben ese nombre porque están constituidas por ( ) campos eléctricos y magnéticos, desfasados 90 uno con respecto al otro.

4. La modulación por pulsos se utiliza exclusivamente para sistemas digitales tales ( ) como PCM, CDM o PLM de Q niveles.

5. Los métodos de modulación por onda continua de multifase permiten transmitir ( ) señales digitales de 4, 8 o 16 PSK.

6. Un circuito oscilador de RF acoplado a una antena puedefuncionar como transmisor ( ) si se opera con una llave de clave Morse.

II. Coloque en el paréntesis la letra que corresponda a la opción que considere que complete las siguientes oraciones.

1. En una onda electromagnética el parámetro que define el número de ondas que se ( ) transmiten por segundo es:
a. La longitud de onda
b. La frecuencia
c. la fase
d. La velocidad

2. La velocidad de propagación de las ondas electromagnéticas es igual a la velocidad（ ) de la luz, esto es:
a. $260,000 \mathrm{Km} / \mathrm{s}$
b. $300,000 \mathrm{Km} / \mathrm{s}$
c. $360,000 \mathrm{Km} / \mathrm{s}$
d. $630,000 \mathrm{Km} / \mathrm{s}$

3. Si una señal de audio varía entre $50 \mathrm{~Hz}$ a $4 \mathrm{KHz}$ y se modula en amplitud con una ( ) portadora de $10 \mathrm{KHz}$ el rango de frecuencias transmitido oscilaría en un rango de:
a. $4 \mathrm{KHz}$ a $14 \mathrm{KHz}$
b. $6 \mathrm{KHz}$ a $14 \mathrm{KHz}$
c. $9.95 \mathrm{KHz}$ a $10.05 \mathrm{KHz}$
d. $9.95 \mathrm{KHz}$ a $14.05 \mathrm{KHz}$

4. Cuando se trasmite una señal modulada en amplitud se puede afirmar que se está （ ） transmitiendo por:
a. BLS
b. BLI
c. DBL
d. BLU

5. El rango de frecuencias de la señal de audio varía entre:
a. $20 \mathrm{~Hz}$ a $20 \mathrm{KHz}$
b. $20 \mathrm{~Hz}$ a $200 \mathrm{KHz}$
c. $20 \mathrm{KHz}$ a $200 \mathrm{KHz}$
d. $20 \mathrm{KHz}$ a $100 \mathrm{KHz}$

6. La banda comercial de los receptores de amplitud modulada varía entre:
a. $53 \mathrm{~Hz}$ a $16.3 \mathrm{KHz}$
b. $530 \mathrm{~Hz}$ a $1630 \mathrm{KHz}$
c. $530 \mathrm{KHz}$ a $1630 \mathrm{KHz}$
d. $88 \mathrm{KHz}$ a $108 \mathrm{KHz}$

7. Con que elemento electrónico se debe proteger la fuente de alimentación de ( ) Corriente directa, de la señal de radio frecuencia para que no sufra daños:
a. Resistencia
b. Condensador
c. bobina
d. Diodo 
Prueba objetiva de acuerdo a las unidades 1 y 2 (continuación).

\section{Complete las siguientes oraciones:}

1. A la señal de audio que produce los cambios de amplitud en la señal de radio frecuencia se la conoce como

2. A la señal de radio frecuencia que varía su amplitud de acuerdo a las variaciones de la señal de audio se le conoce como

3. A la señal resultante de la mezcla de la de audio y la de radio frecuencia recibe el nombre de

4. Los tres tipos de modulación lineal que se utilizan con señales analógicas son

5. Las consisten en un rango de frecuencias comprendido entre 3 $\mathrm{MHz}$ y $30 \mathrm{MHz}$ y sus principales aplicaciones son en: radiodifusión, Radio aficionados, banda civil, gubernamental y militar.

6. Las consisten en un rango de frecuencias comprendido entre 300 $\mathrm{KHz}$ y $3 \mathrm{MHz}$ y sus principales aplicaciones son en: la banda comercial de AM.

7. Las consisten en un rango de frecuencias comprendido entre 30 $\mathrm{KHz}$ y $300 \mathrm{KHz}$ y sus principales aplicaciones son en: Navegación y aeronáutica.

8. El espectro electromagnético abarca desde las señales de radio hasta los

9. El espectro radioeléctrico abarca desde las señales de radio hasta las

\section{Coloque en el paréntesis el número que corresponda:}

1. Eleva el nivel de la señal para ser transmitida por la antena. ( ) Amplificador clase A

2. Permite que la señal de audio pueda hacer variar la ( ) Amplificador clase B amplitud de la portadora.

3. Eleva la señal de la fuente de audio (micrófono, pastilla, ( ) Amplificador clase C etc.) para ser aplicada al amplificador de potencia.

4. Conviertelasseñaleseléctricasenondaselectromagnéticas ( ) Amplificador magnético para ser radiadas al espacio.

5. Eleva el nivel de la señal de audio para lograr una correcta （ ) Oscilador de RF modulación con la portadora.

6. Se encarga de generar la señal portadora.

( ) Modulador balanceado

7. Evita que la señal modulada se atenúe al ser conectada a （）Acoplador la antena.

8. Facilita que la señal de radio circule del emisor al colector ( ) Des-acoplador sin atenuarse

( ) Antena 


\section{Apéndice C. Solución al Ejercicio 1}

Ejercicio 1. Realizar los cálculos correspondientes por el proceso que se elija para determinar la desviación típica con los datos correspondientes al grupo B del $4^{\circ}$ Año de primaria y compárelo con los resultados del grupo A.

1. Determinar el valor de la media de la distribución:

$$
\overline{\mathrm{x}}=\frac{\sum \mathrm{x}}{N}=\frac{715}{11}=65
$$

2. Elevar al cuadrado cada puntaje directo, completar la tabla.

Tabla de puntajes directos cuadráticos para facilitar el cálculo de la desviación típica.

\begin{tabular}{|c|c|}
\hline \multicolumn{2}{|c|}{ Grupo B $(N=11)$} \\
\hline$x$ & $x^{2}$ \\
\hline 100 & 10000 \\
\hline 95 & 9025 \\
\hline 80 & 6400 \\
\hline 75 & 5625 \\
\hline 72 & 5184 \\
\hline 70 & 4900 \\
\hline 68 & 4624 \\
\hline 60 & 3600 \\
\hline 40 & 1600 \\
\hline 35 & 1225 \\
\hline 20 & 400 \\
\hline$\sum x_{A}=715$ & $\sum x_{2}=52583$ \\
\hline
\end{tabular}

3. Sumar el cuadrado del puntaje directo y completar la tabla. Reemplazar los datos en la ecuación:

$$
\sigma_{\mathrm{B}}=\sqrt[2]{\frac{\sum \mathrm{x}^{2}}{N}-\overline{\mathrm{x}}^{2}}=\sqrt[2]{\frac{52583}{11}-65^{2}}=23.56
$$




\section{Apéndice D. Tablas Estadísticas}

Tabla A Porcentaje del área bajo la curva normal entre $\bar{x}$ y $Z$.

Tabla B Valores críticos de $W$ para varios niveles de probabilidad (Wilcoxon).

Tabla C Valores críticos de $U$ para varios niveles de probabilidad Mann-Whitney.

Tabla D Valores críticos de $X_{r}^{2}$ para tres condiciones y varios niveles de probabilidad (Friedman).

Tabla E Valores críticos de $X^{2}$ para varios niveles de probabilidad (Chi cuadrado).

Tabla $\mathrm{F} \quad$ Valores críticos de $H$ a varios niveles de probabilidad (Kruskal-Wallis).

Tabla G Valores críticos de $t$ para varios niveles de probabilidad (prueba $t$ ).

Tabla H Valores críticos de $F$ para varios niveles de probabilidad (Mann-Whitney).

Tabla I Valores críticos de $r$ para varios niveles de probabilidad (correlación de Pearson).

Tabla J Valores de $r_{\mathrm{s}}$ a los niveles de confianza de 0.05 y 0.01 
Tabla A. Porcentaje del área bajo la curva normal entre $\bar{x}$ y $Z$.

\begin{tabular}{|c|c|c|c|c|c|c|c|c|c|c|}
\hline Z & 0.00 & 0.01 & 0.02 & 0.03 & 0.04 & 0.05 & 0.06 & 0.07 & 0.08 & 0.09 \\
\hline 0.0 & 00.00 & 00.40 & 00.80 & 01.20 & 01.60 & 01.99 & 02.39 & 02.79 & 03.19 & 03.59 \\
\hline 0.1 & 03.98 & 04.38 & 04.78 & 05.17 & 05.57 & 05.96 & 06.36 & 06.75 & 07.14 & 07.53 \\
\hline 0.2 & 07.93 & 08.32 & 08.71 & 09.10 & 09.48 & 09.87 & 10.26 & 10.64 & 11.03 & 11.41 \\
\hline 0.3 & 11.79 & 12.17 & 12.55 & 12.93 & 13.31 & 13.68 & 14.06 & 14.43 & 14.80 & 15.17 \\
\hline 0.4 & 15.54 & 15.91 & 16.28 & 16.64 & 17.00 & 17.36 & 17.72 & 18.08 & 18.44 & 18.79 \\
\hline 0.5 & 19.15 & 19.50 & 19.85 & 20.19 & 20.54 & 20.88 & 21.23 & 21.57 & 21.90 & 22.24 \\
\hline 0.6 & 22.57 & 22.91 & 23.24 & 23.57 & 23.89 & 24.22 & 24.54 & 24.86 & 25.17 & 25.49 \\
\hline 0.7 & 25.80 & 26.11 & 26.42 & 26.73 & 27.04 & 27.34 & 27.64 & 27.94 & 28.23 & 28.52 \\
\hline 0.8 & 28.81 & 29.10 & 29.39 & 29.67 & 29.95 & 30.23 & 30.51 & 30.78 & 31.06 & 31.33 \\
\hline 0.9 & 31.59 & 31.86 & 32.12 & 32.38 & 32.64 & 32.89 & 33.15 & 33.40 & 33.65 & 33.89 \\
\hline 1.0 & 34.13 & 34.38 & 34.61 & 34.85 & 35.08 & 35.31 & 35.54 & 35.77 & 35.99 & 36.21 \\
\hline 1.1 & 36.43 & 36.65 & 36.86 & 37.08 & 37.29 & 37.49 & 37.70 & 37.90 & 38.10 & 38.30 \\
\hline 1.2 & 38.49 & 38.69 & 38.88 & 39.07 & 39.25 & 39.44 & 39.62 & 39.80 & 39.97 & 40.15 \\
\hline 1.3 & 40.32 & 40.49 & 40.66 & 40.82 & 40.99 & 41.15 & 41.31 & 41.47 & 41.62 & 41.77 \\
\hline 1.4 & 41.92 & 42.07 & 42.22 & 42.36 & 42.51 & 42.65 & 42.79 & 42.92 & 43.06 & 43.19 \\
\hline 1.5 & 43.32 & 43.45 & 43.57 & 43.70 & 43.82 & 43.94 & 44.06 & 44.18 & 44.29 & 44.41 \\
\hline 1.6 & 44.52 & 44.63 & 44.74 & 44.84 & 44.95 & 45.05 & 45.15 & 45.25 & 45.35 & 45.45 \\
\hline 1.7 & 45.54 & 45.64 & 45.73 & 45.82 & 45.91 & 45.99 & 46.08 & 46.16 & 46.25 & 46.33 \\
\hline 1.8 & 46.41 & 46.49 & 46.56 & 46.64 & 46.71 & 46.78 & 46.86 & 46.93 & 46.99 & 47.06 \\
\hline 1.9 & 47.13 & 47.19 & 47.26 & 47.32 & 47.38 & 47.44 & 47.50 & 47.56 & 47.61 & 47.67 \\
\hline 2.0 & 47.72 & 47.78 & 47.83 & 47.88 & 47.93 & 47.98 & 48.03 & 48.08 & 48.12 & 48.17 \\
\hline 2.1 & 48.21 & 48.26 & 48.30 & 48.34 & 48.38 & 48.42 & 48.46 & 48.50 & 48.54 & 48.57 \\
\hline 2.2 & 48.61 & 48.64 & 48.68 & 48.71 & 48.75 & 48.78 & 48.81 & 48.84 & 48.87 & 48.90 \\
\hline 2.3 & 48.93 & 48.96 & 48.98 & 49.01 & 49.04 & 49.06 & 49.09 & 49.11 & 49.13 & 49.16 \\
\hline 2.4 & 49.18 & 49.20 & 49.22 & 49.25 & 49.27 & 49.29 & 49.31 & 49.32 & 49.34 & 49.36 \\
\hline 2.5 & 49.38 & 49.40 & 49.41 & 49.43 & 49.45 & 49.46 & 49.48 & 49.49 & 49.51 & 49.52 \\
\hline 2.6 & 49.53 & 49.55 & 49.56 & 49.57 & 49.59 & 49.60 & 49.61 & 49.62 & 49.63 & 49.64 \\
\hline 2.7 & 49.65 & 49.66 & 49.67 & 49.68 & 49.69 & 49.70 & 49.71 & 49.72 & 49.73 & 49.74 \\
\hline 2.8 & 49.74 & 49.75 & 49.76 & 49.77 & 49.77 & 49.78 & 49.79 & 49.79 & 49.80 & 49.81 \\
\hline 2.9 & 49.81 & 49.82 & 49.82 & 49.83 & 49.84 & 49.84 & 49.85 & 49.85 & 49.86 & 49.86 \\
\hline 3.0 & 49.87 & 49.87 & 49.87 & 49.88 & 49.88 & 49.89 & 49.89 & 49.89 & 49.90 & 49.90 \\
\hline 4.0 & 49.97 & & & & & & & & & \\
\hline \multicolumn{11}{|c|}{$\begin{array}{l}\text { Como la curva es simétrica, la tabla vale para ir en las dos direcciones, así que } 0.45 \text { negativo también } \\
\text { tiene un área de } 17.36 \%\end{array}$} \\
\hline
\end{tabular}


Tabla B. Valores críticos de $W$ para varios niveles de probabilidad (Wilcoxon).

\begin{tabular}{|c|c|c|c|c|c|c|c|c|c|}
\hline \multicolumn{10}{|c|}{$\begin{array}{l}\text { El estadístico } W \text { denota la suma menor del total de categorías con signo. Para cualquier } N \text { (número } \\
\text { de participantes menos las igualdades) el valor observado de } W \text { es significativo a un nivel de signifi- } \\
\text { cación dado si es igual o menor que los valores críticos que aparecen en la tabla. }\end{array}$} \\
\hline & \multicolumn{4}{|c|}{$\begin{array}{c}\text { Nivel de significación para una prueba } \\
\text { unilateral. }\end{array}$} & & \multicolumn{4}{|c|}{$\begin{array}{l}\text { Nivel de significación para una prueba } \\
\text { unilateral. }\end{array}$} \\
\hline & 0.05 & 0.025 & 0.01 & 0.005 & & 0.05 & 0.025 & 0.01 & 0.005 \\
\hline & \multicolumn{4}{|c|}{$\begin{array}{c}\text { Nivel de significación para una prueba } \\
\text { bilateral. }\end{array}$} & & \multicolumn{4}{|c|}{$\begin{array}{l}\text { Nivel de significación para una prueba } \\
\text { bilateral. }\end{array}$} \\
\hline $\mathrm{N}$ & 0.10 & 0.05 & 0.02 & 0.01 & $\mathrm{~N}$ & 0.10 & 0.05 & 0.02 & 0.01 \\
\hline 5 & 1 & --- & --- & --- & 28 & 130 & 117 & 102 & 92 \\
\hline 6 & 2 & 1 & --- & --- & 29 & 141 & 127 & 111 & 100 \\
\hline 7 & 4 & 2 & 0 & --- & 30 & 152 & 137 & 120 & 109 \\
\hline 8 & 6 & 4 & 2 & 0 & 31 & 163 & 148 & 130 & 118 \\
\hline 9 & 8 & 6 & 3 & 2 & 32 & 175 & 159 & 141 & 128 \\
\hline 10 & 11 & 8 & 5 & 3 & 33 & 188 & 171 & 151 & 138 \\
\hline 11 & 14 & 11 & 7 & 5 & 34 & 201 & 183 & 162 & 149 \\
\hline 12 & 17 & 14 & 10 & 7 & 35 & 214 & 195 & 174 & 160 \\
\hline 13 & 21 & 17 & 13 & 10 & 36 & 228 & 208 & 186 & 171 \\
\hline 14 & 26 & 21 & 16 & 13 & 37 & 242 & 222 & 198 & 183 \\
\hline 15 & 30 & 25 & 20 & 16 & 38 & 256 & 235 & 211 & 195 \\
\hline 16 & 36 & 30 & 24 & 19 & 39 & 271 & 250 & 224 & 208 \\
\hline 17 & 41 & 35 & 28 & 23 & 40 & 287 & 264 & 238 & 221 \\
\hline 18 & 47 & 40 & 33 & 28 & 41 & 303 & 279 & 252 & 234 \\
\hline 19 & 54 & 46 & 38 & 32 & 42 & 319 & 295 & 267 & 248 \\
\hline 20 & 60 & 52 & 43 & 37 & 43 & 336 & 311 & 281 & 262 \\
\hline 21 & 68 & 59 & 49 & 43 & 44 & 353 & 327 & 297 & 277 \\
\hline 22 & 75 & 66 & 56 & 49 & 45 & 371 & 344 & 313 & 292 \\
\hline 23 & 83 & 73 & 62 & 55 & 46 & 389 & 361 & 329 & 307 \\
\hline 24 & 92 & 81 & 69 & 61 & 47 & 408 & 379 & 345 & 323 \\
\hline 25 & 101 & 90 & 77 & 68 & 48 & 427 & 397 & 362 & 339 \\
\hline 26 & 110 & 98 & 85 & 76 & 49 & 446 & 415 & 380 & 356 \\
\hline 27 & 120 & 107 & 93 & 84 & 50 & 466 & 434 & 398 & 373 \\
\hline
\end{tabular}


Tabla C. Valores críticos de $U$ para varios niveles de probabilidad Mann-Whitney.

Tabla $C_{1}$. Valores críticos de $U$ para una prueba unilateral de 0.05; prueba bilateral a 0.10

Para cualquier $n_{1}$ y $n_{2}$ el valor observado de $U$ es significativo a un nivel de significación dado si es igual o menor que los valores críticos que aparecen en la tabla.

\begin{tabular}{|c|c|c|c|c|c|c|c|c|c|c|c|c|c|c|c|c|c|c|c|c|}
\hline & \multicolumn{20}{|c|}{$\mathrm{n}_{1}$} \\
\hline $\mathrm{n}_{2}$ & 1 & 2 & 3 & 4 & 5 & 6 & 7 & 8 & 9 & 10 & 11 & 12 & 13 & 14 & 15 & 16 & 17 & 18 & 19 & 20 \\
\hline 1 & -- & -- & -- & -- & -- & -- & -- & -- & -- & -- & -- & -- & -- & -- & -- & -- & -- & -- & 0 & 0 \\
\hline 2 & -- & -- & -- & -- & 0 & 0 & 0 & 1 & 1 & 1 & 1 & 2 & 2 & 2 & 3 & 3 & 3 & 4 & 4 & 4 \\
\hline 3 & -- & -- & 0 & 0 & 1 & 2 & 2 & 3 & 3 & 4 & 5 & 5 & 6 & 7 & 7 & 8 & 9 & 9 & 10 & 11 \\
\hline 4 & -- & -- & 0 & 1 & 2 & 3 & 4 & 5 & 6 & 7 & 8 & 9 & 10 & 11 & 12 & 14 & 15 & 16 & 17 & 18 \\
\hline 5 & -- & 0 & 1 & 2 & 4 & 5 & 6 & 8 & 9 & 11 & 12 & 13 & 15 & 16 & 18 & 19 & 20 & 22 & 23 & 25 \\
\hline 6 & -- & 0 & 2 & 3 & 5 & 7 & 8 & 10 & 12 & 14 & 16 & 17 & 19 & 21 & 23 & 25 & 26 & 28 & 30 & 32 \\
\hline 7 & -- & 0 & 2 & 4 & 6 & 8 & 11 & 13 & 15 & 17 & 19 & 21 & 24 & 26 & 28 & 30 & 33 & 35 & 37 & 39 \\
\hline 8 & -- & 1 & 3 & 5 & 8 & 10 & 13 & 15 & 18 & 20 & 23 & 26 & 28 & 31 & 33 & 36 & 39 & 41 & 44 & 47 \\
\hline 9 & -- & 1 & 3 & 6 & 9 & 12 & 15 & 18 & 21 & 24 & 27 & 30 & 33 & 36 & 39 & 42 & 45 & 48 & 51 & 54 \\
\hline 10 & -- & 1 & 4 & 7 & 11 & 14 & 17 & 20 & 24 & 27 & 31 & 34 & 37 & 41 & 44 & 48 & 51 & 55 & 58 & 62 \\
\hline 11 & -- & 1 & 5 & 8 & 12 & 16 & 19 & 23 & 27 & 31 & 34 & 38 & 42 & 46 & 50 & 54 & 57 & 61 & 65 & 69 \\
\hline 12 & -- & 2 & 5 & 9 & 13 & 17 & 21 & 26 & 30 & 34 & 34 & 42 & 47 & 51 & 55 & 60 & 64 & 68 & 72 & 77 \\
\hline 13 & -- & 2 & 6 & 10 & 15 & 19 & 24 & 28 & 33 & 37 & 42 & 47 & 51 & 56 & 61 & 65 & 70 & 75 & 80 & 84 \\
\hline 14 & -- & 2 & 7 & 11 & 16 & 21 & 26 & 31 & 36 & 41 & 46 & 51 & 56 & 61 & 66 & 71 & 77 & 82 & 87 & 92 \\
\hline 15 & -- & 3 & 7 & 12 & 18 & 23 & 28 & 33 & 39 & 44 & 50 & 55 & 61 & 66 & 72 & 77 & 83 & 88 & 94 & 1100 \\
\hline 16 & -- & 3 & 8 & 14 & 19 & 25 & 30 & 36 & 42 & 48 & 54 & 60 & 65 & 71 & 77 & 83 & 89 & 95 & 101 & 107 \\
\hline 17 & -- & 3 & 9 & 15 & 20 & 26 & 33 & 39 & 45 & 51 & 57 & 64 & 70 & 77 & 83 & 89 & 96 & 102 & 109 & 115 \\
\hline 18 & -- & 4 & 9 & 16 & 22 & 28 & 35 & 41 & 48 & 55 & 61 & 68 & 75 & 82 & 88 & 95 & 102 & 109 & 116 & 123 \\
\hline 19 & 0 & 4 & 10 & 17 & 23 & 30 & 37 & 44 & 51 & 58 & 65 & 72 & 80 & 87 & 94 & 101 & 109 & 116 & 123 & 130 \\
\hline 20 & 0 & 4 & 11 & 18 & 25 & 32 & 39 & 47 & 54 & 62 & 69 & 77 & 84 & 92 & 100 & 107 & 115 & 123 & 130 & 138 \\
\hline
\end{tabular}

Nota: Los guiones dentro de la tabla indican que no es posible una decisión al nivel de significación indicado porque el número de participantes es demasiado pequeño. 


\begin{tabular}{|c|c|c|c|c|c|c|c|c|c|c|c|c|c|c|c|c|c|c|c|c|}
\hline \multicolumn{21}{|c|}{$\begin{array}{l}\text { Para cualquier } n_{1} \text { y } n_{2} \text { el valor observado de } U \text { es significativo a un nivel de significación dado si es } \\
\text { igual o menor que los valores críticos que aparecen en la tabla. }\end{array}$} \\
\hline & \multicolumn{20}{|c|}{$\mathrm{n}_{1}$} \\
\hline $\mathrm{n}_{2}$ & 1 & 2 & 3 & 4 & 5 & 6 & 7 & 8 & 9 & 10 & 11 & 12 & 13 & 14 & 15 & 16 & 17 & 18 & 19 & 20 \\
\hline 1 & --- & --- & --- & -- & --- & --- & --- & --- & --- & --- & --- & --- & --- & --- & --- & --- & --- & -- & --- & --- \\
\hline 2 & --- & --- & --- & -- & --- & -- & --- & --- & --- & --- & --- & --- & 0 & 0 & 0 & 0 & 0 & 0 & 1 & 1 \\
\hline 3 & --- & --- & --- & --- & --- & --- & 0 & 0 & 1 & 1 & 1 & 2 & 2 & 2 & 3 & 3 & 4 & 4 & 4 & 5 \\
\hline 4 & --- & --- & --- & --- & 0 & 1 & 1 & 2 & 3 & 3 & 4 & 5 & 5 & 6 & 7 & 7 & 8 & 9 & 9 & 10 \\
\hline 5 & --- & --- & --- & 0 & 1 & 2 & 3 & 4 & 5 & 6 & 7 & 8 & 9 & 10 & 11 & 12 & 13 & 14 & 15 & 16 \\
\hline 6 & --- & --- & --- & 1 & 2 & 3 & 4 & 6 & 7 & 8 & 9 & 11 & 12 & 13 & 15 & 16 & 18 & 19 & 20 & 22 \\
\hline 7 & --- & --- & 0 & 1 & 3 & 4 & 6 & 7 & 9 & 11 & 12 & 14 & 15 & 17 & 19 & 21 & 23 & 24 & 26 & 28 \\
\hline 8 & --- & --- & 0 & 2 & 4 & 6 & 7 & 9 & 11 & 13 & 15 & 17 & 20 & 22 & 24 & 26 & 28 & 30 & 32 & 34 \\
\hline 9 & --- & --- & 1 & 3 & 5 & 7 & 9 & 11 & 14 & 16 & 18 & 21 & 23 & 26 & 28 & 31 & 33 & 36 & 38 & 40 \\
\hline 10 & --- & --- & 1 & 3 & 6 & 8 & 11 & 13 & 16 & 19 & 22 & 24 & 27 & 30 & 33 & 36 & 38 & 41 & 44 & 47 \\
\hline 11 & --- & --- & 1 & 4 & 7 & 9 & 12 & 15 & 18 & 22 & 25 & 28 & 31 & 34 & 37 & 41 & 44 & 47 & 50 & 53 \\
\hline 12 & --- & --- & 2 & 5 & 8 & 11 & 14 & 17 & 21 & 24 & 28 & 31 & 35 & 38 & 42 & 46 & 49 & 53 & 56 & 60 \\
\hline 13 & --- & 0 & 2 & 5 & 9 & 12 & 16 & 20 & 23 & 27 & 31 & 35 & 39 & 43 & 47 & 51 & 55 & 59 & 63 & 67 \\
\hline 14 & --- & 0 & 2 & 6 & 10 & 13 & 17 & 22 & 26 & 30 & 34 & 38 & 42 & 47 & 51 & 56 & 60 & 65 & 69 & 73 \\
\hline 15 & --- & 0 & 3 & 7 & 11 & 15 & 19 & 24 & 28 & 33 & 37 & 42 & 47 & 51 & 56 & 61 & 66 & 70 & 75 & 80 \\
\hline 16 & --- & 0 & 3 & 7 & 12 & 16 & 21 & 26 & 31 & 36 & 41 & 46 & 51 & 56 & 61 & 66 & 71 & 76 & 82 & 87 \\
\hline 17 & --- & 0 & 4 & 8 & 13 & 18 & 23 & 28 & 33 & 38 & 44 & 49 & 55 & 60 & 66 & 71 & 77 & 82 & 88 & 93 \\
\hline 18 & --- & 0 & 4 & 9 & 14 & 19 & 24 & 30 & 36 & 41 & 47 & 53 & 59 & 65 & 70 & 76 & 82 & 88 & 94 & 100 \\
\hline 19 & 0 & 1 & 4 & 9 & 15 & 20 & 26 & 32 & 38 & 44 & 50 & 56 & 63 & 69 & 75 & 82 & 88 & 94 & 101 & 107 \\
\hline 20 & 0 & 1 & 5 & 10 & 16 & 22 & 28 & 34 & 40 & 47 & 53 & 60 & 67 & 73 & 80 & 87 & 93 & 100 & 107 & 114 \\
\hline
\end{tabular}


Tabla D. Valores críticos de $X_{r}{ }_{r}$ para tres condicionesy varios niveles de probabilidad (Friedman).

Para cualquier $N$ el valor observado de $X_{r}^{2}$ es significativo a un nivel de significación dado si es igual o mayor que los valores críticos que aparecen en la tabla $D$.

\begin{tabular}{|c|c|c|c|c|c|c|c|}
\hline \multicolumn{2}{|c|}{$N=2$} & \multicolumn{2}{|c|}{$N=3$} & \multicolumn{2}{|c|}{$N=4$} & \multicolumn{2}{|c|}{$N=5$} \\
\hline $\mathrm{x}^{2} r$ & $\rho$ & $\mathrm{x}_{r}^{2}$ & $\rho$ & $\mathrm{x}^{2}{ }_{r}$ & $\rho$ & $\mathrm{x}^{2} r$ & $\rho$ \\
\hline \multirow[t]{9}{*}{4} & 0.167 & 2.667 & 0.361 & 2.0 & 0.431 & 1.6 & 0.522 \\
\hline & & 4.667 & 0.194 & 3.5 & 0.273 & 2.8 & 0.367 \\
\hline & & 6.000 & 0.018 & 4.5 & 0.125 & 3.6 & 0.182 \\
\hline & & & & 6.0 & 0.069 & 4.8 & 0.124 \\
\hline & & & & 6.5 & 0.042 & 5.2 & 0.093 \\
\hline & & & & 8.0 & 0.0046 & 6.4 & 0.039 \\
\hline & & & & & & 7.6 & 0.024 \\
\hline & & & & & & 8.4 & 0.0085 \\
\hline & & & & & & 10.0 & 0.00077 \\
\hline
\end{tabular}

\begin{tabular}{|c|c|c|c|c|c|c|c|}
\hline \multicolumn{2}{|c|}{$N=6$} & \multicolumn{2}{|c|}{$N=7$} & \multicolumn{2}{|c|}{$N=8$} & \multicolumn{2}{|c|}{$N=9$} \\
\hline $\mathrm{X}^{2}{ }_{r}$ & $\rho$ & $\mathrm{X}_{r}^{2}$ & $\rho$ & $\mathrm{x}_{r}^{2}$ & $\rho$ & $\mathrm{x}^{2}{ }_{r}$ & $\rho$ \\
\hline 4.00 & 0.184 & 3.429 & 0.237 & 3.00 & 0.285 & 2.667 & 0.328 \\
\hline 4.33 & 0.142 & 3.714 & 0.192 & 3.25 & 0.236 & 2.889 & 0.278 \\
\hline 5.33 & 0.072 & 4.571 & 0.112 & 4.00 & 0.149 & 3.556 & 0.187 \\
\hline 6.33 & 0.029 & 5.429 & 0.085 & 4.75 & 0.120 & 4.222 & 0.154 \\
\hline 7.00 & 0.012 & 6.000 & 0.052 & 5.25 & 0.079 & 4.667 & 0.107 \\
\hline 8.33 & 0.0081 & 7.143 & 0.027 & 6.25 & 0.047 & 5.556 & 0.069 \\
\hline 7.00 & 0.0055 & 7.714 & 0.021 & 6.75 & 0.038 & 6.000 & 0.057 \\
\hline 9.33 & 0.0017 & 8.000 & 0.016 & 7.00 & 0.030 & 6.222 & 0.048 \\
\hline 10.33 & 0.00013 & 8.857 & 0.0084 & 7.75 & 0.018 & 6.889 & 0.031 \\
\hline 12.00 & & 10.286 & 0.0036 & 9.00 & 0.0099 & 8.000 & 0.019 \\
\hline & & 10.571 & 0.0027 & 9.25 & 0.0080 & 8.222 & 0.016 \\
\hline & & 11.143 & 0.0012 & 9.75 & 0.0048 & 8.667 & 0.010 \\
\hline & & 12.286 & 0.00032 & 10.75 & 0.0024 & 9.556 & 0.0060 \\
\hline & & 14.000 & 0.000021 & 12.00 & 0.0011 & 10.667 & 0.0035 \\
\hline & & & & 12.25 & 0.00086 & 10.889 & 0.0029 \\
\hline & & & & 13.00 & 0.00026 & 11.556 & 0.0013 \\
\hline & & & & 14.25 & 0.000061 & 12.667 & 0.00066 \\
\hline & & & & 16.00 & 0.0000036 & 13.556 & 0.00035 \\
\hline & & & & & & 14.000 & 0.00020 \\
\hline & & & & & & 14.222 & 0.000097 \\
\hline & & & & & & 14.889 & 0.000054 \\
\hline & & & & & & 16.222 & 0.000011 \\
\hline & & & & & & 18.000 & 0.0000006 \\
\hline
\end{tabular}


Tabla E. Valores críticos de $X^{2}$ Para varios niveles de probabilidad (Chi cuadrado).

\begin{tabular}{|c|c|c|c|c|c|}
\hline$g l$ & 0.10 & 0.05 & 0.02 & 0.01 & 0.001 \\
\hline 1 & 2.71 & 3.84 & 5.41 & 6.64 & 10.83 \\
\hline 2 & 4.60 & 5.99 & 7.82 & 9.21 & 13.82 \\
\hline 3 & 6.25 & 7.82 & 9.84 & 11.34 & 16.27 \\
\hline 4 & 7.78 & 9.49 & 11.67 & 13.28 & 18.46 \\
\hline 5 & 9.24 & 11.07 & 13.39 & 15.09 & 20.52 \\
\hline 6 & 10.64 & 12.59 & 15.03 & 16.81 & 22.46 \\
\hline 7 & 12.02 & 14.07 & 16.62 & 18.48 & 24.32 \\
\hline 8 & 13.36 & 15.51 & 18.17 & 20.09 & 26.12 \\
\hline 9 & 14.68 & 16.92 & 19.68 & 21.67 & 27.88 \\
\hline 10 & 15.99 & 18.31 & 21.16 & 23.21 & 29.59 \\
\hline 11 & 17.28 & 19.68 & 22.62 & 24.72 & 31.26 \\
\hline 12 & 18.55 & 21.03 & 24.05 & 26.22 & 32.91 \\
\hline 13 & 19.81 & 22.36 & 25.47 & 27.69 & 34.53 \\
\hline 14 & 21.06 & 23.68 & 26.87 & 29.14 & 36.12 \\
\hline 15 & 22.31 & 25.00 & 28.26 & 30.58 & 37.70 \\
\hline 16 & 23.54 & 26.30 & 29.63 & 32.00 & 39.29 \\
\hline 17 & 24.77 & 27.59 & 31.00 & 33.41 & 40.75 \\
\hline 18 & 25.99 & 28.87 & 32.35 & 34.80 & 42.31 \\
\hline 19 & 27.20 & 30.14 & 33.69 & 36.19 & 43.82 \\
\hline 20 & 28.41 & 31.41 & 35.02 & 37.57 & 45.32 \\
\hline 21 & 29.62 & 32.67 & 36.34 & 38.93 & 46.80 \\
\hline 22 & 30.81 & 33.92 & 37.66 & 40.29 & 48.27 \\
\hline 23 & 32.01 & 35.17 & 38.97 & 41.64 & 49.73 \\
\hline 24 & 33.20 & 36.42 & 40.27 & 42.98 & 51.18 \\
\hline 25 & 34.38 & 37.65 & 41.57 & 44.31 & 52.62 \\
\hline 26 & 35.56 & 38.88 & 42.86 & 45.64 & 54.05 \\
\hline 27 & 36.74 & 40.11 & 44.14 & 46.97 & 55.48 \\
\hline 28 & 37.93 & 41.34 & 45.42 & 48.28 & 56.89 \\
\hline 29 & 39.09 & 42.56 & 46.69 & 49.59 & 58.30 \\
\hline 30 & 40.26 & 43.77 & 47.96 & 50.89 & 59.70 \\
\hline
\end{tabular}

Para cualquier valor concreto de $g l$ el valor observado de $X^{2}$ es significativo a un nivel de significación dado si es igual o mayor que los valores críticos que aparecen en la tabla. 
Tabla F. Valores críticos de $H$ a varios niveles de probabilidad (Kruskal-Wallis).

\begin{tabular}{|c|c|c|c|c|c|c|c|c|c|}
\hline \multirow{2}{*}{\multicolumn{3}{|c|}{$\begin{array}{l}\text { Para cualquier valor de } n_{1,} \\
\text { sayor que los valores crític } \\
\text { Tamaño de los grupos }\end{array}$}} & $\begin{array}{l}\text { el valo } \\
\text { e apare }\end{array}$ & $\begin{array}{l}\text { servad } \\
\text { en la }\end{array}$ & & cati & niv & signific & ón dad \\
\hline & & & \multirow[b]{2}{*}{$H$} & \multirow[b]{2}{*}{$\rho$} & \multicolumn{3}{|c|}{ Tamaño de los grupos } & \multirow[b]{2}{*}{$H$} & \multirow[b]{2}{*}{$\rho$} \\
\hline$n_{1}$ & $n_{2}$ & $n_{3}$ & & & $n_{1}$ & $n_{2}$ & $n_{3}$ & & \\
\hline \multirow[t]{2}{*}{2} & 1 & 1 & 2.7000 & 0.500 & 3 & 3 & 3 & 7.2000 & 0.004 \\
\hline & & & & & & & & 6.4889 & 0.011 \\
\hline \multirow[t]{2}{*}{2} & 2 & 1 & 3.6000 & 0.200 & & & & 5.6889 & 0.029 \\
\hline & & & & & & & & 5.6000 & 0.050 \\
\hline \multirow[t]{2}{*}{2} & 2 & 2 & 4.5714 & 0.067 & & & & 5.0667 & 0.085 \\
\hline & & & 3.7143 & 0.200 & & & & 4.6222 & 0.100 \\
\hline 3 & 1 & 1 & 3.2000 & 0.300 & 4 & 1 & 1 & 3.5714 & 0.200 \\
\hline \multirow[t]{3}{*}{3} & 2 & 1 & 4.2857 & 0.100 & 4 & 2 & 1 & 4.8214 & 0.057 \\
\hline & & & 3.8571 & 0.133 & & & & 4.5000 & 0.076 \\
\hline & & & & & & & & 4.0179 & 0.114 \\
\hline \multirow[t]{5}{*}{3} & 2 & 2 & 5.3572 & 0.029 & & & & & \\
\hline & & & 4.7143 & 0.048 & 4 & 2 & 2 & 6.0000 & 0.014 \\
\hline & & & 4.5000 & 0.067 & & & & 5.3333 & 0.033 \\
\hline & & & 4.4643 & 0.105 & & & & 5.1250 & 0.052 \\
\hline & & & & & & & & 4.4583 & 0.100 \\
\hline \multirow[t]{4}{*}{3} & 3 & 1 & 5.1429 & 0.043 & & & & & \\
\hline & & & 4.5714 & 0.100 & 4 & 3 & 1 & 5.8333 & 0.021 \\
\hline & & & 4.0000 & 0.129 & & & & 5.2083 & 0.050 \\
\hline & & & & & & & & 5.0000 & 0.057 \\
\hline \multirow[t]{5}{*}{3} & 3 & 2 & 6.2500 & 0.011 & & & & 4.0556 & 0.093 \\
\hline & & & 5.3611 & 0.032 & & & & 3.8889 & 0.129 \\
\hline & & & 5.1389 & 0.061 & & & & & \\
\hline & & & 4.5556 & 0.100 & & & & & \\
\hline & & & 4.2500 & 0.121 & & & & & \\
\hline \multirow[t]{6}{*}{4} & 3 & 2 & 6.4444 & 0.008 & 4 & 4 & 4 & 7.6538 & 0.008 \\
\hline & & & 6.3000 & 0.011 & & & & 7.5385 & 0.011 \\
\hline & & & 5.4444 & 0.046 & & & & 5.6923 & 0.049 \\
\hline & & & 5.4000 & 0.051 & & & & 5.6538 & 0.054 \\
\hline & & & 4.5111 & 0.098 & & & & 4.6539 & 0.097 \\
\hline & & & 4.4444 & 0.102 & & & & 4.5001 & 0.104 \\
\hline \multirow[t]{7}{*}{4} & 3 & 3 & 6.7455 & 0.010 & 5 & 1 & 1 & 3.8571 & 0.143 \\
\hline & & & 6.7091 & 03.013 & & & & & \\
\hline & & & 5.7909 & 0.046 & 5 & 2 & 1 & 5.2500 & 0.036 \\
\hline & & & 5.7273 & 0.050 & & & & 5.0000 & 0.048 \\
\hline & & & 4.7091 & 0.092 & & & & 4.4500 & 0.071 \\
\hline & & & 4.7000 & 0.101 & & & & 4.2000 & 0.095 \\
\hline & & & & & & & & 4.0500 & 0.119 \\
\hline \multirow[t]{3}{*}{4} & 4 & 1 & 6.6667 & 0.010 & & & & & \\
\hline & & & 6.1667 & 0.022 & 5 & 2 & 2 & 6.5333 & 0.008 \\
\hline & & & 4.9667 & 0.048 & & & & 6.1333 & 0.013 \\
\hline
\end{tabular}




\begin{tabular}{|c|c|c|c|c|c|c|c|c|c|}
\hline & & & 4.8667 & 0.054 & & & & 5.1600 & 0.034 \\
\hline & & & 4.1667 & 0.082 & & & & 5.0400 & 0.056 \\
\hline & & & 4.0667 & 0.102 & & & & 4.3733 & 0.090 \\
\hline & & & & & & & & 4.2933 & 0.122 \\
\hline \multirow[t]{6}{*}{4} & 4 & 2 & 7.0364 & 0.006 & & & & & \\
\hline & & & 6.8727 & 0.011 & 5 & 3 & 1 & 6.4000 & 0.012 \\
\hline & & & 5.4545 & 0.046 & & & & 4.9600 & 0.048 \\
\hline & & & 5.2364 & 0.052 & & & & 4.8711 & 0.052 \\
\hline & & & 4.5545 & 0.098 & & & & 4.0178 & 0.095 \\
\hline & & & 4.4455 & 0.103 & & & & 3.8400 & 0.123 \\
\hline \multirow[t]{6}{*}{4} & 4 & 3 & 7.1437 & 0.010 & 5 & 3 & 2 & 6.9091 & 0.009 \\
\hline & & & 7.1364 & 0.011 & & & & 6.8218 & 0.010 \\
\hline & & & 5.5985 & 0.049 & & & & 5.2509 & 0.049 \\
\hline & & & 5.5758 & 0.051 & & & & 5.1055 & 0.052 \\
\hline & & & 4.5455 & 0.099 & & & & 4.6509 & 0.091 \\
\hline & & & 4.4773 & 0.102 & & & & 4.4945 & 0.101 \\
\hline \multirow[t]{7}{*}{5} & 3 & 3 & 7.0788 & 0.009 & 5 & 5 & 1 & 7.3091 & 0.009 \\
\hline & & & 6.9818 & 0.011 & & & & 6.8364 & 0.011 \\
\hline & & & 5.6485 & 0.049 & & & & 5.1273 & 0.046 \\
\hline & & & 5.5152 & 0.051 & & & & 4.9091 & 0.053 \\
\hline & & & 4.5333 & 0.097 & & & & 4.1091 & 0.086 \\
\hline & & & 4.4121 & 0.109 & & & & & \\
\hline & & & & & 5 & 5 & 2 & 7.3385 & 0.010 \\
\hline \multirow[t]{7}{*}{5} & 4 & 1 & 6.9545 & 0.008 & & & & 7.2692 & 0.010 \\
\hline & & & 6.8400 & 0.011 & & & & 5.3385 & 0.047 \\
\hline & & & 4.9855 & 0.044 & & & & 5.2462 & 0.051 \\
\hline & & & 4.8600 & 0.056 & & & & 4.6231 & 0.097 \\
\hline & & & 3.9873 & 0.098 & & & & & \\
\hline & & & 3.9600 & 0.102 & 5 & 5 & 3 & 7.5780 & 0.010 \\
\hline & & & & & & & & 7.5429 & 0.010 \\
\hline \multirow[t]{7}{*}{5} & 4 & 2 & 7.2045 & 0.009 & & & & 5.7055 & 0.046 \\
\hline & & & 7.1182 & 0.010 & & & & 5.6264 & 0.051 \\
\hline & & & 5.2727 & 0.049 & & & & 4.5451 & 0.100 \\
\hline & & & 5.2682 & 0.050 & & & & & \\
\hline & & & 4.5409 & 0.098 & 5 & 5 & 4 & 7.8229 & 0.010 \\
\hline & & & 4.5182 & 0.101 & & & & 7.7914 & 0.010 \\
\hline & & & & & & & & 5.6657 & 0.049 \\
\hline \multirow[t]{6}{*}{5} & 4 & 3 & 7.4449 & 0.010 & & & & 5.6429 & 0.050 \\
\hline & & & 7.3949 & 0.011 & & & & 4.5229 & 0.099 \\
\hline & & & 5.6564 & 0.049 & & & & & \\
\hline & & & 5.6308 & 0.050 & 5 & 5 & 5 & 8.0000 & 0.009 \\
\hline & & & 4.5487 & 0.099 & & & & 7.9800 & 0.010 \\
\hline & & & & & & & & 5.7800 & 0.049 \\
\hline \multirow[t]{5}{*}{5} & 4 & 4 & 7.7604 & 0.009 & & & & 5.6600 & 0.051 \\
\hline & & & 7.7440 & 0.011 & & & & 4.5600 & 0.100 \\
\hline & & & 5.6571 & 0.049 & & & & & \\
\hline & & & 5.6176 & 0.050 & & & & & \\
\hline & & & 4.6187 & 0.100 & & & & & \\
\hline
\end{tabular}


Tabla G. Valores críticos de $t$ para varios niveles de probabilidad (prueba $t$ ).

Para cualquier número concreto de $g l$ el valor observado de $t$ es significativo a un nivel de significación dado si es igual o mayor que los valores críticos que aparecen en la tabla.

\begin{tabular}{|c|c|c|c|c|c|c|}
\hline \multirow{4}{*}{$g l$} & \multicolumn{6}{|c|}{ Nivel de significación para una prueba unilateral } \\
\hline & 0.10 & 0.05 & 0.025 & 0.01 & 0.005 & 0.0005 \\
\hline & \multicolumn{6}{|c|}{ Nivel de significación para una prueba bilateral } \\
\hline & 0.20 & 0.10 & 0.05 & 0.02 & 0.01 & 0.001 \\
\hline 1 & 3.078 & 6.314 & 12.706 & 31.821 & 63.657 & 636.619 \\
\hline 2 & 1.886 & 2.920 & 4.303 & 6.965 & 9.925 & 31.598 \\
\hline 3 & 1.638 & 2.353 & 3.182 & 4.541 & 5.841 & 12.941 \\
\hline 4 & 1.533 & 2.132 & 2.776 & 3.747 & 4.604 & 8.610 \\
\hline 5 & 1.476 & 2.015 & 2.571 & 3.365 & 4.032 & 6.859 \\
\hline 6 & 1.440 & 1.943 & 2.447 & 3.143 & 3.707 & 5.959 \\
\hline 7 & 1.415 & 1.895 & 2.365 & 2.998 & 3.499 & 5.405 \\
\hline 8 & 1.397 & 1.860 & 2.306 & 2.896 & 3.355 & 4.041 \\
\hline 9 & 1.383 & 1.833 & 2.262 & 2.821 & 3.250 & 4.781 \\
\hline 10 & 1.372 & 1.812 & 2.228 & 2.764 & 3.169 & 4.587 \\
\hline 11 & 1.363 & 1.796 & 2.201 & 2.718 & 3.106 & 4.437 \\
\hline 12 & 1.356 & 1.782 & 2.179 & 2.681 & 3.055 & 4.318 \\
\hline 13 & 1.350 & 1.771 & 2.160 & 2.650 & 3.012 & 4.221 \\
\hline 14 & 1.345 & 1.761 & 2.145 & 2.624 & 2.977 & 4.140 \\
\hline 15 & 1.341 & 1.753 & 2.131 & 2.602 & 2.947 & 4.073 \\
\hline 16 & 1.337 & 1.746 & 2.120 & 2.583 & 2.921 & 4.015 \\
\hline 17 & 1.333 & 1.740 & 2.110 & 2.567 & 2.898 & 3.965 \\
\hline 18 & 1.330 & 1.734 & 2.101 & 2.552 & 2.878 & 3.922 \\
\hline 19 & 1.328 & 1.729 & 2.093 & 2.539 & 2.861 & 3.883 \\
\hline 20 & 1.325 & 1.725 & 2.086 & 2.528 & 2.245 & 3.850 \\
\hline 21 & 1.323 & 1.721 & 2.080 & 2.518 & 2.831 & 3.819 \\
\hline 22 & 1.321 & 1.717 & 2.074 & 2.508 & 2.819 & 3.792 \\
\hline 23 & 1.319 & 1.714 & 2.069 & 2.500 & 2.807 & 3.767 \\
\hline 24 & 1.318 & 1.711 & 2.064 & 2.492 & 2.797 & 3.745 \\
\hline 25 & 1.316 & 1.708 & 2.060 & 2.485 & 2.787 & 3.725 \\
\hline 26 & 1.315 & 1.706 & 2.056 & 2.479 & 2.779 & 3.707 \\
\hline 27 & 1.314 & 1.703 & 2.052 & 2.473 & 2.771 & 3.690 \\
\hline 28 & 1.313 & 1.701 & 2.048 & 2.467 & 2.763 & 3.674 \\
\hline 29 & 1.311 & 1.699 & 2.045 & 2.462 & 2.756 & 3.659 \\
\hline 30 & 1.310 & 1.697 & 2.042 & 2.457 & 2.750 & 3.646 \\
\hline 40 & 1.303 & 1.684 & 2.021 & 2.423 & 2.704 & 3.551 \\
\hline 60 & 1.296 & 1.671 & 2.000 & 2.390 & 2.660 & 3.460 \\
\hline 120 & 1.289 & 1.658 & 1.980 & 2.358 & 2.617 & 3.373 \\
\hline$\alpha$ & 1.282 & 1.645 & 1.960 & 2.326 & 2.576 & 3.291 \\
\hline
\end{tabular}

Nota: Si el número de $g l$ requerido no aparece en la tabla, usar el siguiente inferior, excepto cuando el número de $\mathrm{gl}$ es muy elevado (muy por encima de 120), en cuyo caso se puede usar la fila correspondiente a infinito $(\alpha)$. 
Tabla H. Valores críticos de $F$ para varios niveles de probabilidad (Mann-Whitney).

Tabla H (1). Valores críticos de $F$ para $\rho<0.05$

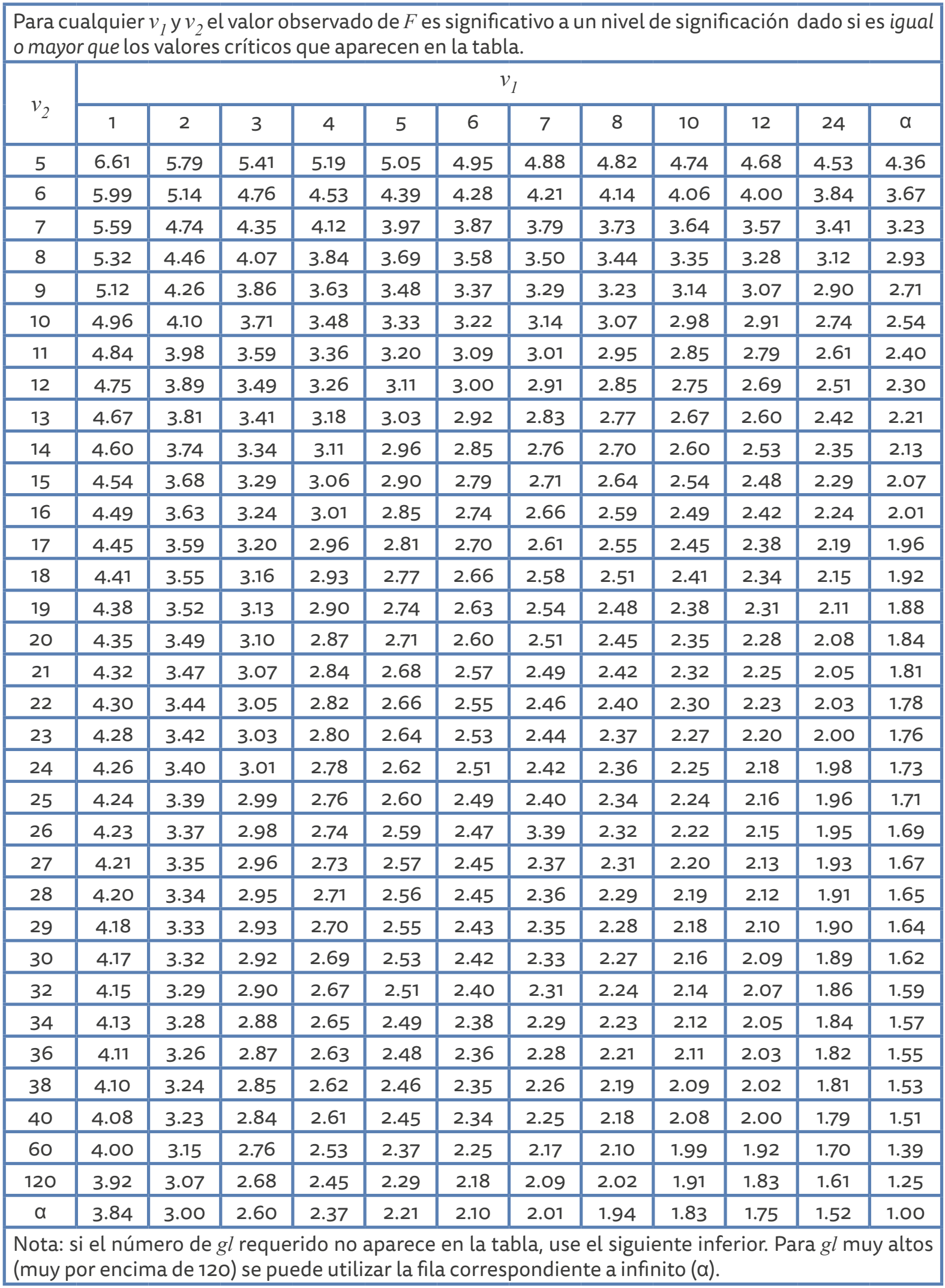


Tabla H (2). Valores críticos de $F$ para $\rho<0.01$

\begin{tabular}{|c|c|c|c|c|c|c|c|c|c|c|c|c|}
\hline \multicolumn{13}{|c|}{$\begin{array}{l}\text { Para cualquier } v_{1} \text { y } v_{2} \text { el valor observado de } F \text { es significativo a un nivel de significación dado si es igual } \\
\text { o mayor que los valores críticos que aparecen en la tabla. }\end{array}$} \\
\hline \multirow{2}{*}{$v_{2}$} & \multicolumn{12}{|c|}{$v_{1}$} \\
\hline & 1 & 2 & 3 & 4 & 5 & 6 & 7 & 8 & 10 & 12 & 24 & $\alpha$ \\
\hline 5 & 16.26 & 13.27 & 12.06 & 11.39 & 10.97 & 10.67 & 10.46 & 10.29 & 10.05 & 9.89 & 9.47 & 9.02 \\
\hline 6 & 13.74 & 10.92 & 9.78 & 9.15 & 8.75 & 8.47 & 8.26 & 8.10 & 7.87 & 7.72 & 7.31 & 6.88 \\
\hline 7 & 12.25 & 9.55 & 8.45 & 7.85 & 7.46 & 7.19 & 6.99 & 6.84 & 6.62 & 6.47 & 6.07 & 5.65 \\
\hline 8 & 11.26 & 8.65 & 7.59 & 7.01 & 6.63 & 6.37 & 6.18 & 6.03 & 5.81 & 5.67 & 5.28 & 4.86 \\
\hline 9 & 10.56 & 8.02 & 6.99 & 6.42 & 6.06 & 5.80 & 5.61 & 5.47 & 5.26 & 5.11 & 4.73 & 4.31 \\
\hline 10 & 10.04 & 7.56 & 6.55 & 5.99 & 5.64 & 5.39 & 5.20 & 5.06 & 4.85 & 4.71 & 4.33 & 3.97 \\
\hline 11 & 9.65 & 7.21 & 6.22 & 5.67 & 5.32 & 5.07 & 4.89 & 4.74 & 4.54 & 4.40 & 4.02 & 3.60 \\
\hline 12 & 9.33 & 6.93 & 5.95 & 5.41 & 5.06 & 4.82 & 4.64 & 4.50 & 4.30 & 4.16 & 3.78 & 3.36 \\
\hline 13 & 9.07 & 6.70 & 5.74 & 5.21 & 4.86 & 4.62 & 4.44 & 4.30 & 4.10 & 3.96 & 3.59 & 3.17 \\
\hline 14 & 8.86 & 6.51 & 5.56 & 5.04 & 4.70 & 4.46 & 4.28 & 4.14 & 3.94 & 3.80 & 3.43 & 3.00 \\
\hline 15 & 8.68 & 6.36 & 5.42 & 4.89 & 4.56 & 4.32 & 4.14 & 4.00 & 3.80 & 3.67 & 3.29 & 2.87 \\
\hline 16 & 8.53 & 6.23 & 5.29 & 4.77 & 4.44 & 4.20 & 4.03 & 3.89 & 3.69 & 3.55 & 3.18 & 2.75 \\
\hline 17 & 8.40 & 6.11 & 5.18 & 4.67 & 4.34 & 4.10 & 3.93 & 3.79 & 3.59 & 3.46 & 3.08 & 2.65 \\
\hline 18 & 8.29 & 6.01 & 5.09 & 4.58 & 4.25 & 4.01 & 3.84 & 3.71 & 3.51 & 3.37 & 3.00 & 2.57 \\
\hline 19 & 8.18 & & & & & 3.94 & .77 & 3.63 & .43 & 30 & 2.92 & 2.49 \\
\hline 20 & 8.10 & 5.85 & 4.94 & 4.43 & 4.10 & 3.87 & 3.70 & 3.56 & 3.37 & 3.23 & 2.86 & 2.42 \\
\hline 21 & 8.02 & 5.78 & 4.87 & 4.37 & 4.04 & 3.81 & 3.64 & 3.51 & 3.31 & 3.17 & 2.80 & 2.36 \\
\hline 22 & 7.95 & 5.72 & 4.82 & 4.31 & 3.99 & 3.76 & 3.59 & 3.45 & 3.26 & 3.12 & 2.75 & 2.31 \\
\hline 23 & 7.88 & 5.66 & 4.76 & 4.26 & 3.94 & 3.71 & 3.54 & 3.41 & 3.21 & 3.07 & 2.70 & 2.26 \\
\hline 24 & 7.82 & 5.61 & 4.72 & 4.22 & 3.90 & 3.67 & 3.50 & 3.36 & 3.17 & 3.03 & 2.66 & 2.21 \\
\hline 25 & 7.77 & 5.57 & 4.68 & 4.18 & 3.86 & 3.63 & 3.46 & 3.32 & 3.13 & 2.99 & 2.62 & 2.17 \\
\hline 26 & 7.72 & 5.53 & 4.64 & 4.14 & 3.82 & 3.59 & 3.42 & 3.29 & 3.09 & 2.96 & 2.58 & 2.13 \\
\hline 27 & 7.68 & 5.49 & 4.60 & 4.11 & 3.78 & 3.56 & 3.39 & 3.26 & 3.06 & 2.93 & 2.55 & 2.10 \\
\hline 28 & 7.64 & 5.45 & 4.57 & 4.07 & 3.75 & 3.53 & 3.36 & 3.23 & 3.03 & 2.90 & 2.52 & 2.06 \\
\hline 29 & 7.60 & 5.42 & 4.54 & 4.04 & 3.73 & 3.50 & 3.33 & 3.20 & 3.00 & 2.87 & 2.49 & 2.03 \\
\hline 30 & 7.56 & 5.39 & 4.51 & 4.02 & 3.70 & 3.47 & 3.30 & 3.17 & 2.98 & 2.84 & 2.47 & 2.01 \\
\hline 32 & 7.50 & 5.34 & 4.46 & 3.97 & 3.65 & 3.43 & 3.26 & 3.13 & 2.93 & 2.80 & 2.42 & 1.93 \\
\hline 34 & 7.45 & 5.29 & 4.42 & 3.93 & 3.61 & 3.39 & 3.22 & 3.09 & 2.90 & 2.76 & 2.38 & 1.91 \\
\hline 36 & 7.40 & 5.25 & 4.38 & 3.89 & 3.58 & 3.35 & 3.18 & 3.05 & 2.86 & 2.72 & 2.35 & 1.87 \\
\hline 38 & 7.35 & 5.21 & 4.34 & 3.86 & 3.54 & 3.32 & 3.15 & 3.02 & 2.83 & 2.69 & 2.32 & 1.84 \\
\hline 40 & 7.31 & 5.18 & 4.31 & 3.83 & 3.51 & 3.29 & 3.12 & 2.99 & 2.80 & 2.66 & 2.29 & 1.80 \\
\hline 60 & 7.08 & 4.98 & 4.13 & 3.65 & 3.34 & 3.12 & 2.95 & 2.82 & 2.63 & 2.50 & 2.12 & 1.60 \\
\hline 120 & 6.85 & 4.79 & 3.95 & 3.48 & 3.17 & 2.96 & 2.79 & 2.66 & 2.47 & 2.34 & 1.95 & 1.38 \\
\hline$\alpha$ & 6.63 & 4.61 & 3.78 & 3.32 & 3.02 & 2.80 & 2.64 & 2.51 & 2.32 & 2.18 & 1.79 & 1.00 \\
\hline
\end{tabular}


Tabla I. Valores críticos de $r$ para varios niveles de probabilidad (correlación de Pearson).

El valor observado de $r$ es significativo a un nivel de significación dado si es igual o mayor que los valores críticos que aparecen en la tabla.

\begin{tabular}{|c|c|c|c|c|c|}
\hline & \multicolumn{5}{|c|}{ Nivel de significación para una prueba unilateral } \\
\hline & 0.05 & 0.02 & 0.01 & 0.005 & 0.0005 \\
\hline & \multicolumn{5}{|c|}{ Nivel de significación para una prueba bilateral } \\
\hline$g l$ & 0.10 & 0.05 & 0.02 & 0.01 & 0.001 \\
\hline 1 & 0.9877 & 0.9969 & 0.9995 & 0.9999 & 1.0000 \\
\hline 2 & 0.9000 & 0.9500 & 0.9800 & 0.9900 & 0.9990 \\
\hline 3 & 0.8054 & 0.8783 & 0.9343 & 0.9587 & 0.9912 \\
\hline 4 & 0.7293 & 0.8114 & 0.8822 & 0.9172 & 0.9741 \\
\hline 5 & 0.6694 & 0.7545 & 0.8329 & 0.8745 & 0.9507 \\
\hline 6 & 0.6215 & 0.7067 & 0.7887 & 0.8343 & 0.9249 \\
\hline 7 & 0.5822 & 0.6664 & 0.7498 & 0.7977 & 0.8982 \\
\hline 8 & 0.5494 & 0.6319 & 0.7155 & 0.7646 & 0.8721 \\
\hline 9 & 0.5214 & 0.6021 & 0.6851 & 0.7348 & 0.8471 \\
\hline 10 & 0.4973 & 0.5760 & 0.6581 & 0.7079 & 0.8233 \\
\hline 11 & 0.4762 & 0.5529 & 0.6339 & 0.6835 & 0.8010 \\
\hline 12 & 0.4575 & 0.5324 & 0.6120 & 0.6614 & 0.7800 \\
\hline 13 & 0.4409 & 0.5139 & 0.5923 & 0.6411 & 0.7603 \\
\hline 14 & 0.4259 & 0.4973 & 0.5742 & 0.6226 & 0.7420 \\
\hline 15 & 0.4124 & 0.4821 & 0.5577 & 0.6055 & 0.7246 \\
\hline 16 & 0.4000 & 0.4683 & 0.5425 & 0.5897 & 0.7084 \\
\hline 17 & 0.3887 & 0.4555 & 0.5285 & 0.5751 & 0.6932 \\
\hline 18 & 0.3783 & 0.4438 & 0.5155 & 0.5614 & 0.6787 \\
\hline 19 & 0.3687 & 0.4329 & 0.5034 & 0.5487 & 0.6652 \\
\hline 20 & 0.3598 & 0.4227 & 0.4921 & 0.5368 & 0.6524 \\
\hline 25 & 0.3233 & 0.3809 & 0.4451 & 0.4869 & 0.5974 \\
\hline 30 & 0.2960 & 0.3494 & 0.4093 & 0.4487 & 0.5541 \\
\hline 35 & 0.2746 & 0.3246 & 0.3810 & 0.4182 & 0.5189 \\
\hline 40 & 0.2573 & 0.3044 & 0.3578 & 0.3932 & 0.4896 \\
\hline 45 & 0.2428 & 0.2875 & 0.3384 & 0.3721 & 0.4648 \\
\hline 50 & 0.2306 & 0.2732 & 0.3218 & 0.3541 & 0.4433 \\
\hline 60 & 0.2108 & 0.2500 & 0.2984 & 0.3248 & 0.4078 \\
\hline 70 & 0.1954 & 0.2319 & 0.2737 & 0.3017 & 0.3799 \\
\hline 80 & 0.1829 & 0.2172 & 0.2565 & 0.2830 & 0.3568 \\
\hline 90 & 0.1726 & 0.2050 & 0.2422 & 0.2673 & 0.3375 \\
\hline 100 & 0.1638 & 0.1946 & 0.2301 & 0.2540 & 0.3211 \\
\hline
\end{tabular}


Tabla J. Valores de $r_{\mathrm{s}}$ a los niveles de confianza de 0.05 y 0.01

\begin{tabular}{|c|c|c|}
\hline$N$ & $\rho=0.05$ & $\rho=0.01$ \\
\hline 5 & 1.000 & -- \\
\hline 6 & 0.886 & 1.000 \\
\hline 7 & 0.786 & 0.929 \\
\hline 8 & 0.738 & 0.881 \\
\hline 9 & 0.683 & 0.833 \\
\hline 10 & 0.648 & 0.794 \\
\hline 12 & 0.591 & 0.777 \\
\hline 14 & 0.544 & 0.714 \\
\hline 16 & 0.506 & 0.665 \\
\hline 18 & 0.475 & 0.625 \\
\hline 20 & 0.450 & 0.591 \\
\hline 22 & 0.428 & 0.562 \\
\hline 24 & 0.409 & 0.537 \\
\hline 26 & 0.392 & 0.515 \\
\hline 28 & 0.377 & 0.496 \\
\hline 30 & 0.364 & 0.478 \\
\hline
\end{tabular}




\section{Referencias Bibliográficas}

Aguirre, G. (1989). Los test proyectivos. Barcelona: Laertes.

Albert, M. (2007). La investigación educativa: claves teóricas. Madrid: McGraw Hill.

Best, J. W. (1981). Cómo investigar en educación. Madrid: Morata.

Bisquerra, A. (2004). Metodología de la investigación educativa. Madrid: La Muralla.

Buendía, L. (1996). Evaluación educativa. Revista de investigación educativa, 12(14), 141 -163. Valencia, España: AIDIPE.

Buendía, L., Colás, M. y Hernández, F. (1998). Métodos de investigación en Psicopedagogía. Madrid: McGraw Hill.

Castañeda, S. (2004). Educación, aprendizajey cognición. Teoría en la práctica. México: El Manual Moderno.

Coolican, H. (2005). Métodos de investigación y estadística en Psicología. México: El Manual Moderno.

Coombs, P. (1971). La crisis mundial de la educación. Barcelona: Península.

Díaz-Barriga, F. y Hernández, G. (2002). Estrategias docentes para un aprendizaje significativo. México: McGraw Hill.

Escamilla de los Santos, J. (2002). Selección y uso de tecnología educativa. México: Editorial Trillas.

González, J., Monrroy, A. y Kupferman, E. (1999). Dinámica de grupos, técnicas y tácticas. México: Pax.

Goode, W. y Hatt, P. (2004). Métodos de Investigación Social. México: Editorial Trillas.

Greene, J. y D’oliveira, M. (2006). Test estadísticos para Psicología. España: McGraw Hill.

Gutiérrez, R. (2006). Manual para el Trabajo Docente. México: Dos Culturas.

Hernández, R., Fernández, C. y Baptista, P. (2014). Metodología de la investigación. México: McGraw Hill.

Levin, J. (1999). Fundamentos de estadística en la investigación social. México: Oxford.

Mateos, A. (2005). Test Psicotécnicos. Madrid: Alfaomega.

Méndez, I., Namihira, D., Moreno, L. y Sosa de Martínez, C. (2001). El protocolo de investigación: Lineamientos para su elaboración y análisis. México: Editorial Trillas.

Morales, P. (2006). Las pruebas objetivas: normas, modalidades y cuestiones discutidas. Madrid: Universidad Pontifica Comillas (UPC). 
Padilla, M. T. (2002). Técnicas e instrumentos para el diagnósticoy la evaluación educativa. Madrid: CCS.

Pagano, R. (1999). Estadística para las ciencias del comportamiento. México: Thomson.

Ponce, L. M., García, F., Gil, B., Martín-Serrano, M. y Rodríguez, M. (2008). Test Psicotécnicos. Colombia: Alfaomega.

Prellezco, J. M. (2010). Diccionario de Ciencias de la Educación. Madrid: CCS.

Quintero, A. M. (2007). Diccionario Especializado en Familia y Género. Buenos Aires: Lumen.

Ramírez, D., Nava, L., Ávila, A., Barrios, G. y Vázquez, M. (2012). Modelo para la participación de padres de familia en la educación inicial y básica. México: SEP-CONAFE. Recuperado de: http://www.conafe.gob.mx/companero-viaje/conafe-fomento/Documents/modeloparticipacion-padres.pdf

Ritchey, J. (2008). Estadística para las ciencias sociales. México: McGraw Hill.

Rodríguez, G., Gil, J.y García, E. (1999). Metodología de la investigación cualitativa. Málaga: Aljibe. Rojas, R. (2007). Guía para realizar investigaciones sociales. Madrid: Plaza y Valdez. Santiago, K. y Lukas, J.F. (2014). Evaluación educativa. Madrid: Alianza Editorial. SEP-IEIA (2013). Manual Técnico de ENLACE. Educación Básica. México: SEP-IEIA. Schultz, P. y Schultz, E. (2002). Teorías de la personalidad. México: Thomson. Tenbrink, T. (2006). Evaluación: guía práctica para profesores. Madrid: Narcea Ediciones. Vázquez, A. (2004). Organización del Aula en educación infantil. España: Ideas Propias. Villaseñor, G. (1998). La tecnología en el proceso enseñanza-aprendizaje. México: Editorial Trillas. 


\section{Índice de Gráficas}

\section{Capítulo 3.}

Gráfica 1. Distribuciones unimodales y bimodales. 102

Gráfica 2. Trazado de la línea base en unidades de desviación típica 110 para $x=65$ y $\sigma \mathrm{A}=11.1$ del ejemplo del Grupo A de $4^{\circ}$ de primaria.

Gráfica 3. Trazado de la línea base en unidades de desviación típica 111 para $x=65$ y $\sigma B=23.56$ del ejemplo del Grupo $B$ de $4^{\circ}$ de primaria.

Gráfica 4. Distribución hipotética de puntajes de calificaciones esperadas. $\quad 112$

Gráfica 5. La distribución de los puntajes reales obtenidos en lectura 112 por un grupo de $3^{\circ}$ de primaria.

Gráfica 6. Porcentaje del área comprendida entre la media $(x)$ y la primera desviación típica $(+1 \sigma)$ sobre el valor de ésta.

Gráfica 7. Porcentaje del área comprendida entre la media $(x)$ y los puntos 1,2 y 3 de desviación típica $(+1 \sigma,+2 \sigma,+3 \sigma)$ sobre el valor de ésta.

Gráfica 8. Porcentaje del área comprendida entre los puntos de desviación típica sobre el valor de la media y sus valores correspondientes por debajo de esta $(-1 \sigma,-2 \sigma,-3 \sigma)$.

Gráfica 9. Posición de un puntaje directo que está a $1.35 \sigma$ por encima de x.

Gráfica 10. Porcentaje del área total bajo la curva normal entre 65 y 80 para $Z=1.35 \sigma$.

Gráfica 11. La porción del área total bajo la curva normal para la cual se busca determinar la probabilidad de que ocurra.

Gráfica 12. Distribución muestral de diferencias como una distribución de probabilidad.

Gráfica 13. Representación gráfica del nivel de confianza de $\rho=0.05$ ( $2.5 \%$ en cada extremo).

Gráfica 14. Representación gráfica del ejemplo con un nivel de confianza de $\rho=0.1118$ ( $5.59 \%$ en cada extremo). 


\section{Capítulo 13.}

Gráfica 15. Gráfica 2 X 2 para ANOVA Bifactorial para muestras relacionadas.

\section{Capítulo 14.}

Gráfica 16. Gráfica 2 × 2 para ANOVA Bifactorial para muestras independientes.

\section{Capítulo 15.}

Gráfica 17. Representación gráfica la tabla de contingencia

"Numero de opción", "Grupo".

\section{Capítulo 18.}

Gráfica 18. Diagrama de dispersión y línea de regresión correspondientes a las variables Explicativa, Explicada y Predictiva.

Gráfica 19. Línea de regresión para los promedios del Bachillerato y el primer semestre de Medicina, con rectas paralelas 1Sy/x arriba y debajo de la línea de regresión. 


\section{Índice de Figuras}

\section{Capítulo 2.}

Figura 1. Proceso que sigue usualmente la observación no sistematizada.

\section{Capítulo 4.}

Figura 2. Secuencia para abrir el programa SPSS versión 20.0

Figura 3. Secuencia para crear la base de datos. 144

Figura 4. Relación entre líneas (características o atributos) 145 y columnas (sujetos o casos).

Figura 5. Introducción de la primera variable Nombre y los valores iniciales $\quad 145$ en las otras casillas.

Figura 6. Cuadro de diálogo para seleccionar el tipo de variable, la anchura $\quad 146$ de los dígitos y los decimales.

Figura 7. Cuadro de diálogo para designar el nombre de la etiqueta. 146

$\begin{array}{ll}\text { Figura 8. Cuadro de diálogo para designar la correspondencia } & 147\end{array}$ de los números con sus atributos.

$\begin{array}{ll}\text { Figura 9. Cuadro de diálogo de Valores perdidos. } & 147\end{array}$

Figura 10. Cuadro de diálogo de columnas y Alineación. 148

$\begin{array}{ll}\text { Figura 11. Cuadro de diálogo de Medida. } & 148\end{array}$

Figura 12. Cuadro de diálogo de Rol. $\quad 148$

Figura 13. Resultados de la segunda variable "Condición 2". 149

Figura 14. Valores ingresados de las variables "Condición 1 y Condición 2". 149

Figura 15. Opción de Etiquetas de valor que muestra la Vista de variables. $\quad 150$

\section{Capítulo 5.}

Figura 16. Designación de variables y sus características. 156

Figura 17. Presentación de los datos arrojados por los participantes $\quad 157$ en la estrategia "los juegos matemáticos".

Figura 18. Cuadros de diálogo para seleccionar la prueba no paramétrica $\quad 158$ de dos muestras relacionadas.

Figura 19. Pasos para ingresar las variables al programa SPSS. $\quad 158$

$\begin{array}{ll}\text { Figura 20. Pasos para ejecutar el programa SPSS para que realice } & 158\end{array}$ los cálculos requeridos. 


\section{Capítulo 6.}

Figura 21. Ventana de diálogo para etiquetar los valores de agrupación. $\quad 164$

Figura 22. Designación de nombre de las variables y características 165 de presentación para la prueba de comprensión.

Figura 23. Presentación de los datos arrojados por los participantes 166 en las estrategias de "lectura".

Figura 24. Presentación de los datos activando las etiquetas de valor. $\quad 167$

$\begin{array}{ll}\text { Figura 25. Cuadros de diálogo para seleccionar la prueba } & 167\end{array}$ no paramétrica de dos muestras independientes.

$\begin{array}{ll}\text { Figura 26. Pasos para ingresar las variables No de condición } & 168\end{array}$ al programa SPSS.

Figura 27. Pasos para ingresar las variables Agrupación al programa SPSS. $\quad 168$

$\begin{array}{ll}\text { Figura 28. Actividad para definir los grupos paso } 1 . & 168\end{array}$

$\begin{array}{ll}\text { Figura 29. Actividad para definir los grupos paso 2. } & 169\end{array}$

Figura 30. Paso para ejecutar el programa SPSS para que realice $\quad 169$ los cálculos requeridos.

\section{Capítulo 7.}

$\begin{array}{ll}\text { Figura 31. Designación de variables y sus características. } & 174\end{array}$

Figura 32. Presentación de los datos arrojados por los participantes 175 en la estrategia "los tres dictados".

Figura 33. Cuadros de diálogo para seleccionar la prueba no paramétrica $\quad 176$ de $\mathrm{K}$ muestras relacionadas.

Figura 34. Transferencia de las variables Condición 1, 2 y 3 para procesar $\quad 176$ los datos con el programa SPSS.

Figura 35. Proceso para entrar al cuadro de diálogo para que el programa $\quad 177$ muestre los datos estadísticos de la media de cada condición.

Figura 36. Proceso para que el programa muestre los la tabla de estadísticos descriptivos.

Figura 37. Proceso para entrar al cuadro de diálogo para calcular el nivel de significación unilateral (exacto).

Figura 38. Proceso para calcular el nivel de significación unilateral (exacto). $\quad 178$

Figura 39. Paso para ejecutar el programa SPSS para que realice $\quad 178$ los cálculos requeridos. 


\section{Capítulo 8.}

Figura 40. Ventana de diálogo para etiquetar los valores de agrupación.

Figura 41. Designación del nombre de las variables y características de presentación para la prueba de matemáticas.

Figura 42. Presentación de los datos arrojados por los participantes en las estrategias de matemáticas.

Figura 43. Presentación de los datos activando las etiquetas de valor.

Figura 44. Cuadros de diálogo para seleccionar la prueba no paramétrica de dos muestras independientes.

Figura 45. Pasos para ingresar las variables condiciones a la lista contrastar variables al programa SPSS.

Figura 46. Pasos para ingresar las variables Agrupación al programa SPSS.

Figura 47. Proceso para que el programa muestre la tabla de estadísticos descriptivos.

Figura 48. Actividad para definir los grupos paso 1.

Figura 49. Actividad para definir los grupos paso 2.

Figura 50. Paso para ejecutar el programa SPSS para que realice

\section{Capítulo 9.}

Figura 51. Designación de variables y sus características para la prueba $t$ (relacionada).

Figura 52. Presentación de los datos arrojados por los participantes

200 en la estrategia "dinámicas grupales vivenciales".

Figura 53. Cuadros de diálogo para seleccionar la prueba paramétrica de dos muestras relacionadas.

Figura 54. Transferencia de la variable Condición 1 para procesar los datos con el programa SPSS.

Figura 55. Transferencia de la variable Condición 2 para procesar los datos con el programa SPSS.

Figura 56. Paso para ejecutar el programa SPSS para que realice los cálculos requeridos para la prueba $t$ (relacionada).

\section{Capítulo 10.}

Figura 57. Ventana de diálogo para etiquetar los valores de agrupación.

Figura 58. Designación de nombre de las variables y características de presentación para la prueba $t$ (independiente).

Figura 59. Presentación de los datos arrojados por los participantes en las proyecciones de los videos tradicional e interactivo.

Figura 60. Presentación de los datos activando las etiquetas de valor.

Figura 61. Cuadros de diálogo para seleccionar la prueba paramétrica 210 de dos muestras independientes.

Figura 62. Pasos para ingresar las variables número de condición al programa SPSS.

Figura 63. Pasos para ingresar las variables Agrupación al programa SPSS. 
Figura 65. Actividad para definir los grupos paso 2. 211

Figura 66. Paso para ejecutar el programa SPSS para que realice 211 los cálculos requeridos.

\section{Capítulo 11.}

Figura 67. Ventana de diálogo para etiquetar los valores de agrupación. $\quad 218$

$\begin{array}{ll}\text { Figura 68. Designación de nombre de las variables y características } & 219\end{array}$ de presentación para la prueba ANOVA Unifactorial (relacionada).

Figura 69. Presentación de los datos arrojados por los participantes 220 en las tres condiciones: sin video, con video tradicional y con video interactivo.

Figura 70. Presentación de los datos activando las etiquetas de valor. $\quad 220$

$\begin{array}{ll}\text { Figura 71. Cuadro de diálogo para seleccionar la prueba paramétrica } & 221\end{array}$ de tres muestras relacionadas.

Figura 72. Pasos para ingresar la variable Condiciones1a3 al programa SPSS. $\quad 221$

Figura 73. Pasos para ingresar la variable Agrupación al programa SPSS. $\quad 221$

Figura 74. Paso para ejecutar el programa SPSS para que realice 222 los cálculos requeridos.

\section{Capítulo 12.}

Figura 75. Ventana de diálogo para etiquetar los valores de agrupación. 230

Figura 76. Designación de nombre de las variables y características de 230 presentación para la prueba ANOVA Unifactorial (independiente).

Figura 77. Presentación de los datos arrojados por los participantes 231 en las tres condiciones.

Figura 78. Presentación de los datos activando las etiquetas de valor. 232

Figura 79. Cuadro de diálogo para seleccionar la prueba paramétrica 232 de tres muestras independientes.

Figura 80. Pasos para ingresar las variables Condiciones1a3 233 al programa SPSS.

Figura 81. Pasos para ingresar las variables Agrupación al programa SPSS. $\quad 233$

Figura 82. Paso para ejecutar el programa SPSS para que realice 233 los cálculos requeridos.

\section{Capítulo 13.}

Figura 83. Designación de nombre de las variables y características de presentación para la prueba ANOVA Bifactorial (relacionada).

Figura 84. Presentación de los datos arrojados por los participantes. 245

Figura 85. Cuadros de diálogo para seleccionar la prueba paramétrica $\quad 246$ de dos variables independientes para muestras relacionadas.

Figura 86. Paso para ingresar las variables Interacción As y Bs al programa SPSS.

Figura 87. Pasos para ingresar las variables Relación al programa SPSS. $\quad 247$

$\begin{array}{ll}\text { Figura 88. Paso para ejecutar el programa SPSS para que realice } & 247\end{array}$ los cálculos requeridos. 
Figura 89. Designación de nombre de las variables y características de presentación para la elaboración de las graficas.

Figura 90. Presentación de los valores de las medias correspondientes.

251

Figura 91. Cuadros de diálogo para seleccionar la prueba paramétrica de dos variables independientes para muestras relacionadas.

Figura 92. Cuadros de diálogo para seleccionar el tipo de graficas que se desean representar.

Figura 93. Cuadros de diálogo para definir los parámetros para graficar las líneas que representan.

Figura 94. Cuadros de diálogo para definir los parámetros para graficar el Eje de categorías.

Figura 95. Cuadros de diálogo para generar la gráfica.

251

252

252

\section{Capítulo 14.}

Figura 96. Designación de nombre de las variables y características 261 de presentación para la prueba ANOVA Bifactorial (independiente).

Figura 97. Presentación de los datos arrojados por los participantes. 263

Figura 98. Cuadros de diálogo para seleccionar la prueba paramétrica de dos variables independientes para muestras no relacionadas.

Figura 99. Paso para ingresar las variables Interacción As y Bs al programa SPSS.

Figura 100. Pasos para ingresar las variables Relación al programa SPSS.

Figura 101. Pasos para ejecutar el programa SPSS para que realice los cálculos requeridos.

Figura 102. Designación de nombre de las variables y características de presentación para la elaboración de las gráficas.

Figura 103. Presentación de los valores de las medias correspondientes. 267

Figura 104. Cuadros de diálogo para seleccionar la prueba paramétrica de dos variables independientes para muestras no relacionadas.

Figura 105. Cuadros de diálogo para seleccionar el tipo de gráficas 268 que se desean representar.

Figura 106. Cuadros de diálogo para definir los parámetros para graficar las líneas que representan.

Figura 107. Cuadros de diálogo para definir los parámetros para graficar el Eje de categorías.

Figura 108. Cuadros de diálogo para generar la gráfica.

\section{Capítulo 15.}

Figura 109. Cuadro de diálogo para designar la correspondencia de los números con sus atributos a la variable Opción.

Figura 110. Cuadro de diálogo para designar la correspondencia de los números con sus atributos a la variable Grupo.

Figura 111. Designación de variables y sus características para la prueba Chi cuadrado.

Figura 112. Valores ingresados de las variables "Opción" y "Grupo". 
Figura 113. Opción de Etiquetas de valor que muestra la Vista de variables. $\quad 283$

Figura 114. Listado de atributos que tiene la variable "Opción". 283

Figura 115. Pasos para realizar la prueba del análisis de tabulación $\quad 284$ cruzada de datos.

Figura 116. Cuadro de diálogo de tablas de contingencia para ingresar

284 el número de Opción.

Figura 117. Cuadro de diálogo de tablas de contingencia para ingresar

284 el número de Grupo.

Figura 118. Cuadro de diálogo de tablas de contingencia para ingresar 285 a Estadísticos.

Figura 119. Recuadro correspondiente a la tabla de contingencia 285 en la opción "Estadísticos".

Figura 120. Cuadro de diálogo de tablas de contingencia para que 286 se muestren los gráficos de barras agrupadas.

\section{Capítulo 16.}

Figura 121. Designación de variables y sus características para la prueba $r$ correlación de Pearson.

Figura 122. Presentación de los Promedios del Primer Semestre 294 y los Promedios del Bachillerato.

Figura 123. Cuadros de diálogo para seleccionar la prueba $r$ correlación 295 de Pearson.

Figura 124. Transferencia de la variable Promedio primer Semestre 295 para procesar los datos con el programa SPSS.

Figura 125. Paso para abrir la ventana de diálogo y las opciones para incluir 296 las variables medias y desviaciones típicas.

Figura 126. Paso para ejecutar el programa para que realice los cálculos requeridos para determinar los valores de las medias y desviaciones típicas.

Figura 127. Paso para ejecutar el programa SPSS para que realice los cálculos requeridos para la prueba r correlación de Pearson.

\section{Capítulo 17.}

Figura 128. Designación de variables y sus características para la prueba 303 $r_{s}$ correlación de Spearman.

Figura 129. Presentación de la Variable X, las Calificaciones y la Variable Y. 304

Figura 130. Cuadros de diálogo para seleccionar la prueba $r$ correlación 304 de Pearson.

Figura 131. Transferencia de la Variable X (participación en clase) 305 para procesar los datos con el programa SPSS.

Figura 132. Transferencia de la variable Calificaciones (Calificación examen 305 aplicado) para procesar los datos con el programa SPSS.

Figura 133. Paso para ejecutar el programa SPSS para que realice los cálculos requeridos para la prueba rs correlación de Spearman. 


\section{Capítulo 18.}

Figura 134. Designación de variables y sus características para

el análisis de regresión lineal.

Figura 135. Presentación de las variables Explicativa (X), Explicada (Y)

y Predictiva $\left(\mathrm{Y}^{\prime}\right)$.

Figura 136. Cuadros de diálogo para seleccionar los gráficos

319

de dispersión de puntos.

Figura 137. Selección del tipo de grafico de dispersión de puntos

319

que se desea utilizar.

Figura 138. Transferencia de la variable Y Explicada al casillero par 1,

320

Variable Y.

Figura 139. Transferencia de la variable X Explicativa al casillero par 1, Variable X.

Figura 140. Transferencia de la variable Y' Predictiva al casillero par 2, Variable Y.

Figura 141. Transferencia de la variable X Predictiva al casillero par 2, Variable X.

Figura 142. Designación de variables y sus características para

la prueba de Regresión Lineal.

Figura 143. Presentación de las Variables X y Y.

328

Figura 144. Cuadros de diálogo para seleccionar la prueba de regresión lineal.

Figura 145. Transferencia de la variable Promedio primer Semestre o variable $Y$ para procesar los datos con el programa SPSS.

Figura 146. Transferencia de la variable Promedio Bachillerato para procesar los datos con el programa SPSS.

Figura 147. Paso para ejecutar el programa SPSS para que realice los cálculos requeridos para la prueba de Regresión Lineal.

\section{Capítulo 19.}

Figura 148. Designación de variables y sus características para la prueba de Regresión Lineal.

Figura 149. Presentación de las Variables $Y_{1} X_{1}, X_{2}$ y $X_{3}$.

Figura 150. Cuadros de diálogo para seleccionar la prueba de regresión lineal.

Figura 151. Transferencia de la variable Promedio primer Semestre

para procesar los datos con el programa SPSS.

Figura 152. Transferencia de la variable Promedio Bachillerato para procesar los datos con el programa SPSS.

Figura 153. Paso para ejecutar el programa SPSS para que realice los cálculos requeridos para la prueba de Regresión Lineal. 


\section{Índice de Cuadros}

\section{Capítulo 2.}

$\begin{array}{ll}\text { Cuadro 1. Sistema de categorías. } & 47\end{array}$

Cuadro 2. Lista de control. $\quad 48$

Cuadro 3. Escala de estimación. $\quad 49$

Cuadro 4. Tipos de preguntas que se pueden elaborar. 57

\section{Capítulo 3.}

Cuadro 5. Resumen de la clasificación de las hipótesis en el enfoque 93 cuantitativo.

\section{Capítulo 4.}

Cuadro 6. Pruebas estadísticas no paramétricas para una sola variable. $\quad 140$

Cuadro 7. Pruebas estadísticas paramétricas. $\quad 141$

Cuadro 8. Pruebas estadísticas de relaciones entre variables. 142

\section{Capítulo 5.}

Cuadro 9. Variables seleccionadas. 156

Cuadro 10. Resultados obtenidos con el programa SPSS para la prueba $\quad 159$ no paramétrica Wilcoxon para dos muestras relacionadas.

\section{Capítulo 6.}

$\begin{array}{ll}\text { Cuadro 11. Designación de variables para la prueba Mann-Whitney } & 165\end{array}$ (independiente).

Cuadro 12. Resultados obtenidos con el programa SPSS para la prueba no paramétrica Mann-Whitney para dos muestras independientes.

\section{Capítulo 7.}

Cuadro 13. Designación de variables para la prueba Friedman 175 (relacionada).

Cuadro 14. Resultados obtenidos con el programa SPSS para a prueba no $\quad 179$ paramétrica Friedman para tres muestras relacionadas.

\section{Capítulo 8.}

Cuadro 15. Designación de variables para la prueba Kruskal-Wallis (independiente). 
Cuadro 16. Resultados obtenidos con el programa SPSS para la prueba no paramétrica Kruskal-Wallis para dos muestras independientes.

\section{Capítulo 9.}

Cuadro 17. Designación de variables para la prueba $t$ (relacionada). 199

Cuadro 18. Resultados obtenidos con el programa SPSS para la prueba $\quad 202$ paramétricat (relacionada) para dos muestras relacionadas.

\section{Capítulo 10.}

Cuadro 19. Designación de variables para la prueba $t$ (relacionada). 208

Cuadro 20. Resultados obtenidos con el programa SPSS para la prueba 212

paramétrica $t$ (independiente) para dos muestras no relacionadas.

\section{Capítulo 11.}

Cuadro 21. Designación de variables para la prueba ANOVA Unifactorial $\quad 219$ (relacionada).

Cuadro 22. Resultados obtenidos con el programa SPSS para la prueba 222 paramétrica ANOVA Unifactorial para tres muestras relacionadas.

\section{Capítulo 12.}

Cuadro 23. Designación de variables para la prueba ANOVA Unifactorial $\quad 231$ (no relacionada).

Cuadro 24. Resultados obtenidos con el programa SPSS para la prueba paramétrica ANOVA Unifactorial para tres muestras independientes.

\section{Capítulo 13.}

Cuadro 25. Designación de variables para la prueba ANOVA bifactorial $\quad 246$ (relacionada).

Cuadro 26. Resultados obtenidos con el programa SPSS para la prueba $\quad 248$ paramétrica ANOVA Bifactorial para muestras relacionadas utilizando el procedimiento Multivariante.

Cuadro 27. Designación de variables para la prueba ANOVA Bifactorial (relacionada).

\section{Capítulo 14.}

Cuadro 28. Designación de variables para la prueba ANOVA Bifactorial (no relacionada). 
Cuadro 29. Resultados obtenidos con el programa SPSS para la prueba paramétrica ANOVA Bifactorial para muestras no relacionadas utilizando el procedimiento Multivariante.

Cuadro 30. Designación de variables para la prueba ANOVA Bifactorial (no relacionada).

\section{Capítulo 15.}

Cuadro 31. Pregunta 1 de la encuesta dirigida a usuarios de la biblioteca. $\quad 274$

Cuadro 32. Designación de variables para la prueba $t$ (relacionada). 282

Cuadro 33. Visor de resultados o visor SPSS de las tablas 286

de contingencias.

\section{Capítulo 16.}

Cuadro 34. Designación de variables para la prueba de Correlación. $\quad 294$

Cuadro 35. Resultados obtenidos con el programa SPSS para la prueba $r \quad 297$

correlación de Pearson.

\section{Capítulo 17.}

Cuadro 36. Designación de variables para la prueba de Correlación de Spearman.

Cuadro 37. Resultados obtenidos con el programa SPSS para la prueba $r_{\mathrm{s}}$ correlación de Spearman.

\section{Capítulo 18.}

Cuadro 38. Designación de variables para el análisis de Regresión Lineal. de Regresión Lineal.

\section{Capítulo 19}

Cuadro 41. Designación de variables para la prueba de Regresión 336 Múltiple.

Cuadro 42. Resultados obtenidos con el programa SPSS para la prueba de Regresión Lineal. 


\section{Índice de Tablas}

\section{Capítulo 3.}

Tabla 1. Puntuación obtenida por los alumnos del Grupo A 96 referente al aprovechamiento.

$\begin{array}{ll}\text { Tabla 2. Puntajes de desviaciones cuadráticas para eliminar los } & 107\end{array}$ números negativos.

Tabla 3. Puntajes directos cuadráticos para facilitar el cálculo 108 de la desviación típica.

Tabla 4. Calificaciones obtenidas por los alumnos del Grupo C 109 de segundo de secundaria en la materia de Historia.

Tabla 5. Ordenar los valores descendentes y asignarles frecuencias. 109

Tabla 6. Relación de puntajes obtenidos de dos muestras 122 de los alumnos de 60 grado de la escuela "Sol".

Tabla 7. Puntajes obtenidos por los alumnos de 30 de primaria que recibieron la información por medio de un video interactivo (experimental) y en forma tradicional (control).

Tabla 8. Relación de puntajes obtenidos por los alumnos de química de los grupos experimental y de control.

Tabla 9. Los puntajes obtenidos por los alumnos antes y después de la proyección de la película.

\section{Capítulo 5.}

Tabla 10. Resultados de la agilidad para resolver problemas de matemáticas con y sin la estrategia "los juegos matemáticos".

\section{Capítulo 6.}

Tabla 11. Resultados obtenidos después de realizar las lecturas impresas en papel y digitales.

\section{Capítulo 7.}

Tabla 12. Resultados obtenidos por los participantes en los tres dictados con respecto a las reglas de ortografía.

\section{Capítulo 8.}

Tabla 13. Resultados obtenidos en la olimpiada de matemáticas por los participantes experimentales. 
Tabla 14. Puntajes obtenidos en la evaluación previa y posterior a la aplicación de las dinámicas grupales del grupo experimental.

\section{Capítulo 10.}

Tabla 15. Análisis comparativo entren el grupo de referencia

y el experimental después de la intervención.

\section{Capítulo 11.}

Tabla 16. Puntajes obtenidos en las tres evaluaciones de acuerdo

\section{Capítulo 12.}

Tabla 17. Puntajes obtenidos por los grupos participantes de acuerdo

a las condiciones establecidas por el investigador.

\section{Capítulo 13.}

Tabla 18. Puntajes obtenidos por los grupos participantes de acuerdo

a las condiciones establecidas por el investigador.

Tabla 19. Interacciones entre A y $B$.

Tabla 20. Interacciones entre A y S.

Tabla 21. Interacciones entre By S.

238

Tabla 22. Calculo de los valores de los resultados elevados al cuadrado.

\section{Capítulo 14.}

Tabla 23. Puntajes obtenidos por los grupos participantes de acuerdo 256 a las condiciones establecidas por el investigador.

Tabla 24. Interacciones entre A y B. 257

Tabla 25. Cálculo de los valores de los resultados elevados al cuadrado. 259

\section{Capítulo 15.}

Tabla 26. Relación del número de opción con el valor asignado de la pregunta 1.

Tabla 27. Relación de respuestas a la pregunta 1 (Grupo experimental y de referencia). 
Tabla 28. Relación de respuestas a la pregunta 1: ¿Del listado siguiente,

\section{Capítulo 16.}

Tabla 30. Relación de evaluaciones correspondientes a la carrera de Medicina.

\section{Capítulo 17.}

Tabla 31. Resultados obtenidos por los alumnos del grupo de $5^{\circ} \mathrm{A}$, de acuerdo a su participación en clase y la calificación del examen aplicado.

\section{Capítulo 18.}

Tabla 32. Relación de los resultados obtenidos por la variable explicativa, explicada y la predictiva.

Tabla 33. Relación de los resultados obtenidos por la variable explicativa, explicada y la predictiva.

Tabla 34. Estimación de la suma de los errores de predicción $\left(Y-Y^{\prime}\right)^{2}$.

\section{Capítulo 19.}

Tabla 35. Relación de evaluaciones correspondientes a la Licenciatura en Enfermería. 


Para contacto con los autores:

vikingomex@hotmail.com

La toma de decisiones en investigación educativa con SPSS

ISBN: 978-607-96359-4-7

Esta publicación digital se terminó de producir en Diciembre de 2015.

Su edición y diseño estuvieron a cargo de:

\section{Qartuppi}

Qartuppi, S. de R.L. de C.V.

http://www.qartuppi.com 


El objetivo primordial que se pretendió con este trabajo fue elaborar un libro de texto que permitiera a los estudiantes de pedagogía facilitar el camino en el análisis estadístico, debido a la dificultad que representa el utilizar la estadística como instrumento para la toma de decisiones cuando se lleva a cabo una investigación dentro del ámbito de la educación.

Este texto busca llevar de la mano al lector para que seleccione la prueba más adecuada al tipo de investigación que esté desarrollando, explicando paso a paso el proceso matemático y el proceso estadístico utilizando el programa SPSS versión 20.0, que le permita determinar si se acepta o rechaza la hipótesis de investigación e identificar los resultados significativos para que cuente con los elementos necesarios para tomar las decisiones que le permitan realizar los ajustes requeridos en la obtención de los mejores resultados o definir el éxito de la investigación.

El texto va dirigido a estudiantes y profesionistas de la educación en los niveles básico, licenciatura y postgrado que desarrollen trabajos de investigación educativa tanto para la elaboración de una tesis como para la realización de una investigación formal, proporcionando al investigador las herramientas estadísticas y los procesos de investigación educativa, utilizando ejemplos simples que le permitan relacionar y seleccionar el que se adecue más a las características del tipo de investigación que requiera realizar.

Es importante resaltar que todos los ejemplos utilizados en las diferentes pruebas son resultado de investigaciones reales que fueron realizadas por estudiantes de diferentes niveles educativos (licenciatura, maestría y doctorado) como producto de trabajos de tesis para obtener un título profesional.

En este libro se pretende que el lector encuentre la respuesta a las siguientes interrogantes: ¿Qué investigar en educación?, ¿Cómo recolectar los datos en la investigación educativa?, ¿Qué se requieres saber sobre estadística?, ¿Qué tipo de estadístico utilizar?, ¿Cuándo utilizar pruebas no paramétricas?, ¿Cuándo utilizar pruebas paramétricas? y, ¿Cómo relacionar las variables?

ISBN 978-607-96359-4-7

Qartuppi 